Markus Köck

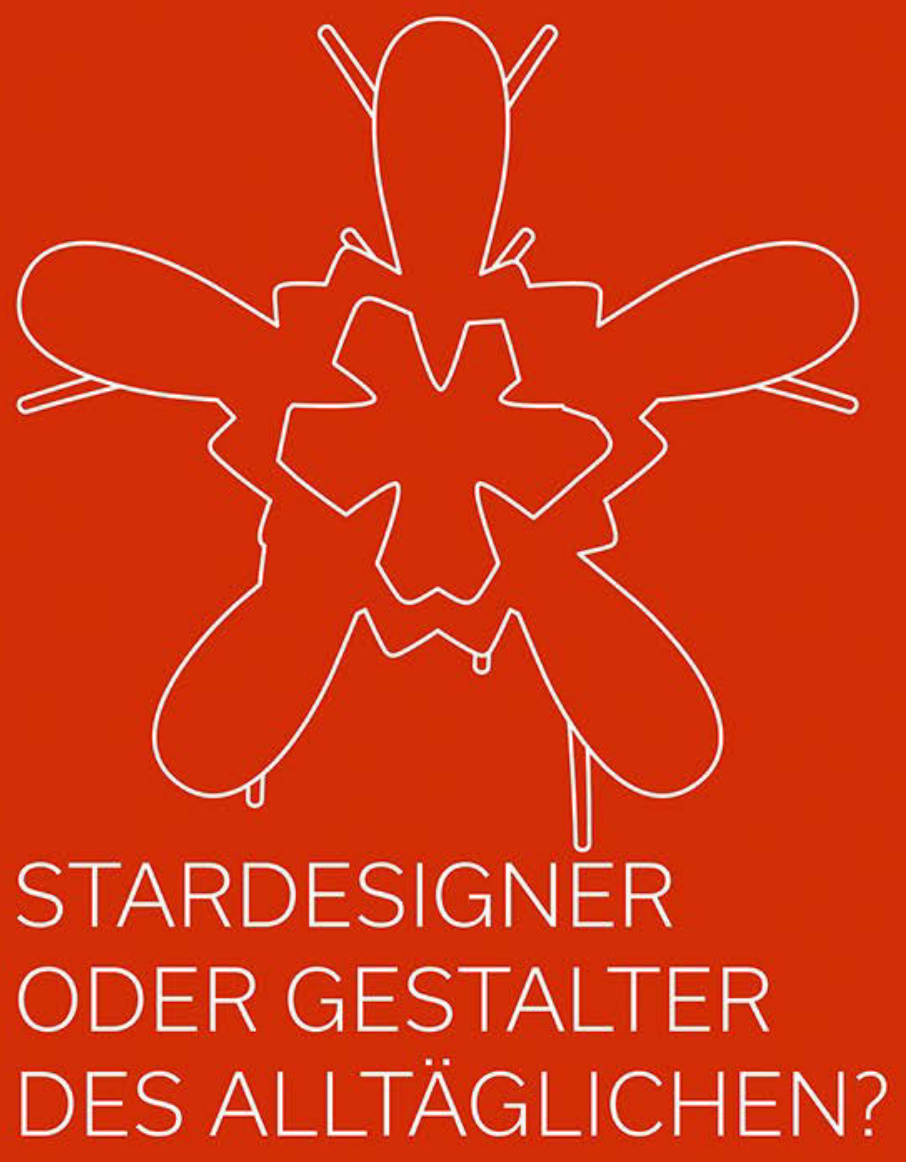

Designrezeption in

der Aufmerksamkeitsökonomie

[transcript] Medien- und Gestaltungsästhetik 13 
Markus Köck

\title{
STARDESIGNER ODER GESTALTER DES ALLTÄGLICHEN?
}

\author{
Designrezeption \\ in der Aufmerksamkeitsökonomie
}


EDITORIAL Mediale Produktionen und gestalterische Diskurse bilden ein vehement zu beforschendes ästhetisches Dispositiv: Medien nehmen nicht nur wahr, sondern werden selbst wahrgenommen und wahrnehmbar(er) insbesondere durch die Grundkonstellationen ihrer oft technischen Artefakte und der diesen voran gehenden Entwürfe, mithin vor der Folie des dabei entstehenden Designs. Die Reihe MEDIEN- UND GESTALTUNGSÄSTHETIK versammelt dazu sowohl theoretische Arbeiten als auch historische Rekapitulationen und prognostizierende Essays.

Die Reihe wird herausgegeben von Oliver Ruf.

DR. MARKUS Köск (Dipl.-Designer Produktdesign), geb. 1967, wurde 2020 an der HBK SAAR bei Prof. Dr. ROLF SACHSSE promoviert. Die HANS-BÖCKLER-STIFTUNG hat ihn für seine Arbeit mit einem ihrer Promotions-Stipendien ausgezeichnet. MARKUS KÖcK forscht zu den Themen Designrezeption, den Auswirkungen von Design im sozialen Kontext und zum Einfluss von Designtheorie auf die Weiterentwicklung gestalterischer Prozesse. Er lehrt seit 2018 an der Fachhochschule MACrOMEDIA in den Studiengängen Medien-, Informations- und Kommunikationsdesign und ist Vorstandsmitglied der DGTF. 
Markus Köck

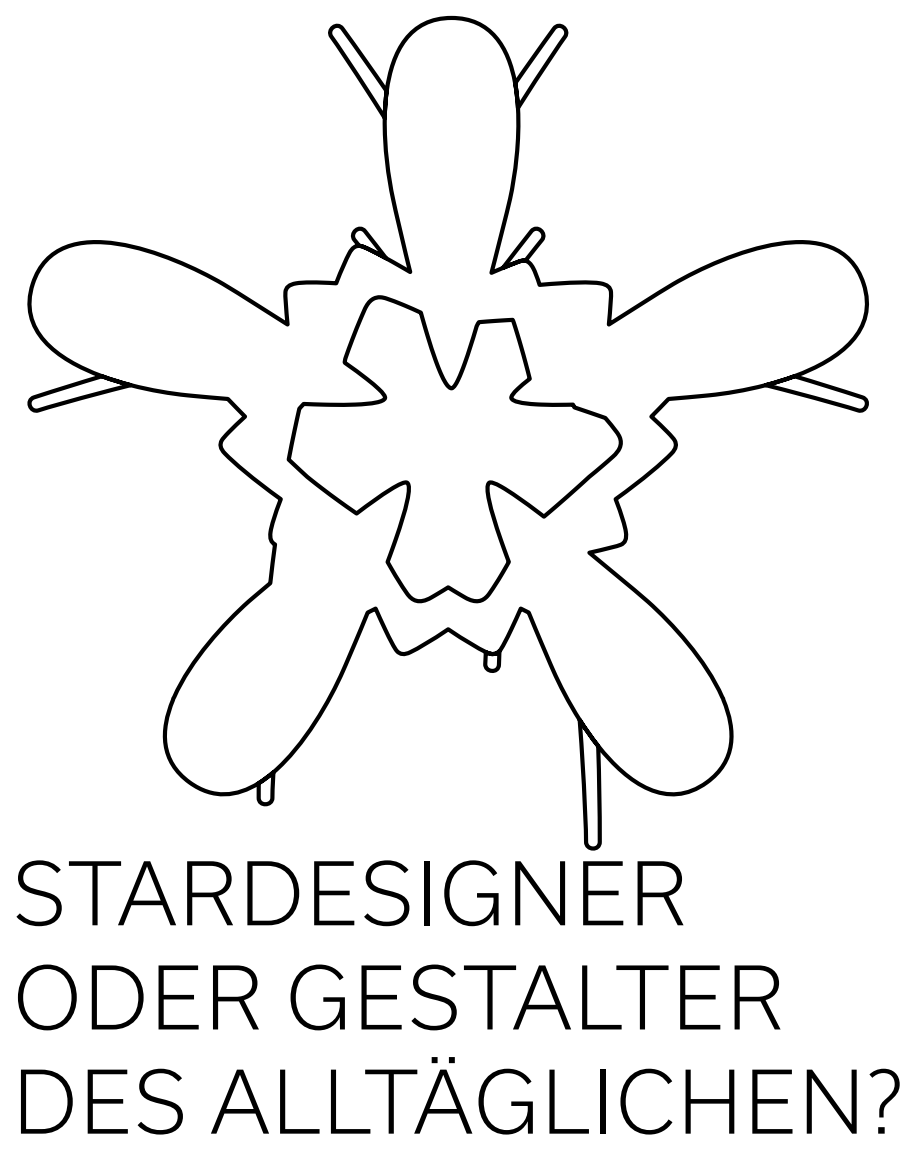

Designrezeption in der Aufmerksamkeitsökonomie [transcript] Medien- und Gestaltungsästhetik 13 
Diese Arbeit wurde von der HOCHSCHULE DER BILDENDEN KÜNSTE SAAR im Mai 2019 als Dissertation angenommen. Erstgutachter Prof. Dr. ROLF SACHSSE, Zweitgutachter Prof. Dr. Michael hofmann. Tag der Disputation: 3. November 2020. Das Forschungsvorhaben wurde von 01/2017-12/2019 mit einem Promotionsstipendium der HANS-BÖCKLER-STIFTUNG gefördert.

\section{Hans Böckler Stiftung}

Diese Publikation wurde im Rahmen des Fördervorhabens 16TOAOO2 mit Mitteln des Bundesministeriums für Bildung und Forschung im Open Access bereitgestellt.

\section{Bibliografische Information der Deutschen Nationalbibliothek}

Die Deutsche Nationalbibliothek verzeichnet diese Publikation in der Deutschen Nationalbibliografie; detaillierte bibliografische Daten sind im Internet über http://dnb.d-nb.de abrufbar.

\section{Erschienen 2021 im transcript Verlag, Bielefeld (c) Markus Köck}

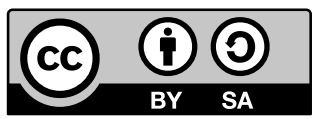

Dieses Werk ist lizenziert unter der Creative Commons Attribution-ShareAlike 4.0 Lizenz (BY-SA). Diese Lizenz erlaubt unter Voraussetzung der Namensnennung des Urhebers die Bearbeitung, Vervielfältigung und Verbreitung des Materials in jedem Format oder Medium für beliebige Zwecke, auch kommerziell, sofern der neu entstandene Text unter derselben Lizenz wie das Original verbreitet wird. (Lizenz-Text: https://creativecommons.org/licenses/by-sa/4.0/deed.de) Die Bedingungen der Creative-Commons-Lizenz gelten nur für Originalmaterial. Die Wiederverwendung von Material aus anderen Quellen (gekennzeichnet mit Quellenangabe) wie z.B. Schaubilder, Abbildungen, Fotos und Textauszüge erfordert ggf. weitere Nutzungsgenehmigungen durch den jeweiligen Rechteinhaber.

Umschlagkonzept: Natalie Herrmann, Theresa Annika Kiefer, Lena Sauerborn,

Elisa Siedler, Meyrem Yücel

Designkonzeption: Andreas Sieß

Gestaltung, Illustration \& Satz: Markus Köck

Druck: Majuskel Medienproduktion GmbH, Wetzlar

ISBN Print: 978-3-8376-5960-3

ISBN PDF: 978-3-8394-5960-7

EPUB-ISBN 978-3-7328-5960-3

https://doi.org/10.14361/9783839459607

Buchreihen-ISSN: 2569-1767

Buchreihen-eISSN: 2703-0849

Gedruckt auf alterungsbeständigem Papier mit chlorfrei gebleichtem Zellstoff. Besuchen Sie uns im Internet: http://www.transcript-verlag.de Bitte fordern Sie unser Gesamtverzeichnis und andere Broschüren an unter: info@transcript-verlag.de 


\section{Inhaltsverzeichnis}

\section{VORWORT - 13}

Zeichen auf dem Weg. Von der beinahe anonymen Gestaltung über die Kunst zum Star-Design: Eine Straße zur Theorie - 15

\section{Einleitung - 19}

Esse est percipi - 21

Zielsetzung und Struktur der Arbeit - 29

Hypothesen - 39

\section{Aufmerksamkeit - 41}

Worte - nichts als Worte? - 43

Aufmerksamkeit als Metaphänomen - 47

Ökonomie der Aufmerksamkeit - 51

Ist Geld durch Aufmerksamkeit ersetzbar? - 51 | Ein Gewebe aus noch unbeachteten Transaktionen und ungeschriebenen Verträgen? - 53 | Thrombosen der Aufmerksamkeit - Auflösung unerwünscht? - 56 | Designer und ihre Kapitalformen der Aufmerksamkeit - 58 | Sich sonnen im Abglanz dritter Beachtlichkeit - 59 | Artefakte verändern die Verhältnisse - 59 | Vergleiche, Vergleiche, Vergleiche .... - 61

Aufmerksamkeit. Wahrnehmung und moderne Kultur - 65 
Aufmerksamkeit, Medien und Ökonomie - 73

Aufmerksamkeit ist keine Selbstverständlichkeit - 74 | Vom Geben und Nehmen im Kleinen und Großen - 76 | Das Kapital in den Köpfen - 78| Kultur und Quote - 81| Kritische Anmerkungen zur neuen Ökonomie der Aufmerksamkeit - 84 | Die Goldtruhen der Seeräuber - 85

Phänomenologie der Aufmerksamkeit - 89

Aufmerksamkeit als Kapital - 103

Mehr als eine Sumpfblüte? - 113

Wie steht es um die Zukunft der Aufmerksamkeit? - 116 | Weiße Flecken auf der Karte des Aufmerksamkeitsreiches - 117 | Paradoxien der Aufmerksamkeit - 118 | Der Kunstmarkt als Abbild der Aufmerksamkeitsökonomie - 120

Kann Aufmerksamkeit wirklich zur Währung werden? - 125

Wie wird Ansehen getauscht? - 129

Ein Theoriemodell für den ökonomieähnlichen Tausch von Ansehen - 131

Eine Zeit- und Nutzenökonomie - 135

\section{Prominenz - 141}

Stardesign und Prominenz - 143

Überlegungen zum Problemfeld - 153

Sind Stardesigner tatsächlich prominent? - 157 Prominenz. Entstehung, Erklärung, Erwartungen - 167 | Der Star und seine Nutzer - 179

Neuausrichtung der Prominenzforschung - 183

Identitätskonstruktive Funktionalisierungen aus der Fanperspektive - 187 | Prominente Designer stehen nicht in der ersten Reihe - 189 
Wohin hat uns das geführt? - 199

Ein Exkurs und seine Anbindung - 203

\section{Anonymität - 209}

Schafft man es auch anonym? - 211

Anonymity in Design - 220 | Das gewöhnliche Design - 225 | Unbekannt - Vertraut »Anonymes « Design im Schweizer Gebrauchsgerät seit 1920 - 231 | Special Issue Anonymous Design - 236

Anhang: Übersetzungen aus dem Japanischen - 242

LOW BUDGET Objectos di quotidiano - 256 | Kaj Franck (1911-1989)

Die designtheoretischen Strömungen unter dem Gesichtspunkt der Anonymität und deren Einfluss auf das Werk von Kaj Franck - 262

Anhang: Kaj Franck: Anonymität, 1965 - 270

Main Street. Design ohne Designer - 274 | Die Essenz der Dinge - 279 | Anonymität als Teil eines Markenkonzepts: MUı, IKEA und MANUFACTUM - 291 | Anonymität ist für Marken kein tragfähiges Konzept - 297

Hat der Ausdruck anonymes Design im 21. Jhd. noch eine Bedeutung und wenn ja: Welche? - 298 Sieben Arten der Herstellung von anonymem Design - 299| Hän dl erkonzepte - 303 | Was bleibt am Ende vom anonymen Design übrig? - 304

\section{Rezeption - 309}

Am Ende war es nur ein Wort: Zwei Rezeptionsstudien - 311

Auswertung mit Blick auf Personen - 314

Philippe Starck - in der Nachfolge von Luigi Colani einfach überall - 317 | 34 Frauen gegen das Bias - 318

Detaillierte Auswertung mit Blick auf die Sprache - 320 
Die mediale Crème de la Crème des Designs in Form ihrer Bezeichnungen - 324

Superstar des Designs, Design-Popstar - 324 | Superstars (of design) - 325 / Popstar der Designwelt, Design-Popstar, Popstar des Grafikdesigns, Rockstar des Designs, Rockstar des modernen Designs - 326 | Weltstar(s) des Designs - 327 | Weltklasse-Designer/in - 328 / Luigi Colani - Designer extraordinaire - 330

Der Stardesigner lebt und lebt und lebt .... - 331 | Auch die Unwiderstehlichkeit ist noch steigerungsfähig - 333

Komparative im Rahmen der untersuchten Publikationen - 334 | Komparative außerhalb der untersuchten Publikationen - 338 / Superlativen ähnliche Bezeichnungen und Superlative innerhalb der untersuchten Publikationen - 340 / Superlativen ähnliche Bezeichnungen und Superlative außerhalb der untersuchten Publikationen - 343

Design-lkonen: Nach oben ist nicht mehr viel Luft - 344 | DesignLegenden: Sind wir auf den Höhen des Olymp angekommen? - 346 Nationalisierung - 350 | Die wörtliche Steigerung der Popularität - 352 | Die Klassifizierung des Designernachwuchses - 354

Differenzierung durch vorgebliche Aktualität - 356

Designklassiker und Designikonen - 361 Re-Popularisierung und ihre Konsequenzen für die Untersuchung - 363 | Gefundene Bezeichnungen für Artefakte - 364 Eine erste Bilanz - 375

Das Wiederkäuen der Wiedergänger - 376

Interne Prognostik bei SCHÖNER WOHNEN: Klassiker von morgen - 379

Was ist ein Designklassiker, was macht ihn aus? - 381

Designklassiker: Ein Kampf gegen das Jetzt? - 389

Klassiker-Profile nach Publikationen - 393

Anhang: Klassiker-Profile von SCHÖNER WOHNEN - 404 
Welche Beweiskraft haben diese Profile? - 414 | Käufer unterwerfen sich den Klassikern - 416

Die Supra-Designklassiker - 418

Von Supra²-Designern und Supra²-Designklassikern - 423

Der Weg zum Ikonischen - 425

Kristallisierter Sinn - 427| Die Macht der Dinge - 430 | Die Erfindung des modernen Klassikers - 434 | Postmodernes Charisma - 436 | The Theory of the Leisure Class - 440 | What was Philippe Starck thinking of? - 442

Zwischenbilanz - 452

Befestigungsliteratur: Die zweite Rezeptionsstudie - 454

Klassiker des Produktdesign - 458 | Hat der Designklassiker im 21. Jhd. einen neuen Bedeutungskern? - 462 | form-Verlag: Sonderhefte Der Klassiker-Boom und Design mit Bestand - 464 | formVerlag: Design-Klassiker - 466 | Geschichte des Designs - 469 | Designatlas von 1850 bis heute - 471 | Topdesign des 20. Jahrhunderts \& Das Buch der Klassiker - 475 | Die Designklassiker. Vom Barcelona-Sessel bis zum iPad - 479| Masters and their Pieces. Best of furniture design - 480

Finale Auswertung der Befestigungsliteratur - 486

Welche Erkenntnisse lassen sich aus den beiden Studien gewinnen? Zehn Schlussfolgerungen - 490

Eine spielerische Anbindung an die tatsächliche Fortifikationsliteratur - 495

Anhänge zu: Philippe Starck - 499 / Giorgetto Giugiaro - 521 | Jasper Morrison - 529 | Luigi Colani - 535 | Matteo Thun - 541 | Gebrüder Bouroullec - 547 | Konstantin Grcic - 553 | Dieter Rams - 559 / Terence Conran - 563 / Ross Lovegrove - 567 


\section{Schlussbetrachtungen - 571}

Aufmerksamkeit - 573

Prominenz - 579

Anonymität - 585

Rezeption - 591

Hypothesen - 601

Ausblick - 607

VII. Literaturverzeichnis - 611 


\section{Dank}

Jedes Thema findet seinen Doktoranden und die Forschung dazu entsteht nie in luftleerem Raum. Über die Jahre entwickeln sich Verbindungen zu Menschen, die unterstützen, begleiten, bestärken, herausfordern, die konstruktiv kritisieren und so dafür sorgen, dass mann diesen Marathon laufen kann.

Hinter der Ziellinie expliziter Dank an: Prof. Dr. ROLF SACHSSE (Doktorvater), Prof. Dr. Michael hofmann (Zweitgutachter und Vertrauensdozent der HANS-BÖCKLER-STIFTUNG), HARTMUT THAMM (Lebensgefährte), ULRIKE SCHLACK (Übersetzungen aus dem Japanischen), meine Lektorin HEIDE DANNER, die die Publikation leider nicht mehr erlebte († 07/2021), Dr. DUNJA MOHR (Promotionscoach der HANS-BÖCKLER-STIFTUNG), meine Freund:innen und hochgeschätzen Kolleg:innen INES VIGNERON-REINHARD, Dr. MARION SCHOENFELD-SCHILZ, Dr. NichOlas QYLL, Dr. TILl ANSGAR BAUMHAUER, Prof. SVen QUAdflieg, Dr. Helga Aichmaier, Prof. Dr. KLAUS Kuenen, SABINE KRELL, PHILIP ZERWECK und stellvertretend für meine Mitstipendiat:innen GÜLLÜ KISA und TORSTEN VOLKER.

Meinen Eltern.

\section{Markus Köck}

STUTTGART, im AUGUST 2021 


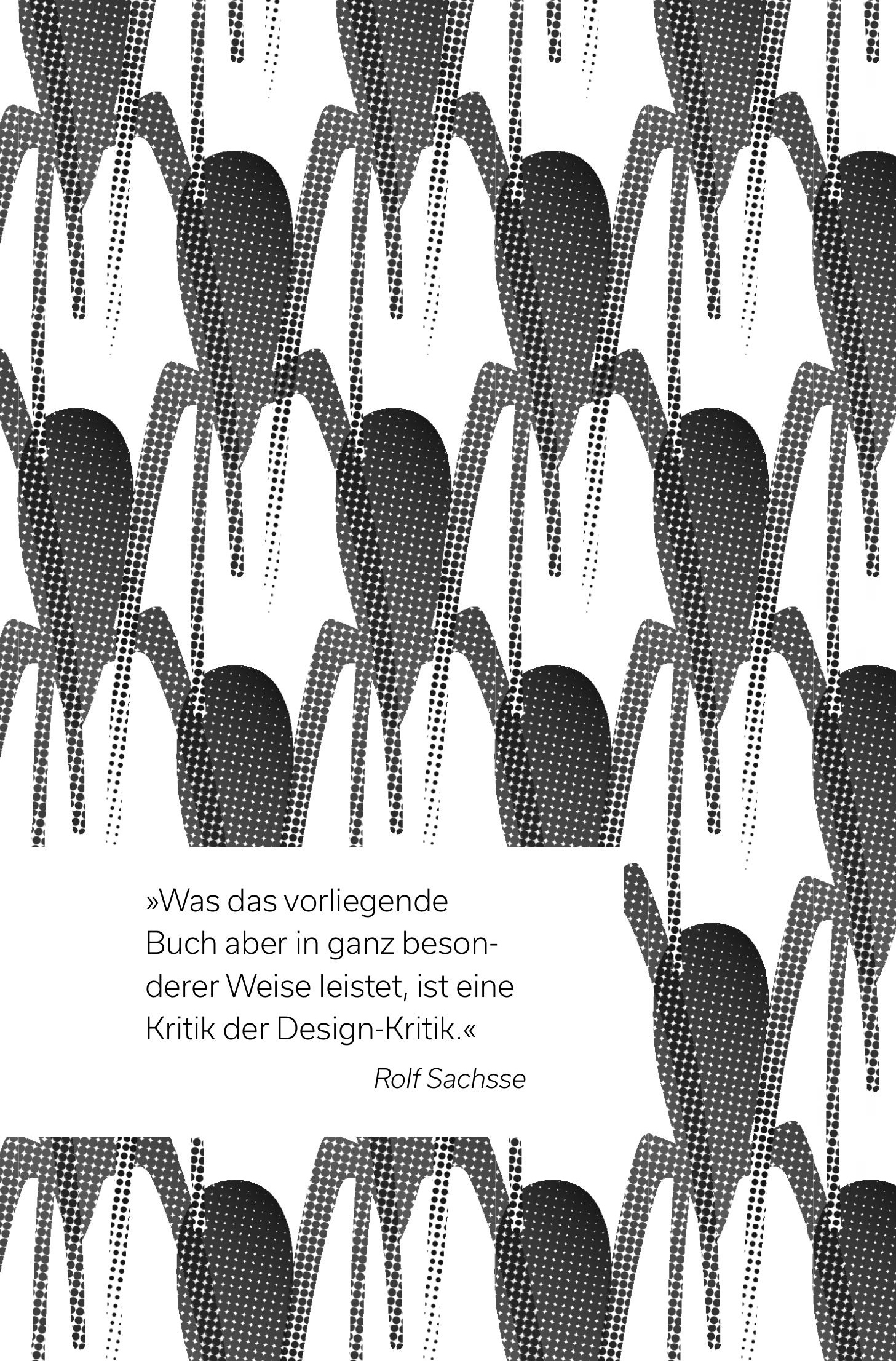




\section{Vorwort}

\section{Zeichen auf dem Weg. Von der beinahe anonymen Gestaltung über die Kunst zum Star-Design: Eine Straße zur Theorie}

Als junger Künstler nahm MARKUS KOECK an einer Gruppenausstellung teil, die ihrem Titel nach seine eigene Entwicklung beschreiben kann: Zeichen auf dem Weg ${ }^{1}$. Dabei sind Zeichen körperlose Erscheinungen, die sich eben nicht auf den Weg machen können, sondern nur durch ihre Wahrnehmung wirken können, mit ROBERT PFALleR: interpassiv. ${ }^{2}$ Performativ werden sie erst im Gebrauch und der kündigt einen Weg an. ${ }^{3}$ Das Ankündigen mittels Zeichen ist im hochmittelalterlichen Latein ein designare und das zeigt wiederum den Weg, den MARKUS KÖcK nahm, um etwas so vorbereiten zu können, dass Sie, liebe Leser*innen es nun in der Hand halten: ein Buch voller Zeichen, und selbst ein Zeichen universitären Fleißes. Es ist ein Zeichen des Wegs, den MARKUS KÖCK nahm.

Zunächst hat er Produkt-Design studiert und als Designer arbeitet er bis heute. Er gehörte zur ersten Studierenden-Generation der neu gegründeten

1 Enzweiler, Jo (Hg.): sichtbar machen, Staatliche Kunstschulen im Saarland, 19242004, Saarbrücken 2006, S.458 (dort ohne Titel)

2 Pfaller, Robert: Ästhetik der Interpassivität, Fundus 175, Hamburg 2009

3 Austin, John L.: Zur Theorie der Sprechakte (How to do things with Words), Stuttgart 1979, S.88-101 
Hochschule der bildenden Künste Saar und diese hatte in ihrem Programm ganz klar die gegenseitige Befruchtung von Design und Kunst während des gesamten Studiums verankert - geschrieben vom Soziologen LUCIUS BURCKHARDT, der eigentlich ein Design-Theoretiker war. ${ }^{4}$ So schwierig es war, diese Verschmelzung von Kunst und Design im Kleinklein des Hochschul-Alltags aufrecht zu erhalten ${ }^{5}$, so einfach war die Lösung für MARKUS KÖCK: Nach dem Abschluss als Designer studierte er noch bildende Kunst, vor allem bei ULRIKE ROSENBACH, die sich den performativen Grundlagen einer körperlich bestimmten Bildhauerei in den - damals noch relativ neuen - Medien wie Video oder Installation widmete. ${ }^{6}$ Und als sich herumsprach, dass mit dem neuen Kunsthochschulgesetz des Saarlandes von 2011 aus der Akademie eine Hochschule mit universitärem Zuschnitt wurde, kam MARKUS KÖcK gleich mit der Idee einer Promotion im Fach Designtheorie zu mir. Denn in den knapp zwei Jahrzehnten zwischen seinem Studium und der Idee einer theoretischen Reflexion seines Tuns waren ihm insbesondere die sozialen Konsequenzen der Gestaltungsberufe deutlich geworden, am eigenen Leib.

Sein eigener Lebensweg läuft nahezu parallel zu einer Entwicklung des öffentlichen Bildes von Künstler*innen, vom unterstützenswerten Kreativberuf ${ }^{7}$ zur neo-liberalen Unternehmerpersönlichkeit ${ }^{8}$ - wobei der Begriff Künstler (ausschließlich in der männlichen Form) mit allen Formen kreativer Berufe identisch gesetzt wird. Vom Design ausgehend, haben sich für MARKUS KÖcK aus der eigenen Praxis und sozialen Erfahrung heraus zwei Pole ergeben, die als einander ausschließende Ansätze gesehen werden können: Während KAJ FRANCK 1965 in seiner finnischen Heimat durch das Postulat für Furor sorgte, dass Designer hinter der Herstellerkennzeichnung zurücktreten sollten und

4 Burckhardt, Lucius: "Die sauberen Lösungen verschmutzen die Umwelt«, in: HBK Saar (Hg.), Nr.1 der Schriftenreihe, Saarbrücken o.J. (1990)

5 Sachsse, Rolf: »The Integration of Art and Design, Creativity and Professionalization «, in: Pfeffermann, Nicole; Gould, Julie (eds.), Strategy and Communication for Innovation. Integrative Perspectives on Innovation in the Digital Economy, Third Edition, Heidelberg Cham 2017, pp.415-424

6 Stäheli, Alexandra; Pulfer René: „A la télévision, ils voient rien. Über mediale Verflechtungen zwischen Kunst und Massenmedien seit den 1960er Jahren«, in: Schade, Sigrid; Sieber, Thomas; Tholen, Georg Christoph (Hg.), SchnittStellen, Basler Beiträge zur Medienwissenschaft Band 1, Basel 2005, S.401-422

7 Fohrbeck, Karla; Wiesand, Andreas; Woltereck, Frank: Arbeitnehmer oder Unternehmer? Zur Rechtssituation der Kulturberufe, eine Untersuchung, Berlin 1976

8 Von Buttlar, Horst (Hg.): Meine erste Million: Unternehmer, Künstler und andere Persönlichkeiten sprechen über das Geheimnis ihres Erfolgs, München 2018 
damit anonym werden - ein Gedanke, den dann MICHEL FOUCAULT in seinen berühmten Satz vom Autor gefasst hat, dessen Gesicht im Sand verschwin$\operatorname{det}^{9}$-, hat GEORG FRANCK 1998 in seinem Essay zur Ökonomie der Aufmerksamkeit ganz im Gegenteil beschrieben, dass alle öffentliche Wirkung zu einer Personalisierung führe, auch im Design. ${ }^{10}$ Was in unseren Gesprächen als eine Untersuchung über das anonyme Design begann, endete schließlich in der Prominenz-Forschung, einem recht neuen Gebiet zwischen Soziologie, Kulturwissenschaften und Designtheorie. Aber auch diese bildet schließlich nur einen Teil der gesamten, hier vorliegenden Untersuchung.

MARKUS KÖCK ist ein genuiner Praktiker, und daraus folgt theoretisch zunächst die Empirie: Ohne eine umfassende Datenlage können keine validen Aussagen getroffen werden, unabhängig von ihrer späteren Verifikation oder Falsifikation. Also muss er nach Daten suchen, in Publikationen und Dokumenten zum Design, selbstverständlich erweitert um die früher verwendeten Begriffe Gestaltung und Entwurf. Und er sucht viel und lange, findet auch sehr viel - in den Kolloquien erscheinen seine Aufzeichnungen als meterlange Graphen und Tabellen, selbst wieder eine Performance zwischen Design und Kunst. Das Ergebnis sind vielfältige Aussagen über das Vorkommen von Gestaltung im Alltag und vor allem in den medial dargebotenen Projektionen eines gelingenden, glücklichen Alltags, dem bei den Leser*innen und Rezipient*innen meist nur eines fehlt: das nötige Geld.

Anonymität lässt sich per definitionem nicht belegen, wohl aber das Gegenteil: die Benennung eines Menschen mit einem Attribut, hier also eines $/ \mathrm{r}$ Designer*in mit dem Präfix sStarı oder den Adjektiven `berühmtı, ১bekanntı, sbedeutend und so weiter. Doch der Teufel solch empirischer Betrachtungen, denen sich MARKUS KÖCK mit allergrößtem Fleiß widmete, steckt im Detail: 'Star ist immer eine Bezeichnung der Person, während sich die adjektivischen Attribute sowohl auf die Person als auf das Objekt der Gestaltung selbst beziehen können: Sind die >Memphisı-Möbel von ETTORE SOTTSASS oder die Zitronenpresse sJuicy Salifı von PHILIPPE STARCK berühmter als ihre Entwerfer? Abgesehen davon, dass aus dieser Sicht das Design weitgehend eine Domäne weißer Männer ist, bedeuten diese Fragen aus Sicht der von MARKUS KÖCK referierten Prominenzforschung, dass es Designer*innen niemals

9 Foucault, Michel: Die Ordnung der Dinge, Frankfurt a.M. 1972, S.462

10 Die hier referierten Positionen werden in der Arbeit ausführlich behandelt und daher an dieser Stelle nicht weiter belegt. 
mehr als zu einer abgeleiteten Prominenz bringen können, in der Kategorie der Filmgeschichte eben als B-Prominenz anzusehen, die Objekte entsprechend eher als B-movies. ${ }^{11}$

Doch auch die Anonymität birgt einige Strukturprobleme der Design-Rezeption, um die es MARKUS KÖCK schließlich geht, und auch diese führt er ausführlich an: Wenn entworfene Gegenstände nicht mehr auf einen einzelnen Menschen rückführbar erscheinen, wird ihre Form aus Vorbildern abgeleitet, mithin ein Kanon gebildet. Dieser wirkt sich wiederum auf die angewandte Kreativität im Entwurf der nächsten, möglicherweise wieder anonymen Objekte aus; jenseits von Rad und Achse waren Transportmittel lange nicht denkbar. Präzise und mit nie nachlassender Insistenz arbeitet MARKUS KÖcK damit die Frage nach dem Nullpunkt des Vorbildes für sämtliche Artefakte dieser Welt heraus und weist selbstverständlich nach, dass diese nicht zu beantworten ist. Doch kurz bevor er sich einer existentialistischen Sinnlosigkeit menschlichen Tuns ergibt, biegt er einmal mehr in die Pragmatik ab: Als Designer*in muss man nicht nur entwerfen, sondern auch verkaufen, und jede Rezeption basiert auf gesellschaftlicher Akzeptanz. Sie wird, wie er gleich zu Beginn seiner Untersuchungen feststellt, durch Vergleiche erworben, die Menschen immerzu zwischen Allem und Jedem anstellen und zur Grundlage ihrer Kommunikation machen. Hier muss gleich auch - und daher passt es hervorragend an den Anfang dieses Buchs - auf die Grenzen des wissenschaftlichen Denkens über ästhetische Gegenstände, wie es das Design nun einmal ist, hingewiesen werden, was MARKUS KÖcK in aller Deutlichkeit hervorhebt. Die Frage nach dem Unsagbaren in einem ästhetischen Urteil - der berühmt-berüchtigte >Geschmackı - zieht sich durch dieses Werk wie der Ariadne-Faden durch das kretische Labyrinth.

Was das vorliegende Buch aber in ganz besonderer Weise leistet, ist eine Kritik der Design-Kritik. Wer immer einmal einen Text zur Design-Geschichte, -Kritik oder -Theorie verfasst hat, kommt nicht umhin, sich angesichts der bei MARKUS KÖCK versammelten Hundertschaften von Zitaten an die eigene Nase zu fassen - wer niemals unter Zeitdruck, angesichts finanzieller Probleme oder in irgendeiner anderen Stress-Situation nicht ebenfalls derartige Floskeln in die eigenen Texte eingebaut hat, möge den ersten Stein werfen. Insofern ist die vorliegende Arbeit auch als wohl begründeter Appell an alle

11 Hayward, Susan: »B-movies«, in: Cinema Studies. The Key Concepts, London New York 2000, pp.49-50 
zu lesen, die über Design schreiben: Seid präzise und vorsichtig in der Wortwahl, bewertet erst nach einer guten Begründung, fragt bei jedem Urteil noch einmal nach seiner Rechtfertigung. Und ein zweiter Appell ist zwischen diesen Zeilen immer zu lesen: Nehmt die sinnliche Dimension aller Gegenstände, die Euch umgeben, und aller Prozesse, die mit Euch ablaufen, in voller Gänze wahr, denn »Mensch ist, wer Naturgebilde in Bilder umformen und diese als eigene Sphäre zu bestimmen vermag. «12

Prof. Dr. Rolf Sachsse

BONN, im JULI 2021

12 Bredekamp, Horst: Der Bildakt. Frankfurter Adorno-Vorlesungen 2007, Neufassung 2015, Berlin 2015, S. 36 


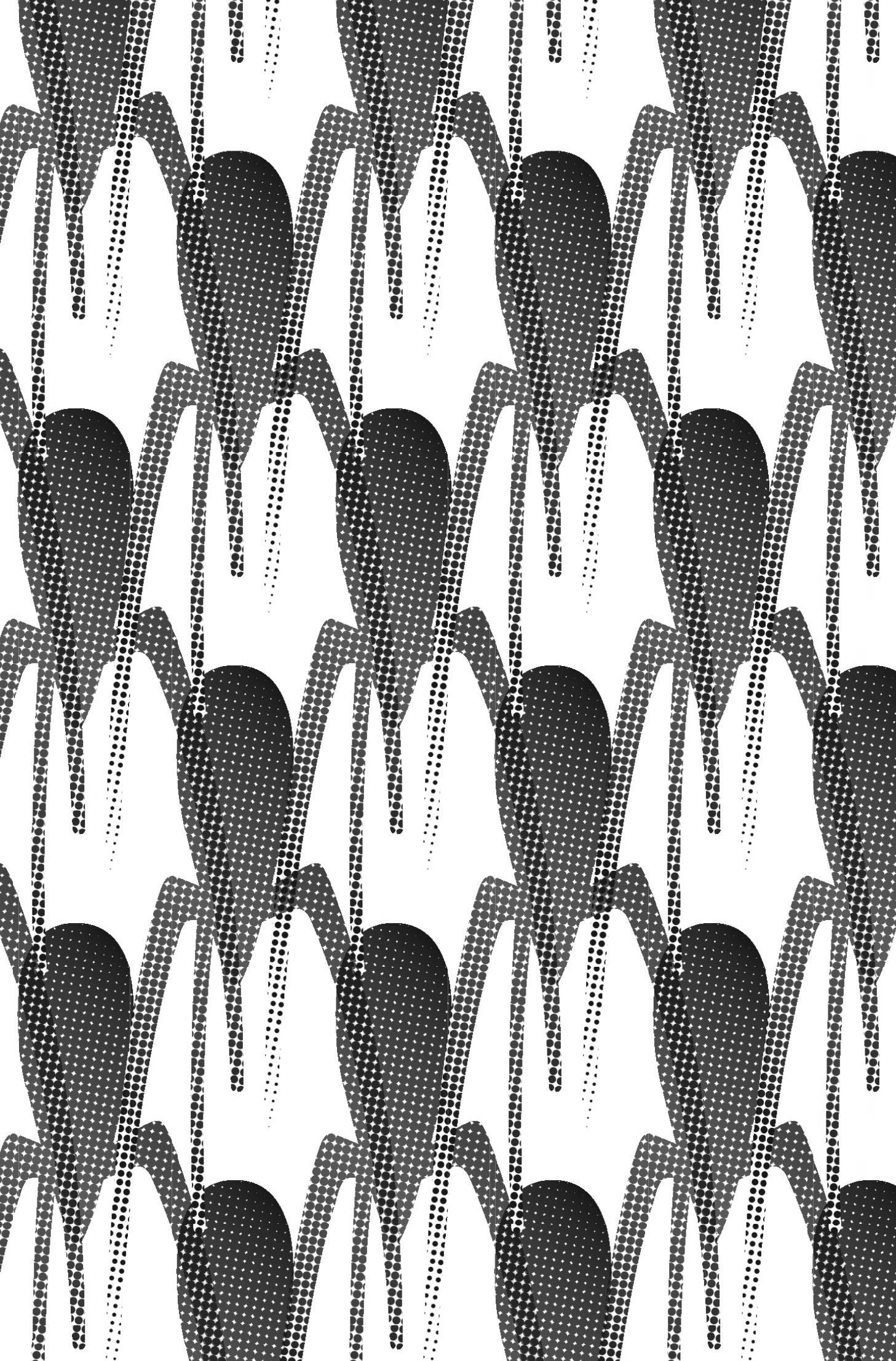


I.

Einleitung 
»Im Grunde tendiert die Menge der nicht im Licht der Öffentlichkeit stehenden Entwerfer gegen unendlich.« 


\section{Esse est percipi}

»Designer haben keine Macht«. So lautet der Titel eines Interviews mit der Designerin INGA SEMPÉ, »Frankreichs kreative[m] Stern« das der TAGESSPIEGEL im Jahr 2012 veröffentlichte. Im Verlauf der Fragen entwickelte es sich zu einer selbst- wie disziplinkritischen Stellungnahme einer Designerin zu ihrem eigenen Metier und der Berühmtheit, die die Journalistin sich zu Beginn sicher nicht so vorgestellt hätte. (MEPLON in: DER TAGESSPIEGEL vom 21.08.2012) [online] https://www.tagesspiegel.de/themen/wohnen/frankreichs-kreativerstern-designer-haben-keine-macht/7027620.html [27.07.2018]

Der Teaser »Inga Sempé ist derzeit Frankreichs innovativste Designerin, die dennoch einen sehr nüchternen Blick auf die Branche wirft. Ein Gespräch über Leere, Überfluss und die Mühsal des Zeichnens." geht dieser Einleitung voran:

»Die vielgefragte französische Designerin Inga Sempé (Jahrgang 1968) hält nichts von viel Tamtam und Plaudereien. Sie gilt als eine der wichtigsten und innovativsten Designerinnen unserer Zeit, aber sie erklärt vor vollen Sälen ohne Umschweife, dass sich ihr Werk nicht verkauft. In Interviews spricht sie mit bestürzender Offenheit über ihre Rückschläge. Selten begegnet man jemandem, der so entschlossen ist, sich ja nicht besser, erfolgreicher oder sympathischer zu geben, als er ist."

Einer Passage über ihre Eltern, den Illustrator JEAN-JACQUES SEMPÉ (den Erfinder von Der kleine Nick) und ihre Mutter METTE IVERS-SEMPÉ, die mit der Formulierung »hat eine gute Reputation als Malerin und Illustratorin« ebenfalls ein adäquates Renommee attestiert bekam, folgte:

"Sie arbeitete nach ihrem Industriedesign-Studium, das sie 1993 in Paris an der renommierten Ecole Nationale Supérieure de Création Industrielle abschloss, bei Marc Newson und Andrée Putman, beide Weltspit- 


\section{STARDESIGNER ODER GESTALTER DES ALLTÄGLICHEN?}

ze, aber um ihre Reputation macht sie kein großes Aufheben. In Italien experimentierte sie mit einer Technik, mit der sie große Aufmerksamkeit erregen [Hervorhebung des Verfassers] sollte: plissieren oder falten. Die ersten Unternehmen, die ihre Entwürfe in die Produktion aufnahmen, waren die italienischen Möbelmarken Cappellini und Edra.»

Was haben wir hier, genauer besehen, vor uns? Den Versuch, auf wenigen Zeilen ein strahlendes, wenn auch leicht angemacktes Bild einer ebenso erfolgwie einflussreichen und auch widerspenstigen Designerinnenpersönlichkeit zu fabrizieren, die, indem sie von ihren Rückschlägen kündet, dem unbefleckten Erfolgstopos widerspricht. Sodann den Nachweis einer renommierten Ausbildungsstätte und die daran anschließende Tätigkeit bei Gestaltern der Weltspitze. Dem nachfolgend der Aufmerksamkeitsauslöser in Form einer USP - »aber um ihre Reputation macht sie kein großes Aufheben." Die Journalistin dafür um so mehr. Machen wir uns kurz bewusst, welche geballte Masse rufkonstituierender oder -befestigender Begriffe für eine einzige Person uns bereits begegnet ist - auf den ersten 19 (nur zum Interview hinführenden) Zeilen plus Bildunterschrift des Web-Artikels:

1. Frankreichs kreativer Stern

2. derzeit Frankreichs innovativste Designerin

3. BILDUNTERSCHRIFT: Französische Avantgardistin. Inga Sempé zählt mit ihren originellen Entwürfen von Haushaltsgegenständen und Möbeln zu Frankreichs Topdesignern. Sie arbeitete schon mit Firmen wie Cappellini, Edra, Magis, Baccarat, Pallucco und David Design zusammen.

4. [d]ie vielgefragte französische Designerin

5. gilt als eine der wichtigsten und innovativsten Designerinnen unserer Zeit

6. nach ihrem Industriedesign-Studium [...] an der renommierten Ecole Nationale Supérieure de Création Industrielle

7. arbeitete [...] bei Marc Newson und Andrée Putman, beide Weltspitze [...]

8. In Italien experimentierte sie mit einer Technik, mit der sie große Aufmerksamkeit erregen sollte

9. Die ersten Unternehmen, die ihre Entwürfe in die Produktion aufnahmen, waren die italienischen Möbelmarken Cappellini und Edra.

Hier wird jemand buchstäblich über den grünen Klee gelobt und in dieser Masse des Lobes verbergen sich zu über der Hälfte nichts als unbelegte Postulate. Fünf Reputationsquellen (3, 6, 7, 8 und 9) werden tatsächlich kenntlich gemacht, von denen sich zwei indirekt aus ihrem beruflichen Werdegang speisen 
(6 und 7) und drei sich auf ihren einerseits publizistischen und andererseits angenommenen geschäftlichen Erfolg beziehen (3, 8 und 9).

Wenn Sein also Wahrgenommenwerden ist, dann wird mit diesem Interview in aller Deutlichkeit auf einen bereits erreichten Status hingewiesen: Erstens, dass diese Frau bereits wahrgenommen wurde und wird. Zweitens, dass und wie sie wahrzunehmen sei - als eine bereits in außergewöhnlichem Maße herausragende Vertreterin ihres Berufsstandes. Zu gleicher Zeit erfahren wir so gut wie nichts darüber, weshalb! Ihr Studium wird durch eine renommierte Hochschule mit Bedeutung aufgeladen (6)- was sie dort tut und ob das schon ein Vorschein wahrgenommener Größe gewesen sein könnte, wird nicht erwähnt. Ihre anschließende Berufstätigkeit bei Gestaltern der Weltspitze (7) macht sich die gleiche argumentative Strategie zunutze: Der Nimbus der Weltgeltung der beiden Bureaus, für die sie tätig war, lässt die Bedeutung für SEMPÉ einfach mitschwingen. Denn wie hätte es diese junge Frau wohl sonst geschafft, in zwei Bureaus von Weltniveau anheuern zu dürfen, als dadurch, dass sie selbst schon so besonders gut in ihrem Metier gewesen ist, dass man sie dort wahr- und annimmt? Beides geschieht jedoch nur in unserem Kopf und auch nur, wenn wir im Besitz des entsprechenden Wissens sind, um den Hinweis auf das französische Schulsystem und die beiden Gestalter zu entschlüsseln.

SEMPÉs USP, das Plissieren und Falten, wird in vergangener Zukünftigkeit gefasst und in den Vorschein einer inzwischen eingetretenen Zukunft gekleidet, die ebenfalls sehr erfolgreich sein soll (8). Ihre Bedeutung als Designerin wie ihr wirtschaftlicher Erfolg soll ferner aus der Zusammenarbeit mit bestimmten Firmen ermessen werden $(3,9)$ - ein Maßstab, der ebenfalls nur durch Kenntnisse über die Akteure des Designmarktes eine weitergehende Bedeutung beim Leser erlangen kann. Bisher ist noch nichts über die berufliche Leistungsfähigkeit dieser Designerin und das, was sie bis zu diesem Zeitpunkt entworfen hat, zu lesen: Außer, dass sie mit »originellen Entwürfen von Haushaltsgeräten und Möbeln« (3) in Erscheinung getreten sei. Trotzdem sollen wir inzwischen von ihr annehmen, dass dieser kreative Stern Frankreichs als die innovativste Avantgardistin unter Frankreichs Topdesignern gelte und darüber hinaus als eine der wichtigsten und innovativsten Designerinnen unserer Zeit, die nach einem Studium an einer renommierten Hochschule und Mitarbeit bei Gestaltern der Weltspitze als vielgefragte, wichtige französische Designerin bereits große Aufmerksamkeit erregt habe, was sich in der Zusammenarbeit mit Firmen wie [...] ausdrücke und dass sie von Cappellini und Edra quasi entdeckt worden sei. 
SEMPÉ hingegen unterläuft diese Strategie. Sie gibt mit ihren Antworten das Bild einer Stardesignerin ab, die einen notwendig verkürzten, doch realistischeren, fast gar nichts glamouröses an sich habenden Arbeitsalltag neben jene dick aufgetragene Jubelschicht stellt. Sie bringt die Autorin damit in die unangenehme Lage, nicht mühelos weiterhin die Jubelperserin einer Stardesignerin geben zu können, wie deren leichtfüßige bis leicht kritisch interessierte und bisweilen auch boulevardeske Fragen es nahezulegen scheinen. Denn ihre Interviewpartnerin lässt sich nicht widerstandslos ins Zaumzeug der Größe schirren, sondern sie antwortet Mal um Mal mit vertiefter und weitergehender Kritik an ihrem Berufsfeld, mit der Schilderung eher glanzloser Details desselben und den Schwierigkeiten des Geldverdienens.

Ebenso nimmt sie zur eigenen Prominenz und den prominenten Kollegen Stellung, die ihrer Meinung nach als »kleine Minderheit die ganze Aufmerksamkeit [Hervorhebung des Verfassers] der Medien« bekämen, obwohl sie "[a]lles in allem [...] fürchterlich wenig im Verhältnis zu der totalen Masse an Objekten, die momentan in der Welt produziert werden « beitrügen. »Dennoch [werde] diese kleine Gruppe, zu der auch ich gehöre [Hervorhebung des Verfassers], durch die Medien immer mehr nachgefragt.«Zugleich sehe sie sich - als bekannte Designerin - mit Vorwürfen konfrontiert, ob sie denn über die Umwelt nachdächte und sich dessen bewusst sei, dass sie mit ihrer Arbeit zum Konsum anrege, was den Unterton trüge, ob sie sich nicht dafür schäme [als Designerin tätig zu sein und eben dieses mithervorzurufen - Ergänzung des Verfassers].

Die relativ zu Beginn gestellte Frage nach ihrem Medienecho wird von SEMPÉ mit dem Konter beantwortet, dass dieses keine Garantie dafür sei, dass man auch ein Einkommen habe (!) und führt im Verbund mit den zuletzt zitierten Zeilen zu des Pudels Kern: der Tendenz der Publizistik, Prominenz durch eine entsprechende Berichterstattung mit überbordender Wortwahl regelrecht zu produzieren: Auf eine so offensichtliche und fast schon plump zu nennende Weise, dass es auch wirklich jedem auffallen muss und natürlich etwas davon im Gedächtnis hängenbleiben soll. Jener Artikel ist in seinen Grundzügen fast schon prototypisch als mustergültige wie maßgebliche Form der Rezeption anzusehen. Mit so vielen lobhudelnden Worten ist ein dahinterliegender Problemkomplex umrissen, der auch im Design als eine der Kernfragen unserer Zeit betrachtet werden muss: Aufmerksamkeit ist zu gewinnen, man muss sie auf sich ziehen, an sich binden, sich einen Ruf erarbeiten, wachsendes Ansehen genießen, letztlich berühmt werden und bleiben und damit auch in allen Stufen in die 
Presse gelangen. Womit der Punkt erreicht ist, an dem mein Erkenntnisinteresse einsetzt: Sind Designer zu den Stars ihrer Branche geworden und soll(t) en sie das sein? Oder sind sie doch nur die Gestalter des Alltäglichen, die Erfüllungsgehilfen der Industrie und die Unterstützer von Konsumentenbedürfnissen - gefangen im Korsett von Aufträgen und deren technischen wie sonstigen Rahmenbedingungen?

Einer der wenigen deutschen Designgeschichtsschreiber hat sich zum Phänomen der Prominenz unter Designern bereits ansatzweise Gedanken gemacht. SELLE merkt in der erweiterten Neuausgabe der Geschichte des Design in Deutschland an, dass in den 8oer Jahren »[d]ie Rolle des Designers [...] neu bestimmbar« erscheine und dass »diese Formbefreiung « ihren Auslöser in Italien habe (SELLE 2007: 268). Er verankert den Beginn des »Medienereignis [ses] Design « in eben jenem Jahrzehnt und weist auch auf einen erheblichen Unterschied zwischen italienischen und deutschen Entwerfern hin, der darin bestehe, dass die Italiener immer »in die übliche Entwurfspraxis integrierte Industriedesigner" gewesen sind, im Gegensatz zu den Deutschen, deren »künstlerisch-individuelle Freiräume« dem »existentielle[n] Hintergrund der Auftrags- und Arbeitslosigkeit « entsprungen seien (ebd.: 269) - eine bittere Bilanz für Deutsches Design als Experiment (EISELE 2000)!

Wenn »[d]ie Hoffnung auf persönliche Erfolge [...] zur ästhetischen Auffälligkeit und Unverwechselbarkeit« zwingt (SELLE 2007: 269), dann führt sie in unerbittlich direkter Linie zur Hauptfigur dieser Arbeit, dem Stardesigner, den SELLE als »Star-Designer« führt und zu dem er natürlich ebenfalls eine Positionierung finden muss. Sie lautet:

»Im Grunde tendiert die Menge der nicht im Licht der Öffentlichkeit stehenden Entwerfer gegen unendlich. Nur wer einen Namen hat, mit dem er aus dem Heer der Konkurrenten herausragt, kann zum Star-Designer aufsteigen [Hervorhebung des Verfassers].« (ebd.: 342)

Sowie ferner:

"Star-Designer wird nur der stets medienpräsente, als überaus beweglich geltende, ökonomisch erfolgreiche, bei bekannten Herstellern in aller Welt Entwürfe streuende Groß-Designer, den man weder mit dem Werkstätten-Entwurfskünstler um 1900, noch mit dem sachlichen > Gestaltingenieur der Ulm-Nachfolgezeit vergleichen kann. Der Star-Designer ist Produkt des Medienzeitalters und der Globalisierung, ein berufssoziologisch noch kaum erfasster Typus, der anzeigt, was heute vom Design erwartet wird: die Verwandlung alles Banalen in eine Schönheitsmaske des Banalen durch die Hand einer Berühmtheit.« (ebd.: 342f) 
"Ob ein Plastik-Papiereimer von Karim Rashid oder Konstantin Grcic transluzid oder opak ist, seinen Zweck auf bestimmte Weise erfüllt oder nicht, ist unerheblich, zur Hauptsache wird die Signatur seiner Herkunft. [...] Objekt und Entwerfer müssen Prominenz behaupten.» (ebd.: 343)

\section{Der persönliche Zugang}

speist sich aus verschiedenen Quellen: Einerseits Artefakte mit funktionalen Defiziten, denen man einen Styling-Überhang attestieren könnte - im Sinne von Verschönerung ohne Verbesserung der Funktion. Andererseits aus dem Kult um Designer wie um Artefakte - auch in Verbindung mit einer kritischen Auseinandersetzung mit der eigenen Rolle: „Der Star-Designer ist Produkt des Medienzeitalters [...]«. Damit ist der Punkt, an dem diese Arbeit ansetzt, klar benannt und infolgedessen steht die Untersuchung eben jener medialen Konstruktion wie simultanen Produktion von Prominenz durch ihre Rezeption im Zentrum des hier versammelten Forschungsinteresses.

Die Phänomene Stardesign und Designklassiker werden an den Punkten betrachtet, an denen sie publizistisch entstehen. Dabei geht es auch um Prominenzierungsstrategien, die so bereits im HOLLYWOOD der Frühzeit erprobt wurden. Die Erringung medialer Aufmerksamkeit für Produkt und Produzent, das In-Gang-Bringen eines Reputationszyklus: Bekanntheit, Interesse, weitergehendes Interesse, geteiltes Interesse, wachsende Bekanntheit etc. etc. ad nauseam.

Doch die Erweiterung um Artefakte erfordert eine wesentliche Verschiebung des Fokus, da Methoden bisheriger Star- oder Prominenzforschung wegen des fehlenden Blicks auf Artefakte nicht einfach auf das Feld des Designs angewendet werden können. Jene Artefakte, die ihre eigentliche Funktion nicht zufriedenstellend erfüllen, aber dennoch aufgrund ihrer exaltierten Form zu weithin bekannten und bestens verkauften Produkten avancieren und damit alle Kennzeichen tragen, die in einer FRANCKschen Aufmerksamkeitsökonomie relevant sind, führen uns zu einem Landsmann SEMPÉs, dem Franzosen PHILIPPE STARCK, dessen Zitronenpresse JUICY SALIF (für ALESSI) zum Kronzeugenartefakt für ein verändertes Verhältnis zu Artefakten auf der Seite der Konsumenten wie auf der Seite der Designer wird. PHILIPPE STARCK und der JUICY SALIF werden im Verlauf dieser Untersuchung auch weiterhin eine besondere Rolle spielen.

Die hier dokumentierte Forschungsleistung ist eine Forschung über Design aus einer designtheoretischen Perspektive, die keine Handlungsanwei- 
sungen oder direkte berufsspezifische Perspektiven für die betrachtete Disziplin anstrebt. Sie darf als Beginn einer Erkundung verstanden werden, die mit der Untersuchung der publizistischen Rezeption von Designern und Artefakten bisher die Außenperspektive untersuchte und im Weiteren Erkenntnisse zur Reaktion der unterschiedlichen Akteure auf diese Rezeption erst wird erbringen können.

Die Frage danach, wie Design wirkt, wird aus meiner Sicht in den vergangenen Jahren aus der Disziplin heraus zunehmend aus der Perspektive der Funktionalisierbarkeit betrachtet. Die Bemühungen laufen auf einen PAWLOWschen Konsumenten hinaus - zur Befriedigung eines gar nicht so sehr versteckten Sicherheitsbedürfnisses auf der Seite der Produzenten. Der Deckmantel der Bedürfniserfüllung verhüllt die Anstrengungen, gestalterische Entscheidungen durch wissenschaftliche Erkenntnisse zu legitimieren und damit auch Investitionen, nur unvollkommen. Die Sicherheit, das Richtige getan zu haben, die Minimierung unternehmerischen Risikos, die Minimierung gestalterischer Fehlentscheidungen im Hinblick auf zu tätigende Investitionen und gesättigte Märkte.

Bemühungen zur wissenschaftlichen Belegung des Geschmacks, letztlich die Operationalisierbarkeit einer passenden Form, die (auch) wissenschaftlich belegbar sein soll und in der Folge quasi eine vorentworfene Verkaufsgarantie abgibt: Man untersuche, wie potentielle Kunden auf Entwürfe reagieren, um damit gestalterische Entscheidungen zu legitimieren wie der Produzent seine Investitionen und mit diesem Erfolgsrezept wird sich das Produkt "natürlich" auch verkaufen. Wenn wir kurz an die Geschichte der Produktentwicklung zurückdenken, muss die Frage erlaubt sein, ob dadurch auch gute Gestaltung realisiert wird. Was Bedürfniserfüllung tatsächlich bedeutet und gute Gestaltung mit Blick auf Artefakte ist, wird jeden Tag in der Disziplin und in der Gesellschaft in allen ihren sozialen Schichten und auch an der Ladenkasse neu verhandelt - mit Hilfe sozialer wie medialer Vorbilder. Ebenso, welche Personen als vorbildgebend zu betrachten seien. Wie die Vorbildhaftigkeit jener Personen und von ihnen entworfener Artefakte zu Stande kommt, ist Kern der vorliegenden Untersuchung. 



\section{Zielsetzung und Struktur der Arbeit}

\section{Zum Stand der Forschung}

Es gibt bisher keine Forschung zur Prominenz im Feld des Designs, die sich ein Bild der Lage in der Form gemacht hätte, wie es mit dieser Arbeit angestrebt wird. Insofern wird das Forschungsproblem hier in dieser Form zum ersten Mal untersucht und es stellt bis dato eine echte Forschungslücke dar ${ }^{1}$.

\section{Zentrale Forschungsfragen}

- Wie entstehen Stars und Designklassiker im Feld des Designs?

- Bestehen signifikante Unterschiede zwischen Alltagsdesign und Stardesign?

\section{Methodik}

Die übergeordnete Forschungsmethode ist der GROUNDED THEORY-Ansatz von GLASER und STRAUSS. Zur Erklärung sozialer Phänomene, von Verhaltens-

1 Das Thema findet zögerlich seinen Weg in die Forschungsöffentlichkeit, wie sich z. B. an einer Bachelorarbeit an der FH POTSDAM erkennen lässt (SEELENMEYER 2016: Superstar Designer. Über die Sichtbarkeit von Designerinnen in der heutigen Grafikelite, Bachelorarbeit im Fach Kommunikationsdesign an der Fachhochschule Potsdam). 
mustern und menschlichem Verhalten bot sie sich als Werkzeug für die Untersuchung des Sozialphänomens Star im Feld des Designs an. Mit Blick auf die quantitative Empirie der beiden Publikationsstudien sind selektive und zufällige Samplings auf der Basis von Vorwissen, jedoch mit eher unkonkreten Hypothesen das passende Vorgehen für eine komparative Analyse der erhobenen Daten und ihre nachfolgende Auswertung.

An einigen Stellen kommt LATOURs AKTEUR-NETZWERK-THEORIE zum Einsatz, da es im Zusammenhang dieser Untersuchung auch um Netzwerke aus menschlichen und nichtmenschlichen Aktanten geht, was sowohl die Mensch-Artefakt-Beziehungen betrifft als auch die Akkumulationsprozesse der Aufmerksamkeit mit ihren begrifflichen Symbolen und der Art, wie sie zirkulieren.

\section{Beschränkungen}

Diese Untersuchung bleibt auf der empirischen Seite eine reine Rezeptionsstudie, die auf diese Weise auch die Produktionsversuche von Prominenz durch einen Teil der Rezipierenden beleuchten kann. Eine Analyse der Rezeption dieser Rezeption und wie sie sich bei Marktteilnehmern auswirkt, steht noch aus.

\section{Beiträge für die Forschungslandschaft}

- Ein ebenso breiter wie präziser Blick auf die sprachlichen Formen der Produktion von Prominenz bzw. wie dies versucht wird. Diese Untersuchung weist nach, dass den verwendeten sprachlichen Steigerungsmitteln über die ihnen eigene Symbolfunktion hinaus keine erkennbaren fachlichen Maßstäbe unterlegt sind und dass sie nur wie Abziehbilder verwendet werden, die man den Designern zur Dekoration einfach anheftet - was keinesfalls absichtslos geschieht.

- $\quad$ Es wird dargestellt, weshalb Designer Prominente der zweiten Reihe sind und bleiben und wie sich die Prominenz im Feld des Designs qualitativ von jener im Feld der Kunst unterscheidet.

- Ein Theoriemodell für den ökonomieähnlichen Tausch von Ansehen belegt, dass in sozialen Feldern und hier im Speziellen im Feld des Designs tatsächlich mit akkumulierter Aufmerksamkeit gehandelt wird. Damit 
kann 20 Jahre nach GEORG FRANCKs Essay nachgewiesen werden, dass eine Ökonomie der Aufmerksamkeit (schon lange) existiert.

\section{Zur Struktur der Arbeit}

Sie ist nach ihrer Einführung in vier große Blöcke gegliedert, deren Verlauf sich schon am Beginn der üblichen Vorgehensweise, in einer Einführung den Stand der Forschung kurz und knapp zu referieren, widersetzen muss - weil es noch keinen spezifischen Stand der Forschung gab und deswegen die Erörterung der Grundlagen als notwendiger Bestandteil in die jeweiligen Kapitel verschoben wird. Die Frage danach, was es im Umfeld schon alles gebe, erweist sich als eine sehr grundsätzliche, sowohl auf dem Territorium der Forschung wie mit Blick auf designspezifische Veröffentlichungen, Ausstellungen etc.. Weil dieses Forschungsvorhaben mit dem Anspruch begonnen wurde, die Untersuchung der Prominenz im Design von Grund auf neu anzugehen, müssen mehrere Einzelaspekte in großer Breite untersucht werden.

\section{Aufmerksamkeit, Prominenz, Anonymität und Rezeption}

sind als Denkflächen im Sinne eines designbezogen grundlegenden Erkenntnisgewinns zum jeweiligen Unterthema anzusehen. Möglichkeiten, den über jedem Kapitel stehenden Begriff im Feld des Designs zu denken, werden weiträumig ausgelotet. Die vorgefundene Literatur stellt in ihrer Breite weniger Stände der Forschung bereit, die im Feld des Designs einfach hätten Anwendung finden können, indem man sich auf diese bezieht und sie ggf. weiterentwickelt. Sie bietet jedoch die Gelegenheit, sehr detailliert über die Einzelaspekte in Verbindung mit dem Design nachzusinnen, um erst am Ende zu einer Synthese anzusetzen. Da die hier referierte Literatur in ihrer Breite nicht nur als Beleg für eigene Überlegungen verwendet wird, sondern durch ihre schiere Existenz erst einen präzisen Blick auf das komplette Feld ermöglicht respektive den jeweiligen Aspekt selbst mitkonstituiert, wird sie als zentraler Bestandteil erachtet und auch so behandelt.

\section{Aufmerksamkeit}

ist der Kernbegriff des zweiten Teils, der seinen gedanklichen Bezugspunkt in GEORG FRANCKs Essay Ökonomie der Aufmerksamkeit. Ein Entwurf aus dem Jahr 1998 setzt. Das Spektrum der versammelten Kritik, die FRANCK diskursiv 
aufgreift sowie anderer Arbeiten, die die Aufmerksamkeit unter gänzlich anderen Gesichtspunkten betrachten, reicht nach Jahren von 2001-2014. Nach einem kurzen Überblick zum Umfang der Schriften, die im Vergleich zu FRANCK betrachtet werden und dem, was dieser selbst bisher zur Aufmerksamkeit veröffentlicht hat, wird selbige definitorisch für diese Arbeit expliziert und darauf folgend FRANCK anhand seiner zeitlich gesehen unmittelbarsten Kritiker genauer unter die Lupe genommen. Weitergehende Überlegungen zur Zeitlichkeit von Designklassikern, die mit FRANCKs Modus des Dauerns kongruent sind und die Ortskurven von Artefakten auch im Zusammenhang mit LATOUR und STERLING anders zu denken versuchen, sowie dazu, wie Abglanz-Prominenz sich im Feld des Designs manifestiert (und wie das wiederum die Anforderungen an die Betrachtung verändert), finden sich im anschließenden Kapitel. Darauf folgt ein ausführlicher Vergleich des Films als Repräsentant des Filmstars mit Artefakten als Repräsentanten der Designer, um daran Implikationen für die Prominenzforschung im Feld des Designs darzustellen.

Selbst, wenn man FRANCKs Essay einmal nicht als defizitär wahrnimmt (was vor allem die Kritiker aus den Reihen der Ökonomietheorie tun), gibt es zur Aufmerksamkeit doch noch deutlich mehr darzustellen: von CRARYs kunstgeschichtlich motivierter Betrachtung über BLEICHER und HICKETHIERS unmittelbare anthologische Abarbeitung an FRANCK und WALDENFELS' Phänomenologie reicht dies bis zu BERNARDYs Nachwirkungsanalyse. Nach dieser Erweiterung um andere Blickwinkel werden die Kernpunkte bilanziert und weitere Positionen herangezogen, die erst im Verlauf der Arbeit an Bedeutung gewinnen und den Denkraum noch einmal wesentlich erweitern. Die nochmalige Frage danach, ob Aufmerksamkeit wirklich zu einer Währung werden könnte und wie Ansehen getauscht wird, führt zu einem eigenständigen Theoriemodell für den ökonomieähnlichen Tausch von Ansehen, das die Frage, ob eine Ökonomie der Aufmerksamkeit existiert, 20 Jahre später mit Ja beantwortet. Mit Überlegungen dazu, welche individuellen Konsequenzen die Aufmerksamkeitsökonomie für ihre Akteure hat, endet der zweite Teil. Ab jetzt wird uns GEORG FRANCK im Verlauf auch immer wieder begegnen.

\section{Prominenz}

gibt dem dritten Teil Inhalt und Titel. Wird Aufmerksamkeit akkumuliert, führt sie in der Konsequenz zu unterschiedlichen Formen der Prominenz, die sich im Feld des Designs für Personen begrifflich als Star-Designer und auf Artefakte bezogen in Form der Designklassiker (Design-Ikonen/Moderne Klas- 
siker) manifestieren. Auf Überlegungen dazu, wie sich Star-Design und Prominenz zueinander verhalten, folgt eine erste Erkundung des Problemfelds. Diese führt im Verbund mit der Abglanz-Prominenz zur Frage, ob Star-Designer tatsächlich prominent sind. Im Verlauf dieser Vorrede wird postuliert, dass Designer als Prominente der zweiten Reihe hinter den von ihnen gestalteten Produkten zurücktreten und danach werden die aktuellsten Veröffentlichungen zur Entstehung von Prominenz - WIPPERSBERG (2007) - und der Nutzbarkeit von Prominenten für den Fan im Sinne identitätskonstruktiver Funktionalisierung - KELLER (2008) - auf ihre Passung im Feld des Designs überprüft. Im speziellen sind WIPPERSBERgs Prominenzierungsspirale und KELLERs Idee des Nutzens für den Fan von weiterführender Bedeutung für die hiesigen Überlegungen. Dann wird die Frage gestellt, ob die Prominenzforschung mit Blick auf das Design neu ausgerichtet werden müsste: Über die Figur des Werk-Stars wird die Verbindung zum Feld der Kunst hergestellt und die identitätskonstruktiven Funktionalisierungen werden am Beispiel der Fans von Modedesignern, Bildenden Künstlern und Produktdesignern mit Blick auf den jeweiligen individuellen und sozialen Nutzen durchdacht. Im Anschluss wird der Transfer von Aufmerksamkeits-Kapital (vgl. RECKWITZ 2012) untersucht, weil im Forschungsumfeld u. a. auch der Begriff der Celebrity Designer Products auftaucht und als ein Beispiel PHILIPPE STARCK mit einer Design-Kollektion für TARGET aufgeführt wird - was sowohl zu einer Betrachtung wie auch zu einer Klärung herausfordert. Dieser Teil endet nach seiner Zusammenfassung mit einem kurzen Exkurs zu Verehrung, Bewunderung und Anerkennung.

\section{Anonymität}

als Gegenpol zum Star-Sein wird im vierten Teil großräumig ergründet. Da das Design, das den Weg in die Medien sucht, findet und nimmt, in dem Design gründet, über das niemand spricht (außer, wenn es nicht gut funktioniert), provoziert »die Menge der nicht im Licht der Öffentlichkeit stehenden Entwerfer [...]« (s. o.) Überlegungen hinsichtlich der Absicht- wie Unabsichtlichkeit von Anonymität. Die innerhalb der Disziplin über die Jahrzehnte immer wieder geführte Auseinandersetzung mit ihr und über sie überrascht in ihrer Breite wie in ihrer Kontinuität. Nach einer kurzen Einführung werden die unterschiedlichen Aspekte in voller Breite diskutiert, denn Fragen nach der Anonymität von Designern und Artefakten sind im Kontrast zum StarSein und den Designklassikern von besonderem Interesse. Die Bandbreite 
reicht von der amerikanischen Masterarbeit Anonymity in Design aus dem Jahr 1966 über die Ausstellungsprojekte Das gewöhnliche Design (1979) und Unbekannt-Vertraut (1987) bis zu einer Sonderpublikation der JAPANESE SOCIETY FOR THE SCIENCE OF DESIGN mit dem Titel Special Issue Anonymous Design aus dem Jahr 1993 - im Anhang zum Kapitel die von ULRIKE SCHLACK übersetzten japanischen Texte. Doch sind wir dort längst nicht am Ende: Ein weiteres Ausstellungsprojekt mit dem Titel Low budget. Objectos di quotidiano nimmt den Faden 1997 wieder auf.

Als zweite wissenschaftliche Auseinandersetzung mit der Materie mit einem speziellen wie besonderen Bezug zum Design und zu einem bestimmten Designer wird hier CARITA MERENMIEs' Dissertation herangezogen, mit der sie 1998 an der TU GRAZ promoviert wird: Kaj Franck (1911-1989) Die designtheoretischen Strömungen unter dem Gesichtspunkt der Anonymität und deren Einfluss auf das Werk von Kaj Franck. KAJ FRANCK stößt 1965 eine Anonymitätsdiskussion in Finnland an, die in ihrer nationalen Tragweite im 20. Jhd. wohl einzigartig ist und im Rahmen von MERENMIEs' Arbeit zum ersten und bisher einzigen Mal untersucht wird. Im Verbund mit der japanischen Publikation wirft sie auch Fragen nach nationalen Designkulturen und -traditionen und ihrem spezifischen Verhältnis zur Anonymität auf. Mit den Ausstellungsprojekten Main Street. Design ohne Designer (2009) und Die Essenz der Dinge (2010) kommt die Auseinandersetzung auf jener Meta-Ebene im Rahmen dieser Arbeit zu ihrem Ende.

Danach wird Anonymität als Teil von Markenkonzepten am Beispiel von IKEA, MUJI und MANUFACTUM betrachtet. Nach einer Antwort auf die Frage, welche Bedeutung der Ausdruck anonymes Design im 21. Jhd. noch haben könnte, schließt Teil vier mit einer Auflistung von insgesamt sieben unterschiedlichen Arten, Anonymität herzustellen (die aus der Literaturbeschau hervortraten), einer weiteren kurzen Reflexion zu den Händlerkonzepten und kulminiert in der Frage, was am Ende noch als Bedeutung des Ausdrucks anonymes Design übrig bleibt.

\section{Rezeption}

Mit der publizistischen Rezeption kommt auch die allmähliche Produktion der Prominenz in Gang. Designer werden in der Presse zu Stardesignern, Topdesignern, Kultdesignern, Weltklasse-Designern u. ä. hochgeschrieben und so ist jenes Phänomen an seiner wahrnehmbaren Spitze zuallererst ein sprachliches. Infolgedessen wird es im fünften Teil Zeit, die Ergebnisse der beiden quantita- 
tiven empirischen Studien darzustellen, mit denen einerseits »[d]er Star-Designer [als] [...] Produkt des Medienzeitalters [...]« und andererseits Designklassiker (sowie auch Design-Ikonen und Moderne Klassiker) untersucht werden.

Die erste Studie fand - komplett internetgestützt - im Zeitraum von JULIAUGUST 2013 statt. Sie umfasst sechs Jahrzehnte eines Korpus von 13 deutschsprachigen Zeitungen und Zeitschriften, der in einem ersten Suchlauf auf das Vorkommen der Suchwörter Stardesigner, Stardesignerin, Designerstar und Designstar hin durchforstet wurde. Ein zweiter Suchlauf zu Artefakten im gleichen Publikationskorpus ging zu Beginn nur vom Begriff Designklassiker aus. Beide Suchläufe waren, der grundgelegten Forschungsmethode entsprechend, als selektive Samplings angelegt, die aufgrund der vielen Beifänge in der Konsequenz zu zufälligen Samplings ausgeweitet werden mussten. Im Herbst 2014 wurde die Entscheidung getroffen, die Suche aufgrund (damals) aktuell relevanter Entwicklungen nochmals fortzuführen, in diesem Fall zwei Publikationen genauer zu betrachten und zugleich den Korpus im Ganzen nochmals zu erweitern.

Nach einer ersten Darstellung der Auswertung mit Blick auf Personen folgt eine Detaillierung mit Blick auf die verwendeten sprachlichen Mittel. Um Artefakte in Form von Designklassikern und Designikonen geht es danach. Die Beschreibung der Konsequenzen, die die gefundenen Anzeichen für gezielte Re-Popularisierung für die erste Studie hatten, wird gefolgt von den im Korpus gefundenen Bezeichnungen für Artefakte. In einer ersten Bilanz werden gefundene Artefakte und bereits ermittelte Star-Designer abgeglichen. Im Weiteren geht es um Belege für gezielte Re-Popularisierung, um die interne Prognostik zu den "Klassiker[n] von morgen « im Magazin SCHÖNER WOHNEN und nachdem analysiert worden ist, auf welch unterschiedliche Weisen definiert wird, was ein Designklassiker sei, werden die Klassiker-Profile nach Publikationen in all ihrer Herrlichkeit ausgebreitet. Die Jahrzehnt-Profile drängen förmlich dazu, nach einer Vergleichbarkeit zwischen publizistisch populären Designern und populären Artefakten zu suchen. Der Weg dorthin wird durch die Einführung der Komposita Supra- und Supra-Designklassiker sowie Sup$r a^{2}$-Designer geebnet. Ab dann zieht das Ikonische uns hinan, denn mit den publizistischen Belegen alleine ist es nicht getan: Auch das Verhältnis von Menschen zu Artefakten verlangt danach, genauer betrachtet zu werden. Die Reihe der dazu herangezogenen Autoren reicht von MIKLAUTZ über KOHL und BREUER bis zu LENZE, um nach einem Kurzbesuch bei VEBLEN das vorläufige Ziel zu erreichen: den JUICY SALIF und damit wieder PHILIPPE STARCK, der LLOYD und SNELDERS (2003) zu der Frage inspiriert, was sich dieser wohl bei dessen 
Entwurf gedacht haben könnte. Diese Frage ist überaus bedeutsam, denn in Anbetracht einer im Wesentlichen funktionalistisch geprägten Gestaltungstradition werden durch dieses Artefakt die Bedingungen für den Erfolg eines Entwurfs auf den Kopf gestellt. Der Analyse von LLOYd und SNELDERs' Artikel folgt unmittelbar eine Auswahl von Betrachtungen zum JUICY SALIF aus den Federn von COLLINS, ECO, NORMAN, SELLE und ALBERTO ALESSI selbst, die in einer persönlichen Bewertung dieses Identifikationsartefaktes gipfelt.

Eine Zwischenbilanz gibt Auskunft darüber, welches Verhältnis sich aus wissenschaftlicher Sicht zwischen Menschen und Artefakten entwickelt hat. In zehn Kapiteln werden die Ergebnisse der zweiten Studie vorgestellt, die im Herbst 2017 anhand acht ausgewählter Bände von hier als Befestigungsliteratur benannten Publikationen stattfand. Nach einer einführenden Explikation der hiesigen Bedeutung des Begriffes werden neben Klassiker des Produktdesign (EISELE 2014)

1. die Buchreihe Design-Klassiker des FORM-Verlags (1997-2004),

2. Geschichte des Designs (HAUFFE 2014),

3. Design-Atlas von 1850 bis heute (MORTEO 2010),

4. Top Design des 20. Jahrhunderts (JAHR 1999),

5. Das Buch der Klassiker (SCHÄFER 2011),

6. Design-Klassiker. Vom Barcelona-Sessel bis zum iPad (WILKINSON 2013) sowie

7. Masters and their Pieces: Best of Furniture Design (ROTH 2012)

auf ihren Beitrag zur Klassikerproduktion hin untersucht und daraufhin überprüft, ob denn in jenem populärpublizistischen Teilgebiet, das ebenfalls noch zur Produktion von Bereichsprominenz beiträgt, nachweisbare Maßstäbe für die Produktion von Bedeutungen zu finden sind. Die finale Auswertung der Befestigungsliteratur führt zu zehn Schlussfolgerungen hinsichtlich der Erkenntnisse, die sich in summa aus den beiden Studien gewinnen lassen. In den Anhängen zum Kapitel Rezeption sind in der Reihenfolge der Personen-Rangliste sämtliche Zitatstellen aus dem Korpus der ersten Studie versammelt, um der Volatilität der Internet-Suchergebnisse entgegenzuarbeiten und ein auch weiterhin zur Verfügung stehendes Analyse-Fundament bereitzustellen.

Die Coda schließlich im sechsten Teil mit finalen Betrachtungen zu jedem der vier dann zurückliegenden Großkapitel, die von einer Überprüfung aller Hypothesen gefolgt und mit einem Ausblick abgeschlossen wird. 




\section{Hypothesen}

Insgesamt sechs Hypothesen werden im Verlauf der Untersuchung überprüft:

1. Der FRANCKsche Aufmerksamkeitsbegriff lässt sich auf Artefakte ebenso anwenden wie auf Personen.

2. Stardesign hat eigene Aufmerksamkeitsstufen. Wird eine bestimmte Aufmerksamkeitsschwelle nicht überschritten, sinkt das Artefakt in die Aufmerksamkeitslosigkeit zurück.

3. Artefakte können vom Alltagsdesign zum Stardesign überwechseln, da es sich um Zuschreibungen handelt, nicht um Eigenschaften des Designs.

4. Star-Qualität als Produktmerkmal: Wird schon im Entwurf versucht, den Starfaktor zu antizipieren und zu integrieren, die Zuschreibung zu entwerfen?

5. Der Ruhm eines Gestalters kann sich auf die Bewertung der Artefakte auswirken wie vice versa.

6. Der Funktionsraum von Artefakten hat sich verändert - für Designer wie für Nutzer. 


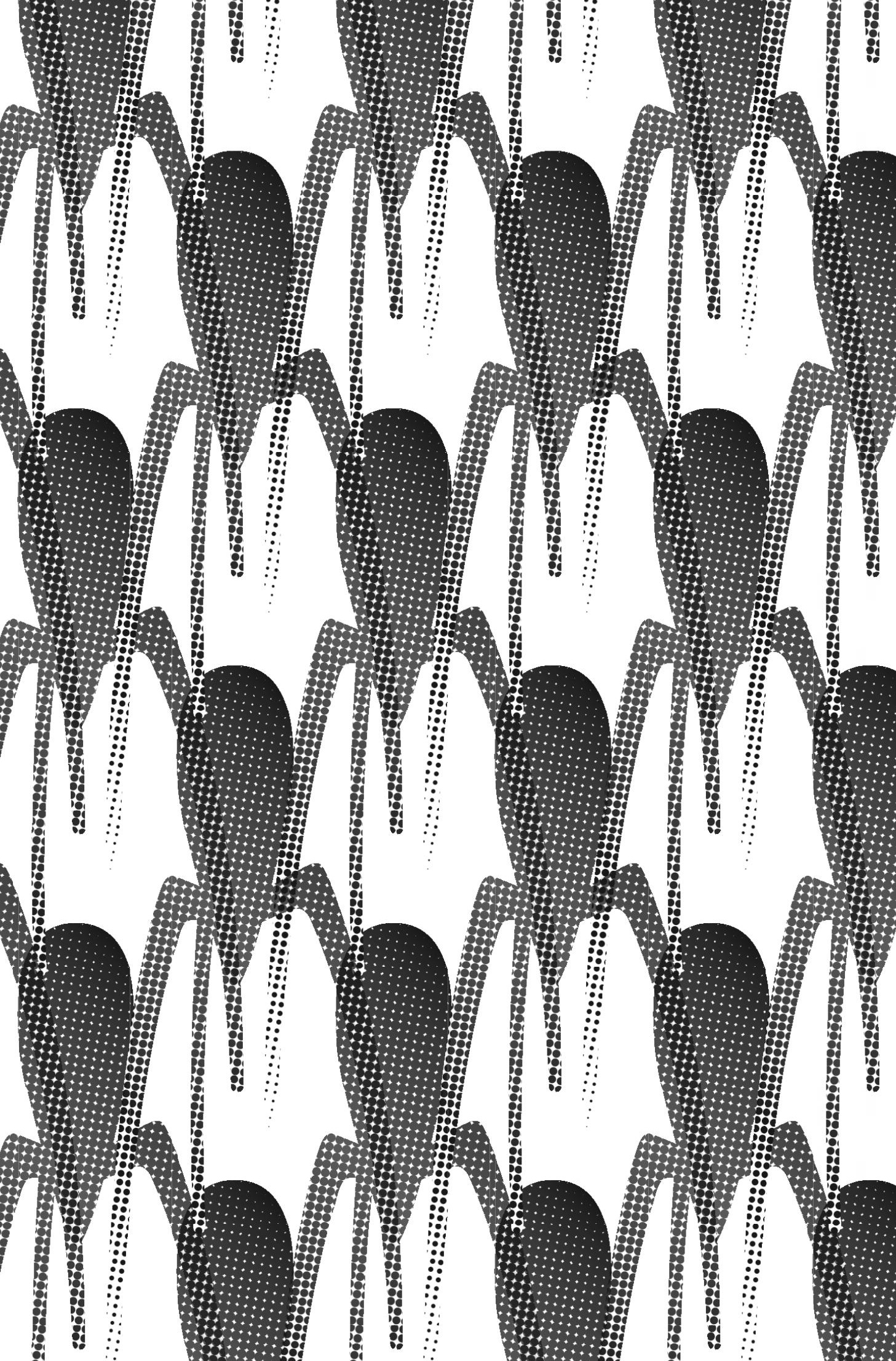


II. Aufmerksamkeit 



\section{Worte - nichts als Worte?}

Aufmerksamkeitsökonomie ist das Schlagwort bestimmter gesellschaftlicher Debatten der späten goer und der frühen Nullerjahre, die sich bis in das zweite Jahrzehnt des 21. Jhd.s ziehen und auch gegenwärtig nicht beendet sind. Sie gehen überwiegend zurück auf Aussagen und Veröffentlichungen des Architekten und Volkswirtschaftlers GEORG FRANCK (ab 1989) und des Physikers MICHAEL GOLDHABER (seit 1997), bei diesem mit einem Fokus auf die Sphäre der Netz-Ökonomie. Im deutschsprachigen Raum verstand es vor allem GEORG FRANCK, das nötige Aufmerksamkeitspotential mit seinen Veröffentlichungen zur Aufmerksamkeitsökonomie für sich zu erschließen - daneben noch FLORIAN RÖTZER mit Artikeln in TELEPOLIS, dieser jedoch verstärkt erst ab FRANCKs erster Buchveröffentlichung.

Diskursiv aufgegriffen wird GEORG FRANCK zuerst in der Publikation Attention Please! Online-Kommunikation und Aufmerksamkeit von BECK und SCHWEIGER im Jahr 2001. BLEICHER und HICKETHIER folgen ein Jahr später mit Aufmerksamkeit, Medien und Ökonomie. Im Bereich der Kunstgeschichte verfasste JONATHAN CRARY 2001/2002 mit Suspensions of Perception: Attention, Spectacle and Modern Culture (Aufmerksamkeit. Wahrnehmung und moderne Kultur) eine vielbeachtete Schrift. WALDENFELS versucht sich 2004 mit der Phänomenologie der Aufmerksamkeit an einer Grundlegung. BERNARDY nimmt den Faden zehn Jahre später noch einmal auf und legt mit Aufmerksamkeit als Kapital 2014 eine Nachwirkungsanalyse FRANCKscher Gedanken vor, die sich ganz eng an die Ökonomie der Aufmerksamkeit anlehnte und deren Gedankengebäude in einem sehr weit ausgreifenden europäisch-philosophischen Zusammenhang einbettet. Jüngst - 2016 - erscheint MÜLLER et al.: Aufmerksamkeit. Neue 
humanwissenschaftliche Perspektiven, dessen Klappentext die Aufmerksamkeit als »ein Schlüsselkonzept gegenwärtiger humanwissenschaftlicher Forschung" charakterisiert. Grund genug, ihr mit Blick auf ihre Auswirkungen im Feld des Designs ein ganzes Kapitel zu widmen.

Das Spektrum der eben erwähnten Autoren begrenzt die hier zum Thema Aufmerksamkeit referierten fremden Arbeiten (jedoch ohne MÜLLER et al. sowie GOLDHABER, bei beiden Veröffentlichungen aufgrund differierender Schwerpunkte, bei letzterem zu allererst wegen der angloamerikanischen Perspektive, aber auch wegen des zu starken Bezuges zur Netzökonomie). Am Ende dieses Kapitels findet sich eine ausführliche Betrachtung weiterer Ansätze, die erst im Verlauf der Arbeit an seinen Grundfesten in den Blick kamen und für so wichtig erachtet werden, dass sie eine zusätzliche intensivere Auseinandersetzung notwendig erscheinen lassen.

Außerdem wird ein Theoriemodell für den ökonomieähnlichen Tausch von Ansehen vorgestellt, das sich im Rückblick nicht einfach als logische Konsequenz aus dem Verlauf der Betrachtungen ergibt. Da es aber ein mehr als nur skizzenhaftes Ergebnis intensiven Nachdenkens über die Plausibilität von FRANCKs Argumentation darstellt, muss es mit eingeschlossen werden. Der Handel mit Aufmerksamkeit - speziell: akkumulierter sozialer Aufmerksamkeit - mit der in einer Ökonomie des Geldes gar nicht gehandelt werden kann, findet tatsächlich statt: Dies wird anhand verschiedener Beispiele demonstriert, die auch aufzeigen, dass es eines theoretischen Ersatzes des ökonomischen Modells durch ein aufmerksamkeitsbasiertes gar nicht bedarf, da beide wie bisher parallel existieren können.

Die Fokussierung auf GEORG FRANCK wird mit seiner Bedeutung für den deutschsprachigen Raum begründet, der in dieser Dissertation als Bezugsrahmen gesetzt wird und mit einem in seinen theoretischen Überlegungen verborgenen Ansatz, der - ohne das jemals empirisch einzulösen - eine Tragweite anstrebt, die in der Betrachtung des sozialen Phänomens Aufmerksamkeit weitreichende Konsequenzen auch für andere Disziplinen hat. DAHINDEN geht so weit, einen »sozialwissenschaftlichen Paradigmenwechsel« wegen des Einbezugs »[...] nicht monetäre[r], sweiche[r] \& Güter wie z.B. soziales Ansehen als eine zusätzliche Dimension des rationalen Handelns« anzunehmen. (DAHINDEN IN: BECK UND SCHWEIGER 2001: 47).

1989 veröffentlicht GEORG FRANCK im MERKUR 486 erstmals unter dem Titel Die neue Währung Aufmerksamkeit. (IEMAR, TU WIEN), [online] http:// www.iemar.tuwien.ac.at/publications/franck_1989c.pdf [14.05.2018] Danach folgen diverse Essays und 1998 sein Schlüsselwerk Ökonomie der Aufmerksam- 
keit. Ein Entwurf. Im Anschluss 2005 noch Mentaler Kapitalismus: Eine politische Ökonomie des Geistes. Die essayistische Herangehensweise des Autors zeitigt eine Oberflächlichkeit, die oft kritisiert wird, weil im Vergleich zu einem empirisch gestützten wissenschaftlichen Vorgehen Sprache in einer eher an WARBURGs Schlagbilder erinnernden Art eingesetzt und betrachtet wird. Damit liegt FRANCK jedoch genau auf der Ebene der in der Presse üblichen Art der Fachlichkeit, mit der bis heute über Star-Designer berichtet wird.

Mit dem in seinen Essays schlummernden Potential greift er dennoch weit aus in den Bereich der Desiderate für andere Forschungsbereiche. Seine ausgespielten Bälle wurden oder werden noch angenommen, so z. B. am Exzellenzcluster LANGUAGES OF EMOTION der FU BERLIN, wo man interdisziplinäre Emotionsforschung betreibt. Die dort betriebene Forschung zu Verehrung und Bewunderung ist Gegenstand eines Gesprächs, das ich 2014 mit INES SCHINDLER führen konnte (siehe: Exkurs am Ende des Kapitels Prominenz). Diesem und den noch folgenden Kapiteln wird vorangestellt, dass im Rahmen dieser Arbeit keine vollumfängliche Darstellung der jeweils angerissenen Einzelthemen A) möglich ist und B) angestrebt wird. Infolgedessen wird C) jetzt und auch im Folgenden keine Aufarbeitung GEORG FRANCKs und anderer Arbeiten im monographischen Sinne oder als Taxonomie zur Aufmerksamkeit vorgenommen, sondern jene in eigene Überlegungen eingewebt, dieselben kritisiert oder zu Kronzeugen gemacht, wo es angebracht erscheint. 
»Der Bekanntheitsgrad der Person ist sogar noch mehr als ein Schatz."

Georg Franck 


\section{Aufmerksamkeit als Metaphänomen}

Die Art der Aufmerksamkeit, um die es in dieser Arbeit gehen soll, ist nicht die Art, wie sie, in der Psychologie fußend, u. a. von JAMES unter selektiver auditiver oder visueller Aufmerksamkeit gefasst wird:

"Every one knows what attention is. It is the taking possession by the mind, in clear and vivid form, of one out of what seem several simultaneously possible objects or trains of thought. Focalization, concentration, of consciousness are of its essence. It implies withdrawal from some things in order to deal effectively with others, and is a condition which has a real opposite in the confused, dazed, scatterbrained state which in French is called distraction, and Zerstreutheit in German." (JAMES 1890: 403)

Weder rein psychologische noch neurophysiologische Aspekte sollen hier im Fokus stehen. Gleichwohl hängen die dem Ganzen zu Grunde liegenden Phänomene, um die es in diesem Kapitel nicht unmittelbar geht, untrennbar mit dem Metaphänomen Aufmerksamkeit zusammen, das herausgearbeitet werden soll. Metaphänomen wird in dem Sinne verwendet, dass ein als übergeordnet gedachter Begriff von Aufmerksamkeit - die auch als soziale Aufmerksamkeit bezeichnet werden kann - die Facetten unserer physiologischen Wahrnehmung der Welt (die Lenkung unserer Aufmerksamkeit je Sinn) ergänzt. Er wird als Einheit betrachtet, die in der Summe eine größere Tragweite hat und die nicht als ein nur physiologisches, sondern als ein in diesem speziellen Fall vornehmlich psychosozial zu betrachtendes Phänomen zu verstehen ist. Die Aufmerksamkeit als Begriff soll hier verstanden werden als im weitesten Sinne - sozial wirksame Form von Beachtung oder auch soziale Aufmerksamkeit. Diese Beachtung setzt nicht notwendigerweise Beachtlich- 


\title{
STARDESIGNER ODER GESTALTER DES ALLTÄGLICHEN?
}

keit als Grund oder Anlass voraus, wie sie GEORG FRANCK in seinem Versuch über die Aufmerksamkeit so fasst:

\begin{abstract}
"Der Bekanntheitsgrad der Person ist sogar noch mehr als ein Schatz. Ab einem gewissen Grad der Bekanntheit wirft der Schatz von sich aus Einkommen ab. Wer hinreichend bekannt ist, findet schon allein aufgrund des Grads seiner Bekanntheit Beachtung. Der Schatz rentiert [Hervorhebung im Original] sich. Er wirft Zinsen ab in der Form, daß seine Beachtlichkeit selber zum Faktor der Wertschöpfung wird. Die Aufmerksamkeit, die die Großverdiener in Sachen Aufmerksamkeit einnehmen, gilt nicht nur ihrer erbrachten Leistung, sondern immer auch dem Faktum ihrer Bekanntheit selbst." (FRANCK 1998: 114)
\end{abstract}

Ist Beachtlichkeit - noch - nicht vorhanden, wird sie durch sich akkumulierende Aufmerksamkeit ja sogar erst konstituiert. Die Akkumulation von Aufmerksamkeit und damit eine Akkumulation der Beachtlichkeit sind zwangsläufig konsekutiv - sofern sie bemerkt werden. GEORG FRANCK selbst geht in seinem Essay so weit, der Beachtlichkeit einen eigenen Kurswert zuzuweisen, den er in den Begriffen Prestige, Reputation, Prominenz und Ruhm verortet (ebd.: 121f). Treffend beschrieben wird dort auch die Idee der allmählichen Trennung von Beachtlichkeit und Anlass:
"Mit wachsendem Reichtum wird der ursprüngliche Grund der Beach- tung zunehmend durch die Attraktivität, die die Beachtlichkeit von sich aus entwickelt, überdeckt. Das Einkommen, das als Zins und Zinseszins anfällt, riecht nicht mehr nach dem Ursprung. Auch die Verrenkungen, die man einmal unternahm, um im Mittelpunkt zu stehen, sind verges- sen, wenn sich die anderen krumm machen, um etwas von der beachtlich gewordenen Aufmerksamkeit zu erhaschen." (ebd.: 128)

FRANCKs Überlegungen kulminieren in sinnstiftender Weise in Bezug auf Aspekte, die im Rahmen dieser Arbeit von Bedeutung sein werden, in einer fokussierten Betrachtung der Fachkompetenz in den Reihen der "[h]ohe[n] und populäre[n] Kultur« (ebd.: 161). Seine bedeutsame Differenzierung liegt in der Aufteilung der Rezeptionsseite, die demnach aus mehreren Publika bestünde, u. a. aus einem Fachpublikum, das einem Laienpublikum ein rezipierbares Angebot macht. Genau so wird das später auch bei WIPPERSBERG (2007) zu finden sein. Die Spezialität der Beachtlichkeit innerhalb des Fachpublikums und in der nachgeordneten Beachtung dieser Beachtung durch ein Laienpublikum besteht aus GEORG FRANCKs Sicht in ihrer Verschachtelung: 
In diesem Vermögen ist nicht einfach Beachtung, sondern Beachtung gewichtet nach Kompetenz beziehungsweise Reputation der jeweils beachtenden Person, akkumuliert. In die Beachtung, die zählt, ist Beachtung, die zählt, verschachtelt. (ebd.: 161)

Eine überhaupt erst beachtbare Kompetenz innerhalb der Fachwelt - auf die man aufmerksam werden kann - setzt also ein gewisses Vermögen an Beachtlichkeit voraus, nach innen wie nach außen. Die Plausibilität und die Potenz dieser Kompetenz müssen auf der Basis einer individuellen Einschätzung der für kompetent erachteten Person bewertet werden. Hielte man die bewertende Person im Vergleich zu anderen für kompetenter, bekäme auch ihre Bewertung ggf. mehr Gewicht, sofern man sie für die eigene Meinungsbildung heranzöge. Die von anderen zugeschriebene Kompetenz ist für sich gesehen jedoch noch kein hinreichender Grund, diesem Wertmaßstab zu (ver-)trauen, was ihre Berechenbarkeit von außen deutlich beeinträchtigt. 
»Aufmerksamkeit ist ein komplexes Phänomen, das aus verschiedenen Perspektiven betrachtet werden kann.« 


\section{Ökonomie der Aufmerksamkeit}

GEORG FRANCKs Überlegungen zur Aufmerksamkeitsökonomie haben beträchtlichen Wirbel verursacht und wirken bis heute nach, wie man auch anhand jüngster Veröffentlichungen feststellen kann. Seine sprachliche Darstellung wirkt auf den ersten Blick stringent, weil er sie ganz direkt an beobachtbaren Phänomenen aus dem sozialen Umfeld anlehnt. Defizite seiner Argumentation tun sich jedoch dort auf, wo sie empirisch zu belegen sind - was er aber gar nicht angestrebt zu haben scheint, denn sonst hätte er sein Unterfangen einerseits anders angehen und andererseits in einer anderen Form als der eines Essays bilanzieren müssen. Leider bleibt von seinem Versuch nichts als diese gefühlt hohe Plausibilität übrig, wie sich bald schon am Nachhall in verschiedenen Publikationen zeigt (vgl. z. B. BECK und SCHWEIGER 2001).

\section{Ist Geld durch Aufmerksamkeit ersetzbar?}

Die Überprüfung darauf, ob Aufmerksamkeit möglicherweise ökonomisierbar wäre oder auch im Rahmen von Wirtschaftstheorien operationalisierbar, muss nicht zwangsläufig zielführend in dem Sinne sein, dass die Propositionen GEORG FRANCKs ihren Anspruch als das Ökonomiemodell der Zukunft einlösen. HUMMEL und SCHMIDT leisten das in BECK und SCHWEIGER mit einer Analyse der Ökonomie der Aufmerksamkeit in Bezug auf ihre Verwertbarkeit als ökonomische Theorie bereits recht früh. Ihr einleitender Zweifel lautet: 


\section{STARDESIGNER ODER GESTALTER DES ALLTÄGLICHEN?}

"Der Zusammenhang zwischen Aufmerksamkeit und Geld ist [...] von den Vertretern der Ökonomie der Aufmerksamkeit nicht klar genug herausgearbeitet und stellt bestenfalls den Versuch eines Analogieschlusses dar, aus dem aber Konsequenzen gezogen werden, die nicht tragfähig sind." (HUMMEL und SCHMIDT in: BECK und SCHWEIGER 2001: 93f)

GEORG FRANCK selbst hat schon Bedenken zur Entwicklung der Aufmerksamkeit in Richtung einer Währung in der Ökonomie der Aufmerksamkeit formuliert:

"Zur Ausbildung einer Währung kommt es, indem eines der Handelsgüter bevorzugt zum Zweck des Weitertauschens eingetauscht wird. Das Gut wird zum gültigen Zahlungsmittel, wenn die Bevorzugung allgemein und dadurch besiegelt wird, daß man es eintauscht, weil die anderen es bevorzugen. Indem es sich als Zahlungsmittel durchsetzt, wird es zugleich zum verbindlichen Maßstab, mit dem der Wert tauschbarer Güter gemessen wird. Eben dieser Maßstab ist es, der im zwischenmenschlichen Tausch der Beachtung fehlt. Sein Fehlen verhindert, daß die Verschiedenheit der Wertschätzung, die meine Aufmerksamkeit von anderen erfährt, in einen einfachen, sozial abgestimmten Wert kollabiert. Am Fehlen einer geeigneten Währung bricht sich die Neigung zum Äquivalenzdenken. So mag es zwar in einem jeden der Köpfe ein Preissystem für fremde Aufmerksamkeit geben, das System schaut dann aber in jedem Kopf wieder anders aus." (FRANCK 1998: 97)

Was die generelle populäre Rezeption dieses Essays wie seine vorherrschende Auslegung angeht, muss man aus heutiger Sicht feststellen, dass er seine Zweifel sehr bis zu leise formuliert hat und sie deswegen mit hoher Wahrscheinlichkeit gerne überlesen wurden und werden. HUMMEL und SCHMIDT begründen die Einordnung der Ökonomie der Aufmerksamkeit als Theoriegefasel anhand von vier Kategorien, die SCHNEIDER (1995: 164-214, zitiert nach HUMMEL und SCHMIDT: 95) für wissenschaftliche Theorien in der Betriebswirtschaftslehre aufgestellt hat. Dieser verlangt dafür

1. eine Problemstellung,

2. einen Strukturkern,

3. des weiteren Musterbeispiele und

4. Hypothesen.

Nur »wenn alle vier Merkmale gegeben« seien, läge eine »vollumfängliche» Theorie vor. (HUMMEL und SCHMIDT in BECK und SCHWEIGER 2001: 95). Um »Theoriegefasel « handele es sich laut SCHNEIDER dann, wenn »nur beabsichtigte Anwendungen eines bildhaften Vergleiches als Lösungsidee genannt« würden, »die Einzelheiten der Abgrenzung von Begriffen und ihrer logischen 
Beziehung untereinander (der Strukturkern) [...] aber im Dunkeln [...]« blieben. HUMMEL und SCHMIDT bilanzieren FRANCKs Ökonomie der Aufmerksamkeit konsequenterweise so:

»Zusammenfassend ergibt sich für die Autoren der Eindruck, dass hier ein offensichtlich vorhandenes und breit diskutiertes Phänomen der New Economy [Hervorhebung im Original] zur Ökonomie bzw.Ökonomik verbrämt wird, ohne reflektierend über weitere Ursachen und Zusammenhänge in diesem Umfeld nachzudenken. Von der Verwendung des Ausdrucks rökonomische Theorier sollte daher im Zusammenhang mit der Aufmerksamkeitsökonomie bis auf weiteres Abstand genommen werden." (ebd.: 105)

\section{Ein Gewebe aus noch unbeachteten Transaktionen und ungeschriebenen Verträgen?}

Wenn die Geldwirtschaft nicht durch eine Ökonomie der Aufmerksamkeit ersetzt wird, weil die Idee einer Aufmerksamkeitsökonomie nicht als ökonomische Theorie taugt, dann müssen die Stellen genauer betrachtet werden, an denen die beiden Systeme sich miteinander verschränken.

SIEGERT (in: BECK und SCHWEIGER 2001: 119) ist der Ansicht, dass es in Zukunft auf die »reibungslose Kopplung der beiden Währungen ankomme [...] - wobei sie die Meinung vertritt, die Geldökonomie werde »zunehmend immateriell« (ebd.: 119). Sie betrachtet gerade das Beispiel der Stars als Beleg dafür, dass die Aufmerksamkeitsökonomie keine Alleinstellung erlangen könne, da sie nie an den Punkt komme, an dem sie »für sich allein genüg[e]« (ebd.: 119), sondern immer nur Mittel zum Zweck des realen Geldverdienens bliebe. Trotzdem gesteht sie der Aufmerksamkeit noch den Status eines Währungsäquivalents zu. Auch GEORG FRANCK schreibt in Mentaler Kapitalismus über die

»[...] Schnittstellen zwischen der Ökonomie des Geldes und der Ökonomie der Aufmerksamkeit. Von keiner Wachstumsschwäche sind der medial vermittelte Sport, die Unterhaltungsindustrie, die Boulevard- und Regenbogenpresse befallen. Unabhängig von Konjunkturen wachsen Werbung, PR und Produktdesign. Mediendesign, visuelle Kommunikation und Branding sind Berufsfelder, die nach wie vor expandieren. Mode, Kosmetik, Fitness und plastische Chirurgie wachsen zuverlässig weiter trotz des seit langem schon hohen Niveaus der Nachfrage. Kurz, der Wunsch, gesehen zu werden, sorgt für Wachstum nicht nur in der Ökonomie der 


\section{STARDESIGNER ODER GESTALTER DES ALLTÄGLICHEN?}

Aufmerksamkeit, sondern auch in der Ökonomie des Geldes.« (FRANCK 2005: 150)

Die Geldwirtschaft und die Auswirkungen akkumulierter Aufmerksamkeit, die nicht nach den Maßstäben einer echten Ökonomie gemessen werden können, verschränken sich demnach deshalb miteinander, weil Kaufentscheidungen oder allgemeiner wirtschaftliche Entscheidungen als Folge von Aufmerksamkeitsentscheidungen getroffen werden können. Der einstige Modebegriff Aufmerksamkeitsökonomie umschreibt die Auswirkungen von Wertbeimessungen in größeren sozialen Zusammenhängen, die allem Anschein nach tatsächlich in der Gesellschaft zwischengespeichert werden können; in diesem Punkt gibt es eine Übereinstimmung mit DAHINDEN (vgl. DAHINDEN in: BECK und SCHWEIGER 2001: 44).

Zwischengespeicherte Aufmerksamkeit manifestiert sich, weil bestimmte Prozesse oder auch Rituale sozialen Handelns in Begriffe gefasst, gelernt, verstanden und verwendet werden können (s. u.). Als echtes Tauschmedium scheint die Aufmerksamkeit trotzdem nicht zu taugen, hier wird vorläufig DAHINDEN (ebd.: 44) gefolgt und noch einmal an GEORG FRANCKs Zweifel aus dem vorherigen Abschnitt erinnert: Das Problem der Konvertierbarkeit, der eine echte, greifbare und verbindliche Quantifizierung sowie Standardisierung der Aufmerksamkeit vorausgehen muss, damit ein verlässlicher Gradmesser wie Geld entsteht, bleibt bestehen. Dennoch wird Aufmerksamkeit in einem übertragenen Sinne konsumiert. Sie kann keine »[...] rein abstrakte, symbolische Größe dar[stellen] [...] (ebd.: 45), weil sie einen wirklichen Gebrauchswert hat. DAHINDEN rettet ein Substrat von GEORG FRANCKs Überlegungen in jene Sphäre herüber, die in diesem Rahmen für bedeutsam und bedenkenswert sowie entwicklungsfähig gehalten wird:

"Sein Ziel ist es nicht, neue und u. U. auch überraschende Hypothesen für die empirische Forschung bereitzustellen, sondern viel grundlegender, eine neue, interdisziplinäre Perspektive zu skizzieren, die, falls erfolgreich, wohl zu einem sozialwissenschaftlichen Paradigmenwechsel führen könnte [Hervorhebung des Verfassers]. Die Theorie, die er vorstellt, ist zwar durchaus empirisch informiert in dem Sinne, dass er sich auf allgemein bekannte Beobachtungen beruft. Empirisch geprüft oder prüfbar sind seine Aussagen in der vorliegenden Form allerdings nicht. Das ist bedauernswert, weil es in der intellektuellen Debatte um den ökonomischen Imperialismus durchaus Bemühungen gibt, nicht-monetäre, sweicher Güter wie z.B. soziales Ansehen als eine zusätzliche Dimension des rationalen Handelns einzubeziehen und auch zur quantitativen Modellierung einzusetzen. [...] Zwar kann nicht jede Aussage der Ökonomie der Aufmerksam- 
keit, wie sie von Goldhaber und Franck entworfen wurde, als plausibler Theorieansatz akzeptiert werden. Dennoch beinhalten ihre Ausführungen Elemente, die als innovative Theoriebruchstücke bezeichnet werden können, die neue Einblicke auf [sic] bekannte empirische Phänomene ermöglichen. Diese Theoriebruchstücke gehen über die Beschreibung von Phänomenen im Geldmarkt hinaus, sind mit anderen Worten also von Bedeutung für eine Sozialökonomie der Aufmerksamkeit [Hervorhebung des Verfassers]. (ebd. 47)

"Aufmerksamkeit ist ein komplexes Phänomen, das aus verschiedenen Perspektiven betrachtet werden kann. Die ökonomische Perspektive ist dabei zweifelsohne von Bedeutung, muss allerdings ergänzt werden durch die theoretischen und empirischen Befunde der Kommunikationswissenschaft. Ein wichtiger Bezugspunkt zu einem sozialökonomischen und damit interdisziplinären Verständnis von Aufmerksamkeit könnte das Konzept des Nutzens sein, das sowohl in der Ökonomie als auch der Kommunikationswissenschaft (Nutzenansatz) von zentraler Bedeutung ist." (ebd. 54)

Akkumulierte Aufmerksamkeit braucht (und hat) ephemere wie bleibende Beweismittel: Face-to-face-Kommunikation, Presseberichte, Bücher, Forschungsarbeiten, Texte im Internet, Radio- und Fernsehsendungen. Dort bleibt sie gespeichert und kann abgerufen werden. Eine individuelle Bewertung dieser angebotenen Wertmaßstäbe kann nicht ausbleiben, weswegen diese Zwischenspeicherung auch nur potentiell als verlustfrei gedacht werden kann. Sie ist nicht verlässlich quantifizierbar und damit kein verbindlicher Gradmesser. Die Entscheidung, fremde, durch akkumulierte Aufmerksamkeit zum Ausdruck kommende Bewertungen zu übernehmen oder nicht, ist stets mit individuellen Wertmaßstäben verknüpft sowie mit dem durch sie evtl. zum Ausdruck kommenden Statusstreben. Als Reaktion stehen prinzipiell drei Optionen zur Verfügung. Fremde Wertmaßstäbe lassen sich

1. übernehmen oder

2. nicht; genau so gut kann aber auch

3. zu dieser Zeit noch keine Anbindung zum eigenen Aufmerksamkeitsrelief (vgl. WALDENFELS 2004) hergestellt werden, weswegen man auf ein Sinnangebot nicht aufmerksam wird und es sich so nicht darin niederschlägt.

Verführerisch an einem solchen Sinnangebot ist - möglicherweise sogar unabhängig von seiner jeweiligen Quelle -, dass es sich schon wie das Ergebnis einer Übereinkunft präsentiert bzw. der Anbietende sich hypothetisch mittels seiner von ihm angenommenen oder ihm zugeschriebenen Autorität da- 
rauf verlassen kann, dass es so wahrnehmbar ist. Hier schließt - im Vorgriff auf das Kapitel Rezeption - die Auswertung der empirischen Publikationsstudien an, deren faktischer Beweis lautet, dass Begriffe wie Stardesigner und Designklassiker eher als Schlagbilder denn als Schlagworte und ohne tiefergehende Begründung verwendet werden, die keine wirklichen Wertmaßstäbe darstellen - wie z. B. bei BREUER beschrieben (BREUER 2001: 12; vgl. auch WARBURG 1920: 35, 46f).

\section{Thrombosen der Aufmerksamkeit - Auflösung unerwünscht?}

Der Kreislauf der Aufmerksamkeit hat eigene Gerinnungsfaktoren. Begriffliche Gerinnsel der Beachtlichkeit von Menschen und Objekten - wie Prestige, Reputation, Prominenz und Ruhm (für die Artefakte der Klassiker) - entstehen, wie wir bei GEORG FRANCK sehen, wenn Aufmerksamkeitsplättchen um Aufmerksamkeitsplättchen im Verlauf der Zeit miteinander verklumpt und sich der freien Zirkulation der Beachtlichkeit als Hindernis in den Weg stellt. Im Gegensatz zu einer echten Thrombose, von der man sich wünscht, dass sie sich von selbst wieder auflösen möge, sind diese Venenentzündungen und Gerinnsel hingegen hochwillkommen - dass sie sich vergrößern mögen, um noch an Beachtlichkeit zuzulegen, ebenso.

Der Verlauf der Zeit ist jenen Begriffen für die anwachsende Beachtlichkeit von Artefakten ebenfalls schon eingeschrieben, der Designklassiker führt das Überdauern im Begriff mit sich. Überdauern als Modus des Dauerns wurde als Ausdruck von GEORG FRANCK in dessen Essay Die Zeit: eine soziale Konstruktion? verwendet. Darin setzt er sich ausführlich mit der Paradoxie des permanenten Jetzt auseinander:

"Die Art und Weise, auf die die Welt im Jetzt da ist, ist das zeitliche Werden und Vergehen ihrer Zustände. Es ist immer nur ein Zustand, der sich im Jetzt präsentiert. Andererseits ist es immer jetzt. Also ist die Präsenz kein einfacher Modus des Existierens. Sie ist ein Modus des Dauerns [Hervorhebung des Verfassers], denn es ist jetzt, seitdem die Zeit vergeht. Die Zustände jedoch, die im Jetzt auftauchen, dauern gerade nicht. Mit dem Vergehen der Zeit ist gemeint, daß der Zustand der Welt, der sich im Jetzt präsentiert, niemals derselbe ist. (FRANCK 2004: 1) [online] http:// www.iemar.tuwien.ac.at/publications/GF_prog.pdf [14.05.2018] 
Legte man Designklassikern ein derartiges Zeit- und Jetzt-Verständnis zugrunde, müssten Idee und Begriff der Zeitlosigkeit grundsätzlich hinterfragt oder neu definiert werden. Dazu haben u. a. LATOUR und LOWE und auch STERLING Anstöße gegeben. Der Designklassiker ist - dem obigen Betrachtungsansatz folgend - auch nur ein Hindernis im Kreislauf von Neuheiten und Beachtlichkeiten, jedoch ebenfalls ein erwünschtes, eben wegen seiner als bleibend angesehenen Mustergültigkeit. Begriffe, die das Verständnis solcher Zustandsveränderungen im Verlauf der Zeit verändern können, werden 2011 von LATOUR und LOWE vorgeschlagen, die anregen, Kunstwerke als Trajektorien zu beschreiben (vgl. LATOUR und LOWE in: BARTSCHERER und COOVER 2011: 108f). NEUBERT führt in diesem Zusammenhang im Artikel Vom Disegno zur Digital Materiality [...] aus, dass man

»[u]nter diesem Begriff [...] in der Physik die Ortskurve eines Elements [versteht], also den Bewegungspfad in Raum und Zeit. Im mathematischen Sinn zielt der Begriff der Trajektorie dagegen vereinfacht formuliert auf die Zustandsveränderung eines komplexen Systems. Nimmt man beide Aspekte zusammen, definiert die Trajektorie damit ein spezifisches Verhältnis von Transport und Transformation, genau jenes Verhältnis also, das für die Beschreibung von Medienvorgängen innerhalb der Akteur-Netzwerk-Theorie von zentraler Relevanz ist und das nach Latour für die Mediationstypen sowohl der Wissenschaft wie der Kunst einschlägig ist." (NEUBERT in HENSEL und SCHRÖTER 2012: 54)

Auch BRUCE STERLING wird mit seinem Neologismus des SPIME ins Spiel gebracht, der sich vom festen Objekt löst - was jener »am Beispiel einer im Supermarkt erstandenen Flasche erläutert«:

"Yet that bottle of wine was a momentary congelation of material and energy flows. That bottle of wine was once sunlight on Italian earth, lakes of grape juice, yeast in fermentation tanks, wood pulp for the label, colored inks, cork from Spain [...] plus a Californian grocery chain reacting to consumer trends and stocking a brand with some shelf appeal. Then i found it, bought it and consumed it. It continued as a dissociated flow of recyclable glass, consumed paper, hydrating fluids and a narcotic in my blood stream, long since metabolized.، Das Produkt, um das es geht, besteht also aus einem fluktuierenden Netzwerk von Dingen, Personen und Interessen, das sich nur kurzfristig als Weinflasche stabilisiert. Für Sterling ergibt sich die Identität des Produkts daher nicht auf der Ebene des Materials, sondern auf der Ebene der Information.« (ebd.: 55) 


\title{
Designer und ihre Kapitalformen
} 58 der Aufmerksamkeit

Sie nehmen nach dem FRANCKschen Modell unterschiedliche Kapitalformen zu gleicher Zeit ein; mindestens Reputation, die nach innen, unter Kollegen und im Fachpublikum zählt sowie Prominenz, die eher nach außen wirkt. Hält sich ein Designer lange genug am Markt, kommen u. U. auch Prestige und Ruhm hinzu:

\begin{abstract}
»Reputation [Hervorhebung im Original] ist Reichtum - oder genauer: Wohlhabenheit - an Beachtung, die von ihrerseits beachteten Personen gezollt wird. Im Vergleich zur Prominenz ist das Kapital, das die Reputation darstellt, spezifisch alt. Weil die Beachtung seitens ihrerseits beachteter Personen nicht so leicht in rauhen Mengen zu haben ist, bedeutet Reputation eine der Art nach zwar feine, im Umfang jedoch eher bescheidene Form des Reichtums. Wächst die Reputation, dann wächst sie eher in Richtung des Ruhms als der Prominenz. Auch in ihren bescheidenen Formen aber muß sich die Reputation aber [sic] rentieren. Reputation hat nur, wer Beachtung auch dafür einnimmt, daß er dafür bekannt ist, in den einschlägigen Kreisen bekannt zu sein." (FRANCK 1998: 119)
\end{abstract}

Reputation kann aufgebaut werden, sie kann aber ebenso Schaden nehmen und es gibt Forscher sowie Lehrstühle, die sich mit Reputationsmanagement beschäftigen, so z. B. das FÖG - Forschungsinstitut Öffentlichkeit und Gesellschaft an der UNIVERSITÄT ZÜRICH unter der Leitung von MARK EISENEGGER, das u. a. mit einem Reputations-Monitor "fortlaufend die medienvermittelte Reputation von rund 50 Schweizer Unternehmen« erfasst. (FÖG UNIVERSITÄT ZÜRICH) [online] http://www.foeg.uzh.ch/analyse/repdossier.html [14.05.2018]

Außerdem das Institut für Kommunikations- und Medienwissenschaft Abteilung Kommunikationsmanagement und Public Relations an der UNIVERSITÄT LEIPZIG (COMMUNICATION CONTROLLING) [online] http://communication controlling.de/ [14.05.2018) oder das ECRS - European Centre for Reputation Studies (ECRS) [online] http://www.reputation-centre.org/en/research.html [25.10.2015; der Server existiert inzwischen nicht mehr] Ohne diesen Aspekt jetzt vertiefen zu wollen, werden hier stellvertretend für die dort durchgeführten Forschungsarbeiten hervorgehoben:

- eisenegger und ImHof 2007: Das Wahre, das Gute und das Schöne: Reputationsmanagement in der Mediengesellschaft (FÖG UNIVERSITÄT ZÜ- 
RICH) [online] http://www.foeg.uzh.ch/analyse/publikationen/Wahr_ Gut_Schoen_2007_d.pdf [14.05.2018]

- LIEHR et al. 2009: Reputationsmessung: Grundlagen und Verfahren (COMMUNICATION CONTROLLING) [online] http://www.communicationcontrolling.de/fileadmin/communicationcontrolling/pdf-dossiers/communicationcontrollingde_Dossier1_Reputationsmessung_April2009_o.pdf [14.05.2018]

\section{Sich sonnen im Abglanz dritter Beachtlichkeit}

Nimmt man das FRANCKsche Szenario zur Blaupause (FRANCK 1998: 131f), so gibt es den Abglanz der Person nur innerhalb einer unmittelbaren Entourage des Stardesigners oder der Stardesignerin. Das ist eine Konstellation, die sich in der Designsphäre problemlos lokalisieren läßt. Man denke nur an das Studium oder Praktika bei Platzhalter, die erste wichtige Anstellung im Büro oder bei der Firma Platzhalter oder die ersten bedeutenden Aufträge von Platzhalter. Ein entscheidender Unterschied besteht für Designer und den Abglanz ohne eigenen Glanz jedoch darin, dass sich das vermittels dritter Hand eingenommene Renommée nicht unbegrenzt strecken oder weiterverwenden lässt - es ist letztlich nur eine Art Anschubfinanzierung, bei der es darauf ankommt, dass sie von kundigem Verstand rezipiert und bewertet wird: ganz im Sinne verschachtelter Beachtlichkeit. Liefern kann und muss in diesem Fall der Designer selbst - ohne eigene Vorleistung und entsprechende Bemühungen, um überhaupt in den Vordergrund zu treten, ist auch in diesem Fall fast alles nichts.

\section{Artefakte verändern die Verhältnisse}

Starforschung im bisherigen Sinne, die ihre Karriere in der Filmforschung begann, beleuchtet die Verhältnisse zwischen Star, Medien und Publikum. Gleiches gilt für Musik, Politik und Sport, lediglich der führende Begriff muss noch durch Musiker, Politiker oder Sportler ersetzt werden. Die jeweiligen Ergebnisse sind natürlich nicht austauschbar. Die Starforschung im Feld des Designs hingegen muss weitere Akteure in den Blick nehmen - die Artefakte. Dadurch 
verändert sich das Dreiecksverhältnis zu einem Vierecksverhältnis und nichtmenschliche Aktanten kommen zwangsläufig ins Blickfeld.

Wenn FRANCK darüber schreibt, dass es möglich sei, sich auch ohne eigenen Glanz im Abglanz dritter Beachtlichkeit zu sonnen (s. o.), so ist dies - zumindest auf den ersten Blick - im Zusammenhang mit einem Artefakt nicht möglich, denn dieses kündet im LATOURschen Sinne als ein Intermediär erst einmal von nichts außer sich selbst. Erst die Bewertung des Artefakts erzeugt seine Beachtlichkeit oder bringt weitere hervor und sie bringt den Bewertenden in die Rolle eines Mediators, der eine der möglichen Bedeutungsebenen des Artefaktes mitkonstituiert oder verändert. Abglanz FRANCKscher Prägung ist im Fall von Designern und Artefakten zumindest nicht auf dem Wege möglich, wie es z. B. beim Filmstar geschehen kann, indem man es auf eine nicht wirklich planbare Weise bewerkstelligt, sich in dessen (als solche wahrgenommene) Entourage einzureihen. Wo sich der Abglanz einer Person noch mit einer gewissen Sicherheit lokalisieren lässt, sorgen die Artefakte für neue Unschärfen, erzeugen sie doch einen eigenen Abglanz, der aus der Reputierlichkeit ihrer selbst entsteht - diesen Abglanz erwerben Designer sich für diese z. B. durch die Auszeichnung mit Designpreisen und so erstrahlen jene nicht nur im direkten Abglanz derselben. Als direkte Folge davon könnte der Abglanz der Artefakte hypothetisch ebenso auf die Designer zurückwirken wie deren Abglanz auf die Artefakte abstrahlen könnte.

Was man tun müsste, um diese Beziehungen näher zu betrachten, wäre eine Art designsoziologisches (oder gar designethnologisches) ray tracing mit einem an die ANT angelehnten Vorgehen und Methoden qualitativer Sozialforschung - was die Grenzen des im Rahmen dieser Untersuchung möglichen gesprengt hätte. Die Kommunikationswege sind anhand folgender Szenarien vorstellbar: Ein Designer erreicht über das Artefakt die Nutzer, gleichermaßen adressiert er aber auch die Medien, welche über den Designer berichten und damit auf einem anderen Weg den Nutzer erreichen. Gleichfalls können Medien über den Designer und die von ihm entworfenen Artefakte berichten und die Nutzer adressieren, so dass dieser als möglicher Fixationspunkt wahrgenommen werden kann. Die versammelte Menge der Nutzer wird jedoch nicht zu einem Publikum der Art, wie es in der Starforschung betrachtet werden kann, weil es Fan-Phänomene in einer Tragweite, wie sie sich im Zusammenhang mit Stars beobachten lassen, unter den Käufern von Artefakten mit hoher Wahrscheinlichkeit nicht gibt. Dies wird in den Kapiteln Prominenz und Rezeption noch vertieft werden. 


\section{Vergleiche, Vergleiche, Vergleiche ....}

Man gerät zwar in Versuchung, gleich den FRANCKschen Analogieschlüssen, eine Ebene der Vergleichbarkeit zu postulieren, da der Film in der Beziehung zwischen Filmstar und Rezipient die Rolle des Artefakts einzunehmen in der Lage zu sein scheint - doch in einer Anlehnung an die DE SAUSSUREsche Denkweise ist der Film letztlich nur der Signifikant für das Signifikat Filmstar. Als eigenständiges Produkt repräsentiert ein Film nur die Fertigkeiten der darin vorkommenden und an der Gesamtherstellung beteiligten Personen. Er kann gesehen, gehört und erinnert werden und hat über seine Rezeption hinaus keinen weiteren Nutzen - im Vergleich zu einem Artefakt, das greifbar, benutzbar und physisch präsent bleibt. Dieses gibt zwar auch Auskunft über die Fähigkeiten seiner Schöpfer, bietet aber einen weiteren, differierenden Nutzen, der in der tätlichen Benutzung liegt und nicht mehr unmittelbar in der Verbindung zum Hersteller; das Artefakt ist direkter Träger seiner Fertigkeiten, der Film transportiert die Fertigkeiten seiner Erzeuger nur, so lange er rezipiert wird. Danach verwandelt letzterer sich vollständig in einen Grund zur Erinnerung. Eine wertende Aussage wie Konstantin Grcic hat mit ... einen sehr guten Stuhl entworfen ist nicht vergleichbar mit einer nur scheinbar ähnlichen Form einer Bewertung wie dieser: Armin Müller-Stahl liefert hier ein ergreifendes Zeugnis seiner Schauspielkunst ab ( - Namen sind in diesem Zusammenhang völlig willkürlich herausgegriffen und dienen lediglich der Illustration; ebenso könnten die beiden Sätze rein zufällig mit schon auffindbaren Äußerungen übereinstimmen).

Stuhl und Film sind - wenngleich unterschiedlicher Natur - Artefakte. Man kann zuhause auf einem Stuhl sitzen, während man einen Film ansieht, so zu gleicher Zeit also Rezipient zweier Artefakte mit differierenden Nutzungsarten sein. Danach besteht die Möglichkeit, über Stuhl und Film zu reden: Vom Film, der eine bestimmte Form rein sprachlichen Austauschs erzwingt, wird man berichten können, ob man ihn gut oder schlecht gefunden habe und weshalb. Vom Stuhl, ob man gut oder schlecht auf ihm gesessen habe und womöglich auch, weshalb.

Kommuniziert man über diese Erfahrungen mit Dritten, so führt der Austausch über den Film womöglich dazu, dass diese den Film im Kino ansehen, ausleihen und/oder ein Trägermedium erwerben. Der Austausch über den Stuhl könnte dafür sorgen, dass der Stuhl erneut, von Dritten, gekauft wird - was aber das Ergebnis einer wesentlich längeren und komplexeren Entschei- 
dungskette sein wird als jener der Entscheidung für einen Film. Die Hinzufügung eines Artefaktes zu einem Hausstand erfordert - bleiben wir bei dem gegebenen Beispiel - im Fall des letzteren den Einsatz einer größeren Menge Geldes sowie weitergehender Überlegungen hinsichtlich der Raumökonomie, der Stilistik, der Einpassung in die bereits bestehende Umgebung, den etwaigen Ersatz/die Umplatzierung oder gar Entfernung anderen Mobiliars und nicht zuletzt auch der sozialen Passung.

Spricht man mit anderen über verschiedene Schauspieler, so sind diese auf der Basis jeweils individueller geschmacklicher Präferenzen miteinander vergleichbar - man kann aber immer nur über das reden, was diese an unmittelbaren physischen Fähigkeiten aufzubieten haben (vgl. LUDES in: FAULSTICH und KORTE 1997). Dies ließe sich noch auf einer Ebene mit den ergonomischen Qualitäten/dem Sitzkomfort unterschiedlicher Stühle denken. Davon abgetrennt lässt sich auch über einen Film als Ganzes diskutieren. Man kann ihn in seiner Gesamtheit, auch unabhängig von oder auf der Basis dessen, was die einzelnen Darsteller bieten, gut oder schlecht finden und in diese Bewertung werden verschiedene Einzelbewertungen einfließen, deren Gewichtung auch wieder von individuellen Präferenzen abhängig ist. Was als gut oder schlecht gilt, muss individuell ausgehandelt werden und führt zu letztlich nur schwer verallgemeinerbaren Maßstäben.

Sitzkomfort bei Stühlen ist im Gegensatz dazu schnell ausgemacht und diskutierbar. Die geschmackliche oder lebensweltliche Einordnung ist etwas Anderes. Der primäre Gebrauchswert des Stuhles ist im wahrsten Sinne das Be-Sitzen. Der primäre Gebrauchswert des Films ist die Immersion in die und das emotionale Erleben der Filmhandlung. Sein sekundärer Gebrauchswert besteht darin, dass man sich darüber mit anderen unterhalten kann. Hierbei ist man wohl meistens darauf angewiesen, die Handlung oder andere wichtige Aspekte im Gespräch zu rekreïeren, da in der direkten Erlebnissituation im Kino selten ohne Beeinträchtigung anderer Kinobesucher live über das Gesehene gesprochen werden kann - oder die am Gespräch beteiligten Personen gar nicht zur selben Zeit am gleichen Ort waren. Im heimischen Umfeld stellte sich die Situation in Verbindung mit der Rezeption auf einem Trägermedium natürlich anders dar. Eine der Signalfunktionen eines Stuhles, die es ermöglicht, eine geschmackliche Aussage in die Welt zu stellen, ohne selbst etwas zu sagen, bleibt seiner dreidimensionalen Präsenz wegen andauernd vorhanden - gleichwohl sie rezipiert werden muss und Kenntnisse voraussetzt, um wirken zu können. 
Möchte man eine geschmackliche Aussage mit einem oder über einen Film machen, die auch auf einen selbst abstrahlt, so blitzt dessen Signalfunktion ausschließlich im Gespräch mit einem Gegenüber auf und bleibt darüber hinaus unbemerkt. Der Film bleibt unbesprochen stumm, wogegen das dreidimensionale Artefakt immer auch zu einer stummen Aussage für (oder auch gegen) eine Person fähig ist - je nachdem, wer aus welcher Perspektive urteilt. Eine Reaktion auf das Artefakt Stuhl durch Dritte ist auch dann möglich, wenn zwischen Eigentümer und Dritten kein Wort gewechselt wird - seine pure Präsenz lässt mannigfaltige Erwägungen Dritter über den Eigentümer zu, ohne ein Gespräch zu erfordern; erst eine womöglich angestrebte Überprüfung führt es - dann fast zwangsläufig - herbei.

Ein Vergleich der Ideen von Aufmerksamkeit zeigt, dass diese - wie sollte es auch anders sein - mitnichten auf einer gemeinsamen Basis stehen. In zeitlichem Ablauf steht GEORG FRANCK im Jahr 1998 als Auslöser am Beginn einer Reihe von Autoren, die eine Zeitspanne von 13 Jahren abdecken und von JoNATHAN CRARY (1999/2002) über die in der Anthologie von HICKETHIER und BLEICHER (2002) versammelten sowie BERNHARD WALDENFELS (2004) bis zu JÖRG BERNARDY (2014) reichen. Es wäre reine Vermessenheit, anzunehmen, GEORG FRANCK und MICHAEL GOLDHABER hätten alle zu ihren eigenen Publikationen angestiftet - gleichwohl ist das Thema bis heute de rigeur, nimmt man CRARY mit seiner Suche nach der Entstehung des Phänomens und BERNARDY mit seiner Nachwirkungsanalyse (als aktuellster ausführlicher betrachteter Veröffentlichung) zu Polen dieser Durchforstung. 
»Man kann durchaus in einer ständigen Krise der Aufmerksamkeit einen entscheidenden Aspekt der Moderne sehen, [...] «

Jonathan Crary 


\section{Aufmerksamkeit. Wahrnehmung und moderne Kultur}

CRARY greift für eine Begründung des modernen Phänomens der Aufmerksamkeit zeitlich gesehen am weitesten von allen hier betrachteten Autoren zurück und lokalisiert ihre Entstehung auf der Schwelle vom 19. ins 20. Jhd.. Für ihn ist das »Problem der Zerstreuung, das im späten neunzehnten Jahrhundert auftaucht«, gekoppelt mit der "parallel dazu auf den verschiedensten Gebieten stattfindenden Konstruktion eines aufmerksamen Beobachters" (CRARY 2002: 47f). Er hält die modernen Menschen für dieses Phänomens so geläufig, »daß wir die schnelle Verschiebung unserer Aufmerksamkeit von einem Ding aufs andere als natürlich [Hervorhebung im Original] akzeptieren" (ebd.: 33) und vertritt die

»Auffassung, daß es sich bei der modernen Zerstreuung nicht [Hervorhebung im Original] um die Zerstörung von stabilen oder snatürlichen Arten vertiefter, werthaltiger Wahrnehmung handelt, sondern um einen Effekt [Hervorhebung im Original] und in vielen Fällen auch einen konstituierenden Bestandteil der zahlreichen Versuche, bei menschlichen Subjekten Aufmerksamkeit zu produzieren.« (ebd. 2002: 47f)

CRARY behauptet, »[...] daß Aufmerksamkeit und Zerstreuung nicht außerhalb eines Kontinuums gedacht werden können, in dem beide, als Teile eines sozialen Felds, in dem dieselben Imperative und Kräfte diese wie jene stimulieren, unablässig ineinander übergehen.« (ebd. 2002: 47f) 


\title{
STARDESIGNER ODER GESTALTER DES ALLTÄGLICHEN?
}

In seiner deutschen Übersetzung trägt das Buch einen Titel, der der Idee einer Aufhebung oder Auflösung der Wahrnehmung leider gänzlich beraubt ist und dem auch die Anlehnung an DEBORDs Societé du Spectacle fehlt, auf die CRARY in einem Vergleich von DEBORD und FOUCAULT ausführlich eingeht. Die Bedeutungsmöglichkeiten des Titels fallen in der Übersetzung so wesentlich flacher aus als im Original, was mit dieser Passage belegt werden kann:

\begin{abstract}
"Der amerikanische Originaltitel meines Buches - Suspensions of Perception: Attention, Spectacle, and Modern Culture [Hervorhebung im Original] - ist sowohl evokativ als deskriptiv: worauf es mir ankommt, sind verschiedene Bedeutungsmöglichkeiten, die im Wort suspension [Hervorhebung im Original] mitschwingen. Zunächst möchte ich einen gewissen Zustand andeuten, ein Zusehen oder Zuhören, das so versunken ist, daß es eine Ausnahmesituation gegenüber den Normalbedingungen darstellt und zu einer suspendierten Zeitlichkeit wird, zu einem Hinausschweben aus der Zeit. Im Wort attention [Hervorhebung im Original] wiederum schwingt etwas von einer 'Spannung<, von 'Gestrecktwerden< und auch von ,Warten ein, die Möglichkeit, etwas in einem Zustand des Staunens und der Kontemplation festzuhalten, in dem das aufmerksame Subjekt unbeweglich ist und zugleich des Halts ermangelt. Suspension [Hervorhebung im Original] ist jedoch auch eine Tilgung oder Unterbrechung, womit ich auf eine Störung, ja auf eine Negation der Wahrnehmung selbst hindeuten möchte. Ich verfolge das ganze Buch hindurch die Idee einer Wahrnehmung, die sowohl [Hervorhebung im Original] eine Versunkenheit, eine Absorption als auch [Hervorhebung im Original] eine Absenz oder ein Aufschub sein kann.« (CRARY 2002: 19 \& CRARY 1999: 10)
\end{abstract}

RIBOT und HELMHOLTZ lassen CRARY zum Kern seiner Argumentation gelangen, der in der Erfindung von Technologien zur Fesselung, Lenkung und Ausdehnung der Aufmerksamkeit des individuellen Betrachters sowie der Entwicklung des subjektiven Sehens liegt:

"Théodule Ribot beobachtete genau, daß >die Aufmerksamkeit ein abnormer, ein Ausnahmezustand ist, der nicht lange dauern kann, weil er im Widerspruch mit der Grundbedingung des menschlichen Lebens steht: dem Wechsek. Zuvor bereits hatte Helmholtz notiert: 'Ein anhaltender Ruhezustand der Aufmerksamkeit ist ... kaum für einige Zeit zu unterhalten. Der natürliche, ungezwängte Zustand unserer Aufmerksamkeit ist herumzuschweifen zu immer neuen Dingen.« (ebd.: 58)

Noch einmal deutlicher wird CRARYs Blickrichtung, als er zum Ende des 19. Jhd.s bei RICHARD WAGNER anlangt und an dessen Beispiel konstatiert: 


\section{AUFMERKSAMKEIT. WAHRNEHMUNG UND MODERNE KULTUR}

"Das bedeutsamste Kulturphänomen, das in der zweiten Hälfte des neunzehnten Jahrhunderts im Schnittpunkt von Problemen des Theaters, des Schauspiels und psychischer Kontrolltechniken steht, ist vielleicht das Opernwerk Richard Wagners. Noch nach seinem Tod war Wagners ästhetische Erbschaft sowohl von Problemen der perzeptuellen Aufmerksamkeit wie von solchen der sozialen Kohäsion gleichermaßen untrennbar.« (ebd.: 197)

"Gewisse im frühen zwanzigsten Jahrhundert geführte Debatten über die Auswirkungen der Massenkultur, in denen Zerstreuung als Gegenbegriff zu einer selbstbewußt-kontemplativen Wahrnehmung fungierte, vorwegnehmend, beklagte Wagner die Allgegenwart von zerstreuten Weisen der kulturellen Konsumtion. [...] Wagners Konzeption der deutschen Oper postulierte ein Publikum, das während einer ganzen Vorstellung zu einer angespannten, kontinuierlichen [Hervorhebung im Original] Aufmerksamkeit fähig sein würde.« (ebd.: 199)

CRARY sieht bei WAGNER offensichtlich zu gleicher Zeit die Konzentration und die Ausdehnung der Aufmerksamkeit des Individuums auf einen »anhaltende[n] Ruhezustand «(s. o.) wenn nicht verwirklicht, so doch angestrebt. Wenige Seiten später nimmt er noch einmal mit vÉRON Bezug auf die zeitgenössische Rezeption:

"Schon bald nach der ersten Aufführung in Bayreuth hat die französische Kritik die konkrete Umformung bemerkt, die Wagner am Erlebnis des Zuschauers vorgenommen hatte. Eugène Véron schrieb 1878, Wagner richte alles so ein, >daß der Zuschauer ausschließlich mit dem Schauspiel beschäftigt ist und nicht von fremden Eindrücken abgelenkt werden kann ... nichts könnte die Aufmerksamkeit von dem Punkt, auf den sie sich zu konzentrieren hat, abziehen،. Es handle sich, meinte er, um eine Art traumhafter Hellsichtigkeit, die sich vom normalen Wachzustand unterscheide.» (ebd.: 201f)

Damit legt CRARY ein neues Schlachtfeld an, auf dem als Folge der »modernen Erfahrungen von sozialer Separation und subjektiver Autonomie« (ebd.: 14) durch den Einfluss der Aufmerksamkeitstechnologien die Zerstreuung erst in die Welt gebracht wird. Mithin verursacht also ein erweitertes Angebot erst das Problem, individuelle Aufmerksamkeit auf etwas zu konzentrieren und stellt also auch an die Produzenten der Aufmerksamkeitsgründe die Anforderung, für einen hinreichenden Anreiz zu sorgen, überhaupt Aufmerksamkeit auf ihr Angebot zu richten. 


\section{STARDESIGNER ODER GESTALTER DES ALLTÄGLICHEN?}

»In diesem neuen System von Objekten, das auf der ständigen Produktion des Neuen gegründet war, wurde die Aufmerksamkeit, wie die Forscher herausfanden, von der regelmäßigen Einführung von Neuheit aufrechterhalten und gesteigert. Dieses Aufmerksamkeits-Regime war synonym mit dem, was Nietzsche als modernen Nihilismus beschrieben hat: eine Erschöpfung der Bedeutung, ein Verfall der Zeichen. Wenn die Aufmerksamkeit zum notwendigen Bestandteil von Subjektivitätstheorien wurde, dann weil sie angesichts der Prozesse von Austauschbarkeit und Äquivalenz ein Mittel zur Rettung oder zur Simulation von Einzigkeits- und Identitätserfahrungen zu sein schien.» (CRARY 2002: 105f)

Hier besteht ein unmittelbarer Zusammenhang zu RECKWITZ und dessen Text Die Transformation der Sichtbarkeitsordnungen (2015):

"Die ökonomischen Märkte sind damit mehr und mehr als Märkte für kulturelle Güter strukturiert. Sie sind hyperkompetitiv und dadurch gekennzeichnet, dass eine Überproduktion kultureller Güter mit jeweils neuartigen und daher in der Nachfrage höchst unberechenbaren kulturellen Qualitäten im Aufmerksamkeitswettbewerb um ein notwendig begrenztes Publikum buhlt, das seine Aufmerksamkeitsbereitschaften in hohem Maße ungleich verteilt. Zwischen den singulären Objekten - und den mit ihnen verbunden Organisationen oder Individuen - auf den kulturellen Märkten, die die Art von nobody-knows-Märkten mit extremer Ungewissheit annehmen, herrscht folglich ein ausgesprochen heftiger Kampf um Sichtbarkeit." (RECKWITZ 2015) [online] http://www.soziopolis.de/ beobachten/kultur/artikel/die-transformation-der-sichtbarkeitsordnungen/ [14.05.2018]

Von dessen thesenartig zusammengefassten Überlegungen sind die beiden folgenden im Kontext von CRARY von Interesse, weil sie Diskussionen über die Aufmerksamkeit und ihre Märkte um eine veränderte Betrachtung von Beobachtenden und Beobachteten erweitern:

»In der neuen Sichtbarkeitsordnung ist das Verhältnis zwischen Beobachtern und Beobachteten prinzipiell nicht mehr asymmetrisch, sondern symmetrisch: Im Prinzip kann jeder Beobachter, kann jeder Publikum sein - und im Prinzip kann jeder auch zum Beobachteten werden. Die beiden Subjektpositionen sind für den Einzelnen daher prinzipiell austauschbar: Abwechselnd kann er zum Subjekt oder Objekt von Aufmerksamkeit avancieren. Der Beobachterstatus kommt hier nicht privilegierten Institutionen zu, sondern ist ein generalisierter innerhalb der mobilen Öffentlichkeit. Die prinzipiell universale Struktur der Beobachtung ist in ihrer faktischen Ausformung jedoch in hohem Maße unberechenbar. Kennzeichnend ist die Dynamik eines aufmerksamkeitsökonomischen Wettbewerbs der Beobachteten um die Gunst des Publikums. Er führt zu höchst ungleichen Positionen zwischen den wenigen mit erhöhter und je- 


\section{AUFMERKSAMKEIT. WAHRNEHMUNG UND MODERNE KULTUR}

nen vielen mit verminderter Sichtbarkeit. Diese Aufmerksamkeitsasymmetrien, die Gewinner und Verlierer schaffen, lassen sich auch quantitativ etwa in Form von Rankings abbilden."

"DerWettbewerb umüberregionaleSichtbarkeit-ob nunin einem begrenzten professionellen Kontext, einem beruflich-privaten Freundschaftsnetzwerk oder in einer populären nationalen oder gar internationalen Arena - ist das grundsätzlich Neue: Die Subjekte in der Disziplinargesellschaft wurden in jeweils begrenzten Lokalitäten jedes für sich zur Sichtbarkeit gezwungen, im Kulturalisierungskomplex findet hingegen eine aktive, gewollte Konkurrenz um Aufmerksamkeit statt: Das Subjekt begehrt, gesehen zu werden. [Hervorhebung im Original] Dieses Begehren setzt sich entsprechend in einen permanenten Vergleich der Beobachteten untereinander um. Verglichen werden freilich nicht mehr die sachlichen Leistungen vor dem Hintergrund eines fixen Maßstabs des Richtigen, sondern der Erfolg auf dem Aufmerksamkeitsmarkt. In einem zweiten Schritt kann dieses Begehren nach Sichtbarkeit sich damit in den sozialen Zwang verwandeln, gefälligst spräsent zu sein, um nicht soziale Nachteile beruflicher oder privater Art zu riskieren.«

Bemerkenswert ist an RECKWITZ' Darstellung, dass die Positionen von Beobachtenden und Beobachteten immerfort wechseln, sowie, dass sich sowohl CRARY als auch RECKWITZ auf FOUCAULTS Überwachen und Strafen aus dem Jahr 1975 beziehen, um ihre unterschiedlichen Vorstellungen von Aufmerksamkeitsregimen zu entwickeln. CRARY schreibt schon darüber, dass die Aufmerksamkeit

»[...] untrennbar [ist] von dem, was Foucault als sdisziplinäre Institutionen beschrieben hat, allerdings in Umkehrung seines panoptischen Modells, in dem das Subjekt ein Objekt [Hervorhebung im Original] von Aufmerksamkeit und Überwachung ist. Das heißt, daß sich im modernen Aufmerksamkeitsbegriff eine Neukonfiguration dieser disziplinären Mechanismen ausdrückt. [...] Seit dem frühen zwanzigsten Jahrhundert ist das aufmerksame Subjekt nämlich Bestandteil einer Interiorisierung [Hervorhebung im Original] disziplinärer Imperative, in denen die Individuen auf direktere Weise für ihre eigene effiziente oder profitablere Verwendung in diversen sozialen Konfigurationen verantwortlich gemacht werden." (CRARY 2002: 64)

Das wird von RECKWITZ 2015 so formuliert (s. o.):

»Die Subjekte in der Disziplinargesellschaft wurden in jeweils begrenzten Lokalitäten jedes für sich zur Sichtbarkeit gezwungen, im Kulturalisierungskomplex findet hingegen eine aktive, gewollte Konkurrenz um Aufmerksamkeit statt: Das Subjekt begehrt, gesehen zu werden ." [Hervorhebung im Original] 
So wird als Folge dieser Neukonfiguration das Subjekt mutwillig zum Objekt, indem die Auflagen der disziplinarischen Gesellschaft nicht mehr von außen an es heranbranden und es dadurch zum Spielball fremder Zwänge machen, sondern das Individuum diese internalisiert und von sich aus mit Wohlverhalten zur Sichtbarkeit, nach Ansehen und Konformität strebt. Schafft sich so jeder sein eigenes Panopticon? Nach diesem kurzen Sprung in die Gegenwart noch einmal zurück zu GEORG FRANCK, der ebenfalls schon den »organisierte[n] Kampf um die Aufmerksamkeit« ins Feld führt:

\begin{abstract}
"Der verbindliche Stil unserer Epoche ist eine Medienästhetik, weil alles, was öffentliche Geltung gewinnen will, entweder durch die Medien hindurch muß oder in der Konkurrenz mit der Attraktionskraft der Medien bestehen muß. Die Ästhetik, die der organisierte Kampf um die Aufmerksamkeit eines tendenziell weltweiten Publikums hervorbringt, ist weniger ein Kunst- als ein Überlebensstil.« (FRANCK 1998: 174)

»Wir machen die eigenartige Beobachtung, daß die Ökonomie der Aufmerksamkeit zum Ausgang der Art systematischer Zwänge geworden ist, wie sie einmal ganz den materiellen Produktionsverhältnissen zugeschrieben wurden.« (ebd.: 18o)
\end{abstract}

Wo stehen wir mit CRARY nach diesem neuerlichen Blitzlicht und mit Blick auf die Aufmerksamkeit im Allgemeinen? Ihn interessiert nicht, »ob ein empirisch identifizierbares mentales oder neurologisches Vermögen der Aufmerksamkeit existiert oder nicht« (CRARY 2002: 28f). Er hat die Chuzpe, den Graben zwischen FOUCAULT und DEBORD zu schließen, indem er durchaus überzeugend darlegt, dass in DEBORDs Gesellschaft des Spektakels sich »die Entwicklung einer Technologie der Trennung manifestiert« und »daß das Spektakel aus vielfachen Strategien der Isolation besteht", die »der von Foucault in Überwachen und Strafen [Hervorhebung im Original] entsprechen (ebd.: 64f). CRARY stellt die Vermutung in den Raum, Aufmerksamkeit sei erst am Ende des vorvergangenen Jhd.s regelrecht produziert worden und belegt dies mit einer Fülle von Quellen, die letztlich konstatieren, dass »in vielen sozialen Bereichen heute ein Zusammenwirken von panoptischen Techniken und Imperativen der Aufmerksamkeit stattfindet« (ebd.: 66), dass also die Individuen jene vormals externen Kontrollbestrebungen internalisiert haben und so auf paradoxe Weise zu Trägern und Perpetuenden des Systems werden.

Ein Ansatz, um jene imaginären Gemeinschaften aus Produzenten, Käufern, Experten, Interpreten und Rezipenten zu fassen, die dafür verantwortlich sind, dass es einen Klassikerkorpus gibt (wie z. B. auch von BREUER in Die Erfindung des Modernen Klassikers und mit der im Kapitel Rezeption vor- 
gelegten empirischen Studie nachgewiesen), ist CRARYs Idee einer Interpretationsgemeinschaft (ebd.: 44) als neuer Raum, den er zuvor als »Feld dieser Behauptungen und Praktiken und das von ihnen hervorgebrachte Netzwerk von Wirkungen« (ebd.: 28f) beschrieb, das aus einem »dyadischen System von Subjekt und Objekt ein triadisches mache:

»[...] ein wechselnder und vermittelnder Raum von sozial artikulierten physiologischen Funktionen, institutionellen Imperativen und einer langen Reihe von Techniken, Praktiken und Diskursen, die sich auf die Wahrnehmungserfahrung des Subjekts in der Zeit beziehen." (ebd.: 44)

Hier könnte auch ein Zusammenhang zum Neo-Tribalimus im Sinne von MAFFESOLI (1988) bestehen sowie zum Ansatz einer Geschmacksgemeinschaft nach SCOTT LASH. Die Konstitution der »Aufmerksamkeit in der Moderne durch diese Formen der Äußerlichkeit, [...] nicht durch die Intentionalität eines autonomen Subjekts« (CRARY 2002: 44) erschafft die aufmerksamen Beobachter als zwangsläufige Konsequenz von verändertem Sozialverhalten und nur als Ergebnis einer Reaktion auf etwas anderes - wenn auch auf der Basis vorhandener Verhaltensmöglichkeiten. Seine These, dass mit der Produktion der Aufmerksamkeit auch die Zerstreuung in die Welt gekommen sei, führt unausweichlich auch zu Problemen mit der Unaufmerksamkeit, über die er sinniert:

\begin{abstract}
"Insbesondere im Kontext der neuen Formen industrieller Großproduktion begann die Unaufmerksamkeit den Charakter einer Gefahr, eines ernsten Problems anzunehmen, auch wenn es oft genug eben die modernen Arbeitsbedingungen waren, die Unaufmerksamkeit hervorbrachten. Man kann durchaus in einer ständigen Krise der Aufmerksamkeit einen entscheidenden Aspekt der Moderne sehen, insofern die wechselnden Konfigurationen des Kapitalismus, mit ihrer endlosen Abfolge von neuen Produkten, Reizquellen und Informationsströmen, Aufmerksamkeit und Zerstreuung ständig über neue Grenzen und Schwellen zwingen und dann mit Methoden des Managements und der Regulierung von Aufmerksamkeit reagieren.« (ebd.: 23)
\end{abstract}

So schafft man also die Phänomene, die man hinterher einzuhegen sucht. Die kapitalistische Verwertungslogik führt dazu, dass auch aus den »Methoden des Managements und der Regulierung von Aufmerksamkeit« (s. o.) wieder neue Märkte entstehen können. Leben wir also in einem Zeitalter, in dem es notwenig zur Verunaufmerksamung kommen muss? Kommt das Individuum erst in einem Zustand der Ausmerksamkeit wieder an den Punkt, an dem der ständige Zwang zu Selbstpräsentation und Selbstkontrolle aufgehoben werden kann? 
»Aufmerksamkeit ist selbst kein eigenständiger Bewußtseinsakt und auch keine Eigenschaft des Bewußtseins als Ganzem." Jens Eder 


\section{Aufmerksamkeit, Medien und Ökonomie}

Dieser Sammelband untersucht vier Jahre nach GEORG FRANCKs Essay »das Phänomen sAufmerksamkeit, seine ökonomischen Strukturen und Funktionen sowie die Aufmerksamkeitsstrategien unterschiedlicher Medien, des Films und der Literatur (aus dem Klappentext). HICKETHIER ruft schon in seiner Einleitung eine "Krise der Aufmerksamkeit« aus und verweist auf SCHULZE (HICKETHIER in: BLEICHER und HICKETHIER 2002: 5), der im Zusammenhang mit dem Erlebnismarkt formuliert: "Auch Zeit, Aufmerksamkeit und Anerkennung sind Gegenleistungen [Gaben; Hinzufügung des Verfassers], die den Erlebnisanbietern heftige Konkurrenzkämpfe wert sind.« (SCHUlZE 1996: 423)

Die Reihen der Autoren werden durch EDER, PUNDT, STRUBE, METELMANN, BADE und LEHNING repräsentiert. Alle nehmen Bezug auf FRANCK, sie gehen einerseits kritisch mit dessen Ideen um, sie sehen andererseits aber auch ihr Potential und bemühen sich um Antworten auf die durch ihn aufgeworfenen Fragen. (vgl. BLEICHER im Vorwort) 


\section{Aufmerksamkeit ist keine Selbstverständlichkeit}

EDER leistet wichtige Begriffsarbeit und strebt eine Klärung davon an, was Aufmerksamkeit sei. Er bietet auch eigene Definitionsversuche an und zugleich arbeitet er seine Sicht auf die Unvollständigkeit von GEORG FRANCKs Gedankengebäude heraus. Zunächst werden dessen Ausführungen von ihm in einem ersten Versuch interpretiert, aus dem herauszulesen ist, dass er die Unschärfe des Essays nicht akzeptieren will:

»[...] Franck scheint so etwas im Sinn zu haben wie einen Modus [Her-
vorhebung im Original] der Informationsauswahl und -verarbeitung:
Jemand, der aufmerksam ist, sammelt und verarbeitet nicht nur Infor-
mationen über einen Gegenstand, sondern tut dies in bewußter Weise
[Hervorhebung im Original]. Aufmerksamkeit wäre demnach eine Selek-
tion und Verarbeitung von Informationen, die mit Bewußtheit vor sich
geht.« (EDER in: BLEICHER und HICKETHIER 2002: 20)

Fern von einem phänomenologischen Ansatz in der Tiefe von WALDENFELS (s. u.) bindet EDER die Definition an die Wahrnehmenden, die bei GEORG FRANCK als Wahrnehmungsfaktoren mit eigenen Eigenschaften keine Rolle spielen was ein echtes Defizit von dessen Argumentation darstellt:

"Denn etwas gilt als neu und erzeugt Aufmerksamkeit nur innerhalb eines bestimmten Kontextes von Wissen und mentalen Schemata auf der Seite der Wahrnehmenden. Aber es sind nicht rein systemische, unpersönliche sSelektoren`, systeminterne Kriterien, die sin letzter Instanz، darüber entscheiden, swas als neu gilt‘. Die Beschaffenheit des Gegenstandes bzw. Ereignisses ist nicht egal, sondern auf das Zusammentreffen seiner Eigenschaften mit denen der Wahrnehmenden kommt es an.« (ebd.: 25)

Ein weiterer Präzisierungsansatz EDERs zielt auf eine genauere Definition des Aufmerksamseins:

»Überdurchschnittlicher Intensitätsgrad intentionaler Erlebnisse [Hervorhebung im Original] - so lautet mein aus Phänomenologie und Psychologie abgeleiteter Vorschlag zu einer Bestimmung eines ersten Begriffs von sAufmerksamkeit،. Ein Lebewesen ist genau dann aufmerksam auf einen Gegenstand, wenn es überdurchschnittlich intensive intentionale Erlebnisse hat, die auf diesen Gegenstand gerichtet sind. Diese Bestimmung erhebt keinen Anspruch auf Vollständigkeit - dazu müßte man u. a. die spezifische Art der Aufmerksamkeits-Intensität genauer definieren. [...] Dieser Definitionsansatz macht jedenfalls eines deutlich: Aufmerksam- 


\section{AUFMERKSAMKEIT, MEDIEN UND ÖKONOMIE}

keit ist selbst kein eigenständiger Bewußtseinsakt und auch keine Eigenschaft des Bewußtseins als Ganzem. Sie ist weder eine Fähigkeit noch ein Prozeß, wie in manchen Definitionen angenommen wird. Aufmerksamkeit als Grad ist in ontologischer Hinsicht vielmehr ein `Momentı, ein Akzidens von verschiedenartigen einzelnen Bewußtseinsakten - ein Teil oder Zug von ihnen, der von ihrer Existenz abhängig ist wie die Farbe eines Balles von der Existenz des Balles." (ebd.: 29)

Zur Definition der Arten von Aufmerksamkeit, wie man sie schätzt und wie man diese einschätzt, hat er ebenfalls wichtiges beizutragen:

"Zu wenig deutlich wird bei Franck jedoch, daß die Aufmerksamkeit auf Personen besonders stark mit Werten und Emotionen verknüpft ist, die positiv, aber auch negativ sein können: Man will Aufmerksamkeit nur als Liebe oder Bewunderung, nicht als Spott oder Verachtung. Nur in dieser Form gilt sie als Einkommen. Daher müsste in einer Ökonomie der Aufmerksamkeit festgehalten werden, daß nur positiv-wertige Aufmerksamkeit ein Haben ist, negativ-wertige ein Soll. Nicht einmal dies gilt jedoch uneingeschränkt: Negative Aufmerksamkeit von der richtigen Seite (den 'Spießern`, >Chaoten`, ,Ignoranten`) kann ein Haben sein, wie Franck selbst bemerkt. Und positive Aufmerksamkeit ein Soll: Ein Kunstwerk von Richard Prince mit dem Titel 'Criminals and Celebrities, (1986) versammelt neun Pressefotos von ,Verbrechern und Berühmtheiten`, die gerade ungewollter Aufmerksamkeit ausweichen, indem sie ihre Gesichter vor der Kamera schützen. Das Werk führt sowohl vor Augen, wie Menschen aus Angst und Scham negativer Aufmerksamkeit zu entgehen trachten, als auch, daß ihnen positive Aufmerksamkeit zu viel werden kann. Es gilt also zu bedenken, daß das Tauschobjekt Aufmerksamkeit sich nicht nur hinsichtlich seiner Meßbarkeit weitaus unberechenbarer verhält als das Tauschobjekt Geld. U. a. diese Tatsache macht es fraglich, ob die Rede von einer Aufmerksamkeits-Ökonomie mehr ist als eine Metapher.« (ebd.: 38f)

Neben der immer wieder geäußerten Kritik, dass wenig mehr als eine Ökonomie-Metapher oder auch -analogie in GEORG FRANCKs Überlegungen stecke, liefert gerade EDER damit wichtige Denkanstöße, um das Phänomen der Aufmerksamkeit wieder mit und ursächlich bei den Wahrnehmenden zu denken - anstatt nur die Strategien zu durchdenken, die unsere Aufmerksamkeit lenken und fesseln sollen oder die Auswirkungen sozialer Handlungen auf einer Metaebene und als System zu betrachten. Einmal davon abgesehen, dass sich Aufmerksamkeit wecken und aufmerken gegenseitig bedingen, sind und bleiben es Bedeutungszuschreibungen von Individuen, die diesem großen, sozialen serious game zu Grunde liegen. Die Wertvorstellungen und Aufmerksamkeits-Trigger jener Individuen sind es, die eine allmähliche Prädisposition für 
bestimmte Aufmerksamkeits-Erreger herbeiführen - was sich ebenso einfach formulieren lässt, wie es schwer zu fassen ist, denn beide Komponenten unterliegen einer permanenten Veränderung.

\section{Vom Geben und Nehmen im Kleinen und Großen}

PUNDTs Kritik am FRANCKschen Diskus setzt u. a. bei der Konstruktion der "sozialen Umwelt" an und bezieht FRANCKs Differenzierung zwischen awareness (nach innen) und attention (nach außen) mit ein:

"Sie funktioniert durch den Trick, den anderen Menschen genau das gleiche Bewußtsein zu unterstellen, aus dem heraus es sie beobachtet und darüber hinaus von der Annahme auszugehen, auch die anderen Menschen setzten bei ihrer Beobachtung der Umwelt die gleiche Konstruktion des anderen Bewußtseins voraus. [...] Die intuitive Annahme, auch in den anderen Menschen stecke das Gleiche sbeseelte Wesen ‘ wie im eigenen Selbst und der Umkehrschluß, daß auch wir uns darauf verlassen können, von den anderen als Träger eines spezifischen Bewußtseins betrachtet zu werden, wird also zu einer anthropologischen Grundvoraussetzung unserer Existenz und unseres Verhaltens. Auch wenn sich dieser Mechanismus manchmal als eine fehlbare Konstruktion des Bewußtseins herausstellen kann, so ist er doch die einzige Möglichkeit, einen Anschluß an die Außenwelt aufzubauen. Der Aufmerksamkeit wird dabei eine zweifache Aufgabe zugeschrieben: Sie hat sowohl einen Innen(awareness) als auch einen Außenbezug (attention); die Aufmerksamkeit für das eigene sDasein [Hervorhebung im Original] ist immer gekoppelt an die Aufmerksamkeit für die Umwelt." (PUNDT in: BLEICHER und HICKETHIER 2002: 53)

Die Selbstaufmerksamkeit sich wahrnehmender Selbste führe zur Konstruktion der "sozialen Umwelt", zur Welterschließung und zum "Anschluß an die Außenwelt«, als ein Ergebnis von Verhandlungen: Wahrnehmung ist also ohne Aufmerksamkeit nicht zu haben. PUNDT sieht den

»Reiz [von FRANCKs, Ergänzung des Verfassers] [...] Theorieansatz [...] in der extremen Vereinfachung und Verschränkung dieser Gegenstandsbereiche durch ihre analoge Rückbeziehung auf den einen zentralen Begriff der Aufmerksamkeit. Der Preis, den er dafür bezahlt, ist die Unschärfe, die der Begriff durch diese umfassende Verwendung erlangt. Diese Unschärfe steht zwar nicht im Widerspruch zu seiner Definition von Aufmerksamkeit als einem doppelten Prozeß einer gezielten Wahrnehmung bestimmter Vorgänge in der Umwelt und der Konzentration auf das ei- 
gene Ich. Problematisch daran ist jedoch, daß Aufmerksamkeit zu einem Platzhalter für eine Reihe von Dingen wird, die je nach Kontext zwischen einem Selektionsprozeß bei der Informationswahl und der Suche nach Anerkennung schwanken können.« (ebd.: 63)

Eben diese Polyvalenz ist es, die die gefühlt hohe Plausibilität der FRANCKschen Ökonomieanalogie erst ermöglicht. Wird die Bedeutung von Aufmerksamkeit entgrenzt, ist dies Voraussetzung für ihre breite Anschlussfähigkeit und zugleich ihre Achillesferse. Wenn die »[...] neue (kapitalistische) Maxime lautet [...] >Ich bin, wer mich kennt« (ebd.: 66) und Besitz (in der Art, wie er von VEBLEN mit »conspicuous consumption " gefasst wird,) nicht mehr Zentrum und Ziel des Statusstrebens sind, dann wird gesellschaftliche Anerkennung zum Beziehungsspiel mit hypothetisch anderen Gewinnern und Verlierern als bisher. Doch wäre diese Schlussfolgerung richtig? Würde nicht einfach - die FRANCKsche Unschärfe voraussetzend - theoretisch das Geld durch die Aufmerksamkeit ersetzt und verblieben so nicht alle im neuen Kapitalismus der Aufmerksamkeit an ihren vorherigen Positionen? Sollte man also doch davon ausgehen, dass die traditionellen Geldgewinner in gleichem Maße die neuen Aufmerksamkeitserreger, -attraktoren und -gewinner sein werden und die vermeintlich neue Währung Aufmerksamkeit eigentlich immer schon der Kassiber war, der jetzt ans Tageslicht gezerrt werden soll? Auch PUNDT sieht die Idee eines Gesellschaftsspiels des als ob schon im Entwurf FRANCKs angelegt:

\begin{abstract}
"Demgegenüber ist die Aufmerksamkeit, die im massenmedialen Maßstab getauscht wird, jedoch nur ein - wie Franck richtig erkannt hat Spiel, bei dem so getan wird, als würde so etwas wie Aufmerksamkeit getauscht. Im Grunde genommen sind sich die Kommunikationspartner dieses Spiels jedoch egal, ihre Beziehung ist eine zweckgebundene Konstruktion." (ebd.: 71) [ - die auf den herkömmlichen gesellschaftlichen Spielregeln basiert. Hinzufügung des Verfassers]
\end{abstract}

Was für PUNDT an FRANCK von wirklichem Belang ist und auch eine tatsächliche Erweiterung der Medientheorie(n) darstellen würde, macht er in diesem Absatz deutlich:

"Bei aller Kritik an Franck zeigt sich dennoch, daß der Blick auf die facettenreiche Verwendung von Aufmerksamkeit als gesellschaftliche, individuelle, ökonomische oder mediale Ressource einer im Wandel begriffenen (Medien-) Welt interessante Details zutage fördern kann. Genauer zu klären bleibt aber noch, wie sich die anthropologische Dimension der sozialen Aufmerksamkeit [Hervorhebung des Verfassers], das Bedürfnis seine Rolle im anderen Bewusstsein zu spielen in vorhandene Theoriekonzepte einpassen ließe. Bei aller Problematik ontologischer Erklärungsansätze, 


\section{STARDESIGNER ODER GESTALTER DES ALLTÄGLICHEN?}

die Wesenszüge des Menschen quasi aus sich selbst heraus entwickeln, ist doch gerade bei vielen zeitgenössischen Medientheorien die Tendenz zu beobachten, den Faktor Mensch aus der Mediengeschichte zu verabschieden.«(ebd.: 71f)

Sein Lösungsvorschlag, nach dem es nur darauf ankommen werde, »die anthropologische Dimension der sozialen Aufmerksamkeit [...] in vorhandene Theoriekonzepte ein[zu]passen«, dürfte das Problem nicht verringern. Es käme darauf an, vorhandene Theoriekonzepte um die soziale Aufmerksamkeit zu erweitern und dadurch zu verändern oder ganz neu anzusetzen - was erheblich mehr Aufwand bedeuten dürfte -, um eben jenen Paradigmenwechsel herbeizuführen, den DAHINDEN schon als Potential in GEORG FRANCKs Essay angelegt sieht.

\section{Das Kapital in den Köpfen}

STRUBE arbeitet an anderen FRANCKschen Fehlstellen weiter, z. B. der Frage nach der Akkumulation von Aufmerksamkeit sowie dem Aufmerksamkeitsgefälle zwischen Star und Fan. Wie angesammelte Aufmerksamkeit gespeichert werden könne und auch, wie sie transferiert werden würde, dazu lässt GEORG FRANCK sich nicht sehr detailliert aus; er formuliert lediglich, dass der »Tausch der Aufmerksamkeit nicht durch einfache Übertragung bewährter Methoden rekonstruier[t] [...] « werden könne (vgl. FRANCK 1998: 78f). Vorher stellt er schon fest, dass man "Aufmerksamkeit [...] einnehmen, die eingenommene [...] aber nicht weitertauschen« könne. FRANCK selbst hält schon den Gedanken »Beachtung zu horten und zu Reichtümern anzuhäufen« für absurd. Er sucht damals seinen Ausweg so:

"Allerdings gilt es, nun genauer zu schauen. Aufmerksamkeit kann zwar als solche nicht weitergetauscht werden, sie kann aber sehr wohl einen Tauschwert annehmen. Ihr Tauschwert hängt unter anderem von dem Einkommen an Beachtung ab, das die beachtende Person bezieht. Zweitens ist die Aufmerksamkeit, die von prominenter Seite und in den publikumsorientierten Berufen eingenommen wird, durchaus anonym. Für den Grad der Prominenz und den Erfolg beim Publikum ist das Quantum ausschlaggebend.« (vgl. für die vorstehenden drei Zitate ebd.: 73) 
An dieser Stelle passt STRUBEs Bild vom Aufmerksamkeitssparkonto ins Spiel, das zwangsläufig in irgendeiner Form existieren müsse:

»Das Aufmerksamkeitssparkonto

Aufmerksamkeit kann [...] akkumuliert und weitergegeben werden«, konstatiert Florian Rötzer in >Telepolis` (Rötzer 1999, S. 1). >Reputation ist das konsolidierte Einkommen an sachverständiger Beachtungı, schreibt Georg Franck (Franck 1998b, S. 3). Wie sich das Einkommen an Aufmerksamkeit aber akkumulieren soll, erklären beide nicht." (STRUBE in: BLEICHER und HICKETHIER 2002: 79)

Präziser wird es, als sie jenes Aufmerksamkeitssparkonto in den Gedächtnissen von Individuen und Kollektiven verortet:

"Die Aufmerksamkeitsakkumulation in den Köpfen der anderen verabsolutiert dieses Verhältnis von Einzelperson und Kollektiv, indem sie es auch in der Umkehrung verwirklicht: Nicht nur ist das individuelle Gedächtnis abhängig vom sozialen Umfeld, sondern der Reichtum (oder auch: Tauschwert) des einzelnen generiert sich dadurch, in wie vielen Gedächtnissen er wie stark gespeichert ist. Doch die Definition von Gedächtnis als sSpeicherung wird inzwischen als überholt angesehen. Hartmut Winkler urteilt, sdaß die Speichermetapher wesentliche Eigenschaften des menschlichen Gedächtnisses [u. a. Inhaltsbearbeitung und - Veränderung, Relevanzprüfung, Affektbindung; Anm. K. S.] verfehlt und damit als inadäquat aufgegeben werden muß (Winkler 1997, S. 87). Winkler, stellvertretend für viele, favorisiert eher Modelle, die die Gedächtnistätigkeit snicht mehr als Aufbewahrungs-, sondern als Konstruktionsarbeit konzeptualisieren (Winkler 1997, S. 88), wie es beispielsweise Siegfried J. Schmidt (1991) tut. Indem man die Akkumulation von Aufmerksamkeit als Verwertungsprozeß [Hervorhebung im Original] beschreibt, wäre auch die Definition von Aufmerksamkeit als Kapital möglich. In gewisser Weise versucht dies Rötzer: 'Prominenz - als Produkt der Aufmerksamkeit - heckt sich selbst, wie Marx dies vom Kapital gesagt hat‘, (Rötzer 1998a, S. 62)." (ebd.: 80)

Das Problem des Transfers ist damit jedoch immer noch nicht ausreichend beleuchtet. Ausgehend von einer Konstruktionspraxis in actu in Anlehnung an die Konstruktionsarbeit am eigenen Gedächtnis kann er nur auf sprachlichem Wege stattfinden: Indem Worte, die soziale Bedeutungen verkörpern, als Repräsentanten von Wertmaßstäben mündlich oder schriftlich weitergegeben und ausgetauscht werden. Die Kenntnis dieser Wertmaßstäbe versetzt die Kommunizierenden in die Lage, sie im Rahmen individueller Konstruktionsarbeit anzunehmen oder abzulehnen und damit in ihr eigenes Gedächtnis einzubauen. Diese Repräsentanten von Wertmaßstäben liegen auch als laten- 


\title{
STARDESIGNER ODER GESTALTER DES ALLTÄGLICHEN?
}

te Aufmerksamkeitsspeicher in Form von Publikationen verschiedener Art, in Fernseh- und Filmbeiträgen und Wettbewerben nebst den zugehörigen Trophäen vor. Ihre Latenz erklärt sich durch ein in ihnen schlummerndes Potential, das sich erst bei der und durch die Rezeption ergeben kann. Kenntnis von in ihnen schlummernder Reputation erlangt man erst durch tätige Selbstaneignung oder durch Vermittlung Dritter und immer sind dafür Kenntnisse unterschiedlicher Art nötig. STRUBE gibt ihrer Argumentation eine interessante Wendung, indem sie das Anerkennungsverhältnis, das zwischen Stars und Fans besteht, aus der Perspektive des Stars als egoistisch motiviert beschreibt und den Fan als versteckten Nutznießer seiner eigenen Aufmerksamkeitsgabe zu positionieren versucht:

\begin{abstract}
"Der sjenseitige Wert der Aufmerksamkeit besteht nun nach Franck in einer Hochschätzung desjenigen, von dem man Zuwendung an Aufmerksamkeit zu erhalten wünscht. Das Anbeten eines Stars wäre demnach die Überhöhung der Wertschätzung des anderen mit dem Ziel, sich selbst begehrenswert zu machen. Daß die Fans [Hervorhebung im Original] aber doch Fans [Hervorhebung im Original] bleiben und die Stars [Hervorhebung im Original] die an sie herangetragene Aufmerksamkeit nicht in gleichem Maß erwidern, mag an deren umgekehrt zu niedriger Wertschätzung des Fans liegen. Durch das überhöhte Bild, das die Fans [Hervorhebung im Original] vom Star [Hervorhebung im Original] haben, wird es möglich, daß dessen kleinste Geste als Aufmerksamkeitsgabe interpretiert wird. Fan-Sein wäre demnach eine zweckrationale Entscheidung, weil dadurch der Eigenanteil an der Aufmerksamkeitsgewinnung gegenüber den nicht selbst steuerbaren Einflüssen optimiert wird.«(ebd.: 81f)
\end{abstract}

Die Asymmetrie des Star-Fan-Verhältnisses wird mit der Interpretation einer »kleinste[n] Geste als Aufmerksamkeitsgabe «schmerzhaft genau beschrieben und ändert sich auch durch den letzten Satz nicht: Die Frage, die sich stellt, ist, ob durch die Betonung des »Eigenanteil[s]« nicht Selbstbeschwichtigung betrieben wird, um die Sehnsucht nach der Zuwendung des Stars im Zaum halten zu können und in diesem einseitigen Abhängigkeitsverhältnis immer noch eine Form von Selbstachtung zu bewahren. 


\title{
Kultur und Quote
}

METELMANN arbeitet die Differenzen heraus, die GEORG FRANCK im Rahmen seines Essays im Verhältnis zu BOURDIEU sieht, um das Missverständnis aufzuklären, dass

\begin{abstract}
„Franck selbst [...] im Vergleich die Nähe des Bourdieuschen Grundtheorems der Rationalität bzw. der Optimierung zu seinem eigenen Vorgehen feststellte, [...] sich aber wieder mit dem Hinweis auf Distanz [brachte], daß es sich in der Ökonomie der Aufmerksamkeit um rwirkliches Kapitak handele, während das ssymbolische Kapitak Bourdieus nur kapitalartige Züge trage (ebd., 120).« (METELMANN in: BLEICHER und HICKETHIER 2002: 88)
\end{abstract}

Er schließt an:
»Bourdieus Herangehen an die Ökonomie aus Sicht soziologischer Fra- gestellungen, das den Kern seiner Theorie berührt und sich auch in der spezifischen Verwendung bestimmter Termini niederschlägt, hat dabei m. E. auch zu einem Mißverständnis des sSymbolischen Kapitals« Bour- dieus durch Franck geführt. Franck deutet es, wie schon anfangs ausge- führt, im umgangssprachlichen Sinne als ein >Als-ob-Kapital, das aber eben nicht im engen Sinne ökonomisch ist. Bourdieu jedoch, so hat er an anderen Stellen als den von Franck zitierten aus den Feinen Unterschie- den [Hervorhebung im Original] vielleicht deutlicher dargestellt, versteht symbolisch im Sinne von rals Zeichen der sozialen Praxis fungierend: [Bourdieu-Zitat gestrichen, der Verfasser] Zentral ist also die Dopplung und Relationalität der Kapitalformen: Es gibt nicht nur kulturelles $\mathrm{Ka}$ - pital [Hervorhebung im Original] wie z.B. Bildung und Titel auf der ob- jektiven Seite, sondern auch Symbolisches Kulturelles Kapital [Hervorhe- bung im Original] auf der subjektiven Seite, wenn z.B. Akademiker ihrer Ausbildung einen gewissen gesellschaftlichen Stellenwert und Rang zu- rechnen.«(ebd.: 93f)

Zieht man in diesen Zusammenhang die Argumentation von STRUBE (s. o.) mit hinein, hat BOURDIEUs Symbolisches Kulturelles Kapital ohne Weiteres eine Anschlussfähigkeit zu deren Aufmerksamkeitssparkonto - oder umgekehrt. Die Objektivität der Institutionalisierung in Form von Bildungsabschlüssen und Titeln hebt sich bei BOURDIEU zwangsläufig ab von jener sozialen Praxis, aus der sie hervorgeht. Doch wird mit dieser eine immaterielle Dimension von Aufmerksamkeit weitergegeben, die, wie man bisher schon sehen konnte, nicht institutionalisiert und wohl auch nicht institutionalisierbar ist - was der Grund dafür sein könnte, dass GEORG FRANCK es nur als »Als-ob-Kapital« 


\section{STARDESIGNER ODER GESTALTER DES ALLTÄGLICHEN?}

betrachtet hat. Dessen Defizit liegt darin begründet, dass auch seine angeblich handelbare Aufmerksamkeit nichts anderes darstellt und auch nicht zur Begründung einer ökonomischen Theorie taugt. METELMANn bilanziert die Grundkonzepte von BOURDIEU und FRANCK so:

"Bourdieu arbeitet anders als Franck nicht mit einem [Hervorhebung im Original] Begriff von Kapital, sondern unterscheidet mehrere [Hervorhebung im Original] Formen. Die Verbindung zwischen diesen unterschiedlichen Formen denkt er als Transformationen [Hervorhebung im Original]. Franck hingegen operiert mit der Analogie [Hervorhebung im Original] zwischen den beiden Ebenen des materiellen und des mentalen Kapitalismus. Dabei ist wiederum der Ansatzpunkt für die Einbringung der Ökonomie, nämlich deren Unterstellung eines optimierend-effizienten Rationalitätsbegriffs, sehr ähnlich. Beide Autoren wollen jedoch davon ausgehend zeigen, daß dieser Begriff von Ökonomie, der historisch eine Verengung darstellt (siehe Anmerkung 10), nicht zur Beschreibung sozialer Realität ausreicht.« (ebd.: 95f)

Die Vermittlungsebene zwischen den beiden sieht metelmann dort, wo die Aufmerksamkeit quantifiziert werden soll und was das je nach gesellschaftlicher Schicht aussagt:

"Ich denke dabei insbesondere an die anthropologische Dimension der Aufmerksamkeit als Dasein [Hervorhebung im Original], die Francks ursprünglichen Entwurf grundierte. Ein solches ahistorisches und entsoziologisiertes Konzept ist mit Bourdieus ,Feld«-Denken gänzlich inkompatibel. Eine Vermittlung ist denkbar, sobald man zu klären beginnt, wer genau wieviel Aufmerksamkeit spendet bzw. was Aufmerksamkeit in der Medien- und Informationsgesellschaft feld-/schichtenspezifisch bedeutet.« (ebd.: 103)

Das Bedürfnis, Aufmerksamkeit zu quantifizieren, hat nach der Reichweitenmessung für Print- und AV-Medien und erst recht nach Einführung von Online-Medien durch die Messbarkeit von Klicks ein neues Begehrlichkeitslevel erreicht - verständlicherweise. Doch auch hier ist den Beteiligten klar geworden, dass Reichweite (quantifizierbar) nicht mit Relevanz (qualifizierbar) gleichzusetzen ist. Gleichwohl gibt es seit 2012 das Angebot eines sogenannten AIX - eines Aufmerksamkeitsindex, von dem der Anbieter behauptet, Aufmerksamkeit sei damit erstmals monetär quantifizierbar: 


\section{AUFMERKSAMKEIT, MEDIEN UND ÖKONOMIE}

"Der AIX misst das Potenzial der Medien, die Aufmerksamkeit der Nutzer aufsichzuziehen.AufmerksamkeitfürverschiedeneMediengattungenwird damit erstmals crossmedial vergleichbar." (GOLDMEDIA) [online] http:// www.goldmedia.com/aktuelles/presse/newsroom/aufmerksamkeits-index/\#c10667 und http://de.slideshare.net/goldmedia/120222-goldmediaaufmerksamkeitsindex [14.05.2018]

\section{Zur Verdeutlichung des dahinterliegenden Konzepts noch ein paar unkom- mentierte Zitate aus der obigen Fundstelle:}

»Nutzer geben Aufmerksamkeit ... ... Medien sammeln Aufmerksamkeit ....... und verkaufen sie gegen Geld ..." (Folie 3)

»Der Aufmerksamkeits-Index (AIX) quantifiziert die Kosten (sowohl direkt als auch indirekt in Form von Aufmerksamkeit), die ein Nutzer pro Stunde Medienkonsum aufbringt. Offenbar versprechen sich die Konsumenten von hoch involvierenden Medien (z.B. Kino) bzw. passgenauen Informationen (z.B. in Fachzeitschriften) einen besonders hohen Nutzen. Medien, die eher nebenbei konsumiert werden, - etwa Radio und Musik - kommen nur auf geringe Werte im Aufmerksamkeit-Index." (Folie 7)

»Für eine Stunde Medienaufmerksamkeit zahlen die Deutschen im Durchschnitt 18Ct! Dieser Betrag setzt sich zusammen aus direkten Kosten und Gebühren sowie den Aufmerksamkeitskosten (oder indirekte Kosten: durch Werbungtreibende querfinanziert). Die höchsten direkten Kosten pro Stunde fallen beim Kino an $(3,95 €)$. Aufmerksamkeitskosten bei Zeitschriften (die oft sehr spezielle Zielgruppen ansprechen) sind hoch. Den geringsten AIX-Wert generieren die Hörfunker mit nur ০,०4€.« (Folie 9)

"Der Goldmedia-Aufmerksamkeit-Index beschreibt das Verhältnis von Medienumsätzen und Mediennutzungszeit. Da die Umsätze stärker gestiegen sind als die Nutzungszeit, ist der Aufmerksamkeits-Index über alle Mediengattungen 2010 höher als fünf Jahre zuvor.« (Folie 10) 


\section{Kritische Anmerkungen zur neuen Ökonomie der Aufmerksamkeit}

BADEs Artikel schließt trotz eines zeitlichen Abstandes von aktuell 16 Jahren zu dieser Arbeit nahtlos an die aktuellsten Entwicklungen aus der vorherigen Betrachtung an:

"Am Beispiel der Medien läßt sich zeigen, daß das Ringen um die Aufmerksamkeit eng mit der monetären Ökonomie verkoppelt und in dieser fundiert ist. Die Einschaltquote, der lediglich eine repräsentative Stichprobenerhebung von ca. 5100 Haushalten zugrunde liegt, wird für das Fernsehen zu der alles bestimmenden Währung [Hervorhebung im Original], die über Erfolg oder Mißerfolg von Programmen, Sendern und Stars entscheidet und die auf dem Werbemarkt die Verhandlungsbasis für die angestrebten finanziellen Einnahmen ausmacht (vgl. Altmeppen 1998, 3). Im Hinblick auf die ökonomische Verwertbarkeit ist die Massenbzw. Zielgruppenattraktivität für die Medien das entscheidende Qualitätsmerkmal, dem allerdings keine operationalisierbaren Kriterien für die Qualität der Programme zugrunde liegen. [...] Die Quote bzw. die von den Medien eingehandelte Aufmerksamkeit steht aufgrund der fehlenden Preisbindung weder in einer Beziehung zum ökonomischen Wert der (Informations-) Angebote noch zu ihrer Qualität." (BADE in: BLEICHER und HICKETHIER 2002: 182)

Die »ökonomische Verwertbarkeit« ist mit der Etablierung eines Aufmerksamkeitsindexes auf einer neuen Stufe angelangt. Die Messung hat sich hinsichtlich der Quantifizierung wohl absolut gesehen nicht wesentlich verändert; die qualitative Differenz von mehr als eineinhalb Jahrzehnten liegt in der Behauptung, heutzutage das Aufmerksamkeitspotential pro Medium quantifizieren zu können. Auf der Basis dieser Behauptung werden die real zu zahlenden Aufmerksamkeitskosten für Werbungtreibende errechnet. Der Begriff wird hier so verstanden, dass er für die Kosten steht, die von diesen zu zahlen sind, um in einem Medium X die potentielle Aufmerksamkeit eines Nutzers Y zu erreichen. Diese Differenzierung ist wichtig, da auch eine Form der Aufmerksamkeitskosten existiert, die vom Nutzer/Kunden aufgebracht werden muss: In Form des Aufwandes, den es ihn kostet, bestimmte Medien zu konsumieren, wobei dieser über die Beschaffung des Mediums (direkte Kosten) hinausgeht und eher als Teil der Aufmerksamkeitsleistung (indirekte Kosten) zu verstehen ist, die dafür vom eigenen täglichen Aufmerksamkeitspotential abgezweigt werden muss. Ein letztes Zitat aus BADEs Text harrt wohl 
noch einer Überprüfung in jenem Marktsegment, das im Rahmen dieser Arbeit eine Rolle spielt:

"Der offenbar wieder wachsende Stellenwert, der der Aufmerksamkeit bei den zwischenmenschlichen Interaktionen in der Auseinandersetzung mit den sich verschärfenden Widersprüchen einer kapitalistischen Ökonomie zukommt, könnte als ein Indiz dafür gelten, daß einzelne Menschen oder Institutionen (z. B. die Wissenschaft), damit begonnen haben, an alternativen Lebens- und Überlebensstrategien zu arbeiten und der unbedingten Verwertungslogik des Marktes in dieser Weise etwas entgegen setzen möchten.« (ebd.: 191)

Hinsichtlich der Einlösung in einem so sehr aufmerksamkeitsfixierten Bereich wie der Tätigkeit von Designern im Rahmen von Wirtschaftskreisläufen sind Zweifel daran angebracht, auch 16 Jahre später noch.

\section{Die Goldtruhen der Seeräuber}

LEHNINGs Beitrag merkt man an, dass zur damaligen Zeit der Umgang mit Seitenabrufen und deren Bedeutung die neue Religion und das noch unbekannte Land sind:

»Je mehr Informationsabrufe und -erzeugnisse eine Person im Informationsnetzwerk initiiert, umso größer die Wertschätzung [Hervorhebung im Original], die ihr in der neuen Ökonomie entgegengebracht wird. Das Erzeugen wie das Abrufen von Information produziert nicht nur direkt Kapital, es zeigt an der Art der Nachricht auch, welche potentiellen Werte der Informationserzeuger in Zukunft erbringen wird. Der Distributionskanal für Waren ist eröffnet." (LEHNING in: BLEICHER und HICKETHIER 2002: 195)

In Zeiten eines schon wieder abflauenden Influencer-Marketings, nachdem die Apologeten der Aufmerksamkeitsökonomie schon längst die Relationship Economy als das next big thing ausgerufen haben, stehen

»Medienstars [...] für Kapital-Bündelungen an der Oberfläche der Erzählungen unserer Alltagskultur. Allein die Eigenschaft, für kurze Zeit im Zentrum jener sich überschlagenden Diskursproduktion gestanden zu haben, erzeugt Profit und beschäftigt untergründige Informationsbeschaffungs-, Übermittlungs-, Speicher- und Analysesysteme. Wer heute über aktuelle Bildende Kunst, Musik, Lyrik oder Theater als Handelsgut nachdenkt, wird sie in intensivster Kollaboration mit der vernetzten Ökono- 


\section{STARDESIGNER ODER GESTALTER DES ALLTÄGLICHEN?}

mie finden. Bei aufwendigen Filmprojekten, in denen neue Techniken eingesetzt werden oder in Computer-Games spielen scheinbar immer noch die - echten oder virtuellen - Stars die Hauptrolle und repräsentieren die Fixpunkte, an denen Aufmerksamkeit sich bricht. Wie bei der Betrachtung des Arbeitsplatzes zählt jedoch bei den komplexen Produkten der vernetzten Ökonomie mehr als je zuvor, was und wer insgesamt im Hintergrund mitarbeitet. Hinter den sichtbaren Kulissen sind geordnete Technologie-Systeme aktiv. Der Star wird zum kalkulierbaren Anteil des Gesamtbudgets reduziert und kann fast immer problemlos ersetzt werden.« (ebd.: 203)

Überaus interessant ist diese Passage, wenn man sich noch einmal vor Augen führt, in welchem zeitlichen Abstand sie zu dieser Arbeit verfasst wurde. Die Aussage, der "Star [werde] zum kalkulierbaren Anteil des Gesamtbudgets reduziert«, der »fast immer problemlos ersetzt werden« könne, kann aus heutiger Sicht nicht so stehen bleiben. Der Aufwand, einen Star hervorzubringen, mag zwar durchaus im Sinne von Durchschnittswerten kalkulierbar sein, doch eine verlässliche Mechanik dafür existiert ebenso wenig, wie es ein planbares Angebot gibt: Selbst, wenn man in Anrechnung bringt, dass es einen ständig verfügbaren Pool von Menschen gibt, die ins Rampenlicht drängen und eine nennenswerte Menge an Personen, Strukturen, Institutionen und Publikationen, die Willens oder dafür geschaffen worden sind, neue Stars zu küren. Der unsichtbare Rest des Eisberges, mit dem man die Mühlen der Starproduktion am Laufen hält, hat immer noch nicht die Oberhand über die (Geschmacks-) Massenentscheidungen gewonnen, die die Existenz von Stars mit herbeiführen. 

»Die Bestimmung des

Aufmerkens, die wir

kennen, ist die der Zu-

und Abwendung."

Bernhard Waldenfels 


\section{Phänomenologie der Aufmerksamkeit}

WALDENFELS begibt sich auf die "Suche nach der Aufmerksamkeit und stellt gleich zu Beginn eine Reihe von wichtigen Fragen:

"Ist Aufmerksamkeit ein Geschehen, ein Ereignis, ein Akt, eine Dispositi-
on, ein Können, eine Pflicht, ein Geschenk? Offensichtlich hat sie von al-
lem etwas. Doch würde ihr selbst nichts Auffälliges anhaften, so wäre sie,
was sie häufig ebensosehr ist: ein Gelegenheitsthema, das alsbald Wichti-
gerem weicht." (WALDENFELS 2004: 9)

Betrachtet man die Aufmerksamkeit mit dem Ansatz der Phänomenologie, die »beobachtbaren Sachen als solche« zu ihrem Untersuchungsgegenstand zu nehmen, so ist ein interessanter Aufhänger zur Untersuchung von etwas gegeben, das allenfalls in Ansätzen beobachtbar ist .... (vgl. UTB-ONLINE-WÖRTERBUCH PHILOSOPHIE) [online] http://www.philosophie-woerterbuch.de/ online-woerterbuch/?tx_gbwbphilosophie_main[action]=show\&tx_gbwbphilosophie_main[controller]=Lexicon\&tx_gbwbphilosophie_main[entry] $=672 \& c H a s h=61759 a 44820$ c074c6bb3e6eef3336af2 [11.07.2016; nicht mehr im Netz verfügbar: »Die Online-Version des Philosophie Wörterbuches wurde zum 09.04.2018 vom Netz genommen.«])

Eben jenes Auffällige, das ihr anhafte, beschäftigt GEORG FRANCK wie WALDENFELS - ersterer wertet sie zu einer Ökonomie der Auffälligkeiten auf und geht ihrer Erscheinung nach, letzterer betrachtet sie als »die betreffende Sache selbst« (s. o.). Auch WALDENFELS kommt nicht an JAMES vorbei, begnügt 


\section{STARDESIGNER ODER GESTALTER DES ALLTÄGLICHEN?}

sich aber nicht mit dessen basaler Feststellung, dass ein jeder wisse, was Aufmerksamkeit sei (s. o.), sondern hängt an dessen Bild der individuellen Selektion seine Idee der Reliefbildung auf:

"Die zentrale Funktion, die von der Aufmerksamkeit an dieser Stelle übernommen wird, ist die der Reliefbildung [Hervorhebung im Original]. William James, der das Werk der Aufmerksamkeit ausdrücklich mit dem eines Bildhauers vergleicht, spricht im gleichen Atemzug von Selektion (1960, Bd. I, S. 288), wie man es auch heute vielfach tut, indem man mit Filtern und Rastern operiert. Doch die Redeweise ist höchst mißverständlich. Sie erweckt den Eindruck, als würde lediglich einiges ausgesondert, anderes weggelassen, einiges ausgelassen, anderes ausgesperrt und als bestünde das Aufmerksamkeitsfeld aus einem Repertoire katalogisierter Daten, aus denen man sich nach Bedarf bedient. Doch eine Aufmerksamkeit, in der die Erfahrung sich organisiert, in der Neues entsteht und in der nicht nur Erfahrungsbestände verwaltet werden, leistet mehr und anderes. Sie sorgt dafür, daß in der Ausbildung eines >Beachtungsreliefs، einiges hervortritt [Hervorhebung im Original], anderes zurücktritt [Hervorhebung im Original], wie bei einem Relief, das ähnlich wie die Relevanz sprachlich auf das lateinische Wort relevare (= aufheben, abheben) [Hervorhebung im Original] zurückgeht. Dem entspricht auf seiten des Aufmerkenden ein Vorziehen und Zurückstellen [Hervorhebungen im Original]. Auf diese Weise wird etwas zum Thema [Hervorhebung im Original]. Was hervortritt, tritt nicht nur aus der Fläche heraus, es bildet auch den Mittelpunkt eines thematischen Feldes [Hervorhebung im Original], das nach Nähe und Ferne zum thematischen Kern gestaffelt ist. Was nicht zum Thema gehört, tritt an den Rand [Hervorhebung im Original]. Genauer müßte es heißen: es wird an den Rand gedrängt. Zentrum und Rand sind keinesfalls statische Größen, sondern Produkte einer ständig sich erneuernden Zentrierung und Marginalisierung." (WALDENFELS 2004: 101f)

Diese ständige Veränderung durch hervor- und zurücktretendes, das auch noch individuell verschieden ausgeprägt ist, lässt die Simplifizierungen FRANCKs so unbrauchbar erscheinen. Gerade sie ermöglichen es jenem aber auch, die Aufmerksamkeit zum Schlüssel für einfach alles zu erklären, was ihn wiederum so plausibel erscheinen lässt! Die andauernde Anpassung des individuellen Aufmerksamkeitsreliefs ist ein Teil der Konstruktionsarbeit an unserem Gedächtnis - um etwas bevorzugen und anderes hintüber fallen lassen zu können, muss dem etwas vorausgehen:

»Einen ersten Ansatzpunkt liefert unsere Unterscheidung zwischen primärer und sekundärer Aufmerksamkeit, allerdings nur dann, wenn der sekundären Aufmerksamkeit eine genuine Leistung der Wiederholung [Hervorhebung im Original] zugebilligt wird. Eben das, was uns auf un- 


\section{PHÄNOMENOLOGIE DER AUFMERKSAMKEIT}

gewohnte und ungeahnte Weise auffällt, was uns überfällt und überrascht, wiederholt sich derart, daß es sich in einen Fall verwandelt; es wiederholt sich andererseits auch nicht, da das, was vorfällt und auffällt, nicht schlechthin unter ein Gesetz fällt. Das Unwiederholbare im Wiederholen erzeugt eine produktive Spannung: erst, wenn das Moment des Unwiederholbaren verdrängt und vergessen wird, bleiben bloße Mechanismen zurück. Für die Umsetzung des Unwiederholbaren in wiederholbaren Gestalten und Bewegungen lassen sich verschiedene Faktoren angeben, von denen hier einige benannt seien. An erster Stelle ist die Auslesefunktion [Hervorhebung im Original] zu nennen. Bei entsprechender Kodierung verwandelt sich das, was uns auffällt, in ein erkennbares und erstrebbares Etwas, dem ausgesuchte Merkmale [Hervorhebung im Original] und Wirkmale [Hervorhebung im Original] zugeordnet werden. Auf diese Weise wissen wir, was oder wer auf uns zukommt, und wir können uns darauf einstellen. Wie die Gestalttheorie bereits klar erkannt und die Neurobiologie auf neue Weise entdeckt hat, kommt es zu einer Bevorzugung [Hervorhebung im Original]. Denn würde alles wiederholt, so würde sich nichts wiederholen. Die Erfahrung gliche dem reinen Fluß, in den wir nicht nur zweimal nicht, sondern selbst einmal nicht als in denselben steigen können.« (ebd.: 121f)

Doch reicht diese Bevorzugung noch nicht aus - entscheidend ist die Art, in der wir »angerührt und angesprochen werden«:

"Beim Aufmerken kommt es nun nicht nur darauf an, daß Auffälliges sich von Unauffälligem abhebt oder daß der Aufprall des Sinnesschocks in einen Prozeß des Auffallens und Aufmerkens übergeht, es kommt zugleich darauf an, daß wir gerade so und nicht anders [Hervorhebung im Original] angerührt und angesprochen werden. Das Auffällige muß eine gewisse Verführungskraft [Hervorhebung im Original] entfalten, es muß etwas Verlockendes [Hervorhebung im Original] (Einladendes, Erfreuliches, Anziehendes) oder umgekehrt etwas Abschreckendes [Hervorhebung im Original] (Abstoßendes, Fürchterliches. Lästiges) an sich haben und dadurch unsere Zu- oder Abwendung auslösen; das heißt, es muß an unser Begehren, an unsere Triebe und Interessen appellieren. Dieser Appell setzt die bereits erwähnte Verzögerung voraus, eine >Polsterzeitı, in der sich die Verführungskraft entfalten kann. [...] Das interesselose Wohlgefallen, das Kant für die Anschauung des Schönen in Anspruch nimmt, trägt Züge einer Geisterbeschwörung, die das, was sie beschwört, keineswegs zum Verschwinden bringt. Hierbei ist allerdings zu unterscheiden zwischen einem originären Begehren, das aus der Ferne und der Fremde kommt, und einer sekundären Form von Bedürfnissen, denen sich Güter und Werte sowie Praktiken der Bedürfnisbefriedigung zuordnen lassen. Diese Differenz wird ihr volles Gewicht erst dann erhalten, wenn wir die Anderen in Betracht ziehen, die an unsere Aufmerksamkeit appellieren.« (ebd.: 136) 
Hieran zeigt sich, dass ein Grundproblem der Aufmerksamkeitsökonomie in der Intersubjektivität begründet liegt. Die Tatsache, dass wir die Verführungskraft von etwas in unser Aufmerksamkeitsrelief einbauen und dieses auch von einem anderen Bewusstsein - HUSSERL zugrundelegend - in einem Analogieschluss annehmen können, legt auch den anderen Kommunikationskanal automatisch mit an. Aus diesem Grund ist es einem anderen Bewusstsein möglich, uns auf dieser sekundären Bedürfnisebene der Güter und Werte verführen zu wollen und zu können - wie umgekehrt. In jenem Moment, in dem Bedürfnisbefriedigung als etwas gedacht werden kann, das ansteuerbar ist, können auch Strategien zu ihrer Operationalisierbarkeit erdacht werden. Das potentielle Scheitern eben jener Strategien ist gleichfalls mit angelegt, denn wie WALDENFELs oben schon feststellt, folgt der Prozess der individuellen Reliefbildung keinerlei Gesetzmäßigkeiten. Auch er weist darauf hin,

»[...] daß die Verführungskraft der Dinge eine Einfallspforte öffnet für alle Arten von Einflußnahme, auch für den medial vermittelten Einfluß der ökonomischen Reklame und der politischen Propaganda. Fragwürdig wird die Einflußnahme, wenn die Verlockung des Begehrens auf eine bloße Tauschwirtschaft der Lüste und auf eine Befriedigung bestehender oder hergestellter Bedürfnisse herabgesetzt wird. Die umworbene und angestachelte Aufmerksamkeit droht jederzeit in eine umgarnte und gegängelte Aufmerksamkeit abzugleiten, die nur noch sucht, was sie im Grund schon kennt, und verfolgt, was sie im Grunde schon hat." (ebd.: 136f)

Dennoch sucht die »angestachelte Aufmerksamkeit « doch stets auch das, was sie bevorzugt und verwandelt es in einen Fall, auf den sie sich wieder beziehen kann (s. o.). Weshalb sie das tut, bleibt an dieser Stelle ungeklärt. Doch dies in eine Gängelung umzuwerten, die den an unsere Aufmerksamkeit appellierenden allein in die Schuhe geschoben würde, geht wohl an der Sache vorbei und lässt individuelles Handeln außer Acht. WALDENFELS tritt danach einen großen Schritt zurück, um die Zuwendung wie HUSSERL »als einen Initialakt des Ich« festzulegen:

"Die Bestimmung des Aufmerkens, die wir kennen, ist die der $\mathrm{Zu}$ - und $\mathrm{Ab}$ wendung. Dies klingt nach einer disjunktiven Ja/Nein-Entscheidung. Doch damit stünden wir bereits auf dem Boden einer sekundären Aufmerksamkeit, die aus vorhandenen Möglichkeiten die geeignetste auswählt und alles andere wegläßt. In der primären Aufmerksamkeit genießt demgegenüber die Zuwendung einen Vorzug; denn jede Abwendung setzt bereits eine minimale Zuwendung voraus, sofern etwas auftritt, wovon [Hervorhebung im Original] wir uns wieder abwenden. Darin stecken eine Reihe weiterer Probleme, die wir zunächst auf sich beruhen lassen kön- 
nen. Soviel läßt sich schon hier sagen: Die Zuwendung schlägt als Hinwendung, als Hinsehen und Hinhören, eine bestimmte Richtung ein. Da ich selbst an der Zuwendung maßgeblich beteiligt bin, qualifiziert Husserl sie als einen Initialakt des Ich, der in allen weiteren Formen der Beobachtung, Beschreibung oder Beurteilung enthalten ist." (ebd.: 138f)

Aufmerksamkeit ist definitorisch das begriffliche Gegenteil von Zerstreuung. Das Gegenteil von Aufmerksamkeit ist allerdings auch eine reine Definitionsfrage. Am Ende reduzieren sich Ablenkung oder Abwendung, die nicht notwendiger Weise in Zerstreuung münden müssen, vom Prinzip her auf verschobene Aufmerksamkeit - für die wir einen anderen Begriff nebst Bewertung erfunden haben. Wendet man seine Aufmerksamkeit von etwas ab, für das man sie bis zu diesem Zeitpunkt hatte und in der Folge auf etwas anderes, das ab dann in den verschobenen Fokus der Aufmerksamkeit gerät, so wird dieses Abziehen der Aufmerksamkeit vom einen für etwas anderes als Ablenkung oder Abwendung bezeichnet - dann begriffen als eine Eigenschaft des anderen, ablenkenden. Dieser bewusst oder unbewusst ausgeführte Schwenk, das Abwenden, kann sodann auch als negative Eigenschaft des ablenkenden anderen aufgefasst und bezeichnet wie bewertet werden. Damit ließe sich diese Handlung sogar theoretisch als von eigenem Wollen entkoppelte klassifizieren - womit wir an einem Punkt angekommen sind, wie ihn WALDENFELS auch weiter unten als »ein Geschehen [...]« thematisiert, »[...] das wir nicht willentlich und wissentlich in Gang setzen" und dies, obwohl der oder die Aufmerkende selbst seine/ihre Aufmerksamkeit vom einen auf das andere verlagerte. Die Frage weshalb spielt keine Rolle. Und was fangen wir in diesem Zusammenhang erst mit denjenigen an, die mutwillig nach Zerstreuung suchen? RIвОт schreibt 1890 über sie:

"Our daily speech usually contrasts with attention the state called sdistraction;; but this state in our language (the French) has an equivocal sense. It designates certain states of the mind, apparently, very similar, yet at bottom totally contrary. We call sdistracted ‘ people whose intelligence is unable to fix itself with any degree of persistence, and who pass incessantly from one idea to another, at the mercy of their most transient whims, or of any trifling events in their surroundings. It is a perptual state of mobility and dispersion, which is the very reverse of attention. [...] But the term >distraction is also applied to cases entirely different from this. Thus there are people who, wholly absorbed by some idea, are also really sdistracted in regard to what takes place around them; they afford no hold to external events, and allow the latter to flit by without penetrating their minds. Such people appear incapable of attention for the very reason that they are very attentive. Many scholars have been noted for 


\section{STARDESIGNER ODER GESTALTER DES ALLTÄGLICHEN?}

their >distraction and so well known are the instances that it is useless to cite them." (RIBOT 1890: 78f)

Doch weiter mit WALDENFELS: Die Intersubjektivität führt notwendigerweise zur Interattention wie zu Aufmerksamkeitspraktiken und auch einer Aufmerksamkeitspolitik im Rahmen einer Aufmerksamkeitsökonomie - womit GEORG FRANCKs Schlüsselbegriff auch von WALDENFELS ins Spiel gebracht wird, obwohl jener sich nicht in dessen Literaturliste wiederfindet:

»Daß die Aufmerksamkeit in ein Kräftefeld eingebettet ist und daß Aufmerksamkeitstechniken und Aufmerksamkeitsmedien von Machtbeziehungen geprägt sind, kam bereits zur Sprache. Nun geht es darum zu zeigen, auf welche Weise Aufmerksamkeit und soziale Macht, Aufmerken und Aufmerkenlassen nach Art einer Interattention [Hervorhebung des Verfassers] miteinander verknüpft sind. Selbst wenn die Prozesse des Auffälligwerdens und der wechselseitigen Einwirkung sich nicht decken, so bleibt die Frage, worin sie sich berühren. Dies legt den Gedanken nahe, daß es nicht nur eine Macht der Aufmerksamkeit gebe, sondern umgekehrt auch eine Auffälligkeit bzw. Unauffälligkeit der Macht. Die Aufmerksamkeit gewinnt eine praktische Dimension, wenn es zur Ausbildung von Aufmerksamkeitspraktiken kommt und sich eine Aufmerksamkeitspolitik wie auch eine Aufmerksamkeitsökonomie herausbildet.« (WALDENFELS 2004: 228f)

Im System der Aufmerksamkeitsökonomie werden auch Machtverhältnisse erzeugt, die sich auf alle Systemteilnehmer auswirken:

"Die Steuerung der Aufmerksamkeit bleibt nicht beschränkt auf die Steuerung von Kräften in einem Aufmerksamkeitsfeld, sie potenziert sich in Form einer Selbst- und Fremdsteuerung [Hervorhebung im Original], einer Einwirkung auf uns selbst und Andere, die wir mit einem geläufigen Wort als Aufmerksammachen [Hervorhebung im Original] bezeichnen. Damit erreicht das Aufmerksamkeitsgeschehen seine soziale Dimension. Die Wirkkraft, die an dieser Stelle tätig wird, bezeichnen wir als Macht [Hervorhebung im Original]." (ebd.: 233)

Ein Vermögensbegriff, wie ihn GEORG FRANCK in seiner Ökonomie der Aufmerksamkeit als Gesprächsstoff, als Vermögen an Beachtlichkeit oder auch in der Verkörperung als Ruhm vorstellte, ist für WALDENFELS in diesem Zusammenhang zunächst nicht anwendbar - er siedelt die Macht, die bei GEORG FRANCK aus akkumuliertem Aufmerksamkeitskapital besteht, stattdessen beim Sichdurchsetzen im Aufmerksammachen an: 


\section{PHÄNOMENOLOGIE DER AUFMERKSAMKEIT}

»Entscheidend ist nun, daß Macht, also auch die Macht der Aufmerksamkeit, zunächst kein Vermögen darstellt, das jemand hat oder erwirbt. Macht zeigt sich ursprünglich in actu [Hervorhebung im Original], als Machtausübung, als Machtgeschehen. Nur so läßt sich ein soziales Zwischenfeld denken, das den Zwischenereignissen der Aufmerksamkeit entspricht. Machteinwirkung bedeutet weder eine kausale Einbeziehung, die einen Urheber, aber keinen Adressaten kennt, noch eine ziel- oder regelbestimmte Kooperation, in der alle Einwirkungen koordiniert sind. Machteinwirkung besteht vielmehr in einem Sichdurchsetzen gegen Andere [Hervorhebung im Original] oder gegen mich als Anderen [Hervorhebung im Original]. Genauer gesagt geht es darum, daß im Anderen bzw. in mir selbst ein mögliches anderes Selbst [Hervorhebung im Original] zum Zuge kommt. Dieses Gegeneinander ist also nicht mit Konkurrenz oder Feindschaft gleichzusetzen, als ginge es jedem lediglich um sich selbst im Gegensatz zum Anderen oder auf dessen Kosten. Das Machtgeschehen steht in enger Beziehung zum Aufmerksamkeitsgeschehen, wo mir etwas auffällt und nicht vielmehr [Hervorhebung im Original] anderes. Dieses unvermeidlich selektive Vielmehr wiederholt sich im Aufmerksammachen." (ebd.: 234f)

Bemerkenswert werden seine Ausführungen, wenn er erläutert, wo sich Anonymität aus seiner Sicht im System der Aufmerksamkeit verorten lässt, dass Namenlosigkeit in einem negativen und einem positiven Sinne existiert und was die Anonymität mit der Aufmerksamkeit verbindet:

"Die Nahtstelle, die Aufmerksamkeitsmechanismen und Aufmerksamkeitserfahrung miteinander verbindet und zugleich trennt, fällt in einen Bereich der Anonymität. Anonymität bedeutet Namenlosigkeit, dies jedoch nicht in dem rein negativen Sinne, daß etwas nicht mit einem Eigennamen versehen wurde. Dies würde auf jede Kirsche, die wir essen, auf jede Mücke, die uns sticht, und auf jeden Stromstoß zutreffen, den die Neuronen in unserem Gehirn abfeuern. Eine solche Namenlosigkeit würde außerdem Namensgeber voraussetzen, die ihrerseits bereits Namen tragen. Namenlos in einem positiven Sinne ist nur, was oder wer sich der Benennung entzieht, aber eben deshalb der Namenssphäre angehört, so wie Odysseus, der sich paradoxerweise >Niemand،, also wörtlich >Nicht-jemand [ [...] nennt. Diese Anonymität tritt in verschiedenen Formen auf, als hintergründige Namenlosigkeit dessen, der durchaus einen Namen empfangen hat und auf ihn hört, oder eben als Namenlosigkeit der Art und Weise, wie wir uns normalerweise verhalten." (ebd.: 251f)

Negative Namenlosigkeit entsteht also, wenn »etwas nicht mit einem Eigennamen versehen « wird - dieses »etwas « schließt somit auch Artefakte ein; sonst hätte WALDENFELS den Sachverhalt auf die interpersonale Ebene beschränken müssen - er impliziert aber schon eine Unterscheidung zwischen Handelnden und Behandeltem. Diese negative Namenlosigkeit setzt die persön- 
liche Bezeichnung als ein identifizierbares Individuelles voraus, doch schon auf der Basis generischer Bezeichnungen. Somit ist die WALDENFELSsche Vorstellung an die Idee der Individualität geknüpft und nur vor diesem Hintergrund ist sein Gegensatzpaar überhaupt denkbar. Nur als ein das System wissend mitkonstituierender Teilnehmer ist das paradoxe Verhalten möglich, der Namenssphäre anzugehören und sich ihr zugleich zu entziehen. Gleichwohl würde auch hier gelten, dass, so, wie man laut einem der WATZLAWICKschen Axiome nicht nicht kommunizieren kann, die Namenlosigkeit schlechterdings unmöglich ist. Auch Odysseus kann sich nur »Nicht-Jemand «nennen, weil es die Jemande dadurch gibt, dass sie begrifflich bereits gefasst sind und die $\mathrm{Ne}-$ gation dieses Begriffes damit erstens möglich und zweitens verstanden wird. Sieht man sich nun in Bezug auf Artefakte speziell die Kategorien genauer an, um die es in dieser Arbeit geht, so lässt sich feststellen, dass ein anonymes Artefakt in WALDENFELSscher Lesart in einem positiven Sinne namenlos wäre, weil es der Namenssphäre angehört. Im speziellen Fall kann es sich aber der Benennung auch gar nicht entziehen, weil es menschengemacht ist und damit zumindest einen Gattungsbegriff zugeordnet bekommt. Denn nichts menschengemachtes kommt in die Welt, ohne dass es einen Begriff dafür gibt. Wir gehen aber noch einen Schritt weiter, indem wir die Sphäre der Individualität auf Artefakte ausdehnen, denen wir in analogem Transfer individuelle Namen geben, mit denen wir sie identifizieren können. Was das über uns als Schöpfer von Dingen und unser Verhältnis zu ihnen aussagt, muss für den Moment unerörtert bleiben. Nehmen wir PHILIPPE STARCK als sinnfälliges Beispiel, so kaufen wir nicht einen Stuhl, sondern den COSTES CHAIR, MISS TRIP oder auch LOUIS GHOST, kein Telefon, sondern OLA, wir kaufen keine Zitronenpresse, sondern den JUICY SALIF:

"Naming is ambitious because Starck is perfectly aware that naming an
object, like naming a child, is a ritual that endows it with its own per-
sonality. The strange shiny thing on the kitchen table is ımy Juicy Salif,,
not sStarck's lemon squeezer«. Starck explains that by being named and
known, objects and things enter into our consciousness, and so merit
our care and remind us of our duty of love. Choosing an unusual or even
quirky name reinforces this process, as does indulging in wit and hu-
mor." (MORGAN 1999: 75)

Auffällig an MORGANs Aussage ist in diesem Zusammenhang die Betonung des Rituals der Namensgebung, mit dem das Artefakt eine eigene Persönlichkeit geschenkt bekomme. Damit entgeht es also negativer Namenlosigkeit? Sind wir in der Übertragung menschlicher Eigenschaften auf Gegenstände somit 
immer noch animistisch tätig? Ebenso bemerkenswert ist WALDENFELs' Vorstellung »einer vollendeten Namhaftigkeit«, die einen durch Medien ungebrochenen Kontakt voraussetzt. Das widerspricht der Namhaftigkeit, wie sie sich in Fan-Star-Verhältnissen darstellt, jedoch zur Gänze, weil WALDENFELS sie auf der Ebene des direkten zwischenmenschlichen Kontaktes ansiedelt, den es in einer Fan-Star Beziehung in der Mehrzahl der Fälle nur als parasoziale Interaktion geben kann:

„Man kann die Aufmerksamkeitsskala bis an das obere Ende einer vollen-
deten Namhaftigkeit verfolgen oder bis an das untere Ende einer vollstän-
digen Namenlosigkeit. Das erste Extrem würde einen direkten Kontakt
voraussetzen, der durch kein Medium gebrochen wäre, so daß einer dem
anderen ganz und gar als er [Hervorhebung im Original] oder sie selbst
[Hervorhebung im Original] entgegenträte. Doch darin liegt ein Para-
dox; denn das Als schließt gerade ein reines Selbst aus. Denkbar ist eine
solche Erfahrung nur als Übererfahrung, in der die Namenlosigkeit sich
in einem Überschuss an Fremdheit [Hervorhebung des Verfassers] bekun-
det, [...] oder aber als sozialer Kurzschluß, der das Gegenüber zu einem
Etwas degradiert und es schutzlos dem Zugriff eines Kontrahenten aus-
liefert.« (WALDENFELS 2004: 253)

»Überschuss an Fremdheit« wird im Vorgriff in direkten Bezug zum Zustand des Noch-nicht-Kennens gesetzt, der in der Bilanz des Kapitels zur Anonymität als verbliebene Kern-Bedeutung für die Anonymität von Artefakten festgestellt werden wird. Steigt mit diesem in der Aufmerksamkeitsökonomie der reine "value of unfamiliarity« wie er in einem Interview mit BLAKLEY, LANHAM und MERKOSKI zur Sprache kommt?

\begin{abstract}
"And it's just a general question about the value of unfamiliarity in an economy of attention [Hervorhebung des Verfassers] - that newness, the thing that we don't understand, the thing we don't recognize. Sometimes that's the only thing we notice, in a shelf that's got a bunch of crap on it that we've bought a million times before. Oh, this is new." [BLAKLEY in: LANHAM und MERKOSKI 2008: 22] [online] https://learcenter. $\mathrm{org} / \mathrm{pdf} /$ EconofAttention.pdf [31.01.2019]
\end{abstract}

Das Neue, Andere als noch Unbekanntes - wäre das wirklich alles, was in der Aufmerksamkeitsökonomie als Attraktions- und Distinktionsfaktor noch zählte? Der »Überschuss an Fremdheit« birgt jedenfalls das Potential seines Abbaus in sich, dazu bedarf es aber eines individuellen Erkenntnisinteresses. Die Macht kommt als »sozialer Kurzschluß « auf eine gefährliche Art in der Degradierung zum »Etwas « zum Ausdruck, mit der gesellschaftlicher Ausschluss durch ein Wegsprechen von Individualität ausgeübt werden kann, mithin Na- 


\section{STARDESIGNER ODER GESTALTER DES ALLTÄGLICHEN?}

menlosigkeit im oben bereits erwähnten negativen Sinne erzeugt wird. Zur Frage, was Aufmerksamkeit sei, dringen wir mit dem folgenden Zitat vor und stellen fest, dass WALDENFELS CRARY gelesen haben muss:

„Wenn die Aufmerksamkeit letzten Endes ein Geschehen ist, das wir nicht willentlich und wissentlich in Gang setzen, so stellt sich gleichwohl die Frage, ob es nicht einer Suspension der Aufmerksamkeit bedarf, um das Aufmerksamkeitsgeschehen als solches zu erfassen. Andernfalls gäbe es lediglich wechselnde attentionale Besetzungen und Verschiebungen, deren Dynamik ungeklärt bliebe. Das Aufmerken auf das Aufmerksamkeitsgeschehen stellt uns vor Rätsel, die der Philosophie von ihren Anfängen her nicht unvertraut sind. Eine philosophische Frage zeichnet sich nämlich dadurch aus, daß ihre Behandlung auf den Status des Fragenden zurückschlägt. Dieses tua res agitur [Hervorhebung im Original] ist niemals Sache bloßer Mechanismen, die sich um nichts kümmern." (WALDENFELS 2004: 262)

An diesem Punkt macht WALDENFELS es sich freilich etwas zu einfach und er verrät beinahe seine Sache - konstatiert er doch relativ früh schon mittels der individuellen Selektion die Reliefbildung, die beinahe automatisch dem nicht wissentlichen und unwillentlichen entgegenstünde. Das geht uns allein schon deswegen an, weil wir die Aufmerksamkeit in all ihren Facetten durch die von uns geschaffenen Begrifflichkeiten mit in die Welt gebracht haben. Auf einer vorsprachlichen Ebene mag es noch angehen, ein instinktgesteuertes Aufmerksamwerden als einen bloßen Mechanismus zu klassifizieren, doch mit diesem kümmert sich dann ein Lebewesen als Teil seines Verhaltens um sich selbst. Wenn WALDENFELS jedoch anregt, die Aufmerksamkeit sei auszusetzen, um sich mit dem Aufmerksamkeitsgeschehen als solchem beschäftigen zu können, so ist das im Bereich der schon von ihm erwähnten Paradoxien anzusiedeln. Man kann nicht aufmerksam das Aufmerksamkeitsgeschehen als solches erfassen, ohne auf das Aufmerksamkeitsgeschehen aufzumerken, nachdem es einem aufgefallen ist - auch wenn dazu eine Distanz des Betrachtenden zum Betrachteten notwendig wird. Die Reflexion darüber erfordert eine Zuwendung wie eine zeitweilige Fixierung darauf und ist damit kein »bloßer Mechanism[us], [der] sich um nichts kümmer[t]«. Gegen diese rein mechanistische Sichtweise spricht er sich selbst einige Seiten später aus:

"Am Ende stellt sich die Frage nach der Art und Weise, wie Aufmerksamkeit sich überhaupt als ein Aufmerksamkeitsgeschehen fassen läßt. Braucht Auffälliges, um aufzufallen, nicht den Kontrast eines Unauffälligen, das unbemerkt bleibt? Liegt im Unauffälligen und Unscheinbaren nicht eine Form der Zurückhaltung, die auf ihre lautlose und heimliche 
Art aufmerken läßt? [...] Wir haben wiederholt unterschieden zwischen einer primären [Hervorhebung im Original] Aufmerksamkeit, in der etwas auf unvorhergesehene und neuartige Weise zum Vorschein kommt, und einer sekundären [Hervorhebung im Original] Aufmerksamkeit, in der Bekanntes wiederkehrt, in der die Deckung und Erwartung sich zur Wachsamkeit festigt und die Aufmerksamkeit in der Aufmerksamkeitsbereitschaft ihren Rückhalt, aber auch ihren Vorbehalt findet. Die Techniken, Praktiken und Medien, die sich als Zwischeninstanzen zwischen Auffallen und Aufmerken schieben, tragen auf je spezifische Weise zur Sedimentierung von Auffälligkeiten und zur Habitualisierung des Aufmerksamkeitsverhaltens bei. So entsteht eine Welt der Aufmerksamkeit, die sich gegenüber der tierischen Merkwelt dadurch auszeichnet, daß sie als Aufmerksamkeitskultur Teil einer historisch tradierten Kulturwelt ist. In ihrer Selbstverständlichkeit hat sie selbst etwas Natürliches.» (ebd.: 283)

Hier werden sie gestellt, die Fragen, die in wihre[r] Behandlung auf den Status des Fragenden zurück[schlagen]«! Der Kontrast des »Unauffälligen, das unbemerkt bleibt«, kann erst entstehen, wenn das Auffällige als sein Gegenteil definiert ist, die Dichotomie erschaffen wird. Dann stellt sich auch die Frage, ob dadurch, dass im Aufmerken auf das eine immer auch sein Gegenteil mitgemeint werden muss, eine Un-Auffälligkeit eigentlich gar nicht mehr möglich ist - was auf eine verquere Weise schon in der paradoxen Frage WALDENFELS' aufscheint, ob »nicht eine Form der Zurückhaltung [...] auf ihre lautlose und heimliche Art aufmerken« ließe. Nimmt man diesen Ansatz ernst, dann ist auch in einer mutwilligen Zurückhaltung die Auffälligkeit mitgemeint und auch die Zurückhaltung besitzt dann eine Qualität der Auffälligkeit - ein Vergleich mit MORRISON und FUKASAWAS SUPERNORMAL drängt sich hier ganz unmittelbar auf. So würde der Unterschied zwischen Zurückhaltung und Auffälligkeit quantifizierbar werden und die Auffälligkeit des Auffälligen wäre nur eine um den Faktor X auffälligere Auffälligkeit als die Auffälligkeit der Zurückhaltung, die wir im Vergleich als ein in den Vordergrund drängen bemerken und bezeichnen - als »Teil einer historisch tradierten Kulturwelt«. WALDENFELS bilanziert seine Suche nach der Aufmerksamkeit in einer Bruchstückhaftigkeit, die entweder »den Boden des Vertrauten nicht verl[asse]« oder »die Aufmerksamkeitswelt veränder[e]«:

"Doch schon der natürliche Gang der Erfahrung ist voller Bruchstellen, an denen die Aufmerksamkeit umschwenkt, sich abschwächt oder vollends aussetzt. Das Aufmerken hebt damit an, daß etwas auffällt und sich ereignet; eben dies markiert den wunden Punkt der Aufmerksamkeit, der verhindert, daß das Aufmerken sich in Aufmerksamkeitsmechanismen stabilisiert und der Aufmerkende sich hinter einen Aufmerksamkeitspanzer zurückzieht. Das Auffallen hat etwas Anarchisches und Atechnisches, 


\section{STARDESIGNER ODER GESTALTER DES ALLTÄGLICHEN?}

das sich der definitiven Bemächtigung und der uneingeschränkten Machbarkeit entzieht. Die Bruchstellen und Einbrüche sind von verschiedener Art. Dazu gehören Störungen und Ablenkungen, wo die Aufmerksamkeit umzuschwenken [Hervorhebung im Original] droht. Dies kann bedeuten, daß anderes [Hervorhebung im Original] auffällt und die Thematik sich ändert, es kann aber auch besagen, daß alles auf andere Weise [Hervorhebung im Original] auffällt, daß alles in ein neues Licht rückt und Unerhörtes sich Gehör verschafft.« (ebd.: 283f)

Unsere Aufmerksamkeit trägt also das Mittel zur Zerstörung ihrer eigenen Festigkeit bereits in sich, das schon wirkt, noch bevor sie sich im (oder um den?) Aufmerkenden als "Aufmerksamkeitspanzer« verfestigen kann. Sie ist nicht regulierbar, sie produziert sowohl ihre "Störungen « als auch die "Ablenkung" gleich mit und sie kann ebenso dazu führen, dass unsere »Aufmerksamkeitswelt« selbst sich verändert. So verkörpert sie das Prinzip des Wandels, denn "Ein anhaltender Ruhezustand der Aufmerksamkeit ist ... kaum für einige Zeit zu unterhalten. Der natürliche, ungezwängte Zustand unserer Aufmerksamkeit ist herumzuschweifen zu immer neuen Dingen.« (CRARY 2002: 58; HELMHOLTZ zitierend) 

»Das Ich muss auffallen, Aufmerksamkeit auf sich ziehen und sich selbst darstellen.« 


\section{Aufmerksamkeit als Kapital}

\section{Formen des mentalen Kapitalismus}

Der Ansatz BERNARDYs erscheint deshalb bemerkenswert, weil er - lange, nachdem die Halbwertszeit der medialen Wirksamkeit der Aufmerksamkeitsökonomie vorüber zu sein scheint -, noch einmal an FRANCKs Arbeiten ansetzt und die Wirkungsgeschichte von dessen Ideen betrachtet. Auch dieser Autor kommt nicht daran vorbei, den Aspekt der vielfach kritisierten Unwissenschaftlichkeit von FRANCKs Vorgehen wahrzunehmen - doch scheint dieser auch genau das zu sein, was ihn daran interessiert:

"Der für die Untersuchung interessante und zugleich herausfordernde Aspekt von Georg Francks Ökonomie der Aufmerksamkeit [Hervorhebung im Original] ist ihre kontroverse Beziehung zur Wissenschaft. Einerseits übt Franck in mehreren Hinsichten Kritik an der Wissenschaft, die somit sein direkter Adressat zu sein scheint. Die Wissenschaft ist nicht nur unfähig, eine vernünftige und richtige Definition von Aufmerksamkeit zu liefern, mit dem vermehrten Streben einzelner Wissenschaftler nach Reputation und Aufmerksamkeit hält auch die Eitelkeit Einzug in die Wissenschaften. Andererseits erläutert Georg Franck in einem Interview, dass er mit seinem Entwurf zur Aufmerksamkeitsökonomie kein wissenschaftliches Werk schreiben wollte. Stimmt Georg Francks Selbsteinschätzung und wie lässt sich seine Wissenschaftskritik mit dieser Aussage vereinbaren? Ist die Ökonomie der Aufmerksamkeit [Hervorhebung im Original] tatsächlich so unwissenschaftlich angelegt, wie er behauptet und beruht sie nicht vielmehr auf Grundlagen und Theorien aus den Geisteswissenschaften? Wenn die essayistische Form in weiten Teilen unwissenschaftlich sein mag, so ist die starke Anbindung an die soziolo- 


\section{STARDESIGNER ODER GESTALTER DES ALLTÄGLICHEN?}

gische und philosophische Geistesgeschichte nicht zu übersehen. Die vorliegende Untersuchung will den Diskurs der Ökonomie der Aufmerksamkeit [Hervorhebung im Original] in einem philosophischen Kontext rekonstruieren." (BERNARDY 2014: 3f)

BERNARDY hat alles gelesen, was an wesentlichen Schriften in der Nachfolge FRANCKs verfasst wurde. Die breite philosophiegeschichtliche Anbindung ist im Rahmen dieser Arbeit von untergeordneter Bedeutung. Spannend wird es jedoch, wenn er das Ansehen als »fremde Macht« zu SARTRE in Bezug setzt:

"Franck zufolge entpuppt sich das gesellschaftliche System des Ansehens letztlich als unkontrollierbarer Prozess mit endogenen Variablen. Das Unkontrollierbare besteht darin, dass dem Menschen im Ansehen eine sfremde Macht gegenübertritt, die ihn im Kern angeht und ihn in seinem Inneren trifft: [...]« (ebd.: 73f)

SARTRE thematisiert aus BERNARDYs Sicht »das Verhältnis zwischen fremdem Ansehen und innerer Berührung auf eine existentialphilosophische Weise«, worin nach Lesart des letzteren eine Anschlussmöglichkeit für FRANCKs Gedanken gegeben ist:

"Eine solche existentialphilosophische Dimension hat Franck auch vor Augen, wenn er seine Gedanken zu Vergesellschaftung und Versklavung darlegt. Francks Begriff der Versklavung ist in seiner Bedeutung eng verwandt mit Sartres Begriff der Knechtschaft.« (ebd.: 74)

\section{Im Weiteren führt BERNARDY aus:}

"Allgemein lässt sich feststellen, dass sich Sartres Position einer gesellschaftlichen Verknechtung und Francks Konzeption eines Marktpreises in einem Punkt treffen: Das Individuum ist den Urteilen und Bewertungen anderer aus jeweils unterschiedlichen Gründen ausgeliefert. Sartres Gedanken der Verknechtung und Entfremdung finden sich allerdings in Francks gesellschaftstheoretischem Konstrukt eines Marktes des gesellschaftlichen Ansehens wieder. Die Macht und die Freiheit des Anderen berühren in beiden Fällen das Innerste des Subjekts und entziehen sich dessen direkter Kontrolle. Der >Dritter bei Franck und der >Andere bei Sartre sind Urheber der Urteile und Werte, auf deren Grundlage es, mit Franck gesprochen, zu einer Abstimmung über das gesellschaftliche Ansehen kommt. Die Freiheit des Ich ist sowohl nach Sartre als auch Franck durch die genannten Werturteile eingeschränkt. Die Frage, die Sartre nach der Knechtschaft und Verobjektivierung des Ich gestellt hat, wird bei Franck unter der Frage nach der Marktpreisbildung des Selbstwerts geführt. [...] Wenn man sich die Differenzen der beiden Ansätze anschaut, dann wird zunächst deutlich, dass Sartres Intersubjektivitätstheorie dem Erkennen und Einschätzen des Anderen um einiges kritischer gegenüber- 
steht als Francks Ökonomie der Aufmerksamkeit. Während der Einzelne nach Franck im direkten Austausch noch einschätzen kann, wie er beurteilt wird, ist es nach Sartre nicht möglich, auf Werturteile einzuwirken oder diese auch nur zu erkennen. In dieser Unmöglichkeit des Einwirkens und Erkennens besteht für Sartre gerade das Potential der Knechtschaft verborgen [sic]. Trotzdem ist es gerade Sartres Vorstellung eines gegenseitigen Bewertens und Urteilens, die mit Francks Vorstellung eines 'Systems des Ansehensı vereinbar ist.« (ebd.: 79f)

Es verwundert, dass BERNARDY in diesem Zusammenhang keinen Bezug zu FOUCAULTs Überwachen und Strafen herstellt, wie er von CRARY und auch RECKWITZ herausgearbeitet wird - hat er ihn doch selbst in einer Nebenbemerkung zur Disziplinargesellschaft kurz wegen der »Effizienzsteigerung der Individuen « durch »Prestige, Reputation, Prominenz und Ruhm « als "positive[n] Bewertungs- und Überwachungsrahmen« angesprochen. (vgl. ebd.: 90). Auch WALDENFELS muss einem in diesem Zusammenhang noch einmal in den Sinn kommen, wenn jener das "Aufmerksamkeitsgeschehen « in seiner "soziale[n] Dimension « betrachtet (vgl. WALDENFELS 2004: 233) sowie von »Macht« spricht (ebd.: 234f) und zuvor schon die Gefahr einer "gegängelte[n] Aufmerksamkeit « hervorgehoben hat (ebd.: 136f). Die Götter der neuen Ökonomie der Aufmerksamkeit, die FRANCK zwangsläufig in der Sozialfigur des Stars verkörpert sieht, streift BERNARDY als eigenständigen Gegenstand nur kurz - sie scheinen ihn eher im Rahmen einer systemischen Betrachtung zu interessieren sowie in Reflexionen über die "Möglichkeit einer Anbindung vom Francks Ökonomie der Selbstwertschätzung an eine Theorie der Selbstdarstellung« (vgl. hierzu auch ebd.: 142f):

"Am Ende bleibt es bei dem größten gemeinsamen Nenner, dass Celebrities Idole für eine erfolgreiche Selbstvermarktung und Selbstdarstellung sind. Inwiefern sie für moralische Werte wie etwa Verbindlichkeit, Vertrauen oder Integrität stehen, wird nicht thematisiert, wobei doch konkrete Fälle wie Guttenberg, Wulff und Schavan gelungene Beispiel dafür sind, wie der moralische Gesichtsverlust auch einen öffentlichen Tod nach sich ziehen kann.» (ebd.: 93f)

Natürlich ist jener »öffentliche[...] Tod « durch den »moralische[n] Gesichts verlust « selbst ein Beispiel für das Vorhandensein jenes Systems des Ansehens. Ein Beispiel zumal für ein fehlgeleitetes Verständnis der Selbstwertschätzung zugunsten einer scheinbar anforderungsoptimierten Selbstdarstellung in einem Feld wechselseitiger Beeinflussung: 


\section{STARDESIGNER ODER GESTALTER DES ALLTÄGLICHEN?}

"Was in den Besprechungen und Kritiken zu Francks Entwurf bisher kaum gesehen wurde, ist die Möglichkeit einer Anbindung von Francks Ökonomie der Selbstwertschätzung an eine Theorie der Selbstdarstellung. Was meint Franck mit dem Kult des Selbstbildes und der eigenen Rolle im fremden Bewusstsein, um die es beim Streben um Aufmerksamkeit seiner Auffassung zufolge geht? Stellt die Praxis der Selbstdarstellung vielleicht eine fundamentale Bedeutung im Streben nach einer Rolle im anderen Bewusstsein dar? Setzen das Streben nach Aufmerksamkeit und der Kult des Selbstbildes nicht sogar ein bestimmtes Maß an Selbstdarstellung voraus? Denn, um der Rolle willen, die die eigene Person im anderen Bewusstsein spielt, inszenieren wir die shohe Kultur der Attraktivität (ÖdA, 13). Wie könnte aber jemand eine Rolle im fremden Bewusstsein spielen, ohne selbst diese Rolle auch darzustellen? In Anknüpfung an Simone Dietz, die die Frage nach der Menschenwürde der Rampensau [Hervorhebung im Original] im Hinblick auf die neue Welle der Selbstdarstellungskultur in den Massenmedien in einem medienethischen Kontext diskutiert hat, möchte ich versuchen, den Zusammenhang zwischen Selbstdarstellung und Selbstwertschätzung herauszuarbeiten. Die erste offensichtliche Verschränkung von Selbstwertschätzung und Selbstdarstellung besteht in der Annahme, dass die Selbstdarstellung eine Form der Aufmerksamkeitsbeschaffung ist. Wenn das Achtgeben auf andere und der Einsatz von Aufmerksamkeit die Hauptwege zur Einnahme von Aufmerksamkeit sind, dann muss sich das Selbst bemerkbar machen. Das Ich muss auffallen, Aufmerksamkeit auf sich ziehen und sich selbst darstellen. Die Rampensau, die sich rim Zentrum der Aufmerksamkeit postiert, verdeutlicht eine extreme Form davon. Die Selbstdarstellung muss daher als probates Mittel angesehen werden, nicht nur um seine Rollen zu koordinieren, sondern um an Aufmerksamkeit und fremde Wertschätzung zu kommen.« (ebd.: 142f)

Bezieht man das eben zitierte auf den o. a. »moralische[n] Gesichtsverlust « zurück, so stellt der Betrug jener Doktoranden (vgl. ebd: 93f) den Versuch dar, "an Aufmerksamkeit und fremde Wertschätzung zu kommen «, indem die Regeln eines Systems bewusst missachtet werden, das laut FRANCK eine »standardisierte Karriere[...] « vorsieht (vgl. FRANCK 1998: 151) - in der Hoffnung, dass nicht auffliegen würde, was in diesem Fall nicht hätte auffliegen dürfen, um den Betrug gelingen zu lassen und in der Folge zum »öffentlichen Tod" führte. Solch eine Form der Selbstdarstellung findet im Rahmen einer koordinierten Regelverletzung der eigenen Rolle statt und wird wohl »als probates Mittel angesehen«. BERNARDY schließt sich auch den Argumenten von HICKETHIER und PUNDT aus dem bereits vorgestellten Band Aufmerksamkeit, Medien und Ökonomie an: 
"Das universalistische Moment von Franck zeigt sich in dieser Identifikation der Aufmerksamkeit mit beinahe jeder möglichen Form des kommunikativen Austauschs in allen seinen verschiedenen Stufen, Abstufungen und Nuancen der Wertschätzung. Daher ist die Kritik berechtigt, dass die Ökonomie der Aufmerksamkeit mit ihrem universalistischen Anspruch gegen die Aufspaltung akademischer Diskurse als eine >Metatheorie der postindustriellen Mediengesellschaft erscheint und damit als welterklärerisches Modell vergeblich die gesellschaftliche ,Welt auf einen Nenner zu bringen versucht." (BERNARDY 2014: 126) [BERNARDY bezieht sich mit den beiden in Anführungszeichen gesetzten Passagen auf Artikel von PUNDT und HICKETHIER in BLEICHER und HICKETHIER 2002; Hinzufügung des Verfassers]

Eines von BERNARDYs Hauptargumenten gegen die Wissenschaftlichkeit von FRANCKs Texten ist eine Hypothese, die

"[...] lautet, dass Francks Entwurf weniger gegen die Wissenschaft gerichtet ist als vielmehr selbst ein Beispiel für die Medialisierung und Popularisierung wissenschaftlicher Kommunikation darstellt. Die Ökonomie der Aufmerksamkeit [Hervorhebung im Original] ist selbst als ein Produkt des von Franck diagnostizierten gesellschaftlichen Wandels in der Wissenschaft anzusehen." (ebd.: 162)

Auf in die Schlussrunde. „Ob implizit oder explizit, Franck versammelt in seinem Entwurf zahlreiche unterschiedliche Diskursansätze und daher können Zweifel aufkommen, ob der Aufmerksamkeitsdiskurs überhaupt als eigener Diskurs geführt werden kann. In einer kurzen Synthese« listet BERNARDY »die Ergebnisse der Untersuchung « auf (vgl. ebd.: 162-164) und fasst dort alle philosophischen Kontexte und Diskurse zusammen, die von FRANCKs Essay gestreift zu werden scheinen. Im wesentlichen wird hier gezeigt, wo FRANCK sich bedient hat und eben keinen eigenständigen Diskurs etabliert, sowie, wo er aus BERNARDYs Sicht fehlgeht. BERNARDYs Argumentation und Nachweise folgen selbstredend allen Regeln der Wissenschaftlichkeit. Nachdem er sich bis dahin über mehr als hundertfünfzig Seiten erkennbare Mühe gegeben hat, darzulegen, inwieweit er FRANCK für relevant und fehlgegangen hält, schlägt er ihn in seiner Stretta in allen wesentlichen Punkten ungespitzt in den Boden. Da wäre zunächst die Frage nach der Wissenschaftlichkeit, die er - noch Stärke mit Schwäche gleichsetzend - komplett verneint und FRANCKs Entwurf als Rampensau klassifiziert (vgl. DIETZ in KANNETZKY und TEGTMEYER 2007: 119-142): 


\section{STARDESIGNER ODER GESTALTER DES ALLTÄGLICHEN?}

»Es ist unmöglich, Sinn, Ziel und Wesen [Hervorhebung im Original] von Wissenschaft auf einen Nenner zu bringen. Die Wissenschaft kann man weder als einheitliches Stück noch als homogene Inszenierung charakterisieren. Dennoch möchte ich drei Dinge als wesentliche Kriterien für wissenschaftliches Vorgehen postulieren: die Überzeugungsleistung durch argumentative Beweiskraft, das Geben von Beispielen und die Arbeit mit Quellenangaben. Der Ökonomie der Aufmerksamkeit [Hervorhebung im Original] mangelt es genau an diesen drei Kriterien. Sie geht vor allem behauptend und ohne Quellenangaben vor. Sie gibt nur wenige Beispiele. Hierin bestehen Stärke und Schwäche des Entwurfs. [Hervorhebung des Verfassers] Er ist in diesem Sinne eine Rampensau, die sich auf Kosten anderer implizit enthaltener Diskurse als selbstständiger Diskurs darstellt." (BERNARDY 2014: 178f)

Dieser Aspekt wird nochmals vertieft und der »medienästhetische[...] Selbstdarstellungsstil« gegeißelt:

"Die Darstellung der entworfenen Gedanken und Thesen geschieht wie gezeigt oft auf Kosten bereits etablierter Theorien und formulierter Gedanken. Der Diskurs der Aufmerksamkeitsökonomie wird auf Kosten anderer Diskurse aufgestellt und die Behauptung eines mentalen Kapitalismus verspricht mehr als mit argumentativer Beweiskraft gehalten werden kann. Um in der Sprache der Bühne zu bleiben, könnte man sagen, dass sich die Ökonomie der Aufmerksamkeit [Hervorhebung im Original] nicht in das Stück oder in die Inszenierung einfügt, sondern stattdessen in manchen Teilen einen medienästhetischen Selbstdarstellungsstil verfolgt [...] Die Ökonomie der Aufmerksamkeit ist eine künstlerische Grenzgängerin, die immer wieder die Grauzone zwischen Rampensau und eigenständigem Diskurs überschreitet. Dieser clevere Regelverstoß ist einer der Gründe für ihre herausragende Suggestivkraft und Evidenz." [Hervorhebung des Verfassers] (ebd.: 179)

Verwunderlich, dass hier die mangelnde Einfügung »in das Stück oder die Inszenierung« kritisiert wird, wo wenige Zeilen zuvor noch zu lesen ist, dass es »unmöglich [sei], Sinn, Ziel und Wesen [Hervorhebung im Original] von Wissenschaft auf einen Nenner zu bringen «, da man »Wissenschaft [...] weder als einheitliches Stück noch als homogene Inszenierung charakterisieren« könne. Eine gewisse Eigentümlichkeit liegt auch darin, dass BERNARDY sich bei seinem Verriss trotzdem immer noch bemüht, ein Betthupferl in der Hand zu halten, während er den Schierlingsbecher reicht. Zum bösen Schluss wird ihm hier noch einmal ausführlich Raum gegeben:

"Für welchen konkreten Wandel in den Wissenschaften steht die Ökonomie der Aufmerksamkeit [Hervorhebung im Original] denn nun genau und kann sie als ein philosophisches Buch bezeichnet werden? Die Tatsache, dass Georg Franck als Architekt und Volkswirt ein sphilosophi- 
sches Buch verfasst hat, kann als Ausschlusskriterium noch nicht ausreichend sein, denn schließlich sind auch im Wissenschaftsbetrieb längst etablierte Philosophen wie Ludwig Wittgenstein und Paul Virilio als Architekten tätig gewesen. Wie auch immer man Francks Entwurf im Einzelnen bewerten mag, folgende These möchte ich als Ausblick formulieren: Die Ökonomie der Aufmerksamkeit [Hervorhebung im Original] stellt ein aussagekräftiges Beispiel für die allgemeine Popularisierung wissenschaftlicher Inhalte dar, die sich in der zweiten Hälfte des 20. Jahrhundert [sic] verstärkt abzeichnet. Dabei geht es nicht mehr ausschließlich um die Vermittlung und vereinfachte Darstellung wissenschaftlicher Inhalte, sondern auch um das Entwerfen eigener Gedanken, Theorieansätze und Meinungen. Bezogen auf die Philosophie wird dieser Trend mit einem Ausspruch von Karl Popper auf den Punkt gebracht: 'Alle Menschen sind Philosophen.< Die Ökonomie der Aufmerksamkeit [Hervorhebung im Original] ist das beste Beispiel dafür, dass sich auch Nicht-Philosophen und Wissenschaftler aus anderen Disziplinen zu philosophischen Themen äußern und eigene philosophische Entwürfe veröffentlichen können. Dies ist dann auch nach der Logik des mentalen Kapitalismus nur konsequent, denn wenn wirklich alle Menschen Philosophen sind, bedeutet dies, dass jeder Mensch mit beliebigem Hintergrund philosophische`Bücher veröffentlichen und sogar höhere Auflagen erzielen kann als etablierte Philosophen aus dem akademischen Wissenschaftsbetrieb. Ein Blick auf die Sachbuch-Bestsellerlisten der letzten Jahre zeigt, dass sich Qualität und Anspruch auch massenhaft durchsetzen können. Denn auch in Zeiten der Popularisierung gilt es Kriterien und Gesichtspunkte zu finden, mit denen populärwissenschaftliche Beiträge bewertbar sind. Der Wechsel von der akademischen Bühne zur massenmedialen Öffentlichkeit darf nicht zur Folge haben, dass man schreiben und erzählen kann, was man will. Auch bei massenwirksamen Veröffentlichungen, die auf wissenschaftlichen Kontexten beruhen, kann und muss beurteilt werden können, ob bestimmte Inhalte adäquat oder falsch umgesetzt wurden. Ebenso trägt der Autor eine gewisse Verantwortung gegenüber anderen wissenschaftlichen Werken, Theorien und Autoren, deren grundlegende Einflüsse auf die vermeintlich neuartigen und eigenen Ansätze deutlich gemacht werden müssen. Der Begriff der Rampensau bietet sich als nützliches Kriterium für die Bewertung gelungener populärwissenschaftlicher Darstellungen und Selbstdarstellungen an.« (ebd.: 184)

Dieser Erguss wird nicht ohne ein paar abschließende Gedanken stehengelassen. Wenngleich konzediert werden muss, wie sorgfältig BERNARDY FRANCK zerlegt hat und dass es sich um fundierte Kritik handelt, so gipfelt dieses Fazit doch in einer exemplarisch verkörperten Festschreibung einer Zweiklassengesellschaft der Wissenschaftsliteratur, deren Gewinner BERNARDY und deren Verlierer FRANCK heißen soll. Die argumentative Strategie des Löffelchens voll Zucker setzt sich hier in bereits gut vorbereiteter Perfidie fort: Wie eine pervertierte »kleinste Geste als Aufmerksamkeitsgabe«, die eigentlich das Wert- 
schätzungs-(Miss-)Verhältnis der Fan-Star-Beziehung charakterisiert (vgl. STRUBE in: BLEICHER und HICKETHIER 2002: 81f). Vorwürfe, die BERNARDY

110 zu FRANCK formuliert, werden mit vergiftetem Lob konterkariert, das diese allenfalls ein klein wenig entkräftet.

Richtet man den Blick durch diese letzten Zeilen, wie es die populären 3D-Illusionen der goer Jahre des 20. Jhd.s erfordern, so tritt das Bild eines Autors hervor, der die Tatsache, dass der besprochene ebenfalls ein Wissenschaftler sein könnte, nicht in Abrede stellen kann. Er scheint jenem anhand berühmter Vorbilder (thematisch überaus angemessen ...) sogar eine goldene Brücke zu bauen. Unter Quellenangabe (!) erlaubt er ihm - als Disziplinfremdem - nachträglich, das tun zu dürfen, was jener damals unternommen hatte. Spätestens bei Erwähnung der im Vergleich zu akademischen Veröffentlichungen höheren Auflagenzahlen in der "massenmedialen Öffentlichkeit» scheint er aber am Gestade des Neides angeschwemmt worden zu sein, was sich vor allem in der Impertinenz äußert, derjenige sein zu wollen, der, stellvertretend für das System, dem Paria FRANCK und anderen vorschreiben darf, was »man schreiben und erzählen kann" - ohne ihn nochmals zu erwähnen, sondern nur noch zu insinuieren, dass jener gemeint sei. Ob der Rückzug in das anonyme man am Ende für einen sauberen Verriss sorgt, kann bezweifelt werden. Erst Recht, weil BERNARDY sich, ironisch betrachtet, ursprünglich u. a. daran aufhing, dass FRANCK seinen Universalschlüssel Aufmerksamkeit auch im Schloss des Wissenschaftsbetriebes zu drehen versuchte. Ein Vertreter dieses Wissenschaftsbetriebes jedenfalls biss zurück.

Ein Beispiel dessen, was FRANCK in der Ökonomie der Aufmerksamkeit u. a. beschreibt, ist sein Essay wohl bis heute. Den von BERNARDY herbeigewünschten Aufmerksamkeitsdiskurs (vgl. ebd.: 167), der, um noch einmal auf DAHINDEN zurückzukommen, zu einem "sozialwissenschaftlichen Paradigmenwechsel führen könnte« (vgl. DAHINDEN in: BECK und SCHWEIGER 2001: 47), scheint es noch nicht zu geben. Der Nagel lässt sich komplett einschlagen mit der Feststellung, dass auch BERNARDY außer seiner Kritik an FRANCK keinen eigenen Beitrag zu diesem gewünschten Diskurs geleistet hat. 

»l imagine an attention tax that aspiring cultural producers must pay."

Michael Erard 


\section{Mehr als eine Sumpfblüte?}

Die vorstehend diskutierten Arbeiten verlangen nach einer Bilanz. Zudem sollen sie noch durch einige Überlegungen zu Veröffentlichungen anderer Autoren erweitert werden, um die bis jetzt gesteckten Grenzen zu überschreiten. Das Ziel ist, sich Klarheit darüber zu verschaffen, ob die im Vorfeld viel gescholtene Aufmerksamkeitsökonomie mehr als eine amüsierte Notiz in einer Marginalspalte wert ist und ob nach aller Kritik etwas Weiterführendes verbleibt, das genügend Substanz aufwiese, die ein Weiterdenken lohnte. Im Rückblick ist bei CRARY eine Argumentationskette zur Konstitution einer »Aufmerksamkeit in der Moderne« ohne »die Intentionalität eines autonomen Subjekts« (CRARY 2002: 44) zu verfolgen. Diese entwickelt er zu einem Aufmerksamkeitsregime, in dem Zerstreuung automatisch mit entsteht und innerhalb dessen Probleme durch Unaufmerksamkeit heraufbeschworen werden, die »das aufmerksame Subjekt « zum »Bestandteil einer Interiorisierung [Hervorhebung im Original] disziplinärer Imperative« werden lassen. Daran schließt RECKWITZ 2015 nahtlos an, als er - ebenfalls in Bezug auf FOUCAULTs Überwachen und Strafen - konstatiert: "Das Subjekt begehrt, gesehen zu werden [Hervorhebung im Original].« (RECKWITZ in: SOZIOPOLIS am 28.09.2015) [online] http://www.soziopolis.de/beobachten/kultur/artikel/die-transformation-dersichtbarkeitsordnungen/ [31.01.2019].

Damit explizieren schon zwei Autoren in deutlichem zeitlichem Abstand, dass BeNTHAMs Panopticon sich mittlerweile zum von außen nach innen gewendeten Bestandteil der inneren Konstitution des Subjekts in der Aufmerksamkeitsgesellschaft gewandelt haben könnte. Aus BLEICHER und HICKETHIER 
werden als zentrale, weil im Vergleich zu GEORG FRANCK differierende und die Betrachtung erweiternde Gedankengänge nochmals herausgehoben:

1. EDERs Präzisierung, dass es in GEORG FRANCKs Essay nur um die »Aufmerksamkeit [...] als Liebe und Bewunderung, nicht als Spott oder Verachtung« gehe, diese aber ganz »besonders stark mit Werten und Emotionen verknüpft [sei], die positiv, aber auch negativ sein können: [...]« und dass deshalb »das Tauschobjekt Aufmerksamkeit sich nicht nur hinsichtlich seiner Meßbarkeit weitaus unberechenbarer [verhalte] als das Tauschobjekt Geld.«(EDER in: BLEICHER und HICKETHIER 2002: 38f)

2. PUNDTs Vorschlag, »die anthropologische Dimension der sozialen Aufmerksamkeit [...] in vorhandene Theoriekonzepte ein[zu]passen« (PUNDT in: ebd. 71f).

3. STRUBEs Idee, dass es ein Aufmerksamkeitssparkonto gebe, das in den Gedächtnissen von Individuen und Kollektiven verortet sei und dass »der Reichtum (oder auch: Tauschwert) des einzelnen [...] sich dadurch [generiere], in wie vielen Gedächtnissen er wie stark gespeichert« sei (STRUBE in: ebd. 80). Zudem erweitert sie das Feld um den Begriff der Aufmerksamkeitsgabe und öffnet damit eine Tür zu MAUSS, die es gestatten würde, die Ökonomiemetapher beiseite zu legen, um anders über soziale Aufmerksamkeit nachzudenken (STRUBE in: ebd. 81f).

4. BADE ruft uns nochmals ins Gedächtnis, dass »das Ringen um die Aufmerksamkeit eng mit der monetären Ökonomie verkoppelt und in dieser fundiert ist«. Mit Blick »auf die ökonomische Verwertbarkeit [...] [sei] die Massen- bzw. Zielgruppenattraktivität für die Medien das entscheidende Qualitätsmerkmal, dem allerdings keine operationalisierbaren Kriterien für die Qualität der Programme zugrunde liegen.« (BADE in: ebd. 182)

Der Aufmerksamkeits-Index (AIX) der Firma GOLDMEDIA stellt seit dem Jahr 2012 die neueste Entwicklung in puncto »Quantifizierung von (Medien-)Aufmerksamkeit« dar, der herkömmliche Reichweitenmessungen um den Faktor Aufmerksamkeit erweitert (s. o.). Auch hier werden die beiden Sphären lediglich im Hinblick auf ihre Koppelung betrachtet und bleiben damit nur eine Weiterentwicklung bereits bestehender Methoden, mit denen Aufmerksamkeit in Geld umgerechnet wird. Zudem handelt es sich um eine andere Art der Aufmerksamkeit als die soziale, nämlich die individuelle, wenn lediglich Medienumsätze ins Verhältnis zur Mediennutzungszeit einzelner Nutzer gesetzt werden. Eine der erfolgreichsten Monetarisierungsformen nicht 
wirklich qualitativ messbarer Aufmerksamkeit als Vorgänger des AIX stellen bis heute noch immer die Entgelte dar, die für Anzeigen, Fernseh- und Kinospots zu zahlen sind.

Bei WALDENFELS spielen neben seinen Ausführungen zur Reliefbildung (vgl. WALDENFELS 2004: 101f) die Intersubjektivität und die Interattention die größte Rolle, weil sie der Aufmerksamkeit »eine praktische Dimension« geben, "wenn es zur Ausbildung von Aufmerksamkeitspraktiken kommt und sich eine Aufmerksamkeitspolitik wie auch eine Aufmerksamkeitsökonomie herausbildet.« Nur im Entstehen einer "Aufmerksamkeitspolitik« habe auch das Entstehen von Macht einen Sinn und "erreich[e] das Aufmerksamkeitsgeschehen seine soziale Dimension." (vgl. ebd.: 228, 233) Diese Macht und auch die »Verführungskraft der Dinge« können aus seiner Sicht dazu führen dass »[d]ie umworbene und angestachelte Aufmerksamkeit [...] jederzeit in eine umgarnte und gegängelte Aufmerksamkeit abzugleiten droht, die nur noch sucht, was sie im Grund schon kennt, und verfolgt, was sie im Grunde schon hat." (ebd.: 136f) Das Gängeln erinnert an CRARYs und RECKWITZ' Bezüge auf FOUCAULT. WALDENFELS entschied sich gegen die Verwendung der ökonomischen Metapher und stattdessen dafür, dass die »Macht der Aufmerksamkeit« nicht als »Vermögen« bezeichnet werden könne, »das jemand ha[be] oder erw[erbe]« (vgl. ebd.: 234f). Die Beschreibung der Anonymität im Sinne einer positiven und negativen Namenlosigkeit als Nahtstelle zwischen »Aufmerksamkeitsmechanismen und Aufmerksamkeitserfahrung" (ebd.: 251f) einerseits und die enge Bindung an die Individualität andererseits bestärkt die Entscheidung, der Betrachtung der Anonymität ebenfalls ein komplettes Kapitel zu widmen.

BERNARDYs Betrachtungen erreichen mit dem Vergleich von SARTRES Knechtschaft und FRANCKs Versklavung (vgl. BERNARDY 2014: 73f) den Punkt, der auch für CRARY und RECKWITZ und deren Vorstellung von Aufmerksamkeitsregimen eine wesentliche Rolle spielt: »Das Individuum ist den Urteilen und Bewertungen anderer aus jeweils unterschiedlichen Gründen ausgeliefert." (ebd.: 79f) - was sich zu der »umgarnte[n] und gegängelte[n] Aufmerksamkeit« von WALDENFELS gesellen lässt, denn BERNARDYs Idee, »dass die Selbstdarstellung eine Form der Aufmerksamkeitsbeschaffung« sei (ebd.: 142f), mit der ein Individuum andere Individuen zur Herausgabe eines Teils ihres Aufmerksamkeitspotentials auffordert, ist kongruent mit RECKWITZ' Diktum, dass das »Subjekt begehr[e], gesehen zu werden« (s. o.).

Es erscheint plausibel, dass es in einem Aufmerksamkeitsregime mit einer Aufmerksamkeitspolitik auch eine »Macht der Aufmerksamkeit« geben 
muss (s. o.), die man auf verschiedenen Wegen und in verschiedenen Formen zu erringen sucht.

\section{Wie steht es um die Zukunft der Aufmerksamkeit?}

MICHAEL ERARD schreibt 2009 A Short Manifesto on the Future of Attention und spielt darin einige beinahe dystopische, ökonomisch wohl begründete Szenarien durch, die die Idee einer Aufmerksamkeitsökonomie herrlich respektlos verdrehen. Der Text wird hier in meiner freien Übersetzung und als Zusammenfassung seiner Argumentation wiedergegeben. (ERARD in: DESIGN OBSERVER am 08.12.2009) [online] http://designobserver.com/feature/a-shortmanifesto-on-the-future-of-attention/10297 [12.01.2019].

Die ironische Kernfiktion: Ausgehend von den beiden Annahmen, Kostenlosigkeit sei eine Verteilungsstrategie, die Aufmerksamkeit auf sich ziehe und zeitliche Kürze (auch im Sinne von Verknappung?) ebenso, stellt er zunächst einmal fest, dass kostenlos nicht zukunftsfähig sei und kurz immer unter Preis gehandelt werde. Darauf aufbauend imaginiert er einen Handel der Zukunft, der die benötigte Aufmerksamkeitsspanne als Kern der Produktpreise heranzöge und ein aufmerksamkeitsbasiertes Preismodell hätte, das in umgekehrter Relation zur kognitiven Investition stünde, die man aufwenden müsste, um ein solches Informationsgut zu konsumieren. Alles, was die eigene Aufmerksamkeit nur kurz beanspruche - Beispiele sind Haikus, Klingeltöne und Stoßstangen-Aufkleber -, würde einen Luxus-Preis bekommen, alles, was eine längere Rezeptionszeit erfordere, würde günstiger oder gar kostenfrei abgegeben. Die Logik dahinter ist bestechend: Der Konsument würde dafür, dass er eine kürzere Zeit seines eigenen Aufmerksamkeitspotentials aufzuwenden hat, zugleich belohnt und bestraft. Belohnt, weil er nur einen sehr geringen Teil seiner Aufmerksamkeit für bestimmte Informationsgüter aufwenden müsste. Zu gleicher Zeit bestraft, weil er den höchsten Preis dafür zu entrichten hätte, etwas zu erwerben, dessen Erzeuger sich über die Verkürzung der verlangten Aufmerksamkeitsspanne des Verbrauchers diese Anpassungsleistung - eine Vergrößerung des individuellen Aufmerksamkeitskuchens - vergolden ließe.

Die höheren fixen Kosten, die bei der Produktion von Güter anfallen, die unsere Aufmerksamkeitsspanne länger beanspruchen, würden durch den höherfrequenten Verkauf von Gütern mit kürzeren Aufmerksamkeitsspannen 
wieder eingefahren. So würde eine einzelne Fernsehserien-Episode wesentlich teurer als eine komplette Staffel sein, so wie eine Sechserpackung OREOs an der Tankstelle mehr kostet als die Großpackung im Supermarkt. Eine andere seiner - höchst amüsanten - Ideen ist eine Aufmerksamkeits-Steuer nach Art einer Eintrittsschranke, die jeder aufstrebende Kulturproduzent zahlen müsste: Möchte ich, dass andere mein Buch lesen, muss ich dafür die der anderen lesen. Möchte ich, dass sie es kaufen, muss ich wiederum deren Bücher kaufen. Nur diejenigen, die mit gleicher Münze einzahlen (und dieses - wie? - nachweisen können), dürfen auch tatsächlich etwas mitnehmen. Der eingebaute, normative Druck einer zwingend auszugleichenden Gabe ist unübersehbar. Der fiktionale Charakter dieser Neuinterpretation tritt ebenso klar hervor und doch werden - stark zugespitzt - echte Probleme eines Aufmerksamkeitsmarktes zu Tage gefördert, wenn man ihm in auf der Basis von ökonomischen Regeln in die Tat umzusetzen versucht. Bis heute ist keine dieser Anpassungen zu erkennen.

\section{Weiße Flecken auf der Karte des Aufmerksamkeitsreiches}

Was in der Beschreibung der Aufmerksamkeit im Zusammenhang mit der Aufmerksamkeitsökonomie in allen bisher vorgestellten Beiträgen zu kurz kommt, ist ein Wechsel in der grundsätzlichen Art der Betrachtung, die in DAHINDENs Formulierung eines wünschenswerten Paradigmenwechsels 2002 schon anklingt und sich inzwischen eigentlich in verschiedenen Disziplinen geäußert haben sollte.

Die Arbeit mit, an und über GEORG FRANCKs Essay und das darin zu Tage tretende Gedankengebäude wird überwiegend nur auf der Grundlage des ökonomischen Analogieschlusses geleistet oder - wie bei BERNARDY - in einem philosophischen Bezugsrahmen verortet. WALDENFELs steht mit seiner Phänomenologie allein auf weiter Flur. Irritierenderweise scheint niemand in Erwägung gezogen zu haben, den Begriffen selbst nachzugehen, um diese auf das durch sie ausgedrückte zu durchleuchten.

Denn man kann GEORG FRANCK auch als einen Impulsgeber verstehen - für eine Analyse der in den von ihm versammelten Begriffen verkörperten Prozesse, die in Worten gleichsam Substrate sozialen Handelns darstellen. Zudem findet durch die FRANCKsche Argumentation eines überwiegend me- 
diengetriebenen Prozesses eine starke Einengung auf das Feld der Medienforschung statt, von dem aus eine Kritik angestrebt wurde - denn schon GEORG FRANCK selbst hat den Beginn der Aufmerksamkeitsakkumulation nur in den Medien angesiedelt (vgl. FRANCK 1998: 151).

Doch es ist das soziale Gewebe, aus dem der Auslöser für die Medien hervortreten muss und dort geschieht auch nach der Stiftung eines Anlasses noch etwas: Um sich etablieren zu können, muss der gesetzte Auslöser auf selbiges zurückwirken. Nur durch diese gegenseitige Rückbezüglichkeit kann eine Form der spiralförmigen Steigerung (vgl. WIPPERSBERG 2007) und Selbstverstärkung überhaupt in Gang gesetzt und am Laufen gehalten werden.

\section{Paradoxien der Aufmerksamkeit}

Eine der Paradoxien der Aufmerksamkeitsökonomie wird von NEUBERGER 2008 in Paradoxien des Journalismus beschrieben: es muss erhöhter Aufwand betrieben werden, um überhaupt Aufmerksamkeit zu erlangen und dieser führt nur dazu, dass sie noch knapper wird:

"Quantitäts- und Qualitätsparadoxie verweisen auf die Überforderung des Rezipienten, mit Informationsmenge und -qualität zurechtzukommen. Komplementär dazu gibt es zwei Paradoxien, mit denen die Kommunikatoren konfrontiert sind. Die Aufmerksamkeitsparadoxie ergänzt die Quantitätsparadoxie: Sie liefert eine Erklärung für die wachsende Informationsmenge und den verstärkten Einsatz von Mitteln zur Aufmerksamkeitsgewinnung. Kommunikatoren wollen eine bestimmte Wirkung bei den Rezipienten erzielen. Notwendige Voraussetzung dafür ist das Erringen von Aufmerksamkeit. Da die Aufmerksamkeit der Rezipienten aber absolut begrenzt ist, erweist sich die Konkurrenz um sie als Nullsummenspiel. Steigerbar sind dagegen die Zahl der konkurrierenden Kommunikatoren und die Mittel, die vor allem professionelle Kommunikatoren in Werbung, Public Relations (PR), Journalismus, Unterhaltung etc. für das Gewinnen von Aufmerksamkeit einsetzen. Dadurch entsteht eine paradoxe Situation, die Schmidt (2000: 270; H. i. O.) am Beispiel der Werbung erläutert: 'Je erfolgreicher das Werbesystem Aufmerksamkeit erzeugt, desto unvermeidlicher erzeugt es Aufmerksamkeitsverknappung. Aufmerksamkeit als Voraussetzung für Vermarktung führt zwangsläufig zur Vermarktung von Aufmerksamkeit.« (NEUBERGER 2008: 8) [online] http://www.academia.edu/2581632/Neuberger_Christoph_2008 _Die_Allgegenwart_des_Widerspruchs._Paradoxien_der_Kommunikation_Rezeption_und_Vermittlung_im_Medienwandel._In_Pörksen_Bern- 
hard_Loosen_Wiebke_Scholl_Armin_Hrsg._Paradoxien_des_Journalis-

mus._Wiesbaden_VS_S._37-61._Erw._u._akt._Version [14.05.2018]

Eine weitere Paradoxie besteht darin, dass jenes begrenzte Potential an Aufmerksamkeit nicht nur die Anstrengungen vermehrt, diese zu erlangen, sondern dass auch der Wert der akkumulierten Aufmerksamkeit um so mehr zunimmt - gerade, weil es sich um ein Nullsummenspiel handelt. Anders als bei der künstlichen Verknappung eines Guts, der Begrenzung seiner Zugänglichkeit durch Stückzahl und durch preisliche Maßnahmen - als klassische Limitierung, was ebenfalls ein probates Mittel zur Wertsteigerung darstellt - geht es im Fall der Aufmerksamkeit nicht nur darum, überhaupt einen Teil von etwas zu erlangen, sondern möglichst mehr als die Konkurrenten, wodurch der Wert des errungenen Mehr erheblich steigt. Liegt bei der Limitierung die Eintrittsschwelle durch Stückzahl und Preis von vornherein fest und wäre allenfalls durch Schwarzmarkthandel oder Spekulationskäufe noch mit einer direkten Wertsteigerung zu rechnen, wächst im Gegensatz dazu der Wert der neu hinzugewonnenen und akkumulierten Aufmerksamkeit kontinuierlich an. Die Beachtlichkeit und ihr Wert vermehren sich und dies ist möglich, weil wir begriffliche Qualitätsstufen für Aufmerksamkeit ersonnen haben, durch die eine qualitative Aufwertung stattfindet, obwohl ihre Quelle quantitativ nicht zunimmt. 


\section{Der Kunstmarkt als Abbild der 120 Aufmerksamkeitsökonomie}

KLAMER et al. haben 2011 in ihrem Artikel The economics of attention versucht, die Ökonomie der Aufmerksamkeit als Erscheinungsform im Kunstmarkt zu verorten. (J-STAGE) [online] https://www.jstage.jst.go.jp/article/jace1998/ 2/1/2_1_1/_pdf [07.05.2018]. In einer ersten Feststellung wird formuliert, dass der Kunstmarkt kein kompetitiver Markt mit einer homogenen Produktqualität sei:

"[...] the art market is not competitive: instead of a homogenous product quality, absolute heterogeneity prevails. Every artist, so to say, constitutes its own market. Demand is not for a painting in general, but for a specific artist. Rather than a work, a nname is being bought. As a result, the reputation of the artist, or his artistic value, tends to coincide with the economic value of his. Work. [sic]. "

Sodann folgen ein paar Gedanken über Qualitätsannahmen:

"This process is reinforced by a qualitative characteristic of the art market: radical uncertainty about the good being sold: since the quality of paintings is increasingly difficult to estimate for a lay audience, we tend to rely on experts to make our own judgements (cf Plattner 1996). In other words, experts tell us what to look at, which works only deserve some slight attention and which should be left out entirely; likewise, they operate as brokers for attention."

Danach kommen sie an den Punkt, der an der Aufmerksamkeit für Künstler wichtig ist und in welcher Weise sich dies abspielt:

"Without attention, the artist's chance of selling works to the limited audience decreases considerably [Hervorhebung des Verfassers]. Furthermore, it seems to be the case that in the initial stage, chance is an important factor: >By chance, an artwork may [Hervorhebung des Verfassers] catch the attention of an insider of the art scene who gets curious and begins to ask questions [sic] (Bonus and Ronte 1997, p.111). After that initial stage, a path dependent process seems to unfold: once initial attention is caught, in other words, other people will be more likely [Hervorhebung des Verfassers] to take the artist into consideration." (alle Zitate aus KLAMER et al. 2011: 5)

In wiefern könnte man diese Beobachtungen auf den Designmarkt übertragen? Aus Vereinfachungsgründen wird in diesem Fall die schon oft versuchte Unterscheidung zwischen Design und Kunst nach ihren Funktionen ausgelas- 
sen, die im Kontext als unbedeutend erachtet wird, weil es um unmittelbare ökonomische und auch soziale Auswirkungen geht statt darum, worin beide Disziplinen sich grundsätzlich unterscheiden. Auch, wenn ein Teil der spezifischen Marktausformung für jede eben aus ihrer Unterschiedlichkeit folgt (was später im Zusammenhang mit der ILLUsio eines sozialen Feldes noch einmal ausführlich diskutiert wird).

$\mathrm{Zu}$ beginnen wäre bei der homogenen Produktqualität. Diese kann im Rahmen einer industriellen Produktionsweise in vergleichbaren Märkten als gegeben gelten, scheidet also in der oben vorgetragenen Negation aus und es kann auch nicht von Einzelmärkten im Sinne von Nischenmärkten für einzelne Designer gesprochen werden. Man kauft als reiner Konsument primär keinen STARCK, sondern eine Zitronenpresse von Starck - darin scheint der wesentlichste Unterschied zu bestehen. Denn das Artefakt, das einen wie auch immer gearteten Zweck erfüllen soll, steht generisch vor der Entscheidung für einen bestimmten Designer, während im Falle eines Werkes der Bildenden Kunst fast überwiegend der individuelle Stil der produzierenden Person die Kaufentscheidung bestimmen wird.

Die Reputation eines Designers fällt nicht zusammen mit dem ökonomischen Wert der von ihm entworfenen Produkte, weil diesen andere $\mathrm{Me}$ chanismen zur Preisermittlung und -bildung zugrunde liegen, auf die auch ein individueller Stil im Sinne des Autorendesigns keinen so großen Einfluß hat wie in einem Markt radikaler Verknappung auf Kleinserien und Unikate wie dem der Kunst. Börsenartige Ausschläge im Bereich der Produktpreise gibt es im Designmarkt dadurch nicht, denn die Festlegung der Produktpreise und der Konkurrenzkampf mehrerer Anbieter verhindern Bieterkämpfe, die, wie bei Auktionen, auf der Basis reiner Geldmacht und des entsprechenden individuellen Potentials entschieden werden. Gleichwohl haben spätestens seit dem Neuen Deutschen Design auch Designer wie Hersteller versucht, sich Mechanismen künstlicher Verknappung, wie man sie als Grundfeste des Kunstmarktes kennt, zu Nutze zu machen, um eine höhere Begehrlichkeit für von ihnen geschaffene Artefakte zu erzeugen. Findet derlei in einem kleinseriell-handwerklichen Umfang statt (vgl. z. B. die Einkaufswagen-Variationen von STILETTO oder auch die Chaiselongue LOCKHEED LOUNGE von MARC NEWsoN, die überhaupt nur für den Verkauf bei Auktionen in kleinster Stückzahl produziert wurde), sind diese Prozesse nicht mit einer standardisierten Massenproduktion vergleichbar. Damit fallen sie als Vergleichsebene von vornherein aus. Doch auch in Massenmärkten - vlt. gerade deswegen? - findet man Verknappungs- und Nobilitierungsstrategien vor, z. B. in der Form einer Lim- 
ited Edition. Das Prinzip und seine angestrebte Wirkung sind wohl durchsichtig genug, um hier keiner weiteren Erklärung zu bedürfen.

Zu den Qualitätsannahmen im Allgemeinen: Es gibt im Designmarkt keine so grundsätzliche Unsicherheit über die Qualität der Waren, die verkauft werden, wie sie im Kunstmarkt vorherrscht. Eindeutige Kriterien sind z. B. anhand einer simplen Unterscheidung von erfüllt seine Funktion und erfüllt seine Funktion nicht möglich, ohne dass hierzu Geschmacksurteile oder stilistische Einordnungen getroffen werden müssten. Dennoch kann man ein Laien- und auch ein Fachpublikum im Designmarkt voneinander unterscheiden. Wie stark sich das Konsumentenurteil in diesem Markt von den Einschätzungen von Designexperten abhängig macht, könnte zum Gegenstand eigenständiger Untersuchungen werden. Unbestreitbar kommen auch im Designmarkt institutionalisierte Wertbeimessungsprozesse im Form von Wettbewerben zum Einsatz, die Maßstäbe für gutes Design vorgeben sollen. Ebenso sollen, durch Vergleichstests in Zeitschriften, Bewertungen von Produktqualität ermöglicht werden. Neben diesen muss als ein Beispiel für eine Ideologisierung von Expertenmeinungen nur die GUTE FORM herangezogen werden, die schon auf den Warenkunden des 20. Jhd.s fußte, deren großes Ziel die Verbrauchererziehung war. Im Designmarkt gibt es prima vista keine so starke Orientierung am Expertenurteil zu einer individuellen Stilistik, das mit Empfehlungen über den Verkaufserfolg von Designartefakten entscheidet oder einen qualifizierten Marktzugang überhaupt erst ermöglicht. Die Funktion der »brokers for attention« kommt als Verbreitungsmedien im Designmarkt eher Special-Interest-Magazinen wie ARCHITEKTUR UND WOHNEN, SCHÖNER WOHNEN, den Fachpublikationen wie FORM und DESIGN REPORT oder der Gattung der Befestigungsliteratur zu, die im Kapitel zur Rezeption genauer betrachtet werden. Welche Rolle spielt die Aufmerksamkeit denn dann im Designmarkt?

Künstler finden, wie KLAMER es oben beschreibt, für ihre Produkte einen sehr begrenzten Markt vor und ohne die nötige Aufmerksamkeit sinken die Verkaufschancen für jene erheblich. Die Zufälligkeit des Aufmerksamwerdens auf etwas spiele eine ebenso große Rolle. Im Kunstmarkt seien es jedoch aus seiner Sicht die »insider of the art scene«, deren Neugierde zuerst geweckt werden müsse, so dass in der Folge andere Menschen aufgrund von deren wahrnehmbarem Interesse - auf das man auch erst aufmerksam werden muss ... - einen Künstler in Erwägung ziehen könnten. Natürlich müssen auch im Designmarkt Menschen auf Artefakte aufmerksam werden. Begrenzungen entstehen für Designartefakte jedoch weniger daraus, dass der Markt per se so klein wäre, wie er sich für Güter darstellt, die keinem regelmäßigen 
Bedarf unterliegen, sondern aus einem Überangebot konkurrierender Anbieter im gleichen Markt, die den potentiellen Marktanteil schrumpfen lassen. Ein Expertenzugang mittels Werturteilen ist für die Verbraucher nicht primär notwendig und so könnte auch der Faktor Interesse für einen Designer beim Konsumenten in weniger bedeutsamem Maße von jenen Werturteilen mitbestimmt werden.

Damit sind die wesentlichen Unterschiede einer Abbildung der Aufmerksamkeitsökonomie im Kunstmarkt im Vergleich zum Designmarkt herausgearbeitet. Es wurde gezeigt, dass unterschiedliche Herangehensweisen an die jeweils gehandelten Güter einerseits die spezifischen Ausformungen herbeiführen, wie sie andererseits auch die Angriffspunkte der Aufmerksamkeit bestimmen. 



\section{Kann Aufmerksam- keit wirklich zur Währung werden?}

Weitergedacht und den Ansatz von FRANCK ernstnehmend, muss eine Antwort auf diese Frage gefunden werden: Wann wird eine im Sinne einer Aufmerksamkeitsökonomie relevante Währung, nämlich eine Form reiner Aufmerksamkeit, die erst einmal kein Mittel zum Geld verdienen ist, überhaupt angeboten oder ausgegeben? (vgl. SIEGERT in: BECK und SCHWEIGER 2001: 109-120) Dazu müssen zunächst alle regulären monetär entgoltenen Wege ausgeblendet werden. Was zu der Frage führt, ob eine derart isolierte Betrachtungsweise in irgendeiner Art sinnstiftend oder zielführend ist? Sie kann mit Ja beantwortet werden. Denn Aufmerksamkeit als sozial wirksame Form von Beachtung ist selbst eine (Zwischen-) Währung: Ein nicht wirklich messbarer, aber in Begriffen, Prozessen und Ritualen gefasster Maßstab, der als Interpretationsergebnis u. a. auch aus monetär messbaren Vorgängen in Form von Verkaufszahlen entsteht. Theoretisch wäre sie gruppenunabhängig und soziale Klassen überschreitend. Dennoch sind sowohl Gruppenzugehörigkeit als auch Ansehen nur in Erfüllung von Zugehörigkeitsnormen zu erlangen, die die Zugänglichkeit regeln: als »Verhaltensregeln, die in sozial definierten Einheiten (z.B. Familie) nur für deren Mitglieder gelten« (vgl. FUCHS-HEINRITZ et al. 2013: 759).

Aufmerksamkeit entsteht auch als Ergebnis aus Prozessen institutionalisierter Aufmerksamkeitserzeugungs- und Gratifikationsinstanzen - was jede Form von Wettbewerb abdeckt, bei dem definierte Leistungsnormen abgeprüft werden und deren Erfüllungsgrad bemessen und belohnt wird. Für die 
Erfüllung einer bestimmten Qualitätserwartung wird eine symbolische, artefaktische oder monetär bemessene Auszeichnung als Gratifikation vergeben. 126 Die durch Auszeichnungen entstehende Aufmerksamkeit in Form von Medienaufmerksamkeit für einzelne Personen (die sich in Publikumsaufmerksamkeit verwandeln kann) kann dazu führen, dass z. B. eine größere Anzahl Menschen Konzerte ausgezeichneter Musiker besucht oder Filme ansieht oder dass größere Stückzahlen ausgezeichneter Produkte verkauft werden. Mit einer Auszeichnung ist man in der Lage, einen Teil eines guten Renommees (im Sinne eines guten Rufes, eines hohen Ansehens oder von Wertschätzung) anzusammeln. Auch GEORG FRANCK wählt Renommee als »[...] Oberbegriff für die persönlichen und institutionellen Formen. Das Renommee ist der allgemeinste und hinsichtlich der Zuschreibbarkeit zugleich neutralste Begriff für den rentierlichen Reichtum an Beachtung." (vgl. FRANCK 1998: 134)

Letztlich als messbare Größe relevant ist jedoch nur der ökonomische Erfolg, der auf der Interpretation einer immateriellen Währung beruht. Diese immaterielle Währung, die für den Nutzer aus der Auszeichnung eines Musikers, eines Filmes oder eines Produktes entsteht, ist die von kompetenten (?) Gremien ermittelte und mit der Auszeichnung beglaubigte Preiswürdigkeit. Mit dem daraus entstehende Vertrauen oder Interesse können Aufmerksamkeitsauslöser für Produkte gesetzt werden, die potentiell Konsumakte nach sich ziehen. Man könnte also von miteinander verwobenen, jeweils unterschiedlich gearteten Renommee-Systemen sprechen. Die Währung für den ursächlichen Produzenten ist und bleibt jedoch das Geld! Wir bezahlen nach wie vor mit Geld dafür, dass unsere Aufmerksamkeit erregt wurde und auch hier ist sie wieder nur ein Auslöser für einen weiteren Vorgang, also ein Mittel zum Zweck. An der Fiktion des Designklassikers können wir in actu ablesen, wie man versucht, ein konstruiertes Renommee in stilistische Kanonisierung und Verkaufszahlen umzusetzen. (vgl. BREUER 2001). 




\section{Wie wird Ansehen getauscht?}

Eine der Gelegenheiten, zu denen im Handel mit Aufmerksamkeit eine Form der Stasis (im Sinne eines angehaltenen Prozesses) eintritt, ist im o. a Beispiel des Wettbewerbs gegeben. Die eingenommene und akkumulierte soziale Aufmerksamkeit manifestiert sich in sozialem Handeln und führt nicht mehr dazu, dass sie als Grund für einen Akt des Konsums in Form der Geldausgabe dient. Das bereits erhandelte Renommee der Juroren, ihre personengebundene und öffentlich wertgeschätzte Kompetenz hat im Idealfall dazu geführt, dass sie einem Gremium angehören dürfen, das berechtigt ist, die zu vergebenden Preise zuzusprechen.

Gesetzt den Fall, dass für die Besetzung dieses Gremiums kein Geld fließt, wird durch dieses Handeln von einer Seite tatsächlich mit Aufmerksamkeit für Aufmerksamkeit erregt habende, akkumulierte soziale Aufmerksamkeit gezahlt. Denn Personen, die eine Jury besetzen, sind auf jene aufmerksam geworden, mit denen sie diese besetzen; nach Maßstäben, die ein Vertrauen in deren berufliche Kompetenz und eine öffentliche Wirksamkeit der zu berufenden Personen zu rechtfertigen scheinen, kurz: Weil öffentlich wirksames Ansehen entstanden ist. Wird dieser isolierte Fall herangezogen und zugleich nicht außer Acht gelassen, dass eine Jury kein naturwüchsiges Gremium ist ${ }^{1}$, dann sind für bestimmte Bereiche des sozialen Handelns in unse-

1 ( - worum es in diesem Fall ja gerade geht, dass all dies eben nicht naturwüchsig entsteht - obwohl es in unserem evolutionären Potential angelegt ist, denn sonst hätten wir diese Systeme gar nicht entwickeln können) 


\section{STARDESIGNER ODER GESTALTER DES ALLTÄGLICHEN?}

rer Gesellschaft, die mit diesem Beispiel vergleichbar wären, Bedingungen gegeben, unter denen mit Aufmerksamkeit für akkumulierte Aufmerksamkeit "gezahlt" wird. Das entspricht der Form der Tauschwirtschaft, zu der es in der Ökonomie des Geldes nicht kommt, in einer Ökonomie der Aufmerksamkeit sensu GEORG FRANCK aber kommen soll und muss. Von einer Ablösung der einen durch die andere muss hierfür gar nicht die Rede sein. Eine Anbindung an die Ökonomie des Geldes ergibt sich - wie oben gesehen - immer dann, wenn die Prozesse der Anerkennung dazu führen, dass in ihrer Folge Geld fließt. Für das hier zu formulierende Theoriemodell muss der Geldfluss jedoch ausgeschlossen bleiben.

Es scheint vorläufig angebracht, diese Vorgänge als ökonomieähnlichen Tausch von Ansehen zu benennen: Denn letztlich führt soziale Aufmerksamkeit zum sozialen Wert einer Person, der bemerkt werden kann, in Begriffen wie Anerkennung, Ansehen und Respekt seine Entsprechung findet und damit auch gemessen wird. Anerkennung wird einer Person ausgesprochen, man wird und ist angesehen und hat deshalb Ansehen, in der Steigerung großes Ansehen, man kann es sogar genießen. Für diesen Fall stecken sogar die Blickrichtung und die Blickhäufigkeit im übertragenen Sinne mit im Begriff. Das Ansehen hat immer eine Dimension des Betrachtetwerdens und es wird einem Individuum immer nur von außen zugestanden oder zugeschrieben.

Eine Formulierung wie sich Respekt verdienen legt beredtes Zeugnis ab von unserer Art, in diesem Zusammenhang ökonomische Metaphern zu verwenden. Dergestalt zuspitzend zeichnet sich ein theoretischer Rahmen für die gespeicherte soziale Aufmerksamkeit und das damit zusammenhängende aufmerksame soziale Handeln (im nicht ökonomischen Sinne!) ab, der zu keiner ökonomischen Theorie führen soll - sich diesen Analogien aber dennoch schwerlich wird entziehen können. 


\section{Ein Theoriemodell für den ökonomieähnlichen Tausch von Ansehen}

Strukturalistische Theoriemodelle haben folgende Bedingungen zur Grundlage: $\mathbf{t}=\{\mathbf{k}, \mathbf{i}\}$. $\mathbf{t}$ steht für die Theorie als Ganzes, $\mathbf{k}$ für den Theoriekern (der aus Modellmengen der Theorie besteht), i für die Mengen intendierter Anwendungen und empirischer Phänomene. Angewendet auf das vorstehend skizzierte Beispiel bestehen bis jetzt:

Die Theorie als Arbeitshypothese:

- Ökonomieähnlicher Tausch von Ansehen,

als Theoriekern eine Modellmenge $\mathbf{k}_{\mathbf{i}}$ :

- Aufmerksamkeit wird gegen akkumulierte soziale Aufmerksamkeit getauscht und

eine erste intendierte Anwendung $\mathbf{i}_{\mathbf{1}}$ :

- die Jury; entstanden als Ergebnis eines Tauschs von Aufmerksamkeit für bereits akkumulierte soziale Aufmerksamkeit.

Welche Bedingungen müssen dafür erfüllt sein?

- Beim Zustandekommen des Gremiums darf weder direkt noch indirekt Geld fließen.

Gelten Nebenbedingungen?

- Nein.

Gibt es weitere Modellmengen $\mathbf{k}_{\mathbf{x}}$ ?

- Ja $-\mathbf{k}_{\mathbf{2}}$ : Akkumulierte soziale Aufmerksamkeit kann transmittiert werden.

Gibt es weitere Beispiele für Anwendungen $\mathbf{i}_{\mathbf{x}}$ ?

- Ja. $\mathbf{i}_{\mathbf{2}}$ zu $\mathbf{k}_{\mathbf{1}}$ : Die Politik als Ganzes (durch das Prinzip der Wahl, verstanden als Stimmabgabe für oder gegen etwas oder jemanden). Die Währungsform der Aufmerksamkeit ist in diesem Fall die in Prozentzahlen ausgedrückte Zustimmung oder Ablehnung. Die Wahl, speziell von 


\section{STARDESIGNER ODER GESTALTER DES ALLTÄGLICHEN?}

Personen, ist eine Form des Ausdrucks von Anerkennung ihres Ansehens, für die von ihnen vertretenen Ansichten und ihre bereits etablierte, akkumulierte soziale Aufmerksamkeit, durch die sie zu Kandidaten wurden.

- $\quad \mathbf{i}_{\mathbf{3}}$ zu $\mathbf{k}_{\mathbf{2}}$ : jede Form der (Weiter-)Empfehlung im interpersonalen Bereich oder in der Form von Rankings jeglicher Art (für natürliche und juristische Personen, für Artefakte, für Dienstleistungen etc.). Transmittiert werden Ruf oder Reputation, vermehrt um die individuelle Einschätzung, im positiven wie im negativen Sinne. Zu gleicher Zeit wird damit auch zu Ruf oder Reputation des/der empfohlenen beigetragen.

- $\quad \mathbf{i}_{4}$ : Print-, Fernseh- und Funk-Journalismus. Das Themenspektrum von Zeitungen und Sendungen ist eine Folge von Aufmerksamkeit für etwas, das u. U. schon Aufmerksamkeit erregt hatte.

- $\quad \mathbf{i}_{5}$ : Wettbewerbe ohne Teilnahmegebühr.

Die Jury könnte als Teil des Dispositivs Wettbewerb bei den symbolisch generalisierten Kommunikationsmedien eingeordnet werden, genauer in den Bereich der Macht(ausübung) - in direkter Anlehnung an PARSONS und LUHMANN. In einem verallgemeinernden Sinne soll der Ausarbeitung des Theoriemodells in diesem Rahmen Genüge getan sein. Die Anregung für designferne Forschungsbereiche, sich endlich konkreter der sozialen Aufmerksamkeit zuzuwenden, wird hiermit nochmals ausgesprochen. 

»Am Konvertierungsprozess von Aufmerksamkeit sind also vier Akteure [...] und vier Güter [...] beteiligt.» 


\section{Eine Zeit- und Nutzenökonomie}

So unangebracht die wirtschaftstheoretischen Analogien auch sein mögen, wie schon verschiedentlich argumentiert wurde - nach der Darstellung des Theoriemodells müssen sie zum Abschluss auf eine gewisse Weise doch noch einmal bemüht werden, denn der Umgang mit unserer eigenen Aufmerksamkeit als Tauschende derselben stellt einen kombinierten Zeit- und Nutzenhaushalt dar. Worum es für alle Beteiligten immer geht, ist sowohl das Haushalten mit eigener Aufmerksamkeit - angesichts eines überbordenden Angebots - als auch darum, sie bei anderen für jedwede Art von eigenem Angebot zu wecken. Zeit ist es, die ein Nutzer für ein wie auch immer geartetes Angebot vor dessen Nutzung unentgolten (aus-) gibt.

Sein potentielles Interesse dafür muss unter der Annahme eines individuellen Aufmerksamkeitsreliefs bereits latent bestehen, um in der Folge durch einen Auslöser X erstmals oder wieder geweckt zu werden und sich sodann darauf zu fixieren. Dies jedoch ohne einen echten Empfänger für diese Folge des Aufmerkens - nach einem herkömmlich verstandenen Sender-Empfänger-Modell, in dem der Aufmerkende in diesem Fall aber als Sender betrachtet würde. Durch die Existenz des Medienangebots oder eines Artefaktes besteht eine zusätzliche Transmissionsebene. Hierin liegt die Relevanz im Zusammenhang mit jeglicher Art von käuflichen Artefakten - denn dies gilt für jeden Kauf, bevor es dazu kommt.

Nachdem Geld für ein Angebot (in breitestmöglicher Bedeutung) ausgegeben wurde, hat man einen Nutzen davon, was dazu anregt, noch einmal kurz über den Nutzenansatz im Rahmen der Aufmerksamkeitsökonomie zu reflektieren. Bisher fand die Idee der Nutzens in der von DAHINDEN und vie- 
len anderen verwendeten und erforschten Form ihren Einsatz überwiegend in der Medienforschung:

\begin{abstract}
"Die Medien bilden mit anderen Worten die Schnittstelle, die ,Wechselstuben<, an der Grenze von monetarisierten und nicht-monetarisierten Aufmerksamkeitsmärkten. Die Mediennutzer als die eigentlichen Anbieter von Aufmerksamkeit erhalten für ihr Angebot kein Geld, sondern tauschen die geschenkte Aufmerksamkeit gegen einen Nutzen (Information, Unterhaltung, parasoziale Interaktion etc.). Am Konvertierungsprozess von Aufmerksamkeit sind also vier Akteure (Mediennutzer, Medienunternehmen, Mediennutzungsforschung, Werbetreibende) und vier Güter (Aufmerksamkeit und Mediennutzen, Werbezeit und Geld) beteiligt." (DAHINDEN in: BECK und SCHWEIGER 2001: 50)
\end{abstract}

Ein echtes Tauschangebot der Mediennutzer im Verlauf der Nutzung, das DAHINDEN hier anspricht, ist in seinem Beispiel nicht wirklich gegeben, weil für einen echten Tausch ein personales Gegenüber fehlt. Das lässt die Verwendung der Begriffe Gabe und Tausch in diesem Zusammenhang zunächst problematisch und unpassend erscheinen. Dennoch ist der Vorgang aus der Sicht des (Medien-)Nutzers und auch aus der Sicht des (Medien-)Produzenten keine Einbahnstraße, denn hier tritt wieder eine Form der Speicherung (vergleichbar mit STRUBEs Aufmerksamkeitssparkonto) in Erscheinung - in diesem Fall einer Gabe. Mit Blick auf die noch einige Seiten entfernt liegenden Rezeptionsstudien ein kurzes Spiel zu Entstehung und Tausch von Aufmerksamkeit im Zusammenhang mit Medienangeboten - nach LATOURs Regeln.

Schreibt man einem Medienangebot den Status eines nichtmenschlichen Aktanten zu, dann könnte man zwischen zwei prinzipiell gleichwertigen Markt teilnehmern von einem Tausch im Sinne einer Gabe und ihrer Entgegennahme sprechen und versuchsweise einen nicht-monetarisierten Aufmerksamkeitsmarkt konstruieren. Das Medienangebot wäre handlungsfähig im Sinne eines Intermediärs, der die in ihm gespeicherten Informationen weitergäbe, ohne selbst auf diese einzuwirken. Der Mediennutzer hingegen nähme die Funktion eines Mediators ein, der auf die weitere Rezeption des von ihm entgegengenommenen Medienangebots Einfluss nehmen könnte, wenn er z. B. durch eine Bewertung seiner Nutzung eine qualitative Dimension hinzufügt.

Tausch von Aufmerksamkeit und Gabe fänden also mittels der im Intermediär gespeicherten und aus diesem entnehmbaren Informationen statt, die Ergebnis einer vorherigen Produktion sind; als verlängerter Arm der anderen Tauschpartei, sozusagen. Die Gabe der gespeicherten Informationen wird im Falle eines Kaufes - vom Käufer auf zweierlei Arten erwidert: Mit der Aufmerksamkeit, die vor und nach dem Kauf gegeben wird (die aber vom Empfän- 
ger nicht im klassischen Sinne bemerkt werden kann), sowie mit Geld für den Erwerb. Ob das Medium, wie oben beschrieben, die Schnittstelle oder Wechselstube zwischen den »monetarisierten und nicht-monetarisierten Aufmerksamkeitsmärkten« ist, bleibt fraglich.

Der Tausch, der zum Nutzen für den Käufer führt, findet tatsächlich statt. Doch da die Schwelle für die initiale legitime Rezeption in der Bezahlung mit Geld für das Medienangebot liegt, kann nur davon gesprochen werden, dass das Aufmerken und die in der Folge gegebene Aufmerksamkeit zum Kauf führt, nicht aber davon, dass die Aufmerksamkeit direkt in Geld konvertiert oder als Währungsäquivalent verwendet wird. Es handelt sich um zwei distinkte Mess-Systeme für unterschiedliche Einheiten und eine konkrete Wechselstube gibt es nicht. Ebenso wenig wie einen faktischen nicht-monetarisierten Aufmerksamkeitsmarkt im Vorfeld des Kaufes, denn die Dimension eines solchen ist aufgrund eines Aufmerksamwerdens in Folge jeweils individueller Aufmerksamkeitsreliefs schwerlich zu postulieren.

Man kann die Hypothese aufstellen, dass sich die Gabe der Aufmerksamkeit als Gegengabe für die im (Medien-) Angebot verkörperte Arbeitsleistung betrachten lässt, die erst mit (und nach) der Entrichtung des Kaufpreises wahrnehmbar erbracht wird und damit auch eine immaterielle Gratifikation für diese Leistung darstellt, die ihre Empfänger nur auf Umwegen erreicht. Falls das (Medien-) Angebot ein Verkaufserfolg würde, könnten sich die Produzenten dies als teils ihrer Leistung geschuldeten Verdienst anrechnen oder falls es - wie z. B. bei Publikationen - Reaktionen in Form von positiven Rezensionen, Leserbriefen, Einladungen zu Diskussionsrunden, Gespräche auf Lesereisen etc. gäbe. An diesem kurzen Aufriss für einen Medientyp lässt sich schon erkennen, dass je nach Art des (Medien-)Angebotes zunächst die jeweils möglichen Formen wechselseitiger Gratifikationen bestimmt werden müssten, bevor weiteres bedacht werden könnte.

Dieses Szenario bedeutet für den Zeitschriften- und Büchermarkt, dass auch Publikationen wie jene, die im Kapitel zur Rezeption untersucht werden, einen latenten Nutzen in sich bergen, den potentielle Nutzer erst dann haben, nachdem sie auf diese entweder aufmerksam (gemacht) werden oder selbst aufmerken, sich zu einem Kauf entschließen und danach die im Produkt gespeicherten Informationen zur Kenntnis nehmen sowie diese für sich aus- und bewerten. Als Nutzer wendet man demnach Zeit auf, gibt Geld aus und muss den Nutzen, den man aus dem Erwerb zieht, in einer individuellen Bilanz mit der eingesetzten Zeit und dem ausgegebenen Geld gegenrechnen. Die Aufmerksamkeit des einzelnen Mediennutzers für ein Medienangebot 


\section{STARDESIGNER ODER GESTALTER DES ALLTÄGLICHEN?}

wird mit einer Gratifikation für diesen entgolten, die latent im Medienangebot steckt und auf eine bestehende Erwartungshaltung trifft. Diese kann aber auch im Sinne eines Erstkontaktes den Aufmerksamkeitstrigger für noch folgende Akte des Aufmerkens erst hervorbringen.

Wertet man die in Verkaufszahlen Ausdruck findende Aufmerksamkeit für Medienangebote aus, sind diese eigentlich nur Intermediäre einer quantitativen Dimension. Trotzdem werden deren Verkaufszahlen in ihrer absoluten Höhe zu Botschaften, denen Erfolg und Misserfolg als qualitative Dimensionen durch die Koppelung von positiver und negativer Bewertung an Verkaufszahlen eingeschrieben sind. Hohe Verkaufszahlen sind per se ein Erfolg, niedrige Verkaufszahlen ein Misserfolg. Eine qualitative Bewertung des Nutzens, den ein je individueller Nutzer aus der Rezeption (auch der eines schlecht verkauften Titels) zieht, spielt in diesem Zusammenhang nicht die geringste Rolle: Für den Produzenten bestehen die Kenngrößen, die den verkauften Exemplaren gegenübergestellt werden, aus den Produktionskosten des Medienangebots, die durch den Verkauf wieder eingespielt werden sollen. Ein Verlust in dieser Hinsicht wird dadurch automatisch auch zum Misserfolg. Um diesem Problem entgegenzuwirken, finden sich allseits bekannte Strategien zur Verstetigung von Absätzen bei Zeitungen und Zeitschriften durch Abonnements. In einer abgewandelten Form wird dieses Prinzip in den Bereichen Theater und Konzert auch für gänzlich immaterielle Angebote angewandt - allesamt Methoden, die im Feld des Designs, so wie es hier betrachtet wird, keinen Einsatz finden können. 


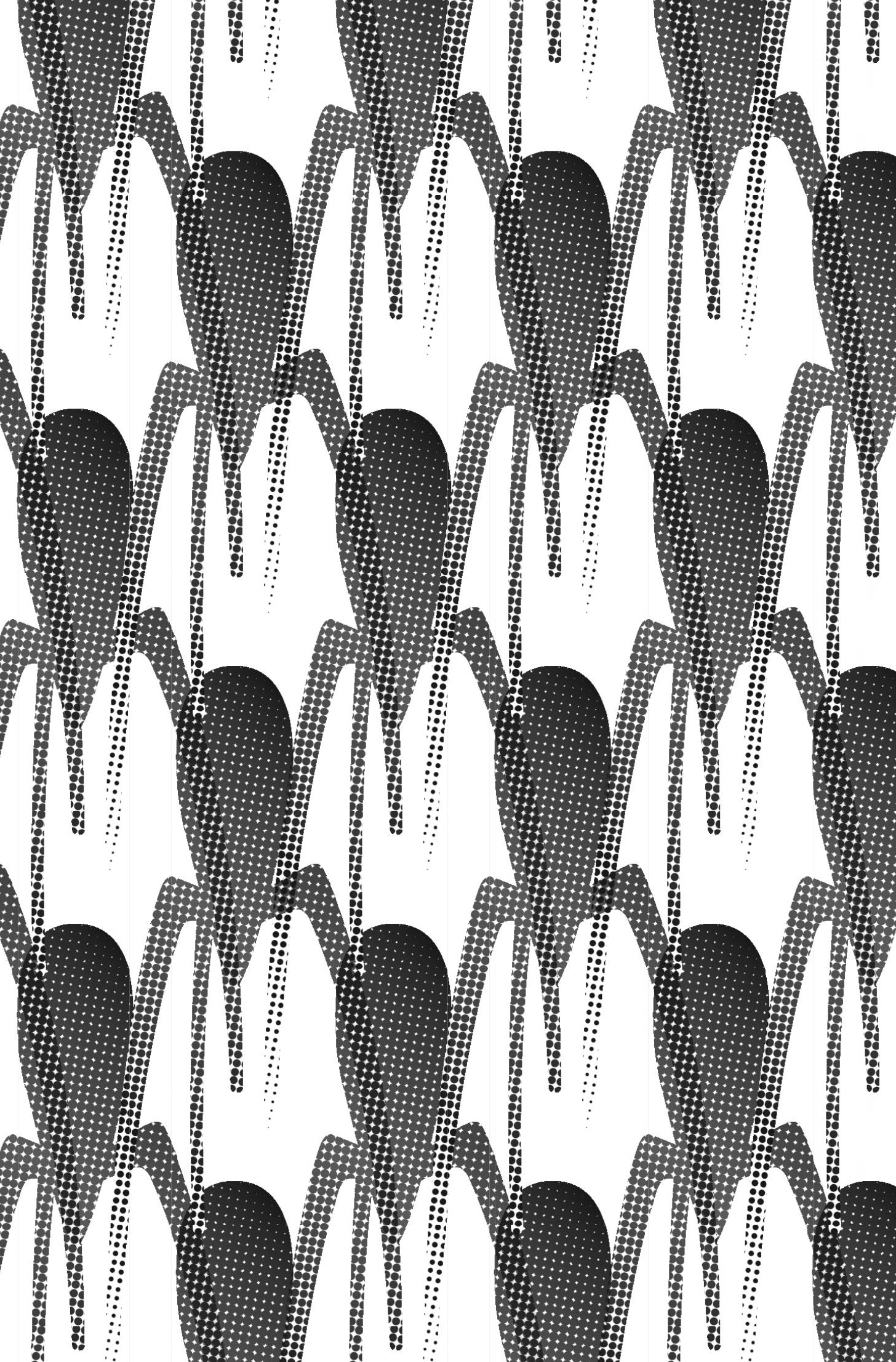




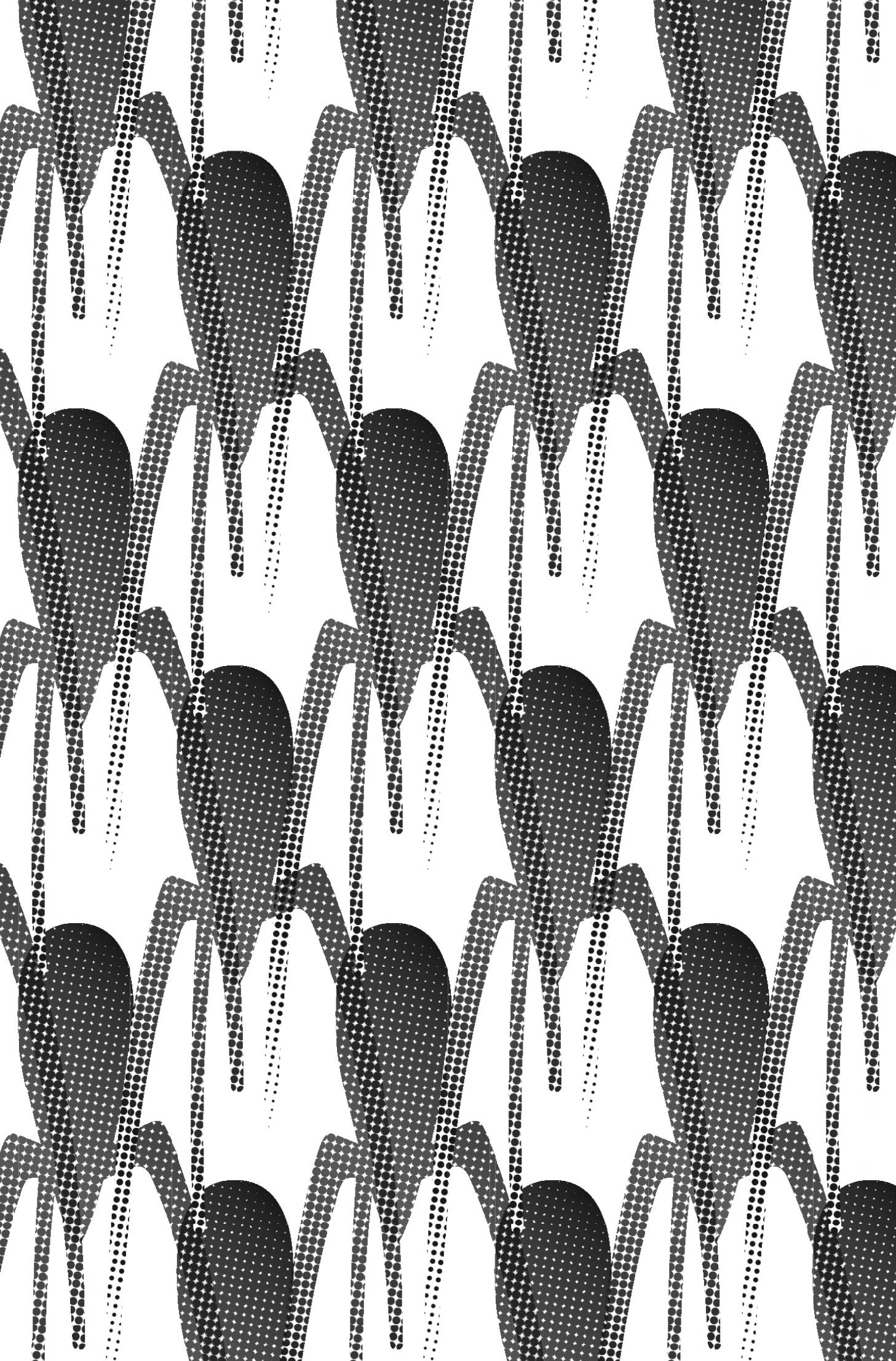


II. Prominenz 
»Niemand ist ein Star, wenn ihn nur seine Freunde schätzen.« Werner Faulstich 


\title{
Stardesign und Prominenz
}

\begin{abstract}
"Der Übergang vom Programm der Hardware zu einem Programm der Software... Der anonyme Designer der mechanischen Produktionsweise wird von einer Designerpersönlichkeit abgelöst, die, exaltiert wie seine [sic] Entwürfe, die Medien als Teil der industriellen Produktion versteht." (HBK SAAR) [online] https://www.hbksaar.de/personen/details/ hullmann [01.06.2021]
\end{abstract}

Auch aus heutiger Sicht scheint HULLMANN damit zunächst ein immer noch aktueller und erstaunlich treffgenauer Prophet zu sein. An der Schwelle zu den goern des 20. Jhd.s stellte dies ein Fazit des Designbooms der 8oer dar und war zugleich die unmissverständliche Selbstbehauptung einer der theoretischen Speerspitzen des Neuen Deutschen Designs. Selbstredend konnte man damals, nachdem das Design aus der Fachzeitschriftenecke auf die Hauptstraße gelangt und als Teil der DOCUMENTA 8 auch in der Kunstwelt sichtbar geworden war, noch nicht so weit vorausblicken, dass der Wandel zum heutigen Umgang mit den audiovisuellen Medien und ein öffentlich zugängliches Internet zu ahnen gewesen wäre. Ebenso wenig wie die Entwicklung von Software für soziale Netzwerke unterschiedlichster Couleur und frei zugängliche Publikationsplattformen. Die Schlagzahl an Veröffentlichungen und das Gerangel um die Aufmerksamkeit eines immer stärker zersplitterten Publikums hätten WARHOL womöglich noch ein ironisches Lächeln entlockt. FAULSTICH schreibt in seiner Vorüberlegung zu einer Theorie des Stars als Herzstück populärer Weltkultur: 


\section{STARDESIGNER ODER GESTALTER DES ALLTÄGLICHEN?}

"Erster Befund: Ein Star wird gemacht - nicht durch Werbung, Kommerz, Religion, Psychologie oder Marketingstrategien, sondern durch uns: die Fans. Die Beziehung ist wechselseitig: Ohne die Fans gibt es keinen Star. Die Voraussetzung seiner Entstehung ist das Vorhandensein einer Vielzahl von Bewunderern. Niemand ist ein Star, wenn ihn nur seine Freunde schätzen. Andererseits stellt der Star auch für seine Fans etwas dar, wonach diese dringend verlangen. Niemand wird zum Star, der den Wünschen seiner Verehrer nicht nachkommt. Das Bedürfnis der Fans nach Stars und der Stars nach Fans ist reziprok." (FAULSTICH in: ROBERTSON und WINTER 2000: 295)

Dieses Kapitel ergründet die Entstehung von Prominenz im Feld des Designs im Vergleich mit BOURDIEUs Theorie zum Feld der Kunst und darüber hinaus im Wesentlichen anhand zweier Veröffentlichungen von WIPPERSBERG (2007) und KELLER (2008). Zudem wird der Frage nachgegangen, inwieweit ein Bedürfnis an Star-Designern besteht - was sich hier, falls dem so wäre, in der Art der publizistischen Rezeption manifestieren sollte. Die Passung der beiden letztgenannten Forschungsansätze, die sich mit der Prominenz in ihrer klassischen Form unter einem Fokus auf personengebundene Fähigkeiten beschäftigen, wird mit Blick auf das Feld des Designs untersucht. WIPPERSBERG und KELLER werden behandelt, weil sich bei beiden Autorinnen sehr spezifische Erkenntnisse finden, die bisherige Untersuchungen zu Fan-Starund Star-Fan-Beziehungen in ihrer Anschlussfähigkeit zum Design-Diskurs deutlich übertreffen. Beide sehen den Prominenten/den Star als Sozialfigur, die auch einen Nutzen für den Fan hat. Sie bringen prominente Personen in eine Position, in der diese aus der Perspektive einer Verwertung ihrer selbst betrachtet werden und WIPPERSBERG im Speziellen legt eine Redefinition des Stars als einer Sonderform der Prominenz vor, die die exaltierte Position wieder in einen erdnäheren Orbit zurückführt.

Star-Phänomene als solche sind menschengemacht. Sie entstehen als Folge von Beachtung, die Individuen zuteil wird und im allgemeinsten Sinne führen sie zu herausgehobenen Positionen innerhalb sozialer Systeme. In unterschiedlichen Ausprägungen existieren sie seit dem Beginn der Stammesgeschichte. Mit fortschreitender Ausdifferenzierung ergeben sich auf allen Gebieten menschlicher Gesellschaften Chancen, sich durch Besonderheiten hervorzutun, damit Aufmerksamkeit zu wecken und auch zu fokussieren. Seit den 7oer Jahren des 20. Jhd.s sind diese Erscheinungen zu Forschungsgegenständen geworden und bis heute stehen Film-Stars, Musik-Stars, Sport-Stars und Politik-Stars im wissenschaftlichen Fokus. Als bisher dominierende Disziplinen sind Sozialwissenschaften, Medienwissenschaften und die Ökonomie- 
theorien zu nennen. Die Prominenz wird von WIPPERSBERG als eine »[...] eigene Art der Realität« beschrieben:

»[..] - genauer gesagt eine sozialpsychologisch konstruierte Realität. An dieser Konstruktion sind mehrere Instanzen beteiligt, das Publikum spielt in Kombination mit der massenmedialen Vermittlung aber die entscheidende Rolle. Venske [Hervorhebung im Original] bezeichnet die Anerkennung des Ruhmes als eines der Grundphänomene des Gemeinschaftslebens. Genau das trifft auch auf Prominenz zu. Ulrich Schneider [Hervorhebung im Original] beschreibt Prominenz als eine sin der breiten Öffentlichkeit vorhandene Annahme über die massenhaft gespendete Aufmerksamkeit vieler Menschen gegenüber einer bestimmten Person`.« (WIPPERSBERG 2007: 249)

LUDES stellt zu Stars fest, dass deren Fähigkeiten im Besonderen an ihre Person gebunden seien und sich nicht beliebig lange aufrechterhalten ließen - sowohl, was ihr Aussehen, als auch, was besondere körperliche Fähigkeiten oder eine ungewöhnliche Stimme beträfe (vgl. LUDES in: FAULSTICH und KORTE 1997: 91). Dies stellt wohl den Hauptunterschied zu Star-Phänomenen im Design dar, denn Star-Designer erlangen ihren Status im Gegensatz dazu durch von ihnen entworfene Artefakte und deren Rezeption, die im Sinne einer FRANCKschen Aufmerksamkeitsökonomie erst Aufmerksamkeitskapital für den Gestalter schafft. Unterstellt man zudem, dass auch den Artefakten ein Aufmerksamkeitskapital erwächst, das im Kreise der Käufer zirkulieren und anwachsen könnte und damit die Wertschätzung derselben vermehrte, würde hypothetisch das Ansehen des Gestalters und des Käufers in der jeweiligen sozialen Vergleichsgruppe ebenfalls steigen können (vgl. FRANCK 1998). Der später betrachtete Designklassiker könnte als Musterbeispiel für diese Vermutung herangezogen werden. Anbetrachts des Umstandes, dass Artefakte eine eigene Prominenz entwickeln, oszilliert dieses Kapitel hin und wieder zwischen der Prominenz von Personen und der von Artefakten und dieses Schillern ist Absicht.

Ein Übertragungsversuch von FAULSTICHs und LUDES' Aussagen auf das Feld des Designs: Stardesign existiert nicht per se, sondern man versucht, es herzustellen und stellt es dadurch auch her - so wie man, wie später noch zu sehen sein wird, prominent ist, weil man prominent ist. Das im Gegensatz dazu nicht herausgehobene Design ist einfach da - seit die Menschheit begann, sich Werkzeuge zu schaffen, mit deren Hilfe eigene Defizite ausgeglichen werden konnten und sie damit ihre Umwelt zu gestalten begann. Die Frage, ob man es als Alltagsdesign oder als anonymes Design bezeichnen sollte, ist zu stellen und wird später auch beantwortet werden. Das nicht heraus- 
gehobene Design teilt mit dem Stardesign den Gegenstand der Bewertung: das Artefakt. Doch da eines nicht aus der Masse herausgehoben wird, unterscheidet sich das andere dadurch erheblich - hauptsächlich in seiner sozialen Wirkung, in der Folge aber auch ökonomisch, das jedoch nicht zwangsläufig. Mit Blick auf eine transzendierende Wirkung und mit starken Anklängen an den von FRANCK verwendeten Aufmerksamkeitsbegriff formuliert KOHL dazu passend (und in Bezug auf den Wert der Ware konträr zu SIMMEL; vgl. MIKLAUTZ 1996: 39f):

"[...] dann liegt der Schluß nahe, daß ein Rest der sozialen Bindungen, die den 'Geist der Gabe in archaischen Tauschverhältnissen ausmacht, auch noch dem Wert der Ware anhaftet. Der Wert der Ware müßte demzufolge umso höher sein, je größer das Quantum an sozialen Beziehungen ist, das sie repräsentiert. Dann wäre es aber nicht die imaginäre Eigenschaft der Ware, aus sich selbst heraus Werte zu schaffen, sondern der ihren Gebrauchswert transzendierende soziale [Hervorhebung im Original] >Mehrwertı, der ihr anthropomorphe Qualitäten verleiht." (KOHL 2003: 113)

Jener Mehrwert manifestiere sich in der Teilhabe am "persönliche[n] Glanz«. Die Tatsache »daß ihnen - ähnlich wie der Gabe - noch ein Teil der Person ihres vermeintlichen Produzenten anhafte[...]«, solle Käufer zum Kauf derart herausgehobener Artefakte bewegt haben (beide Zitate ebd.: 115). Für das Design ist derlei bislang noch so gut wie unerforscht, obwohl - oder gerade weil? - eine unüberschaubare Masse an Artefakten im Konsumgütermarkt angeboten wird, die als Designklassiker, Moderner Klassiker oder Designikone bezeichnet werden und / oder mit dem Zusatz »designed by ... « versehen sind.

Der Hauptgrund, Star-Design(er) noch einmal außerhalb bisheriger Laufrichtungen zu betrachten, ist, dass sehr vielen Untersuchungen zu Starphänomenen eine Relevanz in Bezug auf Artefakte fehlt - wenngleich sie, bezogen auf Marken, vage mitgemeint sein könnten. FAULSTICH bemerkt dazu passgenau, " $[\mathrm{d}] \mathrm{a}$ es bis heute noch keine annähernd zufriedenstellende Theorie des Stars g[ebe]« und dass »[d]as Starproblem [...] zur kulturwissenschaftlichen Bringschuld « gehöre (FAULSTICH in: ROBERTSON und WINTER 2000: 296).

Als Nebenäste werden Celebrity Products und Celebrity Endorsed Products für relevant erachtet, die als Sonderformen eine Ausweitung der Starsphäre auf Produkte versuchen, um die Vermarktbarkeit von Stars als solche (mit einer anderen Art von Fanartikeln) wie auch die von Artefakten zu erweitern. Darüber hinaus gehend die Celebrity Designer Products als "products sold under the name of celebrities famous for their design expertise (ZIMMERMAN und AYOОВ 2004: 9). Deshalb fließt auch dieser Artikel in die Reflexion mit ein. 
Wenn man KELLER in ihrer Betrachtung folgt und den Star als Mittel der Identitätskonstruktion von Star-Nutzern begreift (s. u.), kommt man schnell an einen Punkt, an dem die Erkenntnisse von Veblen und BOURDieu zu wenig zu einer Problemlösung beitragen. Identitätskonstruktion in einer Mixtur aus Abgrenzungs- und Zugehörigkeitswünschen in immer stärker ausdifferenzierten Gesellschaften erfordert eine andere Auseinandersetzung mit Gruppen. Zudem kommt das Phänomen der Idolatrie, wie zINK (2014) es im religiösen und popkulturellen Zusammenhang untersucht, im Erstreckungsbereich dieser Untersuchung schlicht nicht vor. Formte man in Gedanken ein Dreieck aus Aufmerksamkeit, der noch zu betrachtenden Anonymität und der Prominenz, so könnte man die Begriffe einmal nicht als dessen Eck- und Zielpunkte betrachten, auf die etwas zustrebt, sondern sie an seinen Seiten aufstellen. Dann träte die (Spiel-)Fläche deutlicher in den Vordergrund, deren zweite Bande in diesem Kapitel betrachtet werden wird. Solch eine Veränderung würde der Gemengelage viel eher gerecht und fügte sich auch besser zu der von FAULSTICH schon geforderten Multiperspektivität - weil es sich um fließende Übergänge handelt, die monothematisch und -direktional und vor allem auch monokausal nicht mehr zu beschreiben sind.

Wo die angesammelte Aufmerksamkeit, wie es schon bei FRANCK zu finden ist, zu einer Akkumulation der Beachtlichkeit führt, verwendet er für deren Kurswert den Begriff der Prominenz, welche sich auch in der Form, die Star-Designern zuteil wird, nicht davon zu unterscheiden scheint. In jüngeren Veröffentlichungen werden veränderte Betrachtungen sowohl von Stars wie auch der Prominenz versucht. WIPPERSBERG bezeichnet den Star als eine Sonderform der Prominenz und teilt die Einschätzung einiger Autoren (z. B. LUDES und POWDERMAKER), dass »[d]as >Prinzip Star bereits vor der Verwendung des Starbegriffs etabliert" gewesen sei und »bis weit in die Geschichte zurück« reiche; es könne schon bei »den ersten charismatischen Führern, Halbgöttern und Helden der frühgeschichtlichen und antiken Zeit« verortet werden. (WIPPERSBERG 2007: 33). Zudem entwickelt sie (in der Folge von PETERS, FRANCK, RÖTZER und SCHNEIDER) ein eigenes Modell zur Entstehung von Prominenz sowie zur sozialen Annahme von Prominenten, das seither als aktuellster und gültiger Versuch zu gelten hat.

KELLER untersucht den Star als Objekt verschiedener Nutzungen und verschiebt u. a. über den Fokus auf die parasoziale Interaktion und Relationierung eines Ego im Verhältnis zum Star den Blickwinkel auf die Identitätskonstruktion der Star-Nutzer »und damit letztlich [auf] die mediengesellschaftlich geprägten Selbstentwürfe jedes Einzelnen.«(KELLER 2008: Klappentext) 
Darauf scheint es im Großen hinaus zu laufen: Der Star wird im Feld des Designs für seinen Nutzer aus der in sakralen Sphären üblichen, personenbezogenen Idolatrie und auch von der Selbstbeschreibung als Fan weggerückt. Das Verhältnis des Nutzers zu jenem richtet sich nicht mehr auf eine Person als klassischen Zielpunkt einer Fan-Star-Beziehung, womit er sich aus der Perspektive des Käufers betrachtet zur "privaten Vorliebe« entwickelt. (FAULSTICH in: ROBERTSON und WINTER 2000: 295)

LENZE bezeichnet Stars in seiner Untersuchung des postmodernen Charismas als die »Helden des Medienzeitalters« - in einer »Verschränkung von Medienwirkung und rrealer Persönlichkeit«, aber auch in einer Abkehr von seinen »Darstellerqualitäten«, die »in erster Linie seine Person [zum] Gegenstand des öffentlichen Interesses « werden lassen, was ihn als Antagonisten zu RECKWITZ ausweist (LENZE 2002: 154f). Zugleich setzt er im »fetischistische[n] Produkt< [...] zusammen mit dem Starphänomen [den] Ausgangspunkt einer [...] (Re-)Integration des Außeralltäglichen in den Alltag«, weshalb er auch für die Betrachtung der Artefakte noch eine Rolle spielen wird. (ebd: 166). LENZE nimmt - wie WIPPERSBERG - Bezug auf LUDES' Beitrag Aufstieg und Niedergang von Stars als Teilprozeß der Menschheitsgeschichte. Beide machen den dort verhandelten Aspekt der Außeralltäglichkeit zu einem deutlichen Anknüpfungspunkt. Ein Anker:

\begin{abstract}
"Die sneue Unübersichtlichkeitı von Gesellschaften, die sich nicht mehr offensichtlich klar nach Schichten differenzieren lassen, in denen sehr unterschiedliche, sich teilweise stark widersprechende Lebensstile, Werte und Normen um Anerkennung und Durchsetzung konkurrieren, erfordert anscheinend vereinfachende Leitbilder. Diese Leit-Bilder erlauben in der Alltäglichkeit des Arbeits- und Wohnlebens, der Familie und des Verkehrs, sich zumindest oder auch nur mittels Identifikation und Projektion aus dem Dunkel des Lebens in sternengleiche Höhen emporgerissen zu fühlen.« (LUDES in: FAULSTICH und KORTE 1997: 90)
\end{abstract}

Das »symbolische [...] (Aufmerksamkeits)-Kapital« (RECKWITz 2012: 265) legt den Blick auf BOURDIEU und das Feld der Kunst nahe, um der Frage nachzugehen, welche Form von Prominenz von Designern erreicht wird, nachdem über die Sozial-Figur des Werk-Stars eine sinnfällige Anbindung zum Feld der Kunst identifiziert wurde. Mit einer gewissen Vorsicht sind bei BOURDIEU, der seine Erkundungen für seine Feldtheorie hauptsächlich auf dem Gebiet der Literatur durchführt (wenngleich er selbst schon eine Übertragbarkeit auf andere Felder sieht und auch darstellt), verwandt erscheinende Strukturen im Feld des Designs auszumachen. Gleichfalls augenfällig werden dabei noch 
einmal entscheidende Differenzen in der Konstituierung. BOURDIEUs Konsekrationsgrad ist vergleichbar mit den Besonderungskriterien Designklassiker und Moderner Klassiker in ihrem Gegensatz zum Alltagsdesign - »um zu klassifizieren und wohlfeil Gruppen existent werden zu lassen, die durch die Etiketten mehr designiert denn definiert werden, die allererst die Unterschiede, die sie angeblich zum Ausdruck bringen, schaffen sollen.« (BOURDIEU 1999: 200) Gilt im Feld der Kunst (bei BOURDIEU prädominant anhand der Literatur) noch die Regel, dass »unmittelbarer Erfolg etwas Suspektes an sich« habe (ebd.: 237), so ist im Feld des Designs der Verkaufserfolg eines Artefaktes weder anrüchig noch disqualifiziert er (weder Artefakt noch Hersteller noch Designer), wie in manchen Augen die Bezeichnung als Bestseller es täte. Nein, der Verkaufserfolg veredelt in diesem Fall sogar überwiegend, weil Markterfolg ein Erfolgskriterium ist, das zählt (vgl. als Gegensatz ebd.: 344). Auch BOURDIEU findet eine ähnliche Formulierung wie später WIPPERSBERGs »Man ist prominent, weil man prominent ist." (WIPPERSBERG 2007: 60) Bei ihm heißt es: "Das bewirkt auch, warum auf dem Markt Erfolg hat, wer Erfolg hat: Bestseller werden gemacht, indem man ihre Auflagenhöhe veröffentlicht; [...]« (BOURDIEU 1999: 238).

Ähnliches vermag man für die Auszeichnung von Artefakten mit Designpreisen anzunehmen. Solcherlei Aussagen oder Auszeichnungen weisen eine besondere Signalfunktion auf. BOURDIEUs Differenzierung "zwischen den Bestsellern ohne Dauer und den Klassikern, Bestsellern in Langzeitperspektive, die ihre Kanonisierung, also ihren erweiterten und dauerhaften Markt, dem Bildungssystem verdanken" (ebd.: 237f), scheint gleichauf mit der Aufteilung in Alltagsdesign und Designklassiker zu liegen. Der Aspekt der Dauer hat in BOURDIEUs Weltbild jedoch zwangsläufig mit Konsekration zu tun und kommt nur durch diese zustande. Alltagsdesign hingegen kann sich vieltausendfach verkaufen und sich durch zeitliche Dauerhaftigkeit im Absatz wie in der Haltbarkeit auszeichnen - eine Konsekration im Sinne einer im Bildungssystem wirksamen Dauerhaftigkeit, die zu symbolischem Kapital der BOURDIEUschen Sorte führen würde, ergibt sich daraus jedoch nicht.

Im Gegensatz zur Literatur oder der Bildenden Kunst erfolgt die Konsekration des Designs nicht durch die Aufnahme in Bildungspläne. Sie wird durch haldenartig sich ansammelnde Auszeichnungen und oftmals ebenso haltlos auf den Markt gebrachte Publikationen verschiedenster Art behauptet, wie es später im Kapitel Rezeption dargelegt werden wird. Im Feld des Designs sind Auszeichnungen mit Designpreisen und der tatsächliche Verkaufserfolg von Artefakten Erfolgskriterien, die beide Auswirkungen auf eine Steigerung 
der Popularität haben können. Einerseits durch den Impetus, über Auszeichnungen auf den Markt einzuwirken, um die Verkaufszahlen zu erhöhen, andererseits durch den Verkaufserfolg im Markt mit seiner Wirkung nach innen wie nach außen. Die Erhebung in den Klassikerstand (z. B. nach einer langen Verkaufszeit) und die Auszeichnung (für eine lange Verkaufszeit) entsprechen dann der Konsekration und der internen Hierarchisierung des Designs in seinem Feld. Verglichen mit dem Feld der Literatur, wo ein »Bestseller[...] ohne Dauer« (s. o.) einen kurzlebigen, wenn auch zahlenmäßig hohen Verkaufserfolg darstellt, der aber nicht durch eine Einschreibung in den $\mathrm{Ka}$ non (die Konsekration) gewürdigt wird, können sich im Feld des Designs Artefakte gut verkaufen, ohne zu Designklassikern zu werden. Sie können aber auch in den Stand von Designklassikern oder Modernen Klassikern erhoben werden und das ganz gleich, ob sie sich gut verkaufen oder nicht - die Maßstäbe hierfür sind höchst unterschiedlich, wie sich ebenfalls noch erweisen wird.

Der Longseller im Feld des Designs ist eine weitere Variante dieser Kategorie, deren Qualitäten sich u. a. in einer bestimmten Verkaufszeit bemessen, die mindestens acht und maximal 50 Jahre beträgt, der zudem mindestens ein Umsatz von einer Million Euro oder eine Stückzahl von mindestens 100.00o produzierten Exemplaren zugrundeliegen muss. So lauten die Kriterien des Longlife-Design-Award, der seit mehr als 40 Jahren alle drei Jahre von RIDO BUSSE verliehen wird. Wirklich bedeutsam daran ist im hiesigen Zusammenhang das Ende der Auszeichnungsspanne, denn diese sieht auch ein Ende der Wertsetzung durch einen Preis vor und entfernt die einst ausgezeichneten Produkte dann selbstverständlich wieder aus der Riege der auszeichnungsfähigen. Dergestalt wird nur eine temporäre Kanonisierung zugelassen wie auch Wandel akzeptiert.

Dies ist bei BOURDIEU in vergleichbarer Manier als »soziale[s] Altern des Kunstwerks, de[n] unmerkliche[n] Übergang zum Deklassierten oder Klassischen « beschrieben (vgl. ebd.: 403 sowie als Kontext 372f, 379 und 401). Er zeigt auch, dass es eine ausschließlich soziale Transferleistung ist, die dazu führt, dass ökonomische Profite wie die eben zur Sprache gekommenen in symbolisches Kapital umgewandelt werden können (vgl. ebd.: 239). Erst externe Wertsetzungen versetzt die konsekrierten in die Lage, sich selbst einen Namen zu machen. Dieses Anrecht erwerben sie sich wiederum durch die legitime Akkumulation von Konsekrationen und damit, wenn man so will, einem anwachsenden Konsekrationsgrad, den sowohl die konsekrierenden wie auch die von außen auf diese Ausrufung von Qualitätsmaßstäben blickenden bemerken, bewerten und wiederum individuell in Anrechnung bringen. 
Hierzu gibt die Prominenzforschung mit den Kategorien des Fachpublikums und der Bereichsprominenten inzwischen andere Antworten. Sie zeigt einen Ansatz, der eine Verbindung der beiden Sphären im Sinne zunehmender (nicht entwertender) Popularität nahezu zwingend herbeiführt, anstatt auf einer qualitativen Trennung zu insistieren, welche sowohl die Aufwertungswie die Entwertungsbedingungen ehern festschreibt. Prominenzforscher machen für die Entstehung einer breiteren Bekanntheit die Bereichsprominenz (bei BOURDIEU den "Grad feldspezifischer Anerkennung - von diesem aber nur auf die Berufskollegen bezogen) zur Voraussetzung und betrachten die Entwicklung der Prominenz sowohl quantitativ wie qualitativ auf einer anderen Ebene.

BOURDIEUs Ansatz erscheint vor diesem Hintergrund als mikrosoziologisches Vorgehen, während die Prominenzforschung die Vorgänge makrosoziologisch zu erfassen versucht. Qualitative Unterschiede werden mit beiden Ansätzen durch Prominenz- und Reputationsarten und mit unterschiedlichen Arten der Konsekration aufgedeckt, die bei BOURDIEU als externe und interne Konsekration ausdifferenziert sind und damit eine Abwandlung seiner Hierarchisierung darstellen. Gründe für die sichtbaren und wirksamen Aktionen der Akteure beschreibt BOURDIEU mit der illusio : »[...] daß eine gewisse Form der Identifikation mit dem Spiel, des Glaubens an das Spiel und an das, was auf dem Spiel steht und dessen Wert das Spiel erst spielenswert macht, dem Funktionieren des Spiels vorausgeht [...]«. Die »illusio [Hervorhebung im Original, der Verfasser] ist die Voraussetzung für das Funktionieren eines Spiels und zugleich, zumindest partiell, auch sein Ergebnis." (beide Zitate ebd.: 360) 



\section{Überlegungen zum Problemfeld}

In direktem Vergleich mit Untersuchungen konventioneller Starforschung spielt das Sozialleben des Star-Designers für seine Prominenzierung keine Rolle. Als Homestory ist der Lebensbereich in Printmedien eventuell noch gefragt und damit noch am ehesten bei den klassischen Stars angelehnt, ansonsten handelt es sich eher um Portraits im Arbeitsumfeld, die öfter in Fachpublikationen gefunden werden. Als relativ aktuelles Beispiel der Artikel »Die neue H-KLasse«: Ein Portrait des Designers SEBASTIAN HERKNER in der SCHÖNER WOHNEN-Ausgabe vom September 2014 (SCHÖNER WOHNEN SEPTEMBER 2014: 74-80). Das Fan-Umfeld, welches bei klassischen Star-Phänomenen zwingend mit zu untersuchen ist, zerrinnt förmlich in der Individualität der Käufer. Fan-Massen, wie sie sich z. B. bei Sportveranstaltungen, Konzerten, während des Wahlkampfs, im Kino oder im Theater zusammenfinden, trifft man im Zusammenhang des (Produkt-) Designs so gut wie nicht an - allenfalls anlässlich fachspezifischer Veranstaltungen wie Messen, Wettbewerben und deren Preisverleihungen. Dort spricht man jedoch nicht vom Fan, sondern vom Fachbesucher oder ist ein interessierter Konsument.

Die Fronten, an denen die Prominenz im Design zählt, sind die des Verkaufs - mit dem Käufer als alleinigem Gegenüber des Produkts, bei dem der Prominenzierungsraum nur noch mitschwingt - und darüber hinaus die der Geschäftsanbahnung auf unterschiedlichen Ebenen, soweit z. B. Wettbewerbsergebnisse für die Konstitution der Reputation von Designern als entscheidungsfördernd oder -bestimmend, zumindest aber hilfreich zu gelten haben. Im Gegensatz zu den Fans konventioneller Stars haben Käufer von Artefakten keine Veranlassung, sich »mit den vermeintlichen oder wirklichen Schwächen 
eines Stars, die jener entweder heroisch überwindet oder an denen er tragisch scheitert« zu beschäftigen (RAPPE 2001: 2). Das Sozialleben eines Star-Designers bietet ihnen keine Handlungsmuster für den persönlichen Alltag an und parasoziale Interaktionen sind ebenso wenig vonnöten, da die Artefakte zur persönlichen Lebensgestaltung zur Verfügung stehen.

So muss die Performance von Star-Designern unter einem anderen Licht oder aus einer anderen Perspektive gesehen werden: Ausschlaggebend ist ihre Marktpräsenz, die auch in Abhängigkeit von ihren Wettbewerbserfolgen zu sehen ist - was sich sowohl auf Wettbewerbe als auch auf den Wettbewerb im Markt bezieht. Persönliche Authentizität spielt bei der Beurteilung für die Käufer ebenfalls nicht zwangsläufig eine Rolle. Wenn, dann geht es auf einer anderen Ebene um die Stimmigkeit der Passung des Designers zum Auftraggeber. "[D]as physische, zuweilen auch ästhetische Scheitern an einer fremdbestimmten, ikonenhaften Inszenierung« (ebd.: 2) ist ebenfalls größtenteils irrelevant, wenn es auch gelegentlich zu einem Scheitern am eigenen Image oder der eigenen Inszenierung kommen kann. Als Beleg lässt sich z. B. ein Interview in der ZEIT aus dem Jahr 2008 heranziehen, in dem PHILIPPE STARCK sich kokett selbst an den Pranger stellte. Auf dessen Überschrift »Ich schäme mich dafür« folgte: »Philippe Starck ist der Stardesigner der vergangenen zwei Jahrzehnte. Dennoch sagt er heute: ^Alles, was ich gestaltet habe, ist absolut unnötig.« (PRÜFER 2008: 1) [online] http://www.zeit.de/2008/14/DesignerStarck-14 [19.02.2018] Da STARCK bisher keine Veranlassung sah, sich mit reumütig zum Aufmerksamkeitsmarkte getragener Miene endgültig aus dem Geschäft zurückzuziehen, kann dies getrost als ein erneuter publicity stunt gewertet werden.

Ein Hauptproblem bis heute vorliegender Untersuchungen, auch den neuesten zu Verehrung und Bewunderung, liegt darin, dass sie den Aspekt der Gruppe nicht betrachten. Das ändert sich bis zu einem gewissen Grad erst bei ZINK mit ihrer Beschreibung der Verehrergemeinde (ZINK 2014: 294f), wird aber dort nur im sakralen Sinne anhand der JESUS FREAKS und im Feld der Popkultur am Beispiel der Fans von MICHAEL JACKSON untersucht: Analoge Übertragungsmöglichkeiten bestimmter Aspekte im Hinblick auf Vergleichbarkeiten mit dem Feld des Designs wären noch auszuloten. Allgemein wird überwiegend nur das Verhältnis des Einzelnen zum bewunderten betrachtet, die Frage nach der Akkumulation und der Wirksamkeit in die Ebene jedoch nicht beleuchtet. Ein ausformulierter Ansatz zur Gruppendynamik existiert bisher nicht. Der Vergleichs- und Aufstiegsaspekt, wie er bei VEBLEN angelegt ist und auch von BOURDIEU in seinen Arbeiten zu Distinktion und Habitus 
ausgeführt wird, greift noch am ehesten für das Feld des Designs. Er erfasst jedoch die Auswirkungen der Gruppe auf den einzelnen, speziell im vergleichenden Konsum und im Streben nach Status meiner Meinung nach immer noch nur unzureichend und in derzeitigen Jetzt immer weniger. Angesichts der Forschungen zu Emotionen in Gruppen aus den Reihen der Psychologie fehlen Überlegungen zu den Fragen Wie? und Warum?, die mehr erkennen ließen als bloße Feststellungen, dass etwas in einer bestimmten Art existiere. Dazu folgt nach dem Abschluss dieses Kapitels ein kurzer Exkurs zum Stand der Emotionsforschung in der Sozialpsychologie. 
»Um für kompetent zu gelten, muß man zunächst einmal in der Szene Anerkennung finden." Georg Franck 


\section{Sind Stardesigner tatsächlich prominent?}

Eine Antwort auf diese Frage steht noch aus. Strategisch gesehen wird in der Folge mit einem allgemeineren Blick auf die thematische Relevanz der vorstehend bereits erwähnten Autorinnen und den Beziehungen zu verschiedenen anderen Stimmen eine Eingrenzung versucht und danach ein analytischerer Blick auf WIPPERSBERG und KELLER geworfen. Die Entstehung der Sozialfigur des »Kreativen an der Spitze der Aufmerksamkeitsökonomie« und auch des Star-Designers (wie es durch die Erwähnung STARCKs als kreative Marke belegt wird), beschreibt einer der aktuell prominentesten Soziologen auf diese Weise:

»Innerhalb der größeren Menge von Kreativen aller Branchen kristallisiert sich damit eine kleine Gruppe von Super-Kreativen heraus, die selbst über die einzelne Kreativorganisation - die einzelne Beratungsagentur, Fernsehproduktionsfirma etc. - hinaus Sichtbarkeit erlangen. Hier verdrängen die Persönlichkeit und ihr Stil zunehmend das Werk und kreative Produkt. An die Stelle der im eigentlichen Sinne künstlerischen Marke Picasso (wahrscheinlich der erste Künstler des 20. Jahrhunderts, der sowohl Avantgarde als auch höchst erfolgreicher Unternehmer seiner selbst sein konnte) sind damit die kreativen Marken Philippe Starck, Harald Schmid, Tom Peters oder Sarah Wiener oder auf kollektiver Ebene Scholz \& Friends, TASCHEN oder Body Shop getreten. Jene Kreativen an der Spitze der Aufmerksamkeitsökonomie, die damit nicht mehr in einer Kreativorganisation arbeiten, sondern diese selber initiieren oder aber vollständig Selbstunternehmer sind, erhalten Starqualitäten im Rah- 


\section{STARDESIGNER ODER GESTALTER DES ALLTÄGLICHEN?}

men einer spezialisierten oder breiteren Öffentlichkeit, so dass sich die Aufmerksamkeit von den kreativen Produkten mehr und mehr zu den alltäglich-außeralltäglichen Eigenschaften der Kreativen selbst verschiebt - ein Phänomen, wie es wiederum aus den Künstlerbiographien seit der Renaissance vertraut ist." (RECKWITZ in: MOEBIUS und SCHROER 2010: 255)

RECKWITZ insinuiert damit auch, die Prominenz heutiger kreativer Marken sei vergleichbar mit jener der von ihnen ersetzten Künstler-Personenmarken. Meiner Meinung nach sind daran wie am Schluss dieser Darstellung Zweifel angebracht. Das Problem entsteht gerade dadurch, dass für die Art der Betrachtung die Art der Prominenzentwicklung beider Personengruppen gleichgesetzt zu werden scheint. Hier kommt BOURDIEU wieder mit ins Spiel, dessen Feldtheorie in der illusio, der Festschreibung der Handlungsgrundbedingungen des jeweiligen Feldes, die möglichen Handlungen aller Akteure definiert. Diese sind im Feld der Kunst aber fundamental andere als im Feld des Designs. Die »Starqualitäten im Rahmen einer spezialisierten oder breiteren Öffentlichkeit« weisen auf die bei WIPPERSBERG als Teilpublika, als Zielgruppenprominenz und als allgemeines Publikum vertretenen Öffentlichkeiten hin. Bei aller Wiedererkennbarkeit scheint es für Designer im Dienste der Massenproduktion als Idol dennoch fast keinen Platz zu geben. Die Aufmerksamkeit richtet sich nicht »von den kreativen Produkten mehr und mehr zu den alltäglich-außeralltäglichen Eigenschaften der Kreativen selbst« (s. o.), sondern die ikonischen Objekte in Form der Designklassiker, der Designikone oder der Modernen Klassiker bleiben im Vordergrund. Dieser Umstand kann - im Vorgriff auf die Auswertung der noch im Nebel liegenden Rezeptionsstudien - auch bewiesen werden. Eine Idolisierung von Designern, die über die bei GEORG FRANCK beschriebenen Aufmerksamkeitszuwendungen hinausginge und ein Ausmaß annähme, wie es für die Stars gegeben ist, die allein durch ihre Persönlichkeit wirken, findet nicht statt. Der Star-Designer bleibt im Beiboot seiner Entwürfe sitzen. Im Gegensatz zu jener Art Star, der bei GEORG FRANCK als »[...] das verkörperte Versprechen, daß aller Augen auf ihn gerichtet sind «, beschrieben wird (FRANCK 1998: 167), muss im Gegenzug für die Designer festgestellt werden, dass deren

»[...] Rezeptionsseite [...] nicht einfach das Publikum [ist]. Zu ihr gehören auch die Fachleute und Mitproduzenten. [...] Innerhalb dieser Fachwelt beschäftigt man sich mit der Produktion, den Dispositionen und Urteilen der Kollegen beziehungsweise Konkurrenten ähnlich wie im Wissen- 
schaftsbetrieb. Um für kompetent zu gelten, muß man zunächst einmal in der Szene Anerkennung finden." (ebd.: 161)

WIPPERSBERG steuert 2007 eine notwendige Präzisierung eben jener Rezeptionsseite bei, weil sie von Teilpublika und einer in Berufs- und Interessenprominenz aufzuteilenden Zielgruppenprominenz spricht, die auch ein »jeweils korrespondierendes Publikum« hätten, das sich durch die Nutzung anderer Medien vom allgemeinen Publikum unterschiede. Sie führt hierfür die »Special-Interest-Printprodukte und Fachzeitschriften« (vgl. WIPPERSBERG 2007: 252) an. Ähnliches stellt HILDEBRAND schon in den 7oern des 20. Jhd.s im Rahmen eines Essays über den Auftrag der Eliten in unserer Zeit fest: »Zutreffend ist schließlich auch die Feststellung, »daß die Leistungsqualifikation von Personen oft nur von der in-group « [Hervorhebung im Original] beurteilt werden kann.« (HILDEBRAND in: KALTENBRUNNER 1977: 40) Bei GEORG FRANCK gegenlesend, der den oben bereits zitierten Abschnitt zur Verschachtelung von Beachtlichkeit damit fortsetzt, dass »[...] alle, die in der Fachwelt für kompetent gelten, [es] zu einem gewissen Vermögen an Beachtlichkeit gebracht« haben müssen (FRANCK 1998: 161), müsste also die nach Kompetenz gewichtete Beachtlichkeit in der Folge dergestalt nach außen abstrahlen, dass die Maßstäbe eines Teilpublikums vom allgemeinen Publikum, das »für die Entstehung und Aufrechterhaltung von allgemeiner Prominenz verantwortlich" ist, aufgegriffen und ggf. übernommen werden (vgl. WIPPERSBERG 2007: 252). Das Wie? einer allgemeineren Prominenzierung beantwortet WIPPERSBERG mit PETERS, deren Modell auch aus ihrer Sicht bis heute immer noch Gültigkeit beanspruchen kann:

"An der Prominenzierung sind nach Peters [Hervorhebung im Original] folgende Instanzen beteiligt: die einzelnen Gesellschaftsbereiche, aus denen die Prominenten stammen, die Massenmedien und das Publikum. Sie nennt hier bereits jene drei symbiotischen Faktoren, die Prominenz konstituieren. Diese drei sich gegenseitig bedingenden Selektionsschritte werden als eine sich zeitlich nacheinander abspielende Schrittfolge begriffen. Das Modell unterstellt eine Vorauswahl der Kandidaten für Prominenz, bevor die Betreffenden von den Medien vermittelt werden. Diese Vorauswahl passiert innerhalb der einzelnen gesellschaftlichen Subsysteme. Hier wird die Selektion nach jeweils systemimmanenten Mechanismen gesteuert, die von System zu System variieren. Peters [Hervorhebung im Original] geht davon aus, dass auf diese Weise jeweils eigene `Eliten gebildet werden. Diese Eliten entsprechen nicht schon der Prominenz, sondern bilden den Pool, aus dem die Prominenten ausgewählt werden. [...] Mit dem Begriff >Bereichseliten [Hervorhebung des Verfas- 
sers] sollen jene Personen bezeichnet werden, die aus einem bestimmten Gebiet herausragen. Diese Elite ist für Außenstehende nicht immer zu erkennen. Prominent können diese Personen dann werden, wenn sie den Sprung über die Systemgrenze hinweg schaffen, sie müssen zumindest einem spezifischen Laienpublikum bekannt werden. [Hervorhebung des Verfassers] Die Medien wählen nun ihrerseits nach ihren eigenen Kriterien jene Personen aus den Bereichseliten aus, denen mediale Präsenz verschafft werden soll.« (ebd.: 148f)

Jene Publikationen, die ein Feuilleton mit überregionalem Anspruch pflegen, beschäftigen im Idealfall auf dieser Rezeptionsebene fachkompetente Journalisten, die sich auf die vermeintlich fachkompetenten Entscheidungen ihrer Kollegen aus den Redaktionen der Special-Interest-Printprodukte stützen können. Im Designbereich liegen zudem ständig genügend Wettbewerbsergebnisse vor, die - wie Filmpreise - Auskunft über ausgezeichnete Produkte geben (was hier nicht im übertragenen Sinne verstanden wird). Somit können Pfade verschachtelter Beachtlichkeit bis zu einem gewissen Grad identifiziert werden. Die verschachtelte Beachtlichkeit kann als Grundprinzip aller redaktionellen Berichterstattungen im Rahmen von Mainstream- wie Special Interest-Publikationen so wie der später betrachteten Befestigungsliteratur angesehen werden.

Ein allgemeines Publikum lässt sich für diese Fälle unter der Prämisse eingrenzen, dass seine Kaufentscheidungen dabei anhand der Bekanntheit von Designern ausgerichtet werden könnten. Diese resultiert aber nicht zu allererst aus deren Persönlichkeit, wie es von RECKWITZ oben mit der Verschiebung auf die »alltäglich-außeralltäglichen Eigenschaften der Kreativen selbst« angedeutet wird, sondern primär aus dem Abglanz der von ihnen gestalteten Artefakte. Ein Umstand, der eine weitere Parallele zur »Unzahl technischer Reproduktionen« ausweist, die GEORG FRANCK dem Star als "räumlich globale Präsenz" attestiert hat (FRANCK 1998: 167). So, wie Filmstars durch eine hohe Anzahl an Filmkopien zeitgleich eine globale Präsenz erreichen können, liefert im Falle der Artefakte ihre technische Reproduzierbarkeit den Löwenanteil, um diese zu allgegenwärtigen Repräsentanten ihrer Gestalter werden zu lassen. Die massenhafte Präsenz lässt es in diesem Fall zweifelhaft erscheinen, dass die Medien für den qualifizierten Zugang zum Markt alleine zuständig seien, wie es sich im Kunstmarkt mit seinen unikatären oder in der Stückzahl extrem reduzierten Artefakten und Kleinserien darstellt. Das Multimediazeitalter bedingt zudem eine Spreizung der Möglichkeiten, das Publikum über verschiedene Kanäle zu erreichen und es schafft dadurch neue Herausforderungen, diese Kanäle auch zu nutzen - wie es die Anstrengung erhöht, im Mix 
der Optionen nicht unterzugehen. LUDES weist bereits 1997 darauf hin, dass nicht alle den Übertritt in neue Leitmedien bewerkstelligen würden und dass Personengebundenheit nicht mehr zwangsläufig zu den grundlegenden Bedingungen aktueller medialer Starkonstruktionen zählen könne:

\begin{abstract}
"Diese neuartigen Herausforderungen an potentielle Stars gehen im Multimediazeitalter meiner Ansicht nach so weit, daß ein grundlegendes Merkmal von Stars, nämlich ihre Personengebundenheit, teilweise ergänzt und teilweise ersetzt wird. ,Stars der Zukunft werden nicht nur Menschen mit besonders schönen oder außergewöhnlichen Stimmen, mit herausragenden körperlichen Fähigkeiten oder einem besonderen Aussehen sein, sondern - in einer Inflationierung von Ansprüchen und Anspruchserfüllungen (vgl. Münch 1991 und 1995) - zunehmend auch nicht mehr personifizierbare sImages«, corporate identities, Marken oder Produkte. Diese Ausdifferenzierungen aus der Stargeschichte ermöglichen andere Zugangsmöglichkeiten, bieten andere Identifikationschancen, lassen sich umfassender in individuelle Lebensstile und Lebenswelten einordnen." (LUDES in: FAULSTICH und KORTE 1997: 91f)
\end{abstract}

Seine Stimme tritt mit diesen Sätzen deutlich aus dem restlichen Chor der Starforschung hervor - wegen der Erweiterung des Spielraums um Produkte und Marken, denen er zutraut, Position und Funktion von Stars zu übernehmen. Das ist anhand der Entwicklung von Markenstrategien problemlos nachvollziehbar und wird von ZURSTIEGE anhand marktgerecht produzierter "Charakterkern[e] « oder einer "Produktpersönlichkeit« treffend beschrieben (- Verkäufer wären mit dem Produzenten gleichzusetzen):

"Die industrielle Produktion von Gütern in hohen Stückzahlen hatte die anonymisierte Beziehung zwischen Käufern und Verkäufern [Hervorhebung des Verfassers] im Zusammenspiel mit der Werbung notwendigerweise weiter verschärft. Ein >Charakterkern, eine Identität, eine Seeles konnte daher unter diesen Bedingungen nur noch als Eigenschaft der beworbenen Güter in das Marktgeschehen wieder eingeführt werden. Dies ist die Geburtsstunde der Produktpersönlichkeit, deren Charakter zunehmend von der angewandten Psychologie geformt wurde: >Die Möglichkeit, mit Hilfe wissenschaftlicher Methoden die Wahrnehmung von Produkten und Unternehmen durch die Verbraucher - ihre Imagekomponenten - aufzudecken, heißt, diese in den Griff bekommen, sie der Einflußnahme zugänglich machen.r [...] Die Marke und der Kunde sind operative Fiktionen, weil es mit der Umstellung auf anonyme Marktverhältnisse [Hervorhebung des Verfassers] persönliche Beziehungen zwischen Anbietern und Nachfragern nicht mehr gibt und [sic] eben deswegen in symbolisch generalisierter Weise wieder eingeführt werden müssen.« (ZURSTIEGE in: BLASEIO et al. 2005: 174) 
Die oben aufgeführten individuellen Lebensstile und Lebenswelten weisen ebenfalls eine unmittelbare Anschlussfähigkeit zu GEORG FRANCK auf - gerade über die Anbindung, die das Design zu jenen herstellt, weil sie eine so breite stilistische Ausdifferenzierung des Designmarkts mitverursachen. Jener schrieb über die Vorbildfunktion von Stars:

\begin{abstract}
"Ein Star, der nicht vormacht, wie man sich gibt und aufmacht, womit man sich umgibt und in Szene setzt, was man anhat und draufhat, kann keiner werden. Als taste leaders [Hervorhebung im Original] sind sie die Volkserzieher in der Kultur der Auffälligkeit. Weil zum aufsehenerregenden Auftritt stets die richtige Aufmachung gehört, bezieht sich tasteleadership [Hervorhebung im Original] immer auch auf den Konsum an Mitteln zur Selbstdarstellung. Die Anleitung zur Arbeit an der eigenen Attraktivität besteht vor allem anderen in der Unterweisung zur Anschaffung der Dinge, mit denen man sich umgibt, herrichtet und anzieht. Wenn sich der Kreis zwischen dem Starkult und dem Kult um die Attraktivität der eigenen Person schließt, dann hat sich auch der Kreis zwischen Massenkultur und ostentativem Konsum geschlossen." (FRANCK 1998: 169)
\end{abstract}

Wo GEORG FRANCK am Ende über den »ostentative[n] Konsum« noch schnell und sehr geschickt VEBLEN mit einflicht, führt er mit diesem Abschnitt auch das Gegenteil zum Feld des Designs vor Augen: Denn die Rollen werden im Vergleich mit dem tasteleadership des klassischen Stars dort anders zugewiesen und die Verantwortlichkeiten ebenfalls neu verteilt: »Die Anleitung zur Arbeit an der eigenen Attraktivität« wird in einer Agglomeration aus Wettbewerbsergebnissen, Fachpublikationen, Kaufentscheidungen und der Profession der Trendsucher - die einen eigentlich postprognostischen Blick auf die Masse der Konsumenten werfen -, neu ausgehandelt. Die Vorbildfunktion des Stars klassischer Prägung geht auf die Konsumenten mit ihren Kaufentscheidungen über (welche wiederum beobachtet werden) sowie auf jene Akteure, die den Markt beobachten und Vorauswahlen treffen - neutrenddeutsch kuratieren. Der Star-Designer selbst hat damit nichts zu schaffen.

Designer treten als die Prominenten der zweiten Reihe hinter den von ihnen gestalteten Produkten zurück und müssen anderen die Rolle der taste leaders überlassen - den Einkaufenden, die ihre Einkäufe auch zur Verstärkung ihrer eigenen Attraktivität nutzen. Problematisch am Umgang mit dieser Prominenz der zweiten Reihe ist, dass Star-Designer publizistisch wie Stars der ersten Reihe behandelt werden, obwohl sie gerade das nicht sind.

Geschmacksgemeinschaften, in denen sich Konsumenten nolens volens befinden, innerhalb derer sie auch ihre Selbst- und Fremdbezugnahmen ausrichten (vgl. KELLER 2008: 191), dürfen in diesem Kontext ebensowenig au- 
ßer Acht gelassen werden: Wo der Star nach üblichem Verständnis noch selbst sein Angebot ist (primär keinem potentiellen Nutzer verpflichtet und ebenso wenig zur Antizipation eines Publikumsgeschmacks), wo seine Idiosynkrasien um seiner selbst willen geschätzt werden und ihn deswegen beliebt und begehrt machen, muss der Designer im Gegensatz dazu schon im Vorfeld versuchen, mehrere Unsicherheiten zu überwinden. Erstens den Geschmack seines Auftraggebers zu treffen. Zweitens kann er ggf. auch an seinem Personalstil scheitern oder gerade deswegen oder wegen der Abwesenheit eines solchen beauftragt werden. Drittens muss er den Bedarf potentieller Konsumenten richtig einschätzen, um beide Bedürfnisprofile danach mit einer in Serienprodukten mündenden Gestaltungslösung zu beantworten. Deren Annahme im Sinne eines Verkaufserfolgs ist genau so unsicher wie die Annahme eines Stars durch das allgemeine Publikum. Ebenso schwer zu fassen wie die Kriterien für seine Annahme ist der Star selbst - WIPPERSBERG bezeichnet ihn schon zu Beginn ihrer Arbeit als ein zwar allgemein bekanntes, aber schwer zu fassendes Phänomen und fügt ihrer Aufzählung von Synonymen auch die Ersatzautorität hinzu (vgl. WIPPERSBERG 2007: 31f). Diese kann die Rolle der bereits bei GEORG FRANCK als taste leaders erwähnten trennscharf vom Designer abgrenzen, womit man jedoch die von WIPPERSBERG (und FRANCK) intendierte Bedeutung gänzlich hinter sich lässt. Unter dem Aspekt der Fassbarkeit schlägt KELLER in die gleiche Kerbe und erteilt im gleichen Atemzug Erklärungsversuchen eine Absage:

»Beim Versuch der Begründung von Startum wird nicht selten auf abstrakte und vermutlich starinhärente Stimuli wie sstar quality<, scharismas, or saura< [Hervorhebung im Original, KK], 'Ausstrahlung oder >das gewisse Etwas` zurückgegriffen. Auf diese Weise versuchen Beiträger zum Star-Diskurs, ein objektives Charakteristikum auszumachen, das allen Stars gemein sein möge, eine Erklärung des rational Unerklärlichen und empirisch nicht messbaren. Ähnlich wie die Versuche, Authentizität zu beweisen, sind auch diese Bemühungen zum Scheitern verurteilt: Weder Schönheit noch Talent, Authentizität oder andere personale Attribute des Stars bedingen objektivierbar seinen Status, der sich vielmehr aus seiner funktionalen Nutzbarkeit für seine Ko-Aktanten begründet [Hervorhebung des Verfassers]. Ist man sich zudem bewusst, dass auch über Talent, Authentizität und Schönheit von Ego in Kultur unter Rückbezug auf fiktives kollektives Wissen entschieden wird, verlieren Kausalisierungsversuche von Star-Status mit ihrer vermeintlichen Objektivität an Relevanz. Ob vermeintliche Star-Stimuli als Charisma, Aura oder Charme benannt werden - sie verweisen als Erklärungsversuche des Nicht-Erklärbaren auf eine gemeinsame operative Fiktion [Hervorhebungen des Verfassers], deren Inhalt indes verhältnismäßig wenig expliziert ist und somit Anteil an der 


\section{STARDESIGNER ODER GESTALTER DES ALLTÄGLICHEN?}

Distanz fördernden Faszination des Stars hat. Während Startum anhand von Kriterien wie Erfolg, Medienpräsenz, und Prominenz vergleichsweise leicht indizierbar ist, kann auf Star-Qualität oder Charisma als retrospektive Voraussetzung von Startum nur geschlossen werden.« (KELLER 2008: 149)

Isoliert man den letzten Satz, sind mit (wirtschaftlichem) Erfolg und Medienpräsenz zwei Gründe für das Star-Sein von Star-Designern zielsicher ausgemacht. An der Ergründung ihrer Prominenz ist noch zu arbeiten. Die StarQualität des Star-Designers entsteht durch seine öffentlich in Bezugnahmen beglaubigte Leistungsqualifikation. Eine charismatische Wirkung der Persönlichkeit ergibt sich allenfalls durch externe Beschreibungen derselben als Nebenaspekt von Veröffentlichungen oder im unmittelbaren sozialen Kontakt. Im Sinne einer weitergehenden Bedeutung für den Star-Designer-Status ist sie unerheblich. 

»Die Annahme eines

Prominenten zeigt sich

demnach auch in einer

Erinnerungsleistung des

Publikums."

Julia Wippersberg 


\title{
Prominenz. Entstehung, Erklärung, Erwartungen
}

Die Frage, ob Designer, die als Star-Designer bezeichnet werden, tatsächlich prominent in der Öffentlichkeit stehen und auch einen so wahrnehmbaren Prominenten-Status haben resp. woran dieser ggf. zu messen wäre, muss in diesem Zusammenhang beantwortet werden, denn wenn

\begin{abstract}
»[...] Stars [...] als Spitze der Prominenz angesehen werden, auf die alle Elemente der Prominenz zutreffen [...] [sind sie] somit eine Teilmenge der Prominenz. Stars könnten somit als sbesonders prominente Personen angesehen werden, sie stellen aber keine genuine Kategorie (wie Ruhm oder Elite) dar, da sich die Eigenschaften der Prominenz und der Stars nur ihrer Intensität nach unterscheiden. Prominente sind somit eine Vorstufe zum Star: Wer ein Star ist, gilt auch als prominent. Umgekehrt gilt aber: wer prominent ist, hat noch lange keinen Star-Status inne.« (WIPPERSBERG 2007: 35f)
\end{abstract}

Nach Wippersbergs Maßstab sind Designer also bis jetzt ebenfalls nur prominent im Sinne von herausragend, ohne einen Star-Status inne zu haben so, wie es gleich in ihrem Entrümpelungsvorschlag für den Begriff der Prominenz zum Ausdruck kommen wird: Auf Bekanntheit reduziert, rückt die Prominenz auch sprachlich wieder näher zur Anonymität, die im Duden ja u. a. als Nicht-Bekanntheit definiert wird: 


\section{STARDESIGNER ODER GESTALTER DES ALLTÄGLICHEN?}

„Der Begriff Prominenz muss sentrümpelt und vor allem entlastet werden. Ich schlage deshalb vor, beim Begriff Prominenz wieder auf die Ursprungsbedeutung zurückzugehen: das Herausragen. Prominenz soll schlicht die Bekanntheit einer Person bedeuten. Diese Bekanntheit wurde massenmedial erzeugt, beruht auf der Annahme der Person als prominent durch das Publikum und bedarf einer bestimmten Dauer.« (ebd.: 37)

Schon zu Beginn des 20. Jhd.s suchte man nach Auslösern, mit deren Hilfe Personen bekannt gemacht werden können: CARL LAEMMLE, der Gründer von UNIVERSAL STUDIOS, dem auch die Erfindung des Star-Systems heutiger Prägung zugeschrieben wird, war einer von ihnen. Er beendete durch die Bekanntgabe der Vertragsunterzeichnung der Schauspielerin FLORENCE LAWRENCE bei seiner Firma IMP als erster die Namenlosigkeit von Stummfilmdarstellern (vgl. ANDERSON in: LEWIS 2015: 21f). Auf der Basis von Gerüchten über ihren Tod bei einem Straßenbahn-Unfall und einer nachfolgend »korrigierenden " Anzeige (We Nail a Lie; MOVING PICTURE WORLD vom 12. März 1910) brach er mit der bis dahin geltenden Gepflogenheit, die Namen der Filmschauspieler zugunsten der Produktionsfirmen zu verschweigen:

"The blackest and at the same time the silliest lie yet circulated by enemies of the IImp r was the story foisted on the public of St. Louis last week to the effect that Miss Lawrence (the IImp girl, formerly known as the 'Biograph (girl) had been killed by a street car. It was a black lie because so cowardly. It was a silly lie because so easily disproved. Miss Lawrence was not even in a street car accident, is in the best of health, will continue to appear in Imp films, and very shortly some of the best work in her career is to be released." (MCCLINTOCK 2017) [online] http://brightlightsfilm.com/florence-lawrence-truth-behind-we-nail-a-lie-famous-ads1910/ [16.01.2018]

Auf diese Weise wurde der erste in dieser Branche belegbare Fake News-Skandal inszeniert, mit dem er der Konkurrenz die Verbreitung der Falschmeldungen in die Schuhe schob. Damit machte er LAWRENCE, die vorher nur als The Biograph Girl bekannt war (nach der Firma, bei der sie vor IMP unter Vertrag stand), zum ersten Filmstar und lenkte die Aufmerksamkeit gleichzeitig auch auf seine eigene Produktionsfirma. (vgl. KEIL und SINGER 2009: 15, 29 sowie SANDFORD 2010 [online] http://brightlightsfilm.com/florence-lawrencethe-first-movie-star/\#.WLgX4hj_U2U [02.03.2017]. Vorgänge wie der vorstehend beschriebene bildeten die Grundlage für die nun folgenden Ausführungen Von WIPPERSBERG: 
"Ausgangspunkt für die Entstehung von Prominenz ist nun ein Auslöser, dies kann ein snatürlicher Auslöser oder ein 'künstlicher bzw. inszenierter Auslöser sein. Aufgrund des Auslösers, den die charakterlich geeignete Person gesetzt hat, erfolgt die Inszenierung der Person mit allen Mitteln der Öffentlichkeitsarbeit, insbesondere der Personality-PR. Darauf folgt die Vermittlung der Person aufgrund ihres Auslösers und eventuell ihre Inszenierung durch die Massenmedien.« (WIPPERSBERG 2007: 155)

Dass bei der Suche nach Auslösern für Star-Designer die Artefakte im Vordergrund stehen, weil Designer grundsätzlich Werk-Stars sind, darf inzwischen als unstrittig gelten. Wenn wir SCHNEIDER mit seiner »These der möglichen Prominenzquellen « beiziehen, der ebenfalls »[d]ie konkrete Fachleistung im Rahmen der Ausübung einer Tätigkeit in einem gesellschaftlichen Teilbereich [...] als den klassischen Zugang zum Prominentenstatus [...] « bezeichnet (ebd.: 195), dann kann für Designer die Einreichung von Artefakten zu Designpreisen als klassischer Zugang festgelegt werden. Werden selbige in diesem Rahmen ausgezeichnet, so strahlen Auszeichnungen auf Gestalter wie Hersteller gleichermaßen ab. Prominent im von WIPPERSBERG zurückgeführten Sinne wird zuerst ein Artefakt, indem das Produkt durch die Auszeichnung aus der Masse herausragt. Die Form der Prominenz, die den Designern und Herstellern verbleibt, ist nur die des Abglanzes, wie GEORG FRANCK ihn beschreibt, denn Designer können sich im Abglanz der Auszeichnung für die von ihnen gestalteten Produkte sonnen und haben durch die Position des Schöpfers keinerlei Schwierigkeiten, »etwas von diesem Abglanz auf die eigenen Mühlen umzuleiten« (vgl. FRANCK 1998: 131f). Gleiches gilt für den Hersteller, der die Serienproduktion verantwortet.

$\mathrm{Ab}$ jetzt setzen wir für eine Weile LUHMANNs Brille auf, um Design als System unter Bezug auf dessen These von der Unwahrscheinlichkeit der Kommunikation zu betrachten: Mit Anpassungen allerdings, da eine Aufteilung in Adressaten und Mitteilende, wie sie im Rahmen seiner Kommunikation in Systemen gilt, für die auf diesen Aspekt bezogen »interaktionsfreien« Konsum-Akte nicht unmittelbar zielführend ist. Ein Verkaufsgespräch mit einem Verkäufer zur Vorbereitung eines Konsum-Aktes weist diesem lediglich die Rolle eines Mittlers zwischen Artefakt und Käufer zu.

Würde LuHManns These für das Feld des Designs als eine Unwahrscheinlichkeit des Konsums reformuliert, die eine Folge von Ablehnungsentscheidungen sein kann, wäre dies ebenso ertragreich wie die Integration seiner Verbreitungsmedien und eine Betrachtung der Anschlusskommunikation, da ein absichtsvoll gesetzter Auslöser in die Verbreitungsmedien gelangen muss, um 
dort eine Anschlusskommunikation herbeizuführen, damit es zu einer Akkumulation von Aufmerksamkeit kommen kann. Die Potenz der Ablehnungs170 entscheidung liegt im Nichtzustandekommen eines Konsumaktes, dessen Unwahrscheinlichkeit in Wirtschaftskreisläufen von verschiedenen Akteuren mit hohem Aufwand zu verhindern gesucht wird. Geld als symbolisch generalisiertes Kommunikationsmedium verbindet über die Entscheidung für oder gegen einen Kauf die potentiellen Käufer und Produzenten und damit auch deren Subsysteme. Inszenierungs- und Übersetzungsleistungen für eine Vermittlung der Berufsprominenz an das allgemeine Publikum werden von den Verbreitungsmedien übernommen:

\begin{abstract}
»Eine ganz spezifische Form der Inszenierung ist beim Übergang von Berufsprominenz oder Interessenprominenz zur allgemeinen Prominenz gegeben, die sonst nicht notwendig ist. Da sich gerade Berufsprominenz auf große fachliche, von Kollegen anerkannte Leistungen stützt, muss beim allgemeinen Publikum ein Glaube an diese Leistung erzeugt werden, da das allgemeine Publikum mangels Fachkenntnis üblicherweise nicht in der Lage ist, die Leistung fachlich zu beurteilen. Oft steht dabei eine Art ,Übersetzung der fachlichen Leistung - und vor allem auch der Fachsprache - im Vordergrund." (WIPPERSBERG 2007: 224)
\end{abstract}

In Feuilletons mit überregionalem Anspruch wird die Berufsprominenz aus dem Subsystem der Fachzeitschriften unter Verwendung des Begriffes Stardesigner (und seiner Varianten) als vordergründig kleinstem gemeinsamem Nenner für das allgemeine Publikum übersetzt. Am Zustandekommen dieser Übersetzungen sind Journalisten beteiligt, die durch ihre Wahl, weshalb sie worüber berichten, einen eigenen Einfluss auf das Geschehen ausüben:

"Aus der journalistischen Praxis zeigt sich eindeutig, dass die Entscheidung darüber, wer in den Medien als Prominenter vermittelt wird, bei den Redaktionen liegt. Die meisten befragten Journalisten merken unisono an, dass es Personen gibt, um die man bei der Berichterstattung nicht herumkommt. [Hervorhebung des Verfassers] Bei den anderen Personen, vor allem bei jenen, die sich im Schatten der Prominenten bewegen, um selbst prominent zu werden, entscheiden eindeutig die Journalisten nach Sympathie und Antipathie. Wenn Personen sunerträglich werden (ein derartiges Aufdrängen bezeichnet Worm als skommunikative Prostitution`), wird über sie auch nicht mehr berichtet.« (ebd. 232)

Hieran wird auch ersichtlich, dass die Form der Abglanzprominenz im Starsystem konventioneller Ausprägung etwas ganz anderes bewirkt als im Feld des Designs. Ein Designer, der als Folge von Auszeichnungen für seine Entwürfe in den Strudel publizistischer Bemühungen gerät, muss im Gegensatz 
zu jener anderen Art der Prominenz-Mitschwimmer oder auch -Schmarotzer nicht darum fürchten, aufgrund von Penetranz am Rand seiner Scheibenwelt abzustürzen, nur, weil er im Kielwasser seines Entwurfes mitschwimmt. Er drängt sich nicht auf, doch muss er als Schöpfer von Artefakten stets mitgemeint bleiben. Es verhält sich hier eher so, dass man irgendwann um die Berichterstattung über die Designer nicht mehr herumkommt, nachdem Artefakte aus deren Hand ausgezeichnet wurden - wie es in gleicher Weise mit Filmschauspielern geschieht, die Preise für Filmrollen erhalten. Jene Artikel, die Stardesigner als solche erwähnen, liefern nach WIPPERSBERGs Modell einer Prominenzierungsspirale Anlässe für die erforderlichen wiederkehrenden Erinnerungsleistungen. Zur Aufrechterhaltung der Prominenz ist auf der Seite derjenigen, die einmal Kenntnis von einem Prominenten erlangt hatten, eine fortdauernde Bestätigung dieses Status erforderlich, sonst hält die "soziale Konstruktion« nicht an (ebd.: 276f):

"Zur Erhaltung der Prominenz müssen weitere Auslöser oder Bestäti-
gungen und weitere Inszenierungsleistungen gesetzt werden, die zu ei-
ner weiteren massenmedialen Vermittlung führen. [...] Die Annahme ei-
nes Prominenten zeigt sich demnach auch in einer Erinnerungsleistung
des Publikums. Die fortdauernde Annahme durch das Publikum bedeutet
somit eine Bindung der Aufmerksamkeit an den Prominenten (durch tat-
sächliche Zuwendung und die Erinnerung). Weitere Annahme ergibt sich
aus fortdauernder Anschlusskommunikation und fortdauernder reflexi-
ver Auseinandersetzung mit dem Prominenten.« (ebd.: 276f)

WIPPERSBERG arbeitet außer einer mit Ähnlichkeiten zu STRUBEs Aufmerksamkeitssparkonto explizierten »Bindung der Aufmerksamkeit« als einzige Autorin jene Besonderheit heraus, »[d]ie [...] sich darin [zeigt], dass die Akkumulation nicht bei den an Beachtung Reichen passiert, sondern bei jenen, die Beachtung schenken. «(ebd.: 138). Diese gewähren die Beachtung, die von den "an Beachtung Reichen « wiederum referenziert werden kann und nur eine medial referenzierbare Akkumulation der Beachtung der Beachtenden kann die Beachtlichkeit der Beachteten vermehren. Die Prominenz des Star-Designers wird für die Medien mit weiteren Auslösern wie erneuten Wettbewerbsgewinnen oder auch Verkaufserfolgen erhalten. In der Folge sorgen diese $z$. T. für eine Auffrischung der Erinnerungsleistung ihres eigenen Publikums. Sie erzeugen dadurch die nötige Anschlusskommunikation wie auch zuweilen reflexive Auseinandersetzungen, womit zur Bestätigung der Prominenz ebenso beigetragen wie die Prominenz für das allgemeine Publikum aufrechterhalten wird. Neben Zeitschriften aus dem Bereich der Fachpublikationen 
wird mit den Erzeugnissen der Gattung Befestigungsliteratur womöglich versucht, noch deutlich mehr Anlässe für fortdauernde Erinnerungsleistungen zu liefern. Diese sollen eine allgemeine Annahme verstärken - was später noch Thema sein wird.

Hauptfaktor jedoch ist und bleibt das Artefakt, das am Ende seines eigenen Prominenzierungsprozesses durch seine Musealisierung eine vergleichbare kategoriale Spitze wie die des - personenbezogenen - Ruhms erreichen kann. Damit gelangt es auch (als ausgezeichnetes wie als musealisiertes und damit auch kanonisiertes Werk) zu einer eigenen Form der Prominenz. Ein leicht nachvollziehbares Beispiel bieten die Hallen des Museum of Modern Art in New York an: Einmal dort angelangt, ist das Ziel einer offiziellen, allgemeinen Kanonisierung erreicht und wie beim Ruhm ist der ursprüngliche Auslöser, die Frage nach dem Warum? der Aufnahme irgendwann nicht mehr relevant. Die Prominenzierungsspirale kann verlassen werden. Im BOURDIEUschen Sinne wird dem Artefakt und seinem (Mit-)Schöpfer durch diese Konsekration Dauer verliehen wie ein »erweiterte[r] und dauerhafte[r] Markt« verschafft (BOURDIEU 1999: 237f). SELLE schreibt dazu:

"So erfährt manches Produkt die Seligsprechung noch in der Phase sei-
ner Nutzung; die weitere Sakralisierung übernimmt dann das Museum.
Praktisch machen Objekte Karriere auf einer Stufenleiter vom banalen
Serienprodukt, mit spezifischer Anmutung und Bedeutungsdichte so-
wohl vom Design als auch durch den Gebraucher ausgestattet, bis sie in
die Hand von Sammlern fallen, um schließlich in der Ruhmeshalle des
Museums anzukommen. Das Museum ist der Olymp anbetungswürdi-
ger Produkte.« (SELLE 2007: 385)

Das Artefakt kann danach z. B. über den Zusatz Aufnahme in die ständige Designsammlung des MoMA endgültig nobilitiert werden. Es legt seine niedrige käufliche Herkunft ab, die mit einer Steigerung der Begehrlichkeit durch referenzierbare Beachtlichkeit zu einer erhöhten käuflichen (oder nur noch konsekrierten) Begehrlichkeit geworden ist und kommt in seiner Umlaufbahn an, wird im übertragenen Sinne zum Fixstern. Äquivalent dazu wären Einzelausstellungen von Designern zu werten, wie man sie sonst überwiegend bei Bildenden Künstlern findet - als (relativ) aktuelles Beispiel KONSTANTIN GRCIC und The Good, The Bad, The Ugly in der PINAKOTHEK DER MODERNE vom 12.11.2015-16.10.2016 [online] https://www.pinakothek.de/ausstellungen/konstantin-grcic-good-bad-ugly [11.06.2018]. 
Im Dschungel der Zusammenhänge von Design, Prominenz und Wettbewerben keimt allmählich die Frage auf, wo denn letztere in Anbetracht der bei LUHMANN beschriebenen fünf symbolisch generalisierten Kommunikationsmedien Macht, Geld, Liebe, Wahrheit und Kunst einzusortieren wären. Sind sie als reine Machtausübung zu begreifen - wegen der Qualitätsbewertung, der Artefakte unterworfen werden und damit nur Ausdruck von Machtverhältnissen? Oder liegen sie in der Sphäre der Kunst, weil für Designartefakte durch die Auszeichnung auf die gleiche Weise Interesse geweckt werden soll? Einen Schritt weiter gehend, könnte man Wettbewerbe ihrer grundsätzlichen Anlage nach auch als sechstes symbolisch generalisiertes Kommunikationsmedium bezeichnen und damit ein neues zu den bereits bestehenden hinzufügen. Ein Grund hierfür wäre, dass Wettbewerbe gleich jenen fünf anderen in Form von Gewohnheiten soziale Strukturen in Form von Herrschaftsverhältnissen stabilisieren, womit sie ebenfalls verallgemeinerte Bedeutungselemente darstellen. Da Wettbewerbe als eigenständiges System mitnichten gleichartig sind, wird zur Klärung ZAPP für eine Differenzierung von (Design-) Wettbewerben, Preisen und Gütesiegeln herangezogen:

»Die Unterscheidung von Wettbewerben, Preisen und Gütesiegeln ist nicht ganz eindeutig. Bei ersteren kann sich eine Zielgruppe bewerben, um auf einen Preis zu hoffen, andererseits werden viele Preisträger vorgeschlagen. Auszeichnungen und Gütesiegel sollen in die Welt der angebotenen Gegenstände und grafischen Darstellungen Transparenz bringen und Qualitätsmaßstäbe setzen. Der Designbericht für 1997 nennt 44 Auszeichnungen, eine längst nicht erschöpfende Liste. Hinzu kommen noch die vielen internationalen Preise, die es zu gewinnen gibt. Bei der Menge der Qualitätsbekundungen kann man sich des Eindrucks einer Auszeichnungsinflation und mangelnder Tranparenz [sic] nicht erwehren. Die Urteilsfindung erfolgt dabei meistens durch eine Jury. Ohne auf die gruppendynamischen Prozesse einzugehen, ist auch hier anzunehmen, daß die beteiligten Personen gemäß ihrer Vorlieben und ihrer Wertvorstellungen urteilen. Somit besteht in der Vielfalt weder eine Verbindlichkeit noch Vergleichbarkeit, die Kriterien der Entscheidungsfindung sind in vielen Fällen nicht zugänglich. Statt zur Orientierung könnte die Masse der Auszeichnungen zur Verwirrung der Konsumenten beitragen. [...] Allerdings ist die Vielfältigkeit der Preise nicht nur eine Reflektion der Pluralität der vergebenden Institutionen, sondern auch ein Versuch, mit der Komplexität der Warenwelt und der daraus resultierenden Aufgabe der Qualitätsbewertung umzugehen. Eine Bewertung dieses Sachverhalts ist schwierig und sicherlich nicht ohne eine differenzierte Betrachtung der Interessen und Wirkungen für Auszeichnende, Ausgezeichnete und das rezipierende, konsumierende Publikum möglich. In jedem Falle schafft aber das Spektrum der Wettbewerbe und Preise ein Forum für den Diskurs über Designqualität.« (ZAPP 2000: 142) 
Jener »Diskurs über Designqualität«, der mit Hilfe von Wettbewerben angestoßen werden soll, liefert sowohl den Auslöser als auch die Bestätigung der 174 Prominenz in einem. Er stößt damit das selbstreferentielle Ping Pong einerseits an, wie es dadurch andererseits am Laufen gehalten wird: Als eine Art perpetuum mobile inklusive reflexiver Auseinandersetzung, das zwischen Orientierung und Desorientierung oszilliert und aus dem ab einem gewissen Punkt sogar die Prominenz und der Prominente abgeseilt werden:

"Irgendwann löst sich die öffentliche Beachtung vom Ursprungsgrund
und die Aura des Besonderen umgibt einen schon deshalb, weil man von
anderen und vor allem von den Medien beachtet wird: Man ist prominent,
weil man prominent ist. [Hervorhebung des Verfassers] Viele Autoren be-
tonen, dass man, sobald man prominent ist, eben genau deshalb promi-
nent ist. Auch Francks Ökonomie der Aufmerksamkeit beruht auf der
Selbstreferentialität der Aufmerksamkeit. Wer hinreichend bekannt ist,
erlangt allein aufgrund seines Grades an Bekanntheit weitere Bekannt-
heit." (WIPPERSBERG 2007: 60)

KELLER bringt dies im Vergleich dazu sehr knapp zu Papier: »Ist ein Starentwurf einmal medial und parasozial zum Glänzen gebracht, ist weiterer Starerfolg wahrscheinlich." (KELLER 2008: 147) Wenn als Initialzündung für den Status eines Stardesigners also Auszeichnungen bei Wettbewerben zu gelten haben, so muss dieser mit Berichten in der Fachpresse als potentieller Bereichsprominenter vorgestellt und in der Folge angenommen werden - die oben zu findende Argumentation wird hier bis zu einem gewissen Grad noch einmal repliziert.

Sollte die Zuschreibung der Prominenz im entsprechenden Teilpublikum erfolgreich gewesen sein und sich eine Zielgruppenprominenz manifestiert haben, kann sie über die Eisbergspitze Star-Designer einem allgemeinen Publikum als Sinnangebot offeriert werden, um sich in der Folge publizistisch sowohl weiter zu verbreiten als auch nochmals zu verstärken. Die unterschiedlichen Verbreitungsmedien stellen über ihre Vertreter das (Fach-)Publikum bereit und nachgeordnet den allgemeinen Publikumszugang dar.

Eine Erinnerung an LATOUR und seine ANT ist auch an diesem Punkt wieder einmal hilfreich, da Verbreitungsmedien nicht als Intermediäre gelten können. Nach den Mediatoren, die für die Auszeichnungen veranwortlich sind, zeichnen auch Mediatoren für das Zustandekommen dieser Publikationen verantwortlich. Dort wird nicht meinungsfrei zwischen Produzenten und Konsumenten vermittelt, nein: die Medien sind untrennbar an der Konstruktion der Beachtlichkeit beteiligt, sie reichen sie nicht nur durch, ohne auf die 
Art der Vermittlung und durch die Art ihrer Vermittlung Einfluss zu nehmen (s. o.). Zudem werden sie im Rahmen von PR-Strategien auch von der Produzentenseite adressiert, denn schon lange leistet es sich niemand mehr, die zur Verfügung stehenden Kanäle nicht zu nutzen. Ohne eine erste Annahme durch die Verbreitungsmedien (hier besonders in Form redaktioneller Beiträge) kann keine Annahme durch ein Teilpublikum oder ein allgemeines Publikum entstehen - in einer doppelten Verschachtelung, da die Annahme eines andernorts gewährten Status' als Sinnangebot ohne dessen Bestätigung und Wieder-Gewährung nicht möglich ist (vgl. ebd.: 78).

Die naheliegende Frage, wie es vor diesem Hintergrund um die Sinnhaftigkeit von Bemühungen, prominent zu werden, bestellt ist und ob das prominent Werden auf eine standardisierbare Art bewerkstelligt werden könnte - von WIPPERSBERG wird sie unter Bezug auf BOLZ abschlägig beantwortet. Ihre Aufzählung unterschiedlicher prognostischer Unwägbarkeiten macht indirekt WALDENFELS und dessen Ausführungen zur »Ausbildung eines >Beachtungsreliefs« zu ihrem Kronzeugen (vgl. WALDENFELS 2004: 101f). Was letztlich blieb und bleibt, ist die Kontingenz:

»Instantrezepte für die Erlangung von Aufmerksamkeit gibt es nicht. >Die Komplexität unserer Gesellschaft schließt ... Rezepte des Erfolgs, Spielregeln für Sieger aus. Zudem sind Prognosen darüber, was bei wem mit welcher Sicherheit oder Wahrscheinlichkeit in welcher Intensität und Dauer Aufmerksamkeit erregen wird, sehr schwierig, da die Aufmerksamkeit vom jeweiligen Wahrnehmungskontext, der Biografie, den Wert- und Präferenzsystemen der Rezipienten sowie ihren Stimmungen und Erwartungen abhängig ist.« (WIPPERSBERG 2007: 134)

BOLZ’ Diktum zur »Komplexität unserer Gesellschaft « wird im Kontext folgendermaßen fortgeführt: »So wächst das Bedürfnis nach Rezepten mit der Unmöglichkeit ihrer Bewährung« (BOLZ 2011) [online] http://werteindex.de/werte/ [13.04.2018]. Versucht wird es von PR-Strategen natürlich dennoch, die mit wechselnder Überzeugungskraft versprechen, über Rezepte dafür zu verfügen:

mBerühmt wird man heute nicht selten durch Zufall, betont Seemann [Hervorhebung im Original]. Trotz einer hochprofessionalisierten PR scheint die Entstehung von Prominenz oft eher einer ,Versuch-und-Irrtum-Anordnung، zu gleichen. Dieser `Zufall widerspräche nun eindeutig jenen Autoren (wie z. B. Franck [Hervorhebung im Original]), die annehmen, dass Prominenz auf standardisiertem Wege entsteht. Der Widerspruch besteht aber nur scheinbar: Der `Zufall, der zur Prominenz führen kann, kann sich nur auf die Ungewissheit beziehen, ob eine Person beim Publikum auch ankommt und daher angenommen wird. [...] Wolf 


\title{
STARDESIGNER ODER GESTALTER DES ALLTÄGLICHEN?
}

Schneider [Hervorhebung im Original] vergleicht die Chance, prominent zu werden, mit einem Preisausschreiben: Wer gewinnen will, muss zuerst einmal die richtige Lösung finden; dann entscheidet unter vielen Richtigen das Los. Wie man die Lösung findet, dafür gibt es ein paar Rezepte; wie die Verlosung funktioniert, lässt sich allenfalls beschreiben. Diese Verlosung übernimmt bei der Prominenzierung das Publikum.« (WIPPERSBERG 2007: 250)

»[D]ie richtige Lösung « im System des Designs wäre demnach u. a. der Gewinn von Wettbewerben, das Rezept dazu die Einreichung - und dann? Dann müssen die Fach- und die allgemeine Presse es richten, um den Grundwasserspiegel der Prominenzierungs- wie Erinnerungsanlässe für Artefakte wie für Designer nicht zu sehr absinken zu lassen und dadurch den Markterfolg von Artefakten anzukurbeln - wie auch der Markterfolg von Artefakten dafür sorgen kann, dass über Designer berichtet wird:

\begin{abstract}
"Welche von jenen Personen, die Auslöser setzen und die nötige Inszenierungsleistung erbringen, werden aber tatsächlich vermittelt? [...] Auf theoretischer Ebene lassen sich die Nachrichtenwerte nennen. Sie sind besonders für die natürlichen Auslöser entscheidend. In Erfüllung ihrer Informationsfunktion kommen Medienunternehmen an bestimmten Personen nicht vorbei. Da Prominente ja auch aus dem Bereich der Politik, Wirtschaft, allgemein aus Elitepositionen, stammen, sind gerade sie zu vermittelnde Inhalte. Bei Künstlern sind die Chancen auf die massenmediale Vermittlung v. a. durch das Fernsehen auch von der Visualisierbarkeit der künstlerischen Tätigkeit abhängig.» (ebd. 231)
\end{abstract}

Die Visualisierbarkeit ist im Feld des Designs so hoch wie sonst nur im Feld der Kunst, die Erklärungsbedürftigkeit der Gebrauchswaren dagegen sehr gering. Die von Designern miterzeugten Artefakte lassen im Vergleich zu den hochgradig idiosynkratischen Werken Bildender Künstler so gut wie keinen Interpretationsspielraum hinsichtlich ihrer Funktion und setzen auch keinen in diesem Sinne erklärenden Zugang voraus. Die Inszenierung von Artefakten in den entsprechenden Fachpublikationen schließt Missverständnisse von vornherein aus und die dort angestrebte stilistische Vorbildhaftigkeit will rezipiert wie repliziert werden. Haben Designer es im Verlauf ihrer jeweils eigenen Prominenzierungsspiralen einmal so weit gebracht, dass ihre Artefakte musealisiert oder sie als Personen in Einzelausstellungen präsentiert werden (also die gleiche kategoriale Spitze wie im Feld der Kunst erreicht wird) ist jene schon benannte Prominenzstufe erreicht, ab der die oder der Prominente prominent ist, weil sie oder er prominent ist. Oder, wie weiter oben im gleichen Sinne zu lesen ist, man um die Berichterstattung nicht mehr herum 
kommt. Nach der Spirale der Prominenzierung erfolgt die »Verwertung der Prominenten, v. a. durch die Kommunikationsbranche, durch jene Institutionen also, die sie erst prominent gemacht haben.« Neben der Tauglichkeit als »Nachrichtenfaktor« werden »Prominente [...] kommerziell umso nutzbarer, je mehr gesellschaftliche Systeme sie kreuzen." (ebd.: 280)

Wo sich der Nachrichtenfaktor bei WIPPERSBERG noch auf den Star im ursprünglichen Verständnis bezieht und hier im Besonderen wieder auf dessen »alltäglich-außeralltägliche[...] Eigenschaften« (vgl. RECKWITZ in MOEBIUS und SCHROER 2010: 255), muss im Falle der Designer aus oben bereits hinreichend ausgeführten Gründen wieder davon Abstand genommen werden. Designer werden nur aufgrund der von ihnen gestalteten Artefakte zu einem Nachrichtenfaktor, also dem greifbaren Ergebnis ihrer Berufstätigkeit und das in einem eng eingegrenzten Bereich. Es ist zwar durchaus zutreffend, zu behaupten, dass auch Stars nach üblichem Verständnis nur deswegen in den Medien auftauchen, weil ihre Berufsausübung bemerkt und deswegen besprochen wird. Doch Berichte über eine neue Filmrolle, einen Konzertauftritt oder eine Rede im Deutschen Bundestag bleiben untrennbar mit der Person und dem, was diese im Rahmen ihrer psychischen, physischen und intellektuellen Fähigkeiten tat, verbunden. Im Gegensatz zu jenen ephemeren und grundsätzlich immateriellen Arbeitsergebnissen in Form von Erlebnissen und Reaktionen Dritter treten Artefakte - was noch einmal den bedeutsamsten Unterschied zu Persönlichkeits-Stars aufzeigt - als nutzbare Repräsentanten ihrer Gestalter auf und bleiben das auch. Artikel hingegen liefern nur Erinnerungsanlässe oder schüren das Interesse zur Arbeit am eigenen Aufmerksamkeitsrelief.

Das soziale Interesse an der Persönlichkeit von Filmschauspielern und dem Leben dahinter erwächst beinahe automatisch aus ihrer Darstellung von Personen im Rahmen von Filmrollen und der Schilderung von Bezügen, die jene zu diesen Rollen aufbauen. Während man Schauspieler befragt, warum und wie sie ihre Rollen angelegt haben, will man stattdessen von Designern wissen, warum und wie sie etwas so und nicht anders entworfen hätten. Ohne hier tiefer in die Kiste der bereits geleisteten Starforschung zu greifen, ist es ausreichend, festzustellen, dass der konventionelle Star für eine erfolgversprechende publizistische Ausschlachtung deutlich mehr gesellschaftliche Systeme kreuzt, als Designer es tun. 
»Star-Nutzungen werden als Formen personifizierten Differenzmanagements [...] bestimmt [...], die für Ego wie alles Handeln unter der Prämisse des Strebens nach einem positiven Selbstbild stehen« 


\section{Der Star und seine Nutzer}

Mit der »Verwertung der Prominenten« und einer latent geteilten Idee des Nutzens (als einer möglichen Antwort auf die Frage nach dem Warum?), die bei WIPPERSBERG auch als Belohnung bezeichnet wird (vgl. WIPPERSBERG 2007: 263), öffnet sich das Feld für KELLER, die den Nutzen-Aspekt von Stars aus der Perspektive des Fans untersucht. Nutzbarkeit setzt Nutzende und Benutzte voraus, was dazu führt, dass Stars erstmals ernsthaft als von anderen benutzte in den Fokus geraten: "Nicht vermeintlich quantifizierbare Schönheit, Intelligenz oder Talent sind entscheidend für Startum, sondern die Attraktivität des Stars als dessen funktionale Nutzbarkeit für sein Publikum." (KeLLER 2008: 120) Der letzte Halbsatz führt eine entscheidende Wende im Diskurs herbei, weil die Betrachtungsrichtung von KELLER von der Ebene der glorifizierten Einzelperson auf das Publikum und der Fokus auf die es konstituierenden Individuen verlagert wird. Damit kann auch einer der Schwerpunkte bisheriger Starforschung, die parasoziale Interaktion, anders gedeutet werden:

"Der Star wird zum Star durch seine identitätskonstruktiven Funktionalisierungen in Unterscheidungen der Differenz Ego/Star und deren starke, vor allem affektive Besetzungen und Gewichtungen. In ihren medialen Darstellungen und Selbst-Darstellungen verkörpern Stars personalisierte kulturelle Anwendungsmodelle, zu denen sich der Star-Nutzer als Ego positionieren kann. In der parasozialen Bezugnahme auf Stars und deren (Anwendungs-) Stile konturiert sich Ego relationierend und entwirft damit für sich und andere sein Selbst inklusive der ihn beschreibenden, nicht nur ästhetischen Prinzipien und Aversionen. [...] Ego-Star-Relationierungen dynamisieren einerseits Selbst- und Fremd-Bezugnahmen auf Basis medialer Star-Darstellungen in popkulturell verkürzten Verwertungszyklen. Andererseits erlauben Bezugnahmen auf Stars gerade in der 


\section{STARDESIGNER ODER GESTALTER DES ALLTÄGLICHEN?}

sicheren Unbeständigkeit Populärer Kultur kognitive wie kommunikative Selbst- wie Fremd-Fixierung, indem die popkulturelle Maschinerie quasi in ihrer spezifischen Ego-Star-Relationierung wertend verlangsamt wird." [Hervorhebung des Verfassers] (KELLER 2008: 191)

Die wertende Verlangsamung lässt aufmerken und eine Schneise zum Designklassiker und dem Modus des Dauerns schlagen: Mit der Erhebung in den Stand desselben (wahlweise auch eines Modernen Klassikers oder einer Designikone) finden Fixierungen in gleichartig wertender Verlangsamung statt, nur nicht auf einer individuellen Ebene. Dass dies auch nur scheinbar so sein könnte, wird sich später im Kapitel Rezeption zeigen. Stars wie Artefakte werden zu Felsen in der Brandung popkultureller Sturmfluten und markieren persönliche Ausstiegspunkte aus einer unaufhaltbaren Karussellfahrt der Trends. Jeder Fan und jeder Konsument entscheidet im Rahmen einer Unzahl an Möglichkeiten, wo die Ausschlags-Spitzen des persönlichen Aufmerksamkeits-EEGs zu liegen kommen und wie das eigene Aufmerksamkeitsrelief ausgeformt wird, mit dem sowohl interne wie projizierte Selbstbilder konstruiert und konturiert werden: „Dem Fan erscheint der eigene Geschmack unanfechtbar logisch, weil die Egospezifik seiner Unterscheidungen als seiner [Hervorhebung im Original] Unterscheidungen für ihn unhintergehbar bleibt.« (ebd.: 185)

"Stars wurden in ihrer Rolle als Differenzbilder betrachtet, anhand derer Star-Nutzer ihr Selbst ebenso wie ihr Selbst-Ideal Bezug nehmend ausrichten. Damit wird Stars eine nutzerspezifische Selbst- wie Fremd-Orientierungsfunktion zugesprochen; Star-Nutzungen werden als Formen personifizierten Differenzmanagements und kognitive wie kommunikative Unterscheidungen der Differenz Ego/Star [Hervorhebung im Original] bestimmt, die für Ego wie alles Handeln unter der Prämisse des Strebens nach einem positiven Selbstbild stehen.« (ebd.: 256)

KELLER bindet das erfolgreiche Zustandekommen des Star-Status untrennbar an ein erfolgreiches Zusammenspiel der drei daran beteiligten Parteien:

"Star-Status wird in Medien-Star-Entwürfen angezeigt, vom Star selbst in kompatiblen, medial beobachtbaren Selbst-Darstellungen beglaubigt und von Star-Nutzern in reflexivierten Unterscheidungs-Prozessen bestätigt. Stars sind [Hervorhebung im Original] nur dann Stars, wenn von ihnen behauptet wird, dass sie Stars sind - und zwar von Medien, Nutzern und den Stars selbst. Voraussetzung für die soziale Beglaubigung medialer Star-Entwürfe ist, dass eine möglichst große Anzahl von Nutzern durch sie kognitiv, affektiv und moralisch in Schwingung versetzt 
und somit zu Aufmerksamkeitsfokussierungen auf den Star veranlasst werden. [sic] (KELLER 2008: 255)

In KELLERs Explikation liegt eine entscheidende Differenz zu WIPPERSBERGS Ätiologie der Prominenzierung (und deren Bezug auf PETERS). WIPPERSBERG macht als Quelle der Prominenz eine symbiotische Beziehung zwischen »[...] einzelnen Gesellschaftsbereiche[n], aus denen die Prominenten stammen, [den] Massenmedien und [dem] Publikum [...] « aus und lässt den Star, der bei ihr nurmehr eine Sonderform des Prominenten darstellt, als einen seinen Status selbst bekräftigenden Akteur aus. Sie definiert den Star-Status als Ergebnis einer Prominenzierung ebenfalls konsequent als ausschließlich von außen zugeschriebenen und skizziert als Ergänzung eine weitere Beziehung zwischen "Narzissten, [die] sich in den Medien zur Schau stellen und Bewunderung suchen« und »Komplementärnarzissten im Publikum« (WIPPERSBERG 2007: 181). Diese Ergänzung könnte man als nicht ganz treffgenaue Analogie zu KELLERs selbstbehauptetem Star-Status betrachten.

Man kommt jedoch nicht umhin, in der Trennung WIPPERSBERGs eine Wertung des als narzisstisch bezeichneten Verhaltens zu sehen, die bei ihr neben dem neutral beschriebenen System der Prominenzierung zu liegen kommt, während KELLER gänzlich emotionslos das funktionale Verhältnis von Medien, Nutzern und Stars beschreibt. Zu guter Letzt langt aber auch wIPPERSBERG bei einer in sinnfälliger Alliteration gebündelten Trias aus »Prominenten, Presse und Publikum« an, die erstens deckungsgleich mit ihrem ursprünglichen Ansatz bleibt und zweitens eine sehr hohe Übereinstimmung mit KELLER aufweist - abgesehen von ihrem Fokus auf die Hervorbringung der Prominenz als solche. Womit sich auch der Kreis zu LudEs und dem Beginn dieses Kapitels schließt:

"Die Annahme durch das Publikum ist dem zugrunde liegenden Prominenzbegriff immanent und zeigt sich in der den Prominenzbegriff konstituierenden Symbiose von Prominenten, Presse und Publikum. Mit der ersten massenmedialen Vermittlung tritt der potenziell Prominente in die Sphäre des Publikums ein - dort muss er sich dann behaupten. Erst wenn das Publikum ihn als Prominenten anerkennt, ist er prominent. Die produktive Aneignung von Stars durch Fans ist nicht immer eine rein passive Annahme von Starimages als Medienprodukt (Inkorporation), sondern erst die Fans machen die Stars in ihrer Rezeption (Exkorporation).« (ebd.: 248) 
»Kenntnis von den Objekten der Begierde erlangen die Fans in den meisten Fällen über das Fernsehen, Zeitschriften, etc." 


\section{Neuausrichtung der Prominenz- forschung}

Identitätskonstruktive Funktionalisierungen müssen für die Nutzer von StarDesignern ebenfalls als gegeben angenommen werden und somit ist der Blickwinkel zu verändern: Da Star-Designer in dieser Arbeit als Prominente der zweiten Reihe aufgefasst werden, sollte ihre Nutzung auf andere Weise vonstatten gehen, als dies bei konventionellen Stars der Fall wäre, die als Person im Vordergrund stehen. Blicke auf den Kreativen und den Star als Sozialfiguren der Gegenwart (vgl. RECKWITZ, SCHROER in: MOEBIUS und SCHROER 2010: 248ff, 381ff) ließen RECKWITZ in der Folge in Die Erfindung der Kreativität u. a. zu diesen Befunden kommen:

"Drei unterschiedliche Zuschreibungsmuster von Kreativität lassen sich in Bezug auf den Star unterscheiden: der Star als Produzent eines Werks (der Werk-Star); der Star, dessen Gestaltungsleistung sich im Wesentlichen auf sich selbst bezieht (der Persönlichkeits-Star); der Star, dessen Werk in seiner körperlichen Performance besteht (der Performance-Star). Für alle drei Startypen gilt, dass sich die Aufmerksamkeit auf sie richtet, da sie aus der Sicht des Publikums etwas Neues, Ungewöhnliches oder Originelles produzieren. Diese kreative Leistung wird als ästhetisches Ereignis, als sinnlich-affektiver Selbstzweck wahrgenommen. Beim Werk-Star ist das kreative Produkt eben dieses - künstlerische oder anderweitig ästhetisch wirksame - objektivierte Werk und der Star sein faszinierender Repräsentant [Hervorhebung des Verfassers]." (RECKWITZ 2012: 240) 


\section{STARDESIGNER ODER GESTALTER DES ALLTÄGLICHEN?}

Im Falle von Künstlern, Mode- und Produkt-Designern haben wir es mit WerkStars zu tun, auf die in unterschiedlicher Weise reagiert wird und dies ist ihr einziges und zugleich wesentlichstes sinnstiftendes Verbindungselement. Den Fan aus dem Bereich der Popkultur finden wir am plausibelsten noch im Modedesign wieder - dieses System beinhaltet ihn seit langer Zeit wie selbstverständlich und wie selbstverständlich spiel(t)en die Verbreitungsmedien als Zugangspunkte hierbei eine gewichtige Rolle:

»Fanpraktiken sind in der Regel medial vermittelt. Kenntnis von den Objekten der Begierde erlangen die Fans in den meisten Fällen über das Fernsehen, Zeitschriften, etc. Zwar gibt es Fankulturen, die sich über lokale face-to-face-Interaktionen [Hervorhebung im Original] konstituieren, doch die weitere Kommunikation mit anderen Fans geschieht dann mithilfe von Medien." (MIKOS in: MOEBIUS und SCHROER 2010: 109)

Eine Ausrichtung auf Star-Designer - spezieller: als Geschmacksgemeinschaft (vgl. ebd.: 110f) - ist im Modedesign bei weitem die offensichtlichste, denn das komplette System lebt(e) von seiner Zuspitzung auf die kreative Einzelperson, wenngleich auch hier Artefakte (Kleidungsstücke) die hauptsächlich genutzten Kristallisierungspunkte sind:

"Gemeinsame ästhetische Erlebnisse bilden die Basis für den Zusammenhalt der Fangemeinden. Diese Erlebnisse finden gewissermaßen in einem Erfahrungsraum statt, der von skonjunktivem Erkennen< (Mannheim 1980, S. 211f.) geprägt ist. Das konjunktive Erkennen drückt sich in einem gemeinsamen Weltbezug aus, auf den hin alle vergangenen und zukünftigen Erfahrungen innerhalb der Fangemeinde ausgerichtet sind. Dieser Erfahrungsraum bildet die Grundlage kollektiver Orientierungen für mindestens zwei handelnde Subjekte, aber auch für Klein- und Großgruppen sowie für Gemeinschaften und möglicherweise Gesellschaften, denn die 'Kulturgemeinschaft ist aber die umfassendste Erweiterung einer konkreten, konjunktiven Erfahrungsgemeinschaft (Mannheim 1980, S. 226). In diesem Erfahrungsraum spielen unmittelbar ästhetische, sinnlich-symbolische Erfahrungen eine zentrale Rolle. Sie liegen auf der Ebene sogenannter struktur-identischer Erfahrungen. Die als Fans handelnden Subjekte nehmen sich dabei als habituell oder stilistisch verwandt wahr, ohne dass dies kommunikativ manifestiert werden müsste. Ihr Handeln kann als eine Form kultureller Praxis gesehen werden, in der über das gemeinsame sinnliche Erlebnis implizit kommuniziert wird [Hervorhebung des Verfassers].« (ebd.: 112f)

Die Orientierung an der Werkleistung einer kreativen Einzelperson führte und führt nicht selten dazu, dass Marken im Bereich der Mode bei der Staffelübergabe an andere Designer strauchel(te)n. Ein Grund dafür kann sein, dass diese nicht die gleiche gestalterische Handschrift wie die den Firmen- oder Mar- 
kennamen gebende Person oder der vorangegangene Stelleninhaber zeig(t)en. Genauso gut denkbar sind Brüche im Vergleich zu in der Geschmacksgemeinschaft gefühlten Markenimages oder dem Stil einer Marke. Rezeptions- wie Absatzprobleme, die sich aus dieser Personenabhängigkeit ergeben, konnten und können eine Marke schnell in Gefahr bringen. In Zeiten minutenschnell hochkochender Diskussionen in sozialen Netzwerken um ein gerüttelt Maß schneller als ehedem, wie auch die Popularitäts-Kurswerte von Modemarken analog zu Aktienkursen steigen oder fallen können, je nachdem, wie von welcher maßgeblichen Stelle aus Kollektionen kommentiert oder bestimmte ItPieces für eine Saison ausgerufen werden.

Ganz unheimlich im Hintergrund liegt all dem reale Machtausübung zugrunde - auf einer nicht wirklich offiziell legitimierten, sondern praktisch unausgehandelten Ebene. In diesem Zusammenhang ist es relevant, sich noch einmal an die Disziplinargesellschaft zurück zu erinnern. Im Kunstmarkt führen Rezeptionsprobleme solcher Art ebenfalls zum Absturz von Personenmarken, wenn die Popularität der Person nachlässt, ihr Personalstil allgemein nicht mehr so gefragt ist, oder die künstlerische Handschrift sich in eine Richtung verändert, die nicht mehr so gut rezipiert wird wie bisher. Die Überlegungen zu KLAMER et al. im Abschluss des Kapitels zur Aufmerksamkeit haben bereits gezeigt, dass die Reputation von Designern für von ihnen entworfene Produkte im Gegensatz zu den Künstlern nicht mit dem ökonomischen Wert derselben zusammenfällt. Ferner lässt sich feststellen, dass steigende Reputation keine Anlässe für Preissteigerungen bietet, weil Designer in Produktionszusammenhänge eingebunden sind, die sie einer unmittelbaren Autorenschaft und damit auch einer unmittelbaren Attribuierung der Werkleistung entziehen - wenngleich dies u. a. mit der Beigabe designed by ... unterlaufen wird.

Die im Kunstmarkt vorherrschende Verknappung in Form von Auflagenhöhen sowie die Aspekte unverwechselbarer Personalstile, des Unikatären oder des Singulären tragen im Designmarkt nur ein Scherflein im Vergleich zur Massenproduktion von Artefakten bei - trotz der Tatsache, dass seit dem Neuen Deutschen Design auch wieder Klein- und Kleinstserien von Artefakten entstehen. Für das Modedesign kann aber eine Ähnlichkeit ausgemacht werden: dort treibt steigende Markenbeliebtheit im Verlauf der Zeit die Produktpreise mit nach oben - wiewohl die Margen der Händler ebenfalls einen erheblichen Anteil an ihrem Zustandekommen haben und natürlich auch Materialauswahl, Marktsegment, Herstellungsbedingungen, Herkunft und die Anzahl der produzierten Stücke. 


\section{STARDESIGNER ODER GESTALTER DES ALLTÄGLICHEN?}

Auch im Feld des Designs handelt es sich um indirekte Funktionalisierungen wie im Feld der Kunst. Die reale Nutzung erfährt beim Werk-Star jeweils das Artefakt, was Kunst, Mode- und (Produkt-) Design konstitutiv gesehen über grundlegend gleichartige Nutzungsprozesse auf der Konsumentenseite verbindet. Doch anders als bei der Form des Abglanzes, welche für Designer konstatiert werden muss, vermehrt der Abglanz von Kunstwerken im Zusammenhang mit Ausstellungen und Auktionsergebnissen, der dort zugleich als echte, unmittelbare Erweiterung des Starpotentials der Künstler aufgefasst werden muss, auch deren persönlichen Ruhm ganz unmittelbar. Dies ist an jenen teils ungeheuerlichen Ausmaßen zu beobachten, die die Entwicklung von Künstlern zu Personenmarken im Laufe des 20. Jhd.s nahm. Sie sind ein Teil der jeweiligen illusio des betreffenden Feldes.

Einer der wesentlichen Gründe des Anwachsens persönlicher Prominenz ist die unmittelbare Zuschreibbarkeit als Autor eines Werkes und damit ein maximal auf eine Einzelperson verkleinerter Zuschreibungsradius. Der Modedesigner steckt mit einem annähernd gleichen Zuschreibungsradius zwischen dem Künstler und dem Designer fest, obwohl er gleich den anderen Designern im Rahmen der Massenfertigung tätig ist. Vergleicht man diesen Aspekt noch kurz mit den Buchautoren, bleibt auch deren Zuschreibungsradius von gleicher Größe. Doch im Gegensatz zum Kunstmarkt, wo höhere Auflagen fast immer mit der Entwertung des einzelnen Auflagenstückes einhergehen, steigert die mit hoher Auflagenzahl einhergehende Popularität hier ggf. auch die Reputation - sofern Personen und/ oder Institutionen sich wohlwollend über Veröffentlichungen äußern, die im Literaturmarkt den qualifizierenden $\mathrm{Zu}$ gang zum Markt durch Zuschreibungen von Bedeutung herstellen: »[...] die Kritiker wiederum können für ein Buch oder ein Stück nichts Besseres tun, als ihm `Erfolg voraussagen` [...] 《 (BOURDIEU 1999: 238). Eine Grenze zu entwertender Popularität existiert dort selbstverständlich ebenfalls. 


\section{Identitätskonstruktive Funktionalisierungen aus der Fanperspektive}

Betrachtet man diese für die einzelnen Disziplinen unter den Gesichtspunkten direkter (individueller) und indirekter (sozialer) Funktionalisierungen, so kommt man zu diesen Ergebnissen:

Fans von Modedesignern erwerben von diesen entworfene Kleidungsstücke, Modenschauen sind ihre Versammlungsorte. Verhandlungen über den Wert der Artefakte finden quantitativ an der Ladenkasse, qualitativ in den klassischen Verbreitungsmedien, im täglichen Straßenbild, seit geraumer Zeit auch im Internet in Form privater und gesponserter Modeblogs und natürlich auch in den Internetauftritten der bereits bekannten Modezeitschriften statt. Der individuelle Nutzen für den Fan des Modedesigners besteht im Tragen der Kleidung, in Schutz wie Schmuck der Epidermis und in der Selbst-Bezugnahme durch das Wissen, eine bestimmte Marke gewählt zu haben. Der soziale Nutzen ergibt sich durch die Fremd-Bezugnahmen gegenüber anderen Mitgliedern der jeweiligen Geschmacksgemeinschaft unter allen Aspekten, die mit Distinktion, Habitus und Status oder auch Sozialprestige kurz zusammengefasst werden können.

Fans von Künstlern sind ihre Sammler, die Kristallisationspunkte neben den Kunstwerken sind Auktionen und Messen, in deren Verlauf tätig Werte ausgehandelt werden. (; speziell bei Auktionen mit einer darüber hinaus unbekannten Direktheit der Einflussnahme des Käufers auf den aktuellen (und zukünftige) Kaufpreis(e), was wiederum die direktesten Auswirkungen aufnachfolgende Verkäufe hat - in der Beschränkung der pekuniären Zugänglichkeit wie in der Steigerung der Begehrlichkeit.) Der individuelle Nutzen für den Fan des Künstlers besteht in der dekorativen Aufwertung der Wohnumgebung und der Erweiterung der persönlichen Sammlung. Der soziale Nutzen besteht im besondernden Sozialprestige, ein Kunstwerk oder Kunstwerke von » ... « im persönlichen Eigentum zu haben. In Form der Selbst-Bezugnahme durch das Wissen, sich für eine bestimmte Künstler-Personenmarke (die unterschiedlich kanonisiert sein kann) entschieden zu haben. Mit Blick auf die Fremd-Bezugnahmen in einer besondernden Stellung innerhalb dieser spezialisierten Geschmacksgemeinschaft durch die gezielte Streuung der Besitzinformation oder z. B. durch Leihgaben für Ausstellungen oder Museen resp. durch die Gründung eigener Museen.

Fans von Produktdesignern: Warum Fans in einem konventionellen Sinne hier schwerlich auszumachen sind, ist vorstehend schon hinreichend begrün- 
det worden (; doch wäre im Vorgriff auf das Kapitel Rezeption eine noch vor den Konsumenten wirksame Geschmacksgemeinschaft denkbar, die sich - seltsam genug -, schon auf vorgeschobenem Posten in den Verbreitungsmedien manifestieren und das Fan-Phänomen in Form von Reputations-Vorbildern in Artikeln und Buchpublikationen verortbar machen würde. Wenngleich die Verbreitungsmedien für das Design nicht zwangsläufig den alleinigen qualifizierenden Zugang zum Markt darstellen müssen, konstituieren und halten sie dennoch Reputation fest und bewahren sie dergestalt für die Konsumenten auf. Selbstverständlich mit dem Ziel, dass diese rezipiert wird). Der Wert jener Artefakte wird überwiegend in den Verbreitungsmedien verhandelt, er führt zu einer eigenen Prominenz derselben sowie zu ebenfalls bereits hinreichend erwähnten eigenen Bezeichnungen und der Aufnahme in die Designsammlungen unterschiedlicher Museen. Individueller Nutzen für den Fan des Produkt-Designers besteht in der direkten Nutzung der entworfenen Artefakte, die im Vergleich zu den beiden vorstehenden Disziplinen unterschiedlichste Optionen zur Selbst-Bezugnahme anbieten. Der soziale Nutzen entsteht nur in direktem sozialem Kontakt, wenn Fremden, Freunden und Verwandten Zugang zum persönlichen Lebensumfeld (als Versammlungsort) gewährt wird. Oder durch das individuelle Gefühl, Teil einer imaginären Gemeinschaft zu sein, die sich durch die Darstellung von Artefakten und Lebensumfeldern in Verbreitungsmedien resp. durch Einblicke in das Lebensumfeld der eigenen sozialen Kontakte in der jeweils eigenen Vorstellungswelt entwickelt.

\section{Prominente Designer stehen nicht in der ersten Reihe}

Die »Diversifizierung des Starsystems « und der Transfer von »[i]n einem Subfeld erworbene[m] symbolische[m] (Aufmerksamkeits-)Kapital« bieten die perfekte Überleitung von RECKWITz zu The Role of Products in Consumer-Celebrity Relationships an, einem Artikel von ZIMMERMAN und AYOOB (2004):

»Die Ausdehnung und Diversifizierung des Starsystems bedeutet eine quantitativ gesteigerte und qualitativ aufgefächerte mediale Präsenz von Subjekten, denen - ob als [...] bildender Künstler, [...] Modeschöpfer, Designer, Architekt, [...] oder Kreativunternehmer - Leistungen der Kreation von Neuem, primär von ästhetisch Neuem zugeschrieben werden. Diese ästhetische Leistung kann in Form von [...] Bildern und Installationen, [...] Bekleidung, ästhetischen Gebrauchsobjekten, [...] Gebäuden und 


\section{NEUAUSRICHTUNG DER PROMINENZ-FORSCHUNG}

Stadtvierteln [...] und nicht zuletzt auf der Ebene der Stilisierung der Persönlichkeit vorliegen. Die meisten der modernen Startypen bewegen sich damit im Rahmen der expandierenden ästhetischen Ökonomie. Diese Expansion des Starsystems wird von zwei weiteren Tendenzen begleitet: der Erleichterung der Konvertibilität zwischen unterschiedlichen Star- und Kreationstypen sowie der Entstehung von medialen Testformaten zur Starwerdung. Zum einen lassen sich zwischen den spezialisierten Starsubsystemen Prozesse der Konversion und Grenzüberschreitung beobachten: In einem Subfeld erworbenes symbolisches (Aufmerksamkeits-) Kapital und dort unter Beweis gestellte skreative Kompetenz lassen sich dann unter Umständen in ein anderes Subfeld transferieren. (RECKWITZ 2012: 265)

Jene Art des Transfers spielte im Rahmen des hier hauptsächlich referierten Artikels die Hauptrolle. Verglichen wird diese Darstellung mit einer Masterarbeit von MILLER (The changing nature of celebrity from entertainer to entrepreneur: Oprah Winfrey as tastemaker, 2004) und einem Artikel von RINALLO und SAVI (Consuming Stardust: the Consumption of Celebrities Beyond Product Endorsements, 2011). ZIMMERMAN und AYOOB lassen in ihrem Abstract verlauten:

"Celebrities, designed and packaged to elicit an emotional reaction from consumers, appear to be indistinguishable from products. However, their role as characters in narrative creates a very different type of emotional attachment than products enjoy. By both being and being in narrative content, celebrities allow consumers to vicariously experience many new lives, and it is this fantasy connection that makes the consumer-celebrity attachment both strong and long lasting. In this paper we explore how celebrities effect consumers, and we detail how celebrity products support activities that create and grow consumer-celebrity relationships. In addition, we offer some insight into how understanding these activities can both lead to better design of celebrity products and lead to design of future products that form a similar level of attachment with consumers." (ZIMMERMAN und AYOOB 2004: 3)

Die wesentliche Blickrichtung dieser Untersuchung besteht also darin, die Prominenten selbst als Produkte aufzufassen (die schon ununterscheidbar von jenen erscheinen, die eigentlich als solche gelten). Durch den Schwerpunkt in der Prominenzforschung und mit der Stoßrichtung einer Ausweitung parasozialer Interaktionen über Produkte, die die Aspekte »Be« und »Be with« (vgl. ebd.: 11f) in den Vordergrund rücken (am Beispiel des Basketballstiefels NIKE AIR JORDAN anschaulich vor Augen geführt), wird letztlich eine Ausweitung der Starsphäre im Verein mit neuen Absatzmöglichkeiten für maßgeschneiderte Prominentenprodukte angestrebt. Im Verlauf präsentieren die Autoren 


\section{STARDESIGNER ODER GESTALTER DES ALLTÄGLICHEN?}

eine Liste mit sechs Kategorien (die später in ihren Ausprägungen ausgedeutet werden), die anhand einer Sammlung verschiedener Artefakte entstanden ist, welche von den Autoren als »celebrity products« bezeichnet werden. Eine davon scheint eine deutliche Passung zu dieser Arbeit aufzuweisen:

»In order to better understand the role of products in the consumer-celebrity relationship, we collected examples of celebrity products. Products needed to display a clear connection with celebrity to be included. Examples include the tea kettle designed by celebrity architect Michael Graves, a replica sports jersey emblazoned with the name and number of soccer star David Beckham, a Princess Diana commemorative plate, and a Walther P9g pistol that fire [sic] blanks and is identical to the one used by actor Pierce Brosnan in the most recent Bond Films [...].« (ibid.: 7)
"1. Celebrity Content Products
2. Celebrity Endorsed/Placed Products
3. Celebrity Product Surrogates
4. Celebrity Collectables
5. Celebrity Brand Products
6. Celebrity Designer Products« (ibid.: 8)

Die »Celebrity Product Surrogates « stimmen als Kategorie am Ehesten mit den meisten der erwähnten Artefakte (mit Ausnahme des Wasserkessels) überein. In den Vordergrund tritt hierbei, dass sie sich dadurch auszeichnen sollen, dem Konsumenten die Essenz des Prominenten verfügbar zu machen (vgl. ebd.: 9). Für einen Abgleich mit dieser Untersuchung weist die letzte Kategorie die größte Relevanz auf:

"Celebrity Designer Products cover products sold under the name of celebrities famous for their design expertise. Examples include consumer electronics, computer accessories, and house wares designed by architect Michael Graves; sheets, towels and curtains sold through the retailer Kmart under Martha Stewart's name; and retailer Target's sStarck Reality' line of everyday products designed by Philippe Starck.» (ibid.: 9)

Trotz thematischer Relevanz durch die Bezeichnung »Celebrity Designer Products«, ein damit mögliches FRANCKsches Äquivalenzdenken und deren definitorische Fassung in Bezug auf die handelnden Personen als »celebrities famous for their design expertise entsteht in dieser Kategorie der Definition nach der Eindruck, dass ein bereits bestehender Ruf als Bereichsprominenter ohne eine zwangsläufige Bindung an das Feld des Designs im Vordergrund stehen würde. Damit ist auch ein Beleg für eine Fehlausrichtung mancher Prominenzforschung durch kategorische Verschleierung der Begriffe im Hinblick auf das Design gefunden. Ebenso unklar bleibt, ob in ihrem Ansatz mit einer gewis- 
sen Ausschließlichkeit ein Prominenten-Status auf einem beliebigen Gebiet bereits erreicht sein muss, dem dann eine Aktivität als Designer(in) folgt oder ob die Bereichsprominenz im Feld des Designs erworben sein muss. Die drei ausgewählten Personen jedenfalls stellen höchst unterschiedliche Vertreter der Kategorie Celebrity dar, denn sie umfassen einen bereits prominenten Architekten, der auch als Designer tätig ist (s. o.: »the tea kettle designed by celebrity architect Michael Graves«), eine Fernsehmoderatorin, die auch ein Celebrity Entrepeneur ist (s. u.) sowie einen studierten Designer, der seine Prominenz seinem unmittelbaren Berufsfeld verdankt. Der Definition der $\mathrm{Ce}$ lebrity Designer Products, die von ZIMMERMAN und AYOOB geliefert wird, folgt im Verlauf des Artikels keine detailliertere Betrachtung und so bleibt sie rein anekdotischer Natur, sie wird verschenkt.

Die »celebrities famous for their design expertise« stellen sich letztlich als ein Kreis von Personen dar, die wohl am besten durch MARTHA STEWART repräsentiert würden - wobei diese, wie weiter unten noch zu lesen sein wird, als Celebrity Entrepreneur deutlich stimmiger hätte eingeordnet werden können. Um einen reinrassigen Transfer von Aufmerksamkeitskapital, der der Intention der Testimonial-Werbung in ihrer Reinform folgt, kann es in dieser Kategorie weder im Sinne von RECKWITZ noch unter dem Betrachtungsansatz von ZIMMERMAN und AYOOB gehen, denn das originäre Feld eines »Celebrity Designer[s] « wäre nach der hiesigen Betrachtungsweise eigentlich das Design, in dem und mit dem jemand zum Bereichsprominenten wurde oder wird. Unter dieser Einschränkung ist hier nur ein andersartig anschlussfähiger sinnstiftender Transfer zu finden, der sich durch die Besonderheit auszeichnet, dass z. B. die bereits bestehende Popularität eines Designers dazu genutzt werden soll, Aufmerksamkeit für ein Handelsunternehmen über eine Beauftragung im Rahmen von dessen konkreter Berufsausübung zu wecken. Trotz ihrer Begrenzung auf den amerikanischen Markt muss der damals längst weltweit bekannte Franzose STARCK wegen seiner Zusammenarbeit mit TARGET im Jahr 2000 ihre Aufmerksamkeit erregen, wenn auch eher als reines Oberflächenphänomen. Dessen Kollektion für die Supermarktkette stellt auch im Designmarkt durch die breite Anlage der dafür entworfenen 50 Produkte eine Ausnahmeerscheinung dar, weil Designer üblicherweise Einzelentwürfe oder in sich abgeschlossene Produktprogramme in bestimmten Segmenten abliefern. Weiter in die Tiefe geht die Darstellung auch zu diesem Punkt nicht und so bleibt auch STARCK eine weitere Randerscheinung, wie der Artikel keine vertiefenden Ausführungen zu Celebrity-Designern (im Sinne von prominenten Designern) beitragen kann. Über das Postulat hinaus, dass Artefakte die- 
ser Kategorie angehören, sind keine weiteren Belege für ihre Wahrnehmung als solche aufgeführt, die über eine schon beschriebene Offensichtlichkeit der Prominenz der mit ihnen verbundenen Personen hinausgewiesen hätte - was die Beweiskraft im Hinblick auf eine tatsächliche Wirkung im Markt nicht erhöht und wieder einmal ausweist, dass das Ziel einer Untersuchung auch verfehlt werden kann, indem Sachverhalte als Nebenaspekte behandelt werden, die es verdienen, im Zentrum der Aufmerksamkeit zu stehen. Mit der Darstellung der Nutzung als Konsum von Marken-Erzählungen, aber auch als Teil eigener Erzählungen der Konsumenten im Sinne von »Be« und »Be with« werden noch ein paar andere interessante Bereiche gestreift:

"Consumers consume [Hervorhebung im Original] Donna Karen [sic]
clothes by shopping; they project [Hervorhebung im Original] their val-
ues by driving BMW's [sic]; they collect [Hervorhebung im Original] art
deco furniture; and they reflect [Hervorhebung im Original] on their life
experiences through the products they interact with. However, consum-
ers cannot Be [Hervorhebung im Original] their mobile phone, and they
cannot Be With [Hervorhebung im Original] a can of Coca Cola. Without
the ability to be a narrative, consumers can never Be or Be With [Her-
vorhebung im Original] products. If however, products are to gain a sim-
ilar level of attachment as found in the consumer-celebrity relationship,
they will need some method to support activities similar to narrative con-
sumption." (ibid.: 12)

Wo die Schwierigkeiten bei einer Ausweitung der Star-Sphäre mit Hilfe von Celebrity Endorsed Products liegen können, wird am Beispiel des am Markt nicht erfolgreichen MICHAEL JORDAN PALM PILOT expliziert (der ein Jahr nach dem CLAUDIA SCHIFFER PALM PILOT auf den Markt kommt). Dem Produkt fehlt es schlicht an Möglichkeiten zum Celebrity-Konsum im Sinne des »Be with«, es scheitert also daran, parasoziale Interaktionen zu initiieren:

"The PDA is not content containing Michael Jordan, so there is no celebrity consumption. Public use of the product does not project the same values consumers identify with the basketball star.« (ebd.: 13)

Was hierin meiner Meinung nach wesentlich zum Ausdruck gebracht wird, ist die sinnstiftende Verbindung, die für diese Art von mit celebrity content aufgeladenen Artefakten im Hinblick auf parasoziale Interaktionsmöglichkeiten aufgeboten werden muss und die im Vorfeld bereits für das Storytelling mit hinein konzipiert werden müsste. Probleme dieser Art ergeben sich im Gegensatz dazu mit Designern als Werk-Stars und denen von ihnen entworfenen Artefakten überhaupt nicht, denn, wie oben bereits erwähnt, steht als Ergeb- 
nis von deren Berufsausübung jeweils ein Celebrity Designer-Produkt bereit (hier bewusst im Kontrast zu der begrenzten Definition von ZIMMERMAN und AYOоB in der Lesart dieser Arbeit verstanden), das keine Übertragungsschwierigkeiten bei der Integration in das je individuelle Konsumentenleben verursacht, weil es keine Zweifel an seiner Herkunft wie seinem Sinn lässt.

Ein Kleid von Dior ist ein Kleid von DIOR. Auf dem ULMER HOcKER von MAX BILL kann man sitzen - u. a.. Diese Produkte enthalten ihren Autor nach landläufigem Verständnis, so wie es sich z. B. mit einem Gemälde von Anselm Kiefer verhält, das man sich als ein Gemälde von ANSELM KIEFER an die Wand hängt; es ergeben sich keinerlei Identifikationsschwierigkeiten und der primäre Nutzen besteht in der direkten Nutzung, ohne dass ihr eine gedankliche Prominenten-Anverwandlung oder ein Abklopfen auf eine Passung mit der Persönlichkeit des Werk-Stars auf der Seite des Konsumenten vorausgehen muss. Die »celebrity consumption« ist für das Feld des Designs zu größeren Teilen irrelevant, da jene Form des Konsums sich, wie es bei RINALLO und SAVI (2011) ausgewiesen wird, auf drei unterschiedliche Celebrity-Schichten stützt, die als "performer«, »character « und "private self « beschrieben werden. Die Schichten »character« und »private self« spielen für die Konsumenten in Bezug auf Designer keine große Rolle. Mit Sicherheit aber treten Designer als Werk-Stars den Konsumenten als "performer« im Sinne einer »consumption of professional excellence" gegenüber, wenn auch eher als eine Erweiterung zu dem, was bei RINALlo und SAVI definiert wird. Denn das Ergebnis jener "professional excellence« ist eben das, was als Artefakt unmittelbar konsumiert werden kann. Deren Definition einer »consumption of professional excellence unterscheidet sich nur unwesentlich von den »Celebrity Content Products« bei ZIMMERMAN und AYOOB:

"The performer is consumed through the output of his/her profession. The consumption of professional excellence entails a vari ety of consumption practices. For example, in the case of an actor, such practices include going to a movie theatre in the opening weekend of the star's new film; watching DVDs of those movies alone, with the partner or with friends; downloading legally or illegally those movies and collecting them." (RINALLO und SAVI 2011: 803) [online] http://www.acrwebsite.org/volumes/ v38 /acr_v38_16156.pdf [29.01.2018]

»Celebrity Content Products cover content selections made specifically to consume a celebrity. Examples include DVDs of movies staring Tom Cruise movies [sic]; David Bowie albums on tape, vinyl and Compact Disk; the Pro Skater video game where players control a virtual, skateboarding legend Tony Hawk; and TV shows, books, and video games designed 


\section{STARDESIGNER ODER GESTALTER DES ALLTÄGLICHEN?}

around Nickelodeon's animated character Dora the Explorer." (ZIMMERMAN und AYOOB 2004: 8)

ZIMMERMAN und AYOOB lokalisieren im Zuge der Verbreitung der Massenmedien das Potential zur Erschaffung von Prominenten bei den Konsumenten, mit denen letztere auch Langzeit-Beziehungen eingehen, worin sie völlig mit der Verortung der Zuschreibung als generell von außen kommender wie bei WIPPERSBERG und KeLLeR übereinstimmen. Sie geben in einem enttäuschenden Fazit Designern vage Handlungsanweisungen mit auf den Weg, um ein Scheitern von Celebrity Endorsed Products wie den o. a. zukünftig zu verhindern:

\footnotetext{
"By examining how consumers use and benefit from celebrity products, designers can better support the emotional connection that celebrity products provide and even begin to design new products that support a similar level of attachment as found in the consumer-celebrity relationship.« (ibid.: 14)
}

Mit diesen Handlungsanweisungen wird die Unschärfe ihres Artikels letztlich überwunden, da Designer für ZIMMERMAN und AYOOB de facto nicht als selbst prominente Personen im Vordergrund stehen, sondern nur als Teil einer Produktschöpfungskette betrachtet werden.

Über den Celebrity Entrepreneur amerikanischer Prägung kommt die Verbindung zu einer weiteren Masterarbeit aus dem selben Jahr zustande. MILLER bearbeitet darin am Beispiel von OPRAH WINFREY die Auswirkungen sogenannter (Celebrity-) tastemaker (oder auch stilprägender Personen) auf den (amerikanischen) Markt für Konsumgüter. Ihr Blick auf celebrity endorsed products weitet sich mit der Beschreibung von vier unterschiedlichen Arten des Verhaltens aus, die Prominente im Zusammenhang mit der Testimonial-Werbung grundsätzlich an den Tag legen können: A) diese gänzlich abzulehnen, B) sich als Gesicht einer Marke oder für ein bestimmtes Produkt zur Verfügung zu stellen, c) selbst in Verbindung mit einem Industriepartner eigene Produktlinien zu entwickeln (bei ZIMMERMAN und AYOOB als celebrity brand products bezeichnet), D) selbst unternehmerisch tätig zu werden: Mit dem Ziel, als Individuum zur Marke und zum Unternehmen zu avancieren und den Spielraum der eigenen Marke mit eigenen Produkten bewusst und gezielt auszudehnen. Dies wird ausführlich am Beispiel von WINFREY dargestellt (vgl. MILLER 2004: 4, 5, 6, 9f). Zum dritten Punkt bietet MILLER eine definitorische Fassung an, die deutlich weiter als bei ZIMMERMAN und AYOOB reicht: 
"There is a new trend in celebrity endorsement, however, which lends itself to the third level of my definition. Instead of simply promoting a certain product, celebrities today are producing, designing, and creating products for distribution. These celebrities endorse their product lines in an attempt to generate name brand extension. As opposed to simply endorsing products, third level celebrities make a claim of authenticity by asserting their creative control over their products." (MILLER 2004: 6)

"Celebrity Brand Products cover products sold under a celebrity's name that gain credibility not from the celebrity's refined taste, but from consumers' identification with the celebrity's values and lifestyle. These include Mary Kate and Ashley Olsen branded clothing, accessories and cosmetics; the Sean John clothing line from the rap musician and record producer P-Ditty (formerly Puff Daddy); and the clothing line of former TV host Kathy Lee Gifford." (ZIMMERMAN und АYOOB 2004: 9)

In diesem Zusammenhang stellen Aspekte von Authentizität und kreativer Kontrolle im Sinne additiver Autorenschaft bei MILLER eine bedenkenswerte Erweiterung zu ZIMMERMAN und AYOOB dar. Ein damit zum Ausdruck kommender Anspruch, als Co-Autor oder Mit-Schöpfer eines Produktes wahrgenommen zu werden, obwohl sein Entwurf nicht in den Kernkompetenzbereich des Prominenten fällt, könnte dem Versuch entspringen, sich aus dem Abglanz der unterstützten Marke zu lösen, um selbst als Personenmarke in einer anderen Rolle zu glänzen. Paradox daran ist, dass das Testimonial ursprünglich aufgrund seines Potentials ausgewählt wurde, einen Abglanz für die vertretene Marke herbeizuführen: In dem Bestreben, zu gleicher Zeit die Beliebtheit der unterstützten Marke zu erhöhen und die Strahlkraft des Prominentennamens als Personenmarke durch die Markenunterstützung auszuweiten. Doch scheinen Prominente im Sinne ihre eigenen Credibility in solchen Fällen bestrebt, den Eindruck zu erwecken, dass eigener Einfluss ausgeübt wurde, der sie als Persönlichkeit wiederum interessanter - weil vielschichtiger - macht. Das Bild der kreativen Persönlichkeit, die ein beworbenes Produkt nicht nur unterstützt und für ihre Mitvermarktbarkeit Geld erhält, sondern auch in die Gestaltung und Produktwerdung mit einbezogen ist, zeigt, dass das Berufsbild des Designers eine Bereichsprominente aus ganz anderen Bereichen ebenso affizierende Strahlkraft hat.

Der vierte Aspekt in MILLERs Auflistung weist in einer deutlich über ihren Ansatz hinausgehenden Linie direkt zum Autorendesign. Besteht ihre Grundannahme und Voraussetzung für den Celebrity Entrepreneur darin, dass es sich um einen Prominenten aus dem Bereich des Entertainments handeln muss, 


\section{STARDESIGNER ODER GESTALTER DES ALLTÄGLICHEN?}

(»The celebrity as entrepreneur must begin their career as a traditional entertainer. [...] Celebrity entrepreneurs always begin as actors, musicians, talk show hosts and eventually work up to become entrepreneurial.« (MILLER 2004: 56))

wird im Vergleich eine Persönlichkeit dieses Kalibers bei zIMMERMan und AYOOB anhand des Beispiels von MARTHA STEWART in die Kategorie der $\mathrm{Ce}$ lebrity Designer Products einsortiert. Dort wird sie mit MICHAEL GRAVES und PHILIPPE STARCK auf das gleiche Niveau gehoben. Jene Unschärfe in der Kategorisierung disqualifiziert den Ansatz von ZIMMERMAN und AYOOBs Ausführungen eigentlich.

Autorendesigner werden ebenfalls zu Selbst-Unternehmern: Mit dem erklärten Ziel, über einen ganz individuellen gestalterischen Stil, eine wiedererkennbare Handschrift, auch als Designer (darin eher dem Künstler gleich), zur Marke zu werden. Das verbindet sie sehr wohl mit dem Celebrity Entrepreneur. Im Gegensatz zu Designern, die zur Berufsausübung klassischerweise ein eigenes Büro gründen, um von dort aus verfasst Aufträge Dritter zu bearbeiten, verkaufen Autorendesigner ihre im eigenen Auftrag entstandenen Entwürfe oft mit einem ins Künstlerische strebenden Anspruch - ohne erzwungene Rücksichtnahme auf Beschränkungen durch Auftraggeber und natürlich ebenfalls mit dem Ziel wachsenden geschäftlichen Erfolgs sowie zunehmender Bekanntheit. Als qualitativer, den Autorendesigner aufwertender Unterschied tritt der prononcierte Verkauf der singularisierten, eigenen Entwurfsleistung in den Vordergrund - im Gegensatz zur Tätigkeit im Rahmen der Massenproduktion, von der er sich absetzt, womit eine Nähe zum Freiheitsbild des Künstlers behauptet wird. Dieser sieht über den Vorwurf, Auftragskunst zu produzieren, ebenfalls ein Damoklesschwert der Entwertung über sich hängen. KURZ schreibt dazu in Inspirationsmythen:

»Typisch für Autoren-Design ist auch der fehlende Auftrag von außen, denn der Gestalter gibt sich die Aufgabe - wenn er sie überhaupt kennt selbst. Befreit von den Zwängen in Arbeitsgruppen und ohne Rücksichtnahme auf sonst übliche Hierarchien im Produktentwicklungsprozess, fokussiert er sein individuelles Interessensfeld; er gestaltet entweder in Einsamkeit oder ohne Scheu, in die Gebiete von anderen am Werkprozess beteiligten Personen einzudringen und dort zu swildern`. Rick Poynor kommt in seinen Analysen zum Autoren-Design im Bereich der Grafik und Kommunikation zu folgendem Ergebnis: Die selbstfaszination dieser Gemeinder (Poynor 2003: 113) [sic; Quelle falsch; ebd.: 119] ist in der postmodernen Ära so stark, dass man sich als Kommunikationsdesigner nicht mehr mit der Gestaltung von Magazinen zufrieden gibt, sondern in alle Gewerke, auch in die Texte, eingreifen will. Alles sollte nach 


\section{NEUAUSRICHTUNG DER PROMINENZ-FORSCHUNG}

Möglichkeit aus der eigenen Hand des jeweiligen Designers stammen, individuell geprägt und unverwechselbar sein. Indem mit Hilfe der Hochglanzpresse stetig der eigene, angeblich originelle Stil betont wird, setzt sich der Gestalter an die Spitze, erhebt sich und seinen Namen über das Werk, um als Star-Designer [Hervorhebung des Verfassers] selbst dann noch bekannt zu sein, wenn sich seine einzelnen Arbeitsergebnisse im kollektiven Vergessen auflösen.« (KURZ 2014: 224)

Das Autorendesign ist - so betrachtet - als aktuellster Versuch zu werten, die Unsichtbarkeit des Designers in der Massenproduktion zu überwinden, um aus der zweiten Reihe zum Ruhm zu gelangen: Zu jenen Aufmerksamkeits-

"Vermögen in der Größenordnung, die eine sewige Renter versprechen. Der Ruhm macht unsterblich in dem Sinne, daß der Strom der bezogenen Beachtung nie versiegt. Das Anwachsen von Kapitalen in diese Größenordnung setzt voraus, daß auch diejenigen Beachtung schenken, die nicht genau wissen oder verstehen, wofür die Beachtung ursprünglich gezollt wurde. Berühmt ist nur, wer so bekannt ist, daß die Bekanntheit für sich schon ausreicht, um für fortdauernde Beachtung zu sorgen." (FRANCK 1998: 118) 



\section{Wohin hat uns das geführt?}

Weder unter dem Betrachtungswinkel von ZIMMERMAN und AYOOB noch bei MILLER sind Anhaltspunkte dafür zu entdecken, dass Designer zu Prominenten im Sinne von deren Fokussierung der Prominenzforschung werden könnten. Selbst der Autorendesigner mit seiner ins künstlerische strebenden Haltung kann die Anwendungsorientierung seiner Profession nicht einfach vom Tisch wischen, sofern er einen beruflichen Erfolg in seinem Feld anstrebt, der auch an den Kriterien desselben gemessen wird. Ein Ausbruch aus den Beschränkungen der Massenproduktion allein garantiert immer noch kein Gleichziehen mit dem Künstler unter dem Gesichtspunkt einer Zuschreibung als Autor eines Werkes.

Die identitätskonstruktive Funktionalisierung, die von KELLER für die schon benannten Prominenztypen expliziert wird, hallt für Artefakte von Designern am greifbarsten bei ZIMMERMAN und AYOOB wider, die Konsumentenerzählungen im Sinne von Be und Be with beschreiben und damit die Suche nach einer Möglichkeit, Prominente über mit ihnen verbundene Produkte zu erleben - als eine Form parasozialer Interaktion. Solches findet im Rahmen der Nutzung von Artefakten aus der Hand von Designern nach bisherigem Kenntnisstand nicht statt und müsste deshalb auch nicht in dieser Form ergründet werden. Entsprechende Untersuchungen bei und mit Konsumenten lassen eher erwarten, dass der blinde Fleck in Bezug auf Geschmacksgemeinschaften und wie Designer oder ihre Artefakte dort identitätskonstruktiv funktionalisiert werden, möglicherweise beseitigt werden könnte. Über die Zielgruppenprominenz oder auch Berufsprominenz (die bei BOURDIEU, wenn auch mit anderen Konsequenzen, als interne Hierarchisierung beschrieben 
wird) erscheint eine strukturelle Annäherung zum Feld der Kunst möglich. Speziell unter dem makrosoziologisch verallgemeinernden Blickwinkel der

200 Prominenzforschung sind die individuellen Entwicklungen dieser differenten Felder bis zu einem gewissen Grad strukturell vergleichbar. Bei der Betrachtung von BOURDIEU treten entscheidende Unterschiede zwischen den Feldern des Designs und der Kunst zutage und im Ergebnis vergleichbar bleiben nur noch der Transfer von ökonomischen Profiten in symbolisches Kapital sowie die Festschreibung von Wertsetzungen als extern - für deren Produktion können weder der Künstler noch der Designer selbst verantwortlich sein. Die Vergabe dieser Wertsetzungen ist einerseits höchstpersönlicher Natur auf der Seite desjenigen/derjenigen, der sie vergibt/die sie vergeben und damit per se unzugänglich, andererseits ist sie über Wettbewerbe institutionalisiert und damit doch für Adressierungen jener zugänglich, die in Wert gesetzt werden wollen - wiederum als Teil der illusio des Feldes:

1. Auszeichnungen mit Designpreisen,

2. die Nennung von Designern durch die Hersteller der von ihnen entworfenen Produkte,

3. die Besonderung von Produkten über den Zusatz »designed by ...« oder

4. ganze Kollektionen wie die oben erwähnte von STARCK für TARGET und

5. auch die Aufnahme von Artefakten in die Designsammlungen von Museen sowie

6. die Erwähnung in Designgeschichten und Designlexika

sind Varianten der Lorbeerkränze, die im Feld des Designs errungen werden können. Der unüberwindbare Graben bleibt in der Zuschreibbarkeit der konkreten Werkleistung als Autor bestehen, er entsteht auch durch diese und die jeweilige illusio des Feldes lässt nur einen geringen Bewegungsspielraum im Rahmen ihrer Spielregeln zu.

Nach hiesigem Verständnis sind und bleiben Star-Designer prominent, aber nicht in der ersten Reihe, sondern in der zweiten - im Rahmen der Grenzen ihres Feldes wie im Rahmen ihrer Medienpräsenz als Experten ihres Feldes. Sie ragen im WIPPERSBERGschen Sinne heraus und sie werden - wie alle anderen Stars auch - nur herausragen gelassen. Das Problematische an ihrer Rezeption liegt darin begründet, dass sie wie Stars der ersten Reihe behandelt werden, obwohl sie das nicht sind. Sie bekommen den Star-Status angeheftet wie eine Kokarde, aber sie bleiben dennoch Werk-Stars, denen die Zuschreibung als alleiniger Autor der Werkleistung im Sinne des Künstlers versagt bleibt - ein Umstand, der die Hervorbringung der im Rahmen die- 
ser Untersuchung gezeigten Übertragungsstrategien der unterschiedlichen Akteure zu begünstigen scheint. Hatte HULLMANN dem Designer noch die Macht zugeschrieben, »die Medien als Teil der industriellen Produktion« einzusetzen (s. o.) und dadurch den Eindruck erweckt, als Designer könne man in der Rolle eines der Feld-Akteure die Entstehung publizistischer Relevanz im Sinne feldspezifischer Kontrolle über Entwürfe steuern und erzeugen, so muss diese Anmaßung aus heutiger Sicht als gescheitert gelten. Entscheidend ist, dass diese Unschärfe der Rolle in der Abgrenzung zum Werk-Star im Feld der Kunst ebenfalls durch die externe Wertsetzung erzeugt wird: Im Feld selbst, wo die Bereichsprominenz entsteht, wie außerhalb, wo gleichartige Anstrengungen unternommen wurden und werden, um bereits bekannte Rezeptionsmuster einfach zu übertragen und damit andernorts vorhandene Strukturen zu replizieren - größtenteils völlig unkritisch und auch in den Reihen der Wissenschaft. 
»The nation is the imagined community of the state. The consumer tribe is the imagined community of the market." 


\section{Ein Exkurs und seine Anbindung}

\section{Verehrung, Bewunderung und Anerkennung}

Am Cluster LANGUAGES OF EMOTION der FU BERLIN wird interdisziplinäre Emotionsforschung betrieben. Einer der ersten dortigen Forschungsschritte war die Auswertung des Literaturbestandes zum Thema Verehrung und Bewunderung. Neben einem spannenden Einblick in die Disziplin an sich ist der interessanteste Aspekt daran die Beziehung zwischen bewundernder und bewunderter Person - die unwillkürlich an Bezeichnendes und Bezeichnetes denken lässt. Verbindungen, die durch Gefühle der Bewunderung und der Verehrung hergestellt werden, beziehen sich aber immer nur auf ein Individuum und eine verehrte und/ oder bewunderte Person. SCHINDLER et al. stellen klar, dass es eine zwangsläufige Verbindung ins Kultische gebe, im Weiteren auch, dass jene Gefühle in Verbindung mit besonderen Leistungen der bewunderten oder verehrten Person stünden und dass »[...] access to special insights and meanings [...]« (SCHINDLER et al. 2013: 99) zugeschrieben, angenommen oder sogar erwartet würde. Mithin so etwas wie Führung, Maßstab und Erkenntnis für den Bewundernden, der den Bewunderten im Vorsprung oder im Vorteil oder als bevorzugt sieht.

Wie stellen sich solche Phänomene auf überindividuellen Ebenen dar? SCHINDLER et al. schreiben hierzu: »The individual communicates his or her emotions in response to an outstanding other when interacting with his or her social group." (ibid.: 101) Genau dort wird es erst interessant und relevant - bei den sozialen Prozessen in Folge akkumulierter Bewunderung oder Ver- 
ehrung. Der Aspekt des Kultischen kommt im Zusammenhang mit Designartefakten und Designern nicht wirklich zum Tragen, doch werden beim Konsum Fragen des sozialen Vergleichs berührt, die den Aspekt der Bewunderung, der Vorbildhaftigkeit, des Nacheiferns (womöglich auch Mimesis im GIRARDschen Sinne?) oder des Neides auf der Beziehungsebene des Nebenmannes oder der Nebenfrau in einem sozialen Gefüge betreffen. Internalisierung und Imitation spielen eine mindestens ebenso große Rolle im sozialen Vergleich, in der Definition der eigenen sozialen Position und im Statusstreben.

Eine Gruppe, die einen sozialen Status für andere so erkennbar definiert, dass in ihr oder durch sie sozialer Zusammenhalt oder auch eine Attraktivität im Sinne eines dorthin-streben-und-verbleiben-Wollens erzeugt wird, schafft sich diesen Zusammenhalt von innen und grenzt sich nach außen erkennbar ab. Sie muss ihre Zugehörigkeitsnormen darstellen und eine gewisse Durchlässigkeit haben, damit sie ein begrenztes Wachstum an den Tag legen kann, das sich in Abhängigkeit von der erwünschten Exklusivität bemisst, die ein Ergebnis interner Verhandlungen sein wird. Die Bewunderung für diejenigen, die die Zugehörigkeit zu dieser Gruppe behaupten (können), lässt andere potentiell nach einer gleichen oder einer ähnlichen Position streben. Von Gestaltern geschaffene Artefakte können dabei eine entscheidende Rolle spielen: in der Definition der Zugehörigkeitsnormen für die Gruppe sowie als Ursache der Bewunderung, die für diejenigen empfunden wird, die sich diese Artefakte leisten (können).

Verehrung im weitesten Sinne entsteht hierbei durch Erwerb und Eigentum. Artefakte bekommen Signalfunktion, Personen werden bewundert einerseits für ihr Eigentum, andererseits für ihre Gruppenzugehörigkeit. Externe Setzungen von Bewertungsmaßstäben finden durch Wettbewerbe, Fachmagazine, öffentlich wahrnehmbaren Lobpreis, Ausstellungen und Aufnahme in Museumssammlungen statt. Im Zuge dieser Prozesse werden auch einzelne Designer aus der Masse herausgehoben, was aber wohl nie so weit reicht, dass tatsächlich von kultischer Verehrung gesprochen werden könnte. Wirkt sich die Aufmerksamkeit eher in den Bereichen des Verkaufs aus und ist sie ein für Designer wie Produzenten und Verkäufer wichtiger Faktor, so scheint es für den Käufer eher um Fragen der Anerkennung in seinem sozialen Umfeld zu gehen. Gibt es dort Formen parasozialer Interaktion, die diese Gruppen festigen? Parasoziale Interaktionen sind der Definition nach imaginierte Interaktionen mit einem imaginierten Gegenüber, die aber nicht als krankhaft beschrieben werden. Sie spielen im Kontext der Starphänomene eine Rolle und beschreiben das Gefühl, das ein Fan als Kennenlernen der verehrten 
Person aufgrund medialer Übermittlung von Fakten empfindet und dadurch aufbaut, obwohl kein direkter sozialer Kontakt mit der bewunderten Person stattfindet. Wie tauschen sich Nutzer aus, wenn man diese Vorgänge auf einer Ebene betrachtet, die nicht schon auf dem Niveau einer Interessengruppe liegt? Ist es einfach die Gewissheit, dass andere das tun, was man selbst tut und dass das auf eine noch nicht näher beschreibbare Art medial gespiegelt und ego-bezugnehmend wahrgenommen wird?

Womöglich ist es nur die vielhundert- oder -tausendfache Addition der gleichen individuellen Entscheidung, die sowohl für den Effekt als auch für das Gefühl unausgesprochener Zugehörigkeit verantwortlich ist? Die Anerkennung des eigenen Handelns durch gleiches Handeln der anderen, jedoch nicht von außen zugesprochen oder zuerkannt, sondern auf der Ebene der Selbstvergewisserung: Man könnte das dann als einen Teil des Identitätsmanagements benennen und wäre damit wissenschaftlich gesehen bei KELLER (2008, s. o.) angelangt. Fragen, die sich aus diesen Zusammenhängen ergeben:

1. Wie konstituieren Bewunderung und Verehrung Gruppen, falls das für deren Zusammensetzung und Zusammenhalt eine Rolle spielt?

2. Wie bildet sich der Zusammenhalt innerhalb solcher Gruppen mit Bezug auf die von SCHINDLER et al. erforschten Gefühle?

3. Wie funktioniert Bewunderung in der Gruppe?

4. Wie signalisiert sie das nach außen?

5. Wer signalisiert wem den Maßstab oder bestimmt ihn?

Dass diese Fragen für einen anderen Blick aus der Perspektive des Designs plausibel und berechtigt sind, bisher in den zuständigen Disziplinen aber weitgehend unerforscht, stellte sich im Verlauf eines längeren Gespräches mit SCHINDLER in Berlin im Mai 2014 heraus. Mit diesen Überlegungen werden aktuell nur mögliche Forschungsfelder für die Sozialpsychologie markiert. Die Theorie des »costly signalling u und eine Differenzierung nach schwarzem (böser) und weißem (guter) Neid wären Ansatzpunkte, die noch deutlich über das hinausgreifen würden, was BOURDIEU mit Distinktion und Habitus beigetragen hat. Eine Betrachtung in einem größeren Zusammenhang müsste verschiedene Ansätze damit verquicken: von ANDERSONs vorgestellter Gemeinschaft (imagined community) die im Kontext von Nationen und Religionen verwendet wird über WEBERs Vergemeinschaftung bis zu SCOTT LASHs Geschmacks- und JONATHAN CRARYs Interpretationsgemeinschaft. So könnte im Sinne der subjektiv gefühlten Zusammengehörigkeit eines consumer tribe die 


\section{STARDESIGNER ODER GESTALTER DES ALLTÄGLICHEN?}

Perspektive für die Gruppenwirkung im Markt geöffnet werden - so, wie sie hier bei HARARI beschrieben wird:

"The two most important examples for the rise of such imagined communities are the nation and the consumer tribe. The nation is the imagined community of the state. The consumer tribe is the imagined community of the market. Both are imagined communities [Hervorhebung im Original] because it is impossible for all customers in a market to know each other the way villagers knew one another in the past. No German can intimately know the other 80 million members of the German nation, or the other 500 million customers inhabiting the European Common Market (which evolved into the European Community and finally became the European Union). Consumerism and nationalism work extra hours to make us imagine that millions of strangers belong to the same community as ourselves, that we all have a common past, common interests and a common future. This isn't a lie. It's imagination. Like money, limited liability companies and human rights, nations and consumer tribes are intersubjective realities. They exist only in our collective imagination, yet their power is immense." (HARARI 2011: 406)

Das Problem für die Beforschung liegt nun gerade in der Auflösung dieser gefühlten Gruppen in die sie konstituierenden Individuen:

"In recent decades, national communities have been increasingly eclipsed by tribes of consumers who do not know one another intimately but share the same consumption habits and interests, and therefore feel part of the same consumer tribe - and define themselves as such." (ibid.: 407f)

HARARI streift den Komplex bei hoher Plausibilität (aber mit für den hiesigen Kontext wenig passenden Beispielen) naturgemäß nur kurz, da er mit Sapiens eine völlig andere Zielsetzung verfolgt. Er knüpft in der Realität an schon als Fan-Gruppen identifizierbare Quantitäten wie MADONNA- oder MANCHESTER UNITED-Fans und Vegetarier an. Für diese ist eine öffentliche und in einem gewissen Sinne auch verfasste Sichtbarkeit mit einem ebenso leicht erkennbaren wie vermittelbaren Wertesystem auf einem ganz anderen Niveau bereits gegeben.

Ob sich Käufer von Designklassikern wohl einem consumer tribe zugehörig fühlen? Würde ein in Deutschland beheimateter Käufer eines Lounge Chair des Ehepaares EAMEs lieber eine matrimoniale Verbindung mit einer Frankreich entstammenden Käuferin des gleichen Artefakts eingehen, weil sie eine Vorliebe für den gleichen Konsumgegenstand miteinander teilen? So sähe jedenfalls die analoge Übertragung des HARARIschen Szenarios für Vegetarier aus (ebd.: 408). Folgte man dem weiter, wäre die Wahrscheinlichkeit, dass 


\section{EIN EXKURS UND SEINE ANBINDUNG}

ein Käufer eines Barcelona Chair sich mit dem Eigentümer eines Ivar-Regals von IKEA zusammentäte, so hoch wie die Heirat eines Vegetariers mit einem Karnivoren. Lassen wir die Ironie beiseite, tun sich anhand dieser Beispiele verschiedene Probleme auf, die bearbeitet werden müssten: Die Suche nach einem fassbaren consumer tribe muss sich in diesem Zusammenhang an wesentlich loser und unverbindlicher zum Ausdruck gebrachten gemeinsamen Werten orientieren und erst einmal Orte der Übereinkünfte zur Vergewisserung über geteilte Werte ausmachen, die bei Konzerten und Fußballspielen ganz selbstverständlich gegeben sind. Zudem werden in diesen Fällen - sowohl im Verhältnis des Individuums zur Gruppe wie umgekehrt - schon sehr spezifische Wertaussagen präsentiert und geteilt, da das Ziel der Versammlung dem geteilten Wert entspricht: Eine Aussage, die sich in dieser Form über die Käufer von Artefakten nicht treffen lässt. 


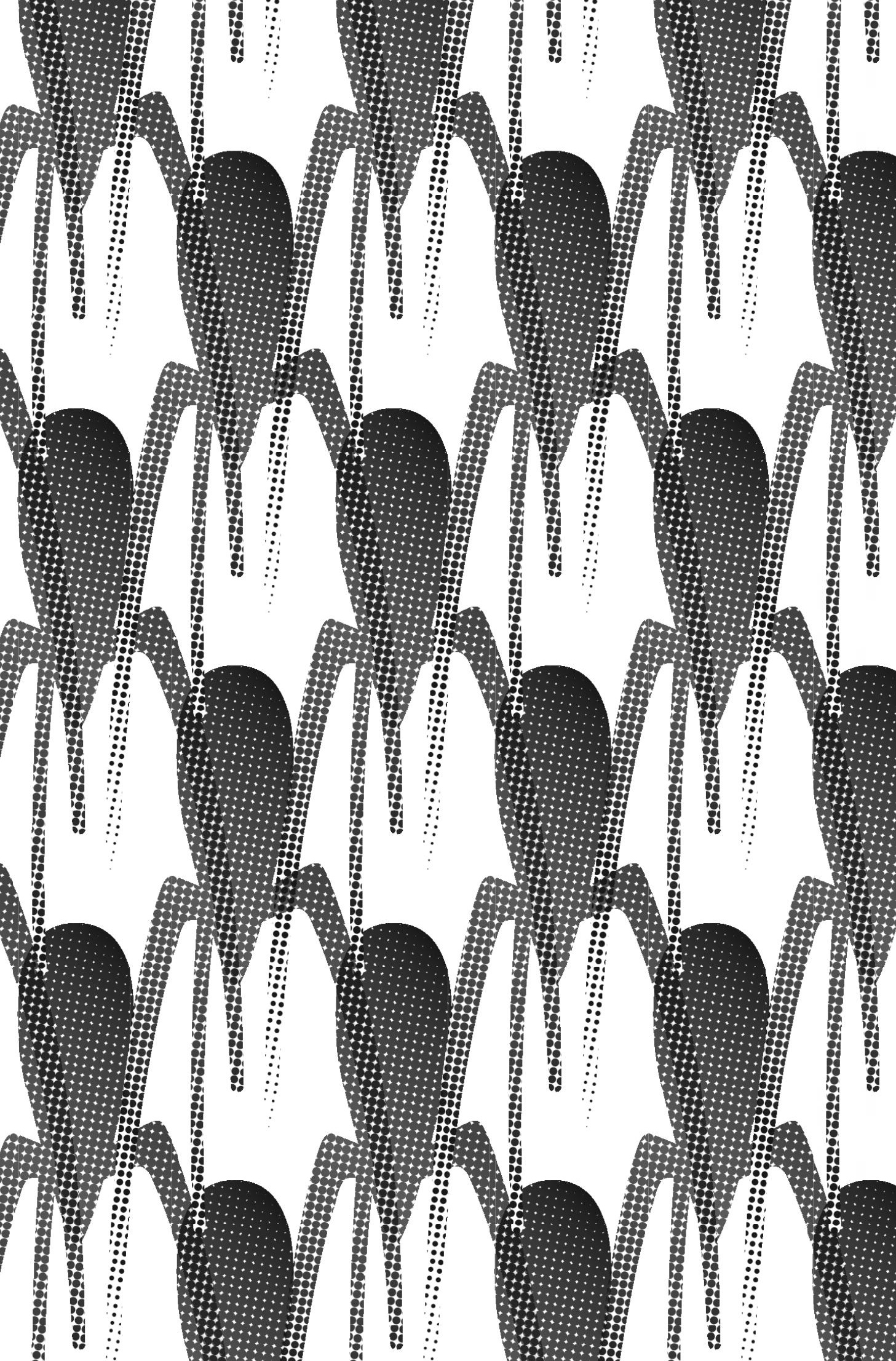


IV. Anonymität 
»anonymität ist ein adel. ich schätze die dienste für die menschheit, auch wenn sie anonym geblieben sind.« 


\section{Schafft man es auch anonym?}

Die Anonymität hat im Kontext dieser Arbeit große Bedeutung - stellt sie doch in einer angenommenen Aufmerksamkeitsgesellschaft als zweiter Teil einer naheliegenden Dichotomie den Gegenpol zum Star-Sein dar. Ihre Geltung wird zunächst für Designer wie für Artefakte angenommen und anhand verschiedener Publikationen untersucht. Schon AICHER lässt sich in die welt als entwurf (1991) unter dem Titel die unterschrift im Kontrast zur Berühmtheit über sie aus:

\footnotetext{
»design ist von der substanz her anonym, selbst wenn seine entwerfer noch so berühmt sind und gehandelt werden wie couturiers. es ist deshalb nicht verwunderlich, dass es großes design gibt, von dem man noch nicht einmal die namen der designer kennt." (AICHER 1991a: 128f)

»anonymität ist ein adel. ich schätze die dienste für die menschheit, auch wenn sie anonym geblieben sind. ich schätze den erfinder des fahrrads, der beißzange, des suppentellers, der türklinke, der schnürschuhe, des dampftopfs, des bierflaschenverschlusses und des flugzeugpropellers, auch wenn wir ihn nicht kennen.« (ebd.: 129)
}

Ein spannender Nebenaspekt ( - noch ... ) wird hier wieder - wie nebenbei - über das Rubrum "großes Design« angesprochen, der nahtlos an den Aufschlag im Forschungsfeld anschließt und sich im weiteren Verlauf zu einer Kernkontroverse zwischen dieser Arbeit und den untersuchten Publikationen wie zu einem zentralen Befund ausweiten wird. Auch AICHER versäumt es, sich darüber auszulassen, was "großes Design« denn sei .... Dass Anonymität ein Adel wäre, macht als ebenso kurze Setzung klar, wie leicht in eine ei- 


\section{STARDESIGNER ODER GESTALTER DES ALLTÄGLICHEN?}

gentlich unverdächtige Auflistung von Artefakten wertende Klassifizierungen (oder auch Verlangsamungen) hineingeträufelt werden können.

Verständlich wird diese Verkürzung selbstredend vor dem Hintergrund, dass hier ein Hauptakteur der HFG ULM schreibt, der als Bildhauer und späterer Dozent für Visuelle Kommunikation - notorisch kleinschreibend - ausgiebig zum und im Feld des Designs Stellung bezogen hat, was mit einer weiteren Lanzenspitze zum Design und zur Designausbildung aus analog und digital (1991) nur kurz angerissen werden soll:

"so degeneriert design zum modischen fetzen einer gewinnmaximierenden gesellschaft, zum modischen billigkleid der konsumanheizung, auch bei kindern, und zur stilfassade einer postmodernen genussgesellschaft. dagegen ist wohl kein kraut gewachsen, vor allem nachdem regierungen entdeckt haben, daß design ein hervorragendes mittel ist, die absatzchancen ihrer wirtschaft zu verbessern und die staatseinnahmen zu erhöhen. und regierungen bestimmen auch die lehrer und leiter, die ausbildungsprogramme und zielsetzungen ihrer designschulen. es wird ein heer von designdeppen herangezogen, die alle am segen teilhaben wollen, den design bringt. es ist ein farbenfroher, ein formenreicher segen.« (aicher 1991b: 74)

Anonymes Design als »Design ohne Designer« (SACHSSE in: WENZL-BACHMAYER 2009) zu bezeichnen, taugt trotz einer gewissen Fragwürdigkeit dieser griffigen Formulierung als Aussage, mit der die überwiegende Zahl industriell hergestellter Produkte zu klassifizieren wäre. Differenzieren müsste man jedoch zwischen Artefakten, deren Gestalter zwar bekannt sein könnte, es aber im landläufigen Gebrauch nicht ist und jenen Artefakten, bei denen keine Zuordnung zu einer Gestalterpersönlichkeit (mehr) möglich ist. Schaut man sich deutsche Warenkunden des 20. Jhd.s an, so fällt auf, dass Hersteller und Gestalter - soweit sie bekannt sind - auch immer genannt werden. Als umfassendster dokumentierter Zugang zum deutschen Warenangebot des 20. Jhd.s können diese Übersichten einen Anspruch auf Vollständigkeit dennoch nicht erheben, da sie schon unter dem Aspekt der Geschmackserziehung zusammengestellt wurden:

"Der präsentierte Warenbestand spiegelt also keineswegs die Produktvielfalt der jeweiligen Epoche, sondern vielmehr das ethisch und ästhetisch motivierte Qualitätsverständnis von Experten, die der Verbraucherschaft ihren strengen Kriterien genügende Waren empfahlen.« (BRÄUER 2004 [DVD], im Vorwort)

Die Idee einer tatsächlichen Anonymität des Designs ist - zumindest anhand dieser Quellen - schon vor dem Beginn tiefergehender Betrachtungen obso- 
let. So wird hier vorerst postuliert, dass Anonymität nur deswegen gegeben ist, weil vor, bei und durch den Verkauf und im alltäglichen Gebrauch nicht die nötige Aufmerksamkeit für Artefakt und Gestalter entstanden ist.

SACHSSE definiert in einem enzyklopädischen Stichwort anonymes Design als ein »[...] Design, dessen Urheber nicht mehr zu ermitteln ist.« Was nicht bedeute, »[...] dass es keinen Urheber gibt: [...]« (SACHSSE 2009: teilweise unveröffentlichter Katalogtext). Das BUNDESAMT FÜR SICHERHEIT IN DER INFORMATIONSTECHNIK fasst »Anonymität im alltäglichen Leben« in Übereinstimmung mit der Definition des DUDEN mit den drei Begriffen Nichtbekanntsein, Nichtgenanntsein und Namenlosigkeit zusammen. Dieser Text enthält einige interessante Überlegungen dazu, was geschehen muss, damit »Identität zur Anonymität wird«:

"1.2 Was muss fehlen, damit Identität zur Anonymität wird? [...] Anonymität kann aber auch durch das Fehlen von Identität definiert werden, was zur Frage nach Bedingungen für das Gegebensein von Identität führt oder anders gefragt: Wieviel muss man über eine Person wissen, damit sie nicht mehr als anonym bezeichnet werden kann? [...]

1.3 Grad der Anonymität Im Jahr 1997 haben sich Michael Reiter und Aviel Rubin in [ReRu 1997] über diesen Aspekt der Anonymität in Zusammenhang mit Kommunikationsvorgängen Gedanken gemacht. Sie definieren als Instanzen innerhalb eines Kommunikationsvorgangs den Sender und den Empfänger und folgern daraus auf Eigenschaften der Senderbzw. Empfängeranonymität. Senderanonymität bedeutet in diesem $\mathrm{Zu}-$ sammenhang, dass einem Beobachter des Kommunikationsvorgangs die Identität des Senders einer Nachricht nicht bekannt ist, die Identität des Empfängers sowie der Inhalt der übermittelten Nachricht jedoch bekannt sind oder sein können.«(BUNDESAMT FÜR SICHERHEIT IN DER INFORMATIONSTECHNIK 2001) [online] https://www.bsi.bund.de/DE/Publikationen/ Studien/Anonym/wasistanonymitaet.html [18.02.2018]

Auf das anonyme Design angewendet - wobei der Beobachter des obigen Kommunikationsvorganges in diesem Fall aus der Betrachtung entfernt wird -, gibt es immer Urheber, die notwendigerweise der Existenz der Artefakte als menschengemachte eingeschrieben sind - was den Sendern entspricht. Das Artefakt als Teil eines gedachten Kommunikationsvorganges wird anonym, weil der Sender dem Empfänger unbekannt ist und es bleibt, also keine personalisierte Identifikationsmöglichkeit besteht. Verliert das Artefakt dadurch seine Identität, weil sein Sender anonym bleibt? Nein. Es verliert einen Teil seiner additiven Identität, die aus dem Artefakt selbst und dem assoziierten Namen des Verfassers der Botschaft entsteht. Einen Empfänger dieser Bot- 
schaft gibt es immer. Sie steckt zu Teilen im Artefakt selbst und zu Teilen im Empfänger, der sie zu dekodieren in der Lage ist. Kennen wir den Sender dieser Botschaft, ist das Design nicht mehr anonym.

Die Art der Anonymität, die mit der Formulierung anonymes Design gefasst wird, ist eine spezifische. In ihrer Auswirkung scheint sie den unvollständigen Botschaften gleichzukommen, wie wir sie im Spiel Stille Post verkörpert finden, in dessen Verlauf nicht mehr alles ankommt, was ursprünglich gesendet wurde. Eine grundsätzliche Verfälschung der Botschaft, wie sie als komischer Aspekt des Spiels geradezu erwartet wird, kann im Falle des anonymen Designs auch bei fehlender Urheber-Identifikation fast völlig ausgeschlossen werden, da Artefakte mehr als nur eine Botschaft transportieren. An ihrer Gebrauchsfunktion ändert dieser Informationsverlust nichts. Die dauerhafte Verknüpfung mit einem Verfassernamen macht in der Aufmerksamkeitsgesellschaft einen Teil der vielschichtigen Funktionen von Artefakten aus. Deshalb könnte man auch zu dem Schluss kommen, dass ein Artefakt so sehr wohl einen Teil seiner Funktion verlöre - dann bliebe festzustellen, dass es zwar nicht seiner Gebrauchsfunktion beraubt wäre, wohl aber seiner repräsentativen. Denkt man den Gedanken zu Ende, dann ist eine Funktion dieser Prägung mindestens beeinträchtigt, wogegen das physikalische Funktionieren auch weiterhin nicht in Frage gestellt ist.

Was z. B. geschähe, wenn die Gebrauchsfunktion eines Artefaktes sich nicht mehr erschlösse, würde zu gänzlich anderen Betrachtungen führen müssen und die tätige Rückeroberung eines verlorengegangenen Funktionszusammenhanges erzwingen. Im Sinne eines von einem Sender an einen Empfänger gerichteten Kommunikationsversuches bleibt jedes Artefakt ein offenes Kommunikationsangebot an jedweden potentiellen Empfänger, ob der Sender nun bekannt ist oder nicht.

Anonymes Design tritt uns im Alltag in verschiedenen Formen entgegen. Mindestens kann anonymes Design ein Design sein, dessen Urheber nicht mehr zu ermitteln ist (s. o.), es kann aber auch anonym sein, weil der Urheber/Designer es vorzieht, selbst nicht in Erscheinung zu treten. Anonymes Design wird gerne auch vereinfachend als Alltagsdesign bezeichnet, wenn es im Alltag seine ihm zugedachte Funktion erfüllt, ohne dass man gezwungen ist, darüber nachzudenken, wie es funktioniert und vor allem dann, wenn es keine Rolle spielt, wer es entworfen, erdacht oder erfunden hat. Viele Gegenstände des alltäglichen Bedarfs scheinen in diese Kategorie zu fallen - ein Grund, weshalb Publikationen, die sich mit Alltagsgegenständen auseinandersetzen, in diesem Kapitel mitbedacht werden. Ein Blick zurück in die Design- 
und Ausstellungsgeschichte förderte einiges an Arbeiten zu diesem Thema zu Tage. Ein knapper Aufriss stellt jene Publikationen zunächst kurz vor - nachfolgend werden sie ausführlich betrachtet. In der Bilanz des Kapitels wird aufgezeigt, dass mehrere Unterarten von Anonymität aus der Literaturschau herauspräpariert werden können.

\section{Anonymity in Design}

DAVID HENSEL ALLISON verfasste 1966 seine Masterarbeit Anonymity in Design an der UNIVERSITY OF IOWA. Sein Fokus lag auf einer damals laufenden Diskussion, die die prospektiv zunehmende Anonymität von Designern und die entwerfende Entstehung anonymen Designs vor dem Hintergrund einer spezifisch Us-amerikanischen Designkultur analysierte.

\section{Das gewöhnliche Design}

Auch in Deutschland hat es schon Bemühungen gegeben, eben jenes in den Fokus der Aufmerksamkeit zu rücken. Liest man sich den Katalog zur gleichnamigen Ausstellung aus dem Jahr 1976 aus heutiger Sicht durch, scheint es, als habe man die Büchse der Pandora geöffnet - erweckt doch schon der einleitende Text den Anschein, dass es sich um ein hochmoralisches Minenfeld handelt, welches nur mit äußerster Vorsicht zu betreten ratsam ist.

\section{Unbekannt - Vertraut}

CLAUde LiCHTENSTEIN konzipierte 1987 in der Reihe Schweizer Design-Pioniere (zusammen u. a. mit FRANCO CLIVIO) die Ausstellung Unbekannt - Vertraut. "Anonymes" Design im Schweizer Gebrauchsgerät seit 1920. Seine Fassung von Anonymität fußt im Alltäglichen und Gewöhnlichen. Die Auswahl der Gegenstände zeigte eine Vorstellung von anonymem Design, das »[...] nicht im Atelier eines ausgebildeten Designers entstanden [...] [ist], sondern in der Werkstatt des unbekannten «Tüftlers» oder im Konstruktionsbüro der Fabrik.«(LICHTENSTEIN 1987: 13)

\section{Anonymous Design}

Die JAPANESE SOCIETY FOR THE SCIENCE OF DESIGN veröffentlichte $1993 \mathrm{im}$ Rahmen ihrer Publikationen eine Sonderausgabe mit dem Titel Anonymous De- 


\section{STARDESIGNER ODER GESTALTER DES ALLTÄGLICHEN?}

sign, die sich ausschließlich mit dem Phänomen anonymen Designs aus Sicht der japanischen Kultur beschäftigte und explizit die »Gegenpole Berühmt-

216 heit und Unbekanntheit« zu Ausgangspunkten nahm. In der Einleitung wird formuliert:

»In der gesamten Diskussion unter den Mitgliedern der Redaktionskommission hat sich folgende Definition des anonymous design [Hervorhebung durch die Übersetzerin] präsent gezeigt: es ist eine geschaffene Design-Handlung, welche aus dem Volk entstanden ist, vom Volk in die Praxis umgesetzt und tradiert wurde und in der inhaltlich Alltagsgegenstände, Kleidung, Bauernhaus-Szenerien und Siedlungen bis hin zu industriellen Produkten Platz finden. Auf der Gegenseite finden sich Produkte, die durch Herstellungsprozesse von Künstlern mit Namensnennung gekennzeichnet sind."(SATOSHI 1993: 2f)

\section{Low Budget}

MATTHIAS DIETZ und MATS THESELIUS setzten 1997 mit der Ausstellung und dem gleichnamigen Katalog Low budget. Objectos di quotidiano den Schlusspunkt unter eine Reihe von Ausstellungen, die vorher schon unter anderen Titeln durch Europa tourte: als Low budget - Der diskrete Charme des Gewöhnlichen. Alltägliches Design aus aller Welt in FRANKFURT A. M. und als World Stuffdie normalsten Sachen der Welt in ROTTERDAM. Ihre Auswahl anonymer Alltagsobjekte unterschied sich sehr deutlich von den anderen Positionen, die hier betrachtet werden, was unter Anderem mit einer selbst auferlegten Budgetgrenze pro Artefakt zusammenhängt. Dieser Versuch ist der Idee von FRIEDL und OHLHAUSER nicht unähnlich, die scheinbare Anonymität durch Sichtbarmachung zu durchbrechen.

\section{Kaj Franck}

CARITA MERENMIES wurde 1998 an der TU GRAZ mit einer Dissertation des Titels Kaj Franck (1911-1989). Die designtheoretischen Strömungen unter dem Gesichtspunkt der Anonymität und deren Einfluss auf das Werk von Kaj Franck promoviert - eine übersehene und womöglich sonst längst dem Vergessen anheim gefallene Debatte, die einmal die finnische Nation erschüttert hatte. 


\title{
Hidden Forms/No Name Design
}

FRANCO CLIVIO sammelt seit vielen Jahren Alltagsgegenstände und publiziert sie (HIDDEN FORMS, 2009) oder stellt sie immer wieder unter dem Titel NO NAME DESIGN aus. Seine Ausführungen zur Anonymität sind nicht so ausführlich, dass sie in einem separaten Unterkapitel abgehandelt werden müssten. Am stichhaltigsten ist diese Passage:

\begin{abstract}
»I search constantly and everywhere: in hardware stores, second-hand stores, junk stores, department stores, and flea markets. I find things there that usually interest no one else. They are unremarkable, everyday things with simple yet refined technical functions; they are anonymously designed objects [Hervorhebung des Verfassers] whose form, construction, operation, or material is out of the ordinary. Things with an raha effects, with an ambitious aesthetic - those that fold up in a surprising way, for example, or are multifunctional or reveal particularly interesting connections." (ebd: 11)
\end{abstract}

CLIVIO kapriziert sich - im Gegensatz zu LICHTENSTEIN - nicht auf eine besondere Ausdeutung der Anonymität. Sie ist für ihn außer der Tatsache, dass die gesammelten Objekte keinem Entwerfer zugeordnet werden können, von untergeordneter Bedeutung. Sein Fokus liegt auf den jeweiligen technischen Besonderheiten und er hebt das Außer-Gewöhnliche, aber auch das Vergleichbare sowie ihre mitunter anspruchsvolle Erscheinung hervor, wobei letztere sich immer aus der von ihm so empfundenen Außergewöhnlichkeit der ingeniösen Lösung ergibt.

\section{Main Street}

Ebenfalls 2009 nahm das WAGNER-WERK MUSEUM POSTSPARKASSE in WIEN unter den Kuratoren MONIKA WENZL-BACHMAYER und ROLF SACHSSE das Design ohne Designer mit der Ausstellung Main Street im Rahmen der VIENNA DESIGN WEEK in den Blick. Es war ein nüchterner Blick, der schon zu Beginn die fahrlässige Verwendung von Begriffen heraushob, indem der Terminus technicus »Anonymes Design« als »sinnleere Metapher« entlarvt wurde. (WENZL-BACHMAYER 2009: 8) 


\section{Die Essenz der Dinge}

2182010 inszenierte das VITRA DESIGN MUSEUM unter dem Ausstellungstitel Die Essenz der Dinge eine Vorstellung von Reduktion und Alltagsdesign und streifte dabei fast zwangsläufig die Gefilde der Anonymität, was sich vor allem in den begleitenden Texten von LANG und ScHWARTZ-CLAUSS niederschlägt.

Dies beschließt die ausführlich betrachteten Publikationen. Was sich bereits andeutet, ist die Vermutung, dass es sowohl herkunftskulturell unterschiedlich geprägte als auch individuell sehr unterschiedliche Vorstellungen und Ausprägungen von Anonymität geben könnte.

Zum Einstieg sei ein weiteres Beispiel vorangestellt. Aus einem unterschwelligem Gefühl für eine spezielle Art von Normalität entstand im Jahr 2006 eine Ausstellung mit dem Titel Super Normal - der sich ab dann auch als ein neuer Terminus technicus etablieren sollte. JASPER MORRISON und NAOTO FUKASAWA konzipierten sie zuerst für LONDON und wiederholten das Ganze 2007 in MAILAND anlässlich des SALONE DEL MOBILE. Beide waren als Designer damals schon hinreichend bekannt und konnten sich damit auf die öffentliche Wirksamkeit ihres Unterfangens beinahe verlassen. Die Begründungslegende stammt von JASPER MORRISON:

"I was having a cup of tea with Takashi Okutani in Milan, during the
2005 Salone del Mobile, talking about projects underway with Muji and
describing to him the Alessi cutlery project and how i was feeling this
approach to design, of leaving out the design [Hervorhebung des Verfas-
sers], seemed more and more the way to go. I mentioned having seen
Naoto Fukasawa's aluminium stools for Magis and how they seemed to
have a special kind of normality about them and he added: super nor-
malk. That was it, a name for what's been going on, a perfect summary of
what design should be, now more than ever." (FUKASAWA und MORRI-
SON 2011: 28)

Unter den Exponaten befanden sich auch einige, die keinem Designer zugeschrieben werden konnten. FUKASAWA führt zum Aspekt der Anonymität im Zusammenhang mit der Supernormalität aus: »[...] sSuper Normalk is the designing of things just as snormak as what we've come to know, albeit in no way anonymous." [Hervorhebung des Verfassers] (FUKASAWA und MORRISON 2006: 21). Grund genug, die beiden Herren als Kronzeugen für die Anonymität schon wieder zu entlassen, denn gleichwohl sie in ihrer Ausstellung auch anonymes Design zeigten, stellt FUKASAWA mit dieser Definition ihrer supernormalen Entwurfshaltung klar, dass es sich dabei keinesfalls um ein anonymes Design 
handeln solle. Dass Designer mit einer anonymen, wie beiläufigen und nicht herausgehobenen Präsentation ihrer Entwürfe so ihre Probleme haben können, lässt sich in seinem Fall anhand einer Begebenheit aus dem Jahr 2005 verdeutlichen - wieder während des SALONE DEL MOBILE -, als FUKASAWA »endlich der internationale Durchbruch« (Quelle: siehe nächstes Zitat) gelang:

"Anlässlich der Möbelmesse in Mailand, dem jährlich stattfindenden wichtigsten Treffen der Einrichtungsbranche, lancierten gleich mehrere namhafte Möbelhersteller Entwürfe des 1956 geborenen Japaners [Hervorhebung des Verfassers]. Die italienische Firma >Magis etwa hatte Fukasawas Hockerserie >Déjà-Vu in ihre Kollektion aufgenommen - zwischen Entwürfen von etablierten Designstars [Hervorhebung des Verfassers] wie Enzo Mari, Ron Arad oder Konstantin Grcic. Ein Ritterschlag für den Japaner [Hervorhebung des Verfassers], der voller Erwartung den Messestand inspizierte, wie er sich heute, rund zwei Jahre später, beim Gespräch in seinem Tokioter Büro schmunzelnd erinnert. Seine Entwürfe fanden sich dort allerdings nicht im Scheinwerferlicht, sondern in der hintersten Ecke. 'Müde Messebesucher ruhten sich darauf aus, sie hatten anscheinend gar nicht verstanden, dass es sich bei den Hockern um brandneue Designstücke handeltes, erzählt er. sDa war ich im ersten Moment schon ein bisschen deprimiert.< Dabei konnte ihm das Messepublikum eigentlich kein größeres Kompliment machen, als die neuen Stühle gleich so unbekümmert und respektlos zu nutzen." (RADERSCHAD in: ART DAS KUNSTMAGAZIN NR. 10/2007: 56-61) [online] http:// www.art-magazin.de/div/heftarchiv/2007/10/OGOWTEGWPPCOPPOG SCRTTGAAOACGROEPASSH/Die-letzten-Dinge-des-Alltags [12.07.2013; inzwischen nicht mehr im Netz verfügbar]

Das bis eben nur kurz Angerissene wird im Weiteren ausführlich betrachtet. Den Originaltexten wird dabei aus nachvollziehbarem Grund viel Raum gelassen. Eine bloße Zusammenfassung oder Paraphrase würde - ebenso wie bei den Textfunden zu Stardesignern (was noch zu zeigen ist) - die Unmittelbarkeit ihrer Beweiskraft schwerlich erhalten, da es sich auch um unmittelbare Untersuchungsgegenstände handelt. Die argumentativen Zusammenhänge werden durch die Zitatwahl herausgearbeitet und von einer kritischen Kommentierung wird selbstverständlich nicht abgesehen. 


\section{Anonymity in Design}

First things first: Ein US-amerikanischer Blick auf die Anonymität. Diese Masterarbeit ist ein bemerkenswertes zeitgeschichtliches Dokument, das Anonymität im Design aus Us-amerikanischer Sicht zu begründen sucht und für die - damalige - Zukunft als geradezu notwendig prognostiziert. Zunächst wird Anonymität für den Geltungsbereich von ALLISONs Arbeit als Abwesenheit individueller Eigenheiten in den Entwürfen gefasst, die aus der Hand von Designern kommen. Er begrenzt Anonymität auf formale Aspekte des Entwurfs und knüpft sie nicht an die Bedingung, ob ein Designer-Name bekannt sei oder nicht.

"The term ranonymity as it is used in this thesis will mean sthe absence of idiosyncrasy in design،. Thus a product that carries no obvious marks of the personality of its designer is ranonymous in the sense intended here; it is sanonymous in this sense whether we know the name of the designer or not." (ALLISON 1966: iii)

Anonymität kommt seiner Ansicht nach nicht aus dem Nichts und das bedeutsamste Beispiel eines zeitgenössischen anonymen Stils ist für ihn vierzig Jahre später immer noch das BAUHAUs (!) - seine Begründung dafür ist mindestens interessant: Die Tendenz zu geometrischer Einfachheit führe zur Anonymität, weil eines Mannes Kubus oder Zylinder eben so sei wie der eines anderen. Ein weiterer Ansatzpunkt ist die Aussage, Großprojekte seien zu komplex, um von einem Individuum alleine bewältigt zu werden: »Big government carries out big projects, such as the space program, which involve design problems that are too complex for solution by an individual." (ebd.: 3f)

Außerdem legt ALLISON seine Argumentationslinie zweigleisig an, weil er sie nicht nur aus der Perspektive des Designs, sondern auch aus der der Architektur begründet. Um zu zeigen, dass in der damaligen Zeit die Tendenz zu zu viel Individualität (!) schon aus ganz unterschiedlichen Richtungen kritisiert wird, führt er BILL, MALONE, NORTHCOTE PARKINSON, DREXLER und EAMES ins Feld. Dieser Argumentationsstrang kulminiert in einem Zitat von LEONARDO RICCI aus dessen Werk Anonymous (2oth century): »In this new world, there is no room for you geniuses. [Hervorhebung des Verfassers] « (RICCI 1962: 98) Mit großem Furor stürmt RICCI - selbst Architekt mit recht individuellem Ausdruck in seinen Bauten - im Kapitel 5, „Farewell Masters; Farewell Geniuses«, am Beispiel von WRIGHT, VAN DER ROHE, LE CORBUSIER, PICASSO, MATISSE und KLEE an gegen jene Genies, die man in der neuen Welt, die er 
sich erträumt, nicht mehr benötigen wird - weil es eine Welt sein soll, die aus gleichberechtigter, arbeitsteiliger Gemeinschaftsleistung hervorgeht anstatt aus leuchtturmartigen Einzelwerken. Diese seien, bei genauerer Betrachtung im Fall der besprochenen Architekten, nichts als egomane Selbstbefriedigung [Einschätzung des Verfassers], weil sie weder auf den Stadtraum noch auf Bauherren oder spätere Nutzer eingingen. Für die Künstler bleibt RICCI eine detaillierte Kritik schuldig; ihre genialische Überflüssigkeit macht er jedoch daran fest, dass die drei letzteren auf keinem gemeinsamen Grund stünden.

Letztlich bedeutsam an jenen Passagen ist ihrem Sinne nach, dass auch Genies mit Beschränkungen umzugehen haben, die sie daran hindern, die damaligen Probleme erfolgreich alleine und im Vollbesitz ihrer Individualität zu lösen oder Antworten auf die Fragen der Menschheit parat zu haben, die sich im Vorschein der damaligen Zukunft stellen. ALLISON nutzt für seine Begründung und als Beweis der Anonymität auch die Anforderungen der Teamarbeit im Design: »When several designers work on a product it tends to display the idiosyncrasies of none of them." (ALLISON 1966: iv) Er fährt fort:

"It was not until the uniting of efforts made necessary by the World Wars that corporate teams were developed to keep pace with our technology. Designing by teams is almost the rule now, rather than the exception. The reason that artists follow other artists, and that designing is being conducted by teams, is that human beings really are not ultimately creative in the true sense of the word. The greater portion of creative endeavors are really nothing more than refinements or combinations in variant degrees of previous results of creative activity. The decreasing role of individuality was no mere chance occurrence. It was instead a natural development, a product of a scientific and technical age.« (ibid.: 8f)

\section{Und weiter unten:}

»The problems involved in producing artistically successful designs that are sanonymous in the sense used in this essay are connected with another meaning of ranonymouss. In our time, design often is the work of a team, and designers sometimes feel that the individual talent has been supplanted by a committee and that the resulting product looks as though nobody had designed it - not exactly the sort of sanonymity the anonymous school wants in their designs. The well-known American industrial designer, Raymond Loewy, attacks the loss of independence in the collective tide in designing: 'A cell of designers inside a huge organization must fight constantly against being reabsorbed into the engineering and marketing or other divisions of that organization. [...] Design does not fit conveniently into corporate structure.« (ibid.: 23f) 
Verschiedene Probleme, die mit der eigentlich eingeforderten Anonymität einhergehen, werden hier sehr kompakt veranschaulicht. Leider wird der Gedanke, dass die anonyme Schule eine Vorstellung davon habe, wie ihre Art der Anonymität aussehen solle - »the sort of sanonymity the anonymous school wants in their designs «-, nicht weiter ausgeführt. Solches wäre überaus spannend gewesen, da die vorhergehende Formulierung deutlich zeigt, dass die anonyme Schule eher weniger Vergnügen daran gehabt haben dürfte, dass die Idiosynkrasien der einzelnen Entwurfsbeteiligten eben nicht mehr zum Ausdruck kamen: »the resulting product looks as though nobody had designed it«.

Später schließt ALLISON mit der Notwendigkeit zur Teamarbeit an, wenn er am Beispiel des Computers behauptet, das Design eben jener Maschine sei keine einfache Aufgabe, sondern viel zu komplex, um von einem Individuum allein bewältigt zu werden - dazu liegt auch eine nahezu identische Aussage im Zusammenhang des space program vor. Es gebe in diesem Rahmen nur sehr wenig Platz für "personal whims « [Marotten, Anmerkung des Verfassers] gebe (ebd.: 12). Sozialer Druck sei ein weiterer Grund für die Entstehung eines anonymen Stils, den ALLISON als in der Entwicklung befindlich betrachtet:

"Another pressure tending to produce an international and anonymous style is the growing socialization of life in the economically developed nations. Industrialism has meant that our environment, as Kepes says, 'more than ever is man mader. This fact places on the designers of the man made objects, which make up a great part of our environment, considerable responsibility for making the environment inhabitable for civilized men. The designers of the Bauhaus thought of themselves as working for the benefit of society as a whole. Today, in 1965, the same sort of social responsibility is being taken on by the designer and to some extent by the industrialist.« (ibid.: 29)

ALLISON bringt seine Überlegungen zur Anonymität mit einem Auszug aus ARTHUR DREXLERs Text The disappearing Object (DREXLER in der SATURDAY REVIEW vom 23. Mai 1964: 13-15) eigentlich schon recht früh im Verlauf seines Essays zu einem konsequenten Ende. Das Zitat weist weit voraus in unsere Zeit mit ihren Black Boxes, die aktuell am besten durch Smartphones verkörpert werden:

»The anonymous character of design then is no chance occurrence. Arthur Drexler explains the reason for the anonymous appearance of twentieth-century design. He argues that there is no reason why a telephone should be an object of sculptured beauty. Drexler continues: >Most design today is still naively conditioned by the desire to make something distinguished, to make interesting what is intrinsicly [sic] uninteresting. The designer of an appliance may, after all, really be required to provide only 
an acceptable box, [Hervorhebung des Verfassers] as were the designers of the Vertical Assembly Building. [auf CAPE CANAVERAL, Ergänzung des Verfassers] What is inside the box is what is really interesting.." [Hervorhebung des Verfassers] (ibid.: 14)

CHARLES EAMES ist der Kronzeuge ALLISONs, der als Einziger aus der Disziplin heraus argumentiert und nicht als Außenstehender, was in Anbetracht von ALLISONs Argumentationslinie nicht weiter verwundert. Deshalb kommt diesem Zitat eine besondere Bedeutung zu:

"In 1960 the famous industrial designer Charles Eames predicted less self-expression for the designer. He stated that the personality of the designer too often stands as a barrier between the intended message and the viewer. > Our real objection arises when such an intrusion fogs subjects of interest and importance. The damage to the message can be accomplished equally well through a self-conscious concern for artistic respectibility [sic], or a desperate drive for originality. In either case, the effort and the personality is apt to show.< [...] Importantly, Eames states that in such a climate of involvement and concern, any drive towards self-conscious originality would quickly disappear. Eames advocates a return to a more anonymous solution to design problems in general, rather than the emphasis on self-expression." (ibid.: 7f)

Aus heutiger Sicht erstaunt EAMEs' überlieferte Aussage, denn was er mit der überwiegenden Zahl seiner Entwürfe gerade nicht einlöst, ist die Forderung nach einem Fehlen individueller Originalität. Dabei müssen wir nicht von vielen absehen, zu denen unter anderen die Beinschienen für die Verletzten des zweiten Weltkrieges zu zählen hätten. Ansonsten zeichnen sich die Entwürfe des Paares EAMEs gerade durch Idiosynkrasien aus, die eben nicht bei anderen gefunden werden oder als Ausdruck eines allgemein akzeptierten Stiles gedeutet werden können, dem sich andere Designer nur zu gerne anschlössen.

Ein paar Zeilen weiter wird eine Aussage NORTHCOTE PARKINSONs kolportiert, der das im Zusammenhang mit der von ihm postulierten Seltenheit des genialischen Designers äußert. Dessen Aussage, Designer seien zumeist recht gewöhnliche Menschen, die verloren wären, gäbe man ihnen zu viel Freiheit und die wesentlich glücklicher seien, wenn sie einem allgemein akzeptierten Stil folgen könnten, kann man heute nur noch als impertinent klassifizieren. (vgl. ebd.: 7f) Mit HUGH M. BOWEN und der HFG ULM kommt ALLISON dann in seiner Zeit an:

"Government and private enterprises cannot be asked to do everything in the development of the future society. Neither can the traditional institutions such as the church and school be asked to do it all. Part of the 


\section{STARDESIGNER ODER GESTALTER DES ALLTÄGLICHEN?}

job will have to depend on the creativity of architects and designers. Hugh $\mathrm{M}$. Bowen maintains that the designer is growing away both from his role as a mere decorator and from pure engineering functionalism with its accompanying attitudes of ras long as it works it is sufficient.، Bowens' description of the contemporary designer seems to fit the men who designed the braun products described in chapter two. It also seems to fit the rationale of the new Hochschule fur Gestaltung [sic] [Hervorhebung im Original] in Ulm. This school is of the Bauhaus variety and emphasizes the combination of individual experiment with team work in design projects, inculcates a sense of social responsibility, and advocates international community of culture. The existence of this institution is not properly to be regard [sic] as a revival of the anonymous style, which has persisted and developed since the closing of the Bauhaus, but as a reinforcement of the chief tendency in contemporary design." (ibid.: 33)

Am Ende dieses Essays liegt die bemerkenswerteste Argumentationslinie in der Fundierung der amerikanischen Forderung nach einem - international gesehen - anonymeren Design im Bauhaus und der Annahme einer Traditionslinie zur HFG, die aus ALLISONs Perspektive gerade ihre Pubertät erreicht hatte. Seine Analyse von BRAUN-Produkten ist für den hiesigen Argumentationszusammenhang nicht weiter wichtig gewesen, weil sie nur darauf abzielt, zu belegen, weshalb die analysierten Artefakte zum Anonymen tendieren - sie wird deshalb außer Acht gelassen.

Eine weitere Besonderheit bleibt das ständig präsente Gefühl eines Aufbruchs in die Zukunft, das Verfolgen einer Sozialutopie, sowohl auf gesellschaftlicher Ebene als auch in der Disziplin selbst. Die Gesellschaft soll sich verändern und die Designer sollen sie, sich und ihre Disziplin verändern. Anonymität werde sich quasi natürlich im Rahmen der Arbeitsteiligkeit entwickeln. Einerseits werde sie gefordert als Konsequenz industrieller Prozesse, die zur Teamarbeit zwängen und aufgrund von Problemen, die zu komplex seien, um von Einzelpersonen vollumfänglich gelöst zu werden. Andererseits aus der Idee heraus, dass der individuelle Genius zu einer Diktatur von Idiosynkraten führe, die einem anonymen Stil als Synthese unterschiedlicher kultureller Einflüsse (!) entgegenstünde. »Where society functions best, individualism and anonymity also flourish best.« (ibid.: 35) 


\section{Das gewöhnliche Design}

Diese Ausstellung ist als Generalangriff auf die Disziplin zu verstehen: Wir befinden uns ab jetzt in einem Minenfeld. Eine bewusste Provokation, 1976 parallel zu einer Jugendstilausstellung auf der MATHILDENHÖHE in DARMSTADT ausgerichtet und wohl der erste Versuch, anonyme Alltagsgegenstände als Das gewöhnliche Design in Form einer Ausstellung vor ein Publikum zu bringen.

Auch dieser Text strotzt selbstverständlich nur so vor Zeitgeist. Zieht man ALLISON im direkten Vergleich heran, so kommt der Aufbruchsgeist, der noch aus dessen Arbeit herausleuchtet, zehn Jahre später zu einem brutalen Halt. Dem drei Jahre nach der Ausstellung veröffentlichten Katalogband entsteigt beim Umblättern mit jeder Seite ein immer dichter werdendes Nebelfeld der Bitterkeit, das wirkt, als hätten die Ausstellungsmacher fortwährend HAUGs Kritik der Warenästhetik wiedergekäut. Man kommt nicht umhin, zu vermuten, sie hätten dies mit Lust getan und wer könnte es ihnen anbetrachts der damals wohl laufenden Debatten verdenken? Bemerkenswert ist, wie noch in der Rückschau bei der Produktion der Publikation an der Idee der unbedingten Richtigkeit des Projektes festgehalten wird. Ein nahezu unerträglich paternalistisches Gehabe spricht aus den Texten der beiden Ausstellungsmacher, von denen man annehmen möchte, sie hätten sich damals schon längst aus Resignation aus ihrer ureigenen Disziplin verabschiedet. FRIEDL bleibt jedoch bis 2009 Professor für Typografie an der FH DARMSTADT und OHLHAUSER ist als Dipl.-Industriedesigner (FH DARMSTADT) bis heute freiberuflich und als Dozent und Verleger tätig. Zum Einstieg zwei Zitate, die in bewundernswerter Offenheit die damalige Wahl- und Erklärungslosigkeit der Kuratoren dokumentieren und zugleich den Erziehungsanspruch verdeutlichen:

"Was jedoch vordergründig konzeptionslos erschien, war letztlich die Offenheit der Ausstellungsmacher, zuzugeben, vorläufig keine bündige Erklärung geben zu können, warum diese alltäglichen Dinge so gut und vernünftig gestaltet sind. [...] Die nicht fachkundigen Besucher der Ausstellung wurden durch einen kurzen Begleittext darauf hingewiesen, daß sie mit diesen Gegenständen ihr tägliches Leben durchführen. Sie konnten lernen, daß Design nicht erst - wie es die Medien suggerieren - ab einer bestimmten Preisklasse beginnt, und daß jene Gegenstände in ihrem Leben eine mindestens ebenso wichtige Rolle spielen wie das >Design «." (FRIEDL und OHLHAUSER 1979: 11f) 


\section{STARDESIGNER ODER GESTALTER DES ALLTÄGLICHEN?}

»Die Ausstellung wollte provozieren. Sie zeigte Produkte, deren Design wir als selbstverständlich und nicht mehr verbesserungsbedürftig betrachten. Die Studenten sollten sich fragen, was sie nun wirklich wollen. Ob sie tatsächlich ,fertige Produkte wollen oder ob sie weiter in der Schizophrenie verharren wollen, den wissenschaftlichen Apparat für das sendgültiger Design zwar stetig zu verfeinern, gleichzeitig aber die [sic] gesellschaftlich vereinbarte und von den Medien gepflegte Rolle des Designs als dem jeweils neuesten Schrei zuzustimmen. Die Ausstellung konnte auf diese Probleme hinweisen und Kritik an der Produktion des Überflüssigen üben; eine Lösung bietet sie natürlich nicht an. Immerhin ist sie der persönliche Protest der betroffenen Designer. Ein Ausdruck des Unmuts gegenüber jedem ambitionierten und programmatischen Design von der guten Form bis zum Sozial- und Billig-Design, das schließlich doch nur zur bloßen Verkaufsmasche gerinnt. [...] So wurde die Auswahl der Gegenstände nach nicht weiter reflektierten Gesichtspunkten spontan und gefühlsmäßig getroffen und im Laufe der Vorbereitungen immer wieder ebenso unreflektiert revidiert.« (ebd.: 18f)

Designer wie Industrie, Publikum und Studenten bekommen hier zu gleichen Teilen ihr Fett weg, so wie auch implizite Kritik an der Jugendstilausstellung und an Museumsausstellungen generell geübt wird:

"Versuche, eine Zeit durch museale Selektion zu erhöhen, gelingen fast immer: Wie die Wirklichkeit aussah, wird unterschlagen. Die gewöhnlichen Dinge, die in unserer Ausstellung zu sehen sind, sind wichtiger [Hervorhebung im Original] als die Objekte des Jugendstils. Denn mit unseren Dingen wurde keine Kultur fürs Museum erfunden, sondern wird alltägliches Leben durchgeführt. [...] Die Ausstellung findet in einer Designschule statt. Sie zeigt Dinge, die fertig [Hervorhebung im Original] sind. Daß sie es sind, ist die Nachlässigkeit einer Industrie, die nichts Dauerhaftes produzieren darf. Das ist eines der gegenwärtig ausweglosesten Probleme des Designs, der Designausbildung - und allem anderen.« (ebd.: 37)

Designer werden als Bedürfnismanipulatoren gebrandmarkt, die Konsumenten unausgesprochen als fehlgeleitet:

"Das gewöhnliche Design ist der Massenproduktbereich, der für die Bedürfnismanipulatoren auf der einen und die nach sozialer Identität und Differenzierung heischenden Gebraucher auf der anderen Seite uninteressant ist.« (ebd.: 14)

Dass auch die gesamte Designausbildung mitsamt den Studierenden und Lehrenden hinterfragt wird, können die folgenden Zeilen belegen - die in ebenso großem Schwunge geübte Industrie-, Konsum- und Gesellschaftskritik hat bis heute nichts von ihrer Schärfe verloren: 
„Von einem Großteil der Studentenschaft blieb der Appell der Ausstellung unverstanden und wurde allenfalls für überflüssig gehalten. Offenbar eine Folge der fortschreitenden Verschulung des Designstudiums, das die Studenten - die Dozenten sind nicht ausgenommen - nur noch als Vermittlung und Aneignung für die sproblemfreie berufliche Praxis zubereiteten und verwertbaren Wissens begreifen. In einem solchen Klima müssen Problem- und Denkanstöße zum eigenen Selbstverständnis Ratlosigkeit und Aggression hervorrufen." (ebd.: 12)

"Nach dem endlich vollzogenen Bekenntnis zur Massenproduktion klafft die Lücke zwischen Produktkultur und den Weisungen der Designinstitutionen aber ungeschmälert fort. Das liegt einerseits daran, daß der Designer in der betrieblichen Praxis seine Rolle als Anwalt des Gebrauchers nur soweit verwirklichen kann, wie sie dem gewinnorientierten Produzieren des Unternehmens dient. Gewinn kann fortwährend nur erzielt werden, wenn der Verbraucher am Kaufen gehalten wird. Mangels echter Neuentwicklungen fällt dem Designer dabei die Aufgabe zu, vorhandene Produkte derart zu differenzieren, daß sie zum erneuten Kauf stimulieren. Dazu wird sich der Gebraucher allerdings nur bewegen lassen, wenn ihm das neue Produkt über den technischen, funktionalen Nutzen hinaus auch vermittels seiner ästhetischen Erscheinung einen neuen Gebrauchswert verspricht: nämlich zu seiner sozialen Identität und Differenzierung finden zu helfen. Denn die gesellschaftlichen Beziehungen regeln sich als Verhältnisse zwischen den Sachen. In entmutigendem Maße ist der Designer zum bloßen Warenästhetiker degradiert, der die technische Produktion fortwährend ästhetisch manipuliert, um den Menschen immer wieder neue Bedürfnisse in Form von schnell verschlissenen Statussymbolen, Geltungs- und Surrogatobjekten zu liefern.« (ebd.: 13)

Nachdem das geklärt ist, wird eine erweiterte Definition des gewöhnlichen Designs in Abgrenzung zum dadurch notwendig gewordenen Begriff des ungewöhnlichen Designs versucht, an dem sich in einem späteren Text auch noch PETER VON KORNATZKI abarbeitet:

"Eine klare Grenze zwischen dem ungewöhnlichen und dem gewöhnlichen Design gibt es also nicht. Es ist nicht der Unterschied zwischen dem besseren und dem schlechteren Design, nicht in der Stilistik und Formensprache. Es gibt lediglich eine Tendenz zur unauffälligen technischen Funktionsrationalität (zu unterscheiden vom kultivierten Funktionaldesign im Dienst der Umsatzsteigerung), je unbedeutender die Produkte im beschriebenen Sinn werden. Es ist falsch, anzunehmen, die vollkommen unbedeutenden Produkte seien nicht designt. [Hervorhebung des Verfassers.] Ihre Erscheinung wird immer wieder an die veränderten ästhetischen Normen angepaßt. Wenn es nicht mehr zur Absatzerhaltung und -steigerung geschieht, dann offenbar immer noch dann, wenn etwa die Produktionsanlagen ausgetauscht, erneuert oder modernisiert werden, wenn ein vereinfachtes, aber formveränderndes Herstellungsverfah- 


\section{STARDESIGNER ODER GESTALTER DES ALLTÄGLICHEN?}

ren gefunden wird oder wenn anläßlich einer Preiserhöhung mit der Preisaufschrift gleich die gesamte Verpackung neu entworfen wird. (ebd.: 16)

Die Widersprüchlichkeit der folgenden contradictio in adiecto darf man sich auf der Zunge zergehen lassen: „Das gewöhnliche Design ist kein Design.» (ebd.: 38) Ein Satz der provozieren will und der so, wie er steht, Sinn wie Unsinn in sich vereint. Denkt man sich in den zeitbezogen denkbaren Sinn dieser Aussage hinein, bedürfte es noch einiger Zeilen, um den eigentlichen Gedanken textlich auszubreiten.

Damals schätzen sich die Ausstellungsmacher sicherlich glücklich, ihre Ausstellungseröffnung mit einer Einführungsrede von BAZON BROCK nobilitieren zu können und gehen damit auch merklich-unmerklich ihren eigenen Distinktionsbedürfnissen auf den Leim. Dessen ungeachtet hat BROCK wesentliches zum Verständnis von Designartefakten aus der Sicht einer Archäologie des Alltags beizutragen:

"Die Archäologie des Alltags ist zunächst im Bereich der Künste praktiziert worden. Eine ganze Reihe von Künstlern hat sich speziell auf diese Form der Beschäftigung mit Objekten eingelassen. [...] Wir haben 1973 zu diesem Problem in Berlin einen Kongreß veranstaltet, indem wir die führenden Wissenschaftler der einzelnen Disziplinen baten, mit ihren Techniken - die sie anhand mexikanischer und griechischer kultureller Lebenszeugnisse entwickelt hatten - unsere Alltagswelt, beispielsweise einen Stuhl, zu analysieren. Bei dieser Übertragung von Methoden aus einzelnen spezialisierten Kulturbereichen auf die Alltagswelt erschlossen sich in der Tat die Gebrauchsgegenstände in einer Weise, wie man das nicht vermutet hatte und auch nicht vermuten konnte." (BROCK in: FRIEDL und OHLHAUSER 1979: 24)

BROCK kommt auch der Verdienst zu, die Trennung zwischen Hochkultur und Alltagskultur bewusst durchbrochen zu haben, um klarzustellen, weshalb Alltagsgegenstände mit den gleichen Mitteln wie Werke der Kunst untersucht werden sollten:

"Die erste Voraussetzung, die von allen anerkannt wird, ist die, dass es keine Möglichkeit gibt - weder wissenschaftstheoretisch, noch praktisch - hochkulturelle Gegenstände und alltägliche Gegenstände prinzipiell voneinander zu unterscheiden. Das heißt: es besteht prinzipiell keine qualitative Differenz zwischen einem Gemälde beispielsweise von Macke und einem Hemd, das in der Zeit Mackes getragen wurde. [...] Das ist also eine der wesentlichen Voraussetzungen. Sie wird ergänzt durch Erkenntnisse der Wahrnehmungspsychologie von R. Arnheim, aus denen ebenfalls hervorgeht, daß die Unterscheidung zwischen Kunst und All- 
tagsleben oder zwischen Hochkultur und Subkultur nur ein Konstrukt darstellt." (ebd.: 25)

"Die Ausstellungsform signalisiert uns also: Seht diese kümmerlichen Objekte, Reifen, Büroklammer oder Aktenordner einmal genau in der Weise, in der Ihr in Museen gelernt habt, einen Picasso anzuschauen; nur dann habt Ihr eine Chance, diesem Objekt etwas anzusehen, ihm etwas abzunehmen, in diesem Objekt etwas zum Sprechen zu bringen, was mit Eurer unmittelbaren, alltäglichen Lebensgestaltung im Zusammenhang steht, ja diesen Zusammenhang erst ermöglicht.« (ebd.: 36)

VON KORNATZKI wird nun noch einmal breiter Raum für seine Vorstellung von ungewöhnlichem Design gelassen, der die damalige Verfassung der Profession und ihren Blick auf sich - im Verhältnis zur Industrie und der Gesellschaft als Ganzem - wiederum in individuell zeitbezogener Schärfe beschreibt:

»Wir, die Designer, unterscheiden zwischen schlechten und besseren Gegenständen anders. Schlechte Gegenstände sind solche, die nicht (oder nicht von uns) gestaltet sind. Bessere Gegenstände sind alle die, an denen ein bestimmter [Hervorhebung im Original] Gestaltungswille sich äußert. Welcher genau? - Das gerade hält ja die Designer in Trab, das Design in der Diskussion und die Käufer am Kaufen. Wir wissen es nicht. Wir wissen nicht, was wohl einen Gegenstand `besser als andere Gegenstände macht, der durch unsere [Hervorhebung im Original] Köpfe und Hände geht. Wir behaupten es. Wir glauben es. Wir beweisen es sogar. Aber wir sind überrascht, gewöhnliche Gegenstände zu finden, die ungewöhnlich gut [Hervorhebung im Original] gestaltet sind, ohne daß sie durch die Hände oder Köpfe von >Gestaltern ‘ gegangen sind. (Durch die Köpfe und Hände von Menschen aber, die viel vernünftiger gestalten als wir vernunftbesessenen Designer.) [...] Die Ansprüche der Designer und ihr Selbstwertgefühl, das papierene Geschwafel um das Design und seine gesellschaftliche Wertschätzung erscheinen als Farce angesichts der Wirklichkeit des Designs. Nur vier von zehn Absolventen einer Designschule arbeiten als Designer. Unterordnung unter omnipotente Marktstrategen und hirntötende Lohnarbeit sind das, was vom Zauber kultureller Höhenflüge überbleibt. Geld, Verwertbarkeit und Machbarkeit sind die Reizworte, die jene vielbesungene sgute Form ‘ wie Schnee im Sommer dahinschwinden lassen. Es stinkt. Und trotzdem wächst und gedeiht das Design. Und trotzdem sind sich 85\% der Designer sicher, ganz bald schon das zweite Bein auf den Boden zu bekommen. [...] Am Horizont ein Hoffnungsschimmer: die Adaption der Praxis. Eben jener Praxis, deren Zwängen und eindimensionalen Ansprüchen der Designer gerade seinen Abstieg vom 'Kulturvermittler zum Marktbefriediger zu verdanken hat. Doch natürlich auch jener Praxis, die uns Designer und das Design mit Brachialgewalt aus den Elfenbeintürmen vertreibt." (VON KORNATZKI in: FRIEDL Und OHLHAUSER 1979: 39f) 


\section{STARDESIGNER ODER GESTALTER DES ALLTÄGLICHEN?}

So sich der Vorhang hier schließt, sind keine Fragen mehr offen. Wir sehen eine Reihe von Designern vor uns, die den Konsumenten zum Gebraucher machen müssen, um über ihn reden zu können. Dieser Begriff kondensiert gleichsam die gesamte marxistisch fundierte Konsumkritik der damaligen Zeit. Das Wort weist nach innen und nach außen: Es kritisiert die Artefakte, die gebraucht werden sollen und doch nicht zu gebrauchen sind, es kritisiert den Konsumenten, der nach Distinktion und Status heische, anstatt nach dem, was tatsächlich zu gebrauchen sei und es kritisiert die Designer als Bedürfnismanipulatoren, die am langen Arm der Industrie vor sich hin verhungern. Sie werden weder von derselben noch von der Gesellschaft wertgeschätzt.

Zu gleicher Zeit argumentieren eben diese Designer ihre eigene Profession weg, sie halten sich selbst für unzulänglich, verleugnen die Ergebnisse von Arbeitsteiligkeit und Spezialisierung, während sie scheinbar händeringend auch noch diejenigen zu sein wünschen, die eben diese Gesellschaft mitsamt dem Design und durch das Design zu retten hätten. Im letzten Halbsatz findet sich eine Haltung gespiegelt, die sich auf Kongressen und in Publikationen in den vergangenen Jahren wieder mit großem Furor breit macht.

Versucht man, einen gefälligeren Akkord anzuschlagen, so wird hier die Ehre der nichtbekannten, nichtgenannten, namenlosen Handwerker gerettet und der Prozess einer handwerklich fundierten Genese von Artefakten geehrt, wie ihn Jahre später auch LICHTENSTEIN als Basis seiner Ausstellung Unbekannt - Vertraut setzt und auf den CLIVIO mit seiner Sammlung ebenfalls beständig rekurriert. Dennoch mutet es seltsam an, wenn Designer ihre eigene Abschaffung herbeiargumentieren. Eine damals unahnbare Aktualität hat diese Idee wieder im Rahmen der Maker-Bewegung bekommen, innerhalb derer man nach Herzenslust über das Design am eigenen Herd phantasiert und Designer wahlweise noch kostenfrei Entwürfe für die Allmende bereitstellen sollen oder gänzlich überflüssig werden. 


\section{Unbekannt - Vertraut "Anonymes "Design im Schweizer Gebrauchsgerät seit 1920}

Eine weitere Lobeshymne auf ein Design ohne Designer. LICHTENSTEIN singt ein Loblied auf ein schweizer Design, das keines sei. Er preist die Gestaltung aus der Hand derjenigen, die sich weder Designer nennen noch als solche ausgebildet seien. So schließt er nahtlos an FRIEDL und OHLHAUSER an:

»Der Reiz des Gewöhnlichen, Bescheidenen, Unprätentiösen ist ein Thema unserer Zeit und wohl ein Zeichen der Enttäuschung über die uneingelösten (oder uneinlösbaren) Versprechungen der shohen Kultur." (LICHTENSTEIN 1987: 11)

»Was heißt ranonymes< Design? Die ausgewählten Gegenstände zeigen in dem Sinn anonymes Design, als sie nicht im Atelier eines ausgebildeten Designers entstanden sind, sondern in der Werkstatt des unbekannten Tüftlersı oder im Konstruktionsbüro der Fabrik. An ihnen hat, abgesehen von zwei Ausnahmen, die erwähnt werden, kein eigentlicher sDesigner gearbeitet. Um die Produkte zu verkaufen und ihre Qualität hervorzuheben, wurde nicht mit dem Namen eines Designers geworben." (ebd.: 13)

Er postuliert relativ früh ein Inkognito, das daraus resultiere, dass sich »[...] diese personellen Hintergründe in Erfahrung bringen [...] «lassen, dieses aber nicht geschehe (ebd.: 13). Seine Beispiele bewegen sich fast ausschließlich in einem Bereich von Gebrauchsgeräten, die in ihrem spezifischen schweizer Umfeld eine Reihe von Gerätschaften umfassen, die ebensogut von keinem Designer entworfen - wie sie es auch - sein könnten:

»Bei der Untersuchung der verschiedenen Gegenstände haben sich Ähnlichkeiten gezeigt, die sich als diesem Bereich innewohnende Charakterzüge bezeichnen lassen. Die Objekte gründen in der Persönlichkeit ihrer Entwerfer, die ihrerseits mit der Kultur- und Technikgeschichte der Schweiz in ihrem ganzen Denken verbunden sind. Dass den untersuchten Objekten jegliche Theatralik fremd ist, zieht sich durch die gesamte vorliegende Arbeit und ist bestimmend für die Tonart, in der das sanonymer Design hier steht.« (ebd.: 14f)

Die Ausnahme unter seinen Beispielen bleibt die TOBLERONE als einziges Nahrungsmittel - was nicht deren einzige Ausnahme darstellt. Sie liegt auch als einzige zeitlich vor dem Betrachtungszeitraum der Ausstellung und bei einer Schokolade führt höchst selten ein wirklich technischer Funktionszusammenhang zur Formgebung - sieht man einmal ab von der Unterteilung 
in Rippen zur besseren Handhabung und dass Gussformen angefertigt werden müssen. LICHTENSTEIN konzediert, dass die Dreiecksform der leichteren Durchbrechbarkeit dieser Schokolade in Stangenform geschuldet sein dürfte, wofür er jedoch keinerlei Belege beibringt, er muss aber auch »Toblers Sinn für Werbung einen erheblichen Anteil zubilligen, da die "Assoziationen zum Matterhorn", das sich 1939 in einer Reklame findet und ab den 6oer Jahren auch auf der Verpackung abgedruckt wird, in erheblichem Maße zur Formfindung beigetragen haben dürften (vgl. ebd.: 93f). Der Ingenieursanteil ist in diesem speziellen Fall ein geringer, der werbliche Aspekt und die augenfällige Verknüpfung zum Ursprungsland deutlich größer und naheliegender. Wenn von uneitlem Design gesprochen wird, dem »jegliche Theatralik fremd « sei (ebd.: 13f), so hat LICHTENSTEIN sich damit selbst ein Kuckucksei ins Nest gelegt. Die Gestalt der TOBLERONE war und ist auf nichts anderes als auf Wiedererkennbarkeit, Alleinstellung und Markenpräsentation ausgelegt. Weiter unten führt er GIEDION und dessen Werk Mechanization takes command. A contribution to anonymous history als Zeugen an:

"Giedion formuliert es in einer Ausstellungsbesprechung 1929 so: >Auch auf dieser Ausstellung rühren die funktional am besten durchgebildeten Typen von England her. Modelle, die deutlich in ihrer Formensprache die Tradition des 18. Jahrhunderts aufweisen, sind einfach vom Leben zu Standardtypen erhoben worden (Hervorhebung D. H.) [Hervorhebung im Original, der Verfasser]. Man fabriziert sie heute wie vor fünfzig Jahren unverändert und man tut gut daran, sie unverändert zu lassen, denn sie haben eine ausgezeichnete Bequemlichkeit durch ebenso einfache, wie ausgezeichnete Anpassung an den Körper erhalten, so dass geschmäcklerisches Herumbosseln sie nur schlechter machen könnte.< Die hier angesprochenen Gegenstände (in diesem Fall Stühle) verdanken ihre Langlebigkeit nicht zuerst ihrem Schöpfer, der in diesen Fällen nur selten mit Namen bekannt ist, sondern eben dem Leben selbst, das sie zu Standardtypen erhoben hat." (ebd.: 162f)

Das »Leben selbst«: populistisch und unnötig verflacht klingt es hier. Die Tatsache, dass es die Entscheidungen von Individuen sind, die über einen langen Zeitraum messbare Konsequenzen zeitigen, weil Kaufentscheidungen auch Rückwirkungen auf die Produzenten haben, wird einfach unter den Tisch gekehrt: Zugunsten einer griffigen und gefühligen Formulierung, die noch einmal GIEDION affirmiert, ohne sich die Mühe einer differenzierteren Betrachtung zu machen. Gerade auch der zeitliche Abstand hätte dazu herausgefordert. Natürlich muss GIEDIONs Sottise vom "geschmäcklerische[n] Herumbosseln" LICHTENSTEIN wie ein perfekt gekochtes Hauptgericht schmecken, sieht die Planung seines eigenen Menus doch eine gleichartige Geschmacksrichtung 
vor. Die Raffinesse seiner Ausstellung und ihrer Katalogtexte besteht darin, Artefakte ausgewählt zu haben, die uns insinuieren lassen sollen, sie entstünden besser auch weiterhin ganz und gar ohne ein Zutun von Designern. Er sieht sich im Rahmen seiner Bestandsaufnahme als Konservator des Bedrohten:

"Wir wiederholen aber, dass dieses Selbstverständliche gegenwärtig ohnehin in der Gefahr steht, vom technologischen Fortschritt [Hervorhebung im Original] aufgeschluckt zu werden. In der Öffentlichkeit ist zweifellos eine Sensibilität vorhanden für jenen Teil der Umwelt, von dem man merkt, dass man ihn zu verlieren droht. Statt als nostalgischen Blick auf das Bereits-Entschwundene wollen wir diesen Teil aber als das Noch-Gegenwärtige dokumentieren." (ebd.: 14)

Man könnte lachen, wenn es nicht so traurig wäre, bei diesem Hervorheben des Un-Theatralischen:

- " $[. .$.$] den untersuchten Objekten [ist] jegliche Theatralik fremd [...]«,$

- dem zwanghaften Herbemühen einer werkstattnahen Handwerklichkeit: »[n]irgends hat ein Entwerfer fernab von der 'Werkstatt gearbeitet.« - die sei »ohnehin eine Bedingung für jedes ernsthafte Design«,

- dem »[...] Gestaltungswille[n] [, der] eingebunden [sei] in eine handwerklich-technische Haltung und

- dass das Wort Design genutzt wird, die »Entwerfer [aber] mit den Konstrukteuren identisch" sein müssen.

Alles dreht und wendet sich in Richtung einer verqueren Ablehnung und WegArgumentierung des Designs und der Designer, wie sie schon bei FRIEDL und OHLHAUSER zu finden ist. Man kommt nicht umhin, im Lob des Handwerks auch vermeintliche Defizite des nicht offen kritisierten Designs mit formuliert zu sehen - dennoch erachtet LICHTENSTEIN gerade die Handwerklichkeit als eine Grundvoraussetzung des Letzteren. Dass eine Argumentation um den gleichen Aspekt genau gegenteilig geführt werden kann, sieht man im direkten Vergleich zu ALLISON, der die »zwangsläufige« Anonymität herleitet aus den Projekten, die zu groß werden, um von einer Person alleine bewältigt zu werden. LICHTENSTEIN sieht sie dagegen gerade dort blühen, wo »[...] der Erfinder/Handwerker noch weitgehend den Überblick über den gesamten Produktionsprozess hatte (und hat)« und er spezifiziert den Umfang des zu überblickenden Produktionsprozesses nicht (Zitate der drei vorstehenden Abschnitte ebd.: 14f). Hier also die Anonymität im Kleinen, Überschaubaren, dort im Großen; einerseits Anonymität gerade mit dem Überblick über das 


\section{STARDESIGNER ODER GESTALTER DES ALLTÄGLICHEN?}

Ganze, andererseits Anonymität aus der Unüberblickbarkeit. Das »uneitle Design«als Gegensatz zur Theatralik:

"Als suneitles Design sind diese Gebrauchsgüter nicht aufgrund der Analyse von Marktforschern, Produkteplanern, Industrial Designern und Fertigungsingenieuren ins Leben gerufen worden. Soweit sich bisweilen auch [Hervorhebung im Original] von einer Analyse der Marktlage sprechen lässt, erfolgte diese in der Werkstatt. In allen Fällen handelte es sich darum, ein bestimmtes Problem zu lösen, in keinem mündete dies in eine Inszenierung. Die Gegenstände erhalten damit einen Zeugnis-Charakter für eine Realität, die noch wesentlich skonkreter war als in den heutigen Verhältnissen im Zeichen der Mikroelektronik. Sie repräsentieren einen Teil der Realität, die noch nicht vom Verlust an >Common Senser und Anschaulichkeit, vom immer schnelleren Veralten zivilisatorischer Güter geprägt ist. Damit entsprechen diese Gegenstände nicht den Vorstellungen von >Design` im gegenwärtig geläufigen (verfälschten) Sinn, sondern einem verbindlicher gefassten Designbegriff, der neben dem ästhetischen auch den historischen, soziokulturellen und funktionellen Kontext umfasst und aus diesem zu verstehen ist. >Design ‘ wird hier also verstanden als Oberbegriff für einen umfangreichen Prozess, der bei einer Ideenentwicklung beginnt, während einer Entwurfsphase umgesetzt wird und in der Form eines Produktes, einer auf die Bedürfnisse des Benutzers ausgerichteten Lösung endet. Das suneitle Design` zu untersuchen heisst, es dem vorwiegend gefühlsmässig erlebten, emotional erfassten Bereich zu entheben und damit zu einer Auseinandersetzung mit der industriell produzierten Umwelt - die ein mehrdimensionales Wissen bedingt - anzuregen.« (ebd.: 13f)

Bis heute erstaunt es, dass LICHTENSTEIN sich genötigt sah, als Antipoden seiner anonymen Designidee ein Designgefühl der Theatralik zu postulieren, das in Emotionalität im Gegensatz zur Entwurfsneutralität des anonymen Designs gipfelt und dass er ein so tiefes Misstrauen »Marktforschern, Produkteplanern, Industrial Designern und Fertigungsingenieuren " gegenüber an den Tag legt, gleichzeitig aber zu konzedieren in der Lage ist, dass der Tüftler das Gleiche in seiner Werkstatt tue (s. o.).

Gut, man könnte noch einwenden, dass zum Zeitpunkt der Ausstellung der Designboom der 8oer Jahre auch in der scHWEIZ noch nicht abgeflaut war und die Nähe zu ITALIEN lässt auch einen gewissen Schrecken angesichts von MEMPHIS ahnbar werden .... Eigentlich beschreibt LICHTENSTEIN in seinen obigen Zeilen die heutige Realität des Gestaltungsberufs. Doch er wertet in einer aus heutiger Sicht uninformiert und ungerechtfertigt wirkenden Art und Weise, die sich auf formale Konsequenzen als Begleiterscheinungen der Mikroelektronik und die Veränderungen, die darob ausgelöst werden, nicht einzulassen vermag: Die »endgültige« Entstehung der Black Box als To- 
pos im Feld des Designs. In diesem Zusammenhang darf jedoch nicht vergessen werden, dass diese schon von DREXLER als »disappearing object « thematisiert wird, wie bereits bei ALLISON zu lesen ist. Mit dem »Verlust an ,Common Sense« begibt LICHTENSTEIN sich jedoch auf ein Terrain, das seiner Argumentation jegliche Glaubwürdigkeit nimmt und nur noch ein resignierendes Festhalten am Vergehenden atmet. So die Konsumkritik in Wellenbewegungen durch die Geschichte voranrollt, können wir hieran knapp zehn Jahre nach FRIEDL und OHLHAUSER einen erneuten Tidenhub feststellen. 


\section{Special Issue Anonymous Design}

Als gaikokujin über eine fast gänzlich fremde Kultur zu schreiben, birgt spezielle Schwierigkeiten in sich, denn die Wurzeln des anonymen Designs reichen in Japan weit hinein in die Kultur dieser Nation - aus europäischer Perspektive ist sie auch in einer im Ganzen offeneren Welt noch immer reichlich verschlossen. So ist die Sonderausgabe Anonymous Design der Japanische[n] Gesellschaft für Designwissenschaft (JSSD; JAPANESE SOCIETY FOR THE SCIENCE OF DESIGN) überhaupt nur anhand ihrer glücklicherweise ins Englische übertragenen Titel auffindbar gewesen ${ }^{1}$. Die japanische Position zur Anonymität im Design unterscheidet sich noch einmal grundlegend von den schon betrachteten wie von den noch zu betrachtenden. Bei ALLISON sehen wir anonymes Design entstehen als - womöglich erlernbare - professionelle Konsequenz immer komplexer werdender Designaufgaben. Folgen wir FRIEDL und OHLHAUSER wie LICHTENSTEIN auf die Metaebene des Aussortierens und Kategorisierens, dann steht an dessen Beginn und Ende die mutwillige Entfernung der Designer aus ihrer Profession oder die mutwillige Verortung des Designs bei jenen, die sich gar nicht Designer nennen. In Japan betritt man kulturell anders begründeten Boden. Den japanischen Designwissenschaftlern ist das Thema bedeutsam genug, um sich mit den »Gegenpole[n] Berühmtheit und Unbekanntheit« auseinanderzusetzen. HINO EIICHI arbeitet das schon zu Beginn seines Textes Anonymity in Design. Its history and the present state heraus:

"So einfach ist es allerdings nicht, dass die Anonymität im Bereich Design mit der Fragestellung zusammengefasst wird, ob ein Produkt/ eine Sache/ ein Ding einen Namenszug trägt oder nicht, doch eine bessere / treffendere Beschreibung lässt sich wohl nicht finden. Nimmt man nun den japanischen Begriff mumeisei (Unbekanntheit/Namenlosigkeit), steht dem sicher yûmeisei (Bekanntheit/Namhaftigkeit) gegenüber, die Bedeutung ist hier meiner Meinung nach geringfügig anders. Aus diesem Grund möchte ich während meiner Ausführungen als Konzeption zum Gegensatz des mumeisei das shomeisei benennen: die Signatur auf einem Produkt bzw. den Akt der Signatur / Namensgebung." (EIICHI 1993: 1)

1 Aufgrund der beim Erstkontakt spontan überschlagenen Bearbeitungstiefe und Spezifität dieser Position wurden die Übersetzungsrechte für diese Dissertation erbeten. Zwei Texte von MIYAUCHI SATOSHI und HINO EIICHI wurden von ULRIKE SCHLACK ins Deutsche übertragen. 
»Wird innerhalb des Aufsatzes von mumeisei (Unbekanntheit/Namenlosigkeit) gesprochen, so bezieht sich dies auf den Bereich der bildenden Künste. Im Vergleich zur Malerei und Bildhauerei, die ebenso zu den bildenden Künsten gehören, ist im Bereich des Designs eine Nuance des mumeisei enthalten. Kurz gesagt ist es so, dass während das shomeisei (die Signatur auf einem Produkt bzw. der Akt der Signatur/Namensgebung) im Genre der Malerei und Bildhauerei als Selbstverständlichkeit angesehen wird, mumeisei eine Behauptung im anonymous design ist." (ebd.: 1f)

Eine Passage aus der Einleitung des Kapitels von SATOSHI ruft uns in Erinnerung, dass anonymous design

»eine geschaffene Design-Handlung, [ist] welche aus dem Volk entstanden ist, vom Volk in die Praxis umgesetzt und tradiert wurde und in der inhaltlich Alltagsgegenstände, Kleidung, Bauernhaus-Szenerien und Siedlungen bis hin zu industriellen Produkten Platz finden. [...] Auf der Gegenseite finden sich Produkte, die durch Herstellungsprozesse von Künstlern mit Namensnennung gekennzeichnet sind." (SATOSHI 1993: 2f)

Was hier schon als deutlicher Unterschied zu den vorgenannten auffällt, ist die Verortung im Volk, die sich wie selbstverständlich zu Design weiterentwickelt zu haben scheint, ohne die Grenzlinien von FRIEDL und OHLHAUSER oder LICHTENSTEIN zu ziehen, die Design eher als der tradierten Entwicklung auf- wie fast entgegengesetzt und von ihr abgetrennt wahrnehmen. Für EIICHI ist die Namenlosigkeit untrennbar mit dem anonymen Design verbunden. Er begründet die Entwicklung hin zum signierten Artefakt in ihren Anfängen im alten Griechenland:

"Der Grund für die Existenz der Signatur war der, dass man viele Konkurrenten aus dem Weg schaffen wollte, sodass die Aufmerksamkeit auf einen selbst stieg und dies war mit einem wirtschaftlichen Gewinn verbunden. Die Signatur im alten Griechenland lag also in der Beziehung zweier Aspekte des ökonomischen Profits. Die Wortschöpfung ist vielleicht nicht die passendste, aber es ist nicht zu verneinen, dass es den Charakter der Eigenwerbung / den Verkauf des eigenen Namens aufzeigt." (EIICHI 1993: 4)

\section{Er zitiert aus VAN LOONs The Arts (1939) mit der Passage:}

»[...] die Künstler haben begonnen, das Nicht-Signieren aufzugeben, sind zu Persönlichkeiten geworden, die originelle Ideen, eigenen Charakter, eigenen Stil und Namen hatten. Dies geschah am Ende der Gotik-Perioder [Hervorhebung des Verfassers] und das Signieren und Nicht-Signieren (das Vorhanden- bzw Nichtvorhandensein einer Signatur) beschreibt die Grenze zwischen Mittelalter und Renaissance.« (ebd.: 4f) 


\section{STARDESIGNER ODER GESTALTER DES ALLTÄGLICHEN?}

\{Einschub. Das Original zum Vergleich: »But times changed and the artist began to lose his anonymity and became an individual with ideas and idiosyncrasies and a style and a name of his own. When that happened, we can speak of the end of the Gothic period." (VAN LOON 1939: 213)

Zum Verständnis des Kontexts ist auch das Vorstehende wichtig:

"The art of the first six hundred years of the Middle Agess was an anonymous art. The architects built anonymously. The painters and sculptors and miniature makers never bothered to sign their works. It is difficult to imagine such a state of affairs in our age of exaggerated publicity when we build vast and complicated reputations around a name and when it sometimes looks as if painters invariably begin by signing their canvases and then add the picture later as a sort of an afterthought." (ibid. 212)\}

\section{EICHII fährt fort:}

"Das Signieren ist allgemeinen ein Phänomen, welches nach dem Mittelalter mit immer stärker werdendem Selbstbewusstsein aufgetreten ist; es traten Sammler zum Vorschein, Produkte wurden kommerzialisiert und als Produkte zum Kauf und Verkauf angeboten wurden, war quasi eine Signatur zu hinterlassen." (EICHII 1993: 5)

»Bekannt ist, dass die Design-Bewegung der Gegenwart - als Antithese zur Kunst jener Epoche - das Modell im Mittelalter suchte und übernahm. Letztendlich findet sich anonymous design auch an diesem Punkt ein. Man sollte meinen, es existiert am Ursprung zur Kritik gegenüber der Signatur, die das Ziel der Eigenreklame der Künstler hatte und sder Anonymität aus der frommen Seele gegenüber Gott‘. (ebd.: 8)

Jene oben schon mehrfach angesprochene Idee der Eigenwerbung oder auch Eigenreklame stellt die bedeutsamste gedankliche Differenz von EIICHI zu den anderen hier betrachteten Autoren dar. Man kann seine Argumentation direkt an die von ALLISON anschließen, wenn man folgendes liest:

"Bei einem Werk im Design unterscheidet man ein individuelles Werk und ein gemeinschaftliches Werk. Man hört das Argument, dass es sich bei einem Werk, welches während einer Gruppenarbeit des letztgenannten entsteht, um ein Beispiel des anonymous design handelt. Doch es ist nicht einfach, so zu argumentieren, denn einerseits wird wie im Film, der Name des Regisseurs gezeigt, er trägt die Verantwortung, obwohl es voll und ganz eine Gruppenarbeit ist und andererseits wird in Bereichen wie dem Design der Name nicht genannt, obwohl es ein individuelles Werk ist." (ebd.: 11) 
Damit wird auch der Bogen zu KAJ FRANCK und MERENMIES (s. u.) geschlagen. Im Vorgriff auf das noch kommende Kapitel bietet sich im Vergleich schon ein Zitat von KAJ FRANCK an:

"Eine Untersuchung der verschiedenen Faktoren und deren Einfügung in das Ganze erfordert viel Zeit und Arbeit von vielen Leuten, die ihre Ausbildung auf verschiedenen Gebieten erhalten haben. Ein Mitglied dieser Gruppe - und zwar ein sehr wichtiges - ist der Designer. Je grösser die geplante Serie ist, je grösser ist die Verantwortung und je zahlreicher sind die Personen, die diese Verantwortung miteinander teilen." (FRANCK in MERENMIES 1998: Anhang A)

Auch EIICHI bezieht am Ende seines Aufsatzes in ähnlicher Art Position zur namentlichen Kennzeichnung wie zeitlich vor ihm KAJ FRANCK:

"Ich bin der Meinung, dass Produkte von Handwerkern auf jeden Fall den Namen des Herstellers tragen sollten, in der Bedeutung, dass man Verantwortung für die eigenen Werke übernimmt. Dies möchte ich jedoch nicht in der Bedeutung der Signatur wie oben verstanden wissen, sondern im Sinne von kôhyô -> das Veröffentlichen des Namens des Herstellers, und es somit Veröffentlichung nennen.«(EIICHI 1993: 13)

Besonders interessant am Begriff kôhyô sind in diesem Zusammenhang Nebenbedeutungen, mit denen er auch im Sinne von guter Reputation, öffentlicher Meinung und geschäftlichem Erfolg verwendet werden kann (!). Ebenfalls bezieht EIICHI sehr deutlich Stellung gegen ein Design, das nur als Werbemaßnahme für seinen Schöpfer in die Welt kommt und zieht interessanterweise auch den Schluss, dass die amerikanischen Designer sich nicht in dem Sinne und in die Richtung entwickelt hätten, die ALLISON in den 6oern des 20. Jhd.s noch als unausweichlich betrachtet:

"Daher kann ich nicht mit dem Gedanken, der das Thema Signatur nur sehr eng und an der Oberfläche umreißt, übereinstimmen, dass sich Anonymität nur daraus ergibt, ob ein Designer seinen Namen hinterlässt oder nicht. Wie wir oben gesehen haben, liegt das wirkliche Problem darin, dass die Signatur eng mit der Eigenreklame verbunden ist. Aus diesem Grund sollte das Prinzip zum Ziel gemacht werden, zum einen zu verhindern, dass das Design in den durch Eigenreklame bestimmten Merkantilismus hineinfließt und zum anderen in der Tat das Design für das Volk zu suchen. Aus diesen Gründen denke ich, auch wenn es sich um mushomei [Nicht-Signatur/Nicht-Signieren] handelt, ist das Handeln unheimlich vieler amerikanischer Industrial Designer entgegen dem Prinzip des anonymous design. Sie sagen unverblümt und ohne Rücksicht ,Unser Daseinsbeweis ist, wenn sich das Produkt des Auftraggebers verkauft.< In der Tat gestaltet sich die gegenwärtige Gesellschaft so, dass man über- 


\section{STARDESIGNER ODER GESTALTER DES ALLTÄGLICHEN?}

flutet wird mit Markenartikeln und Produkten, von denen man glaubt, sie seien etwas besonderes, dass sich Selbstbehauptung durchsetzt und andere Produkte bei Seite geschoben werden. Und, um Produkte besser zu verkaufen, kommt es zu häufigen Modelländerungen/-anpassungen und Namen von Designern werden deutlich auf der Oberfläche des Produkts gezeigt.« (ebd.: 9)

EIICHI schließt seine Argumentation ab, in dem er die Frage nach der Anonymität mit einer Wendung ins Moralische beantwortet und sich gleichzeitig sehr deutlich von FRIEDL und OHLHAUSER und auch LICHTENSTEIN absetzt, ohne sich bewusst auf diese zu beziehen - denn diese halten schlechterdings alle Gestaltung für die bessere, wenn sie nicht dem Stift eines Designers entspringt - wogegen EICHII eindeutig Stellung bezieht:

"Es ist wichtig, das Bewusstsein für die Schaffung einer Moral des sogenannten Berufsdesigners zu erhöhen, und für die Ausbildung derjenigen, die das Ansinnen haben, Designer zu werden, sich nicht nur auf die Ausdruckskunst in der Designausbildung zu konzentrieren, sondern sich eine Führung bezüglich dieser Moral zu wünschen. Kürzlich ist auf dem Gebiet der Medizin das Leitbild bezüglich der Eignung als Arzt und die Erziehung zur Moral zum Thema geworden; für den Bereich des Designs wäre es ebenso angebracht, sich dieselben Fragen zu stellen. Andererseits im Schatten der Existenz guter Designer darf die Unterstützung durch das Volk nicht fehlen. Das bisherige Design ist aus dem Volk geboren und hat Halt durch das Volk erfahren. Auch mit heutigen Augen gesehen, sind es nicht wenige Dinge, die wundervoll sind. Aber es ist auch Tatsache, dass man nicht sicher sagen kann, dass alles, was aus dem Volk hervorgeht, großartiges/ausgezeichnetes Design ist. Es ist eher so, dass es die Dinge sind, die über lange Zeit mit geschichtlicher Tradition verfeinert und verbessert worden sind, so zu etwas Großartigem geworden sind und Glanz verliehen bekommen haben. Und es wird notwendig werden, ausgezeichnetem Design Halt zu geben, es zu pflegen, und es von dem Design unterscheiden zu können, welches durch Eigenreklame geprägt ist." (ebd.: 12)

Mit diesem knappen Blick in eine fremde Welt anhand der Texte von SATOSHI und EIICHI (ein Desiderat wäre die Übersetzung der kompletten Publikation) ist ein grober Umriss einer japanischen Vorstellung von anonymem Design möglich. An ihrem Beginn steht die Tradierung von Artefakten, die »so zu etwas Großartigem geworden sind und Glanz verliehen bekommen haben«. Wichtig ist auch die Präzisierung, dass ein Artefakt noch kein Beispiel für gutes Design sein müsse, bloß weil es aus dem Volk komme, womit eine gut sichtbare Abgrenzung zu den romantisierend-kritisierenden Vorstellungen zu Tage tritt, die in Das gewöhnliche Design und Unbekannt - Vertraut vor uns 
ausgebreitet werden. Die unterschiedlichen Vorstellungen davon, was gutes Design auf der Basis der jeweiligen Prämissen sei, würden wohl zu sehr interessanten Diskussionen mit den japanischen Kollegen führen. Der bedeutsamste Unterschied zu den hier präsentierten europäischen oder amerikanischen Gedankengebäuden ist sicher jener, die Signatur eines Designers, der in seinem Beruf gleich einem Künstler agiert, der negativ besetzten Kategorie der Eigenreklame zuzuordnen. Versucht man, diese Einstellung innerhalb eines westlichen Diskussionsrahmens wiederzufinden, landet man unweigerlich beim Autorendesign, das ja gerade die »die signierte Entwurfsleistung [...] als Promotionsträger« feiert. (vgl SCHNEIDER 2005: 200) 


\section{Anhang: Übersetzungen aus dem Japanischen von Ulrike Schlack}

\section{On Special Issue »Anonymous Design«}

Zum Sonderheft »Anonymous Design«.

Das Redaktionsteam der Wissenschaftszeitung der Gesellschaft (JSSD) hat sich seit dem Sommer letzten Jahres sowohl mit dem Planungs- als auch mit dem Forschungsausschuss über eine durchgreifende Umorganisierung ausgetauscht. Der Hintergrund dazu war zum einen die Erstellung einer Wissenschaftszeitung, die weiterhin junge Menschen mit Interesse an Design zum Beitritt zur Gesellschaft motiviert und zum anderen die Erstellung einer Aufsatzsammlung.

Das Ergebnis ist, wie Sie sehen können, die Aufsatzsammlung und 4 Sonderhefte inklusive allgemeiner Informationen der Gesellschaft. Bereits erschienen ist das 1. Sonderheft »Was ist aus den Pionieren des Designs geworden?« Nummer 2 trägt den Titel »Gedanken zum anonymous design«. Diese Sonderausgabe in neuer Gestalt ist, kurz gesagt, aus den Inhalten zu den beiden Gegenpolen Berühmtheit und Unbekanntheit heraus entstanden.

Zum im Titel verwendeten "Anonymous Design « hat sich das Redaktionsteam (siehe Nachwort), welches für die Sonderausgaben verantwortlich ist, zunächst Gedanken gemacht, seit wann dieser Begriff eigentlich in Gebrauch ist. Eine klare Aussage konnte aber nicht getroffen werden. Anlass zur Recherche war die Verwendung des Begriffs in dem Buch von Siegfried Gedeon [sic] (Universität Oxford) von 1947 »Mechanization takes command (japanische Übersetzung) mit dem Untertitel »a contribution to anonymous history" (Japanischer Titel). Ferner hat sich mit Bernard Rudowskys "Architecture without architect « ein intensive Bedeutsamkeit eingebrannt. Weiterhin ist im Artikel »Fragt man Jan Niilson/Nachgefragt bei Jan Niilson« in der Ausgabe »Industrial Design« Nr. 112 vom Juli 1981 die Rede davon, dass »in Japan die Methode der Teilnahme der Designer eine Gruppenarbeit und demnach anonymous design ist«, und Industrieprodukte, die sich unmittelbar in unserer Nähe befinden, platzieren sich im Bereich industrial design.

In der Welt des Designs ist, der Erinnerung des Autors zufolge, das Interesse am anonymous design mit der Kanazawa-Studie der Oregon University gewachsen. Dies zum Anlass nehmend ist es denkbar, dass diese populäre Design-Studie die Design-Kultivierung der Generation der 40- und 3ojährigen 
durchdrungen hat. Das Intensive an der Studie war die Tatsache, dass Menschen von weit her aus den Kriegsgewinnerstaaten nach Japan kamen, welches den Krieg verloren hatte, um eine Design-Studie durchzuführen. Zu jener Zeit lud das Land immer mehr namhafte und erfolgreiche Designer aus dem Ausland ein und bot Lehrgänge an; und unverzüglich hatte man eine Situation geschaffen, in der in den wenigen Fachzeitschriften, die es zum Thema Design gab, ausschließlich Platz für ausländische Beiträge war und somit auch ausländische Leserschaft angesprochen wurde. Jedoch waren die Dinge, die es zu studieren und zu erlernen gab eigentlich im eigenen Land zu suchen. Einerseits hat unser Land seit der Meiji-Restauration (Ende der 186oer) den eigentümlich-originären Weg fortgesetzt, in der Erforschung der Bauernhäuser, Gebrauchsgegenstände und des Alltagsleben des "gemeinen Volkes« die Untersuchung materieller Kultur zu sehen. »Die Gesellschaft für Erforschung der japanischen Alltagsgegenstände« ist in diesem Bereich eine führende und einflussreiche Institution in unserem Land. Wir freuen uns sehr, Herrn Asaoka Kenichiro? als Autor gewonnen zu haben und der Sonderausgabe eine besondere Fülle an Inhalt verleihen zu können.

In der gesamten Diskussion unter den Mitgliedern des Redaktionsteams hat sich folgende Definition des anonymous design präsent gezeigt: es ist aus dem Volk/aus der Masse entstanden, wurde vom Volk/von der Masse in die Praxis umgesetzt und eine zustande gekommene/vollendete Design-Tat/ ein Design-Handeln, und inhaltlich finden Alltagsgegenstände, Kleidung, Szenerien von Bauernhäusern und Siedlungen bis hin zu industriellen Produkten Platz. Auf der Gegenseite finden sich Produkte, die durch Herstellungsprozesse von Künstlern mit Namensnennung gekennzeichnet sind. Und Ziel dieser Sonderausgabe soll ebenfalls die Publikation eines Teils der Forschungsergebnisse unserer Mitglieder sein, um somit die Weite und Qualität um den Design-Diskurs auszudehnen und zu vertiefen. Auch ist die Tendenz des hobbyhaften, nicht alltäglichen gegenüber des anonymous design nicht zu verneinen. Anonymous design ist aber ebenso »die Entdeckung einer Richtlinie/ eines Leitfadens für eine vortreffliche Design-Erschaffung", so die zuvor genannte Studie; und die sich anschließende Entwicklung einbeziehend ist es dem Redaktionsteam ein Anliegen, der Frage auf den Grund zu gehen "Warum jetzt anonymous design? « Dies wird in der Debatte am Ende unter dem Titel »Die zeitgemäße Bedeutung des anonymous design« thematisiert.

Nun, die Denk- und Vorgehensweise unter den Mitgliedern des Redaktionsteams bzw. der Autoren stimmen auf keinen Fall überein. Das ist im Allgemeinen in der Forschung des Öfteren so, so wie auch der Unterschied zwi- 
schen "graphy« und »logy«. Ohne es sagen zu müssen, sind die erstgenannten diejenigen, die das Gewicht auf das Festhalten der Tatsachen / Fakten und deren Analyse legen, die letztgenannten sehen den Schwerpunkt im Aufstellen einer Theorie. Es ist keinesfalls die Absicht, die jeweiligen Vorzüge zu erwähnen, doch meine persönliche Sympathie gilt den "graphys«. In alten Büchern suchend und nichts findend, dem Aufgeben nahe fällt einem eine neue Auflage eines Buches in die Hand, selbstredend von den "graphys«. Eine detaillierte Dokumentation, die wohl mit fortschreitender Zeit an Wert gewinnt. Diese Geschichten mit einbeziehend hat sich das Redaktionsteam auf das grundlegende Prinzip geeinigt, einen "graphy«logischen Ansatz zu wählen, der in dieser Ausgabe das (Thema) Design auf einem weiten Gebiet erfasst. Doch so realisierte es sich nicht durchgehend. Grund dafür waren die oben genannten unterschiedlichen Haltungen/ Positionen gegenüber der Forschung.

Die Forschungsmethoden umkreisend fasziniert (mich) die Befürwortung der typologischen Methode, die laut der »Kulturgeschichte der Mechanisierung " wie folgt beschrieben wird: »Die Geschichte des Stils folgt dem Gegenstand in horizontaler Richtung, andererseits strebt die Geschichte der Form in vertikaler Richtung. Betrachtet man Dinge im geschichtsunabhängigen Raum, braucht es beide Sichtweisen.«Willkürlich beurteilend, ist dies die Darstellung der Vereinigung von "graphy« und "logy«. Im heutigen Alltag, der von industriellen Produkten, die durch hochentwickelte Wissenschaft und Technologie überzeugen, umgeben ist, ist es vor allem notwendig, zu theoretisieren und zu erläutern, um jungen Menschen die Bedeutsamkeit des Designs des Volkes/der Masse verständlich zu machen. Andererseits ist die "graphy«-Basis eine dünne und »logy« eine gefährliche. Der typologische Ansatz von Gedeon [sic] sollte aus der eigentümlichen Dokumentation von Tatsachen/Fakten heraus eine Gruppe? mit einem gemeinsamen charakteristischen Merkmal an die Oberfläche kommen lassen. Diese Typologie kreuzt die Geschichte des Stils?, die den Alltag, den Sinn für Ästhetik, die Sitten und Gebräuche in der Gesellschaft umfasst. An dieser Stelle wird vermutlich nun der Sinn des Seins und der Wert der anonymisierten Dinge ans Licht kommen. 


\section{Anonymity in Design. Its History and the Present State}

Anmerkungen zum Text:

[...] Ergänzung für Verständnis (steht aber nicht im Originaltext)

/ Begriffsalternative

\section{nicht eindeutig}

aus dem Text entnommene »Fachbegriffe« in der Fremdsprache

\section{Einführung}

Spricht man von anonymous design, ist es wohl allzu normal, dass stillschweigend auch die Existenz des Gegenteils ins Bewusstsein rückt. Im Englischen ist das Antonym von anonymous onymous, welches allerdings im Allgemeinen nicht so häufig gebraucht wird. Eher bedeutet es, dass man auf einem Produkt den eigenen Namen anzeigt. Der Begriff signature ist hier wohl geläufiger/passender. Das heißt die Signatur des Verfassers/des Herstellers/des Autors / des Produzenten. So einfach ist es allerdings nicht, dass die Anonymität im Bereich Design mit der Fragestellung zusammengefasst wird, ob ein Produkt/ eine Sache/ ein Ding einen Namenszug trägt oder nicht, doch eine bessere/treffendere Beschreibung lässt sich wohl nicht finden. Nimmt man nun den japanischen Begriff mumeisei [Unbekanntheit/Namenlosigkeit] steht dem sicher yûmeisei [Bekanntheit/Namhaftigkeit] gegenüber, die Bedeutung ist hier meiner Meinung nach geringfügig anders. Aus diesem Grund möchte ich während meiner Ausführungen als Konzeption zum Gegensatz des mumeisei das shomeisei benennen: die Signatur auf einem Produkt bzw. den Akt der Signatur/Namensgebung.

Und es gibt noch einen Punkt, der herausgearbeitet werden muss. Wird innerhalb des Aufsatzes von mumeisei [Unbekanntheit/Namenlosigkeit] gesprochen, so bezieht sich dies auf den Bereich der bildenden Künste. Im Vergleich zur Malerei und Bildhauerei, die ebenso zu den bildenden Künsten gehören, ist im Bereich des Designs eine Nuance des mumeisei enthalten. Kurz gesagt ist es so, dass während das shomeisei [die Signatur auf einem Produkt bzw. den Akt der Signatur/Namensgebung] im Genre der Malerei und Bildhauerei als Selbstverständlichkeit angesehen wird, mumeisei eine Behauptung im anonymous design ist. Doch nicht nur im Design, auch in der Welt des Kunsthandwerks taucht das gleiche Problem des shomeisei und mumeisei auf. In diesem Fall gelangt es aber ganz klar als das Problem in der Gestalt Künstler vs. Handwerker an die Oberfläche. Im Grunde war es historisch so, dass 
Künstler auch Handwerker waren. Seit der neueren Zeit wurde zusammen mit der Aufstellung des Konzepts der Kunst/des Kunstbegriffs eine fast gegensätzliche Existenz angenommen. Anonymous design ist nun ein Problem, mit dem wir uns in unserer Zeit gegenwärtig konfrontiert sehen, aber es ist auch ein geschichtliches Problem. Daher möchte ich, um über anonymous design nachzudenken, zunächst das shomeisei in der bildenden Kunst geschichtlich näher betrachten und den Bezug zum gesellschaftlichen Hintergrund suchen.

\section{Das shomeisei in den bildenden Künsten des antiken Griechenlands und Roms}

Im alten Griechenland gab es neben der Zivilbevölkerung - dem Adel und den Bauern - die Handwerker (Techniker), die Berufe/Tätigkeiten innehatten, die der Gemeinschaft der Zivilbevölkerung Dienste leisteten. Diese sollte man 3. Schicht nennen. Und so, wie es Aristoteles in seinem Werk "Politik" beschreibt, hatten die gewöhnlichen / niederen Berufe (Schmiede, Töpfer usw.) kein Wahlrecht, und es gab Kritik daran, sie als Bürger zu bezeichnen. Natürlich gab es unter Handwerkern zahlreiche verschiedene Standpunkte: so war die Aufmerksamkeit der Bürger gegenüber Malern und Bildhauern groß, denn diese waren dem Konkurrenzkampf um die Herstellung von Werken zur Weihung öffentlicher Stätten wie Tempeln ausgesetzt und somit auch wirtschaftlich in einer guten Situation. Aber man weiß auch von Beispielen, bei denen die Gunst von den Bürgern abhing, die nämlich die Vor- und Nachzüge eines Werkes wie bei einer Wahl abstimmten. Somit konnte es nicht gelingen, sich aus der niedrigen/niederen/vulgären 3. Schicht herauszulösen.(Verweis auf Buchtitel: „Die Schöpfer der griechischen Kultur«, 1985.)

An den oben benannten Werken ist fast nie eine Signatur auszumachen. Die Bedeutung dessen liegt darin, dass die Werke zum einen eine Gabe an die Gemeinschaft waren (natürlich gegen Entlohnung) und wie man aus der Logik der Mimesis (Nachahmung) von Platon kennt, der mit Mimesis die Imitation beschreibt, folgende Denkweise Basis war: die Technik der Kunst war eine Technik des Nachahmens und nichts, was mit der Persönlichkeit des Individuums zu tun hatte. Aber in Griechenland, wo der Konkurrenzkampf in der Herstellung sehr groß war, gab es unter den Künstlern selbstverständlich den Grundsatz des Wettbewerbs. Der Maler Zeuxis trug in Olympia stolz sein Obergewand im Karomuster, auf dem er mit gelben Buchstaben seinen Namen eingenäht hatte, um sich zu verkaufen. 
Es war nicht so, dass man gar keine Signaturen fand. Zum Beispiel weiß man aus Schriften damaliger Zeit, dass auf dem Sockel einer Statue, die dem Tempel des Asklepios, des Gottes der Heilkunst, dargebracht wurde, der Name des Herstellers hinterlassen wurde. Auch gibt es rotgemusterte Töpferwaren im attischen Stil, bei denen über 200 Namen der Töpferkünstler bekannt sind. An öffentlichen Plätzen brauchte es auch keine Namen von Künstlern an den Werken, denn der Ruhm verbreitete sich mündlich unter der Bevölkerung. Aber in Fällen der Kreation für private Kunden, die wirtschaftlichen Gewinn mit sich brachten, hatte sich die Signatur durchgesetzt.

Dieses Phänomen [shomeisei] zeigt sich deutlich im Falle von griechischen Künstlern in Rom. Die Römer, die die eigene Kultur als arm verstanden, nachdem sie Kunstwerke als Kriegsbeute aus Griechenland ins eigene Land trugen waren nur zu gierig danach, die hellenistische Kultur für sich einzunehmen. An herrschaftlichen Wohnhäusern der Römer ließ man von Künstlern, die in Athen ihr Handwerk erlernt hatten, zur Zierde Skulpturen im griechischen Stil errichten, die als Patrone des römischen Adels dienten. So siedelten die Künstler von Griechenland nach Rom über und erschufen nach Belieben und Vorlieben ihrer römischen Auftraggeber, um ihnen das Ansehen/ den Ruf von gebildeten Bürgern zu verschaffen, der den Griechen zugeschrieben wurde, zahlreiche Nachahmungen hervorragender damaliger griechischer Bildhauer. (Verweis auf japanischen Buchtitel).

Diejenigen, die nun fern der Heimat ihrem Handwerk nachgingen, hinterließen neben dem Namen des Erstellers des ursprünglichen Werkes auch den eigenen. Es ist ja auch so, dass wir in vielen Fällen nur indirekt durch die Kopien der Kunstwerke Kenntnisse über die großen Meister und ihre Kunstwerke haben. (Verweis auf japanischen Buchtitel). Der Grund für die Existenz der Signatur war der, dass man viele Konkurrenten aus dem Weg schaffen wollte, sodass die Aufmerksamkeit auf einen selbst stieg und dies war mit einem wirtschaftlichen Gewinn verbunden.

Die Signatur im alten Griechenland lag also in der Beziehung zweier Aspekte des ökonomischen Profits. Die Wortschöpfung ist vielleicht nicht die passendste, aber es ist nicht zu verneinen, dass es den Charakter der Eigenwerbung/dem [sic] Verkauf des eigenen Namens aufzeigt.

\section{Die Geburt des Künstlers}

In der westlichen Welt findet man, mit einigen Ausnahmen in der Architektur, keine Signaturen. Die meisten Arbeiten der Künstler waren direkt oder indi- 
rekt für Kirchen bestimmt, waren eine Opfergabe an die Kirche und drückten die fromme Anbetung der Ersteller aus. Aber nach Van Loon (Van Loon »Die

Geschichte der Kunst «/»The Arts of Mankind«, 1960.) ist das nicht die ganze Wahrheit. Er gibt folgende Gründe an: (1) es gab zu jener Zeit fast niemanden, der einen Nachnamen besaß, (2) nach Beendigung der Lehre war es fast nie der Fall, dass man sich von der eigenen Stadt, vom eigenen Kloster entfernt hat, somit kannten die Einheimischen denjenigen Künstler und seine Kunstwerke sehr genau, (3) die Künstler kannten ihre Stellung in der Gesellschaft relativ gut und waren stolz darauf, ein achtbarer Handwerker zu sein und dachten nicht darüber nach, ihren Namen für die Nachwelt zu hinterlassen, (4) die Ausdrucksmethoden der künstlerischen Bewunderung waren zur damaligen Zeit begrenzt. Und »die Künstler haben begonnen, das Nicht-Signieren aufzugeben, sind zu Persönlichkeiten geworden, die originelle Ideen, eigenen Charakter, eigenen Stil und Namen hatten. Dies geschah am Ende der Gotik-Periode " und das Signieren und Nicht-Signieren [das Vorhanden- bzw. Nichtvorhandensein einer Signatur] beschreibt die Grenze zwischen Mittelalter und Renaissance.

Die gesellschaftliche Funktion der Kunst im Mittelalter ist laut Heusingers These als prunkvolle Dekoration von Kirchen zur gedanklichen Führung des Glaubens und der Betonung des Stifters (Huizinga, "Herbst des Mittelalters«, 1976) anzusehen. Man sieht häufig auch die Gestalt des Stifters auf den Altarbildern und seit Dürer nicht nur den Stifter sondern auch den Ersteller selbst, der sich - wie Dürer - auf dem Gemälde des Dreifaltigkeitsaltar [Landauer Altar] verewigt hat; eine Methode, trotz Nichtsignierens, die eigene Gestalt unauffällig in der Masse zu hinterlassen.

Ein altehrwürdiges Beispiel, welches ich bezüglich Signaturen kenne, ist die Signatur Masolinos, die am Deckengemälde der Kollegiatkirche [Lombardei] um 1425 hinterlassen wurde. Seit jener Zeit kam es immer wieder vor, dass Signaturen von Malern angebracht wurden. Was vielleicht noch bekannter ist: das am 16. Mai 1432 fertiggestellte Altarbild des Genter Altar, bei dem am Rahmen ein lateinischer Schriftzug durch die Brüder Van Eyck angebracht wurde. 2 Jahre später hatte der jüngere Van Eyck in das Gemälde »Die Arnolfini Hochzeit« über dem Wandspiegel [der auf dem Gemälde zu sehen ist] den lateinischen Schriftzug »Johannes de Eyck war hier, 1434" eingetragen. Aber ich denke, diese delikate Art der Signatur hat wohl eine gänzlich andere Bedeutung als die der heutigen Maler.

Das Signieren ist allgemeinen ein Phänomen, welches nach dem Mittelalter mit immer stärker werdendem Selbstbewusstsein aufgetreten ist; es traten 
Sammler zum Vorschein, Produkte wurden kommerzialisiert und als Produkte zum Kauf und Verkauf angeboten wurden, war quasi eine Signatur zu hinterlassen (Verweis auf japanischen Buchtitel), und es bezeichnet sicher das Erwachen eines Selbstbewusstseins. Die Entwicklung dieses Selbstbewusstseins, später die Entdeckung des neuen Kontinents, Inbesitznahme von Kolonien, die Verwendung von Schießpulver, die Erfindung des Buchdrucks, die Geburt des Protestantismus, die Stadtentwicklung und die Zunahme der Bevölkerung waren Gründe dafür, dass Kontrollkräfte (Traditionen) im Alltag der Menschen abgeschwächt wurden, die Freiheit im Tun und Handeln der Menschen zunahm und zur Entwicklung hin zur Moderne / zur heutigen Zeit antrieb. (Verweis auf japanischen Buchtitel)

Ist die Erstarkung des Selbstbewusstseins eine Sache, die alle Menschen gleich betrifft, so wäre das kein Problem, aber wenn ein Teil der Bevölkerung nur aufgrund der gesellschaftlichen Stellung Behauptungen anstellt und die Existenz anderer verneint, kommt es zur Diskriminierung zwischen diesen Gruppen. Die Behauptung, Kunst sei ein verächtliches Gewerk und die Malerei eine Wissenschaft, stammte von Leonardo da Vinci. Michelangelos »Ich zeichne nicht mit den Händen, sondern mit dem Kopf«, sagt aus, dass es keine physische Arbeit sondern ein Ausdruck der Seele sei. Diese Behauptungen vom Volk anerkennen zu lassen, würde damit einhergehen, Künstler auf einen höheren Rang in der Gesellschaft anzuheben. Diese Idee wurde von keinem Geringeren als Giorgio Vasari in die Tat umgesetzt. Um 1562 hat er berühmte Maler, Bildhauer und Architekten, die zahlreichen Gilden und Glaubensgruppen angehörten, zusammengerufen und mit Unterstützung des Adels eine Akademie gegründet. Nach seiner Idee sollten - für das Wohl der Künstler - die Gildestrukturen aus dem Mittelalter gänzlich abgeschafft werden, den Künstlern die gleichen Gesellschaftsstrukturen offenstehen und sie bis auf die Stufe der Gelehrten anheben. (Pevsner »Die Geschichte der Kunstaka-

demie «, 1974). Das heißt, dass man im Mittelalter die früheren Handwerkerkollegen geringer schätzte, um den eigenen Rang/ die eigene Stellung anzuheben. Im Mittelalter »war die gesellschaftliche Stellung der Handwerker höher als man vielleicht heute annimmt (John Harvey, The Master Builders 1, 1986).

Die Logik / Beurteilung, die [einerseits] praktisch[-zweckorientierten] Tätigkeiten für niedrig sowie vulgär und [andererseits] unpraktisch-ungebräuchliche Künste für ehrenhaft [und prestigeträchtig] zu halten, war [eigentlich] die Behauptung für die Verteidigung der Interessen des Teils der Bevölkerung, der der [damals] neu entstandenen Gesellschaftsschicht [mit >Bildung،], d. h. der [sogenannten] >Bildungsschicht‘ [dem Bildungsbürgertum?], angehörte. 
Solche Ansichten der Humanisten wurden zu einer starken Macht/ zu einem starken Motor für zukünftig angehende Künstler.

250 Die Geburt der Künstler in der Renaissance ist in der Tat eine bedeutende Begebenheit in der Geistesgeschichte. Ich habe nicht die Absicht, diese Bedeutsamkeit zu verneinen. Aber dort wo Licht ist, gibt es auch Schatten. Die historische Entstehung der beiden Gegensätze Zunftwesen vs. Künstler, die in Frankreich bis zu seiner vollständigen Abschaffung in 1777 angehalten hat, möchte ich hier aber nicht weiter ausführen. Mit der Geburt der Künstler wurde die Signatur zunehmend zu einem allgemeinen Objekt, es war mit dem Erfolg beim Handeln mit Werken verknüpft und wurde gewissermaßen so normal, dass auch gefälschte Signaturen auftraten.

An dieser Stelle darf man die Betrachtung der Maler der Neuzeit nicht außer Acht lassen, die keine Signaturen an ihre Werke angebracht haben, wie zum Beispiel [Caspar David] Friedrich, ein Vertreter des deutschen Romantizismus des 19. Jahrhunderts. Seine Werke waren Glaubensbekenntnisse aber wurden dennoch als Landschaftsmalereien bezeichnet. So nannte man ihn »den Erfinder des Trauerspiels der Landschaftsmalerei«, und er selbst sagte: "göttliche Dinge findet man überall, selbst im kleinsten Sandkorn« und sich nach Unbekanntheit und Unpersönlichkeit sehnend habe er nicht ein einziges Mal seinen eigenen Namen oder das Entstehungsjahr auf einem seiner fertiggestellten Werke hinterlassen, so beschreibt es Herbert von Einem (Verweis auf einen Buchtitel: Herbert von Einem, "Caspar David Friedrich«). So wie man aus seinen Werken erfühlen kann, ist es das Handeln aus einem bescheidenen Herzen heraus gegenüber der Großartigkeit von Gott und der Natur. Als ein Maler unter vielen, die seit der Renaissance ihre Persönlichkeit behaupteten, erinnert er uns eher an die Seele der Maler im Mittelalter.

\section{Anonymität als Mediävalismus}

Wer die Verfechter des anonymous designs waren, welches wir heute als Fragestellung behandeln, weiß man nicht. Aber solange man es mit den Verfechtern/Liebhabern des Mittelalters zu tun hat, war es William Morris, der den Merkantilismus, der nach der Renaissance aufkam, stark kritisierte (Verweis auf Buchtitel: »The Art of the People«, William Morris) und der als Wegbereiter der neuzeitlichen/modernen Design-Bewegung galt. Oder nimmt man Feiningers Holzschnitt: die mittelalterliche Kathedrale, die als Titelblatt des Bauhaus-Manifests mit drei Sternen versehen wurde, die als Symbole für die Künstler, Architekten und Kunstgewerbler galten, oder Gropius' Ausspruch: 
»die Klassendiskriminierung, die eine arrogante Mauer zwischen Handwerkern und Künstlern gezogen hat, abschaffen und eine neue Handwerksgilde / Zunft gründen." (Verweis auf Buchtitel: Gillian Naylor »Bauhaus«) Führt man diese an, so hat man eine ungefähre Vorstellung, wer es gewesen sein könnte. Wichtiger als diese Nachforschung ist aber die Erkenntnis über die Quelle des mumeisei [das Nicht-Signieren] im Mittelalter.

Bekannt ist, dass die Design-Bewegung der Gegenwart - als Antithese zur Kunst jener Epoche - das Modell im Mittelalter suchte und übernahm. Letztendlich findet sich anonymous design auch an diesem Punkt ein. Man sollte meinen, es existiert am Ursprung zur Kritik gegenüber der Signatur, die das Ziel der Eigenreklame der Künstler hatte und »der Anonymität aus der frommen Seele gegenüber Gott«. Natürlich muss man nicht erwähnen, dass die Notwendigkeit besteht, das Konzept von Gott hin zum Volk anders auslegen zu müssen, denkt man wie der Sozialist Morris, der »Kunst, die von dem Volk für das Volk geschaffen werden soll« oder Gropius, der einer der Teilnehmer des sozialistischen Künstlertreffens der »Novembergruppe« war.

\section{Signaturen und Eigenwerbung in der Kunst}

Wie wir durch die oben gemachten Ausführungen gesehen haben, ist die Signatur eines Werkes sehr eng mit dem Aufkommen des Selbstwertgefühls, des Selbstbewusstseins verknüpft. Dies macht auch bei gewissen gesellschaftlichen Notwendigkeiten keine Schwierigkeiten. Wenn aber ein Künstler die Signatur nur für die Anhebung der gesellschaftlichen Stellung seiner selbst/ seines Ichs verwendet, kommt es zur Diskriminierung zwischen Handwerkern und Künstlern. Besonders die Tendenz zur Überlegenheit der Kunst im 19. Jahrhundert hat Einflüsse mit sich gebracht, die diese Diskriminierung/ diese Differenz noch größer hat werden lassen. Es ist auch möglich, dies als Hochmut der Künstler zu interpretieren, die ihr Ego zu sehr behaupteten und meinten »Gott ist tot/Gott gibt es nicht«.

Und natürlich brachte eine Anhebung der gesellschaftlichen Stellung der Künstler einen wirtschaftlichen Nutzen für sie mit sich. Demnach wurde die Signatur auch zu einer Methode für genau diese Eigenwerbung. Besonders im Zuge der Entwicklung des Kapitalismus kam es zur Kommerzialisierung von Produkten/Werken, und sobald Wettbewerb unter Künstlern einsetzte, verstärkte sich diese Tendenz umso mehr. Es wäre möglich, dieses merkantilistische Ergebnis, welches aus der Signatur heraus entstand, Eigenreklame/ Eigenwerbung zu nennen. 
In der Bedeutung der Idee des anonymous design ist nicht in allen Fällen klar, auf welches Handeln es sich im Allgemeinen bezieht, aber für diejenigen, die nach Morris - der die Kunst aus dem Volk heraus befürwortete und den Merkantilismus abgeschafft hatte - den Geist der neuzeitlichen Design-Bewegung angenommen und tradiert hatten, gibt es keinen Zweifel daran, dass es eine Berechtigung der Idee des anonymous design aus den obengenannten Gründen heraus gab.

Daher kann ich nicht mit dem Gedanken, der das Thema Signatur nur sehr eng und an der Oberfläche umreißt, übereinstimmen, dass sich Anonymität nur daraus ergibt, ob ein Designer seinen Namen hinterlässt oder nicht. Wie wir oben gesehen haben, liegt das wirkliche Problem darin, dass die Signatur eng mit der Eigenreklame verbunden ist. Aus diesem Grund sollte das Prinzip zum Ziel gemacht werden, zum einen zu verhindern, dass das Design in den durch Eigenreklame bestimmten Merkantilismus hineinließt und zum anderen in der Tat das Design für das Volk zu suchen.

Aus diesen Gründen denke ich, auch wenn es sich um mushomei [NichtSignatur/Nicht-Signieren] handelt, ist das Handeln unheimlich vieler amerikanischer Industrial Designer entgegen dem Prinzip des anonymous design. Sie sagen unverblümt und ohne Rücksicht »Unser Daseinsbeweis ist, wenn sich das Produkt des Auftraggebers verkauft. (Verweis auf Buchtitel: "Design Diskurs «, Blake Edition, Mitch Black, 1992) In der Tat gestaltet sich die gegenwärtige Gesellschaft so, dass man überflutet wird mit Markenartikeln und Produkten, von denen man glaubt, sie seien etwas besonderes, dass sich Selbstbehauptung durchsetzt und andere Produkte bei Seite geschoben werden. Und, um Produkte besser zu verkaufen, kommt es zu häufigen Modelländerungen/-anpassungen und Namen von Designern werden deutlich auf der Oberfläche des Produkts gezeigt. Das merkantilistische Phänomen, welches man wohl Eigenreklame der Produkte [siehe oben] nennen sollte, ist eine selbstverständliche Debatte solange wir in einer kapitalistischen Gesellschaft leben, so wird behauptet. Wäre dies in Wahrheit mit einem Ertrag beim Volk verbunden, wäre es kein Problem. Ferner ist es Fakt, dass eine Funktion des Designs - durch Individualität und Vielfältigkeit der aktuellen Produkte der heutigen Zeit - die Antwort auf das Verlangen des Konsumenten ist. Es wäre großartig, wäre dies nicht mit Täuschung der Menschen durch Koketterie verbunden wäre [sic].

Am Rande der Bubble-Economy ist es nicht notwendig, dieses Phänomen noch einmal zu beleuchten. Außerdem gab es das Design betreffend, gar keine Bubble. Der nutzlose Verbrauch begrenzter natürlicher Ressourcen, die da- 
raus resultierenden Mengen an Sonderabfall und die Zerstörung der Natur, Phänomene, die durch die Eigenwerbung der Produkte hervorgerufen worden sind, damit steht das Design wohl nicht in Beziehung. Gegenüber der Welt, die das anonymous design sucht, genau an diesem Gegenpol - bei der Verneinung der Eigenreklame - setzt das Ziel des anonymous design an.

Doch an dieser Stelle möchte ich eines hinzufügen: ich habe das Gefühl, dass besonders in Japan in der Debatte um die Anonymität die fehlende gedankliche Tiefe, unabhängig davon, ob dies gut oder schlecht ist, zum Tragen kommt. Ich möchte jetzt nicht das ein wenig veraltete Schema Kapitalismus vs. Sozialismus anführen, aber nach Anschauung der Sozialisten Morris und Gropius existierte die klare Vorstellung einer Gestalt im Volk und die Leidenschaft hin zu einer solchen gesellschaftlichen Reformation war spürbar. Das Für und Wider einer solchen Ideologie mal dahingestellt, der Diskurs in Japan ist in dieser Hinsicht sehr dünn. Wenn in Japan eine Debatte über Anonymität geführt wird, geht es nicht um die Anonymität, die [eben] als eine logische Unvermeidbarkeit/Notwendigkeit hervorgeht, wenn eine Vorstellung über die Gestalt des menschlichen Alltags besteht. Aus diesem Grund verbleibt man an einem Punkt, der nur einen kleinen Teil der Bedeutung einschließt und lediglich die Oberfläche des Problems berührt.

\section{Das Problem der Anonymität in der Gegenwart}

Auch wenn die Idee um das anonymous design seine Berechtigung hat, unterscheidet es sich im Zustand der heutigen Gesellschaft zu dem im Mittelalter, war es doch zu damaliger Zeit nicht allgemein gebräuchlich. Mit der These, dass man besonders in der heutigen Zeit die Wertschätzung dem Individuum gegenüber nicht verneinen kann, wird ein neues Problem aufgeworfen, welches genau an diesem Widerspruch anknüpft. Tsurumi (Verweis auf japanischen Titel: Tsurumi, Shunsuke, 1976) hat die Kunst in 3 Bereiche unterteilt: die reine Kunst (pure art), die Massenkunst (popular art) und die marginale Kunst (marginal art). Die reine Kunst ist die, die von ausgebildeten Künstlern und für ein entsprechendes Fachpublikum erschaffen wird. Die Massenkunst ist die Kunst, die als Gemeinschaftswerk von Unternehme(r)n und ausgebildeten Künstlern entstanden ist und die Volksmasse / die Allgemeinheit als Rezipienten hat. Die marginale Kunst ist von Leihenkünstlern / Hobbykünstlern für ein Leihenpublikum [sic] gemacht. Die marginale Kunst ist offensichtlich, wenn man nach ihrer Definition geht, vollkommen anonymous und Werke aus diesem Bereich tauchen ebenso auf wie Dinge, die sich traditionell um uns 
herum befinden. Auch kennt man es von Beispielen aus Westeuropa, wie die Abbildungen, die in einem Buch vorgestellt werden, das ich gerade zur Hand habe (Verweis auf: Herwin Schäfer »The Roots of Modern Design - Functional tradition in the 19th century«, 1970, Studio Vista, London). Aber ich möchte Anonymität als evidente Tatsache vom Objekt der Abhandlung trennen. Die reine Kunst, die die Signatur als Selbstverständlichkeit beinhaltet wird ebenso nicht als direktes Objekt [der Abhandlung] betrachtet. Thema sollen sein: im Falle der Massenkunst zum Beispiel Design und Film.

Bei einem Werk im Design unterscheidet man ein individuelles Werk und ein gemeinschaftliches Werk. Man hört das Argument, dass es sich bei einem Werk, welches während einer Gruppenarbeit des letztgenannten entsteht, um ein Beispiel des anonymous design handelt. Doch es ist nicht einfach, so zu argumentieren, denn einerseits wird wie im Film, der Name des Regisseurs gezeigt, er trägt die Verantwortung, obwohl es voll und ganz eine Gruppenarbeit ist und andererseits wird in Bereichen wie dem Design, der Name nicht genannt, obwohl es ein individuelles Werk ist.

Man nennt es zwar Design, aber neben der schöpferisch-gestalterischen Aktivität ist auch ein großer Teil des Ausdrucks der Persönlichkeit beinhaltet. Das Recht dazu wird durch ein System geschützt, welches sich durch das Urheber- und Geschmackmusterrecht manifestiert. In der Welt der Technik, die gesellschaftliches Gemeinschaftsvermögen sein sollte, gibt es den Schutz durch das Patentrecht. Bis hin zur Verletzung der Rechte des Gestalters ist auch der gegenwärtige Zustand, in dem jeder seinen persönlichen Erfolg sucht, ein selbstverständliches System. Daher lässt sich sagen, dass es unmöglich ist, sich mumeisei [Namenlosigkeit/Unberühmtheit] in seiner vollkommenen Bedeutung zu wünschen. Aber wichtiger als das ist, wenn man über anonymous design in seiner wahren, befürworteten Bedeutung nachdenkt, folgende Dinge als Basis für das Urteil in Betracht zu ziehen: ob ein Designer das Bewusstsein über den Akt der Eigenreklame hat oder nicht und ob ein Produkt ein Design der Eigenreklame besitzt oder nicht.

Ein solches Urteil ist schwierig. Und es ist keine Sache, die einen Druck durch ein System erfährt. Wir haben keine andere Wahl, als es der Selbsterkenntnis des Designers zu überlassen. Es ist wichtig, das Bewusstsein für die Schaffung einer Moral des sogenannten Berufsdesigners zu erhöhen, und für die Ausbildung derjenigen, die das Ansinnen haben, Designer zu werden, sich nicht nur auf die Ausdruckskunst in der Designausbildung zu konzentrieren, sondern sich eine Führung bezüglich dieser Moral zu wünschen. Kürzlich ist auf dem Gebiet der Medizin das Leitbild bezüglich der Eignung als Arzt und 
die Erziehung zur Moral zum Thema geworden; für den Bereich des Designs wäre es ebenso angebracht, sich dieselben Fragen zu stellen.

Andererseits im Schatten der Existenz guter Designer darf die Unterstützung durch das Volk nicht fehlen. Das bisherige Design ist aus dem Volk geboren und hat Halt durch das Volk erfahren. Auch mit heutigen Augen gesehen, sind es nicht wenige Dinge, die wundervoll sind. Aber es ist auch Tatsache, dass man nicht sicher sagen kann, dass alles, was aus dem Volk hervorgeht, großartiges / ausgezeichnetes Design ist. Es ist eher so, dass es die Dinge sind, die über lange Zeit mit geschichtlicher Tradition verfeinert und verbessert worden sind, so zu etwas Großartigem geworden sind und Glanz verliehen bekommen haben. Und es wird notwendig werden, ausgezeichnetem Design Halt zu geben, es zu pflegen, und es von dem Design unterscheiden zu können, welches durch Eigenreklame geprägt ist. Ein solches Wesen in der Ausbildung ist wünschenswert. Es ist ein Muss, die Anschauungen zu Dingen in der Schulbildung, nicht nur die Basis der Denkweise, sondern auch die Erziehung durch das Elternhaus richtig zu platzieren.

\section{Zum Schluss}

Im traditionellen Kunsthandwerk, womit ich in letzter Zeit zu tun habe, kommen viele Themen in klarer und konkreter Form an die Oberfläche, die mit Anonymität zu tun haben. Leider sprengt dies aber den Rahmen meiner Ausführungen, würde ich dieses Thema noch anreißen. Ich bin der Meinung, dass Produkte von Handwerkern auf jeden Fall den Namen des Herstellers tragen sollten, in der Bedeutung, dass man Verantwortung für die eigenen Werke übernimmt. Dies möchte ich jedoch nicht in der Bedeutung der Signatur wie oben verstanden wissen, sondern im Sinne von kôhyô -> des Veröffentlichens des Namens des Herstellers, und es somit Veröffentlichung nennen. Die Debatte um die Anonymität in der Vergangenheit in gleicher Form an die heutige anzupassen, ist unmöglich. Es ist notwendig, ein neues konkretes Bild zur Anonymität zu suchen. Die Einsicht/Intelligenz/Weisheit vieler Menschen sammelnd, ist es hier und jetzt von Notwendigkeit, über anonymous design zu debattieren, um das Wesen/Leitbild zur »Kunst für das Volk« zu erforschen. 


\section{LOW BUDGET Objectos di quotidiano}

Das Gleiche ist eben nicht dasselbe. Im Reigen der Ausstellungen anonymer Alltagsobjekte nimmt Low Budget aufgrund verschiedener Faktoren eine Sonderstellung ein. Zunächst einmal unterliegt die Auswahl der Artefakte, die im Wesentlichen durch persönliche Einkäufe von MATTHIAS DIETZ und MATS THESELIUS zu Stande kam, konzeptionell bei einem auf 40 D-Mark begrenzten Einkaufsbudget, das pro Artefakt nicht überschritten werden durfte - so die Erklärung in der ZEIT aus dem Jahr 1996:

"Alle Exponate stammen aus Kaufhäusern, Basaren, Souvenirshops, Supermärkten oder Spielzeugläden und sind noch heute erhältlich. Keines der Objekte kostete mehr als vierzig Mark. Sie wurden, nein: werden weder exklusiv vertrieben noch mit einem exquisiten Label verziert. Und deshalb benutzen wir diese namenlosen Dinge, ohne ihrer Gestaltung große Aufmerksamkeit zu schenken. Sie sind uns vertraut in ihrer Anonymität." (HENSS in: DIE ZEIT NR. 11/1996 [online] http://www.zeit.de/ 1996/11/Die_Namenlosen [15.05.2018]

Zudem wird die Ausstellung an jedem neuen Standort durch neue Artefakte erweitert, die mit den Ausstellungsmachern befreundete Designer dem Korpus nach den bestehenden Regeln als lokale Ergänzungen hinzufügen. Ironisch hieran ist, dass ausgerechnet durch die geladenen Gäste der Schleier der Anonymität zerrissen wird, weil man die Namen der Stifter im Katalog bei den Artefakten aufführt. Die Signale, die u. a. mit

- JASper morrison (eine Menge $x$ an Nägeln in Plastikfolie),

- kOnstantin GrCic (Filz-Einlegesohlen),

- javier mariscal (Wasserflasche aus Plastik),

- KURT THUt (Scherenuntersetzer) und

- JAMES IRVINE (Haarklammer aus Metall)

gesendet werden, dürften genau so angekommen sein und auch heute noch so ankommen, wie die Ausstellung gerade nicht gemeint zu sein schien. Bedauerlich und sogar ärgerlich daran ist, dass das Ausstellungskonzept es gar nicht nötig gehabt hätte, mit Star-Designern aufzutrumpfen; haben die Kuratoren doch durch die Preisschranke das Kunststück vollbracht, den Einfluss des persönlichen Geschmacks zumindest pekuniär wirksam zu begrenzen und so zu einem Artefaktbestand zu gelangen, der sich eher in Richtung von Das gewöhnliche Design bewegt - jedoch mit deutlich mehr Humor und gänzlich 
ohne Erziehungsanspruch. Der sprechende Ausstellungstitel wird hier deutlich besser umgesetzt als später z. B. bei Die Essenz der Dinge. Wie so viele der Versuche, das Alltagsdesign zu fassen, ist auch dieser letztlich ein Dokument der Beliebigkeit, wenngleich mit metikulöser Besessenheit ausgeführt. Der Katalog zur Ausstellung beginnt die Betrachtung anonymer Alltagsobjekte mit einem kurzen Text des in LISSABON verantwortlichen Kurators MIGUEL VIEIRA BAPTISTA:

"'Low budgetı sets out to question present-day, material culture and to reformulate questions as [sic] function, effectiveness and value of objects, questions which are closely related to design. All of these anonymous [Hervorhebung des Verfassers] and low-priced objects, in a way, do not raise any questions and frequently serve as archetypes. Due to our natural tendency to ignore them they have been given a new context, in which they can be reinterpreted." (VIEIRA BAPTISTA in: o. v., 1997: 16)

Wird mit dieser Ausstellung tatsächlich ein Adressat nach dem Wert, der Funktion und der Effektivität der ausgestellten Objekte gefragt? Ist es nicht mehr ein Kuriositätenkabinett, das den Besucher staunen lassen soll und kann? Die wenigsten Exponate dürften tatsächlich mit Blick auf ihre Funktion noch Fragen offenlassen und viele davon qualifizieren sich tatsächlich als archetypische Vertreter bestimmter durch Objekte beantwortbarer Funktionsanforderungen. Auf die Frage, ob Menschen eine natürliche Tendenz hätten, "anonyme« Objekte zu übersehen, so dass ein neuer Kontext eine Re-Interpretation ermögliche, wird weiter unten eine Antwort gegeben. GÖREL BYSTRÖM JANARV sinnt in ihrem Beitrag The eye wants to travel über die Beweggründe für die Sammlertätigkeit und die Art der Präsentation als Ausstellung nach:

"What makes two established designers go shopping all over the world for cheap junk? I'm pulled into an enchanted world where these finds from department stores and supermarkets in Eastern Europe and Asia are miraculously transformed into things of magic, items of powerful attraction in art museums all over Europe. Invisible, anonymous [Hervorhebung des Verfassers] things that become visible, remarkable creations. Things that suddenly begin to speak. [...] There's nothing special to what they do. Most of us could do it. Set off for the nearest low budget market and see if there are items that speak to us. Things that tell us something about ourselves. [...] That's what Mats and Matthias have done, although on a larger scale. They, of course, are professional sthing-finders،. But we have one thing in common. Our eye wants to travel. Matthias Dietz often points out that he is not a collector. He is not interested in The Great Collection as a goal and motivation. The esthetic qualities of the objects matter, of course, but it's their soul he's after. Not what's esthetically cor- 


\section{STARDESIGNER ODER GESTALTER DES ALLTÄGLICHEN?}

rect and superficially seductive. IIt's their strange ability to talk to me, to make me notice them and not be able to pass them by! ‘ he says. [...] The same goes for Mats Theselius, An irresistible mystery. Matthias knows that there are certain qualities in items that make him notice them: they must be humorous to a certain degree, a design that makes them fun to look at more than once.« (BYSTRÖM JANARV ibid.: 24)

Die generelle Art der Betrachtung, die hier in ganz wenigen Worten zum Ausdruck kommt (»miraculously transformed into things of magic«), verdient eine kurze, kritische Würdigung. Schon FRIEDL und OHLHAUSER tun es, BYSTRÖM JANARV setzt es hier fort und auch später im Rahmen von Die Essenz der Dinge wird uns dieses Argument in leichter Variation wieder begegnen: die magische Veränderung der Dinge via Auswahl und Ausstellung. Dem wird widersprochen: Auslese allein erhebt ein Artefakt nicht per se zu etwas Besonderem. Sie ist zunächst nur ein Vorschlag, ein Spiel mit dem Kontext, den individuellen Bedeutungen und Bewertungen - beide Gestalter sollten sich dessen bewusst gewesen sein. THESELIUs bringt DUCHAMP als Begründungszusammenhang ins Spiel und legt damit die Achillesferse seiner Argumentation frei:

\footnotetext{
"My starting point as a designer is that i'm always thinking about the essence of things, as if i don't quite understand them and therefore seek the Otherness in them. Their substance. Their force. That which really means something, beyond esthetic principles, beyond function and technique. If you then move them from the crowdedness and anonymity of a store shelf to an exhibition hall, strange things happen. Suddenly they become luminous. You notice them. But with different eyes. It is the same as with Duchamp's >Bottle Dryer in 1914« « (ibid.: 26)
}

Dieser Vergleich offenbart die Schieflage seiner Argumentation am deutlichsten. Die Setzung der Design-Ausstellung Low budget ist nicht mit der vormaligen Setzung von MARCEL DUCHAMP vergleichbar. Wählen Designer Artefakte aus, um sie als solche auszustellen, so ist das Ergebnis, selbst im Rahmen eines Museums, nur eine designethnologische, designarchäologische oder designanthropologische Schau. Die Artefakte stehen aufgrund des ihnen mitgegebenen Kontextes als Designartefakte und aufgrund ihres spezifischen Funktionszusammenhanges für genau das und nichts Anderes. Der sich vor uns entfaltende Reigen offenbart einen Teilaspekt der CONDITIO HUMANA - es sei erlaubt, das an dieser Stelle für einen Moment so breit aufzustellen. Dieses nun zu vergleichen mit einer künstlerischen Setzung zeigt nur einmal mehr einen der vielen Nobilitierungsversuche, mit denen Designer und Kuratoren in den vergangenen Jahrzehnten versuchten, das Design aus der Schmuddelecke der 
Bedürfniserfüllung herauszuholen und den Artefakten oder ihrer Arbeit eine zusätzliche kulturelle Bedeutung zu geben: Neben der, die sie ggf. selbst übersehen haben - oder die ihnen nicht ausreichte. Als DUCHAMP einen Flaschentrockner zum Objekt seiner Kunstausübung machte, musste er sich der möglichen Tragweite seiner Handlung ein Stück weit bewusst gewesen sein und er tat damit weder dasselbe noch das Gleiche wie DIETZ und THESELIUS, sondern viel mehr - aber allein aufgrund einer anderen mitgegebenen oder auch mitschwingenden Bedeutung (und damit basierend auf der illusio des Feldes der Kunst, wie sich bei BOURDIEU zeigt). Die Kunstwelt und speziell der künstlerische Autor werden einerseits durch die Inverkehrbringung eines READY MADES be- und hinterfragt, der Mythos oder auch Topos des genialischen Künstlers und Autors aus seinen eigenen Reihen aufs Schönste karikiert. Andererseits wird der Werkbegriff in Frage gestellt und zugleich quasi die Konzeptkunst mit geboren, weil die Autorenschaft von DUCHAMP nur noch in der Auswahl eines Artefakts und seiner Umwidmung bestand und jeder kapriziösen oder auch virtuosen Kunstfertigkeit im »klassischen Sinne« entbehrte. Weiter wird der Kontext seiner Entstehungsgeschichte hier nicht ausgebreitet. Zur Lektüre nachdrücklich empfohlen sei hierzu Poetik der Nachträglichkeit oder Das Warten des Marcel Duchamp. (LÜTHY in: KERN, KIRCHNER und KOHLE 2004: 461-469) [online] https://www.michaelluethy.de/marcel-duchamp-poetik-dernachtraeglichkeit.pdf [14.01.2019]

Low Budget versucht, die ausgestellten Objekte der Anonymität durch eine besondere Art der Sichtbarmachung zu entreißen und sie dadurch bemerkenswert zu machen: Die Vereinzelung in Museen vor dem Hintergrund der Massenproduktion war den Einkäufern dafür probates Mittel. Die ungeheure Menge industriell produzierter Artefakte und die Grenzenlosigkeit des Reisens erlaubt es ihnen, eine für europäische Verhältnisse exotische Schau zusammenzustellen, die sich darauf verlassen kann, dass viele Artefakte unbekannt sein werden - wenn schon nicht in ihrer Funktion, so doch in der gestalterischen Ausprägung oder unter dem Gesichtspunkt der Markenbekanntheit.

Wie FRIEDl und ohlHAUser, die der Ansicht sind, dass sie ihrem Publikum einen Blick auf sein eigenes, tatsächliches Leben anbieten müssen, weil sie meinen, es nähme das Falsche für wahr und wichtig, glauben auch die Kuratoren und einige der Autoren von Low Budget daran, dass andere Menschen diese Objekte ihres Interesses mutwillig übersähen. Woraus hätten sie dieses geschlossen? Hieran zeigt sich das problematische Spannungsverhältnis, in dem sich alle gestalteten Artefakte befinden, wenn man sie mit unterschiedlichen Wertmaßstäben betrachtet - die Brille verändert den Blick. Betrachtet 
man ein Kondom - das sich auch in der Ausstellung befindet - mit der Brille der Funktionserfüllung, so erwartet man zu Recht, dass es seinen Zweck er260 füllt. Seine Güte als Wert bemisst sich anhand bestimmter Parameter - Tragekomfort, Passform, Dichtigkeit, Allergenfreiheit, Wechselspiel mit Gleitmitteln, etc. etc.. Erfüllt es die gestellten Anforderungen, so hat es einen hohen Wert und nach der Erfüllung seine Aufgabe verliert es - in diesem speziellen Fall - seinen Wert wieder. Nähme man ein beliebiges anderes Artefakt heraus, dessen Gebrauch sich nicht in einer einmaligen Verwendung erfüllte, hätten lediglich andere funktionale Aspekte für dessen Bewertung zu gelten. Daraus kann kurzerhand geschlossen werden, dass eine angemessene Funktionserfüllung noch nicht dazu ausreicht, für besonders bemerkenswert in dem Sinne gehalten zu werden, wie es diese Ausstellung ganz unausgesprochen tut.

Nichtbekanntsein, Nichtgenanntsein oder Namenlosigkeit sind es nicht, was auf diese Exponate zutrifft - anonym werden diese dann, wenn sie vor dem Hintergrund einer Herstellung von Exzellenz betrachtet werden, die sich konstituiert aus Siegen bei Wettbewerben oder durch die Kennzeichnung mit dem Namen bekannter Personen oder Marken. Die Begehrlichkeit an sich entsteht erst nachträglich. Es geht bei der Bewertung immer auch um die geteilten Wertmaßstäbe, nicht nur um individuelle Bedürfnisse - wobei individuelle Bedürfnisse sicherlich von externen Wertmaßstäben überformt werden können und werden. Sogar die Plausibilität eines solchen Wertekonzeptes und seine Verknüpfung mit einem Artefakt birgt einen Aspekt der Absurdität in sich - in direkter Abhängigkeit vom Wert des Artefaktes selbst: Man stelle sich ein Kondom Designed by Jasper Morrison vor und setze dieses in Bezug zu einer seiner Möbelpräsentationen auf dem SALONE DEL MOBILE in MAILAND - damit dürfte unsere Bewertung von Wertmaßstäben im Handumdrehen entlarvt sein.

$\{$ Von der Realität eingeholt wurde diese Fiktion im Jahr 2018, als der amerikanische Modedesigner ALEXANDER WANG in Zusammenarbeit mit dem Kondomhersteller TROJAN eine limitierte (!) Protect your Wang-Kollektion inklusive markenverziertem Kondom auf den Markt brachte.\} (FISHER in: HARPER'S BAZAAR am 18.06.2018) [online] https://www.harpersbazaar. com/fashion/designers/a21601708/alexander-wang-trojan-condoms/ [14.01.2019]

Gleich Low Budget konnte auch SUPERNORMAL (MORRISON und FUKASAWA: 2006) als Terminus technicus seine wie auch immer geartete Qualität gerade und nur dadurch entfalten, dass zwei bekannte Designer ihre Vorstellung von Unbekanntheit und Verschwinden zuerst in einer Kunstgalerie und da- 
nach in der Höhle der Designlöwen als Antithese präsentierten: Es ist zu unterstellen, dass alle Akteure sich sowohl des Potentials der Personen als auch des aufgebotenen Kontrasts bewusst gewesen sein dürften. Ein letzter Blick auf die Überlegungen der Rezensentin der ZEIT, die spekulierte:
"Möglicherweise weit mehr als Produkte von Stardesignern verkörpern diese anonymen, gewöhnlichen Alltagsikonen [Hervorhebung des Verfas- sers] das, was spätere Generationen als typisch für den Zeitgeschmack einsortieren werden. Für uns selbst regen sie in ihrer museal verfremde- ten Vielfältigkeit nicht nur zum Nachdenken über die gestylte Waren- welt der neunziger Jahre an. Natürlich spekuliert die Schau auch mit dem Sinn für Komik und dem Reiz des schlechten Geschmacks. Wo sonst ist Raum für dringliche [sic] Schrullen wie den Strandhandtuchhalter in Kro- kodilsgestalt, schwarze Gummischuhe mit Flechtmuster und Schnür- senkelprägung oder schulheftgroße Ghettobluster [sic] aus zitronengel- bem Plastik? (HENSS in: DIE ZEIT NR. 11/1996) [online] http://www.zeit. de/1996/11/Die_Namenlosen [17.07.2015]

Ohne an dieser Stelle auch nur im Entferntesten auf Fragen nach gutem oder schlechtem Geschmack eingehen zu wollen - hier wird ein Problemkomplex gestreift, den die Ausstellung in dieser Form nicht problematisiert und auf den womöglich an anderer Stelle noch zu schauen wäre: Ein nachzeitlich konstatierter, typischer Zeitgeschmack, der mit deutlich kürzerem Abstand sowie unter prognostischen Gesichtspunkten auch den Kanonisierungsversuchen von SCHÖNER WOHNEN zu eigen ist. Dazu später mehr. 


\section{Kaj Franck (1911-1989) Die designtheoretischen 262 Strömungen unter dem Gesichtspunkt der Anonymi- tät und deren Einfluss auf das Werk von Kaj Franck}

KAJ FRANCKs persönliche Einstellung zur Anonymität führt zu einer der bemerkenswertesten Geschichten im Reigen der hier diskutierten Beispiele. Es ist nicht üblich, dass es zu nationsweiten Gefühlsaufwallungen kommt, wenn ein Designer zum Design öffentlich Position bezieht. Im Falle FINNLANDs und von KAJ FRANCK liegen die Dinge jedoch anders, denn FINNLAND hat nach dem zweiten Weltkrieg durch die Teilnahme an Designausstellungen versucht, sich und "Skandinavien als einen fortschrittlichen, kulturell und politisch selbstständigen Teil Europas zu präsentieren«:

"An diesem Image wurde sehr sorgfältig und zielbewusst gearbeitet. So wurden Erfahrungen über frühere Ausstellungen in den USA und Skandinavien genutzt, um die Ziele dieser Inszenierung zu erreichen. Die skandinavische Natur, die Artefakte der Länder und die Stardesigner wurden zu einem Mythos verschmolzen, hinter dem sich die realen Verhältnisse verbargen und der bis heute seine Wirksamkeit besitzt. Der Weg, Design zu präsentieren, ging über Künstlerpersönlichkeiten, die in der Vermarktung einen Teil ihrer Persönlichkeit zur Verfügung zu stellen hatten. [...] Die >Helden<, jetzt als Stardesigner, in Mythen gehüllt, repräsentierten den Glauben an das Machbare und auch an das Kaufbare, in einer Umwelt, die von den Idealen der USA, in der jeder die Chance auf Erfolg hat, geprägt war.« (MERENMIES 1998: 5)

KAJ FRANCK ist Mitglied der schwedischen Minderheit in FINNLAND und allein schon dadurch in einer privilegierten Position, die MERENMIEs kritisch sieht, ebenso wie den Einfluss seines Lehrers ARTTU BRUMMER auf eine ganze Designergeneration - auch BRUMMER ist ein schwedischstämmiger Finne:

„Um die Anonymität von Kaj Franck zu differenzieren sollte man die Anonymität in seinem eigenen Verhalten und diejenige, die ihm als ein Ideal fungierte, klar von einander trennen. Seine eigene war eine Anonymität des Bürgertums und nicht jene des Volkes, wie es oft interpretiert wird. Er als ein Individuum sah sich als ein Mitglied einer größeren sozialen Gruppe, des schwedischsprachigen Bürgertums in Finnland, die in sich hierarchisch geordnet war. Soziologisch gesehen wurde seine Position dort nicht nur mit seinem Namen sondern auch als eine snatürlicher definiert. Dies findet auch in der Beziehung zur Zeit ihren Ausdruck, da man, diesem Kulturverständnis zufolge, durch die Vorfahren selbst ein Teil der Geschichte wäre. Daher relativiert sich die Bedeutung von Zukunft, die, so gesehen nur ein Teil der Vergangenheit sein könne. Seine Revolte gegen- 
über der bürgerlichen Tischkultur und später gegen den Starkult im Design hatte kein anderes Publikum als die in Frage gestellte Gruppe selbst. Sein Idealbild der Anonymität stammte aus den Anfängen der Arbeiterkultur, aus dessen [sic] alltäglichen Gebrauchsgegenständen. Diese hatte er gründlich erforscht und in einer Sammlung zusammengestellt. Die materielle Umgebung der Arbeiterkultur in seiner Zeit studierte er hingegen nicht, sondern betrachtete sie als eine ausgelöschte Kultur, denn das anonyme Design heute, sah er nicht mehr als einen Teil der heutigen Arbeiterkultur. Als sein Feindbild fungierte der Überfluss an stilistischer Produktion.« (ebd.: 137f)

KAJ FRANCK bringt seine Gedanken zur Anonymität des Designers zu einem Zeitpunkt in die Öffentlichkeit, als er neben TAPIO WIRKKALA und TIMO SARPANEVA längst die Position eines der verantwortlichen Designer bei IITTALA und ARABIA bekleidet und sich als eine der großen Figuren des finnischen Designs sowohl etabliert hat als auch ein Nutznießer der Popularisierungsstrategien der vergangenen Jahre ist:

"Der Starkult, im finnischen Design nunmehr homogener Bestandteil des Artefaktes, wurde von Kaj Frank 1965 mit dem kurzen Text sAnonymität, in dem er die Anonymität des Designers bei seriell hergestellten Massenprodukten verlangte, über Nacht zerstört. In seiner Lehre vermittelte Kaj Franck die Anonymität des Designers als eine innere Eigenschaft, als einen Weg der Produktgestaltung, der eine Bescheidenheit des Gestaltenden sich selbst und seiner Aufgabe gegenüber voraussetzt.« (ebd.: 6)

Im Reigen der schon betrachteten Vorstellungen von Anonymität stellt KAJ FRANCKs Position eine weitere Sonderform dar, denn er differenziert zwischen der Produktion von Einzelstücken, für die er für sich und andere ganz selbstverständlich das Recht beansprucht, sie mit (s)einer Signatur zu versehen und der Gestaltung für den Massenmarkt, dessen Namenlosigkeit (- der Begriff Anonymität wird von ihm zunächst noch nicht verwendet -) nach keiner namentlichen Kennzeichnung verlange:

"In seinem Vortrag vor Ornamo fand Kaj Franck es natürlich, dass ein Kunsthandwerker mit seinem Name [sic] für die Qualität des Produktes bürgt. Allerdings fand er es problematisch, wenn der Künstler (z.B. ein Textilkünstler) um sich herum ein größeres Unternehmen baut, das sich letzten Endes zu einer Industrie entwickelt und er weiterhin seine Produkte signiert. Als gefährliche Folge des Starkults im Design sah er die mögliche Minderung der Qualität, nämlich dann, wenn die Produkte vorwiegend aufgrund des Designernamens gekauft werden und nicht aufgrund ihrer tatsächlichen Qualitäten.» (ebd.: 93) 


\section{STARDESIGNER ODER GESTALTER DES ALLTÄGLICHEN?}

Wie es sich mit diesen wenigen Zitaten schon andeutet, ist KAJ FRANCKs Argumentation nicht unproblematisch. Er pflegt ein gespaltenes Verhältnis zur 264 Anonymität, wenn er sie nicht zu einer generell gültigen Maxime seines gestalterischen Schaffens erhebt - was er auch aus heutiger Sicht ausdrücklich nicht musste. Es ist eine seltsame Form der Doppelmoral, die ihre Erklärung findet in der finnlandspezifischen Mixtur aus wohlgepflegtem Starkult, der eigenen Ausbildung und seiner beruflichen Position, die in einer auf Einzelstücke ausgerichteten Arbeitsweise kunsthandwerkerischer Prägung fundiert ist. Er sieht kein Problem darin, je nach Artefakttyp eine unterschiedliche Einstellung zu pflegen und zugleich den Starkult zu kritisieren, zu dessen hauptsächlichen Nutznießern er sich zählen kann. Sauber begründet klingt dies jedoch nur auf's erste Hinhören. Die Differenzierung zwischen Anonymität, anonymem Design und der Anonymität der Designer legt eine Anschlussfähigkeit an heutige Diskurse offen:

»In Kaj Francks Anonymitätsbegriff können zwei Aspekte voneinander unterschieden werden. Zum einen sdas anonyme Design`, worunter er alte, übernommene Modelle, deren Erzeuger unbekannt waren, verstand, deren ideale Ausprägung er in der Stapelware erkannte. [...] Zum anderen , die Anonymität eines Designers im Entwicklungs- und Herstellungsprozess der Massenproduktion, in dem der Designername, seiner Meinung nach, nicht erwähnt werden sollte.« (ebd.: 103)

Von hier lässt sich direkt zu seinem Manifest aus dem Jahr 1965 überleiten, einem Text, der im Vergleich so interessant ist aufgrund der Tatsache, dass er eine gleich gelagerte Begründung der Anonymität versucht, wie sie auch bei ALLISON (s. o.) zu finden ist:

"Eine Untersuchung der verschiedenen Faktoren und deren Einfügung in das Ganze erfordert viel Zeit und Arbeit von vielen Leuten, die ihre Ausbildung auf verschiedenen Gebieten erhalten haben. Ein Mitglied dieser Gruppe - und zwar ein sehr wichtiges - ist der Designer. Je grösser die geplante Serie ist, je grösser ist die Verantwortung und je zahlreicher sind die Personen, die diese Verantwortung miteinander teilen." (FRANCK in MERENMIES 1998: Anhang A)

Und weiter unten:

"Die Verantwortung für das fertige Produkt muss auf dem Artikel in Form des Namens übernommen werden. Signierte Einzelstücke tragen den Namen des Künstlers, der sie geschaffen hat. Für die in Serie hergestellten Artikel, einerlei, ob es sich um Gebrauchs- oder Dekorationsartikel handelt, sind mehrere Personen verantwortlich. Aus diesem Grunde ist es 
nur natürlich, dass der Name, unter dem der Gegenstand verkauft wird, derjenige der Gruppe ist, die hinter dem Produkt steht, d. h. die Herstellerfirma. Anonymität gilt daher also nur für die Serienproduktion. Der Name des Designers dürfte nicht als erste oder oftmals einzige Information über das Produkt in der Reklame, bei Anzeigen und auf dem Gegenstand vorkommen. Der Sinn eines serienmässig hergestellten Artikels ist, dass er produziert, verkauft und gekauft werden sollte dank seiner Eigenschaften - seien sie nun gut oder schlecht, schön oder hässlich. Es ist nicht so, dass der Designer geheimgehalten werden soll, sondern nur so, dass man sich dem Designer durch den Gegenstand nähern soll, so dass der Gegenstand Grundlage der Beurteilung ist und nicht entgegengesetzt." (ebd.: Anhang A)

Bei aller Vergleichbarkeit zu ALLISON tritt aber auch ein deutlicher Unterschied zutage. Wo jener die Arbeitsteiligkeit und den anwachsenden Umfang gestalterischer Projekte als Hauptzwang für Designer-Anonymität ansetzt, weil eine Einzelperson den gesamten Prozess gar nicht mehr kompetent beherrschen könne, liegt der Akzent bei KAJ FRANCK auf der auf viele Schultern verteilten Verantwortung - eine nicht unwichtige Differenzierung. Vor dem Hintergrund, dass KAJ FRANCK zu gleicher Zeit den Starkult kritisiert und trotzdem sein Nutznießer bleiben will, manövriert er sich mit den folgenden Zeilen in eine verzwickte Lage:

"Es ist nicht richtig, den Designer zum alleinigen Verkaufsargument eines Artikels zu machen. Dieses ist ungerecht gegenüber dem Artikel, dem Verbraucher und dem Designer. Es nimmt dem Artikel seinen Eigenwert als Artikel. Es nimmt dem Verbraucher sein objektives Urteilsvermögen und begrenzt die Freiheit seiner Wahl. Für den Designer ist es gleichzeitig Unter- und Überbewertung. Unterbewertung daher, weil die moralische Verantwortung des Designers einen stark kommerziellen Zug bekommt. Überbewertung daher, weil ihm allein die Verantwortung für einen Artikel aufgeladen wird, dem er die Form und die Farbe und das Dekor gegeben hat und zu dessen endgültiger Ausführung ein Kompromiss, der von anderen als künstlerischen Gesichtspunkten diktiert war, beigetragen haben kann.« (ebd.: Anhang A)

Den blinden Fleck seiner Argumentation scheint er aus tatsächlich nachvollziehbaren Gründen nicht aufspüren zu können oder zu wollen. Es bleibt dennoch erstaunlich, dass er den offensichtlichen Widerspruch nicht wahrgenommen haben sollte, der darin liegt, dass er für seine Unikate genau das wieder in Kraft gesetzt sehen wollte, was er für die Stapelware abzulehnen vorgab und was bei eben jener schädlich sein solle. Denkbar ist diese Differenzierung nur aus einer Haltung heraus, die das Unikatäre als Kunstausübung be- 


\section{STARDESIGNER ODER GESTALTER DES ALLTÄGLICHEN?}

greift und deswegen auch dementsprechend andere Bewertungsmaßstäbe an die eigene Arbeit in diesem Kontext anlegt ( - vgl. wieder die illusio eines sozialen Feldes).

Die Reaktionen der Außenwelt auf jenes Manifest sind erstaunlich - was noch vorsichtig ausgedrückt ist. In ihrer Breite können sie hier nicht dargestellt werden. Kern der gesellschaftlichen Reaktionen sind die offensichtlich verunsicherten Käufer, deren Designer-Nationalhelden ihnen doch zu gleichen Teilen Garanten für einen geschmackssicheren Einkauf sind wie auch Symbole des Nationalstolzes anbieten und damit auch einen Weg, mit einem Einkauf etwas für die eigene Nation zu tun. Die jüngeren Designer, noch nicht in führenden Positionen angekommen, fürchten hingegen um ihre Zukunft, denn sie werden ja bis dahin mit dem Hintergedanken ausgebildet, einmal zu "Nationalhelden« aufsteigen zu können. (vgl. MERENMIES 1998: 81-89) Stellvertretend für die Pressereaktionen wird hier eine Passage aus dem HUFVUDSTADSBLADET zitiert:

"Es ist völlig klar, daß die Bejubelung unserer Glaskünstler und Keramiker viel zu weit gegangen ist und die auf den Weg des gutgeschmierten Publikumstoffs, der sich zum allgemeinen Erstaunen bereit gezeigt hat den Kunsthandwerker genauso willig wie einen Hochstabspringer zu bejubeln, reingerutscht ist. Genauso gutgeölt ist der Künstlername in die Zeitungsberichterstattung eingegangen. Da es gegen das Textwerbungsverbot gewesen wäre, den Unternehmensnamen zu erwähnen, hat man glatt den Designernamen genannt, und es ist nicht mehr als menschlich, wenn ein Unternehmen diese Hintertür zur Textwerbung ausgenützt [sic] hat. (...) Es ist selbstverständlich komisch, daß es allmählich dahingegangen ist, daß auf jeden [sic] alltäglichen Gebrauchsgegenstand ein Weltname kleben soll. Essen mit einem Franck, aus einem Gardberg und trinken aus einem Wirkkala, eingeschenkt aus einem Sarpaneva [Hervorhebungen im Original] « (ebd.: 88f)

MERENMIEs kommt zu einem recht zwiespältigen Schluss, als sie dieses formuliert:

"Abgesehen vom vermarktungstechnischen Aspekt der Anonymität, liegt das Wesen des anonymen Designers nicht in einem formal definierbaren Bereich, wie das Bauhaus es versuchte, sondern auf der ideellen Ebene, die sich als ein psychologischer Vorgang untersuchen lässt. Das Wort >Demut wird oft als eine Charakterisierung dieser Designauffassung verwendet. Da Demut Unterwürfigkeit und auch Tatenlosigkeit bedeuten kann, wäre ein ssoziales Engagement eine zutreffendere Bezeichnung für diese innere Haltung, da anonymes Design sich in seinem Umfeld harmonisch eingliedern will. Die anonyme Gestaltungsweise nimmt die vorhandene Umgebung und dessen [sic] Habitus war und hebt sie als ihr erstes Ent- 
wurfskriterium hervor. Diese Rücksicht auf die Tradition, lokale Gegebenheiten und auf die Wahrnehmung des Benutzers, setzt von einem Designer oder einem Architekten eine innere Sicherheit, die von niemandem eine Bestätigung in Form einer Ehrung oder finanziellen Gegenleistung benötigt, voraus. Die Bestätigung einer gelungenen Arbeit äußert sich als eine stille Selbstverständlichkeit, die sich in ihrer Nutzung nahtlos einfügt. Das Übersehenwerden setzt auch eine Selbstachtung voraus, indem der Entwerfende nach seinem besten Wissen und Gewissen seine Planungsarbeit durchführt, nicht nur um von anderen anerkannt zu werden, sondern auch um seinem Gewissen zu folgen. Mit diesen Prämissen zu arbeiten ist nur denjenigen möglich, die keine Macht und keinen Einfluss anstreben. [Hervorhebung des Verfassers] Es sind jene Gestalter, die keinen Zugang zur Macht haben oder haben wollen und jene, die ihn schon haben. [...] Paradoxerweise werden die erfolgreichsten Entwürfe von Kaj Franck als Remakes mit seinem Name [sic] weltweit, 50 Jahre nach ihrer Entstehung, als modernes finnisches Design vermarktet. Eine Bestätigung der Allgemeingültigkeit seiner Gestaltungsweise und der Nichtrealisierbarkeit seiner Anonymitätsanforderung." (ebd.: 143f)

Von »Gestalter[n], die keinen Zugang zur Macht haben« kann nicht mit Sicherheit gesagt werden, dass sie eine demütige Einstellung zum Gestalten hätten. Von jenen, die ihn expressis verbis nicht haben wollen - den »Zugang zur Macht « - könnte solches schon eher erwartet werden. Designer, die gestalterische Macht im Sinne einer wahrgenommenen, populären und ökonomisch erfolgreichen Arbeit haben, könnten sich bis zu einem gewissen Grad den Luxus dieser Haltung leisten, sofern ihr ökonomisches Wohl nicht davon bedroht würde, so wie KAJ FRANCK wohl dazu in der Lage war. Wie an seinem Beispiel ersichtlich geworden ist, konnte sich auch seine Haltung dem gesellschaftlichen Bemerktwerden weder verschließen noch entziehen. Sie oszilliert zwischen mehreren Polen hin und her:

1. Dem einer moralischen Instanz, die mit aufrüttelnden Worten ihre eigene Disziplin zu mehr Zurückhaltung aufforderte und damit auch wahrgenommen werden, also nicht anonym sein wollte,

2. dem des eigenverantwortlichen Künstlers / Kunsthandwerkers, der seine Erzeugnisse selbstverständlich signierte und

3. dem des demütigen Entwerfers von Stapelware und diese Haltung so weitervermittelnden Lehrers (seit 1945).

Was im Hinblick auf ein noch ausstehendes Fazit des gesamten Kapitels ebenfalls schon deutlich zu Tage tritt, ist der Aspekt mutwilligen Übersehenwerdens (vgl. absichtsvolle Senderanonymität), der von MERENMIES neben den Wunsch nach Anerkennung von anderen gestellt wurde. Ob der immer noch 
anhaltende wirtschaftliche Erfolg von FRANCKs Entwürfen ein Beleg für die "Allgemeingültigkeit seiner Gestaltungsweise« sein kann, darf bezweifelt werden. Wirtschaftliche Gängigkeit als Zeichen von Popularität müsste im Speziellen auf die Hintergründe der damit verbundenen Kaufentscheidungen hin überprüft werden. Dafür genügt es nicht, die gestalterischen Prinzipien einer Einzelperson am Bauhaus anzudocken. Die Gemengelage in der finnischen Designgeschichte, auch verursacht durch das nach dem zweiten Weltkrieg spezifisch auf ein Heranzüchten von Designerpersönlichkeiten ausgelegte Ausstellungsmarketing, dürfte noch lange nachgewirkt und den Blick auf Beweggründe für Kaufentscheidungen nachdrücklich getrübt haben.

Dass KAJ FRANCKs in Teilen halbgare Forderung nach Anonymität an ihm selbst grandios scheiterte und scheitern musste, ist unübersehbar. Seine Forderung nach einem Design, das nicht um des Designs willen in die Welt komme, hörte man so weder zum ersten noch zum letzten Mal. Zum Abschluss muss noch einmal herausgestellt werden, dass KAJ FRANCK sich diese Argumentation und auch sein Streben nach Normativität nur aus der Position heraus leisten konnte, in der er war. Er hätte diese ohne seine privilegierte Herkunft und seinen Lehrer ARTTU BRUMMER sowie den ebenfalls schwedischstämmigen ersten künstlerischen Direktor von ARABIA, KURT EKHOLM, nicht so entwickelt und erreicht. (vgl. JANTUNEN 2011: 56f)

Den inhärenten Widerspruch, ein seine Einzelstücke signierender und damit vollinhaltlich verantwortender Kunsthandwerker zu sein und auf der anderen Seite Stapelware zu entwerfen, bei der er sich hinter den Herstellernamen zurückzog, hat er wohl nicht als solchen gesehen. Zudem ist seine Arbeit für IITTALA und NUUTAJÄRVI auch deswegen ein Sonderfall, weil die von ihm durch Signatur eigenverantworteten Unikate nur unter Mithilfe von ihm geführter Glasbläser entstehen, die damit zu den Erfüllungsgehilfen seiner Gestaltungsideen werden. FRANCKs individuelle handwerkliche Fertigkeiten jedenfalls haben seine Unikate nicht mit zusätzlichem Wert aufgeladen: Es sind sein Wille zum Experiment, seine gestalterischen Entscheidungen und die Setzung als Einzelstücke, die sie von seinem sonstigen Entwurfshandeln unterscheiden:

"Unique pieces were always created with Franck present. This was ideal for him, as he liked working with glassblowers. One-off art glass gave him the opportunity to experiment outside the boundaries imposed by mass production. Kai Franck also liked the chance it offered to discover new methods that could be applied in normal production. Many of his unique pieces were created in bursts of activity for an upcoming exhibi- 
tion or selected customers and often ended up in private collections." (JANTUNEN 2011: 115)

KAJ FRANCK initiierte also Gestaltungsprozesse aus einer Kenntnis der Materialverarbeitung als dritte Person und reproduzierte damit eigentlich nur die arbeitsteilige Industrieproduktion im Kleinen, jedoch für die Herstellung von Unikaten und blieb damit Designer. Die Entstehung seiner Einzelstücke ist eine andere als sie z. B. bei Lichtenstein geschildert wird. Selbst als trainierter Kunsthandwerker war KAJ FRANCK ein Designer, der plante und überwachte, aber in der direkten handwerklichen Fertigung keine Rolle spielte. Seine individuelle Lösung situativer Demut ist so durchaus angreifbar geworden und im Rückspiegel vielleicht gar nicht mehr so demütig oder auch konsequent, wie er sich das zu seinen Lebzeiten dachte. Begründbar wird sie vor dem Hintergrund, in der eigenen Arbeit zwischen Design und Kunst als unterschiedlichen Endergebnissen jeweils individuellen entwerferischen Handelns zu differenzieren, was zumindest einer der gängigen Lehrmeinungen zur Trennung der beiden Bereiche widerspricht. 


\section{Abschrift aus: Merenmies 1998}

\section{Anonymität}

Die Formgebung ist jung in Finnland. Noch vor ungefähr zwanzig Jahren war der grösste Teil alles hier hergestellten Haushaltsporzellans eine direkte oder technisch vereinfachte Kopie eine ausländischen Modells. In den vierziger Jahren bekamen finnische Designer, die für die hiesige Industrie arbeiteten, dann langsam die Möglichkeit, Produkte eines neuen Typs zu formen, Als Ausgangspunkt nahmen sie die Forderungen des täglichen Lebens. Das Resultat waren neue und andersartige Gegenstände, neue Materialkombinationen mit neuen Eigenschaften und neuen Formen. Diese zeigte man der Öffentlichkeit, die sich daran interessiert erwies. Dieses Interesse verbreitete sich über die Grenzen Finnlands hinaus und auch dort wurde die neue Formgebung anerkannt. Das Interesse wuchs und es wurde langsam zu Bewunderung und Enthusiasmus mit einem Hauch von Nationalstolz. In Verkaufs- und Reklamekreisen sah man den kommerziellen Wert der entstandenen Situation sofort ein und stellte den Formgeber von nun an ins Rampenlicht. Einmal angefangen, hat sich diese Entwicklung fortgesetzt und rollt immer noch weiter. Nach und nach hat sie die Grenzen des Vernünftigen überschritten und neigt dazu, ungesunde Formen anzunehmen. Der Designer ist zum vorherrschenden Verkaufstrumpf gemacht worden, und die Begriffe sind unklar, verwirrt und unlogisch geworden.

Sinn der Formgebung ist, Produkte zu schaffen, die dem Menschen dienen, jetzt ist es aber oftmals so, dass der Mensch dem Design-Produkt dient. Zur Bewertung der Schönheit und Brauchbarkeit von Haushaltsgeschirr ist eine ganz neue Beurteilungsgrundlage - der Name des Designers - aufgetaucht. Trotzdem gibt es auch jetzt noch Gegenstände, deren Designer niemand kennt und nach dem niemand fragt. Wer, beispielsweise, kann die Halbkugel als seine Erfindung betrachten? Jene regelmäßig geschwungene Halbkugel, versehen mit einem Henkel, wie z.B. die klassische, weiße Teetasse. Sie wird hergestellt, sie wird gekauft. Gekauft daher, weil sie ein guter und brauchbarer Gegenstand ist.

Wenn man einen Gebrauchsartikel plant, der in Serienproduktion hergestellt werden soll, muss man viele Dinge berücksichtigen. Da das Ergebnis ein Gebrauchsartikel sei soll, muss man als Ausgangspunkt für die Formgebung 
natürlich den Zweck nehmen, für den der Gegenstand gedacht ist und den er so gut wie möglich erfüllen soll. Zur Effektivität gehört - ausser praktischen Eigenschaften wie Qualität und Form - auch Wirtschaftlichkeit. Darüber hinaus soll der Artikel möglichst auch ästhetischen Ansprüchen genügen, er soll ansprechend und angenehm im Gebrauch sein. Alle diese Gesichtspunkte sind wichtig für den Verbraucher und sie werden auch von einem verantwortungsbewussten Hersteller berücksichtigt. Sie sind ausschlaggebend für das Material, die Herstellungsweise, die Eigenschaften und das Aussehen. Eine Untersuchung der verschiedenen Faktoren und deren Einfügung in das Ganze erfordert viel Zeit und Arbeit von vielen Leuten, die ihre Ausbildung auf verschiedenen Gebieten erhalten haben. Ein Mitglied dieser Gruppe - und zwar ein sehr wichtiges - ist der Designer. Je grösser die geplante Serie ist, je grösser ist die Verantwortung und je zahlreicher sind die Personen, die diese Verantwortung miteinander teilen.

Handelt es sich um Dekorationsartikel, so ist der persönliche Einfluss des Künstlers grösser als bei einem Gebrauchsartikel; denn hier ist der Hauptzweck ja nicht, dass der Gegenstand eine bestimmte Funktion erfüllt. Aus dem gleichen Grunde hat auch der Käufer grössere Freiheit, Modeströmungen und der persönliche Geschmack haben mehr Einfluss auf die Wahl. Die Folge davon ist, dass die Dekorationsgegenstände eine sehr vielschichtige Produktgruppe bilden, die sehr schwer zu planen und analysieren ist und die leicht zu einer falschen Verkaufstechnik führen kann. Die Formgebung, die der Schönheit als Selbstzweck dient, und sog. Pop-Verkaufstechnik haben, jede für sich und zusammen, ein Gebiet geschaffen, das gerade wegen seiner Vielschichtigkeit, leicht mit dem vielstrapazierten und verführerisch einfachen Wort Kunst bezeichnet wird. Eine der Grundeigenschaften der Kunst ist Individualität. Wenn ein Dekorationsartikel in Serie hergestellt wird, müssen praktisch durchführbare Lösungen für die Farbgebung, die Grösse und andere Einzelheiten gefunden werden, und diese Gründe zwingen den formgebenden Künstler manchmal dazu, einen Kompromiss gutzuheissen, der von seiner ursprünglichen Idee abweicht. Im Vergleich mit Gebrauchsartikeln ist die Bedeutung des Kompromisses hier grösser, denn die Ursache ist oftmals, dass die ästhetische Auffassung des Künstlers und des Verkaufspersonals nicht übereinstimmen. Ein solcher Kompromiss kann auch individuell sein, aber auch, wenn er gar nicht nötig ist, kann der Künstler eine grössere Serie nicht immer persönlich so überwachen, wie es Voraussetzung sein müsste, sollte eine wirkliche Individualität bewahrt bleiben. Serienherstellung bedeutet auch bei Dekorationsartikeln geteilte Verantwortung. 
Bei signierten Einzelstücken ist die Situation dagegen eine völlig andere. Ein signiertes Einzelstück, das aus Rohmaterial geschaffen ist, das in Kunsthandwerkskreisen Verwendung findet, ist Kunst im gleichen Masse wie ein Gemälde oder eine Skulptur. Es hat einen Eigenwert, der sich nicht von praktischen Gesichtspunkten abhängig macht. Gleichzeitig ist es tatsächlich einmalig, ein Resultat des subjektiven Schönheitserlebnisses und des Schaffensbedürfnisses des einzelnen Künstlers. Es ist auch daher einmalig, da niemals ein genau gleiches Werk geschaffen wird. Ein Kunstwerk entsteht nur einmal, und die Verantwortung dafür trägt ein einziger Mensch, der Künstler.

Die Verantwortung für das fertige Produkt muss auf dem Artikel in Form des Namens übernommen werden. Signierte Einzelstücke tragen den Namen des Künstlers, der sie geschaffen hat. Für die in Serie hergestellten Artikel, einerlei, ob es sich um Gebrauchs- oder Dekorationsartikel handelt, sind mehrere Personen verantwortlich. Aus diesem Grunde ist es nur natürlich, dass der Name, unter dem der Gegenstand verkauft wird, derjenige der Gruppe ist, die hinter dem Produkt steht, d. h. die Herstellerfirma.

Anonymität gilt daher also nur für die Serienproduktion. Der Name des Designers dürfte nicht als erste oder oftmals einzige Information über das Produkt in der Reklame, bei Anzeigen und auf dem Gegenstand vorkommen. Der Sinn eines serienmässig hergestellten Artikels ist, dass er produziert, verkauft und gekauft werden sollte dank seiner Eigenschaften - seien sie nun gut oder schlecht, schön oder hässlich. Es ist nicht so, dass der Designer geheimgehalten werden soll, sondern nur so, dass man sich dem Designer durch den Gegenstand nähern soll, so dass der Gegenstand Grundlage der Beurteilung ist und nicht entgegengesetzt.

Die Absicht mit dieser Anonymität ist, die herrschenden, eigenartigen und unlogischen Verhältnisse in richtige Bahnen zu lenken. Es ist nicht richtig, den Designer zum alleinigen Verkaufsargument eines Artikels zu machen. Dieses ist ungerecht gegenüber dem Artikel, dem Verbraucher und dem Designer. Es nimmt dem Artikel seinen Eigenwert als Artikel. Es nimmt dem Verbraucher sein objektives Urteilsvermögen und begrenzt die Freiheit seiner Wahl. Für den Designer ist es gleichzeitig Unter- und Überbewertung. Unterbewertung daher, weil die moralische Verantwortung des Designers einen stark kommerziellen Zug bekommt. Überbewertung daher, weil ihm allein die Verantwortung für einen Artikel aufgeladen wird, dem er die Form und die Farbe und das Dekor gegeben hat und zu dessen endgültiger Ausführung ein Kompromiss, der von anderen als künstlerischen Gesichtspunkten diktiert war, beigetragen haben kann. 
Anstatt vom Namen des Designers zu leben, sollte der Gegenstand aufgrund seiner eigenen Vorzüge leben, zu denen die Formgebung als ein wichtiger Teil gehört. Dieses sollte die Bedeutung der Formgebung nicht verringern, sondern sie nur in den richtigen Proportionen in der Gesamtheit zurückführen. Die Formgebung ist kein Selbstzweck, sondern ein Mittel, das die Absicht des Gesamten so gut wie möglich ausdrücken soll.

Anonymität ist nur der erste Schritt in die neue Richtung, ein Prinzip. Für ihre Entwicklung und Verwirklichung müssen viele praktische Massnahmen getroffen werden. Die wichtigste von ihnen ist eine laufende, vernünftige Information, die eine Grundlage für eine sachliche Bewertung schaffen kann, indem sie Angaben über den Gebrauch, die Herstellung, das Material, die Eigenschaften - sowie über die Formgebung - des Produktes macht. 


\section{Main Street. Design ohne Designer}

So der Titel einer Ausstellung des otTo WAGNER-MUSEUMs in WIEN, die im Jahr 2009 anonymes, weil alltägliches Gebrauchs-Design versammelte, das als generisch oder quasi archetypisch angesehen werden könne. Er trägt auch die unausgesprochene Frage in sich, ob das Design überhaupt auf der Hauptstraße fährt. Der zugehörige Katalog macht mit dem Ziel einer Fassbarmachung einer Idee von Anonymität wie keine andere der bisher vorgestellten Publikationen deutlich, dass dieses Unterfangen immer scheitern muss, sofern eine Normativität dieses Begriffes angestrebt wird. Im Katalogtext wird auch eine Einhegung der Begriffskombination Anonymes Design versucht, doch schon der Terminus technicus wird von den Ausstellungsmachern am Beginn als "sinnleere Metapher« gekennzeichnet:

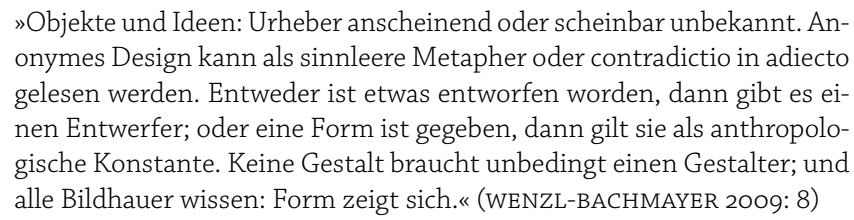

Dies lesend, kommt sogleich LICHTENSTEIN mit seiner Idee des unabsichtlichen Inkognitos in den Sinn. Auch dieser negiert nie die Existenz der Person, durch die ein Entwurf in die Welt kommt. Das Wissen darum sei vorhanden, es habe sich bisher nur »kaum jemand für ihre Arbeit interessiert [...]«. (LICHTENSTEIN 1987: 13) Den Widerspruch, dass eine auf einen Urheber zurückgehende Form dennoch als anonymes Design bezeichnet werden kann und wird, kann man nicht auflösen, weil andere Beweggründe zu dieser Klassifikation führen, als jener, nach einem Urheber zu suchen. Die Behauptung, nicht durch bewussten Entwurf entstandene Formen seien als anthropologische Konstanten zu betrachten, scheint plausibel und wenn eine nicht anthropogene Entstehungsgeschichte die Ursache einer Form ist, benötigt sie auch tatsächlich keinen Gestalter. Sie kommt ohne dessen Zutun in die Welt. Dass ein Bildhauer weiß, dass Form sich zeigt, enthebt die Entstehung einer Plastik dennoch nicht ihrer Anthropozentrik - damit wird nur dem Mythos des genialischen, von seinem Werkstoff getriebenen, halbbewusst-schamanisch agierenden Künstlers Vorschub geleistet. Um der Anbindung an das Design nicht auszuweichen, hier der Versuch einer Präzisierung: Anonymität kann nur innerhalb eines anthropogenen Entwurfsraumes behauptet werden und 
sie ist immer eine Bewertungsfrage, die auf zu vielen individuellen Prämissen beruht, um standardisierbar zu sein.

So erweist sich auch WENZL-BACHMAYER als Zeugin der Vermutung, es gebe verschiedene Anonymitäten. Der rote Faden von Ausstellung und Katalog schlängelt sich entlang der »drei Leben des Designs« - vom Entwurf bis zur Inverkehrbringung über den Gebrauch und die Anonymisierung im Verlauf desselben bis zur möglichen Umnutzung am Ende eines regulären Produktlebenszyklus:

"Klammer dieser drei Lebensabschnitte des Designs ist seine Gestalt, jene Formbindung, die sich im Anblick nicht mehr weiter auflösen lässt und auch sprachlicher Reflexion nur begrenzt zugänglich erscheint. Die Gestalt ist für alle Nutzungsarten, aber auch für die metaphorische Wirkung und oftmals für die metaphysische Etablierung eines Objekts als Klassiker verantwortlich (Breuer 2001). Gestalt ist das konstante Moment einer Wahrnehmung und insofern eine psychologische Kategorie; es hat auch nicht an Versuchen gefehlt, jede Gestalt auf quasi atomisierte Grundbestandteile zurückzuführen, die in ihrer Kombination unverrückbar auf einen festen Form-Nutzungs-Komplex verweisen (Biederman 1987). Doch letztlich kann auch diese Betrachtung nicht erklären, warum welche Form wann wo wie funktioniert - aber es gibt sie, die Modelle der Konstanz im Leben, der Wiedererkennbarkeit in jeder Situation. Und dass diese nicht mehr auf einzelne Gestalter zurückgeführt werden müssen, ist eher ein Segen denn ein Fluch, auch wenn es die Designer gern frustriert." (SACHSSE in: WENZL-BACHMAYER 2009: 10)

Die Ausstellungsmacher stellen die Hypothese auf, gutes Design werde im Gebrauch anonym:
»Im Lauf der Zeit wird alles gute Design anonym, denn es löst seine ent- worfene Gestalt im Gebrauch auf. Dagegen sind fehlerhafte Entwürfe, Monstrositäten und Abweichungen des Normalen für immer mit dem Namen ihrer Formgeber und Produzenten verbunden. Die Bestecke des Ettore Sottsass fallen vom Teller, die Radios von Brionvega und die Fern- seher von Braun waren in ihren technischen Empfangsleistungen sub- optimal.« (ebd.: 9)

Wenn »alles gute Design« anonym wird, was geschieht dann mit dem schlechten? Bleibt es tatsächlich "auf immer mit dem Namen [seines] Formgeber[s] verbunden " und drängt sich (und seine ggf. vorhandenen Malaisen) in den Vordergrund? Ist es nicht so, dass wir das Artefakt bei Nichtgefallen oder Nichterfüllung in die böse Ecke stellen und evtl. sogar dem Vergessen anheim geben? Es wäre zudem doch schade, wenn gutes Design, was immer das auch sei, sich tatsächlich faktisch auflöste - in seine Bestandteile oder wie auch im- 
mer -, denn gerade das wäre ja kein Merkmal guten Designs .... Das Verärgerungspotential der später besprochenen Design-Ärgernisse besteht darin, dass sie ihre Gebrauchsfunktion unzureichend erfüllen. Zieht man »gute[s] Design« als ihr Gegenteil heran, dann hat ein normativer Anspruch an dieses tatsächlich zu sein, dass es seine ihm zugedachte Funktion perfekt erfüllt und nicht durch etwaige Ausfälle oder unangenehme Begleitumstände (sowohl während der Benutzung als auch im stillen Herumstehen) auf sich aufmerksam macht. Womit es wahrhaft anonym im Sinne von unauffällig werden könnte.

Wäre »gutes«, »anonymes« Design also mit unauffälligem Design gleichzusetzen? Hier könnte man ins Schleudern kommen .... Die Designgeschichten des 20. Jhd.s haben jedenfalls gezeigt, dass die reine Funktionserfüllung trotz ihrer himmelschreienden Rationalität oftmals nicht den Gefallen des Verbrauchers findet - womit wir in der schwer fassbaren Sphäre des Geschmacks angekommen sind, den man nicht einfach aus der Ungleichung herausnehmen kann. Im Vorgriff auf spätere Überlegungen ist die Hypothese zu untersuchen, dass der Funktionsraum von Designartefakten um weitere Kategorien erweitert werden muss, da es Funktionen von Designartefakten zu geben scheint, die über ein mageres gut funktionieren hinausreichen. Ein großer Teil industrieller Produktion hat womöglich eine Ätiologie, die sich allein aus einem klassischen Funktionszusammenhang heraus gar nicht explizieren lässt. Interessante Nebenwege abseits der Hauptstraße werden auch beschritten, wenn es um eine Vorstellung davon geht, weshalb Design auf anderem Wege noch oder wieder anonym werden könnte:

\begin{abstract}
»Das Kardanrad mag als typisches Element der anonymen Designgeschichte im Sinn einer Mediengeschichte angesehen werden: Nicht die besseren, schöneren, praktikableren und eleganteren Lösungen setzen sich am Ende durch, sondern die, die in einer Mixtur aus industrieller Fertigungs-Ökonomie und kommunikativer Kanonisierung - die durchaus ideologiekritisch zu beschreiben ist - eines Tages als gegeben akzeptiert wird. Und an diesem Prozess ist kein Designer beteiligt.« (ebd.: 21)
\end{abstract}

Das vorgestellte Kardanrad ist meiner Meinung nach kein Beispiel »der anonymen Designgeschichte«. Was wäre denn anonyme Designgeschichte? Handelt es sich dabei

1. um eine Designgeschichte, die wir noch nicht kennen,

2. eine Designgeschichte der Anonymität,

3. eine Geschichte des anonymen Designs, oder sind es schlicht

4. die noch weißen Flecken innerhalb der Sparten-Historiographie? 
Das Kardanrad kann sehr wohl ein weiteres Beispiel sein für eine Art, Anonymität buchstäblich herzustellen. Ein Artefakt kommt in die Welt, man versucht, es bekannt zu machen und die Marktteilnehmer von der technologischen Überlegenheit, der Schönheit der ingeniösen Lösung etc. etc. zu überzeugen. Doch was geschieht? Eine technologisch differente Lösung wird »eines Tages als gegeben akzeptiert« (s. o.). Die Begleitumstände und auch alle Abwägungen von gut/schlechter/besser spielen keine Rolle mehr, wenn »der böse Markt« es so will. Es ist eine Entscheidung mit den Füßen, bei der die (vermeintlich technologisch) besseren Argumente nicht ins Gewicht fallen. Ist das alles Zufall oder schlicht Wettbewerb, bei dem es immer einen Verlierer geben muss, weil es sonst auch keinen Sieger gäbe? Eine der großen Aufgaben heutiger Designer und der Teams, in denen sie arbeiten, scheint es zu sein, mit den Mitteln der Marktforschung, der Psychologie und der Neurologie immer besser schon im Voraus in den vermeintlichen Nutzer hineinzuschlüpfen - mit dem Ziel, große Investitionen letztlich schon im Vorfeld mit einer imaginären Verkaufsgarantie abzusichern. Cui bono?

Dass Anonymität zwangsläufig irgendwann auch einmal zu einer Frage des Branding werden musste, wird beispielhaft vorgeführt anhand des japanischen Herstellerverbandes MUJI. Im Reigen von Herstellern, die mit unterschiedlichen Konzepten von Anonymität operieren, wird MUJI später noch einmal im Unterkapitel über Herstellerkonzepte (4.1.9) auftauchen. Bemerkenswert an MUJI ist eine eng mit dem traditionellen japanischen Begriff »su< - meaning plain or unadorned « operierende Markenbildung, die das NichtMarke-Sein zum Kernpunkt des Brandings macht, in eigenen Worten auch zu einer "[...] antithesis to the habits of consumer society at that time." (für beide Zitate LUNA und LAUREN 2010: 14) Auch MUJi stellt Anonymität her:

"1980 wurde in Tokyo Muji gegründet, das letzte Glied einer Kette des anonymen und unsichtbaren Designs. Muji ist die Kurzform von $\mathrm{Mu}-$ jiroshi [sic] ryohin, was sich mit keine Marke, gutes Produkt übersetzen lässt. [...] Wer als Designer für Muji arbeitet, muss sich zur Anonymität verpflichten, und selbst diejenigen, die noch Interviews geben, verweisen kaum auf eigene Produkte (Kietzmann 2007). Auch hier ist ein zeitlicher Aspekt zu berücksichtigen: Solange die Einführung dieses Brandings auf dem europäischen Markt noch virulent ist, solange ein Hauch des Fremden durch die Präsentation weht, mag diese Anonymität mit ethischen Werten verknüpft werden, doch irgendwann ist auch diese Phase vorüber - und die Frage der Markenidentität wird im Konzept des Designs neu gestellt. Schon schließt sich der Kreis dieser Betrachtungen, denn die Zusammenarbeit von Thonet, Muji und einer Reihe berühmter Designer kann - je nach Sicht der Dinge - nur bedeuten, dass entweder die 


\section{STARDESIGNER ODER GESTALTER DES ALLTÄGLICHEN?}

Anonymität der Produktentwicklung aufgegeben wird oder aber, dass zuviele Designer-Namen im Umlauf sind."(WENZL-BACHMAYER 2009: 53)

Der Argumentationsbogen von Main Street schließt sich mit der Umnutzung: Der theoretische Rahmen dazu wird mit wenigen Zeilen weit aufgespannt. Die Umnutzung verdient eine breite Betrachtung im Hinblick auf die Beweggründe, die sehr unterschiedlich sein können - doch das kann weder der Ausstellungskatalog leisten, noch wird es im Rahmen dieser Arbeit geschehen. Kernpunkt der Ausstellungsargumentation ist an diesem Punkt die Wiedereinspeisung eines Artefaktes in das alltägliche Leben am Ende seines normalen Produktlebens - jedoch unter anderen Vorzeichen und sozusagen als eine Art von Everyday Design. Teilaspekte der ursprünglichen Funktion, wie z. B. die eines Behältnisses, stellen die Basis für eine funktionale Umnutzung bereit, möglicherweise auch eine Umdeutung, wenn eine ehemalige öffentliche Waschgelegenheit wie die österreichische Bassena zum Blumentrog »mutiert«.

Letztlich verweist dieser Ausstellungskatalog im Vergleich zu allen anderen Publikationen am deutlichsten - und auch in einer irritierenden Traditionslinie mit FRIEDL und OHLHAUSER SOwie mit LICHTENSTEIN - darauf, dass die Hauptstraße der Gestaltung nur zu geringen Teilen von Designern befahren wird. WENZL-BACHMAYER und SACHSSE haben zwar eine Leimrute ausgelegt, an der sie selbst hätten festkleben können, doch begehen sie nicht den Fehler, ihr Publikum bewusst erziehen oder eine bestimmte Seite im Produktionsprozess zu idealisieren oder gar heroïsieren zu wollen. Sie werfen einen nüchternen Blick auf Herkunft wie aktuelle Situation und führen mit ihrem Artefaktreigen auch die Problematik einer zu starken Vereinfachung der Idee des anonymen Designs von anderer Seite vor. So bleiben sie kritisch gegenüber dem Begriff an sich, riskieren auch einen kritischen Blick auf die Jahrhundertdisziplin und öffnen das Feld schon im Sinne einer ökologischen Veränderung, die nicht in einer Apologie HAUGscher Kritik erlahmt - man steht vor einem andersartig aufbereiteten Bestand, der Argumentationslinien öffnet, die auch heute noch nicht ausdiskutiert sind. 


\section{Die Essenz der Dinge}

bietet uns Essentielles und ist eine amour fou mit dem Minimalismus. Obwohl sich die Betrachtung hierbei ebenfalls auf den Aspekt der Anonymität konzentrieren soll, ergibt sich im Verlauf eine kurvigere Route. Zum Einstieg ist festzuhalten, dass diese Ausstellung und die damit zusammenhängende Publikation im Rahmen dieser Untersuchung nur eine begrenzte Beweiskraft erlangen kann. So ein Möbelhersteller, der

1. selbst etliche der schon öfter ins Feld geführten Klassiker in seinem Programm hat, der

2. von der Ausrufung alter und der Schaffung neuer Klassiker auch wirtschaftlich profitiert und der

3. dem Trend zur Musealisierung mit einem eigenen Museum folgt und zugleich Vorschub leistet,

auf diesem Feld eine Ausstellung mit dem Titel nach normativem Anspruch ausrichtet, ist bei allem Respekt für das Ansinnen große Vorsicht geboten und eine Wissenschaftlichkeit, die normativen Charakter haben würde, nicht zu erwarten. Der kühne Anspruch steckt schon im Ausstellungstitel: Die Essenz der Dinge, verstanden als Kunst der Reduktion, die das Design bestimme (eine unbewiesen bleibende Behauptung des Vorworts) soll hier sichtbar gemacht werden. Dem Konzept folgend, wird versucht, die Vielzahl der Wege und Gründe darzustellen, die im Design zur Reduktion führen können und postuliert, dass in einer komplexer werdenden Umwelt bei der »Gestaltung Einfachheit, Funktionalität, Reduktion und Überschaubarkeit anzustreben« sei (VEGESACK in: SCHWARTZ-CLAUS und VEGESACK, 2010: 4).

Es sind die scheinbar ewig gleichen Begriffe und Phrasen, die schon in der Ausstellungsankündigung fallengelassen werden - sie sind beinahe selbst schon Klassiker. Da ist die Rede von den "Ikonen des Stuhl- und Leuchtendesigns«, von »Designklassiker[n] « und auch von der Kunst als der großen Inspiratorin: "Auf der Suche nach geometrischer Abstraktion und Zeichenhaftigkeit bot den Designern auch der Dialog mit der Kunst immer wieder wichtige Impulse [...]«. Als müsse sich Design auf etwas berufen, um Abstraktion als Mittel einzusetzen und eine eigene Zeichenhaftigkeit als Ergebnis zu erzielen! Schon nach wenigen Sätzen sind also alle Knöpfe gedrückt, die eine Designausstellung heutzutage scheinbar drücken muss, um bei designaffinen Besuchern wohlige Schauer kanonischer Wiedererkennungsahnun- 
gen auszulösen - inklusive einer Annäherung an die Kunst. Dann verträgt eine Ausstellung auch "generische Industrieprodukte«:

\begin{abstract}
"Zwischen rweniger ist mehr (Ludwig Mies van der Rohe) und ıweniger, aber besser (Dieter Rams) präsentiert die Ausstellung mehr als 120 Objekte aus über hundert Jahren Designgeschichte. Dazu gehören generische Industrieprodukte ebenso wie zahlreiche Ikonen des Stuhl- und Leuchtendesigns aus verschiedenen Epochen. [...] Das Prinzip der Einfachheit ist eine der größten Herausforderungen, der sich Designer stellen können. Das zeigt sich gerade auch im digitalen Zeitalter.» (VITRA DESIGN MUSEUM) [online] http://www.design-museum.de/de/ausstellungen/detail seiten/essenz-der-dinge.html [15.05.2018]
\end{abstract}

Mit Verlaub: Es werden keine digitalen Objekte ausgestellt! Inwieweit sie im digitalen Raum entstehen oder entstanden sein könnten, wird nicht geklärt. Es wird auch nicht genauer definiert, weshalb ein Warnhinweis dieser Art gegeben werden muss - bedingt denn das »digitale Zeitalter etwa per se, dass die Herausforderung der Einfachheit von der Mehrzahl der Designer nicht mehr angenommen wird? Das digitale Zeitalter ist zunächst nichts anderes als ein binäres. Jenes der banalen Entscheidungsmöglichkeit zwischen o und 1 - wenn man diesen isolierten Bereich herausgreift. Eine noch größere Vereinfachung - außer der keiner Entscheidungsmöglichkeit - ist nicht mehr denkbar. Soll damit also ausgesagt werden, dass durch die in CAD- und VR-Systemen manifeste Digitalisierung des Entwurfsprozesses mehr weniger einfache, unreduzierte, luxurierende Produkte auf den Markt kommen?

Springen wir zur Rückbesinnung kurz an den Beginn der industriellen Produktion, können wir feststellen, dass auch damals mit der Erfindung und Verbreitung von Techniken der Massen(re)produktion keinesfalls nur essentiell reduzierte Produkte in die Welt gekommen sind. Doch beiseite mit dem Spott: Schwierig an dem apodiktisch wirkenden Gestus der Objektauswahl ist mindestens, dass die vielen unterschiedlichen Ideen von Einfachheit, die, je nach Marktsegment, einem Entwurf zugrunde liegen können, nicht hinreichend expliziert werden. Im Katalog finden sich durchaus Spuren für die Ausstellungsbesucher, der enzyklopädische Anspruch, der über allem zu schweben scheint, muss jedoch im Kopf des Betrachters ausgeformt werden.

Schon im »Prolog« des Kataloges manifestiert sich, woran das Projekt scheitern musste: Zeigt er doch bereits einen Reigen von 55 (!) Objekten, der von Sushi-Imitationen, LEgO-Bausteinen, Billard-Kugeln, NIVEA-Creme und einem Golfball, von RAMs' tragbarem Plattenspieler über swatch-Uhren, die Caffètiera MOKA-EXPRESS von BIALETTI, den ZIPLOC-Beutel, einen Stuhl aus 
Glas, die RECLAM-Ausgabe von HOMERs Odyssee, einen Naturschwamm (als einzigem ohne anthropogenen Einfluss entstandenen Ausstellungsobjekt) und Toilettenpapier bis zu einem Fächer aus Bambus und Papier reicht.

Die Beschreibungen der »Werke ${ }^{2}$ geben manchmal, oft aber gar keinen Hinweis auf die Verbindung zu einer Vorstellung von Einfachheit, Reduktion oder Essentialität. Der Korpus wird selten mehr als marginal erklärt und an die kuratorischen Vorstellungen angebunden. Quasi natürlich tauchen Aspekte der Anonymität in den Begleittexten auf. LANG lobt an den »Helden des Alltags« »[d]as anonyme Design einer Heftzwecke oder eines Maßbandes« weil es

»[..] für den Benutzer vertraute Handhabung [bedeutet] und [...] mit sei-
ner unaufdringlich reduzierten Erscheinung eine erholsame Abwechslung
in einer Produktwelt [bietet], in der die lautstarke Rhetorik semantisch
aufgeladener Objekte dominiert - wie bei computergenerierten Möbeln
oder provozierenden Produktkonzepten zwischen Kunst und Design.»
(LANG in: SCHWARTZ-CLAUSS und VEGESACK 2010: 61)

In dieser Passage deutet sich an, wie der zu Beginn gegebene Hinweis, die Prinzipien der Reduktion gälten auch im »digitalen Zeitalter«, ggf. zu verstehen wäre. LANG rekurriert im Verlauf aufzählend auf viele vorangegangene Versuche, das immer wieder anhebende Interesse an den Alltagsdingen in Ausstellungen zu fassen. Sie bezieht sich hier natürlich auch auf Das gewöhnliche Design (DARMSTADT) und andere wie World Stuff in ROTTERDAM, Humble Masterpieces im MOMA in NEW YORK, Under a tenner (LONDON), Everything Design (ZÜRICH) und Super Normal (LONDON, MAILAND, TOKYO). In ihrem Text tauchen - wie an vielen anderen Stellen dieses Kataloges auch - kritisch zu bewertende Passagen wie die nachfolgende auf: »Die meisten dieser Dinge überzeugen weniger durch ihre gute Form, als vielmehr durch ihre schlichte, verständliche Gestalt und ihre Praktikabilität.« (ebd.: 61)

Die Nonchalance, mit der solches geschrieben und veröffentlicht wird, erstaunt immer wieder - in diesem Fall gerade aufgrund eines konstruierten Widerspruchs zwischen einem designideologisch besetzten Begriff, der »[G] ute[n] Form « (der hier nicht so gemeint zu sein scheint) und der Praktikabilität. Falls dadurch angedeutet werden soll, dass die Gute Form in ihrer bisher bekannten Definition inzwischen obsolet sei, wahlweise auch gar nicht prakti-

2 Genau genommen sind es Artefakte. Ein Werk-Charakter, wie er einer Ausstellung bildender Kunst zugrunde läge, ist hier nicht gegeben und entsteht auch nicht einfach durch die Setzung als ausstellungswürdige Objekte. 
kabel oder anders zu fassen ist, misslingt das jedenfalls gründlich. LANG hätte zumindest definieren müssen, inwieweit sich diese, hier abgelehnte (?), »gute 282 Form« von der ideologisch gefassten Ausprägung der Gute(n) Form unterscheidet. Nimmt man ihren Satz so, wie er steht, besteht der Widerspruch in einem Auseinanderdriften von guter Form und guter Form, ohne zu explizieren, was jene neue, "gute Form« denn nun im Gegensatz zur alten Gute(n) Form ausmacht. Man kann es fast als aperçu betrachten, dass in der "schlichte[n], verständliche[n] Gestalt und [...] Praktikabilität« Verdichtungen der landläufigen Ideen von Gute(r) Form in Opposition zu: »was eigentlich?« gesetzt werden. LANG expliziert weiter unten deutlich, worin für sie die Überzeugungskraft des Alltagsdesigns liegt:

"Die Anonymität dieser banalen, aber unverzichtbaren Dinge wirkt heu-
te, da Designer wie Filmstars gefeiert werden [Hervorhebung des Verfas-
sers], nachgerade sympathisch. Diese unprätentiösen Objekte schei-
nen eine personalisierte Autorenschaft gar nicht nötig zu haben - sie
überzeugen durch ihre unaufdringliche Unterstützung menschlicher All-
tagshandlungen. Genau diese Nähe zu unseren Bedürfnissen ist es, die
in einer sich rasant wandelnden Gesellschaft für Aufmerksamkeit sorgt."
(ebd.: 61)

Die Frage, ob es gerade »diese Nähe zu unseren Bedürfnissen ist «, »die [...] für Aufmerksamkeit sorgt«, ist noch zu beantworten. Wenn wenige Zeilen zuvor noch die wie Filmstars gefeierten Designer kritisiert werden, sollte doch ein Problembewusstsein dafür vorhanden sein, dass das unscheinbare, unauffällige, zurücktretende Design sich eben gerade nicht gegen das vorstehend bekrittelte durchzusetzen vermag - jedenfalls nicht im Sinne einer Massenbewegung, die als solche nach außen sichtbar würde. Vielleicht muss es das auch gar nicht, weil es nicht in dem Sinne um Aufmerksamkeit kämpft, wie sich die Kämpfe im Star-Designer-Segment des Designmarktes abspielen. Massenhaftes Alltagshandeln bleibt begrifflich unfassbar, wenn es ohne eine es begleitende und nach aussen kommunizierte Ideologie auskommt und ohne Personen, die A) Deutungshoheit für sich reklamieren und denen diese B) zugesprochen wird - es ist ausschließlich anhand seiner Auswirkungen zu betrachten. Der Hinweis auf eine »sich rasant wandelnde [...] Gesellschaft « führt uns wieder zurück an die Quelle traulichen Beharrens, der dauerhaften und andauernd verfügbaren Produkte, die dem Konsumenten Sicherheit versprechen im Taumel der Zeitläuf(t)e. 
SCHWARTZ-CLAUSS, der Die Essenz der Dinge kuratiert hat und aus dessen persönlicher Sammlung - neben der VON VEGESACKs, von CLIVIO und den VITRA-eigenen Beständen - ein Großteil der Exponate stammt, ist der Verfasser des Haupttextes, der ebenfalls den Titel der Ausstellung trägt. Die bemerkenswertesten seiner Aussagen im Zusammenhang mit der Anonymität sind sicherlich diese:

\begin{abstract}
»Dabei führt der Wegfall jeglicher Handarbeit in der Produktion nicht automatisch auch zu ausdruckslosen Produkten, selbst, wenn der >Monoblock-Stuhl als weltweit meistverkaufter Möbeltyp eher ein Beispiel dafür ist, dass Einfachheit nicht nur billig sein, sondern auch billig aussehen kann. In dem Moment, da der Designer letzte Hand an den Prototypen legt, erhält das Produkt sein endgültiges Gesicht, die Perfektion der anschließenden Realisierung aber birgt auch die Gefahr einer Anonymisierung des Entwurfs [Hervorhebung des Verfassers]. Somit besteht die Kunst bei dieser maschinellen Vereinigung von Material, Technik und Form darin, ihr das Hermetische zu nehmen und den Objekten eine Identität zu geben, die sich nicht erst aus dem Vergleich mit Konkurrenzprodukten ergibt, sondern aus ihrer Entstehung ebenso wie aus der Beziehung zwischen Objekt und Benutzer." (schWARTZ-CLAUSS ebd.: 28)
\end{abstract}

Diese Zeilen widersprechen sich in staunenerregender Manier komplett selbst: Ist im ersten Satz noch davon die Rede, dass die entfallende Handwerklichkeit nicht zu »ausdruckslosen Produkten« führen müsse, wird wenige Zeilen weiter unten die "Gefahr einer Anonymisierung des Entwurfs« beschworen, die aus der massenhaften perfekten Realisierung entstehe. Wie bitte? Perfektion und fehlende Handarbeit anonymisieren also Entwürfe!? Jedenfalls eine Idee, die in dieser Form bisher noch nicht auf dem Plan war. Das müsste dann übrigens auch für den Prototypen eines Stuhles von JEAN PROUVÉ gelten, der mit der Exponatnummer 156 aufgeführt wird - oder kann dieses Kriterium hier nicht zur Anwendung kommen, weil ein Entwurf von JEAN PROUVÉ betroffen wäre?

»Jean Prouvé war Ingenieur, Industrieller und Designer, ein Industriedesigner spar excellencer. Bei diesem von ihm selbst so genannten Standard-Stuhl [Hervorhebung im Original] - ein ebenso preiswertes wie robustes Möbel, das er für die neu aufzubauenden Wohnungen und Einrichtungen im Nachkriegsfrankreich entwickelt hatte - handelt es sich um einen Prototypen, also die Fassung eines Entwurfs, die als Modell für die kommende Serienproduktion dient.« (ebd.: 130) 
Es lohnt, dieses seltsame Verständnis von Anonymität noch ein wenig weiter zu durchdenken - auch in Verlängerung, Ergänzung und Kontrast zu LANG. 284 Ebenso die unausgesprochen dahinter stehende Idee von der Persönlichkeit des handwerkenden oder auch einer Personalisierung durch Unregelmäßigkeiten in der Fertigung. Die Vorstellung von Auswirkungen der Handarbeit im Entwurfs- und Produktionsprozess, die man SCHWARTZ-CLAUSS unterstellen kann, käme nur in individuellen Abweichungen von der massenindustriellen Perfektion eben dieses Produktionsprozesses zu liegen. Spuren des Herstellenden, die eine nostalgischwärmerische Seite in uns anrühren und uns das Gefühl geben, wir hätten etwas ausdrucksstarkes und individuelles vor uns - er schreibt ja, es entstünden »nicht automatisch auch [...] ausdruckslose $[\ldots]$ Produkte $[. ..] \ll$.

Handwerklichkeit im SCHWARTZ-CLAUSSschen Sinne führt also im nochmaligen Umkehrschluss per se und ganz automatisch zu ausdrucksstarken Produkten! Das einzige Kriterium, das hierbei als gültig anzunehmen ist, wäre das der Imperfektion. Die Einfachheit kann es nicht sein, denn das wurde mit dem Hinweis auf das »billig[e] [A] ussehen« des Monoblock-Stuhles als entwürdigende Nichtwertigkeit klargestellt. Die Idee von Wertigkeit, welche hinter dieser Wertung steht, kann als Möglichkeitsraum nur geahnt werden. Eine substantielle Kritik industrieller Produktionsformen und die kritische Würdigung ihrer Bedingungen leistet dieser Text jedenfalls nicht - es ist nicht viel mehr zu hören außer einem leisen: Hinfort mit der industriell-perfekten Massenreproduktion!

Ist denn die Imperfektion, besonders im Rückgriff auf LANGs Ode an die »schlichte, verständliche Gestalt und [...] Praktikabilität« von »unprätentiösen Objekte[n]«, überhaupt ein gesichertes Kriterium? Durch individuelle Abweichungen von einem faktisch möglichen hohen Produktionsstandard können auffallende Schwächen in der Praktikabilität oder auch in der Perfektion der äußeren Erscheinung zum Tragen kommen, die den Gebraucher verärgern. Ist ein ausdrucksstarkes Objekt zugleich in der Lage, LANGs Kriterien der »unaufdringliche[n] Unterstützung menschlicher Alltagshandlungen« ohne "personalisierte Autorenschaft « überhaupt zu erfüllen? Wie sonderbar wirkt in jenem Zusammenhang auch SCHWARTZ-CLAUSS' Betrachtung der Übertrittsphase vom Prototypen zur Produktion, die er als einen Zustand beschreibt, in dem der Gegenstand verschlossen (im Sinne von unzugänglich?) wird! Zugleich ist - ex negativo - von der Identitätslosigkeit die Rede, vom Entstehen einer Identität nur aus eigenem Vergleich und ohne ein Beziehungsangebot des Artefaktes an den potentiellen Benutzer. 
Gehen wir davon aus, dass ein Gegenstand in der Produktion dem Zustand des freigegebenen Prototypen entspricht, dann entsteht »bei dieser maschinellen Vereinigung von Material, Technik und Form « nichts anderes als der vorherige Entwurf. Seine Anonymität oder Verschlossenheit kann dann nur im Entwurf selbst bereits angelegt sein und muss im Prototyp schon zutage treten - wie könnte sie ernsthaft ursächlich aus der massenhaften Vervielfältigung herrühren? Dahinter zu stehen scheint aber ein eher romantisierendes Gegenbild zur massenhaften Serienfertigung, deren seelenlose Glätte so (reichlich verbrämt) kritisiert würde als eine Gefährdung der »Beziehung zwischen Objekt und Benutzer«. Dazu ein Seitenhieb: Der JUICY SALIF ist mein Kronzeuge dafür, dass dem nicht so sein kann. Er ist ein massenhaft reproduzierter Beweis dafür, dass eine Re-Edierung des identischen Artefaktes in anderen Materialien und mit reduzierten Stückzahlen (die auch explizit kommuniziert werden) sich die Mechanismen künstlicher Verknappung und Exklusivierung oder Nobilitierung auf der Basis eines Massenproduktes erfolgreich zu Nutze machen kann, ohne durch die Massenreproduktion in die Anonymisierung abzugleiten! Auch, wenn das Beziehungsangebot dieser als Zitronenpresse komplett untauglichen Zitronenpresse letztlich nur darin besteht, ein Anschauungsobjekt zu sein - in aller Mehrdeutigkeit und Hermetik.

So führt Die Essenz der Dinge auf halber Strecke zu der Erkenntnis, dass wenn dieses Ausstellungsprojekt einen normativen Anspruch hätte einlösen wollen - ein detaillierterer Blick auf die Essenz[en] der Dinge sinnstiftender gewesen wäre sowie eine deutlich wortreichere Beziehungsstiftung zwischen Intention und ausgestellten Artefakten. Die zur Kategorisierung angebotenen Begriffe, unter denen Artefakte subsummiert werden, überzeugen nicht wirklich. Selbst die in SCHWARTZ-CLAUSs' einleitendem Text gegebenen Erklärungen dafür, aus welchen Gründen sie gewählt wurden und wofür sie jeweils stehen sollen, sind nicht wirklich hilfreich. Ihre Bedeutung vermittelt sich auch anhand der unter dem jeweiligen Rubrum versammelten Exponate nicht durchgängig. Am griffigsten erscheinen sie bei Einheit - als Sammelbecken für Entwürfe mit im weitesten Sinne ununterbrochener Form (u. a. GUHLs Gartensessel aus ETERNIT) zu verstehen und bei Transparenz, wo sämtlich durchsichtige Artefakte aus unterschiedlichen Materialien versammelt sind, die von DE PAS/ D'URBINO/LOMAZZIs BLOW UP-Sessel über STARCKs Stuhl LA MARIE u. a. bis zu COLOMBOs Schreibtischlampe NR. 281 (ACRILICO) reichen. Für Transparenz hätte sicher auch SHIRO KURAMATAs Metallsessel HOW HIGH THE MOON stehen können, der jedoch wird unter Auflösung der Form einsortiert - sehr ungewöhnlich im Angesicht der präzise gekanteten und geschweiß- 
ten geometrischen Konturen im gewählten Material Streckmetall. Neben einer gewissen Beliebigkeit bieten die Kategorien sich so lediglich als willkürliche Projektionsflächen für Eigeninterpretationen an. Als Beispiele hierfür werden A) Inspiration, B) Zeichen und c) Vorbild vorgeführt.

A) Inspiration dient als Exempel dafür, worunter der Auswahlprozess der Artefakte litt. Die Kategorie umfasst nur 5 Exponate:

1. Den SIDE CHAIR von FRANK GEHRY aus der EASY EDGES-Kollektion,

2. die Deckenlampe DMD o8, 85 LAMPS von RODY GRAUMANS für DROOG,

3. den Armstuhl CONSUMER'S REST von STILETTO (FRANK SCHREINER),

4. den Hocker NO. 220 (MEZZADRO) der Gebrüder CASTIGLIONI und

5. den Stuhl SEDIA von ENZO MARI.

$\mathrm{Zu}$ vieren der fünf Exponate gibt es im Katalog kurze Texte (ebd.: 11of). Im Haupttext von SCHWARTZ-CLAUSS (ebd.: 28f) werden auch Deutungsmöglichkeiten für den Begriff und die Kategorie angeboten, die zu bemerkenswerten Aussagen über unterschiedliche Designerpersönlichkeiten führen - wovon in diesem Rahmen aber Abstand gehalten wird. Im Folgenden der Versuch einer Deutung, wie hier der Begriff der Inspiration in Verbindung mit den Kernthemen Einfachheit, Reduktion und Essentialität wohl jeweils gemeint sein könnte:

GEHRYs Stuhl aus 48 Lagen Wellpappe, die in jeweils entgegengesetzter Laufrichtung verleimt, mit drei Rundhölzern stabilisiert und mit zwei Lagen Hartfaserplatte abgeschlossen werden, wird mit DIY-Methoden (!) in Verbindung gebracht. Etwa, weil sein Produktionsverfahren im Prinzip auch zuhause mit herkömmlichen Werkzeugen nachvollzogen werden könnte? In Anbetracht seiner aufwendigen Herstellung kann die Frage nach der Ausdeutung in Bezug zum Ausstellungstitel bei diesem Artefakt wohl nur auf formale Aspekte reduziert werden, da der Stuhl sich im Profil auf eine Linie reduziert.

Die Inspiration GEHRYs war womöglich von der Idee angetrieben, aus einer Linie ein dreidimensionales Sitzobjekt zu schaffen. Auf die Frage, weshalb es ausgerechnet dieser Stuhl aus der ganzen EASY EDGES-Kollektion in die Ausstellung geschafft haben könnte, kann man mit den wesentlich expressiveren Formen des WIGGLE CHAIR und des BODY CONTOUR ROCKER verhältnismäßig leicht einen Antwortversuch geben. Als Randnotiz muss auch noch hinzugefügt werden, wie sich hier (in einer Parallele zu einem Anspruch des BAUHAUS') die Idee eines Architekten, einfaches und bezahlbares Mobiliar aus unedlem Material zu schaffen, in der Folge von Markteffekten ins Gegenteil 
verkehrt: Produzent VITRA verkauft das Einzelexemplar des nicht gezeigten WIGGLE CHAIR zu 769,- €. (VITRA PRODUKTE) [online] http://www.vitra.com/ de-de/product/wiggle-side-chair?subfam.id=38853 [15.05.2018]. An diesem Punkt und auch in Anbetracht der direkt folgenden Artefakte muss die Hypothese, dass die Prominenz des Gestalters oder der herstellenden Firma keinen Einfluss auf den Produktpreis haben könnte, wieder ins Wanken geraten ....

Bei GRAUMANs' Lampe scheint sich die Inspiration in der essentiell 85fachen Vervielfältigung einer Glühbirne samt Kabel und Lüsterklemme zu verstecken. Ob das noch für Einfachheit und Reduktion stehen kann, sei dahingestellt. Sehr inspirierend und ganz und gar nicht reduziert ist auch in diesem Fall der Preis, den DROOG für das Artefakt aufruft: 2695,- $€$. (DROOG WEBSHOP) [online] http://www.droog.com/webshop/product/85-lamps [14.05.2018].

Betrachtet man sich den »Stuhl « CONSUMER'S REST in der im Rahmen der Ausstellung gezeigten Form aus der VITRA-Sammlung, die sich deutlich von der Urfassung von 1983 (einem umgeformten READY-MADE) unterscheidet, ist die Frage, wer hier wovon wozu inspiriert wurde, wohl ebenfalls leicht zu beantworteten. Man ist versucht, einen ironisch-konsumkritischen Ansatz mit zu unterstellen, der in soweit subversiv ist, als er die Konsumkritik verkaufen will. In der Produktion ergibt sich eine noch höhere Kompliziertheit als bei GEHRY, da der Stuhl, ähnlich den DIAMOND CHAIRs von BERTOIA, nur in aufwendiger Handarbeit hergestellt werden kann - ein standardisierter Einkaufswagen lässt sich nicht einfach so in die präsentierte Form zwingen. Zudem werden sämtliche Entwürfe von den STILETTO studios nur in Kleinstserie produziert (vgl. ALBUS und BORNGRÄBER 1992: 200).

Eine wieder andere Form der Inspiration liegt dem Hocker MEZZADRO zugrunde, der einen so im Markt verfügbaren Traktorensitz mit einem Stück Bandstahl und einem Holzteil zu einem Sitzmöbel collagiert. Er ist im Ganzen ein normal-komplexer Stuhlentwurf, der sich als Besonderheit einer vollständigen Sitzschale als Halbzeug bedient und, wie in der Anmerkung zu lesen ist, besondere Sorgfalt für die Verbindung der einzelnen Bestandteile erfordert. Dass diese Überlegungen für die lange Verschleppung der Produktion vom Entwurf im Jahr 1952 bis in die 7oer Jahre des 20. Jhd.s verantwortlich sein sollen, klingt sehr nach Mythenbildung.

Zu guter Letzt die SEDIA von ENZO MARI, beinahe die Urmutter aller DIYDesignermöbel (die NR. 14 von THONET natürlich nicht zu vergessen). Heute wieder geschickt in die Diskussion gebracht durch VAN BO LE-MENTZELS HARTZ IV-MÖBEL. MARIs Idee der "Provokation des kommerziellen Establishments« läuft sich nach über drei Jahrzehnten tot, solange man den Bausatz 
für 255,- € bei ARTEK erhalten kann; er hat sich etabliert und der Markt hat über die Provokation gesiegt; ein Klassiker ist entstanden. Heureka!

Ein »Appell an die autonome Kreativität des Verbrauchers « sind weder die SEDIA noch die HARTZ IV-MÖBEL. Sie bieten lediglich den Reiz eines selbstgebauten Designermöbels auf. Doch ist dies ein Aspekt, der im Kampf um die Distinktionsmerkmale bei den wenigsten designaffinen Konsumenten greifen dürfte. Gerade im Statuskampf ist die Idee der Allgemeinverfügbarkeit, die mit einer Formulierung wie der Demokratisierung des Designs ${ }^{3}$ einhergeht, eher ein Ausschlusskriterium.

Zudem wird das Prinzip, den Konsumenten zum Monteur zu machen, z. B. im Falle von IKEA gerne kritisiert - weshalb sollte man das im Falle von ENZO MARI und VAN BO LE-MENTZEL anders handhaben? Etwa, weil es sich bei diesen so verhält wie im Falle des Stuhlentwurfs von PROUvÉ? Genügen der Wille zur Provokation und die kostenfreie Entwurfsunterstützung für armutsgefährdete Menschen, um das Gleiche zu etwas Anderem zu machen? Essentialität, Reduktion und Einfachheit bleiben bei allen vorgenannten Beispielen einfach und uninspiriert auf der Strecke.

B) Zeichen: Hier wird der CD PLAYER von NAOTO FUKASAWA für MUJI einsortiert, zusammen mit einem

- Bakelit-Lautsprecher von PHILIPS,

- dem zWEISCHALENSTUHL von BOdo RAsch,

- dem tUlip Drehstuhl NR. 151 von EeRo SAARINNEN,

- der Tischlampe chistera von Le CHEVALIER/KOECHLin,

- dem PANTON-CHAir,

- dem Beistelltisch E1027 von EILEEN GRAY,

- dem Plattenspieler PHONO BOY von MARIO BELLINI,

- dem Hocker/Stuhl Ko no von SHIRO KURAMATA,

- dem Stuhlobjekt LASSU von ALLESSANDRO MENDINI,

- dem Zig ZAG-Stuhl von GERRIT T. RIETVELD,

- der Kommode cubicolo von ettore sottsass und

- der Stehlampe LUMinAtor von PiEtro chiesA.

3 Eine prinzipiell schwierige Begriffskombination - wie der Quantensprung in seiner Verwendungsform eigentlich dringend diskussionsbedürftig. 
Die Tischlampe von LE CHEVALIER/KOECHLIN wäre aus rein formalen Erwägungen auch mit COLOMBOs NR. 281 vermählbar gewesen - wobei letztere als Zeichen für colombos Persönlichkeit ihrer Form eines "C « wegen wesentlich besser in die Kategorie gepasst hätte. Wie beantwortet man hier die Frage nach dem Zeichen wofür - in Anbetracht der Artefaktauswahl - und: Was ist oder wo liegt die Ebene der Vergleichbarkeit?

c) Vorbild: Der PLY CHAIR von JASPER MORRISON befindet sich im Umfeld einer

- Tischlampe von SYBOLD VAN RAVESTEYN,

- des Armstuhls NR. 9 der GEBRÜder thonet,

- des fauteuil à dossier basculant von le corbusier,

- einer Türklinke von GROPIUS/MEYER,

- Sowie des ULMER HOcKERs von MAX BILL,

- eines anonymen Biedermeier-Kirschbaumstuhls mit Polster,

- der Tischlampe NR. 7344 von SCHWINTZER \& GRÄFF,

- eines Schaukelstuhls der SHAKER,

- des Stuhls NR. 482 von JEAN PROUVÉ

- und einer Skulptur (!) von ANDREA ZITTEL.

Noch einmal die leicht veränderte Frage: Vorbild wofür? Es fehlen die vom Nullpunkt des Vorbildes in die Welt weisenden Traditionslinien mitsamt den Artefakten, die sich auf jenen Nullpunkt berufen würden. Was soll sich aus den Vorbildern entwickelt haben? Man könnte ganz vage vor sich hin vermuten, dass die Beweisstücke mit ihrem Design eine generische Entwurfsrichtung für ihr Segment andeuten sollen. Es zeigt sich letztlich gänzlich banales - dass sich Bezüge in allem sehen lassen. Die Kunst der Erklärung ist es, die dieser Ausstellung auf weiter Strecke fehlt. Mit Blick auf den Aspekt der Anonymität werden ärgerlich unpräzise Aussagen gemacht, die so wirken, als hätte man sie einmal zu Testzwecken in den Raum gestellt und dann dort vergessen.

Von den 158 im Katalog abgebildeten Exponaten werden 14 als anonym bezeichnet; darüber hinaus liest er sich, was die Designer angeht, fast wie ein sattsam bekannter Kanon; eine Quote derjenigen, die von VITRA in deren Programm vertrieben werden, ist ebenfalls dabei. Als besonders im Vergleich zu den schon betrachteten Positionen bleiben in Abweichung vom verfolgten Faden der Anonymität nur LANGs seltsames Verständnis von guter Form und in unmittelbarem Bezug SCHWARTZ-CLAUSS' Idee der »Anonymisierung des Entwurfs« in Erinnerung; wobei die Anonymität bei letzterem und im Kontrast 


\section{STARDESIGNER ODER GESTALTER DES ALLTÄGLICHEN?}

zu LANG eindeutig negativ besetzt ist - denn Identität soll für ihn ja gerade aus der »Entstehung[sgeschichte] « und »aus der Beziehung zwischen Objekt und Benutzer« entstehen.

Daraus ergibt sich ein hoffnungslos überbundener Strauß an eher emotional gelagerten Ansprüchen, die von Designern im Vorfeld gar nicht erfüllt werden können. SCHWARTZ-CLAUSS scheint selbst keine Beispiele für eine gelungene Erfüllung seiner Ansprüche gefunden zu haben, sonst hätten doch einige als solche herausgehoben werden müssen. Oder ist gar der komplette Ausstellungskorpus eine anonymisierte Anklage via Massenreproduktion? In aller Willkür wird die bei FRANCO CLIVIO ausgeborgte Klistierbirne (CLIVIO, HANSEN Und MENDELL 2009: 47, 136, 138, 230) herausgegriffen: dort ist die Beziehung zwischen Objekt und Benutzer recht greifbar .... Als ironisches Fazit dazu verbleibt die genüßliche Feststellung, dass SCHWARTZ-CLAUSS' Gegenbild zur Anonymität sich in LANGs Schreckbild der »lautstarke[n] Rhetorik semantisch aufgeladener Objekte« konkretisiert.

Dem Bedürfnis nach bedeutungsschwanger klingender Expertenkommentierung wird mit den versammelten Texte Genüge getan und für den unkritischen Designliebhaber bleiben damit bestimmt keine Fragen mehr offen. Bei Hinterfragung enthüllen diese Texte leider auch wortreiche Inhaltslosigkeit und unausgegorene Gedankengebilde. Was Die Essenz der Dinge sei? Es bleibt auch in diesem Fall eine reine Geschmacksfrage und das wird sie auch weiterhin bleiben - denn schon ein individuell anderer Blickwinkel verändert den Blick auf die »Einfachheit, Funktionalität, Reduktion und Überschaubarkeit«. In einem letzten Zitat implodiert diese Designerprosa ganz von selbst: »[...] die Kunst der Reduktion ist letztlich eine Schule des Sehens: Sie trainiert ein unvoreingenommenes Sehen ohne Regeln.« (ebd.: 39) 


\section{Anonymität als Teil eines Markenkonzepts:} MUJ, IKEA und MANUFACTUM

Anonymität ist ebenfalls ein Thema für Händler und Produzenten, wenn sie zu einem zentralen Aspekt ihrer Geschäftstätigkeit aufgewertet wird. Sofern Produkte als Folge eines Markenkonzepts anonym bleiben sollen, stehen sie in engem Zusammenhang zum vorliegenden Untersuchungsthema. Als Beispiele werden hier MUJI, IKEA und MANUFACTUM betrachtet, bei denen die Marke immer im Vordergrund steht. Zwecks Beleg und Bezug zu GEORG FRANCK ein Einstieg mit einem weiteren Zitat aus der Ökonomie der Aufmerksamkeit:

"Ein Symbolismus, der durch die Medien erst so recht zum Zug kommt, ist der der Marken. Eine Marke symbolisiert etwas über Sitz, Aussehen und Preisklasse hinaus. Sie symbolisiert das Image. Die Marke gründet, wenn sie ankommt, eine Art Club. Durch die Wahl der richtigen Marken kann man gesellschaftliche Stellung auch nach dem Verschwinden des verbürgten Herkunftszeichens noch recht genau symbolisieren. Insofern ist es kein Wunder, daß Marken zum Fetisch werden. Bemerkenswert ist jedoch die Art und Weise, auf die es gelingt, Marken mit der Kraft von Fetischen zu begaben. Marken werden zu Fetischen, indem Hersteller als juristische Personen - zu Stars aufgebaut werden." (FRANCK 1998: 175)

MUJI (mu jirushi ryô hin = Qualitätswaren ohne Marke) eröffnet hier den Reigen der Marken-Stars. Dort praktiziert man seit 1980 eine besondere Form der Anonymität:

"Das Design ist wichtig, nie aber der Name des Designers oder des Designbüros. MUJI nennt seine Designer nicht und es gibt auch kein Autorendesign als solches. Gleichwohl startete MUJI 2003 sein ,World MUJI-Projekt: Gestalter aus der ganzen Welt - darunter so namhafte Persönlichkeiten wie Jasper Morrison, Sam Hecht und Tokomo Azumi, Enzo Mari - wurden eingeladen, neue Produkte für MUJI zu entwerfen. In der Sympathie dieser Designer und in ihren - natürlich minimalistischen - Entwürfen zeigt sich, dass der Grundgedanke von MUJI weltweit die Menschen anspricht und für sie bedeutsam ist: >Die Ideen, die sich bei MUJI sammeln, sind rentdeckte Universalität und keine zufälligen Einfälle oder temporäre Ideen.r [Hervorhebung im Original] Die entstandenen Produkte sind von hoher Gestaltqualität und sogar bereits zu kaufen, doch MUJI erwähnt mit keinem Wort die prominente Urherberschaft: Denn ein gutes Produkt spricht für sich und braucht keinen schmückenden Namen, der evtl. sogar blendet.« (BEUTTEL, 2004: 18f) [online] http://www.japanologie. uni-frankfurt.de/_Dateien/_Texte/Jap2_21_muji_B_Beutel.pdf [05.08.2015] (Inzwischen nicht mehr im Netz verfügbar) 
Was bei MUJI in den Vordergrund tritt, ist der Anspruch, sehr wohl eine Marke zu sein, die aber postuliert, keine sein zu wollen - obwohl sie alle Aspekte für sich durchdefiniert hat, die zu einer Marke gehören. MUJI verkörpert eine Haltung, die aus der japanischen Kultur heraus begründet wird, was zum Gesamtausdruck des Unternehmens samt aller seiner Produkte führt und zur erzwungenen Anonymität der für es tätigen Gestalter, die generischer entwerfen müssen.

IKEA unterscheidet sich davon in mehrfacher Hinsicht. Einerseits im Sortiment, denn IKEA ist primär ein Möbelhaus, das darüber hinaus auch noch für alle abgedeckten Wohnbereiche mit den passenden Accessoires aufwartet. Das Unternehmen stellt außer seinen Produktnamen mit dem ergänzenden Lebensmittelangebot sowie den Restaurants die greifbarste Anbindung an seine Herkunftskultur her. Andererseits ist IKEA der Hersteller-Händler, der wie kein anderer auf das Prinzip DIY baut. Möbel in transportfreundlichen Verpackungseinheiten in die Einrichtungshäuser zu liefern und die Kunden den Aufbau erledigen zu lassen, hat kein anderes Unternehmen so konsequent umgesetzt. Im Vergleich zur Anonymität der Gestalter bei MUJI scheint IKEA auf den ersten Blick einen ähnlichen Weg zu gehen. Nach außen gibt es vorgeblich keine bekannten oder bekanntgegebene Designer. Im Katalogband Democratic Design - Möbel für die Menschheit heißt es dazu:

\begin{abstract}
„Einer für alle, alle für einen« singt Campino von den Toten Hosen. Dieser Refrain gab die Idee für das folgende Interview. Hundert oder auch mehr Stimmen von allen Ikea-Designern sind zu einem einzigen Gespräch mit einem für alle sprechenden Democratic Designer verschmolzen. Und das aus einem einzigen Grund: Weil es bei Ikea den großen Designstar weder gab, noch gibt und auch nie geben wird. Hier ist die Gruppe der Guru und der Designtitan das Team, welches an den gemeinsamen Aufgabenstellungen arbeitet.« (UBER 2009: 26)
\end{abstract}

Im Internetauftritt und den Katalogen sind jedoch außer der Kennzeichnung "Design: IKEA of Sweden« immer wieder die Namen der Designer zu finden. In den Möbelhäusern werden an vielen Stellen Gestalter mit Bild neben ihren Entwürfen präsentiert. Man kann sich die Frage stellen, ob dadurch versucht wird, gezielt den Eindruck von Besonderheit aufzubauen und die Produkte selektiv mit einem zusätzlichen Starfaktor aufzuladen. Es ist zu erwarten, dass Konsumenten Produkte, die ihnen im Vergleich zum übrigen Sortiment als sichtbar herausgehoben präsentiert werden, anders wahrnehmen können / sollen/werden: 
"IKEA requires its customers to believe that they are buying into high culture. Products are marketed as innovative design in the tradition of Scandinavian Modernists like Jacobsen and Saarinen. The stores feature photographs of the designers - artistic black and white portraits, suggesting that each piece is the work of a famous Swedish designer rather than an anonymous design team. These recall the photographic portraits of Bauhaus designers. They play on the Modernist concept of the designer as heror. Is there any basis for this claim? IKEA does seem to have a comparable strategy to that of the Bauhaus, which dreamed of producing good, functional design cheap enough to be universally available."(MJ5446, 2011) [online] https://architecture.knoji.com/ikea-transforming-the-design-ofthe-home-part-2/ [14.05.2018]

IKEA wie MUJI müssen sich, obwohl sie global agieren, nicht um die Lokalisierung ihres Sortimentes kümmern, was ihre Anschlussfähigkeit in unterschiedlichen Ländern angeht. Sie pflegen einfach ihre Eigenheiten, weil sie sich darauf verlassen können, aufgrund ihrer Rolle als Kulturbotschafter geschätzt und gekauft zu werden. Die Herkunftskultur als mitverantwortliches Alleinstellungsmerkmal wird als der dem Design zugrunde liegende Kern wahrgenommen und bestimmt alles - von der Markenführung bis zum Marketing. Sie wird zum Kern der Markenakzeptanz. Mit geringen Ausnahmen, wie sie im Artikel Blonde Möbel von KASPAR MEULI in einer Ausgabe des NZZ FOLIO niedergeschrieben wurden (- eine aktuelle Stellungnahme von Seiten des Unternehmens war dazu bis dato nicht zu erhalten):

»Kein Land auf dieser Welt, so die Ikea-Strategen, das für ihr Unternehmen kein potentieller Markt wäre. Das Ikea-Konzept funktioniere überall. Der Beweis: Man habe sich noch von keinen Auslandsengagement wieder zurückziehen müssen. Und das, obwohl es weltweit in allen Geschäften das Gleiche zu kaufen gibt - oder vielleicht gerade deswegen. Anders Dahlvig sieht jedenfalls absolut keinen Grund, sich lokalen Märkten anzupassen. ২Ob in China, Russland, Manhattan oder London`, erklärte er kürzlich der ,Financial Timesı, >die Leute kaufen dieselben Dinge. Unser Sortiment ist überall gleich. Würden wir es anpassen, wären wir einfach eines unter vielen Geschäften. Doch unsere Idee ist, einzigartig zu sein unverkennbar skandinavisch und unverkennbar Ikea.r [...] Konzessionen an die lokale Lebensart machte Ikea bisher nur in einem Land - in den USA. Nachdem die Läden während Jahren massive Verluste geschrieben hatten, erwies sich die Anpassung als letzter Ausweg. Die Amerikaner, so war den aus Älmhult entsandten Entwicklern klar geworden, wollen alles ein bisschen grösser. Zur Illustration brachten sie eine Truthahn-Attrappe mit nach Hause. Die Schlussfolgerung war, dass für Amerika bestimmte Esstische künftig so groß sein mussten, dass darauf ein ordentlicher Turkey Platz hat. Die Rechnung ging auf. Heute sind die USA nach Deutsch- 


\section{STARDESIGNER ODER GESTALTER DES ALLTÄGLICHEN?}

land und England Ikeas drittgrösster Markt.« (MEULI in: NZZ FOLIO NR. 10, Oktober 2001: 98)

MANUFACTUM mit dem Slogan Es gibt sie noch, die guten Dinge hat eine alltagsarchäologische und auch moralische Haltung, die sich deutlich von den beiden zuvor betrachteten Unternehmen unterscheidet, aber ebenso die Anonymität der Gestalter zur Konsequenz hat, weil der Markenartikel den Vorrang bekommt - eine Haltung, wie sie auch dem Artikel von HINO EIICHI entnommen werden kann. Aus den Statements von KAJ FRANCK ist sie gleichfalls herauszulesen:

"Wir haben uns vorgenommen, Dinge zusammenzutragen, die in einem umfassenden Sinne gut sind, nämlich nach hergebrachten Standards arbeitsaufwendig gefertigt und daher solide und funktionstüchtig, aus ihrer Funktion heraus materialgerecht gestaltet und daher schön, aus klassischen Materialien (Metall, Glas, Holz u. a.) hergestellt, langlebig und reparierbar und daher umweltverträglich. Das Ergebnis unserer Mühen legen wir Ihnen hier online vor. Etwa 8500 in diesem weiten Sinne gute Dinge sind hier versammelt, vielfach Klassiker, langlebig nicht nur aufgrund von Technik und Material, sondern auch, weil sie über allen Moden und Trends stehen." (MANUFACTUM) [online] http://www.manufactum. de/uns-c-33/?campaign=kurzlink/Unternehmen [21.07.2015; inzwischen nicht mehr so im Netz verfügbar]

Die Seite ist noch vorhanden, der Text jedoch gegenüber dem ersten Zitat deutlich verändert. Eine Abwandlung des Originaltextes fand sich in einer Stellenanzeige wieder:

"Die Manufactum GmbH \& Co. KG ist ein Handelsunternehmen, das sich als Anbieter der sguten Dinger mit einem Sortiment hochwertiger Gebrauchsgüter an Endkunden wendet - dies mit einem außergewöhnlichen Katalog, mit neun Warenhäuser [sic] in großen Städten Deutschlands und einem sorgfältig gepflegten Internetauftritt. Wir bieten Artikel an, die in einem umfassenden Sinne gut sind, nämlich nach hergebrachten Standards arbeitsaufwendig gefertigt und daher solide und funktionstüchtig, aus ihrer Funktion heraus materialgerecht gestaltet und daher schön, aus klassischen Materialien (Metall, Glas, Holz u. a.) hergestellt, langlebig und reparierbar und daher umweltverträglich." (MANUFACTUM) [online] https://www.manufactum.de/ausbildung-kaufmann-frau-grossaussen-handel-waltrop-c-4173/ [15.05.2018] 
Unverkennbar eine moralische Einstellung, die die gute Funktion in Verbindung mit einem rein utilitaristischen Designgedanken von jenen Produkten fordert, die in das Sortiment aufgenommen werden. Man könnte dabei fast schon von einem Sammlungsverständnis sprechen:

\begin{abstract}
»Die eigentlichen Objektbeschreibungen lesen sich wie die Inventarkarten eines Museums oder, wie der Journalist Harry Nutt es ausgedrückt hat, wie ein Museumskatalog. Durch sie wird sozusagen ein Echtheitszertifikat für die ausgewählten Gegenstände gegeben. Neben den Massen werden die Funktion und die Begründung für die Gestaltung genannt, wenn es sich um Gebrauchsobjekte handelt, wie im vorliegenden Beispiel um Gläser:
\end{abstract}

,Poschinger Rotweinkelch 2 Stück. Mit grosser Kelchoberfläche, die die Raumtemperatur (die für die meisten Rotweine richtige Wärme) aufnimmt und bewahrt. Der Kelch schliesst sich nach oben ein wenig, so dass sich das Bouquet gut entfalten kann. Volumen 0.2 1.Höhe $17.5 \mathrm{~cm}$. Gewicht 195 g. (Bestellnr. 39258)« (BÖNISCH-BREDNICH in: GYR 2002: 156)

MANUFACTUM ist ein klassischer Händler, der, im Gegensatz zu den beiden anderen, nicht produziert. Die Marke, die alles zusammenfasst, bleibt identitätsbildend - auch wenn Herstellernamen im Katalog geführt werden. In den Selbstäußerungen des Unternehmens als Retter verlorengehender Kultur lässt sich ein Gestaltungsverständnis erkennen, das mit Macht in eine Handwerklichkeit vor dem Bauhaus zurückzustreben scheint - bei einem gleichzeitig deutlich wahrnehmbaren, unbedingten Erziehungsanspruch durch das Sortiment. Hervorzuheben ist die Wendung "aus ihrer Funktion heraus materialgerecht gestaltet und daher schön«. Sie verweist durch sich hindurch nur auf eine Haltung zur Gestaltung, die auch LICHTENSTEIN schon in Unbekannt - Vertraut an den Tag legt. Ein Blick auf die Sortimentsentwicklung zeigt, dass sich MUJI und MANUFACTUM ähnlicher sind, als man zunächst vermuten würde, denn beide haben programmatisch bedingt nur sehr begrenzte Sortiments-Änderungen im Lauf der Zeit zu verzeichnen. Ganz im Gegensatz zu IKEA, dessen Programm jedes Jahr zum Sommer wechselt und das auch "Jahr für Jahr jedes fünfte Produkt im Sortiment« ersetzt (MEULI in NZZ FOLIO NR. 10, Oktober 2001: 95f).

Bei MUJI verkörpert sich in den angebotenen Produkten eines der zugrundeliegenden Motti: „gerade genug «; was im Umkehrschluss bedeutet, dass jedes Artefakt, das diesen Zielpunkt erreicht, so bleiben kann und nicht durch etwas Neues verdrängt werden muss. Sortimentserweiterungen sind hier notwendige Ergänzungen, um das Kaufinteresse des geneigten Publikums den- 


\section{STARDESIGNER ODER GESTALTER DES ALLTÄGLICHEN?}

noch wachhalten zu können. In Anbetracht der angestrebten Langlebigkeit der vertriebenen Waren müssen auch Produkte mit einem kürzeren Verbrauchszyklus im Angebot sein, um den Punkt einer möglichen Marktsättigung so lange wie möglich hinauszuschieben.

Für MANUFACTUM beschränkt sich das Sortiment durch den Primat von Sammlung, Rettung und Entdeckung und durch das angepeilte Käufer-Segment ebenfalls zwangsläufig. Das lässt sich auch daran ablesen, dass durch die jüngste Erweiterung in den Bereich Gastronomie mit dem Angebot BROT \& BUTTER eine Markenspreizung versucht wird, um ein weiteres Wachstumsfeld neben dem fast schon notwendig selten und auserlesen bleibenden Stammsortiment zu schaffen. Schließlich muss der bedrohte Charakter für das elitär-bewusst einkaufende Klientel erhalten bleiben. Damit wurde eine ebenso raffinierte wie stimmige Entscheidung getroffen - auch wenn Lebensmittel im MANUFACTUM-Katalog nicht wirklich neu sind. Das nachfolgende Zitat verdeutlicht zum Abschluss, wie sämig man die Sprache der geneigten Kundschaft um den Mund fließen lässt, um eine möglichst stimmige Passung zur allumfassenden Hausphilosophie zu erzielen:

"Manufactum brot\&butter begreift Lebensmittel wieder in ihrem ursprünglichen Sinn - als Mittel zum Leben. Dabei geht es weder (wie im Feinkosthandel) allein um das exquisitere Lebensmittel noch (im Sinne eines ideologischen Biohandels) allein um die Abwesenheit von Schadstoffen, sondern es geht um rrichtige Lebensmittel in des Wortes umfassender Bedeutung: gut, stimmig und integer. Und es geht um das Bewahren von Differenzen, um den Unterschied zwischen landwirtschaftlicher und industrieller Produktion, um die Vielfalt von Kulturlandschaften und ihnen angepaßter Nutztierrassen, um die Authentizität eines örtlich und jahreszeitlich getönten Geschmacks und schließlich darum, daß ein in langen Zeiten geknüpftes Netz subtiler Kulturtechniken der Nahrungsmittelveredelung nicht völlig zerreißt. In diesem Sinne umfaßt das Sortiment von brot\&butter all das, was eine gut ausgestattete Vorratskammer birgt: Lebensmittel, also z.B. Brot, Nudeln, Essig und Öl, Gewürze, schonend eingekochte Marmeladen und Konfitüren, Konserviertes, Wein und Spirituosen, ausgewählte Süßwaren, Kaffees und Tees aus kleinen Röstereien und nachhaltig wirtschaftenden Anbaugebieten, Käse, Vorzugsmilch aus der Region und andere Milchprodukte von Kühen mit Weidegang und schließlich auch Wurst und Fleischwaren von artgerecht gehaltenen, alten Nutztierrassen." (MANUFACTUM) [online] http://www.manufactum.de/ manufactum-brot-und-butter-c-34/ [15.05.2018] 


\section{Anonymität ist für Marken kein tragfähiges Konzept}

Mit der Anonymität ist es nicht so weit her, wie es sich vom konzeptionellen Ausgangspunkt her anließ: Keines der drei Unternehmen kann den hehren Anspruch der Unauffälligkeit und Zurückgezogenheit durchhalten. Jedes muss schon aus Gründen des wirtschaftlichen Handelns als solches in Erscheinung treten und das allein widerspricht bereits den drei Kernbegriffen der DUDENschen Definition: Nichtbekanntsein, Nichtgenanntsein und Namenlosigkeit.

Die Mechanik des Geheimtipps ist für stabile wirtschaftliche Entwicklungen reichlich unsicher: Wird eine Gruppe von Conoscenti geschaffen, die gewillt sind, sich selbst durch ein gut gehütetes Eingeweihtenwissen von anderen abzugrenzen, stellt diese auch den begrenzten Konsumentenzugang im Markt für das Unternehmen dar. Das erfordert zu Beginn ein ausgedehntes Durchhaltevermögen und in der Folge sensible Beobachtungsarbeit, um Sättigung und Überdruss zu erkennen. Das Ziel muss sein, die eigene Begehrlichkeit auch weiterhin zu erhalten. Dies lässt sich bei MUJ sehr gut feststellen.

So bleiben nur noch Einzelaspekte im Rahmen des eigenen wirtschaftlichen Handelns übrig, anhand derer sich eine propagandistische Idee von Anonymität entwickeln lässt, die man als operative Fiktion nach außen ins Markenbild zu integrieren versucht - was aber von keinem der drei vorgestellten Konzerne wirklich durchgehalten wird.

Letztlich kokettieren IKEA und MUJI nur noch damit, weil sie sich dem überwältigenden und auch verlockenden Druck zur Nennung und Nutzung von Designernamen in einer ihnen genehmen und auch nutzenden Weise längst gebeugt haben. Einzig MANUFACTUM als Fachhändler lebt noch ein Markenkonzept aus, das - fast - gänzlich auf Namensnennung und die Zuschreibung zu Einzelpersonen verzichtet: Aber selbst dort kommt man nicht ohne die WAGENFELD-Lampe WA24 und seine Mehrzweckleuchte aus. (MANUFACTUM) [online] https://www.manufactum.de/suche/?q=Wagenfeld [15.05.2018]. 


\section{Hat der Ausdruck anonymes Design im 21. Jhd. 298 noch eine Bedeutung und wenn ja: Welche?}

Am Ende der Kavaliersreise kann festgestellt werden, dass es das anonyme Design eigentlich nicht gibt - so wie es kein Design ohne Designer gibt und zu gleicher Zeit existiert es auf einer anderen Diskussionsebene eben doch. Grundsätzlich werden Artefakte auf der Basis unterschiedlicher Bewertungsmaßstäbe einfach für anonym erklärt. Die grundlegende Definition der Anonymität als Nichtbekanntsein, Nichtgenanntsein und Namenlosigkeit trifft für die überwiegende Zahl der hier betrachteten Artefakte nicht zu. (DUDEN) [online] http://www.duden.de/rechtschreibung/Anonymitaet [20.02.2018]

Ihre Schöpfer sind oder waren bekannt - sie geraten nur zuweilen in Vergessenheit, so dass Anonymität höchstens eine fallweise Geltung erlangen kann oder konnte. Zudem bleiben Artefakte nicht prinzipiell namenlos, da es auf generischer Ebene bereits Bezeichnungen für diese gibt. Also wissen wir mindestens, worum es sich handelt, wenn schon nicht, von wem sie stammen. Zugleich ist festzuhalten, dass nur drei der betrachteten Autoren das Design der für anonym erklärten Produkte von den Designern fernhalten möchten - was sich in der moralischen Schelte von FRIEDL und OHLHAUSER und auch von LICHTENSTEIN manifestiert. Es besteht auch kein Zweifel daran, dass sie gestaltet sind. Was in Frage steht, sind unterschiedliche Aspekte der Berufsausübung, wie z. B. der Art der Gegenstände, die gestaltet werden (sowohl welche als auch wie) und das Verhältnis zur Öffentlichkeit. 


\section{Sieben Arten der Herstellung von anonymem Design}

Was bei der Betrachtung in den Vordergrund rückte, war die Herstellung von Anonymität. Sie wurde in jüngerer Zeit fast schon lehrbuchhaft erzeugt durch die Anforderungen von Marken, die sich vor Personen schoben - wie sich in den Gefilden des Stardesigns zunächst Personen vor Artefakte zu schieben schienen. So hat das anonyme Design, nehmen wir es für den Moment wieder als existent an, mehr mit Personen als mit Artefakten zu tun. Wurde in der Einleitung dieses Kapitels noch verknappt formuliert, dass es verschiedene Formen von Anonymität zu geben scheine, so bietet sich inzwischen ein deutlich differenzierbareres Bild, denn mehr und mehr ging es im Lauf der Jahrzehnte auch darum, wie sich zur Anonymität zu verhalten wäre.

Anonymes Design NR. 1 \& NR. 2: In den 6oern des 20. Jhd.s lagen ALLISON und KAJ FRANCK mit purer (?) Koinzidenz zeitlich fast gleichauf, wenn der eine ein Zeitalter der Anonymität für Designer anbrechen sah und das auch zu begründen wusste: Als Zurückweichen der Personen aufgrund der veränderten Anforderungen des Berufsfeldes. Das kann als Anonymitätstyp 1 bezeichnet werden. Der andere dagegen machte den persönlichen Rückzug der Designer aus der ersten Reihe zu einer Frage individueller moralischer Entscheidungen im Angesicht industrieller Serienproduktion - was als Anonymitätstyp 2 klassifiziert wird.

Immer noch bedeutsam klingt ALLISONs Formulierung, dass Anonymität für den Geltungsbereich seiner Arbeit nur »the absence of idiosyncrasy in design« bedeute, ob man den Designer nun kenne oder nicht - Senderanonymität spielte für ihn keine Rolle. Anonymität wurde für ihn herstellbar durch eine bestimmte Art, zu gestalten, die man noch einmal als Abwesenheit eines Personalstils reformulieren könnte. Man darf auch nicht die Feststellung vergessen, dass die Teamarbeit in unübersichtlicheren Großprojekten jene individuellen Eigenheiten ebenfalls verschwinden lasse. Damit steht ein Solitär auf dem Spielfeld, der den bisher gewonnenen Erkenntnissen ans Schienbein tritt, weil ALLISON als einziger aller betrachteten Autoren behauptet, dass Anonymität regelrecht gestaltet werden könne bzw. zwangsläufig entstehen müsse oder werde - sofern man sich in der eigenen Profession den Anforderungen des anbrechenden Zeitalters unterwerfe oder anpasse. 
Ans Schienbein trat sich eigentlich auch KAJ FRANCK. Sein Versuch, einerseits (Teil-)Anonymität zu erreichen und andererseits den Rückzug hinter die Mar300 ke zugunsten des Massenprodukts doch nicht ganz so absolut werden zu lassen, scheiterte - ideologisch betrachtet - zumindest teilweise, indem er sich das signierte Unikat als Schlupfloch aus der Namenlosigkeit freihielt. Er steht ebenfalls allein und auf eine andere Art völlig ungeschlagen auf dem Spielfeld, weil er es - der Vorgang scheint tatsächlich nahezu völlig vergessen - wie kein anderer zu Wege gebracht hatte, durch eine Pressestunde und vermittels eines einzigen Textes seine ganze Nation zu erschüttern. Seine Bemühungen, den Namen des Entwerfers aus dem Visier der Konsumenten zu nehmen und an dessen Stelle Produktinformationen zu setzen, um eine realistischere Bewertung von Produkten zu erreichen, waren ein teilweise ehrenwerter Versuch, der an seiner eigenen Popularität und dem menschlichen Bestreben nach Auszeichnung von Menschen und Dingen scheiterte. MASER kommt einem hier mit seinem Begriff der Wertsetzung in den Sinn und man könnte auch Anschluss bei MIKLAUTz im Zusammenhang mit der Besetzung mit Bedeutung finden.

KAJ FRANCK wollte dem (seriellen) Artefakt die Chance geben, sich von seinem Schöpfer zu emanzipieren und verlangte dafür vom Designer den demütigen Rückzug in die Anonymität. Da er seine öffentliche Wirksamkeit erst nach dem Erringen hinreichender Aufmerksamkeit erzielen konnte, war dieser Rückzugsversuch nur möglich und bedeutsam, weil sein Fundament in der ersten Reihe stand und auch dort verblieb. Vor diesem Hintergrund scheint es letztlich nicht wirklich (ursächlich) darauf anzukommen, was Designer sagen oder nicht sagen. Letztlich kann jegliche wahrgenommene Entscheidung von anderen als bemerkenswert klassifiziert werden, sich ab dann dem Einfluss des Verursachers entziehen und in der Folge heteronome Prozesse anstoßen. Die Akteure derselben könnten sich genauso gut einen feuchten Kehricht darum scheren, was ein Designer zu seiner Profession sagt oder schreibt. In KAJ FRANCKs Fall taten sie es nicht.

Anonymes Design NR. 3: Dieses finden wir bei FRIEDL und OHLHAUSER beschrieben. Deren Art, auf das Design zu schauen, wiederholte sich in Abstufungen und Variationen im Rahmen verschiedener Ausstellungen und Publikationen interessanterweise ungefähr in Jahrzehntabständen. Es war bei ihnen weniger ein Anonymitätstyp (hier dennoch der dritte), der sich dem geneigten Designer als Verhaltens-Matrize anbot, als das Bestreben - im Extrem gedacht Designer nichts mehr gestalten zu lassen und dergestalt die eigene Disziplin 
in der Anonymität zu versenken. Gestalten würden demnach nur noch die Nicht-Designer außerhalb der Scheinwerferkegel.

FRIEDL und OHLHAUSER waren die ersten geistigen Brandstifter dieser Art und damit unmittelbare Vorläufer von LICHTENSTEIN, DIETZ und THESELIUS sowie von MORRISON und FUKASAWA. Ihr »[...] gewöhnliche[s] Design ist kein Design«. (FRIEDL und OHLHAUSER 1979: 38) Sie konzedierten zwar »es [sei] falsch, anzunehmen, die vollkommen unbedeutenden Produkte seien nicht designt", doch die durchdringende Meinung war, dass die Gestaltung der gewöhnlichen, unbedeutenden Dinge nicht von Designern geleistet wurde, weil sich dies nicht in den Dienst der Umsatzsteigerung stellen lasse (vgl. ebd.: 16). Sie gingen so weit, zu suggerieren, Designer seien eigentlich gar nicht in der Lage, gewöhnliche Dinge zu gestalten, so wie es auch VON KORNATZKI in seinem damaligen Beitrag formulierte (vgl. ebd.: 39).

Anonymes Design NR. 4: LICHTENSTEIN variierte FRIEDL und OHLHAUSER nur schwach, ohne deren Grundhaltung, dass anonymes Design besser nicht von Designern gestaltet werde, wirklich anders zu fassen. Sein Argumentationsstrang unterschob unausgesprochen, vieles entstünde auch in Zukunft besser ohne Designer. Seine Vorstellung, anonymes Design sei theatralikfrei mit einem quasi unabsichtlichen Inkognito, wird als Anonymitätstyp 4 in die Reihe aufgenommen.

Anonymes Design NR. 5: Die Überlegungen von HINO EIICHI im Rahmen der Publikation der JSSD, anonymes Design als verkörperte Abwesenheit von Eigenreklame und auch als eine Frage der »Moral des sogenannten Berufsdesigners« (vgl. EIICHI 1993: 12) zu definieren, wird als Anonymitätstyp 5 klassifiziert. In Japan scheint zudem geschichtlich die stärkste Verwurzelung in der Gesellschaft gegeben zu sein und aus Sicht der Theorie auch der geringste gedankliche Abstand zwischen Designer und Gesellschaft zu bestehen. Gestaltung soll sich in Japan in den Dienst des Nutzers stellen und nicht zum Ruhm ihres Schöpfers führen, wenngleich die Verantwortung für das Produkt über die Herstellerkennzeichnung - ebenso wie von KAJ FRANCK gewünscht - übernommen werden sollte.

DIETZ und THESELIUS lagen ebenfalls auf dieser Linie und fuhren für sich den Erfolg ein, mit ihrer Ausstellungsreihe durch den Kunstgriff der Budgetbegrenzung pro Artefakt-Einkauf eine der überzeugendsten Interpretationen des "namenlosen « Alltagsdesigns geschaffen zu haben. Sie ist dennoch nicht frei von den Einflüssen des persönlichen Geschmacks, der, als vermeint- 


\section{STARDESIGNER ODER GESTALTER DES ALLTÄGLICHEN?}

liche Objektivität maskiert, als treibende Kraft hinter allen Ausstellungen seit Das gewöhnliche Design steht. Ihre Anonymitätsvorstellung unterscheidet sich ebenfalls nicht wesentlich von LICHTENSTEIN, denn auch ihr Impetus für die Ausstellung war lediglich, die ausgewählten Alltagsobjekte durch eine Vereinzelung im Museum dem Übersehenwerden zu entreißen.

Jenes Übersehenwerden steht recht eindeutig auf einer Stufe mit LICHTENSTEINs unabsichtlichem Inkognito. Sie waren jedoch die ersten, die sich auf das gefährliche Spiel einließen, das Willkürliche und ihren persönlichen Geschmack, dass »etwas« an jenen Artefakten sie berührt und dadurch zum Kauf "gezwungen habe«, tatsächlich als Grund anzugeben und diesen auch genügen zu lassen - anders als FRIEDL und OHLHAUSER, die nichts als ihre Planlosigkeit zum Besten gaben. DIETz und THESELIUS' Haltung findet sich weiter unten in einem etwas sachlicheren Begründungszusammenhang bei WENZL-BACHMAYER wieder:

»Insofern sei für die folgende Auswahl an Ideen und Gegenständen eine alte mathematische Grundbedingung vorausgesetzt: Diese Auswahl ist willkürlich, jedoch hinreichend begründet und notwendig reduziert.« (SACHSSE in: WENZL-BACHMAYER 2009: 11)

Anonymes Design NR. 6: SACHSSE postulierte, »[...] gute[s] Design [werde] anonym, denn es lös[e] seine entworfene Gestalt im Gebrauch auf.« (ebd.: 9). Das Hauptcharakteristikum dieser Anonymität durch Gebrauch ist es, selbige ebenfalls auf eine andere Art herzustellen, sie für den Gebraucher im Gebrauch entstehen zu lassen, da die Artefakte dabei »verschwinden«. Nach dem Erlernen ihrer Gebrauchsfunktion verbleiben keine Fragen an sie oder Widerstände in der Nutzung derselben. Sie werden zu nicht mehr hinterfragten, automatisierten und dadurch auf eine andere Art unauffälligen Teilen des eigenen Alltags. Diese Position verschränkte zudem als einzige die Idee des guten Designs mit der der Anonymität und dieser eine Satz versenkte eine komplette Geschmacksdebatte, ohne sie zu führen - was auch an dieser Stelle nicht nachgeholt werden wird.

Anonymes Design NR. 7: Die Essenz der Dinge bringt uns auf die Zielgerade. Dort tauchte anonymes Design in LANGs Text "mit seiner unaufdringlich reduzierten Erscheinung « als »[...] erholsame Abwechslung in einer Produktwelt« auf, »in der die lautstarke Rhetorik semantisch aufgeladener Objekte dominiert [...]«. Die von ihr beschworene »Anonymität dieser banalen, aber unverzichtbaren Dinge« und deren »unaufdringliche Unterstützung mensch- 
licher Alltagshandlungen « sortieren ihre Idee beim Anonymitätstyp 6 ein. (vgl. SCHWARTZ-CLAUSS Und VEGESACK 2009: 61) SCHWARTZ-CLAUSS' Diktum der Gefahr einer Anonymisierung des Entwurfs durch die Perfektion der anschließenden Realisierung wird aus Respekt für eine abwegige Idee als der guten Dinge siebtes gewertet. (vgl. ebd.: 28)

\section{Händlerkonzepte}

Aus deren Betrachtung lässt sich abschließend folgern, dass anonymes Design als absichtsvolles Inkognito vor dem Hintergrund, eine Marke positionieren zu müssen, ein schwer ins Markenbild integrierbares Hindernis darstellt und letztlich nur als operative Fiktion, als ein so-tun-als-ob, noch Geltung erlangen kann. Für eine begrenzte Zeitspanne und bei entsprechender Seltenheit im Vergleich mit der Konkurrenz verspricht dieses Vorgehen eine unerhörte Alleinstellung, doch auf Dauer sind der Drang zur und die Forderung nach Bekanntheit zu stark. Kaum eine Formulierung fasst den Problemkomplex besser zusammen als sich einen Namen machen. Eigene Arten anonymen Designs, die sich von den bereits ermittelten unterscheiden würden, gab es in diesem $\mathrm{Zu}$ sammenhang nicht. 


\section{Was bleibt am Ende vom anonymen Design übrig?}

Nach der dritten oder vierten Wiederholung muss man sich doch staunend eines fragen: Welche Erklärung ließe sich wohl dafür finden, dass im Lauf der Jahrzehnte wieder und wieder Ausstellungen konzipiert wurden (und wahrscheinlich noch werden), die den Ver- oder Gebraucher (was auch immer man in diesem Zusammenhang bevorzugte) an das Alltagsdesign heranführen sollten, als wäre es die letzte terra incognita, die auf diesem Erdenrund noch existiert?

Besonders verwunderlich (je weiter die Betrachtungen ausgriffen) war und ist es, dass diese Ausstellungen wieder und wieder von Designern angestoßen und konzipiert wurden und werden. Noch dazu von Designern, die oft in hohem Maße von dem Aufmerksamkeitspotential profitierten, das sie hatten und die fast immer in gänzlich anderen Marktsegmenten tätig waren als die Gegenstände, die sie für ihr jeweiliges Real-Utopia auswählten.

Jenes Gefühl, das sich schon bei Das gewöhnliche Design zum ersten Mal manifestierte, verfestigte sich mit jeder weiteren Ausstellung, die in die gleiche Kerbe schlug: Es waren vorherrschend die Designer, die anscheinend den Überdruss an ihrer eigenen Profession dadurch abreagierten, dass sie Ausstellungen konzipierten, in denen größtenteils Hohelieder auf ein Design ohne Designer gesungen wurden. Auf diese Weise wurde Kritik an der eigenen Profession in einer Radikalität geübt, dass man sich fragen musste, wieso es keinen dritten Weg zu geben schien. Im Kapitel zur Prominenz war bereits zu sehen, dass diese Entwicklungen des Marktes sowieso überwiegend außerhalb ihres Einflusses liegen.

Jene Haltung, das Design wegzulassen wurde in den vergangenen zwei Jahrzehnten aufs einprägsamste durch JASPER MORRISON vorgelebt, der in seiner Außenwirkung am liebsten hinter seinen Entwürfen verschwinden möchte und es doch nicht kann. (PRÜFER in DIE ZEIT 22/2010) [online] http:// www.zeit.de/2010/22/Einfach-Jasper-Morrison [15.05.2018] Um dieses Ziel zu erreichen, hat er sich auf eine Entschlackung seiner Entwürfe zurückgezogen, die in einem Personalstil endete, der in hinterhältigster Perfidie die Absichten seines Schöpfers konterkariert - indem er dadurch wiedererkennbar wird. Auch JASPER MORRISON muss sich trotz (oder gerade wegen?) SUPERNORMAL damit abfinden, dass kein Designer sich einer sozialen Bewertung seiner Entwürfe entziehen kann, dass auch er gekauft wird wegen seiner Haltung, auf deren Basis ein Teil des Design-Markts (wie so oft) das Kunststück 
fertigbringt, eine Antihaltung als schick zu deklarieren und konsumierbar zu machen. Letztlich werden damit Distinktionsbedürfnisse angesprochen und Distinktionspotentiale ausgeschöpft, die sich aus der in Entwürfe gegossenen Haltung speisen.

Ebensolches Kopfschütteln ergreift einen, wenn man sich die Frage stellt, wieso diese oder jene Einstellung nicht einfach nebeneinander existieren können? Dies soll keinesfalls relativierend klingen, doch kann man inzwischen überdeutlich erkennen, dass scheinbar nichts davon ohne eine allesumspannende Begleit- und Beglückungsideologie auskommt - es gab, was die jeweiligen »Heilsversprechen « angeht, kein sowohl als auch, sondern nur ein entweder oder. So eignet allen betrachteten Ausstellungen die Tendenz, auch Maßstäbe für entwerferisches Handeln - in allerbester Unauffälligkeit - darstellen zu wollen und Verbrauchererziehung zu betreiben. Womit sie sich nicht im Geringsten von den Warenkunden des frühen 20. Jhd.s unterschieden, wenn sie auch medial einen teilweise anderen Weg wählten. Sogar die Akteure sind im Prinzip noch identisch. Aktuellere Bemühungen zur Geschmackserziehung heben sich aber dadurch deutlich von den Altvorderen ab, dass sie die Abschaffung ihrer selbst mitpropagieren.

Die Beschreibung sieben differierender Arten anonymen Designs weist nach, dass Anonymität, je nach Herangehensweise oder Begründungszusammenhang, nicht gleich Anonymität ist und belegt zugleich die Eingangsvermutung, dass aufgrund dieser unterschiedlichen Anonymitäten kein einzig wahres anonymes Design existiert, schon gar nicht mit einem objektivierbaren Anspruch. Als Synonym für das Übersehenwerden, für ein Verbleiben im Unpersönlichen, wurde Anonymität von den hier betrachteten Publikationen in ihrer Ausprägung auf unterschiedliche Arten festgeschrieben und durch die Definition gleichzeitig zwangsweise überwunden.

Denn letztlich beendet schon das Bemerken den Zustand der Anonymität und die weitere Beschäftigung mit dem bisher unbemerkten, unpersönlichen, ungewussten hebt ihn gänzlich auf. Somit ist sie - zumindest für Artefakte eine toxisch ambivalente Kategorie, die nur als eine abstrakte Vorstellung von Nichtbekanntsein, Nichtgenanntsein und Namenlosigkeit tatsächlich noch Anonymität "garantiert «. Im Kern kann sie im Feld des Designs für nichts anderes mehr stehen als für einen Zustand des Noch-nicht-Kennens - vergleichbar dem Bild eines »Überschuss[es] an Fremdheit« (WALDENFELS 2004: 253). Dieser formuliert hierzu schon: 


\section{STARDESIGNER ODER GESTALTER DES ALLTÄGLICHEN?}

"Am Ende stellt sich die Frage nach der Art und Weise, wie Aufmerksamkeit sich überhaupt als ein Aufmerksamkeitsgeschehen fassen läßt. Braucht Auffälliges, um aufzufallen, nicht den Kontrast eines Unauffälligen, das unbemerkt bleibt?« (ebd.: 283)

Löst die Behauptung der Anonymität am Ende gar das Versprechen einer »magischen Veränderung" ein (vgl. BYSTRÖM JANARV in O. V., 1997: 24), weil die Bezeichnung mit ihr verstärkte Aufmerksamkeit für etwas auslöst, das bis dahin tatsächlich anonym bleiben konnte, da es bis zu diesem Zeitpunkt keine Aufmerksamkeit erregt hatte? 


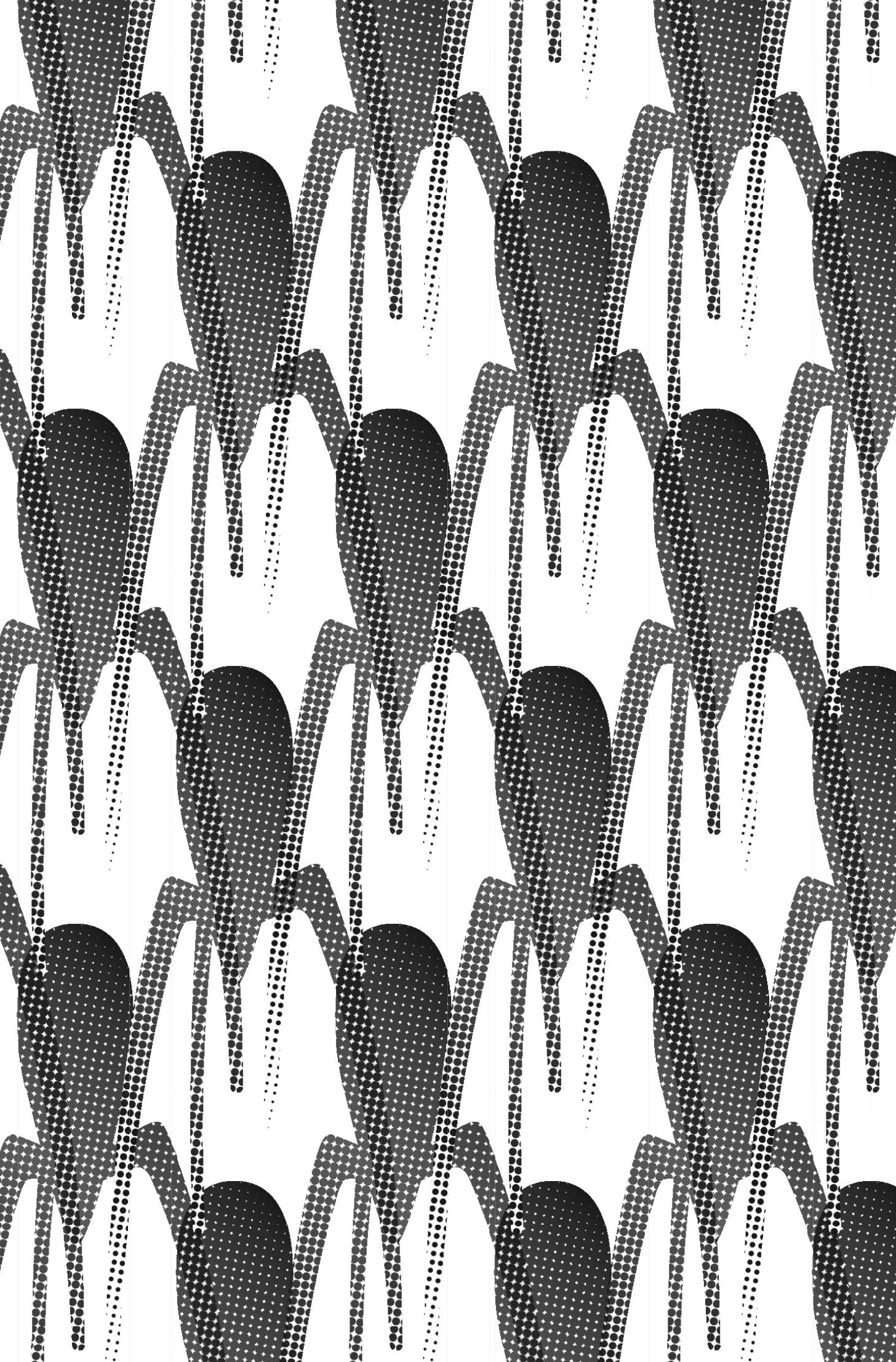




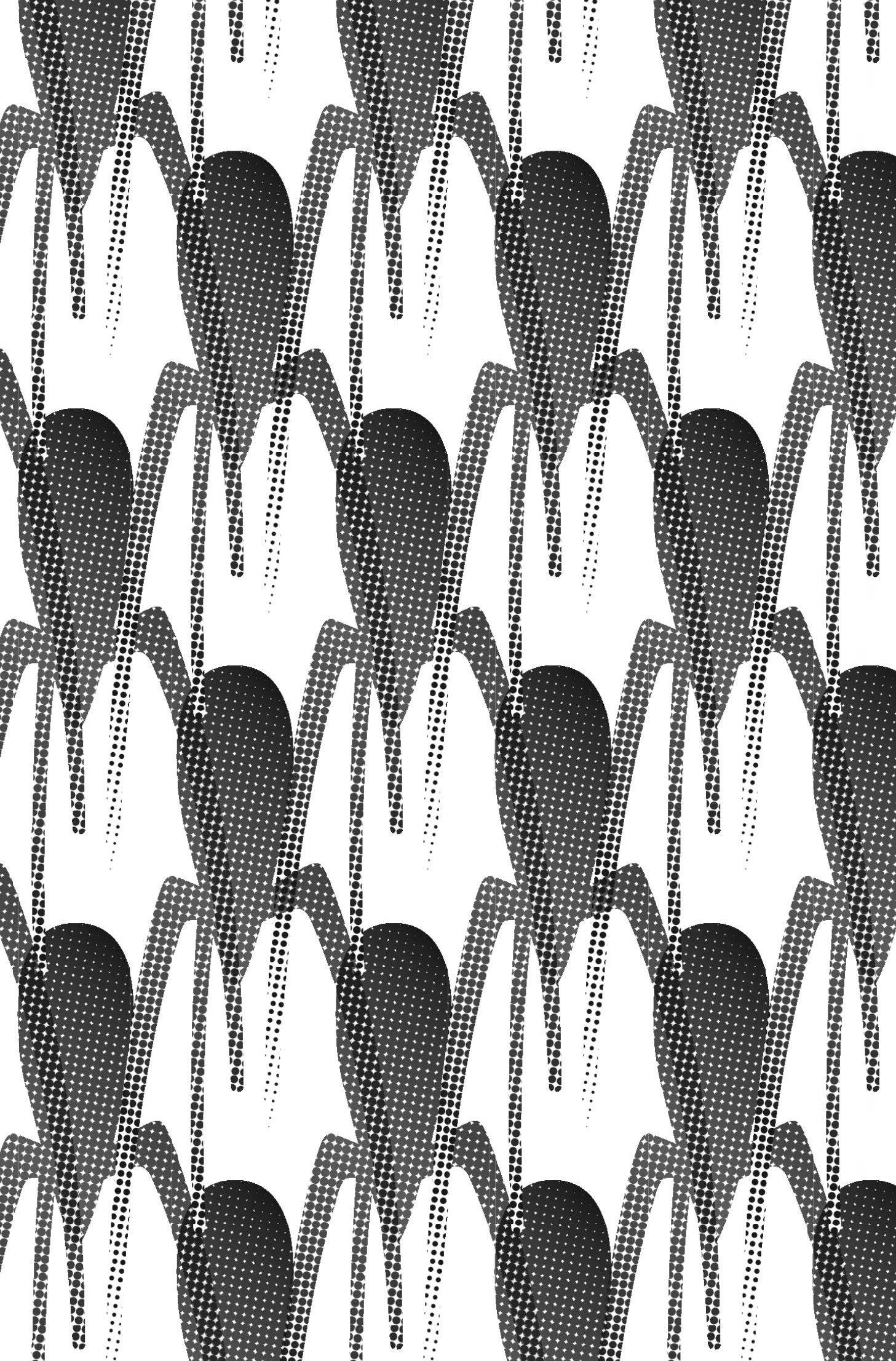


Rezeption 
»Die Überzeugungskraft liegt häufig in einer blitzartig aufleuchtenden Plausibilität, bei der man nicht nachfragt.« 


\section{Am Ende war es nur ein Wort: Zwei Rezeptionsstudien}

Stardesign ist in Bezug auf seine Verbreitung zuallererst ein sprachliches Phänomen und mit den Bezeichnungen Stardesigner und Designklassiker werden ganz bewusst Wertmaßstäbe transportiert. Diese konstituieren sich sprachlich und werden durch Sprechakte oder schriftlich übermittelt. Der Nachdruck, mit dem GLASER und STRAUSS im Rahmen des Kapitels Ähnlichkeiten zwischen der Feldforschung und der Arbeit in den Bibliotheken darauf hinweisen, dass Bibliotheken und Zeitschriftenartikel eine nicht zu unterschätzende Datenquelle darstellen, lieferte den entscheidenden Anstoß zu der auf den folgenden Seiten beschriebenen Exploration:

»Jedes Buch, jeder Zeitschriftenartikel repräsentiert zumindest eine Person, die das Äquivalent zum Informanten des Ethnologen oder zum Interviewpartner des Soziologen ist. In diesen Publikationen streiten Menschen, verkünden Stellungnahmen, argumentieren mehr oder weniger eloquent und beschreiben - nicht anders als der Forscher es im Feld erlebt - Ereignisse oder Szenen. Man muss diese Stimmen in der Bibliothek nur entdecken, um sie für seine Analysen fruchtbar zu machen." (GLASER und STRAUSS 2008: 169f)

Dem folgend drängt sich die Auswertung einer Gruppe von Publikationen geradezu auf, um die Formen medialer Star-Konstruktionen zu analysieren und so Abstand zu einer kunstwissenschaftlichen, auf Ästhetik basierenden Betrachtung zu gewinnen - mit dem Ziel, eine amoralische Betrachterpositi- 


\section{STARDESIGNER ODER GESTALTER DES ALLTÄGLICHEN?}

on einnehmen zu können. In designgeschichtlicher Perspektive findet dieses Vorgehen bei WALKER sowohl Erwähnung als auch Unterstützung. Er warnt jedoch auch schon davor, Repräsentativität anzunehmen:

„Wie lassen sich für die Designgeschichte Daten über Rezeptionsvorgänge erheben? Mehrere Methoden sind anwendbar: [...] 2. Durch Prüfung der bisherigen Beurteilungen: [Hervorhebung im Original] Die Besprechungen von Produkten und Gebäuden usw. in Zeitungen, Zeitschriften und historischen Darstellungen. Da die Autoren Fachleute sind, Journalisten, Experten, Kritiker, könnten ihre Urteile bei aller Detailkenntnis und allem fundierten Wissen trotzdem nicht repräsentativ sein.« (WALKER 1992: 211)

Wer Stardesigner und was Designklassiker sind, wird zunächst anhand der Presseresonanz eingegrenzt und so für den Nachgang nutzbar gemacht. Die Auswahl eines Publikationskorpus anhand objektiv nachvollziehbarer Kriterien soll einen Überblick erbringen, der so weitestgehend frei von einer persönlichen Wertung durch individuelle, möglicherweise durch eigenes Vorwissen getrübte Entscheidungen bleiben kann. Untersucht werden anhand ihres kompletten, im Internet auffindbaren Bestandes:

1. ARCHITEKTUR \& WOHNEN,

2. ART DAS KUNSTMAGAZIN,

3. DER SPIEGEL,

4. DER STANDARD,

5. DESIGN REPORT,

6. DIE PRESSE,

7. DIE WELT,

8. DIE ZEIT,

9. FRANKFURTER ALLGEMEINE ZEITUNG,

10. FORM,

11. NEUE ZÜRCHER ZEITUNG,

12. SCHÖNER WOHNEN und

13. SÜDDEUTSCHE

Vorrangige Auswahlkriterien für den Korpus sind: 1.) ein Feuilleton mit überregionaler Bedeutung, 2.) die angenommene Zielgruppe der Publikation und 3.) der Zuschnitt als Fachpublikation. DIE PRESSE, DER STANDARD und die NEUE ZÜRCHER ZEITUNG decken für ÖSTERREICH und die SCHWEIZ den restlichen deutschsprachigen Raum repräsentativ ab. Die FORM und der DESIGN REPORT sind als Fachpublikationen im Sinne einer Kontrollgruppe zu verstehen, da sie sich vom Zuschnitt her so gut wie ausschließlich an Designer (und 
Designliebhaber) wenden. Die Untersuchung fand im Kern von Juli bis August 2013 statt und umfasst den kompletten digital vorhandenen Bestand der o. a. Publikationen. Sie wurde im Herbst 2014 aufgrund aktueller Entwicklungen noch einmal fortgeführt und 2017 mit einer zweiten Studie in ausgewählten Bänden der hier so benannten Befestigungsliteratur komplettiert. Besonders herausgehoben werden muss im Vorfeld, dass es sich bei allen untersuchten Texten nicht um als solche gekennzeichnete Werbung handelt, sondern sämtlich um redaktionelle Veröffentlichungen. Die zeitliche Rahmung schließt zudem neuere journalistische, mit indirekter Werbung vermischte Formate (sog. Advertorials) weitestgehend zuverlässig aus, die nicht mehr so leicht von »echten« journalistischen Texten unterscheidbar sind.

Aus der Sicht des Jahres 2019 wäre eine neuerliche Online-Studie in dieser Form nicht mehr durchführbar. In Anbetracht der Volatilität und der teils deutlich abnehmenden Durchsuchbarkeit der Archive infolge fortwährender Umstrukturierungen, Designumstellungen und dem Wechsel von Content Management-Systemen sowie vor dem Hintergrund neu errichteter Bezahlschranken war der Zeitpunkt, zu dem diese Studie durchgeführt wurde, eindeutig ihr Kairos.

Gezielt nach Personen gesucht wurde zu Beginn mit den Begriffen Stardesigner, Stardesignerin und Designerstar sowie Designstar. Im Verlauf der Recherche weitete sich das Wortfeld sehr schnell erheblich aus. Alle gefundenen Bezeichnungen wurden deshalb sowohl dokumentiert als auch klassifiziert. Während der Laufzeit wurden auch alle Fundstellen außerhalb der untersuchten Publikationen einbezogen, um den Reichtum an Beschreibungen möglichst nicht einzuschränken - diese fanden aber nur in Bezug auf die verwendeten Begriffe in die Auswertung Eingang. Rückblickend ging die Suche für ein an den Maßstäben und Methoden der Grounded Theory orientiertes Forschungsvorhaben durchaus unorthodox vonstatten. Die Suchbegriffe für die selektiven Samplings, die wenig später zu zufälligen Samplings ausgeweitet wurden, stellten de facto schon die Kernkategorien dar, so dass die Empirie im Prinzip als Prozess des Reverse Engineering ablief, mit dem versucht wurde, herauszufinden, wie es zur Bildung dieser Kategorien kommt und ob sie durch tatsächlich benennbare Wertmaßstäbe gestützt werden.

Ein weiterer Suchlauf im gleichen Publikationskorpus ging zunächst nur vom Begriff Designklassiker aus. Identisch zum Vorgehen für die Star-Designer begann die Suche mit einem selektiven Sampling. Auch der Verlauf dieser Untersuchung machte sehr schnell deutlich, dass die Eingrenzung auf ein Suchwort zu viele davon abweichende Bezeichnungen und damit auch jede 
Menge Artefakte ausgeblendet hätte. Deshalb wurde die Suche zu einem zufälligen Sampling ausgeweitet, um auch darüber hinaus gehende Funde in die 314 Auswertung einbeziehen zu können. Anders als bei den Star-Designern wurden durch die hinzutretenden Begriffe auch weitere Kernkategorien entdeckt, die nicht als bloße Variationen betrachtet werden können. Zur Vereinfachung werden ARCHITEKTUR \& WOHNEN SOwie SCHÖNER WOHNEN ab jetzt mit A\&W und sw abgekürzt.

\section{Auswertung mit Blick auf Personen}

Zum Einstieg ein Blick auf die Berufsfelder, in denen die gesuchten Begriffe nebst ihren Varianten auftauchen: Produktdesign, Automobildesign (mit einem Schwerpunkt in ITALIEN), darüber hinaus Yacht-Design und ein wenig Architektur, was der Übertragung der Berufsbezeichnung Designer auf Architekten geschuldet ist. Zudem findet sich der Begriff auch im Bereich der Computerspiele, die in dieser Untersuchung aber keine Rolle gespielt haben.

Die Untersuchung weist 247 individuelle Funde von Designerinnen und Designern aus, die in der Presse mit Star-Attributen unterschiedlichster Art versehen werden. Davon sind 34 Personen weiblich und 213 männlich. Innerhalb des systematisch untersuchten Publikationskorpus werden 131 Personen gefunden (davon 10 weiblich), 116 außerhalb (davon 24 weiblich).

Auffällig ist - neben dem generellen Mangel an weiblichen Personenfunden - von Beginn an, dass in der Kontrollgruppe der Fachpublikationen die Anzahl der gefundenen Personen und Artefakte am geringsten bleibt. Die gezielt untersuchten Publikationen führen nur zwei Frauen als Stardesignerin und eine als Stardesigner auf, eine einzige wird dort auch mit zwei unterschiedlichen Bezeichnungen versehen. Der unspezifische Beifang ergibt eine Liste von vierzehn Frauen, die als Star-Designerin ausgewiesen werden, davon eine mit einer durch eine Stadtzugabe nationalisierten Variante.

Aus der Masse der Fundstellen im Erstreckungsbereich der gezielt untersuchten Publikationen muss nun ein Untersuchungskörper geformt werden, der abarbeitbar bleiben soll. Dazu wird ein streng numerisches Vorgehen gewählt. Die zehn am häufigsten gefundenen Personen sollen für die weitere Bearbeitung als Referenzgruppe dienen. Der Begriff Fundstellen steht hier nur für die Anzahl unterschiedlicher Publikationen pro gefundener Person, nicht für die Anzahl der gefundenen Artikel. Wenn Personen in weniger als 
drei Publikationen gefunden werden, fallen sie aus der Berücksichtigung für die Auswahl heraus. Bei gleichen Anzahlen werden zu Personen, die schon in der Rangfolge auftauchen, weitere, die ebenfalls diese Fundzahl aufweisen, mit hineingenommen.

Als Sortierkriterium für diese Fälle wurde 2014 zunächst eine alphabetische Sortierung in der Reihenfolge ihrer Nachnamen gewählt. Aus Sicht des Jahres 2016 erschien es notwendig, anhand der Anzahl der Artikel als zweitem Kriterium umzusortieren, binnendifferenziert wird dann wieder anhand des Nachnamens. Dadurch ergibt sich jedoch keine Veränderung im Bestand: Lediglich vier Personen wechseln noch die Position. Die folgende Liste basiert im Ganzen auf 228 Artikeln, die Listenplatzierten werden im Anhang zu diesem Kapitel mit allen Textpassagen und den betreffenden Fundwörtern aufgeführt:
1. PHILIPPE STARCK; 12 Fundstellen, 98 Artikel
2. GiORgetTo giUgiaro; 8 Fundstellen, 24 Artikel
3. JASPER MORRISON; 8 Fundstellen, 11 Artikel
4. LUIGI COLANI; 7 Fundstellen, 20 Artikel
5. MATTEO THUN; 7 Fundstellen, 19 Artikel
6. die Gebrüder BOUROUlLEC; 6 Fundstellen, 18 Artikel
7. KONSTANTIN GRCIC; 6 Fundstellen, 18 Artikel
8. TERENCE CONRAN; 6 Fundstellen, 7 Artikel
9. DIETER RAMS; 6 Fundstellen, 7 Artikel
10. ROSS LOVEGROVE; 6 Fundstellen, 6 Artikel

Das Ergebnis ist in Bezug auf das Geschlecht unzweideutig: Star-Designer im Bereich des Produktdesigns sind auf Basis der quantitativen Such- und Sortierkriterien ausschließlich Männer. Alle Suchworte wurden so weit wie möglich geschlechtsneutral oder auch geschlechterumfassend gewählt und waren nicht dazu geeignet, ein derartiges Ergebnis tendenziell hervorzurufen. Auch bei der Auswahl der Fundstellen wurde den Suchwörtern folgend aufgenommen und nicht nach Geschlechtern gewertet. Aus der obigen Differenzierung ist ebenso zu ersehen, dass der Begriff der Star-Designerin sehr wohl verwendet wird, aber viel häufiger außerhalb des untersuchten Publikationskorpus anzutreffen ist. Der Vollständigkeit halber wird die Darstellung zunächst um die Personen mit jeweils fünf, vier und drei Fundstellen ergänzt: 


\section{STARDESIGNER ODER GESTALTER DES ALLTÄGLICHEN?}

1. Je fünf Fundstellen: RON ARAD, TOM DIXON, ADRIAN NEWEY, KARIM RASHID

2. Je vier Fundstellen: BERTONE, ALESSANDRO MENDINI, ETTORE SOTTSASS, WALTER DA SILVA

3. Je drei Fundstellen: WERNER AISSLINGER, Gebrüder CAMPANA, ACHILLE CASTIGLIONI, HARTMUT ESSLINGER, MARC NEWSON, ANDRÉE PUTMAN (die Alibi-Star-Designerin; s. u.)

Nimmt man die unspezifischen Fundstellen aus dem Beifang hinzu, finden sich auch acht der zehn Designer der o. a. Rangliste außerhalb des untersuchten Korpus und das Bild stellt sich ein wenig verändert dar:

1. Luigi COLANI; 11 Fundstellen (oben Platz 4)

2. PHilipPe STARCK; 5 Fundstellen (oben Platz 1)

3. DIETER RAMS; 3 Fundstellen (oben Platz 10)

4. die Gebrüder BOURoullec; 2 Fundstellen (oben Platz 6)

5. GiORgetTo GiUgiaro; 2 Fundstellen (oben Platz 2)

6. KONSTANTIN GRCIC; 2 Fundstellen (oben Platz 8)

7. ROSS LOVEGROVE; 2 Fundstellen (oben Platz 9)

8. Matteo thun; 1 Fundstelle (oben Platz 5) 


\section{Philippe Starck - in der Nachfolge von Luigi Colani einfach überall}

Außer in der FORM wird PHILIPPE STARCK als einziger Designer in allen systematisch untersuchten Publikationen gefunden, zumeist auch mit mehr als nur einem Artikel pro Publikation. Daraus kann rein quantitativ abgeleitet werden, dasS STARCK im untersuchten Publikationskorpus mit den angelegten Suchkriterien im deutschsprachigen Raum der medial populärste Star-Designer des vergangenen Jahrhunderts ist. Ihm voraus geht nur LUIGI COLANI, der damit als einzig legitimer Vorgänger bestätigt wird. Nach STARCK ist bis dato niemand mehr mit einer ähnlichen Kombination aus Entwurfstätigkeit, öffentlichkeitswirksamem Auftreten und einer derart starken Akklamation in Bezug auf die Presseresonanz in Erscheinung getreten. MATTEO THUN, der im Text des folgenden Interview-Ausschnitts ebenfalls als Stardesigner bezeichnet wird, äußert sich zu STARCK und COLANI so:

REINHARD RENGER: "Sie sagen heute, es gäbe keine klare Handschrift, die die einzelnen Thun-Objekte verbindet. Wie passt das zusammen mit der Chiffre von Matteo Thun, dem Stardesigner?« MATTEO THUN: "Für mich gibt es zwei fantastische Figuren im Designbereich: den schillernden Luigi Colani und Philippe Starck. Starck besitzt formale Visionen und geniale Kommunikationsfähigkeiten. Seine Handschrift hat einen Wert. [Hervorhebungen des Verfassers] Meine Handschrift ist diametral entgegengesetzt. Sie passt sich jeder Marke und Situation an. Heute sind 8o Prozent der Produkte meines Studios nicht mehr ssigniert, sondern verkaufen sich, weil sie Innovationen enthalten." [Die Namen von Interviewer und Interviewtem wurden den Originalzitaten vorangestellt; Hinzufügung des Verfassers] (RENGER in: DIE ZEIT NR. 44/2005 [online] http://www.zeit.de/2005/44/Thun_LT [04.09.2016] Inzwischen nicht mehr aufrufbar wegen eines XML-Darstellungsfehlers. [20.02.2018]. 


\section{Frauen gegen das Bias}

Um dem Eindruck entgegenzuarbeiten, die Studie sei durch ein Bias verfälscht, werden nun auch die gefundenen Frauen, die mit Ausnahme von ANDRÉE PUTMAN in weniger als drei untersuchten Publikationen erwähnt werden, mitsamt den gefundenen Begriffen aufgelistet. Jede Nennung entspricht hierbei auch einem Artikel. Im Ganzen sind es 34 Frauen, von denen zwei im Korpus wie im Beifang vorkommen - HELLA JONGERIUS und PATRICIA URQUIOLA. Mit Blick auf die anfänglichen Suchworte werden 17 Personen (ohne Doppelungen) als Stardesignerin bezeichnet, insgesamt vier als Designstar und nächsten Designstar sowie eine als Designerstar. Im Publikationskorpus finden sich diese Namen:

- $\quad$ ART DAS KUNSTMAGAZIN

nächsten Designstar: CHRISTIEN MEINDERTSMA

Topdesignerin: PATRICIA URQUIOLA

- DER SPIEGEL

Stardesignerin: ANDRÉE PUTMAN

- DER STANDARD

Stardesignerin: ANDRÉE PUTMAN, CHARLOTTE PERRIAND

- DIE PRESSE

Stardesignerin: LUDOVICA PALOMBA

- DIE WELT

renommierte Designerin: HELLA JONGERIUS

- DIE ZEIT

Jungstar der italienischen Designszene: MIRIAM MIRRI

- NZZ

Altmeisterin, Stardesignerin: ANDRÉE PUTMAN

- SCHÖNER WOHNEN

Designlegende: EILEEN GRAY

Designstar: ILSE CRAWFORD, INGA SEMPÉ, PATRICIA URQUIOLA

eine der bedeutendsten und erfolgreichsten Designerinnen Schwedens: MONIKA FÖRSTER

Stardesigner: PATRICIA URQUIOLA

zählt zu den bedeutendsten Designerinnen des 20. Jahrhunderts: RAY EAMES 
AM ENDE WAR ES NUR EIN WORT: ZWEI REZEPTIONSSTUDIEN

Unspezifisch:

- Designerstar: LISA BENGTSSON

- Ikone: PATRICIA URQUIOLA

- Kultdesigner: PHOEBE COLEMAN

- Stardesignerin

ANGELIKA ZWERENZ, CLAUDIA CARPENDALE, CLAUDIA GOLDSCHMIDT, FAYE TOOGOOD, FLEUR DE KOOKYSE, KELLY HOPPEN, KRISTA SACHOR, LOUISE CAMPBELL, MATALI CRASSET, NICKY POERTGEN, PIEKE BERGMANS, SYBILLE DE MARGERIE, ZAHA HADID

- Topdesignerin: HELLA JONGERIUS, PATRICIA URQUIOLA

Zusammengesetzte Begriffe und längere Formulierungen:

- Ausnahme-Designer: MASAYO AVE

- die namhafte Designerin: TEIJA BRUHn, ZAHA HADID, PAOLA NAVONE

- eine der schillernden Persönlichkeiten der internationalen Designszene: MARVA GRIFFIN

- Weltklasse-Designerin: JETTE JOOP, PATRICIA URQUIOLA 


\section{Detaillierte Auswertung mit Blick auf die Sprache}

Die fassliche Spitze eines damit sowohl vage als auch sehr konkret postulierten Wertstandards kommt in der Verbindung des Gedankenbilds Star mit dem Begriff Designer und der Assoziierung zum Namen von Personen zum Ausdruck, womit kurz und knapp sehr konkrete Qualitätseinschätzungen für die Leserschaft erzeugt werden sollen. BREUER weist in Die Erfindung des modernen Klassikers schon auf ABY WARBURG und seinen Begriff der Schlagbilder hin - wofür auch in diesem Zusammenhang eine hohe Plausibilität angenommen werden kann:

"Die Überzeugungskraft liegt häufig in einer blitzartig aufleuchtenden Plausibilität, bei der man nicht nachfragt. Wirkmächtig sind sie insofern, als sie bald ihre eigene sself fulfilling prophecy sind: Die Wirklichkeit bringt den Nachweis schon bei.« (BREUER 2001: 12)

$\begin{array}{lll}\text { Begriff } & \text { Korpus } & \text { unspe } \\ \text { Stardesigner } & 225 & 29 \\ \text { Designstar } & 197 & 1 \\ \text { Altmeister } & 5 & 8 \\ \text { Kultdesigner } & 2 & 16 \\ \text { Popstar, Superstar } & 6 & 6 \\ \text { Ausnahme-Designer } & 0 & 25 \\ \text { Topdesigner } & 0 & 16 \\ \text { Weltklasse-Designer } & 2 & 4 \\ \text { der namhafte Designer } & 1 & 20 \\ \text { der berühmte Designer } & 0 & 5 \\ \text { der bekannte Designer } & 9 & 1 \\ \text { (auch in Verbindung mit international) } & \end{array}$

Der dargestellte quantitative Vergleich dominierender Begriffe basiert im Ganzen auf 228 Artikeln. Der erste Eindruck ist, dass das Kompositum Star-Designer immer einen qualifizierenden Zusatz zum Designernamen darstellt, der unhinterfragt akzeptiert werden muss, da er nicht durch Begründungen oder Erklärungen für diesen Wertmaßstab gestützt wird. Besonders auffällig ist, dass sprachliche Übersteigerungen des Renommees von Personen durch Begriffe wie Kultdesigner, Ausnahme-Designer und Topdesigner wie auch alter- 
nativ durch die Behauptung von Namhaftigkeit gerade im Rahmen des unspezifischen Beifangs besondere Ausmaße annehmen und in dieser Form im Publikationskorpus keine Entsprechung finden. Andere Begriffe wie Popstar, Superstar und Weltklasse-Designer treten auf beiden Seiten mit einer Seltenheit auf, die ihrer steigerungsstufengebundenen Rarität entspricht. Der Begriff Stardesigner ist - mit überragender Dominanz im Publikationskorpus generell schnell bei der Hand, wird aber sehr breit durchvariiert. Im Verlauf der Untersuchung sammelte sich eine Palette von 46 klassifizierbaren Bezeichnungen mit unterschiedlichen Variationen an, die zunächst zur Gänze in alphabetischer Folge dargestellt werden:

1. Altmeister des Designs

Altmeister des deutschen Designs, Altmeister des italienischen Designs, der italienische Altmeister des Designs, Turiner Altmeister

2. Antistar des Designs

3. Ausnahme-Designer

der griechische/japanische Ausnahmedesigner, des holländischen Ausnahmedesigners, der holländische Ausnahme-Designer, den italienischen Ausnahme-Designer

4. berühmtester deutscher Industriedesigner

5. Branchenstar

6. dem außergewöhnlichen Designer

7. der bekannte Designer

der bekannte Münchner Designer, der international bekannte Designer

8. der bedeutende Designer

9. der bedeutendste deutsche Produktdesigner

10. der berühmte Designer

der berühmte Franzose (im Zusammenhang mit Star-Designer) »[...] erläutert Star-Designer Ronan Bouroullec. Gemeinsam mit Bruder Erwan hat der berühmte Franzose >Corniches für Vitra gestaltet.«

11. der namhafte Designer/die namhafte Designerin namhafte Industriedesigner

12. der renommierte Designer/renommierte Designerinnen

13. Designlegende

des legendären Industriedesigners, Legende des technischen Minimalismus

14. Designer mit großen Namen

15. Design-Papst 


\section{STARDESIGNER ODER GESTALTER DES ALLTÄGLICHEN?}

16. Design-Popstar der Postmoderne

17. Designstar/Design-Star/Design-Stars/Designerstar(s)

bayerischer Design-Star, Designstar aus Frankreich, der deutsche Designstar, der französische Designstar, des italienischen Designstars, des New Yorker Design-Stars, des niederländischen Designstars, die japanischen Designstars, italienische Designerstars, Münchner Designstar, vom finnischen Designstar

18. Design-Überflieger

19. Designer von Weltrang

20. die Madonna unter den Designern

21. fantastische Figuren im Designbereich

22. Großmeister Japans Design-Großmeister

23. Ikone

Designikone, Gestalter-Ikone, Ikone des modernen Designs, die Ikone des Industriedesigns, die Ikone des deutschen Industriedesigns, Ikonenmacher

24. internationale Designgrößen

25. Kultdesigner der britische Kultdesigner, der französische Kultdesigner, die nationalen Kultdesigner

26. Megadesigner

27. Meisterdesigner

28. Meister des Designs

29. Meister-Designer

30. Oberdesigner

31. ostdeutsche Designer-Elite

32. Popstar

33. Popstar der Designwelt

34. Popstar des Designs

35. prominente Designer

36. renommierte Gestalter

37. Rockstar des Designs / Rockstar des modernen Designs

38. Star

Star der britischen Designszene

39. Stardesigner/Stardesignerin

Amsterdamer Stardesignerin, dem ersten Stardesigner Österreichs, dem kanadischen Star-Designer, den sympathischen Stardesigner, 


\section{AM ENDE WAR ES NUR EIN WORT: ZWEI REZEPTIONSSTUDIEN}

der deutsche Stardesigner, der finnische Star-Designer, der international bekannte Stardesigner, der niederländische Stardesigner, der österreichische Stardesigner, der renommierte Hamburger Stardesigner, der renommierte Stardesigner, der schwäbische Stardesigner, der schweizer Stardesigner, der spanische Stardesigner, der Stardesigner der vergangenen zwei Jahrzehnte, der südfranzösische Stardesigner, der Südtiroler Stardesigner, der Turiner Stardesigner, des dänischen Stardesigners, des Hamburger Stardesigners, des Pariser Stardesigners, einer der ersten Stardesigner, ein indischer Stardesigner, Englands Stardesigner, sextravertierterer, ausländischer Stardesigner ‘, Frankreichs Stardesignerin, Italiens Stardesigner, Londoner Stardesigner, McLarens Stardesigner, Star-Designer aus New York, Stardesigner der Nachkriegszeit, vom amerikanischen Stardesigner, vom britischen Stardesigner, vom englischen Stardesigner, vom gefeierten Stardesigner des Art Nouveau, vom italienischen Stardesigner, vom Pariser Stardesigner, von dem belgischen Stardesigner

40. Star-Gestalter Italiens Star-Gestalter

41. Superstar Superstar des Designs, Superstar des Industriedesigns, Superstar of design

42. Weltklasse-Designer/Weltklasse-Designerin

43. Weltstar des Designs

44. Weltstar des Mediendesigns

45. Wunderkind der finnischen Designszene

46. Topdesigner/Topdesignerin die italienische Topdesignerin, die spanische Topdesignerin 


\title{
Die mediale Crème de la Crème des Designs 324 in Form ihrer Bezeichnungen
}

Zum Beleg werden auf den folgenden Seiten sämtliche Wortfunde in ihrem Kontext zitiert und durch Kursivierung hervorgehoben. Diese liegen überwiegend in Quellen verborgen, die sich außerhalb des systematisch untersuchten Publikationskorpus befinden und sie umfassen auch Personen, die nicht Eingang in die weiter oben bereits gezeigte Rangliste finden. (Über-)Steigerungen zum Popstar, Superstar des Designs oder auch Weltklasse-Designer lassen - wie KELLER es ausführt - die Sozialfigur des Stars zur sollübererfüllenden werden:

"In Relation zum >Durchschnitts<-Star lässt sich der Superstar abschließend als sollübererfüllender Star beschreiben: Wer in medialen Darstellungen und Selbst-Darstellungen ebenso wie in Nutzer-Bezugnahmen als Superstar bestätigt wird, gilt zugleich als sehr erfolgreich, sehr prominent, ist infolge häufiger medialer Thematisierung einer großen Anzahl von Rezipienten bekannt, veranlasst Rezipienten als Star-Nutzer zu affektiven, kognitiven und moralischen Bewertungen und wird in Wechselwirkung mit diesen Bewertungen parasozial auch in Identitäts-Unterscheidungen funktionalisiert.« (KELLER 2008: 199)

\section{Superstar des Designs, Design-Popstar}

\author{
LUIGI COLANI
}

"Dieser Superstar des Designs hat für AGOS das Design ihrer neuen Computerserie Opus Magnum ${ }^{\circledast}$, geschaffen." (goyellow.de) [online] https:// www.goyellow.de/home/computer-hersteller-agos-computer-ug-berlin. $\mathrm{html}[20.02 .2018]$

»Luigi Colani, der Design-Popstar, wurde ebenso wie Kai Stania bereits mehrmals mit dem begehrten Red Dot Design Award ausgezeichnet und ist an der neuen Möbelkollektion der Firma Schütz beteiligt." (genuss.de) [online] https://www.genuss.de/sonstiges/rattan-punktetfuer-die-umwelt/ [20.02.2018] 


\section{Superstars (of design)}

KONSTANTIN GRCIC, ROSS LOVEGROVE, GAETANO PESCE, KARIM RASHID

"Karim Rashid, Gaetano Pesce, Ross Lovegrove, Luigi Colani, Konstantin Grcic. Superstars of design, who grown [sic] their careers in different periods of time and different social circumstances, will present their artistic specialties and creative concepts. This exclusive performance of the magnificent five will take place on April the 2oth, beginning from 20:30, at the new Superspace gallery that is taking big steps towards its own place on the cultural map of Belgrade." (OzLER 2006) [online] https:// www.dexigner.com/news/8295 [20.02.2018]

\section{MARC NEWSON}

"Diese Entwicklung hat in kürzester Zeit auch schon ihre Superstars hervorgebracht, und der Neo Rauch der Objektgestaltung heißt ganz zweifelsfrei Marc Newson [Hervorhebung des Verfassers]. Die >Lockheed Lounger des Australiers, eine spätestens durch Madonnas Video zu >Rain` bekanntgewordene Kreuzung aus Recamiere und Bomberflugzeug, wurde vor anderthalb Jahren bei Sotheby's in New York bei einer Million Dollar zugeschlagen. Ursprünglich hat Newson die Sitzobjekte mal für weniger als zehntausend verkauft, und der Händler, der für die Liege eine Million hingelegt hat, wollte jetzt schon wieder 2,5 Millionen dafür haben. So viel zu den Gewinnmargen." (FRANKFURTER ALLGEMEINE SONNTAGSZEITUNG am 01.04.2007, NR. 13, S. 31) 


\title{
Popstar der Designwelt, Design-Popstar, Popstar des Grafikdesigns, Rockstar des Designs, Rockstar des modernen Designs
}

\author{
KARIM RASHID
}

\begin{abstract}
"Der >Popstar der Designwelt hat sich dem entzückenden weißen Rücken des Xperia ${ }^{\mathrm{TM}}$ arc $S$ gewidmet und eine limited Edition des unverwechselbaren Back Covers designt. Ein inspirierendes Video zeigt den Ausnahme-Künstler in seinem Loft und beschreibt die Eigenschaften, die sein Design und das Xperia $^{\mathrm{TM}}$ arc $\mathrm{S}$ einen." (HÄBERLEIN \& MAUERER) [online] http://www.haebmau.de/Kunden/Sony-Mobile/Karim-Rashidfuer-Sony-Ericsson-Xperia-arc-S [02.07.2013; inzwischen nicht mehr im Netz verfügbar]
\end{abstract}

\section{LUIGI COLANI}

"Das zwanzigste Jahrhundert platzt auch hier naturgemäß aus allen Nähten: Hochaktuell gerade Salvador Dalí als erster Popstar des Jahrhunderts (so oder so ähnlich im Moment fast überall zu lesen), Luigi Colani als der rerste Popstar des Designs` (so der SWR), gefolgt vom >Popstar des Kabarettsı (NZZ Online), nämlich Helmut Qualtinger. Rudolf Nurejew, ganz klar, ist >Popstar des Balletts`, entsprechend Leander Haußmann als `Popstar des deutschen Theaters (Goethe-Institut) und, eine besonders aparte Idiotie, >der Popstar des Krieges: Mohammed Said al-Sahhaf (im Internet zu lesen).«(FRANKFURTER ALLGEMEINE ZEITUNG, 13.05.2004, NR. 111/SEITE 33) [online] http://www.faz.net/aktuell/feuilleton/kommentar-pop-die-wette-gilt-1157718.html [04.09.2018]

NEVILLE BRODY

"Design-Popstar Nie zuvor wurden visuelle Innovationen aus der Typografie so schnell und so umfassend aufgegriffen und kopiert. Da man dieses Phänomen eigentlich nur aus dem Bereich der Popmusik - beginnend mit den Beatles und den Stones - kannte, nennt man Brody auch den ersten Popstar des Grafikdesigns." (ALLNER in: PRINT \& PRODUKTION 3/2004: 32-34) [online] https://mkh.incom.org/action/open-file/12198; [20.02.2018]

\section{PHILIPPE STARCK}

»Von der Zahnbürste bis zur Bushaltestelle - es gibt kaum einen Alltagsgegenstand, den der Franzose Philippe Starck noch nicht designt hätte. Luxusphantasien wie das voll verspiegelte Badezimmer machten ihn zum >Rockstar des Designsı. Keiner hat das Lebensgefühl der achtzi- 


\section{AM ENDE WAR ES NUR EIN WORT: ZWEI REZEPTIONSSTUDIEN}

ger und neunziger Jahre in eine so aufregende Formensprache gebracht wie der französische Star-Designer und Innenarchitekt Philippe Starck. [...] Übertroffen wird der Designer Starck in seiner eigenwilligen Kreativität und pulsierenden Energie nur noch von dem Innenarchitekten Starck: Als >Kulträumer werden seine Ausstattungen schon seit Jahren gefeiert. Und als 1989 die Innenräume des New Yorker Hotels >Royalton fertig waren, sorgten die komplett verspiegelten Badezimmer dafür, dass er zum >Rockstar des modernen Designsı ausgerufen wurde." (SIEDENBERG in: SPIEGEL ONLINE vom 28.07.2000) [online] http://www. spiegel.de/kultur/gesellschaft/philippe-starck-verzierung-des-alltagsa-87015.html [26.03.2018]

\section{Weltstar(s) des Designs}

Der an keiner anderen Stelle aufgefundene KURT WEIDEMANN fällt als zweiter Grafikdesigner gleich NEVILLE BRODY aus dem Untersuchungsraster.

\section{LUIGI COLANI}

»Mit der Serie ArtCollection ist AGOS neue Wege gegangen. Design wird hier ergänzt durch Kunst und den Anspruch auf Individualität. Die neuste [sic] Serie von AGOS vereint Display und Computer. Luigi Colani, Weltstar des Designs, hat das Gehäuse entworfen. Der Nutzer hat die Möglichkeit den Computer an seinen ganz persönlichen Lifestyle anzupassen."(AGOS) [online] http://www.agos.com/news/warum_markt.asp [25.07.2013; inzwischen nicht mehr im Netz verfügbar]

RON ARAD, ETTORE SOTTSASS, KONSTANTIN GRCIC

"Das Düsseldorfer NRW-Forum Kultur und Wirtschaft geht jetzt dieser Frage nach. In der Ausstellung ,UFO. Grenzgänge zwischen Kunst und Design', die ab Samstag geöffnet ist, stellen die Kuratoren Werner Lippert und Petra Wenzel 44 Werke von 25 Künstlern vor. Darunter Objekte von Weltstars des Designs wie Ron Arad, Ettore Sottsass und Konstantin Grcic sowie Werke von Berühmtheiten der Kunst wie Richard Prince, John Armleder und Joseph Kosuth." (HOFFMANS in: WAMS vom 17.05.2009) [online] http://www.welt.de/wams_print/article3753852/Kann-denn-Design-Kunst-sein.html [20.02.2018]' 


\section{STARDESIGNER ODER GESTALTER DES ALLTÄGLICHEN?}

\section{KURT WEIDEMANN}

"Der Designer und Typograph Kurt Weidemann ist am Mittwoch im Alter von 88 Jahren gestorben. Er galt als einer der einflussreichsten Gestalter weltweit und war auch Ehrenmitglied des Art Directors Club für Deutschland (ADC). Dessen Vorstandssprecher Jochen Rädeker schreibt zum Tod Kurt Weidemanns: > Das ist für uns alle, für den ADC ein ganz großer Verlust. Er war mit 88 Jahren unser ältestes Mitglied, er war einer der ganz wenigen Weltstars des Designs. Es gibt kaum jemanden, vielleicht keinen, der die Design- und Kommunikationslandschaft in Deutschland in den letzten 6o Jahren so geprägt hat wie er. (WEBER in: W\&V vom 31.03.2011) [online] http://www.wuv.de/agenturen/kurt_weidemann_ist_gestorben [20.02.2018]

\section{Weltklasse-Designer/-in}

\section{LUIGI COLANI}

"Man muss sich auf ein anderes Sitzerlebnis einstellen, wenn man in Designermöbeln von Luigi Colani sitzt. Trotz seines italienischen $\mathrm{Na}-$ mens ist der Weltklasse-Designer ein gebürtiger Berliner. Seine designerischen Leistungen waren nie erklärungsbedürftig. Durch unzählige Entwürfe hat Colani seine designerische Linie längst abgesteckt." (METZNER in: wohnmoebel-blog.de) [online] http://www.wohnmoebel-blog.de/ wohnzimmer/couch-sessel/26-colani-sitzen-wie-auf-einer-wolke [07.09.2016, inzwischen nicht mehr im Netz verfügbar]

JETTE JOOP

"Wenn eine weltklasse Designerin und Mutter einen Kinderwagen entwirft, ist das Ergebnis unschlagbar. Der Jette Joel Air Kombikinderwagen Lufträder + Cybex Aton 4 Babyschale sieht daher auch super aus und ist besonders alltagstauglich." (kinderwagen.com) [online] http:// www.kinderwagen.com/jette-joel-air-kombikinderwagen-luftraeder-cybex-aton-4-babyschale-dessert-beige- $c$ ?jt=1\&js=100\&jsid=24405\&jcp=guenstiger.de [20.02.2018]

\section{RICHARD SAPPER, GIORGETTO GUIGIARO}

"Nachdem jedoch Jobs das Ruder wieder übernommen und seinen Motivationsvortrag gehalten hatte, entschied sich Ive zu bleiben. Doch Jobs wollte zunächst einen Weltklasse-Designer von außen holen. Er verhandelte mit Richard Sapper, dem Designer des IBM ThinkPad, und mit Gior- 


\section{AM ENDE WAR ES NUR EIN WORT: ZWEI REZEPTIONSSTUDIEN}

getto Giugiaro, dem Designer des Ferrari 250 und des Maserati Ghibli I. Dann sah er sich jedoch auch einmal genauer im Design-Studio von Apple um und kam dort mit Ive, dem freundlichen, hochmotivierten und ernsthaften Leiter der Abteilung in Kontakt." (ISAACSON in: SPIEGEL 41/2011: 78-81) [online] http://www.spiegel.de/spiegel/print/d-8o818247. html [17.04.2018]

\section{ETTORE SOTTSASS}

"Die erste Ausstellung in der Vitra Design Museum Gallery ist dem italienischen Weltklasse-Designer Ettore Sottsass gewidmet." (moebelkultur. de) [online] http://www.moebelkultur.de/news/vitra-design-museumneue-ausstellungsflaeche-zeigt-sottsass/14061.html [20.02.2018]

\section{PATRICIA URQUIOLA}

"Was bei einer Weltklasse-Designerin wie Urquiola unzureichend ist, tut dem Werk des weitaus unbekannteren Benesch merkwürdigerweise gut.« (BAUER in: ARTNET MAGAZIN am 30.07.2009) [online] http://www.artnet.de/magazine/patricia-urquiola-und-markus-benesch-daab-verlagkoln/ [18.07.2013, inzwischen nicht mehr im Netz verfügbar] 


\section{Luigi Colani - Designer extraordinaire}

Niemand anderer wird - überwiegend außerhalb des systematisch untersuchten Publikationskorpus (dieselben in Klammern) - mit einer so großen Anzahl ebenso unterschiedlicher wie außergewöhnlicher Formulierungen bedacht:

1. der wohl populärste deutsche Designer

2. des ersten Design-Popstars

3. Popstar des Designs (F.A.z.)

4. Superstar des Designs

5. Superstar of design

6. Kultdesigner

7. Topdesigner (DIE ZEIT)

8. Weltklasse-Designer

9. bedeutendster zeitgenössischer Designer der Welt,

10. Weltstar des Designs.

Nimmt man die Anzahl dieser Funde hinzu, übertrifft LUIGI COLANI als einziger PHILIPPE STARCK in der Häufigkeit der Publikationen, die ihn erwähnen und in der Masse unterschiedlicher Bezeichnungen. 


\section{Der Stardesigner lebt und lebt und lebt ....}

»Wahrscheinlich sind sie ja jetzt erst einmal vorbei, die Zeiten des exklusiven (und oft genug reichlich nutzlosen) Editionendesigns und des damit verbundenen Hypes um Stardesigner, Nachwuchs-Stardesigner und Stararchitekten, die ein bisschen im Design herumdilettieren. Der seit Jahren von fast allen Akteuren des Designbetriebes gepflegte Kult um die Designerpersönlichkeit und die von ihr geschaffenen Objekte fand hier freilich nur ihren sichtbarsten Ausdruck." (FRENZL in: DESIGN REPORT 4/2009) [online] http://www.designreport.de/Fachartikelarchiv/31968320/DasUngewoehnliche-im-Gewoehnlichen.html [05.07.2013; inzwischen nicht mehr im Netz verfügbar]

Solches mutmaßt FRENZL also schon 2009. Doch auch neun Jahre später kann davon noch keine Rede sein. In den Medien haben sich Prozesse dieser Art schon lange verselbstständigt und sie laufen zu routiniert ab, um A) aus sich heraus zu einem Ende zu kommen und B) muss nachgefüttert werden. Der Markt mit seinem unaufhörlichen Bedarf an Neuerungen, die die Geldbeutel der Konsumenten öffnen sollen, benötigt den Nachwuchs, der herangezogen werden muss, ebenso wie stetig neue Klassiker.

Mag auch die Möglichkeit, eine große gemeinsame Öffentlichkeit für sich zu vereinnahmen, verloren gegangen sein, so bietet doch die Zersplitterung in Zielgruppenpublika weiterhin ein breites Betätigungsfeld. Eine Übereinstimmung mit WIPPERSBERGs Ansatz der Zielgruppenprominenz ist unübersehbar (vgl. WIPPERSBERG 2007: 161f). Folgt man in diesem Zusammenhang nochmals den Spuren von GEORG FRANCK und einem seiner ersten Essays zur Ökonomie der Aufmerksamkeit bzw. seiner Idee des mentalen Kapitalismus, so kann man nicht mehr annehmen, dass die Medien nur das publizieren, wovon sie sich selbst Aufmerksamkeit versprechen - respektive wovon sie annehmen, dass es ihr Publikum interessiere:

»Diese Macht ist den Medien allmählich erst zugewachsen. Die maschinelle Reproduktion von Wort, Ton und Bild bildet bloß den technischen Ausgangspunkt. Auch hat die Nachfrage nach Information nicht als solche die Medien groß gemacht. Was sie groß gemacht hat und was ihr Wachstum weiterhin sichert, das ist die geniale Geschäftsidee, dem Publikum Information anzubieten, um an seine Aufmerksamkeit zu kommen. Ohne das aufmerksame Einkommen, das die Publikation verspricht, wäre noch nicht einmal das Verlagswesen recht in Gang gekommen. Wenn in Büchern und Zeitschriften nur erschienen wäre, was von vornherein kommerziellen Erfolg versprach, dann sähe die literarische Landschaft anders als die 


\section{STARDESIGNER ODER GESTALTER DES ALLTÄGLICHEN?}

bestehende aus." (FRANCK in: MERKUR September 1993, 47. Jahrgang, Heft 534, 749f;) [online] https://volltext.merkur-zeitschrift.de/journal/ mr_1993_o9 [05.03.2018]

In einem weiteren gedanklichen Schritt folgt daraus, dass gerade nicht angenommen werden kann, dass ein öffentliches Interesse allein die Autoren zur Verwendung der gefundenen Begriffe in jenen Artikeln veranlasst hat. Es sollte also ein wie auch immer gelagertes Interesse zur Konstitution eines Starkorpus vorhanden sein. Anders lässt sich (zumindest anfänglich) sowohl der Wille zur Benennung im Sinne eines Wertmaßstabs als auch die Häufigkeit des Einsatzes nicht sinnstiftend explizieren - könnte man davon ausgehen, dass diese Bezeichnungen mit Bedacht und nicht wie beiläufig verwendet werden. Star-Designer in der im Rahmen der Recherche vorgefundenen Form sind Sinn-Angebote, semantisch gesehen illokutionäre oder auch propositionale Akte. Wer hat etwas von ihnen - und wenn ja, was? Was veranlasst zu dieser Bewertung und mit welchem Ziel? Ein Sinn-Angebot dieser Form hat einen Normierungsanspruch und verlangt danach, als Orientierungsbake wahrgenommen zu werden. Es wird von jenen, die es anbieten, mit hoher Wahrscheinlichkeit mit diesem Anspruch in die Welt entlassen. 


\section{Auch die Unwiderstehlichkeit ist noch steigerungsfähig}

An ihrer permanenten Selbstüberbietung wird sowohl auf journalistischer wie auch auf Herstellerseite seit den 8oern des 20. Jhd.s gearbeitet. Schon ein Jahr später (s. o.) klagt FRENZL im DESIGN REPORT 06/2010 in seiner Kolumne:

"Der renommierteste Designpreis! Best of the best! Der Preis der Preise! Der Designer des Jahres, ach was, des Jahrhunderts! - Wettkampf und Kräftemessen liegen in der menschlichen Natur. Aber kann es sein, dass uns im Zeitalter der Aufmerksamkeitsökonomie ein bisschen die Superlative durchgegangen sind? Müssen wir im Design da unbedingt mitmachen? Kann ein Entwurf nur dann gutes Design sein, wenn er genauso voller Labels klebt wie der Anzug eines Formel-1-Piloten? Ist der Typus des kompetitiven Kreativen längst zur Norm geworden? Und muss eigentlich jeder Entwurf als innovativer Designklassiker, bahnbrechende Neuentwicklung oder millionenfach verkaufter Bestseller daherkommen? [Hervorhebungen des Verfassers] (FRENZL in: DESIGN REPORT 06/2010) [online] http://epaper.design-report.de/2010/o6/?page= 14 [15.12.2013, inzwischen nicht mehr im Netz verfügbar]

Aber sicher muss das so sein! So scheint es ihm die publizistische Rezeption hinterher zu rufen. Im Rahmen der Untersuchung finden sich größere Mengen an Komparativen, Superlativen verwandte Bezeichnungen und Superlative für die Besten der Besten, mit deren Hilfe belegt werden kann, dass kein Ende in Sicht ist. Alle gefundenen Formulierungen werden auf den folgenden Seiten in ihrem Kontext wiedergegeben. 


\section{Komparative}

334 im Rahmen der untersuchten Publikationen

eine der bedeutendsten und erfolgreichsten Designerinnen Schwedens

"Inspiriert von den kleinen Püppchen entwarf Monica Förster, eine der bedeutendsten underfolgreichsten DesignerinnenSchwedens, ihre >BabuschkarGefäße."(ScHÖNER WOHNEN) [online] http://www.schoner-wohnen.de/ news/214467-aufbewahrungs-set-babuschka-von-monica.html [20.02.2018]

einem der bedeutendsten Architekten und Designer der Nachkriegsmoderne

"Das Talent, zu einem der bedeutendsten Architekten und Designer der Nachkriegsmoderne zu werden, war Eero Saarinen in die Wiege gelegt." (scHÖNER WOHNEN) [online] http://www.schoener-wohnen.de/design-legenden/219155-eero-saarinen-1919-1961-.html [20.02.2018]

einen ihrer bedeutendsten Gestalter

"In der Nacht auf Samstag ist der international bekannte Designer Hannes Wettstein nach einer langwierigen Krankheit gestorben. Mit ihm verliert die Schweiz einen ihrer bedeutendsten Gestalter." (ESCHBACH in: NZZ 07.07.2008) [online] http://www.nzz.ch/aktuell/feuilleton/uebersicht/suche-nach-den-archetypen-von-morgen-1.777824 [20.02.2018]

einer der begehrtesten Designer der Welt

"Es macht mir viel Spass, immer wieder Personen zu entdecken, an deren Talent ich glaube, und sie zu fördern. Natürlich freut es mich sehr, wenn diese dann berühmt werden. Jasper Morrison ist heute einer der begehrtesten Designer der Welt, Marc Newson wurde von Ford beauftragt, eine neue Autoserie zu entwerfen, und Tom Dixon ist zum ArtDirector von Habitat ernannt worden. Dieser Erfolg bestärkt mich: Ich hatte sie richtig eingeschätzt! Und das ermutigt mich dann zu meinen neuen Entdeckungen.« (MEIER in: NZZ 07.04.2001) [online] http://www. nzz.ch/aktuell/startseite/article7B5WO-1.485028 [20.02.2018]

seit den 80er-Jahren einer der bekanntesten Designer weltweit

"Außenminister Bernard Kouchner wolle seine sehr, sehr markante, sehr interessante, sehr kreative Präsidentschaftı, sagte Starck. Das Außenamt in Paris bestätigte, dass der Designer für die EU-Präsidentschaft verschiedene Gegenstände entwerfen soll. Starck ist seit den 8oer-Jahren einer der bekanntesten Designer weltweit. Er hat Saftpressen und Stühle, Badezimmer und Leuchten sowie die Innenausstattung Dutzender Hotels entworfen, darunter auch für die Luxusappartements 'Yoo< in München und das Hotel >Costes` in Paris.« (WELT ONLINE vom 03.04.2008) [online] 


\section{AM ENDE WAR ES NUR EIN WORT: ZWEI REZEPTIONSSTUDIEN}

http://www.welt.de/welt_print/article18656oo/Stardesigner-Starck-sollFrankreichs-Image-aufpolieren.html [20.02.2018; inzwischen nicht mehr im Netz verfügbar]

einer der einflussreichsten zeitgenössischen Industriedesigner Deutschlands

"Für Konstantin Grcic, einer der einflussreichsten, zeitgenössischen Industriedesigner Deutschlands, war der italienische Altmeister schon immer eine kreative Quelle der Inspiration: ,Ettore Sottsass war der radikalste Designer unserer Zeit - dafür habe ich ihn bewundert.« (ART DAS KUNSTMAGAZIN am 07.01.2008) [online] http://www.art-magazin.de/ design/3168/ettore_sottsass_nachruf; [12.07.2013; inzwischen nicht mehr im Netz verfügbar]

einer der innovativsten und erfolgreichsten Designer seiner Zeit

"Seine knallrote Kofferschreibmaschine >Valentiner machte Sottsass Ende der sechziger Jahre weltberühmt und war der Anfang eines neuen Designverständnisses. Das Multitalent prägte kommende Generationen ebenso als Fotograf, Architekt und Schriftsteller. Am Silvestermorgen starb einer der innovativsten und erfolgreichsten Designer seiner Zeit. Wir baten einige seiner Freunde und europäische Stardesigner um ein paar letzte Worte.« (ART DAS KUNSTMAGAZIN am 07.01.2008) [online] http://www.art-magazin.de/design/3168/ettore_sottsass_nachruf [12.07.2013, inzwischen nicht mehr im Netz verfügbar]

einer der ersten Stardesigner

"DER STANDARD: Sie gelten als einer der ersten Stardesigner. Wie denken Sie heute über diesen Begriff? colAnI: Ich wurde vom Pasadena Art Center College mit dem Visionary Design Award für mein Lebenswerk ausgezeichnet, vom französischen Salon d'Automobile bekam ich den Grand Prix de Design, und das London Design Museum hat mir eine ganze Ausstellung gewidmet. In China nennt man mich den da Vinci des Kunststoffzeitalters ... Ehre, wem Ehre gebührt." (HAUSENBLAS in: DERSTANDARD am 26.06.2009) [online] http://derstandard.at/15778369154 10/Interview-mit-Luigi-Colani-Nimm-deine-Maeuse-und-verschwinde; [20.02.2018]

einer der gefragtesten deutschen Designer

"Sie sind einer der gefragtesten deutschen Designer. Aber wir haben gehört, dass Sie privat gar kein Sofa besitzen. Stimmt das?« (SIEBKE in: MANAGER MAGAZIN am 10.06.2011) [online] http://www.managermagazin.de/lifestyle/stil/a-767191.html [20.02.2018] 


\section{STARDESIGNER ODER GESTALTER DES ALLTÄGLICHEN?}

einer der renommiertesten deutschen Designer

"Konstantin Grcic, einer der renommiertesten deutschen Designer, gestaltet seit Neuestem auch Sofas. Selbst sitzt er allerdings lieber auf Stühlen." (SIEBKE in: MANAGER MAGAZIN am 10.06.2011) [online] http://www.manager-magazin.de/lifestyle/stil/a-767191.html

[20.02.2018]

einer der renommiertesten Designer Italiens

"Matteo Thun, 49, gebürtiger Südtiroler, ist einer der renommiertesten Designer Italiens. Er lebt in Mailand und hat verschiedenste Alltagsgegenstände entworfen, u. a. für Swatch, AEG und Villeroy \& Boch, außerdem schuf er das Interieur des sider-Designhotels in Hamburg. (WAMS 14.04.2002) [online] http://www.welt.de/print-wams/article6o2 386/Sehnsucht-nach-Karibik.html [20.02.2018]

einer der renommiertesten deutschen Industriedesigner

„Elmar Flötotto hatte 2007 die Markenrechte am Unternehmen seines Bruders erworben. Gemeinsam mit seinem Sohn Frederik arbeitet er seither daran, das einstige Kerngeschäft neu zu beleben. Die beiden Unternehmer waren sich schnell einig, dass als Designer eines neuen Stuhls nur einer infrage kommen konnte: Konstantin Grcic, einer der renommiertesten deutschen Industriedesigner. Schliesslich gibt der Münchner Designstar mit seinen Entwürfen der Unruhe eine Form." (NZZ am 27.01.2012) [online] http://www.nzz.ch/aktuell/startseite/fuers-lebenlernen-1.14568027 [20.02.2018]

Design-Popstar der Postmoderne, einer der wichtigsten zeitgenössischen Designer

"Der Design-Popstar der Postmoderne Philippe Starck, 1949 in Paris geboren, ist einer der wichtigsten zeitgenössischen Designer. Sein Prinzip heißt Reduktion, 'Ethik des Weglassensı. Starck will Dauerhaftes schaffen und haßt jede Form von Wegwerfästhetik. Seine radikale Verschönerung des Alltags, durch Architektur oder Produktdesign, reicht von der Fliegenklatsche bis zur Hotel-Inneneinrichtung." (WAMS am 04.09.2005) [online] http://www.welt.de/print-wams/article131652/Der-Design-Popstar-der-Postmoderne.html [20.02.2018]

einer der wichtigsten zeitgenössischen Designer

"Philippe Starck: Der Sohn eines Flugzeugkonstrukteurs wurde 1949 in Paris geboren und begann seine Karriere als Art Director im Modehaus von Pierre Cardin - da war er gerade mal 20 Jahre alt. Nach einem Abstecher in die USA kehrte er nach Frankreich zurück und arbeitete als Produktdesigner. Seine eigene Firma, Starck Products, gründete er 1979. International bekannt wurde er drei Jahre später, als er die Räume von François Mitterrand im Elysée-Palast neu gestaltete. Heute ist Starck einer der wichtigsten zeitgenössischen Designer. Der Medienstar war 


\section{AM ENDE WAR ES NUR EIN WORT: ZWEI REZEPTIONSSTUDIEN}

dreimal verheiratet und hat zwei Töchter und einen Sohn." (PITTNER in: MANAGER MAGAZIN am 03.01.2006) [online] http://www.managermagazin.de/magazin/artikel/a-380718-3.html [20.02.2018)

einer von Finnlands bekanntesten, zeitgenössischen Designern

"Harri Koskinen ist einer von Finnlands bekanntesten, zeitgenössischen Designern. Nun hat er eine Küche inklusive neuem Stauraumkonzept für die Marke Saari Kitchen entworfen.« (scHÖNER WOHNEN) [online] http://www.schoener-wohnen.de/news/214771-modul-kuechesilta-von-harri-koskinen.html [20.02.2018]

\section{Komparative mit "zählt« in Variationen}

der zu den absoluten Designstars zählende

"Auf die Frage ,Was ist Ihnen peinlich?, antwortete der zu den absoluten Designstars zählende 44-jährige Brite einmal: ১Öffentlich aufzutreten‘." (HILPOLD in: DER STANDARD am 24.06.2004) [online] http://derstandard. $\mathrm{at} / 1698272$ [20.02.2018]

zählt zu den bedeutendsten italienischen Designern

"Der Italiener Ettore Sottsass zählt zu den bedeutendsten italienischen Designern. Eine besondere Vorliebe hatte er für Produkte aus Keramik. Das Hetjens-Museum in Düsseldorf zeigt einige Keramik-Werke des Designers in einer Sonderausstellung." (SCHÖNER WOHNEN) [online] http://www.schoener-wohnen.de/news/208558-keramik-von-ettoresottsass-in-duesseldo.html [20.02.2018]

zählt zu den bedeutendsten Designerinnen des 20. Jahrhunderts

»Ray Eames zählt zu den bedeutendsten Designerinnen des 20. Jahrhunderts: Sie und ihr Mann Charles Eames bildeten eine Arbeitsgemeinschaft, aus der einige der wichtigsten Möbelentwürfe der Designgeschichte hervorgingen.« (SCHÖNER WOHNEN) [online] http://www. schoener-wohnen.de/news/216330-vitra-zeigt-den-film-eames-the-archit .html [20.02.2018]

zählt nun zu den wichtigsten britischen Designern

"Möbel von Habitat, berühmt für ihr minimalistisches Design, musste man nicht mehr unbedingt haben. Das könnte sich jetzt wieder ändern, Tom Dixons wegen. Der zählt nun zu den wichtigsten britischen De signern. Sein erfolgreichster Entwurf heißt Jack light, eine sechsarmi ge Plastiklampe, auf der man sogar sitzen kann und die bisher 10 ooomal verkauft wurde."(SCHNEIDER in: DIE ZEIT NR. 26/1999) [online] http:// www.zeit.de/1999/26/Mitarbeiter_der_Woche [20.02.2018] 


\section{Komparative}

\section{außerhalb der untersuchten Publikationen}

eine der schillerndsten Persönlichkeiten in der internationalen Designerszene

"Erik Spiekermann, 1947 in Deutschland geboren ist eine der schillerndsten Persönlichkeiten in der internationalen Designerszene." (HANZER auf stadtgespraeche.com) [online] http://www.stadtgespraeche.com/ interviews/index.html [12. 07. 2013, inzwischen nicht mehr im Netz verfügbar]

einem der berühmtesten Designer der Gegenwart

»In Originalverpackung, exklusiv entworfen für Bitburger von Luigi Colani - einem der berühmtesten Designer der Gegenwart" (ebay-Kleinanzeige) [online] http://www.ebay.de/itm/Bitburger-Mini-Truck-Editionvon-Luigi-Colani-viertes-Modell-/262427739443; [02.09.2016, inzwischen nicht mehr im Netz verfügbar]

einer der angesehensten zeitgenössischen Designer weltweit

"Luigi Colani ist einer der angesehensten zeitgenössischen Designer weltweit. Der 84-jährige Colani ist vielfach preisgekrönt und hat zuletzt unter anderem die 140 Disziplinskulpturen für die Olympischen Spiele 2008 in Peking gestaltet. Für seine neue Tapetenkollektion >Visions، hat sich der exzentrische Italiener [sic] mit einem deutschen Mittelständler zusammengetan - der Marburger Tapetenfabrik. So sehen die Tapeten von Luigi Colani aus." (t-online.de am 14.01.2013) [online] http:// www.t-online.de/heim-garten/wohnen/id_61582562/colani-tapeten2013-die-neuen-tapeten-von-luigi-colani.html [20.02.2018]

international einer der bedeutendsten und erfolgreichsten Designer unserer Zeit

"Peter Maly ist international einer der bedeutendsten und erfolgreichsten Designer unserer Zeit. Es gibt fast nichts, was er noch nicht entworfen hat. Viele seiner Entwürfe bekamen den begehrten GOOD DESIGN AVARD [sic].« (EVERDING in: GOLFWELT ONLINE am 17.10.2011) [online] http:// golfwelt.com/artikel/people/design-made-peter-maly [02.09.2016, inzwischen nicht mehr im Netz verfügbar]

\section{Komparative mit "zählt« in Variationen}

zählt zu den besten Designerinnen Europas

»Topdesignerin Patricia Urquiola: Patricia Urquiola zählt zu den bes ten Designerinnen Europas." (galerie-terramica.de 2011) [online] http:// 


\section{AM ENDE WAR ES NUR EIN WORT: ZWEI REZEPTIONSSTUDIEN}

www.terramica.de/topdesignerin-patricia-urquiola/ [28.04.2014, inzwischen nicht mehr im Netz verfügbar]

zählt international zu den bekanntesten Designern unserer Zeit

"Luigi Colani zählt international zu den bekanntesten Designern unserer Zeit. Nun hat der zwischen Mailand, Karlsruhe und Shanghai pendelnde Kosmopolit mit Gastprofessuren in Bremen, Mailand, MexikoStadt und Shanghai mit ,Visions eine neue Tapetenkollektion für die Marburger Tapetenfabrik kreiert." (t-online.de am 14.01.2013) [online] http:// www.t-online.de/heim-garten/wohnen/id_61582562/colani-tapeten2013-die-neuen-tapeten-von-luigi-colani.html [20.02.2018] 


\section{Superlativen ähnliche Bezeichnungen und Super- lative innerhalb der untersuchten Publikationen}

Autodesigner des Jahrhunderts

»Der bereits in der Automotive Hall of Fame verewigte und vor einigen Jahren von einer grossen internationalen Jury sogar zum sAutodesigner des Jahrhundertsı gekrönte Maestro [GIORgetTo GIUGIARO; Hinzufügung des Verfassers] machte aber auch noch in den letzten Jahren Furore.« (NZZ am 29.04.2007) [online] http://www.nzz.ch/aktuell/wirtschaft/ uebersicht/kein-erfolg-ohne-gutes-design-1.576310 [20.02.2018]

bedeutendster Autodesigner des Landes

"Welche Chancen hat ein Auto made in Switzerland? ,Wir wissen, dass wir ein Risikoprojekt fahren`, sagt der deutsche Designer Murat Günak, CEO von Mindset und Projekt-Initiator mit bemerkenswerter Karriere. Von der deutschen Presse wird er als bedeutendster Autodesigner des Landes gefeiert. Bis 2007 war er beim Volkswagenkonzern Vizepräsident und Chefdesigner, bei Peugeot prägte er die Modellpalette vom 206 bis zum 607, bei Mercedes war er für die Marken Maybach und Mercedes-Benz verantwortlich, so auch für den extravaganten SLR McLaren. Für den sympathischen Stardesigner ist klar, dass die Kunden bisher kein Vertrauen in Elektroautos hatten, weil es exotische Produkte waren.(NZZ am 08.04.2008) http://www.nzz.ch/lebensart/auto-mobil/ mit-sportlicher-eleganz-richtung-nullemission-1.703934 [20.02.2018]

bedeutendster zeitgenössischer Designer der Welt

"Ullrich Eitel, Leiter des Familienunternehmens, ist seit Jahren ein Bewunderer Luigi Colanis, der 2009 als bedeutendster zeitgenössischer Designer der Welt ausgezeichnet wurde." (NOLTEMEIER in: DER MALER- UND LACKIERMEISTER 3/2013: 78) http://www.fzarchiv.sachon.de/ Zeitschriftenarchiv/Maler-und_Lackierermeister/2013/03_13/ML_03-13 _76-80_Ein_Hauch_von_Luxus.pdf?kein=rewrite: [20.02.2018]

der bedeutendste deutsche Produktdesigner

"Der , bedeutendste deutsche Produktdesigner, Träger des Großen Verdienstkreuzes des Verdienstordens der Bundesrepublik Deutschland, Ehrendoktor des Royal College of Art, sitzt an seinem Schreibtisch in Kronberg im Taunus, die weißen Haare gescheitelt, die runde Eulen-Brille auf der Nase, und gibt sich bescheiden [DIETER RAMS; Hinzufügung des Verfassers].« (ZUBER in: DIE ZEIT am 22.10.2010; Übernahme aus SCHÖNER WOHNEN) [online] http://www.zeit.de/lebensart/2010-10/braun-dieterrams \& https://www.schoener-wohnen.de/moebel/29726-rtkl-dieter-rams [20.02.2018] 


\section{AM ENDE WAR ES NUR EIN WORT: ZWEI REZEPTIONSSTUDIEN}

der unumstrittene Star der deutschen Designszene

"Beweis für die Ausnahmestellung, die der 41jährige mittlerweile genießt. Grcic ist der Darling der Münchner und unumstrittene Star der deutschen Design-Szene. Einer, der mit 41 museumsreif ist. Von dem die Kollegen voller Hochachtung sprechen. Und mit dem das Goethe-Institut Sympathiewerbung für Deutschland im Ausland betreibt." (WEISS in: WAMS ONLINE am 12.03.2006) [online] http://www.welt.de/print-wams/article1396og/Wer-ist-eigentlich-Konstantin-Grcic.html [20.02.2018]

der zu den absoluten Designstars zählende

"Auf die Frage >Was ist Ihnen peinlich? ?, antwortete der zu den absoluten Designstars zählende 44-jährige Brite einmal: ১Öffentlich aufzutreten`." (HILPOLD in: DER STANDARD ONLINE am 24.06.2004) [online] http://derstandard.at/1698272 [20.02.2018]

des legendüren Industriedesigners

"Ein elegantes Doppel ist es, das Salz- und Pfeffer-Set des legendären Industriedesigners Wilhelm Wagenfeld. Die ersten von ihm gestalteten Streuer hießen damals ,Zwillinger. In den 196oer Jahren waren die beiden in fast jedem Haushalt zu finden. Nun kehrt der Designklassiker in der Ausführung von 1954 als Neuauflage zurück." (SCHÖNER WOHNEN) [online] http://www.schoener-wohnen.de/news/tipp-des-tages/213576-wmf-mitsalz-und-pfefferstreuer-editio.html [20.02.2018]

Designer von Weltrang

"Stardesigner entwerfen Teppiche für Ruckstuhls >Edition 2013 ' Designer von Weltrang konnte die Schweizer Teppichmanufaktur Ruckstuhl für ihre neue 'Edition 2013 ' gewinnen. Die ist seit Jahresbeginn zu haben. Sechs international bekante [sic] Designer sind dabei, unter anderem Arik Levy aus Paris, das schwedische Büro Claesson Koivisto Rune oder Patricia Urquiola. Die Motive der neuen Tepiche [sic] reichen von stilisierten Palmblättern über dunkeltonige Polyeder bis hin zu traditionellen Mustern." (SCHÖNER WOHNEN) [online] http://www.schoener-wohnen. de/news/216647-stardesigner-entwerfen-teppiche-fuer-ruc.html [20.02.2018]

die größten Designer des 20. Jahrhunderts

"Design-Legenden. Die größten Designer des 20. Jahrhunderts und ihre wichtigsten Entwürfe im Porträt - von Arne Jacobsen über Charles und Ray Eames bis hin zu Achille Castiglioni." (SCHÖNER WOHNEN) [online] http://www.schoener-wohnen.de/design-legenden [20.02.2018] 


\section{STARDESIGNER ODER GESTALTER DES ALLTÄGLICHEN?}

\section{Handvoll internationaler Topdesigner}

"Auf den ersten Blick ein ungewöhnlicher Ort, den französischen Designer Ronan Bouroullec zu treffen, der gemeinsam mit seinem Bruder Erwan zu einer Handvoll internationaler Topdesigner gehört." (HAUSENBLAS in: DER STANDARD ONLINE am 26.09.2013) [online] http://derstandard.at/ 1379291943363/Die-Brueder-Bouroullec-Wir-streiten-fast-immer [20.02.2018]

niemanden Geringeren als den weltweit angesehenen Stardesigner

"Olive hat es sich einiges kosten lassen, seinen HiFi-Musik-Server >Opus aufhübschen zu lassen. Die Macher aus San Francisco haben niemanden Geringeren als den weltweit angesehenen Stardesigner Karim Rashid engagiert." (SCHÖNER WOHNEN) [online] https://www.schoenerwohnen.de/news/schoener-wohnen-news/91315-olive-mit-opus-no-4von-karim-rashid.html [20.02.2018]

so etwas wie der Popstar unter den zeitgenössischen Designern

"Karim Rashid ist so etwas wie der Popstar unter den zeitgenössischen Designern. Für den italienischen Leuchtenhersteller Axo Light entwarf der schrille Amerikaner mit ägyptischen Wurzeln nun eine LEDLeuchte, die nicht nur aussieht wie eine nordafrikanische Trompete, sondern auch so heißt: >Nafir» « (scHÖNER WOHNEN) [online] http://www. schoener-wohnen.de/news/2146oo-neue-leuchte-von-karim-rashid.html [20.02.2018)

gehören zu den Top Ten des internationalen Designs

"Erwan und Ronan Bouroullec gehören zu den Top Ten des internationalen Designs - RONDO sprach mit Ronan über Ludwig XIV., Hässlichkeit und Bruderzwist." (HAUSENBLAS in: DER STANDARD am 26.09.2013) [online] http://derstandard.at/1379291943363/Die-Brueder-Bouroullec-Wir-streiten-fast-immer [20.02.2018]

\section{Wunderkind der finnischen Designszene}

"Panasonic, Cassina, Issey Miyake, Iittala, Swarovski, Finlandia Vodka. Mit einer derart prestigeträchtigen Riege von Auftraggebern können nur wenige Designer aufwarten - und schon gar nicht im vergleichsweise zarten Alter von 36 Jahren. Harri Koskinen wird dementsprechend als Wunderkind der finnischen Designszene gehandelt." (воКЕм in: DESIGN REPORT 06/2007) [online] http://www.designreport.de/ Fachartikelarchiv/1000001491/Skandinavische-Funktionalitaet.html [28.04.2014 inzwischen nicht mehr im Netz verfügbar] 


\title{
Wunderkind des Autodesigns
}

"Man kann sagen, dass etliche der Modelle, die zum internationalen Ruf deutscher Autos als nicht nur zuverlässige, sondern auch formschöne Fahrzeuge beitrugen, von einem Franzosen entworfen wurden - der, als er all diese Wagen entworfen hatte, noch keine vierzig Jahre alt war. Was macht ein solches Wunderkind des Autodesigns heute? [PAUL BRACQ; Hinzufügung des Verfassers]« (MAAK in: FRANKFURTER ALLGEMEINE SONNTAGSZEITUNG am 14.10.2012) [online] http://www.faz.net/aktuell/ technik-motor/motor/design-genie-paul-bracq-meisterwerke-fuer-50omark-11924544.html?printPagedArticle=true\#pageIndex_o [20.02.2018]

\section{Superlativen ähnliche Bezeichnungen und Super- lative außerhalb der untersuchten Publikationen}

der meist gefeierte und kommerziell erfolgreichste Designer weltweit

\begin{abstract}
"Das unter der Federführung der Vivacon AG geschlossene Joint Venture verfügt über die Exklusivlizenz für den Bau und die Vermarktung von Philippe-Starck-Immobilien in Deutschland. Philippe Starck gilt als der meist gefeierte und kommerziell erfolgreichste Designer weltweit. Die Yoo Deutschland $\mathrm{GmbH}$ wird hochwertige Designerwohnungen in den Toplagen der deutschen Metropolen entwerfen, bauen und verkaufen." (SCHRIEWER in: PRESSRELATIONS PRESSEPORTAL am 19.11.2003) [Online] http://presseservice.pressrelations.de/standard/result_main.cf-

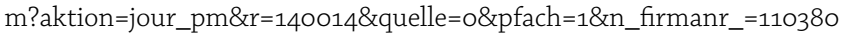
\&sektor=pm\&detail=1 [20.02.2018]
\end{abstract}

der wohl populärste deutsche Designer

"Colanis ungeheures Talent als Entwerfer wird nur noch durch seinen Hang zur exaltierten Show getoppt. Der wohl populärste deutsche Designer verbindet Fidel Castros Redegabe mit der Inszenierungssucht eines Salvador Dalí. Colani ist eine Welt für sich." (HERWIG in: BADISCHE ZEITUNG am 01.08.2008) [online] http://www.badische-zeitung.de/kultursonstige/der-designer-der-rasanten-linie--3996409.html [20.02.2018]

\section{keinen geringeren als}

keinen geringeren als Star-Designer Philippe Starck

"Auch Sanitärhersteller Duravit mischt seit Mitte 2010 hier mit und hat keinen geringeren als Star-Designer Philippe Starck mit dem Entwurf beauftragt. Er sollte Designanspruch und Duschkomfort miteinander 


\section{STARDESIGNER ODER GESTALTER DES ALLTÄGLICHEN?}

in Verbindung bringen (sKs berichtete in Ausgabe 4.2010). (stein.keramik.sanitär 1.2012: 35) [online] http://wu4eob2cl.homepage.t-online.de/ downloads/112neueprodukte.pdf [20.02.2018]

keinen geringeren als den Stardesigner Matteo Thun

"Modern, menschlich, lebensnah ist die Devise der trendigen Hotelkette. Sie versteht sich rals Alternative zu kühlen Hotelhallen, steifen Restaurants und langweiligen Zimmern`, wie es im Werbeprospekt heißt. Um diesen [sic] Anspruch gerecht zu werden hat, hat man keinen Geringeren als den Stardesigner Matteo Thun gewonnen, der für Firmen wie BMW, Villeroy \& Boch und Mövenpick tätig gewesen ist. (PASDZIOR in: HAMBURGER ABENDBLATT am 16.11.2012) [online] http://www.abendblatt.de/ reise/article111173843/Stardesigner-Matteo-Thun-trifft-Jugendstil.html [20.02.2018]

\section{Design-lkonen: Nach oben ist nicht mehr viel Luft}

Am oberen Ende der Skalen nimmt die Variationsbreite der verbalen Steigerungsmöglichkeiten deutlich ab. Und dennoch: Nach den Superlativen und vor der Legende folgt die Ikone in Variationen. Der DuDENschen Definition folgend ist sie ein "Kultbild der orthodoxen Kirche mit der Darstellung heiliger Personen oder ihrer Geschichte« bzw. eine "Person oder Sache als Verkörperung bestimmter Werte, Vorstellungen, eines bestimmten Lebensgefühls o. Ä. Beide Bedeutungen können in Anbetracht der Funde als gemeint gelten. (DUDEN) [online] http://www.duden.de/rechtschreibung/Ikone [20.02.2018].

\section{Designikone}

"Mr. Impossibler nennt Designikone Philippe Starck seinen Entwurf von einem Stuhl, der jahrelang nicht gebaut werden konnte. Das Material hat nicht gestimmt. Inzwischen hat der Meister zusammen mit Kartell eine Lösung gefunden - und erklärt im Interview, wie es geht." (scHÖNER wOHNEN) [online] http://www.schoener-wohnen.de/tipps-trends/29396rtkl-philippe-starck-im-interview-bei-kartell [20.02.2018]

Ikonenmacher unter den Designern

"Auch mit 73 Jahren gilt Peter Schmidt als Ikonenmacher unter den Designern. Doch der Wahlhamburger gibt nicht nur Produkten und Firmen ein Gesicht. Auch Bühnenbilder und Konzerthäuser gehören zu seinem Repertoire. In seinem neuen Projekt gestaltet Schmidt sogar die Zu- 


\section{AM ENDE WAR ES NUR EIN WORT: ZWEI REZEPTIONSSTUDIEN}

kunft." (REICH in: MANAGER MAGAZIN am 28.09.2011) [online] http:// www.manager-magazin.de/lifestyle/stil/a-788057.html [20.02.2018]

Außerhalb des untersuchten Publikationskorpus werden gefunden:

angehende Ikone

"So bleiben auch die wichtigsten Fragen ungestellt und unbeantwortet. Was macht eine angehende Ikone zur Ikone [PATRICIA URQUIOLA; Hinzufügung des Verfassers]? Man erfährt es bis zur letzten Seite nicht. Fast könnte man meinen, die fast beliebige Anordnung der Produkte und die mangelnde Behandlung der Details käme einer gewissen Unnahbarkeit der Designerin gleich - der Designer als Phantom hinter einer Masse von Formen? Das Buch wird seinem Gegenstand einfach nicht gerecht." (BAUER in: ARTNET am 30.07.2009) [online] http://www.artnet.de/magazine/ patricia-urquiola-und-markus-benesch-daab-verlag-koln/ [18.07.2013, inzwischen nicht mehr im Netz verfügbar]

Ikone des modernen Designs

"Er gilt als Ikone des modernen Designs: Karim Rashid. Der in New York ansässige, berühmte Industrie-Designer anglo-ägyptischer Abstammung ist weltweit begehrt aufgrund seiner außergewöhnlichen Kreativität und seines beeindruckenden Produkt-Designs. Der vielseitig begabte Allrounder ist beileibe nicht nur Designer, sondern auch ein begnadeter Architekt, Innenausstatter, Schriftsteller, Künstler, Modeschöpfer, Redner und DJ.« (WIESER in: www.gorenje.de am 17.01.2011) http://www.gorenje.de/ presse/presse/archiv/2011/01/6141-Karim-Rashid-Designer-aus-Leidenschaft [20.02.2018] 


\section{Design-Legenden:}

346 Sind wir auf den Höhen des Olymp angekommen?

Im Internetauftritt von sw werden auf einsamem Posten die Designlegenden vorgestellt. Bemüht man hierzu ein weiteres Mal den Duden, so findet man als mögliche Bedeutungen des Begriffs der Legende u. a. dieses: »Person oder Sache, die so bekannt geworden ist, einen solchen Status erreicht hat, dass sich bereits zahlreiche Legenden um sie gebildet haben; Mythos « sowie "ausschmückende Darstellung, glorifizierende Erzählung, Geschichte« und auch »etwas, was erzählt, angenommen, behauptet wird, aber nicht den Tatsachen entspricht«. Was hiervon zutreffend wäre, muss der Spekulation anheimfallen. (DUDEN) [online] http://www.duden.de/rechtschreibung/Legende [20.02. 2018] Die Liste von sw umfasst 14 Männer und zwei Frauen, denen zur Einleitung der Portraits vorangestellt wird: »Die größten Designer des 20. Jahrhunderts und ihre wichtigsten Entwürfe im Porträt - von Arne Jacobsen über Charles und Ray Eames bis hin zu Achille Castiglioni." (SCHÖNER WOHNEN) [online] http://www.schoener-wohnen.de/moebel/9389-thma-design-legenden [20.02.2018] Sodann folgen unter den Bildern der vorgestellten Designerinnen und Designer kurze Teaser-Texte, innerhalb derer ACHILLE CASTIGLIONI als Einziger "zum ersten italienischen Design-Star« erklärt wird. Was sich sonst noch so findet, ist in vertrauter Manier kursiv hervorgehoben und wird darüber hinaus umkommentiert gelassen.

\section{Arne Jacobsen}

"Keiner versöhnte Geometrie und sinnliche Formen wie er: Mit dem sperStuhl wurde Arne Jacobsen zum erfolgreichsten Designer Skandinaviens - und Hersteller Fritz Hansen zur Weltfirma." (MECKE in: SCHÖNER WOHNEN) [online] https://www.schoener-wohnen.de/designerlexikon/17653-dlxk-arne-jacobsen\#37995 [20.02.2018]

Charles und Ray Eames

"Architekt trifft Kunststudentin: Fürs Wohnen wird die Begegnung von Charles und Ray Eames zur wichtigsten des 20. Jahrhunderts. Nie wieder hat Design so entspannt-elegant ausgesehen." (MECKE in: SCHÖNER WOHNEN) [online] https://www.schoener-wohnen.de/designer-lexikon/ 17615-dlxk-charles-und-ray-eames\#37996 [20.02.2018] 


\section{AM ENDE WAR ES NUR EIN WORT: ZWEI REZEPTIONSSTUDIEN}

Le Corbusier

"Ganze Architektengenerationen wollten so sein wie Le Corbusier: kühl, intellektuell und der Funktion verpflichtet. Das machte seine Möbel zu Kultobjekten des 20. Jahrhunderts." (MECKE in: SCHÖNER WOHNEN) [online] https://www.schoener-wohnen.de/designer-lexikon/ 17754-dlxk-le-corbusier-charlotte-perriand\#37440 [20.02.2018]

Achille Castiglioni

"Autoscheinwerfer zu Leuchten und Treckersitze zu Hockern - sein Entwurfsprinzip war die kühl kalkulierte Pointe. So wurde Achille Castiglioni zum ersten italienischen Design-Star." (MECKE in: SCHÖNER wOHNEN) [online] https://www.schoener-wohnen.de/designer-lexikon/ 17597-dlxk-achille-castiglioni\#37739 [20.02.2018]

Walter Gropius

»Seine Vision vom gestalterischen Neuanfang begründete in den $20 e r$ Jahren den kühlen Look der Moderne. Nie wieder war Deutschland so Avantgarde wie in Gropius` [sic] Bauhaus-Schule." (SCHÖNER WOHNEN) [online] https://www.schoener-wohnen.de/designer-lexikon/17637-dlxk-waltergropius\#37720 [20.02.2018]

Verner Panton

»Poppige Räume wie die von Panton hatte man zuvor noch nie gesehen. Und mit seinem Freischwingerstuhl aus Kunststoff erlöste der Däne nicht nur das nordische Design von der Fixierung aufs Holz." (MECKE in: SCHÖNER WOHNEN) [online] https://www.schoener-wohnen.de/moebel/31563rtkl-verner-panton-1926-1998 [20.02.2018]

\section{Eileen Gray}

"In der Welt des Wohnens ist die Frau aus Irland die schillerndste Figur des 20. Jahrhunderts." (MECKE in: SCHÖNER WOHNEN) [online] https:// www.schoener-wohnen.de/designer-lexikon/17627-dlxk-eileen-gray\# 37609 [20.02.2018]

Alvar Aalto

"Design braucht den menschlichen Bezug, forderte der Finne Alvar Aalto. Weich geschwungenes Holz war sein Lieblingsmaterial - die naturnahe nordische Antwort auf Le Corbusier und die kühlen Bauhaus-Puristen.» (MECKE in: SCHÖNER WOHNEN) [online] https://www.schoener-wohnen. de/moebel/31806-rtkl-alvar-aalto-1898-1976 [20.02.2018]

Joe Colombo

"Container, serielle Möbelelemente, bunte Kunststoffobjekte: Der Mailänder Colombo hat das Wohngefühl der 7oer-Jahre erfunden, aber selbst 


\section{STARDESIGNER ODER GESTALTER DES ALLTÄGLICHEN?}

nicht mehr erlebt."(MECKE in: SCHÖNER WOHNEN) [online] https://www. schoener-wohnen.de/designer-lexikon/176o7-dlxk-joe-colombo\#37759 [20.02.2018]

Jean Prouvé

»Mit Möbeln aus Stahlblech und Sperrholz, so robust gebaut wie Häuser, zeigte der Franzose die Schönheit der reinen Konstruktion." (ScHÖNER WOHNEN) [online] https://www.schoener-wohnen.de/designer-lexikon/ 17739-dlxk-jean-prouve\#37130 [20.02.2018]

Ludwig Mies van der Rohe

„Er öffnete das Haus zur Natur, indem er Wände auf Stahl und Glas reduzierte. Ludwig Mies van der Rohe war ein Erfinder der Moderne und ein Meister der Proportion." (SUNDERGELD in: SCHÖNER WOHNEN) [online] https://www.schoener-wohnen.de/designer-lexikon/17709-dlxk-ludwigmies-van-der-rohe\#37610 [20.02.2018]

Frank Lloyd Wright

"Der bedeutendste Baumeister Amerikas entwarf in sieben Schaffensjahrzehnten Möbel, Museen und Hunderte von Häusern. Viele sind heute Ikonen der Moderne." (SUNDERGELD in: SCHÖNER WOHNEN) [online] https://www.schoener-wohnen.de/designer-lexkon/17567-dlxk-franklloyd-wright\#37348 [20.02.2018]

Ettore Sottsass

»Er gründete die Design-Gruppe Memphis und kreierte eine Schreibmaschine mit Sex-Appeal. Seine Arbeiten bereicherten die Postmoderne mit Kontroversen, Spaß und Emotionen." (SUNDERGELD in: SCHÖNER WOHNEN) [online] https://www.schoener-wohnen.de/designer-lexikon/17558dlxk-ettore-sottsass-jr\#37477 [20.02.2018]

Wilhelm Wagenfeld

„Wilhelm Wagenfeld war der erste Industriedesigner Deutschlands. Sein erklärtes Ziel: Massenartikel sorgfältig und trotzdem preiswert zu gestalten." (SIEBKE in: SCHÖNER WOHNEN) [online] https://www.schoenerwohnen.de/designer-lexikon/17585-dlxk-wilhelm-wagenfeld\#37405

[20.02.2018]

\section{Eero Saarinen}

"Der in Finnland geborene Sohn eines Architekten kam als Teenager in die USA und wurde zu einem Pionier der organischen Form. Was er gestaltete, war pure Eleganz - vom Stuhl bis zum Flughafen«. (SUNDERGELD in: SCHÖNER WOHNEN) [online] https://www.schoener-wohnen.de/ designer-lexikon/17693-dlxk-eero-saarinen\#37536 [20.02.2018] 
Gerrit Rietveld

"Entwürfe wie der `Zickzack-Stuhl und der >Rot-Blaue Stuhl sind Ikonen der Moderne, doch der Niederländer war weit mehr als Designer der De-Stijl-Bewegung." (SUNDERGELD in: SCHÖNER WOHNEN) [online] https://www.schoener-wohnen.de/moebel/33048-rtkl-gerrit-rietveld1888-1964 [20.02.2018]

Mit der schon vorgestellten Rangliste vergleichend fällt auf, dass keine der hier angebotenen Legenden dort zu finden ist - obwohl sw zu den untersuchten Publikationen zählt. Dies erlaubt einerseits eine Annahme in Bezug auf die zeitliche Gültigkeit der Bezeichnung Star für das Spielfeld dieser Publikation. Sie scheint sich in Anbetracht der Sterbedaten jener Legenden eher auf lebende Personen zu begrenzen. Andererseits verleitet es zu der starken Vermutung, dass die Gültigkeit dieser Sinn-Angebote zunächst verhandelt werden müsste, bevor sich diese dann nach und nach schleichend einstellen könnte, also im Sinne eines Trickle-Down-Effekts durchzusickern begänne. Diese noch verborgene Mechanik lohnte sicher eine nähere Betrachtung. Denn einer der erstaunlichen Aspekte daran ist, dass das Postulat, das an der Spitze steht, seine Einlösung nicht bezeugen können muss. Die deutlich zugespitzte und dennoch vage bleibende Idee eines Leitbildes oder einer Leitfigur genügt den Autoren schon: Der Maßstab ist gesetzt wie eine Setzung in der Bildenden Kunst und soll so akzeptiert bzw. dann im Idealfall auch so weiter transportiert werden - um vielleicht auf diese Weise Eingang ins kollektive Gedächtnis zu finden. 


\section{Nationalisierung}

Mit nationalen Zuschreibungen tut man sich sowohl in DEUTSCHLAND wie auch in ÖSTERREICH und der SCHWEIZ ein wenig schwer und spricht sie generell für Designer außerhalb des eigenen Sprachraumes häufiger aus. Ein Ausschnitt aus dem vorstehend präsentierten Gesamtbild kann dies noch einmal verdeutlichen. Zu diesem Zweck werden hier nur die Formulierungen in der Aufzählung belassen, die einen nationalen oder im weiteren Sinne geografischen Zusammenhang herstellen. Personen aus Deutschland sind zusätzlich noch einmal mit kursiver Schrift hervorgehoben:

1. Altmeister des Designs

Altmeister des deutschen Designs, Altmeister des italienischen Designs, der italienische Altmeister des Designs, Turiner Altmeister

2. Ausnahmedesigner

der griechische/japanische Ausnahmedesigner, des holländischen Ausnahmedesigners, der holländische Ausnahme-Designer, den italienischen Ausnahme-Designer

3. Designstar/Design-Star/Design-Stars/Designerstar(s) bayerischer Design-Star, Designstar aus Frankreich, der deutsche Designstar, der französische Designstar, des italienischen Designstars, des New Yorker Design-Stars, des niederländischen Designstars, die japanischen Designstars, italienische Designerstars, Münchner Designstar, vom finnischen Designstar

4. Japans Design-Großmeister

5. die Ikone des deutschen Industriedesigns

6. Kultdesigner der britische Kultdesigner, der französische Kultdesigner

7. ostdeutsche Designer-Elite

8. Star Star der britischen Designszene

9. Stardesigner/Stardesignerin

Amsterdamer Stardesignerin, dem ersten Stardesigner Österreichs, dem kanadischen Star-Designer, der deutsche Stardesigner, der finnische Star-Designer, der niederländische Stardesigner, der österreichische Stardesigner, der renommierte Hamburger Stardesigner, der schwäbische Stardesigner, der schweizer Stardesigner, der spanische Stardesigner, der 


\section{AM ENDE WAR ES NUR EIN WORT: ZWEI REZEPTIONSSTUDIEN}

südfranzösische Stardesigner, der Südtiroler Stardesigner, der Turiner Stardesigner, des dänischen Stardesigners, des Hamburger Stardesigners, des Pariser Stardesigners, ein indischer Stardesigner, Englands Stardesigner, ([i]m Vergleich zu denjenigen) extravertierterer, ausländischer Stardesigner, Frankreichs Stardesignerin, Italiens Stardesigner, Londoner Stardesigner, Star-Designer aus New York, vom amerikanischen Stardesigner, vom britischen Stardesigner, vom englischen Stardesigner, vom italienischen Stardesigner, vom Pariser Stardesigner, von dem belgischen Stardesigner

10. Star-Gestalter Italiens Star-Gestalter

11. Wunderkind der finnischen Designszene

12. Topdesigner/Topdesignerin die spanische Topdesignerin, die italienische Topdesignerin 


\section{Die wörtliche Steigerung der Popularität}

Für einen Teil der gefundenen Beschreibungen wird eine Ordnung im Sinne zunehmender Popularitätssteigerung vorgeschlagen. Von der Bekanntheit als geringster Aufmerksamkeitsstufe bis zur Designlegende ist es ein weiter Weg, der sich über fein austarierte Steigerungsformen in den Designolymp hinaufwindet. Virtuos werden die von FRANcK herausgehobenen Kategorien Reputation, Prestige und Ruhm für das Feld genutzt, mit geografischen Lokalisierungen kombiniert, dann wechseln sie über in die Sphäre der Stars, werden erneut steigernd lokalisiert, bedienen sich anschließend noch in der Fundgrube des Pop-Diskurses, um über die Kurve der Weltgeltung schließlich legendär zu werden. Dem Ordnungsvorschlag zu Grunde gelegt wird das Gefühl eines steigenden Reputationsdruckes, der dem Publikum mit diesen Sinnangeboten scheinbar vermittelt werden soll:

- der bekannte Designer

- der namhafte Designer

- der renommierte Designer

- der international bekannte Designer

- der bedeutende Designer

- der berühmte Designer

- der Stardesigner, Stardesigner mit Länderbeigabe im Genitiv

z. B. Frankreichs Stardesignerin Andrée Putman, Italiens Stardesigner Ettore Sottsass

- der international bekannte Stardesigner

- der Popstar des Designs

- der Superstar des Designs

- der Weltklasse-Designer/Weltstar des Designs

- Designlegende

Ähnliches geschieht auch an anderer Stelle im Internet; als Beleg für den vorgestellten Ansatz führe ich die Seiten www.designlegends.org an. Dort wird eine »Hall of Fame for Design« angeboten, »[1]isting the Worlds' Best Designers, The Best of Best Architects, Innovators and Creatives. "Die dort vorgefundenen Einstiegs- und Steigerungsstufen legen eine deutliche Parallele zur vorgeschlagenen Sortierung offen. Sie werden hier in der Originalreihenfolge mit Übersetzung gezeigt, die mit Schrägstrichen angeschlossenen Alternativen stehen für jeweils alternative Bedeutungsmöglichkeiten: 
AM ENDE WAR ES NUR EIN WORT: ZWEI REZEPTIONSSTUDIEN

- Rising Star of Design (Aufsteigender Star des Designs)

- Design Star

- Design Hero (Design-Held)

- Distinguished Designer (Angesehener/bedeutender/hervorragender Designer)

- Prestigious Designer (Namhafter Designer)

- Famous Designer (Berühmter/bekannter Designer)

- Renowned Designer (Renommierter Designer)

- Glorious Designer (Ruhmreicher Designer)

- Legendary Designer (Legendärer Designer)

(www.designlegends.org) [online] http://www.designlegends.org/about.php [26.02.2018] 


\section{Die Klassifizierung des Designernachwuchses}

lässt wie selbstverständlich ebenfalls unterschiedliche Begriffskombinationen auftauchen. Zur Abgrenzung von den arrivierten verwendet die Presse z. B. das Adjektiv experimentierfreudig und sofort hat man ein Bild des ikonoklastischen Nachwuchses vor Augen, der gegen die etablierten, in der Routine gefangenen anrennt. Ein perfektes Beispiel dafür ist MAARTEN BAAS: Er imitiert im Rahmen seiner Abschlussarbeit im Jahr 2002 mit verbrannten Möbeln, die landläufigen Klassikervorstellungen entstammen, trefflich die Zerstörung von »Heiligtümern«. Als Basis seiner Serie Smoke baut er sie in seine persönliche Prominenz-Gleichung ein und lässt mit diesem Kunstgriff sogar die MEMPHIS-Truppe (speziell ALESSANDRO MENDINI, den er damit ironisch doppelt) reichlich alt aussehen. (maartenbaas.com) [online] http://maartenbaas.com/smoke/vintage/ [26.02.2018]

Ein genialer PR-Schachzug, der die damalige Langeweile des Alt-Italieners und dessen Versuch, die Erstarrung im Möbelmarkt mit überarbeiteten Klassikern zu durchbrechen, auf ein überraschend neues Niveau hebt und durch die Tabuverletzung ganz eindeutig nach Aufmerksamkeit hechelt. Gleichwohl trägt auch BAAS' Strategie eigentlich nur in gleicher Weise zu einer Befestigung des Klassikerkorpus bei, währenddessen der Tabubruch ihn ebenfalls in die Reihe der beachteten befördert - was sich auch im Rahmen dieser Untersuchung wieder als funktionsfähig erweist, da er soeben kurz vorgestellt wurde.

Substantive wie Hoffnung geben derselben Ausdruck, dass aus so bezeichneten Personen einmal »etwas wird «: ein erfolgreicher Star, mit dem man Staat machen kann - eine heftige Hypothek, z. B. für eine »jüngste deutsche Designhoffnung«, 2005 über STEFAN DIEZ ausgesprochen. (www.moebelmarkt.de) [online] http://www.moebelmarkt.de/beitrag/ideal-houses-cologne-nachwuchsversus-altmeister-dieter-rams [26.02.2018].

Der Begriff Talent wird mit jung oder neu vor den Karren gespannt, der Newcomer tut genau das und wem sonst gar nichts mehr einfällt, dem bleibt ja noch der Star: Garniert mit Vokabeln der Jugendlichkeit oder der Nachzucht, der Zukünftigkeit, der Weltläufigkeit, gerne auch verbrämt mit Anglizismen oder gänzlich in Fremdsprache. Die Verbalaufzucht des Designernachwuchses legt deutliche Parallelen offen zur Analyse des Klassikermarktes durch BREUER in Die Erfindung des modernen Klassikers: 
AM ENDE WAR ES NUR EIN WORT: ZWEI REZEPTIONSSTUDIEN

1. der neue Star der spannenden niederländischen Designszene

2. die neuen Stars der Zukunft

3. internationale Jungstars

4. Japans kommender Designstar

5. jüngste deutsche Designhoffnung

6. junge, experimentierfreudige Designer

7. junge(n) Stardesigner(n)

8. Jungstar der italienischen Designszene

9. Jungtalente

10. Nachwuchsstars

11. neue Talente

12. Newcomer des Jahres

13. Rising Star of the Year

14. Shooting Stars der internationalen Designszene 


\title{
Differenzierung durch vorgebliche Aktualität
}

\begin{abstract}
Als »Aktuelle Star-Designer« werden online im Designer-Lexikon von sw nach den »Beliebte[n] Klassiker[n] 12 Personen vorgestellt. Mit Hervorhebungen dokumentiert sind hier jeweils der Teaser-Text und das Kurzprofil (alle Teaser-Texte finden sich auf der Startseite, die Texte folgen auf den jeweiligen Profilseiten). (schÖNER WOHNEN) [online] https://www.schoener-wohnen. de/designer-lexikon [26.02.2018]
\end{abstract}

\section{Erwan \& Ronan Bouroullec}

"Um diese Jungs reißen sich selbst die größten Möbelhersteller: Die Bouroullec-Brothers haben mit ihrem Design sogar Phillippe Starck [sic] überholt."

"Von einem `Oui dieser beiden großen Jungs träumen die besten Möbelfirmen der Welt; die Brüder aus der Bretagne haben ihren Landsmann Philippe Starck in wenigen Jahren überrundet. Woran man das merkt? Dass sie sich nicht mehr bei den Firmen bewerben, sondern die Firmen bei ihnen. Glücklich, wer sich zu ihren frühen Förderern zählen kann wie Vitras Rolf Fehlbaum oder Julio Cappellini, der sie 1997 entdeckte. Philippe Grohe musste vier Jahre Geduld haben, bis er jetzt eines der ambitioniertesten Projekte präsentieren konnte: ein Bouroullec-Bad, das so zeitlos aussieht, als sei es schon immer da gewesen. Souverän spielen die beiden mit Erwartungen: Teller in einer neuen Alessi-Kollektion sind, für das Auge kaum sichtbar, leicht asymmetrisch, und an ihren Axor-Badewannen lassen sich die Armaturen verschieben; Stühle erinnern

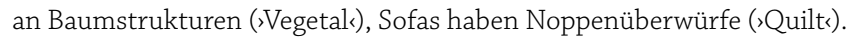
Die Brüder, die heute beide mit Designerinnen liiert sind, kamen nicht gleichzeitig zum Gestalten. Ronan, das Zeichentalent, war einige Jahr [sic] Solist, bis sich ihm Erwan mit Material- und Technikexperimenten anschloss."(SCHÖNER WOHNEN) [online] https://www.schoener-wohnen.de/ designer-lexikon/17595-dlxk-erwan-ronan-bouroullec\#37378 [26.02.2018]

Humberto \& Fernando Campana

"Das Campana-Geschwisterpaar beweist fast beiläufig, dass aus vermeintlichem Müll tolle Möbel und überraschendes Design entstehen können."

"Alles geht: Fundholz, Plastikschläuche, Lederreste - aus allem lässt sich ein Sessel bauen. Die Campanas aus dem brasilianischen São Paulo erfanden einen vitalen Arte-Povera- Mix - gefällig, aber politisch und designerisch gewollt unkorrekt. Viele ihrer Objekte gibt's nur in Kleinserien, aber bei Alessi zeigen auch Mikado-ähnliche Schalen oder Uhren ihr anarchisches Collageprinzip. Jurist Humberto flüchtete aus einer Anwaltskarriere, 


\section{AM ENDE WAR ES NUR EIN WORT: ZWEI REZEPTIONSSTUDIEN}

versuchte sich als Bildhauer, bis er mit seinem Architekten-Bruder Fernando seine Bestimmung im Design fand." (SCHÖNER WOHNEN) [online] https://www.schoener-wohnen.de/designer-lexikon/17593-dlxk-humbertofernando-campana\#37393 [26.02.2018]

Stefan Diez

"Sein Design ist so zurückhaltend wie seine Persönlichkeit: Stefan Diez' jährlich erscheinende Stuhlversionen begeistern Kritiker wie Käufer."

"Diez war Assistent von Grcic, nachdem der bei Morrison gearbeitet hatte: Selten lassen sich Einflüsse und Weiterentwicklungen so klar (und so schön) verfolgen. Der in München arbeitende, als Person sehr zurückhaltende Schreinersohn Diez fasziniert Jahr für Jahr mit neuen Stuhlversionen, ebenso einfach in der Erscheinung wie klug in der Konstruktion. (sCHÖNERWOHNEN) [online] https://www.schoener-wohnen.de/designerlexikon/17756-dlxk-stefan-diez\#37448 [26.02.2018]

Naoto Fukasawa

»Vom Geheimtipp zum trendweisenden Designer: Naoto Fukasawa zählt seit seinen Entwürfen für Magis und B\&B zu den Stars der Szene."

"Nicht für den optischen Verschleiß entwerfen, sondern für die Substanz; das beste Design ist jenes, das man nicht wahrnimmt: Selbst Fukasawas Rhetorik zelebriert die schöne Form. Lange kannten nur Eingeweihte den Japaner als den prägenden Mann hinter der trendigen Basics-Marke Muji, die ihren Kultstatus vor allem aus dem demonstrativen Verschweigen ihrer Designer bezieht. Mit dem Boom des Zen-Designs wird Fukasawa nun auch als Person populärer - was er nicht unbedingt mag: 'Es erschreckt mich, wenn Leute Dinge wegen meines Namens kaufen. S Schwer zu vermeiden, seit seine poetisch-minimalistischen Objekte bei Magis, Boffi oder B\&B im Angebot sind - mit Star-Vermarktung. Und wo bei Muji eine Art spannungssteigerndes Geheimnis war (ist das Objekt von Fukasawa oder einem anderm [sic] Stardesigner?), überrascht er bei den klassischen Labeln mit einem ganz anderen Effekt. Staunend steht man vor Fukasawa-Design und fragt sich: Wie schafft er es nur, auch neue Objekte so sympathisch vertraut wirken zu lassen? ,Kinder zeichnen von allein das Archetypischer, erklärt er, ,für Designer ist gerade das besonders schwer.« (SCHÖNER WOHNEN) [online] https://www.schoenerwohnen.de/designer-lexikon/17621-dlxk-naoto-fukasawa [26.02.2018]

Konstantin Grcic

"Mit Witz, Forschergeist und Akrebie [sic] zum Erfolg. Konstantin Grcics Design ist längst ein Exportschlager >Made in Germany<." 


\section{STARDESIGNER ODER GESTALTER DES ALLTÄGLICHEN?}

"Auch im Design sind die Deutschen fürs Nützliche und Rationale zuständig. Umso verblüffender, wie der in München geborene Grcic (sein jugoslawischer Vater gab ihm die vielen Konsonanten mit) zu Deutschlands Super-Exportdesigner wurde. Seine Hauptwerkzeuge: Forscherakribie, mehr noch aber Intellektualität und raffiniert versteckter Witz; zu erleben etwa in einem Bücherregal (`Esı), das wackelt und doch höchst stabil ist; oder in einem rätselhaften Stuhl ('Chair One`), aus dessen Gittersitzschale alles statisch nicht Notwendige weggestanzt wurde. Grcic hat mit einer Lehre zum Möbelschreiner in britischer Arts-and-Crafts-Tradition begonnen, studierte am London Art College bei Jasper Morrison und war ein Jahr lang dessen Assistent, bevor er sich in München mit der Berufs- und Lebensform selbstständig machte, die ihn in England so fasziniert hatte: der Gestalter als Pionier und Experimentator. Beharrlich nennt er sich Industriedesigner, obwohl er erfolgreich den Prototypen des Autorendesigners spielt, voller Eigensinn und sperriger Tiefe: 'Es kann nicht richtig sein<, sagt er, ’wenn neues Design sofort Gefallen findet‘. (scHÖNER WOHNEN) [online] https://www.schoener-wohnen.de/designer-lexikon/ 17631-dlxk-konstantin-grcic\#37526 [26.02.2018]

\section{Jonathan Ive}

"Er verwandelt Computer und Handys in Designer-Stücke. Jonathan Ive ist als Chef-Designer bei Apple maßgeblich am Erfolg des Konzerns beteiligt."

»Kein Designer hat das beginnende Jahrhundert so geprägt wie er: Nicht nur der Kult um die Computermarke Apple geht zu großen Teilen auf den Briten Jonathan Paul Ive zurück, vielleicht noch wichtiger sind die Sekundärwirkungen. So fand Apples Chefdesigner nicht nur weltweit faszinierende, intuitiv zu verstehende Oberflächen für die neuesten technischen Visionen von iMac, iPod oder iPad. Mit den lackähnlichen, spiegelnden Oberflächen löste er einen langen Weiß-Boom aus und hat mit seinen abgerundeten Ecken großen Anteil an der 6oer-Renaissance. Sympathisch: Er habe viel von Braun-Legende Dieter Rams gelernt, sagt Jonathan Ive." (SCHÖNER WOHNEN) [online] https://www.schoener-wohnen.de/ designer-lexikon/17651-dlxk-jonathan-ive\#37573 [26.02.2018]

\section{Hella Jongerius}

"Hella Jongerius beweist mit ihrer Arbeit, dass gutes Design nicht teuer sein muss. Ihre Stücke findet man in edlen Auktionshäusern - oder bei Ikea.«

"Jongerius [sic] Vasen von ihr gibt's für 30 ooo Dollar (Einzelstück) oder für knapp 35 Euro bei Ikea. Die in Berlin lebende Holländerin hat weder dem Kunst- noch dem Massenmarkt gegenüber Berührungsängste - aber eine Aversion gegen Design ohne Tiefgang. Nachdenklicher als viele Kollegen sucht sie nicht nur des Dekors wegen Mischformen zwischen Handwerk und Massenproduktion, etwa in arabesken Applizierungen an strengen Formen. 'Das Handwerkliche kommt von dem ro- 


\section{AM ENDE WAR ES NUR EIN WORT: ZWEI REZEPTIONSSTUDIEN}

mantischen Mädchen vom Landı, sagt sie sund das Industrielle von der Powerfrau in mir! Die Absolventin der Eindhovener Designakademie landete '94 mit einer Gummivase bei Droog ihren ersten Erfolg, heute gehört sie zu den Vitra-Stars." (scHÖNER WOHNEN) [online] https:// www.schoener-wohnen.de/designer-lexikon/17655-dlxk-hella-jongerius\# $37593[26.02 .2018]$

Jehs+Laub

"Das Designer-Duo Jehs+Laub fügt Vertrautes und Neues in Perfektion zusammen und gehört zu den Überfliegern der Szene."

"Premieren bei Cor und Cassina und parallel bei Knoll und Fritz Hansen: Auf keine deutschen Designernamen wird derzeit strategisch so hoch gesetzt wie auf die des Duos aus Stuttgart. Das Talent der beiden: Sie collagieren neue Technologien und die Substanz vertrauter Stilelemente zu entspannten Neuschöpfungen. So nutzten sie für ihre Wiederbelebung leichter Cocktailsessel Know-how aus der Autoindustrie, beim kissenähnlichen Cor-Sofa dagegen waren es Erfahrungen einer Nordafrikareise, die sie uralten arabischen Sitzkomfort in Design-Coolness übersetzen ließen. Markus Jehs und Jürgen Laub über ihre interne, selbstregulierende Arbeitsmethode: 'Einer ist ignorant, der andere penetrant.« (sснӧNER WOHNEN) [online] https://www.schoener-wohnen.de/designerlexikon/17752-dlxk-jehslaub\#40870 [26.02.2018]

Inga Sempé

"Der Vater ein berühmter Illustrator, die Tochter eine erfolgreiche Designerin: Inga Sempés Objekte sehen nicht ohne Grund aus wie gezeichnet."

"Sie hört es nicht gern, aber es ist pure Biografie: Inga Sempés Vater ist auch der kreative Vater des sKleinen Nicks. Eine ganze Generation wuchs mit seinen zarten Strichfiguren auf. Auch Inga Sempés Objekte scheinen wie gezeichnet: Gefaltete Lampenschirme aus Plissee oder Waffelmuster in Polsterbezügen leben von grafisch-liebevollen Effekten. Niedlich aber sollen ihre Objekte nicht sein. Wenn das von der Pariserin verlangt wird, reagiert sie trotzig; ebenso, wenn man sie in Schulen einordnen will. Am Anfang jedes Projekts steht die Alltagsbeobachtung. Bei ১Ruchér etwa, dem Sofa, das aussieht, als sei eine Decke über eine Bank geworfen worden, ging es um den idealen Platz für die schnelle Zeitungslektüre." (sCHÖNER wOHNEN) [online] https://www.schoener-wohnen.de/ designer-lexikon/17657-dlxk-inga-sempe\#37502 [26.02.2018]

Patricia Urquiola

"Mit ihrem ungewöhnlichen Mut zur Opulenz punktet die gebürtige Spanierin Patricia Urquiola bei Design-Fans und internationalen Herstellern." 


\section{STARDESIGNER ODER GESTALTER DES ALLTÄGLICHEN?}

„Vor ihr galt das Prinzip: Frauen kaufen Möbel, aber erdacht werden sie von Männern. Erfolgreiche Designerinnen konnte man an den Beinen eines Stuhles abzählen. Die spanische Architektin, die seit 20 Jahren in Mailand lebt, hat alles verändert. 197 Produkte von 16 Herstellern ‘ findet die Stylepark-Anfrage im Herbst 2010. Vor allem dank ihr fassten viele Firmen wieder Mut zur Opulenz; und bekamen, was im architektonisch-puristischen Zeitgeist verschwunden war: Flechtwerk, Muster, Dekor und eine Art 1001-Nacht-Ethno-Mix mit Farb- und Formzitaten aus aller Welt. Nur bei genauerem Hinsehen entdeckt man auch eine ruhigere Urquiola, Schülerin von Achille Castiglioni und Piero Lissoni - etwa in kubistischen Sofas (iTuftyc) oder in Betten mit einem smarten Detail: Das Kopfteil von >Clip < lässt sich so flexibel verstellen, als sei es ein Mantelkragen. Hinter jeder starken Frau steht eine andere starke Frau: In der Firmenchefin Patrizia Moroso hat Patricia Urquiola eine Vornamens- und Seelenverwandte gefunden. Moroso hat als Erste an sie geglaubt und bekommt bis heute immer die gewagtesten neuen Urquiola-Entwürfe." (SCHÖNER WOHNEN) [online] https://www.schoener-wohnen.de/designer-lexikon/ 17599-dlxk-patricia-urquiola [26.02.2018]

Die Formulierung "Aktuelle Stardesigner« leistet als Sonderform der Nobilitierung im Rahmen dieses von »Designexperten« verfassten Online-Desig nerlexikons ihr Teil, um eine Differenzierung zu den »Beliebte[n] Klassiker[n]« zu erzielen, unter denen sich auch eine größere Zahl der zuvor gezeigten »Designlegenden« befindet. Zudem wird mit ihr einmal mehr das Verständnis des Zeitrahmens belegt, der in sw im Zusammenhang mit dem Begriff Star zur Anwendung kommt, wenngleich dieser nicht ganz durchhaltbar erscheint.

Dort werden Stars als noch lebende und eher jüngere Personen markiert. STEFAN DIEZ (*1970) ist der jüngste »[a]ktuelle Stardesigner «, knapp gefolgt von JONATHAN IVE (*1966; eine echte Besonderheit - zumal für eine Wohn-Zeitschrift - einen Gestalter aufzunehmen, der keinerlei Wohnmöbel oder Accessoires gestaltet). NAOTO FUKASAWA hat sich erst recht spät »[v]om Geheimtipp zum trendweisenden Designer entwickelt ( ${ }^{1955}$; im Portrait auch als »Der Anonyme« bezeichnet; wohl wegen seiner Arbeit für MUJI). Auch PATRICIA URQUIOLA, die 201858 Jahre alt wurde, wird nach dem unerbittlichen Rotationsprinzip demnächst wohl eher zur Klassikerin aufrücken müssen, als deklassiert zu werden. Wenngleich sie das nicht selbst in der Hand haben wird. 


\section{Designklassiker und Designikonen}

In GEORG FRANCKs Ökonomie der Aufmerksamkeit ist auch dies zu finden:

"Was Thorstein Veblen zu Beginn des Jahrhunderts noch als den sStil der feinen Leuter beschrieben hat, ist längst zum Volkssport geworden: der ostentative Konsum. Waren es einst die Häuser, die man dem Namen nach kannte, die um rconspicuous consumption konkurrierten, so ist es inzwischen schwerer, überhaupt noch ohne Schaueffekt zu konsumieren. Wenn es nun aber ganz normal geworden ist, um des Imponierens willen zu konsumieren, dann stellt der Konsum auch noch einmal neue Anforderungen an die Werbung. Der Konsum im Dienst der Attraktivität verlangt nach bewährten und schon vorab mit Renommee geladenen Attraktoren. Markenpflege und Produktdesign haben dann nicht mehr nur die simple Aufgabe, die Kundschaft zu überrumpeln, sondern auch die subtile, die Ware für den Blickfang spezialtauglich zu machen. Die Dinge selber müssen dann mit dem Versprechen versehen werden: Ich bin etwas ganz besonderes und wirke unwiderstehlich. Dafür wiederum genügt es nicht schön und auffällig zu sein. Es muss auch auffallen, daß (Hervorhebung im Original) sie auffallen. Oder anders: Der Eindruck muß eigens noch inszeniert werden, daß die Sache auf alle Eindruck machen wird." (FRANCK 1998: 71f)

Dass und wie dieser Eindruck inszeniert und vor allem auf welche Weise ein Designklassiker produziert wird, hat BREUER in Die Erfindung des modernen Klassikers schon präzise herausgearbeitet. Kein anderer Begriff, der im Grunde alles zusammenfasst, was FRANCK mit Bezug auf VEBLEN formuliert, macht den Komplex so wiedererkennbar wie der Designklassiker, der seit den 8oern des 20. Jhd.s eine beispiellose Verwertungskarriere vorzuweisen hat. Er kann es locker mit dem Star-Designer aufnehmen in seinem Potential, als Ausdruck angesammelter Beachtlichkeit zu gelten. GEORG FRANCK ist schon damals der Ansicht, dass »Prestige, Reputation, Prominenz und Berühmtheit« deutlich mehr umfassen können als »Formen persönlichen Eigentums [...] natürliche[r] Personen«:

"Die Formen rentierlichen Reichtums an Beachtung sind aber nicht auf natürliche Personen beschränkt. Auch Institutionen und sogar Veranstaltungen können Prestige genießen, Reputation gewinnen und eventuell Ruhm erlangen.«(ebd.: 134)

BERNARDY erweitert den gedanklichen Raum noch um »[...] Marken, Objekte, Lebensstile [...]« und stellt damit postum die Anschlussfähigkeit zum empiri- 


\section{STARDESIGNER ODER GESTALTER DES ALLTÄGLICHEN?}

schen Teil dieser Untersuchung her (vgl. BERNARDY 2014: 91). Artefakte werden hier der DUDENschen Definition folgend im archäologischen Sinne als "Gegenstand, der seine Form durch menschliche Einwirkung erhielt" resp. im bildungssprachlichen Sinne als "etwas von Menschenhand Geschaffenes" betrachtet. (DUDEN) [online] http://www.duden.de/rechtschreibung/Artefakt [26.02.2018].

Da das Magazin A\&W 2012 eine Ansammlung von 94 Entwürfen mit dem Begriff Design-Ikonen benannte, folgte nach dem ersten Suchlauf zum Designklassiker ein weiterer Suchlauf nach der Design-Ikone sowie den Design-Ikonen in sämtlichen Publikationen. Diese Funde wurden ebenso um ihren kompletten Beifang ergänzt. Der Auflistung voran schon jetzt eine Bemerkung: Nicht eine der von A\&W so bezeichneten Ikonen führt im Text einen Hinweis darauf, weshalb sie eben das seien. Der Begriff der Ikone findet sich auch nicht mehr in den nachstehend zitierten Texten, er steht lediglich als Postulat in Form der Überschrift am Beginn des Netzbeitrags. 


\section{Re-Popularisierung und ihre Konsequenzen für die Untersuchung}

Eine Re-Popularisierungswelle, die seit 2011 Spuren in verschiedenen bereits untersuchten Publikationen hinterlassen hat, führte 2014 noch eine entscheidende Veränderung im Korpus herbei. Nach der ursprünglichen Laufzeit der Studie trat SW, eine Publikation von GRUNER + JAHR, im Heft 6/2014 mit dem Poster "99 Designikonen aus 11 Jahrzehnten « an.

Im Kontext betrachtet kam annähernd unmittelbar davor A\&W aus dem JAHRESZEITEN-Verlag in der Ausgabe 01/ 2012 mit einer Phalanx von 94 "DesignIkonen « auf den Markt (so auch der Stand im Internet am o8.09.2016). (ARCHITEKTUR UND WOHNEN) [online] http://www.awmagazin.de/design-style/ designerportraets/galerie/design-ikonen\#page1 [26.02.2018].

Aus dieser Koinzidenz (?) wurden Konsequenzen gezogen. Die bereits ermittelten Artefaktbestände (von A\&W und sw) wurden um sämtliche InternetSuchergebnisse zu Design-Ikonen aus dem Webauftritt von A\&W erweitert. Zudem wurde das Designikonen-Poster von sw in den Bestand integriert und das Buch Moderne Klassiker. Möbel die Geschichte machen in der 10. Auflage von 1989 ebenfalls mit aufgenommen. Die 19. Auflage von 1998 dient als Kontrollmedium.

Diese nachträgliche, enorme Vergrößerung der Untersuchungsbasis hat die Suche nach übergreifenden und internen Mehrfachnennungen zum Ziel, in diesem Fall speziell auf A\&W und sw bezogen, um auch eine Rangliste der Artefakte erstellen zu können, die mit den gefundenen Designern abgeglichen werden kann. Eine Engführung auf der Basis dieser beiden Publikationen ist deshalb konsequent, weil nur jene in ungeheurem Umfang zur Konstitution des Klassiker-Korpus beitrugen und bis heute beitragen.

Das Buch Moderne Klassiker. Möbel die Geschichte machen, das als Folgeprodukt einer Artikelserie von Sw entstanden ist, (vgl. CACCIOLA 2008: 37f), kam erstmals 1982 auf dem Markt und ist bis 1998 in 19 Auflagen erschienen. Es kann als Inkunabel und Anstoß für weitere zeitgenössische Befestigungsliteratur gelten - was hier nicht im Sinne von tatsächlicher Fortifikationsliteratur verstanden wird, sondern als eine Art Publikation, die einen Klassikerkorpus einer gewissen Variationsbreite wieder und wieder in die Hirne des geneigten Publikums zu hämmern sucht. 


\section{Gefundene Bezeichnungen für Artefakte}

Designklassiker ist als einziger Begriff in allen untersuchten Publikationen zu finden, der Klassiker in DIE ZEIT und sW, die Ikonen des Industriedesigns im DESIGN REPORT, der F.A.Z. und der NZZ. Design-Ikonen/Designikone in A\&W, der F.A.Z. und in Sw, die Kultobjekte ausschließlich in DER SPIEGEL und last but not least die Klassiker des Industriedesigns in der F.A.Z.. Nach jedem Fund eines neuen Begriffes wurden alle untersuchten Publikationen ebenfalls auf dessen Vorkommen hin überprüft. Nachfolgend werden alle Wortfunde im Detail aufgelistet. Wurden Designer aus der bereits ermittelten Rangliste im Zusammenhang mit den gesuchten Begriffen gefunden, werden sie in Klammern aufgeführt. Soweit selbige benannt werden, sind auch die betreffenden Artefakte mit aufgelistet, für die der Begriff verwendet wird (alle Hervorhebungen durch den Verfasser, sofern nicht anders gekennzeichnet).

\section{Architektur \& Wohnen}

Designklassiker, Design-Legende, Designer-Ikone (DIETER RAMS: Regalsystem 606)

"Designklassiker: Regalsystem 606. Das Regalsystem 606, das Dieter Rams für Vitsoe entwarf, ist eine Design-Legende. Der neue deutsche Showroom zeigt, wie vielfältig man sie nutzen kann: in einem bewohnten Appartement. An einem Freitag im August schaute der Meister selbst in München vorbei. Dieter Rams, 79, die deutsche Designer-Ikone, der einstige Chefgestalter von Braun, besichtigte mit seiner Frau das Appartement im dritten Stock des Hauses Nummer 41 in der Sendlinger Straße. Seit Kurzem wohnen dort Monika Hary und Michael Haberbosch. Und arbeiten. Was bei dem Ehepaar aber sowieso nicht zu trennen ist, wie jeder sofort erkennt, der die Wohnung betritt. Überall hängen und stehen Varianten des 'Regalsystems 606،, bei dem verschiedene Böden, Kästen und Schubladenelemente variabel in Schienen aus Aluminium gesteckt werden. Entworfen 1960, gilt es als idealtypisch für Rams' Vision, mit möglichst wenig Design möglichst viel Freiheit in der Gestaltung zu ermöglichen«. (ARCHITEKTUR UND WOHNEN) [online] http://www.awmagazin.de/ design-style/designerportraets/artikel/designklassiker-regalsystem-6o6 [26.02.2018) 


\section{AM ENDE WAR ES NUR EIN WORT: ZWEI REZEPTIONSSTUDIEN}

\section{Design-Ikonen, Klassiker}

Design-Ikonen wird von A\&W als Überschrift einer Ansammlung von 94 Artefakten verwendet. (DIETER RAMS: PHONOSUPER SK4; PHILIPPE STARCK: Stuhl COSTES; JASPER MORRISON: THINKING MAN'S CHAIR; KONSTANTIN GRCIC: Leuchte MAYDAY, Stuhl ONE; Gebrüder BOUROULLEC: Sofa ALCOVE).

"Wie ein >Ufo unter Dampflokomotiven wirke die Radio-Phonokombination >SK 4، gegenüber den Radio-Modellen der Nierentisch-Epoche, schrieb einst der sSpiegek." (ARCHITEKTUR \& WOHNEN) [online] http://www.awmagazin.de/design-style/designerportraets/galerie/design-ikonen/page/ 28\#page34 [26.02.2018]

"Das Café Costes selbst wurde 1994 geschlossen, aber der eigens für das Café entworfene ,Costes Chair ist seit 1985 beim italienischen Hersteller Driade in Produktion. Der Dreibeiner (konzipiert, um den Kellnern das Umrunden der Stühle zu erleichtern) ist zum Klassiker geworden. Er verbindet die Eleganz der 8oer mit Anlehnungen an das Art déco." (ARCHITEKTUR \& WOHNEN) [online] http://www.awmagazin.de/design-style/ designerportraets/galerie/design-ikonen/page/28\#page81 [27.02.2018]

"Jasper Morrison ( $\left.{ }^{*} 1959\right)$ hatte Anfängerglück. Er wurde bei seiner Abschlussausstellung am Royal College of Art, London, von Zeef Aram entdeckt, dem zu der Zeit interessantesten Designgaleristen und -unternehmer Londons. Der lud den jungen Briten ein, einen Stuhl zu entwerfen für eine Ausstellung in seinem Londoner Geschäft. So kam es, dass der 'Thinking Man's Chair (1986) des damals 27-Jährigen in einer Ausstellung zwischen Exponaten von namhaften Designern wie Norman Foster und Edouardo Paolozzi zu sehen war." (ARCHITEKTUR \& WOHNEN) [online] http://www.awmagazin.de/design-style/designerportraets/galerie/ design-ikonen/page/28\#page87 [27.02.2018]

"Seine Leuchte 'Mayday für Flos entwarf der mittlerweile bekannteste deutsche Designer Konstantin Grcic $\left({ }^{*} 1965\right)$ bereits 1999. Zwei Jahre später wurde eben die mit dem begehrten 'Compasso d'Oror ausgezeichnet und gehört seitdem auch in die Sammlung des New Yorker MoMA.« (ARCHITEKTUR \& WOHNEN) [online] http://www.awmagazin.de/ design-style/designerportraets/galerie/design-ikonen/page/28\#page104 [27.02.2018]

"Das Projekt wurde zu einer strapaziösen, aber bereichernden Forschungsreise. Anders als viele andere Möbel der Gegenwart hinterlässt »Chair One" einen bleibenden Eindruck. Wer ihn einmal gesehen hat, kann ihn nicht wieder vergessen." (ARCHITEKTUR \& WOHNEN) [online] http://www.aw magazin.de/design-style/designerportraets/galerie/design-ikonen/page/ 28\#page109 [27.02.2018] 


\section{STARDESIGNER ODER GESTALTER DES ALLTÄGLICHEN?}

»Mit dem `Alcoves-Sofa für Vitra ist den Brüdern Ronan (*1971) und Erwan Bouroullec (*1976) ein großer Wurf gelungen. Mit ihm wollten die Franzosen ein Möbel schaffen, das sich dem Menschen anpasst und nicht umgekehrt." (ARCHITEKTUR \& WOHNEN) [online] http://www.aw magazin.de/design-style/designerportraets/galerie/design-ikonen/page/ 28\#page113 [27.02.2018]

\section{art Das Kunstmagazin}

\section{Designklassiker, Designikone, Möbelikone}

Hier wird der LOUNGE CHAIR von EAMES in der Rang der »Möbelikone des 20. $J h d s «($ s. u.) erhoben. Kein anderer Journalist hat sich in irgendeinem der anderen Artikel zu einer Zuspitzung dieser Art hinreißen lassen.

»Häufig stehen auch Designklassiker Pate: Grcic' massiver Eschestuhl ,Leopoldar ähnelt dem Armlehnstuhl >Barrelı von Frank Lloyd Wright." (KUNZ in: ART DAS KUNSTMAGAZIN 06/1998: 71-77) [online] http://www. art-magazin.de/div/div/heftarchiv/1998/6/EGOWTEGOTTHPAPOGWT ROAWAE/Junges-Design.-Ideen-vor-Ideologie [18.07.2013, nicht mehr im Netz verfügbar]

"Der >Designklassiker , von dem sich die >Memphis`-Designer noch ironisch distanziert hatten, spielte eine immer größere Rolle." (SCHLÜTER in: ART DAS KUNSTMAGAZIN 04/2005: 68-77) [online] https://www.artmagazin.de/div/heftarchiv/2005/4/OGOWTEGWPPSPRPOGEECPCGC RSWWGWTRWWCRE/Zukunft-ist-ein-Projekt-von-gestern [18.07.2013, nicht mehr im Netz verfügbar]

"Designklassiker >Embryo Chair, mit dem Marc Newson 1988 seinen internationalen Durchbruch hatte« (ART DAS KUNSTMAGAZIN online am 25.07.2007; Bild 10 von 14) [online] https://www.art-magazin.de/design/ 828/nature_design_ausstellung_in_zuerich? $\mathrm{cp}=10$ [18.07.2013, nicht mehr im Netz verfügbar]

"Mit dem Eintritt Marcel Breuers in die Möbelwerkstatt des Bauhauses begann eine außergewöhnliche Gestalterlaufbahn. Eine Retrospektive in Dessau unterstreicht, wie zeitgemäß Breuers Designklassiker immer noch sind. Weniger jedoch als Ausweis einer avantgardistisch-revolutionären Haltung, denn als bürgerliches Distinktionsmoment. [...] Unter dem Namen 'Wassily startete Breuers Stahlklubsessel in den Sechzigern als Neuauflage seine bis heute andauernde Karriere als internationale Design-Ikone und metallisch-geschwungenes Geschmackssymptom." (NEDO in: ART DAS KUNSTMAGAZIN am 05.06.2012) [online] https://www. art-magazin.de/design/51806/marcel_breuer_dessau [18.07.2013, nicht mehr im Netz verfügbar] 


\title{
AM ENDE WAR ES NUR EIN WORT: ZWEI REZEPTIONSSTUDIEN
}

\begin{abstract}
"Vielleicht steckte hinter dem in der Zeitung angepriesenen Ledersessel ja wirklich die Möbelikone des 20. Jahrhunderts - der "Lounge Chair " von Charles und Ray Eames, entworfen 1956. [...] Und da standen sie nun in voller Schönheit: mehrere Exemplare des >Lounge Chair in schwarzem Leder und Palisanderholz, zusätzlich veredelt durch die Patina der Antiquität. Der Verkäufer hatte die zurückgelassenen Designklassiker nach dem Tod eines Mieters gefunden. Ein Glück für Pinkner. Die EamesMöbel waren seine erste Trophäe und entfachten seine Sammlerbegierde." (DOGRAMACI in: ART DAS KUNSTMAGAZIN 07/2002: 66-76) [online] https://www.art-magazin.de/div/heftarchiv/2002/7/EGOWTEGWPPW PCPOGWTRWPEPP/Klassiker-zum-Besitzen [18.07.2013, nicht mehr im Netz verfügbar]
\end{abstract}

\section{Der Spiegel}

\author{
Designklassiker, Kultobjekte \\ (KONSTANTIN GRCIC: Stuhl MYTO; PHILIPPE STARCK: Zitronenpresse JUICY SALIF)
}

"Auf der wichtigsten Möbelmesse sSalone Internazionale del Mobiler in Mailand hat Grcic im April einen neuen Freischwinger vorgestellt, das sind Stühle ohne Hinterbeine, deren Sitzfläche den Besucher sanft auf und nieder wippen lässt. >Myto heißt der nackte Kunststoffsessel, ein >Designklassiker ( $(F A Z$ ), der seinen Schöpfer wieder einmal szum eigentlichen Star der Messer (`Neue Zürcher Zeitung`) gemacht hat. (MUSALL in: SPIEGEL SPECIAL 4/2008: 106) [online] http://www.spiegel.de/ spiegel/spiegelspecial/d-57570824.html [05.03.2018]

\section{Unter der Überschrift »Kultobjekte und Kommerz >Hübschmachen hat nichts mit Design zu tun « wird im Interview mit ANSGAR EIDENS und in einer Fotostrecke (Nummer 4/15) der JUICY SALIF von PHILIPPE STARCK gezeigt und beschrie- ben:}

$m m$ : "Wo sind die Grenzen einer solchen Entwicklung?" eidens: [Hervorhebungen im Original, der Verfasser] „Überall da, wo man zur Übertreibung neigt und Design zum Selbstzweck wird. Die Zitronenpresse, die Philippe Starck in 8oer Jahren [sic] gezeigt hat, wurde zum edlen Designgegenstand hochgejubelt, ist aber in der Küche völlig unbrauchbar [Hervorhebung des Verfassers]. Das Objekt wurde zwar berühmt, hat aber auch ein wenig Schuld am Image der Designbranche als entbehrlich und nett, als snice to haver." mm: »Die Zitronenpresse steht in etlichen Museen. Das ist doch auch nicht schlecht. « eidens: [Hervorhebungen im Original, der Verfasser] „Starcks Zitronenpresse ist ein interessantes Experiment der formalen Übertreibung und ein gelungener PR-Coup. Aber mit Design hat sie nichts zu tun. Ich bin Starck aber nicht böse, ist er doch ein ge- 


\section{STARDESIGNER ODER GESTALTER DES ALLTÄGLICHEN?}

nialer Gestalter mit vielen guten Ideen. Er hält mit seinem provokanten Auftreten die Diskussion in Gang.»

Untertitel zum Bild: »Übertrieben: Die Zitronenpresse von Philippe Starcke [sic] zeigt, wie weit man eine funktionale Form dehnen kann. Als Küchengerät mag man das Objekt gar nicht mehr verwenden. Dafür sieht es zu mondän aus - und ist einfach unpraktisch.« (KAUFMANN in: MANAGER MAGAZIN am 31.01.2011) [online] http://www. manager-magazin.de/unternehmen/artikel/a-742014.html sowie http:// www.manager-magazin.de/unternehmen/artikel/a-742014-4.html und http://www.manager-magazin.de/fotostrecke/fotostrecke-64020-4.html [21.12.2018]

\section{designreport}

Designklassiker, Ikonen des Industriedesigns, Inkunabeln des Industriedesigns

"Die monografische Abhandlung einzelner Klassiker/Ikonen/Inkunabeln des Industriedesigns scheint in diesem Kontext die vielfach gepflegte designhistorische Hintertür zu sein, um sich am empirischen Handwerk der Rekonstruktion des betrieblichen Entstehungsprozesses vorbeimogeln zu können. Denn so lässt sich viel einfacher eine Designgeschichte schreiben, die aus einzelnen Produkten zu bestehen scheint, wie Gerda Breuer es anhand des Phänomens >Designklassiker überzeugend dargelegt hat." (BURSCHEL in: DESIGN REPORT 09/2005) [online] https:// www.designreport.de/DRMainFachartikelarchivDruckDetail.asp?artikelid=1000000812\&action=print\&object=DR\&db=FAArchiv [18.07.2013, nicht mehr im Netz verfügbar]

"Gijs Bakker wurde 1942 in Amersfoort geboren. Zusammen mit seiner Frau Emmy van Leersum (1930 bis 1984) beeinflusste er das niederländische und internationale Schmuckdesign vor allem in den 6oer Jahren nachhaltig. Er arbeitete in den Bereichen Architektur, Ausstellung, Schmuck und Möbel beispielsweise für Unternehmen wie Artifort, Castelijn, Cor Unum, DMD oder Polaroid. Seine frühen Möbelentwürfe, wie der sStrip Chair von 1974, gelten als niederländische Designklassiker.« (FRENZL in: DESIGN REPORT 06/2002) [online] https://www.designreport.de/DRMain FachartikelarchivDruckDetail.asp?artikelid=1000001658\&action=print\& object=DR\&db=FAArchiv [18.07.2013, nicht mehr im Netz verfügbar]

«Welcher Designer kann einen Fünf-Milliarden-Mal-Entwurf vorweisen? Doch obwohl die Perlflasche von Günter Kupetz einer der wohl meistproduzierten Designklassiker ist und sogar zum Briefmarkenmotiv wurde, ist ihr Urheber nur wenigen bekannt." (HETTLAGE in: DESIGN REPORT 05/2006) [online] https://www.designreport.de/Fachartikelarchiv/ 1000000116/Kein-Kuenstler.html [18.07.2013, nicht mehr im Netz verfügbar] 


\section{AM ENDE WAR ES NUR EIN WORT: ZWEI REZEPTIONSSTUDIEN}

"Allzu sehr scheint man sich auf die Bekanntheit Wagenfelds, auf den ästhetischen Reiz und die selbst erklärende Kraft seiner Arbeiten zu verlassen. Ob sich dem Publikum so erschließt, weshalb etwa die Eierbecher aus Cromargan oder die aus dem gleichen Material gefertigten, millionenfach verkauften Butterdosen zu Recht als Ikonen des Industriedesigns gelten? Es ist ja gerade die Selbstverständlichkeit ihrer Erscheinung, die einen leicht vergessen lässt, welch perfekte und bis heute vorbildliche Synthese von Funktionalität, Materialgerechtigkeit und formaler Langlebigkeit, von Ressourcen schonender und zugleich rationaler Produktion Wagenfeld mit diesen Stücken gelang." (REMMELE in: DESIGN REPORT 04/2005) [online] http://jubel25.design-report.de/DRMainFachar tikelarchivDruckDetail.asp?artikelid=1000000105\&action=print\&object $=\mathrm{DR} \& \mathrm{db}=$ FAArchiv [18.07.2013, nicht mehr im Netz verfügbar]

\section{Die Presse}

\section{Designklassiker, Klassiker}

"Damals wie heute heißt das Konzept: Hundert Designer, zehn Kuratoren, zehn Designklassiker. Unter den Juroren finden sich bekannte Designer wie der Brite Tom Dixon, Kreativdirektor von Habitat, Journalisten, etwa von der italienischen Designbibel >Domus oder von >I.D.<, Kuratoren, Galeristen, Kritiker und ein Designschuldirektor. Aus 24 Ländern haben sie 100 junge, aufstrebende Kreative ausgewählt, von denen man in letzter Zeit schon einiges gehört und gesehen hat - oder aber in nächster Zeit hören und sehen wird." (ZNIDARIC in: DIE PRESSE am 12.04.2007) [online] https://diepresse.com/home/leben/mode/297187/ Ins-Netz-gegangen-?from=suche.intern.portal [18.07.2013, nicht mehr im Netz verfügbar]

»Plötzlich gab es einen Sessel, der dem Zeitgefühl der 68er-Generation entsprach: der Sitzsack, ein auf jede Bewegung reagierendes Etwas zum Herumlümmeln in Bodennähe. Drei italienische Gestalter hatten lange experimentiert, Sand, Wasser, sogar Tischtennisbälle als Füllung erwogen, bis sie die formlose Lederhülle mit kleinen Polystyrol-Kugeln füllten. Seither ist der 'Saccor ein Designklassiker, aus den Jugendzimmern nicht mehr wegzudenken, nach wie vor originalgetreu produziert und tausendfach kopiert.« (VOGEL in: DIE PRESSE am 09.06.2008) [online] https:// diepresse.com/home/kultur/news/389610/Design_Das-Sitzgefuehlder-68er?from=suche.intern.portal [21.12.2018]

"Was macht einen Designklassiker aus? Er ist unverwechselbar und unabhängig von Moden. Und manchmal ändert er sogar die Gewohnheiten seiner Benutzer. Am Anfang steht eine außergewöhnliche Idee. Im besten Fall wird ein Verkaufshit daraus, im schlechteren eine Vorlage für abertausende Billigkopien. Und irgendwann steht das Ding dann im Muse- 


\section{STARDESIGNER ODER GESTALTER DES ALLTÄGLICHEN?}

um. Warum? Das versuchen wir anhand einiger ausgewählter Objekte, die ihre ganz eigenen Kapitel in der Designgeschichte haben, zu eruieren. [...] Spaß-Design. Memphis sollte in den Achtzigern eine ganze Liga von Designern beeinflussen. So auch den Franzosen Philippe Starck. Der 1949 in Paris geborene Sohn eines Flugzeugdesigners war und ist so was wie der Popstar unter den Designern. Denn seine Kreationen funktionieren wie Hitsongs: gute Hookline, leicht verständliche Melodieführung, quasi ein optischer Ohrwurm. [...] Und genau dafür steht ein gutes Möbel. Es verändert nicht nur die Wohnlandschaft, sondern auch die Sicht der Benutzer. Je intensiver es dies tut, um so mehr hat es das Zeug zum Klassiker. Zum Designklassiker." (OBERLECHNER in: DIE PRESSE am 11.10.2005) [online] https://diepresse.com/home/leben/wohnen/138825/Klassische-Mitbewohner_Zeitlose-Moebelstuecke?from=suche.intern.portal [18.07.2013, nicht mehr im Netz verfügbar]

\section{Die Welt}

\section{Designklassiker}

(JASPER MORRISON: Polstermöbel für CAPPELLINI; PHILIPPE STARCK: ZitronenpresSe JUICY SALIF \& Wasserkessel HOT BERTAA)

"Zwar fühlt Cappellini sich durch die Präsentation in Europas größtem Museum geehrt, doch sieht er seine Möbel lieber auf dem Marmorboden des neuen Geschäfts als in den spektakulären Vitrinen der Pinakothek: `Man muss sie doch benutzen können<, sagt er und nimmt auf der roten, geschwungenen Sitzfläche von >Three Sofa de Luxe، Platz - einem erst zehn Jahre jungen und bereits zum Designklassiker avancierten Polstermöbel von Jasper Morrison." (BURKHARDT in: WELT AM SONNTAG am 01.12.2002) [online] https://www.welt.de/print-wams/article104246/Dirigent-des-Designs.html [21.12.2018]

\section{"Designklassiker}

Die ,Traumfabrik Alessi hat zahlreiche Klassiker hervorgebracht: die berühmte Zitronenpresse `Juicy Salifı von Philippe Starck, den Wasserkessel >Hot Bertaar von Michael Graves [sic] oder den Kaffeekocher s9ogor von Richard Sapper. Seit Kurzem gibt es Alessi-Produkte auch in einem vom Architekten und Designer Hani Rashid entworfenen Shop in Hamburg zu kaufen." (WELT AM SONNTAG am 22.10.2008) [online] https:// www.welt.de/wams_print/article2627973/In-vielen-Kuechen-zu-HauseDesign-von-Alessi.html [05.03.2018, nicht mehr im Netz verfügbar] 


\section{Die Zeit}

Designklassiker

Deutsche Designklassiker wird als Attribut für die Entwürfe der HFG ULM verwendet, u. a. auch für den PHONOSUPER SK4. Außerdem wird in einem Interview mit MATTEO THUN derselbe als Stardesigner bezeichnet - dies spielt im Kontext jedoch nur insoweit eine Rolle, als jener selbst eine Aussage zum Thema Designklassiker macht.

»Ein Stück der modernen städtischen Identität repräsentiert die kleine Ausstellung zur Hochschule für Gestaltung, die unter Max Bill und Otl Aicher in den fünfziger Jahren Designklassiker wie den Braun-Plattenspieler hervorbrachte. Hier entstand auch jene Sitzgelegenheit, die noch heute den Namen der Stadt in alle Welt trägt: der Ulmer Hocker." (GÖRICKE in: DIE ZEIT NR. 41/2011) [online] http://www.zeit.de/2011/42/ Museumsfuehrer-Ulm [21.12.2018)

"In Italien ist das Industriedesign immer ein Bestandteil des Architekturstudiums gewesen. Deutschland hat einen anderen Weg beschritten, weil man dort im Sinne des angelsächsischen Systems den kleinen Maßstab von der Logik des großen Maßstabs abkoppelt. Der Bau eines Hauses folgt dort einer anderen Logik als der Bau eines Stuhles. Im Bauhaus gab es andere Ansätze, aber die wurden missverstanden. Zum Beispiel an der Ulmer Hochschule für Gestaltung - dort wurden Form und Funktion dahingehend pervertiert, dass die Funktion einem Objekt seine Seele raubt, die Anima verloren geht. Es entstanden deutsche Designklassiker, die zwar alle Qualitäten der Funktionalität berücksichtigten, aber wenig Herz hatten." (RENGER in: DIE ZEIT NR. 44/2005) [online] http://www. zeit.de/2005/44/Thun_LT [05.03.2018, Fehlermeldung »XML-Verarbeitungsfehler: nicht wohlgeformt«, nicht darstellbar]

\section{Frankfurter Allgemeine Zeitung}

Die ehemals frei zugänglichen Artikel der F.A.z. sind mittlerweile mit einer Bezahlschranke versehen und deshalb zumeist nicht mehr ohne einen $\mathrm{Zu}$ gang aufrufbar.

Designklassiker, Design-Ikonen, Ikonen des Industriedesigns, Klassiker des Industriedesigns

"Ihr >Lounge Chair ist ein zeitloser Designklassiker. Ihre stapelbaren Kunststoffstühle stehen noch heute in Kantinen und Studentenwohnhäusern. Ihre Architekturentwürfe zählen zu den Vorreitern der Postmo- 


\section{STARDESIGNER ODER GESTALTER DES ALLTÄGLICHEN?}

derne. Jetzt zeigt Wien das Werk des Designerpaares Charles (1907-1978) und Ray Eames (1912-1988). Charles und Ray Eames hatten zeitlebens Erfolg: Über 40 Möbelsysteme gingen in Massenproduktion." (VOGEL in: faz.net am 06.07.2001) [online] http://fazarchiv.faz.net/document/showSingleDoc/FAZN_\%7BC665EB80-04E6-46C3-931A-2132AoDA2309\%7 $\mathrm{D} ? \mathrm{KO}=\& \mathrm{DT}$ _from $=\&$ timeFilter $=\&$ timePeriod $=$ timeFilter\&dosearch $=\mathrm{y} \&$ sext $=0 \& c r x d e f s=\& N N=\& B C=\&$ search $\_$in $=q \& q=$ Designklassiker\&sorting $=\& D T \_$to $=\& C O=\&$ maxHits $=30 \&$ offset $=30 \& C N=\&$ toggleFilter $=\& a n n-$ $r=5496$ \&highlight $=\% 5$ CeJxzs9LiorNKSS 3 OTM\%2FLzkksLs7MTi1SUOBys4rHKg4AdzMPiA\%3D\%3D\%5C\#start [18.07.2013]

"Seibel hat schon jetzt etwas, auf das man stolz ist. >Wir entwickeln unter dem Namen >Mono Design-Ikonen der Besteckbranche, die lange gültig und auch nach 20, 30 oder 50 Jahren noch Bestseller sind, ist er überzeugt." (FRANKFURTER ALLGEMEINE ZEITUNG 10.02.2007, NR. 35, s. 17) [online] http://fazarchiv.faz.net/document/shoSingleDoc/FAZ_FD1200702109 68843 ?KO=\&DT_from=\&timeFilter=\&timePeriod=timeFilter\&dosearch $=y \&$ sext $=0 \& c r x d e f s=\& N N=\& B C=\&$ search_in $=q \& q=$ Frankfurter $+F r \% C_{3}$ $\%$ BChjahrsmesse + Design\&sorting $=\& D$ T_to $=\& C O=\&$ maxHits $=30 \& C N$ $=\&$ toggleFilter $=\& a n n r=1216639$ \&highlight $={ }_{5}$ CeJxzsgLiorNKKypNzchKzCgqzkotLk5VUACLJeZlp5UWlaQWgfkpqcWZ6XlApptVPKlaAKQoILA\%3D\%5C\#start [18.07.2013]

"Bekannt wurde Zanuso vor allem durch mittlerweile zu Ikonen des In dustriedesigns avancierte Objekte, die er - vor allem in den sechziger Jahren in Zusammenarbeit mit seinem Kollegen Richard Sapper - kreierte: so zum Beispiel das aufklappbare Telefon ,Grillo<, das für Siemens entstand, das Kofferradio >TS 502 oder die unvergeßlichen Fernsehapparate >Doney`, 'Algok und >Black ‘ für Brionvega. (VILLINGER in: FRANKFUR TER ALLGEMEINE ZEITUNG NR. 161/2001: 44) [online] http://fazarchiv. faz.net/document/showSingleDoc/FAZ_FD1N20010714985829? KO=\& DT_from $=\&$ timeFilter $=\&$ timePeriod $=$ timeFilter\&dosearch $=$ new\&sext $=0$ \&crxdefs $=\& N N=\& B C=\&$ search $\_$in $=q \& q=P o p+m u \% C_{3 \% 9 F t e+s e i n}+$ Der + italienische+Designer + Marco + Zanuso+ist + gestorben $+\&$ sorting $=\& D T_{-}$ to $=\& C O=\&$ submitSearch $=$ Suchen $\&$ maxHits $=\& C N=\& \&$ toggleFilter $=\&$ annr $=755444$ \&highlight $=\% 5$ CeJxzs9LiorOqSswrLc5XUAAyi1Mz88CMgvwCMJ1bWlxckgphJhYlQ1RlliTmZKbmZRYnZoCkMotLwHR6anFJflFSKsSMlNTizPS81CIoBoS7WcXT10IA3JVBVg\%3D\%3D\%5C\#start [18.07.2013]

"Wer quellfrisches Naß in den Handel brachte, mußte seine eigenen, unverwechselbaren Behältnisse herstellen. Das änderte sich 1950 mit der Gründung des Verbands deutscher Mineralbrunnen: Erst wurde der >Urheberschutz، aufgehoben, dann kreierte man 1969 jene Glasform, die längst zu einem Klassiker des Industriedesigns avancierte. Die taillierte o,7-LiterFlasche mit Schraubverschluß - die unhygienischeren Bügelverschlüsse hatten ausgedient - trug nicht unwesentlich dazu bei, Mineralwasser zu 


\section{AM ENDE WAR ES NUR EIN WORT: ZWEI REZEPTIONSSTUDIEN}

einem Markenprodukt zu machen." (KLEIN in: FRANKFURTER ALLGEMEINE ZEITUNG 28.01.1996, NR. 4, S. 12) [online] http://fazarchiv.faz.net/ document/showSingleDoc/FAS_F19960128WANDER-10o?KO=\&DT_ from $=$ \& timeFilter $=\&$ timePeriod $=$ timeFilter\&dosearch $=$ new $\&$ sext $=0 \& c r-$ xdefs $=\& N N=\& B C=\&$ search_in $=q \& q=$ Ein + Wasser + gegen + die + Engbr\% $C_{3}$ $\%$ BCstigkeit $+\&$ sorting $=\& D T$ To $=\& C O=\&$ submitSearch $=$ Suchen $\&$ max Hits $=\& C N=\& \&$ toggleFilter $=\& a n n r=10638$ \&highlight $=\% 5$ CeJxzsgLior MqTywuTi1SUAAyo1PTU\%2FPArNS89KSiotTikszo7NTMEohYJkQuJTMVSLtZxZOvGQCMeCM8\%5C\#start [18.07.2013]

\section{form}

\section{Designklassiker \\ (KONSTANTIN GRCIC: ohne Nennung eines Entwurfs.)}

"Zu den alten und neuen Designklassikern gehören unter anderem der Kugelsessel Sunball von Günter Fedinand Ris, der Well Tempered Chair von Ron Arad, sowie Modelle von Eero Aarnio, Verner Panton, Tord Boontje, Fernando und Humberto Campana, Konstantin Grcic." (FORM) [online] https://www.form.de/w3.php?nodeId=108\&showComplete=1\&newsId \%5B2204\%5D=1064\#2204 [18.07.2013, nicht mehr im Netz verfügbar]

\section{Neue Zürcher Zeitung}

Designklassiker der Zukunft, Ikonen des Industriedesigns (KONSTANTIN GRCIC: Stuhl MYTO)

"Der eigentliche Star der Messe ist Konstantin Grcic. Der Münchner zeigt - rund vierzig Jahre nach Verner Pantons Meisterwerk - seinen lang erwarteten Freischwinger aus Kunststoff, 'Mytor. Der stabile Rahmen des als Monoblock angelegten Stuhls geht in eine netzartig durchbrochene Rückenlehne und Sitzfläche über. Im sicheren Bewusstsein, dass es sich um einen Designklassiker der Zukunft handelt, wird der Stuhl nicht nur auf der Messe, sondern auch in der Sala d'Onore der Triennale präsentiert." (ESCHBACH in: NZZ am 19.04.2008) [online] https://www.nzz.ch/ stars_und_selbstdarsteller-1.713889 [21.12.2018]

"Ein Pionier funktionalen Glasgeschirrs war der Bauhaus-Schüler Wilhelm Wagenfeld. Seine in der Ausstellung präsentierten Milchkrüge, Tee kannen und Eierkocher aus Borosilikatglas gehören zu den Ikonen des Industriedesigns." (MEIER in: NZZ am 08.12.2011) [online] https://www. nzz.ch/die_faszination_amorpher_transparenz-1.13557157 [05.03.2018] 
STARDESIGNER ODER GESTALTER DES ALLTÄGLICHEN?

\section{Süddeutsche}

374 Designklassiker

(PHILIPPE STARCK: Stuhl LOUIS GHOST; Kindervariante LOU LOU GHOST)

"Sie alle warten mit hochwertigen Kindermöbeln auf, gern auch in Form von Mini-Designklassikern wie Mies van der Rohes >Barcelona Chair (4640 Euro), Arne Jacobsens `Modell 3177 (420 Euro) oder Philippe Starcks transparenten [sic] > Louis Ghostı, der in der Kindervariante >Lou Lou Ghost، (76 Euro) heißt." (KUPITZ in: sÜDDEUTSCHE am 04.09.2011) [online] http:// www.sueddeutsche.de/leben/designer-inneneinrichtung-fuer-den-nach wuchs-mein-haus-mein-auto-mein-kinderzimmer-1.1138204-2 [05.03.2018] 


\section{Eine erste Bilanz}

Fünf Designer der bereits ermittelten Star-Designer-Rangliste werden auch als Urheber von Artefakten gefunden, die die Bezeichnung Designklassiker tragen. Es tauchen auf:

- $\quad$ Dieter RAMS (PHONOSUPER SK4, Regalsystem 606)

- PHILIPPE STARCK (Zitronenpresse JUICy SALIF, Wasserkessel HOT BERTAA, Stühle COSTES und LOUIS (LOU LOU) GHOST)

- KOnStAntin GRCic (Stühle MYTO und One, Leuchte MAYdAY)

- die Gebrüder bouroullec (Sofa Alcove) und

- JASPER MORRISON (Polstermöbel für CAPPELLINI und Stuhl THINKING MAN'S CHAIR)

Von DIETER RAMS abgesehen handelt es sich ausnahmslos um Designer, die erst seit den 8oern des 20. Jhd.s im Markt vertreten sind, was sich mit dem Aufkommen der Designklassiker im 20. Jhd. deckt. In RAMs' Fall sind es Produkte, die der geläufigen Auffassung eines Klassikers am ehesten entsprechen, da es sich zum Teil um Entwürfe handelt, die schon sehr lange am Markt sind, wie das Regalsystem 606, das seit 1960 von VITSCE produziert und verkauft wird. Damit stellt es einen jener eher seltenen Fälle eines Produktes dar, das sich tatsächlich über einen langen, ununterbrochenen Zeitraum am Markt halten kann, womit ein Teil seines Klassikerstatus legitimiert wird.

Im Falle des Plattenspielers PHONOSUPER SK4, der im Team von RAMS / GUGELOT gestaltet wurde, verhält sich die Sache anders: Das Produkt ist nicht mehr neu am Markt verfügbar und sein Klassikerstatus bezieht sich eher auf eine bestimmte Art der Gestaltung. Diese kann, nationalisierend wie auch im Rahmen des deutschen Funktionalismus, als klassisch deutsch bezeichnet werden und wird wohl deshalb als mustergültig angesehen.

Ebenso finden sich Übereinstimmungen unter den Gestaltern der als Design-Ikonen benannten Entwürfe bei A\&W und sw: Es sind immerhin vier und schon der erste Blick zeigt, dass die Bandbreite der Artefakte zusammenschrumpft zu einer fast schon vorhersagbaren Wiederholung des Gleichen:

- DiETER RAMS / hANS GUGELOT mit PHONOSUPER SK4,

- konstantin grcic mit dem Stuhl chair one und der Leuchte mayday,

- JASPER MorRison mit dem Stuhl thinking MAN's chair und

- PHilippe StARCK mit dem Stuhl costes. 


\section{Das Wiederkäuen der Wiedergänger}

Mit dem Septemberheft des Jahrgangs 2014 der Zeitschrift Sw wird der aktuellste Beleg für gezielte Re-Popularisierung geliefert, der in diese Untersuchung Eingang findet. Auf der Titelseite tönt die größte Überschrift: »Einrichten mit Klassikern - wie man mit Design-Ikonen wohnt«. Zudem findet sich dort in einem orangenen Kreis der Hinweis »Mit Design-Poster! 99 Möbelklassiker«. Zu diesem Poster wird auf S. 62 bemerkt:

"Dieser Ausgabe liegt das Poster s99 Designikonen aus 11 Jahrzehnten bei. Die Auswahl zu treffen fiel uns nicht leicht angesichts der Fülle an Klassikern und Reeditionen - doch hier sind sie: die 99 Favoriten der Redaktion zum An-die-Wand-Hängen.« [Hervorhebung des Verfassers]

An dieser Stelle wird zum allerersten Mal (!) überhaupt so etwas wie ein Maßstab erwähnt - was er taugt, steht auf einem anderen Blatt. Das »Special: Wohnen mit Klassikern« ab S. 45 liefert die dazugehörigen Artikel: »Nie war das Möbeldesign des 20. Jahrhunderts beliebter als heute. Wie man mit Klassikern einrichtet - und welche Versionen jetzt neu zu haben sind«. Zur Illustration sind dort versammelt:

1. Die EAMES-Garderobe HANG IT ALL; von HELLA JONGERIUS für VITRA mit neuen Farben versehen (1953/2012)

2. Bugholzstühle à la THONET (vermutlich zeitgenössisch)

3. ein EERO SAARINEN-Tisch Modell 173 mit Marmorplatte (1956)

4. eine POUL HENNINGSEN-Lampe Modell PH5 (1957)

5. ein BARCELONA-Stuhl von LUDWIG MIES VAN DER ROHE (1929)

6. das MAYOR-Sofa von ARNE JACOBSEN (1939) und

7. die GRÄSHOPPA-Stehleuchte von GRETA GROSSMAN für GUBI (1947).

Ab s. 46 zeigt im Artikel »Stück für Stück« »[d]er schwedische Art-Direktor Joel Berg [...] in seinem Stockholmer Apartment, wie gut sich Klassiker aus 15 Jahrzehnten miteinander vertragen«. Dieser Artikel beleuchtet nichts als die Gründe für Herrn Bergs Sammlertätigkeit und verweist auf die Anlässe für ihren Erwerb: »Fast alles sind Stücke, die eine Schlüsselrolle in der Designgeschichte spielen, sei es dank der Verwendung neuer Technologien, innovativer Materialien oder neuer Formensprache.« Ab S. 54 heißt es: »Schön, Euch wiederzusehen « und »[w]ir erklären, warum Klassiker das Einrichten erleich- 
tern und woher die wiederentdeckte Liebe für diese Möbel kommt." Der Griff in die Klischee-Kiste gestaltet sich dann z. B. so:

»Bei einem Designklassiker wissen die Leute: Er ist langlebig, zeitlos und funktional<, erklärt Demetrio Appoloni, Präsident von Knoll Europe. >Das passt in unsere Zeit der wirtschaftlichen Unsicherheit und des gesellschaftlichen Wandels. Wir haben die Erfahrung gemacht, dass Leute gerne Möbel kaufen, die eine Geschichte haben. Das vermittelt ihnen das Gefühl von Sicherheit und Kontinuität. In Zeiten der Zukunftsangst kauft man wohl lieber qualitätsbewusst und zeitlos, anstatt sich auf Experimente einzulassen. Ein Stück, das sich schon 50 oder 80 Jahre lang bewiesen hat, weckt Vertrauen.«

Handelt es sich hierbei noch um einigermaßen nachvollziehbare Gründe für den Erwerb von Bekanntem und Vertrautem, so sträuben sich die Nackenhaare bei Sentenzen wie dieser:

"Die handwerkliche Perfektion eines Wegner-Stuhls und der Werkstattcharme eines Prouvé-Möbels geben unserem Alltag ein Gefühl von Authentizität und vermitteln eine Direktheit, die in der digitalisierten Arbeitswelt zusehends verloren geht.«

Auf s. 62 erklärt in einem Kurzinterview ROLF FEHLBAUM (Sproß der Firmengründerfamilie und Verwaltungsratsmitglied von VITRA) wieder einmal, »Was Möbel zu Ikonen macht«. Es ist so enervierend wie müßig und zugleich spannend, sich mit FEHLBAUMs Antworten zu beschäftigen: Vor allem, weil er das erstaunliche Talent an den Tag legt, sich auf geringstem Zeilenraum mehrfach zu widersprechen. Natürlich muss die Bewährung und das sich auf lange Zeit durchsetzen als Merkmal des Klassikers im Munde geführt werden, aber auch die Relevanz von Reeditionen wird in Frage gestellt, weil diese nur auf den Markt kämen, da sie von »[...] bekannten Designer[n] oder Architekten stammen«:

»Der Rückgriff auf Dinge, die zu einer anderen Zeit entstanden sind, zeugt von der Schwierigkeit, eigene, unverwechselbare Objekte unserer Zeit zu kreieren.«

Dieser Ausspruch aus dem Mund des Mannes, dessen Firma mit EAMES, PANTON, NELSON, PROUVÉ, SAARINEN, GEHRY und seit neuestem CORAY eine beträchtliche Anzahl an selbsterwählten und auch re-edierten Klassikern im Programm hat! Das Apodiktische seiner Aussagen harrt noch der Überprüfung. So wäre es z. B. überaus spannend, die Hundertschaften von Epigonen zu se- 


\section{STARDESIGNER ODER GESTALTER DES ALLTÄGLICHEN?}

hen, gegen die sich der EAMESsche LOUNGE CHAIR durchgesetzt haben soll, "weil er offenbar auf unnachahmliche Weise Tradition und Moderne verbindet und die Radikalität dieses Schrittes uns offenbar immer noch berührt«.

Die relative zeitliche Nähe zur Veröffentlichung von A\&W und die Verwendung des gleichen Begriffes durch sw ließ vermuten, dass es eine hohe Deckungsgleichheit an Design-Ikonen geben könnte. Tatsächlich werden im Ganzen 37 der von A\&W in diesen Rang erhobenen Entwürfe auch auf dem Poster von sw aufgeführt. Darüber hinausgehende Mehrfachfunde zwischen A\&W und sw erreichen die Zahl von 63.

Doubletten ergeben sich für A\&W intern zwei, wenn man den internetbasierten Suchbestand ihrer als Designklassiker bezeichneten Artefakte mit den als Design-Ikonen benannten Artefakten vergleicht: das Sofa 31-3 von POUL KJÆRHOLM und den Hocker 600 von ALVAR AALTO. Interne Doubletten zwischen den Internetfunden und dem Design-Ikonen-Poster bei sw kommen auf die Zahl von 34 .

Tripletten für SW finden sich 3 - als Basis dafür werden herangezogen: die Internetfunde, das Poster und das Buch Moderne Klassiker. Möbel die Geschichte machen. Das Ergebnis; der Sitzsack SACCO von GATTI, PAOLINI und TEODORO, der LOUNGE CHAIR von EAMES und das Wandregal STRING von NISSE STRINNING. 


\section{Interne Prognostik bei SCHÖNER WOHNEN; Klassiker von morgen}

Ebenso spannende Erkentnisse treten im Rahmen einer Analyse der internen Voraussagen in der Publikation Moderne Klassiker. Möbel die Geschichte machen zutage. In ihrer 10. Auflage findet sich hinter jedem Kapitel ein Ausblick mit der Frage »Sind sie die Klassiker von morgen? « Es liegt auf der Hand, die Qualität der (selbsterfüllenden?) Prophezeiung anhand der 19. Auflage von 1998 zu überprüfen:

- Kapitel 1: Stühle; 19895 Prognosen, 1998 o Aufnahmen

- Kapitel 2: Armlehnstühle; 198911 Prognosen, 19984 Aufnahmen

- Kapitel 3: Esstische; 198911 Prognosen, 1998 z Aufnahmen

- Kapitel 4: Lampen 1; 198915 Prognosen, 19989 Aufnahmen

- Kapitel 5: Einzelmöbel; 19898 Prognosen, 19983 Aufnahmen

- Kapitel 6: Sessel; 198910 Prognosen, 19984 Aufnahmen

- Kapitel 7: Lampen 2; 198910 Prognosen, 19985 Aufnahmen

- Kapitel 8: Sofas / Polsterelemente; 19898 Prognosen, 19985 Aufnahmen

- Kapitel 9: Sofatische/Servierwagen; 198913 Prognosen, 19983 Aufnahmen

- Kapitel 10: Betten/Liegen; 19898 Prognosen, 19984 Aufnahmen

- Kapitel 11: Regale/Anbausysteme; 19897 Prognosen, 19982 Aufnahmen

- Kapitel 12: Hocker/Schaukelstühle; 19894 Prognosen, 19982 Aufnahmen

An der Zahl von insgesamt 110 Neunominierungen als potentielle Klassiker von morgen in der 10. Auflage von 1989 kann man bereits gut ablesen, dass ein veritables Interesse daran bestand und besteht, das Phänomen des Klassikers publizistisch unbedingt auch in die Zukunft fortzuschreiben. Bringt man dann noch in Anrechnung, dass von den 110 Kandidaten die wahnwitzige Zahl von 92 in die 1980er fällt, also in der selbst aufgestellten Zehnjahresschranke zu liegen kommt - was natürlich konsequent ist -, so manifestiert sich das Bild eines Durchlauferhitzers als passende Metapher für dieses Druckerzeugnis.

Die noch verbleibenden 18 Nominierungen liegen ausnahmslos in den 1970ern. Der Klassikerkorpus vor den 7oer Jahren des 20. Jhd.s scheint für die Macher von sw also befestigt. Eine Binnen-Differenzierung ist an dieser Stelle aus Effizienzgründen entfallen: Sie wurde nicht als sonderlich erfolgversprechend betrachtet, angesichts der Unberechenbarkeit einer Summe aus 


\section{STARDESIGNER ODER GESTALTER DES ALLTÄGLICHEN?}

kuratorischen Re-Editionsauswahlen und Konsumentenentscheidungen. Im Weiteren aufschlussreich an der Publikation ist in ihrer 19. Auflage, dass keine Prognosen mehr aufgestellt werden. Die Spökenkiekerei von 1989 weist im Jahr 199844 der 110 nominierten Artefakte als Eroberer von Plätzen in den publikationseigenen Hitlisten aus. Die Darreichungsform dieses normativen Ansatzes verändert sich mit den Jahren etwas: Er taucht als Prämisse auch 2011 wieder in Das Buch der Klassiker auf - dieses Mal wird seine Stichhaltigkeit jedoch nicht mehr auflagenweise und rückblickend "pseudo-überprüft«, sondern mit der publikationseigenen Autorität einfach postuliert:

"200 Wohnobjekte dürfen sich jetzt mit dem SCHÖNER-WOHNEN-Logo->Neuer Klassiker schmücken. Wir glauben: Sie stehen stilbildend für unsere Zeit.« (SCHÄFER 2011: 6) 


\section{Was ist ein Designklassiker, was macht ihn aus?}

»Wie wird eigentlich ein für den Konsum hergestellter Gebrauchsgegenstand zu einem Designklassiker? Wie entsteht die Bedeutung eines Artefakts?« (KRÄMER in: ARTMAGAZINE am 02.06.2009) [online] http://www. artmagazine.cc/content41775.html [05.03.2018]

Der Designklassiker ist und bleibt zunächst der Gebrauchsgegenstand, der er vor der Erhebung in den Klassikerstand war. Doch so oft, wie die obige Frage gestellt wird, wird auch geantwortet: Durchaus mit Unterschieden, doch immer wortreich - was die Suche nach einem kleinsten oder größten gemeinsamen Nenner provoziert. Entnommen sind die folgenden Antworten auf diese Frage überwiegend verschiedenen Bänden der später betrachteten Befestigungsliteratur. Alle Kursivschreibungen im Verlauf der Zitate stammen vom Verfasser und wurden zur besseren Vergleichbarkeit vorgenommen:

"Was ist ein Designklassiker? Ein Designklassiker ist ein Möbelstück, das zunächst einmal einen hohen Bekanntheitsgrad aufweist, der sich meist auch aus einem hohen Wiedererkennungswert speist. Sodann wartet ein Designklassiker natürlich auch mit einer außerordentlichen Qualität auf, die den Klassiker unbeschadet durch die Zeiten trägt. Ein Designklassiker ist darüber hinaus von einer gestalterischen Klasse, die von zeitgeistgebundenen, ephemeren Moden entbunden ist - ein Designklassiker ist sozusagen immer und überall schön - und dies kann ja, auch wenn nicht alle Aspekte gleichermaßen zutreffen, für Klassiker aller denkbaren ästhetischen Genres gelten. Meistens ist ein Designklassiker zum Zeitpunkt seines Entstehens derart innovativ, dass alles, was bis dahin als Stand der Technik bzw. des Designs galt, weit überholt wird. So war (und ist) beispielsweise der Panton Chair das Nonplusultra unter den Kunststoff-Freischwinger [sic], die nur aus einem Stück gefertigt sind. Dieser Designklassiker ist also nicht einfach nur ein Stuhl schöner Form, sondern auch praktisch angewandte Physik." (CAIRO. DER BLOG FÜR DESIGNMÖBEL UND ACCESSOIRES) [online] http://blog.cairo.de/ category/designklassiker/ [05.03.2018]

»Was ist ein Designklassiker?

- Ein Klassiker übersteht alle Zeitmoden, denn er ist in Design, Funktion, Gestaltung in seiner Zeit wegweisend, trendsetzend und stilbildend. Er altert nicht.

- Seine Eleganz beruht auf der Klarheit seiner Form, Güte seiner Materialien, Funktionalität. 


\section{STARDESIGNER ODER GESTALTER DES ALLTÄGLICHEN?}

- In allen Epochen hat sich die Avantgarde der bildenden Künstler auch mit den Dingen des täglichen Gebrauchs beschäftigt. Produkt-Klassiker gibt es vom Automobil bis zum Zahnstocher." (GELL 2010: Folie 5) [online] http://s4aeo3d2af38a5827.jimcontent. com/download/version/1441279320/module/9921047921/name/ Designklassiker.pdf [05.03.2018)

"Was macht eigentlich einen Möbelklassiker aus? Ganz gewiß das Gleiche, was auch für die klassischen Werke der Musik und der Literatur gilt: Harmonie von Form und Inhalt, eine universale, zeitlos gültige Formensprache: Diese Reife der Gestaltung hebt den Klassiker der Moderne über das Mittelmaß der zeitgenössischen Produkte turmhoch hinaus. Denn das klassische Design, das bescheinigen sogar die höchsten Gerichte, ist reine persönliche geistige Schöpfung, eine Innovation im Funktionellen und Formalen, die mehr ist als modische Originalität. Zur Klassikerqualität gehört stets auch die Reduktion auf das Wesentliche. Sie zeigt sich in der Klarheit der Konstruktion und Einfachheit der Form. Um dorthin zu gelangen, braucht der Designer neben künstlerischer Intuition ein hohes Maß an Rationalität." (JAHR 1998: 5)

»Klassiker stehen heute für höchste ästhetische Qualität. In der Literatur oder Musik heißt es manchmal: Sie stehen so hoch über allem, dass wir in unserem Alltag keinen rechten Zugang mehr zu ihnen finden. Beim Design ist es eher umgekehrt. Gerade das letzte Jahrhundert hat eine Fülle legendärer Entwürfe hervorgebracht, die auch heute Gestalter faszinieren und sie bei der Suche nach den Formen von morgen inspirieren. Dieses Buch ist eine Bestandsaufnahme und präsentiert jung gebliebene Möbel und Wohnaccessoires aus dem 20. Jahrhundert. Und die stärksten Stücke von heute, denen wir prophezeien, dass sie auch morgen noch Gültigkeit haben werden." (SCHÖNER WOHNEN 2O11B: 3)

"Die Auswahl: 10 Jahre ist das 21. Jahrhundert alt. Welche Möbel werden für diese Dekade typisch sein? Später, durch den Filter der Zeit, wird man das leicht sehen - aber heute? 30.000 neue Möbel werden jedes Jahr auf der Kölner Messe gezeigt - plus Leuchten, Bad- und Küchenaccessoires. 800 Kandidaten schafften es über mehrere Runden bis ins Finale: Es sind die Favoriten der Redakteure, die Lieblinge unserer Stylisten und Architekten. 6 Juroren sollten schließlich entscheiden, paritätisch geteilt: drei aus der Redaktion, dazu drei renommierte Experten von außen, damit keine Betriebsblindheit aufkommt. 200 Wohnobjekte dürfen sich jetzt mit dem SCHÖNER WOHNEN-Logo->Neuer Klassiker schmücken. Wir glauben: Sie stehen stilbildend für unsere Zeit.«(SCHÖNER WOHNEN 2011B: 6)

»Was macht ein Möbelstück zum Klassiker, welche Möbel verlieren auch nach Jahrzehnten nichts von ihrer Anziehungskraft? Ein entscheidendes Kriterium ist sicherlich das Design, denn gutes Design ist dauerhaft und übt auch nach vielen Jahren noch eine Faszination aus. Ein Entwurf 


\section{AM ENDE WAR ES NUR EIN WORT: ZWEI REZEPTIONSSTUDIEN}

wirkt dauerhaft frisch und begeistert auch noch nachfolgende Generationen, weil er eine Idee vermittelt, die immer aktuell ist. Ein Klassiker darf den Zeitgeist repräsentieren, aber nicht modisch sein. Eine zeitlose Form, auf das Wesentliche reduziert, muss nicht nur ästhetisch sein, sondern vor allem ihrer Funktion gerecht werden. Zum guten Design gehört neben der Form auch die Auswahl der passenden Materialien und Farben. Und welche Klassiker sind alltagstauglich, und können auch heute noch in unsere Wohnung und in unsere Leben integriert werden? Niemand wohnt gerne in einem Museum, Möbel müssen also Anforderungen an den Alltag gerecht werden und müssen langlebig, pflegeleicht und vor allem funktional sein. Im vorliegenden Buch werden Möbelentwürfe der letzten 100 Jahre bis heute präsentiert, die das Zeug zum Klassiker haben. Sie werden nicht zu Kunstobjekten stilisiert, sondern überzeugen vor allem im täglichen Gebrauch. Sie lassen sich problemlos in unseren Alltag integrieren, denn alle werden heute noch produziert.« (ROTH 2013: 7)

Bis jetzt erzeugen diese Zitate auf knappem Raum einen Mini- oder auch Maximalkonsens, der in ein Konglomerat aus Zeitlosigkeit, Innovation, Funktionsgerechtigkeit, Gültigkeit und Vorbildhaftigkeit mündet. 
STARDESIGNER ODER GESTALTER DES ALLTÄGLICHEN?

\section{Klassiker aus der Sicht der Wissenschaft}

Auch die wissenschaftliche Perspektive wartet mit verschiedenen Ansätzen auf. BREUER lässt sich zum Klassiker kurz und trocken aus:

"Die Erfindung des Klassikers dient vielmehr dazu, eine Konvention aufzustellen, eine Verabredung über den Status von Bildern, Objekten und Texten, ein Prozess, der immer wieder neu aufgefrischt werden muss, indem man ihm neue Klassiker beifügt.» (BREUER 2001: 118)

KÜSTER räsoniert in der Phänomenologie der Form:

"Markenartikel und Markenzeichen sind ein fester Bestandteil unserer Produktwelt. Im Lauf der 'Evolution der Artefaktform se Formen als sehr erfolgreich herausgestellt. Designklassiker weisen eine Invarianz hinsichtlich der Zeit auf: Sie sind vor vielen Jahren entstanden und passen noch heute in die Zeit hinein. Sie eignen sich damit besonders gut zur Beurteilung ihrer Formqualitäten. Markenartikel, die sich zumeist im Verlauf der letzten einhundert Jahre etablieren konnten, bilden gewissermaßen die Archetypen aller nachfolgenden Produktgenerationen." (KÜSTER 2001: 175)

CACCIOLA formuliert in einem Exkurs im Rahmen ihrer Untersuchung zu Reeditionen:

"Als ,Klassiker (Lat.: Adj.: >classicus : ’zur höchsten Kategorie angehörig؛) definiert sich im Deutschen: rein Künstler oder Wissenschaftler, dessen Werke über seine Zeit hinaus als mustergültig anerkannt worden sindk. Auf Italienisch bezieht sich das Adjektiv sowohl auf einen Schöpfer, als auch auf ein Werk: , [ciò] che è considerato modello esemplare, di opera o di artistar. Die ersten Belege für den Ausdruck smoderne Klassiker in Italien und in Deutschland folgen konsequent der unterschiedlichen Semantik der jeweiligen Definition." (CACCIOLA 2008: 364)

\section{EISELE umreißt in Klassiker des Produktdesign:}

"Ein ,Klassiker zu sein, ist kein objektives Merkmal eines Designobjekts. Vielmehr entstehen Designklassiker in komplexen Prozessen gesellschaftlicher Auseinandersetzung und Aneignung. Prädestiniert dafür, sich als Designklassiker zu etablieren, sind Produkte, die in ihrer eigenen Zeit und darüber hinaus als besonders gültige Gestaltungslösungen verstanden werden. Es sind Produkte, die Maßstäbe gesetzt haben, indem sie über Generationen hinweg als besonders wichtig oder gar vorbildhaft anerkannt wurden; Objekte, die durch Zeigen und Abbilden, durch Reden und Schreiben immer wieder neu reflektiert und durch museale und mediale Inszenie- 
rungen zu einem System von Bedeutungen geworden sind; Objekte, die weit über ihren praktischen Nutzen hinausweisen: Ob im musealen Kontext wie ein Kunstobjekt präsentiert oder medial zum Mythos überhöht, wurden Produkte, die ursprünglich für einen zutiefst alltäglichen, praktischen Gebrauch entwickelt wurden, zu Objekten der Begierde und/oder der sozialen Distinktion." (EISELE 2014: 9)

Wie selbstverständlich hat auch GEORG FRANCK in der Ökonomie der Aufmerksamkeit sein Scherflein zur Definition des Klassischen beigetragen:

"Klassisch ist nicht das Ältere als solches, klassisch wird das in die Jahre gekommene, das der Trivialisierung widersteht, obwohl es sich auf breiter Front durchgesetzt hat. Klassisch wird, was sich trotz des schwindenden Seltenheitswerts hält. Es ist eine Widerstandskraft gegen die Inflationierung, die das Klassische vom Originellen unterscheidet." (FRANCK 1998: 165)

Folgt man diesem Zitat, hat also überhaupt erst das in der Alltäglichkeit angekommene Artefakt eine Chance, zum Klassiker zu werden. CACCIOLA einschließend entsteht damit eine Alltäglichkeit höchster Qualität - die nur in nachzeitlicher und damit inaktueller Betrachtung und Bewertung festgeschrieben werden kann. Popularisierung und der mögliche Verlust von Distinktionspotential durch breite Erreichbarkeit zählen vor diesem Hintergrund nicht. Anders als im Bereich des Grundnutzens, in dem eine starke Verbreitung zur Vergewöhnlichung führt, kommt es beim Klassiker gerade nicht dazu:

»Commoditization: Vergewöhnlichung bzw. de[r] Verlust der Einzigartigkeit. [...]

Real Commoditization - Produkte stellen perfekte Substitute dar

Quasi Commoditization - aus Anbietersicht bestehen zwar Produktunterschiede, Verbraucher sind aber nicht in der Lage, diese (kognitiv) zu erkennen

Perceived Commoditization - Verbraucher nehmen fälschlicherweise an, dass sich die Produkte nicht mehr unterscheiden« (JARASS 2007: Folie 56) [online] www.jarass.com/Lehre/Vorlesungen/ws2007_2008/kapitel_12_ absatzplanung.ppt [05.03.2018]

Selbst nachdem Klassiker die Schwellen erstrebenswerter Marktdurchdringung überschritten haben, soll ihre massenhafte Verbreitung also kein Problem darstellen - wenn man davon ausgehen kann, dass die ins Visier zu nehmenden Designklassiker sich dadurch auszeichnen. Dass es hunderte unterschiedlicher Stühle auf dem Markt gibt, hinderte und hindert "Experten" dennoch nicht daran, »maßgebliche« Artefakt-Auswahlen in zigfacher Größen- 
ordnung zu treffen: Eher bringt es sie wohl dazu. Was das Sitzen als solches angeht, könnte man noch davon ausgehen, dass alle im Markt befindlichen Produkte tatsächlich "perfekte Substitute« füreinander darstellen müssten. Dennoch können die Konsumenten immer noch mehr als genügend Produktunterschiede an ihnen feststellen und deswegen nicht annehmen, »dass sich die Produkte nicht mehr unterscheiden«. Wenn auch sicherlich nicht in allen Fällen, so ist der Klassiker in der Mehrzahl der Fälle ein »High Involvement Produkt[...]«:

\begin{abstract}
"Die Frage, ob ein Produkt für einen Käufer mit hohem oder niedrigen Involvement verbunden ist, hängt im Wesentlichen vom Kaufrisiko ab, das der Käufer subjektiv wahrnimmt. High Involvement Produkte sind für den Kunden in irgendeiner Weise wichtig, z.B. weil sie etwas mit seiner Persönlichkeit zu tun haben oder weil ein relativ hohes finanzielles oder sonstiges Risiko mit dem Kauf verbunden ist." (TEIA INTERNET AKADEMIE LEHRBUCH VERLAG) [online] https://www.teialehrbuch.de/ Kostenlose-Kurse/Marketing/15145-High-und-Low-Involvement-Entscheidungen.html [03.07.2018]
\end{abstract}

Für die weitere Betrachtung von als Designklassiker bezeichneten Artefakten soll ab jetzt die Klassiker-Definition des DUDEN gelten: »Künstler oder Wissenschaftler, dessen Werke, Arbeiten als mustergültig und bleibend angesehen werden «; »klassisches Werk; etwas, was klassisch geworden ist «. (DUDEN) [online] http://www.duden.de/rechtschreibung/Klassiker [05.03.2018]

Auch die Definition des Adjektivs klassisch bringt noch interessante Aspekte bei, als sie nicht nur auf die antike Klassik Bezug nimmt, sondern auch dieses festschreibt: »(in Bezug auf Aussehen oder Formen) in [althergebrachter] mustergültiger Weise [ausgeführt], vollendet, zeitlos«; »herkömmlich, in bestimmter Weise traditionell festgelegt und so als Maßstab geltend«. (DUDEN) [online] http://www.duden.de/rechtschreibung/klassisch [05.03.2018].

Fragen nach einer exemplarischen Mustergültigkeit von Entwürfen, nach der Begründung von Traditionslinien oder auch nach Produktverwandtschaften, die sich auf jene Entwurfsprinzipien, die von einzelnen Artefakten verkörpert werden sollen, entweder stützen oder berufen, müssten für jedes als Designklassiker oder Moderner Klassiker bezeichnete Artefakt individuell untersucht und beantwortet werden. Das kann im Rahmen dieser Untersuchung nicht geleistet werden.

Besonders bemerkenswert erscheint bei der Durchsicht aller als Designklassiker und als Design-Ikonen benannten Artefakte, dass sie beim besten Willen nicht der o. a. Definition genügen. Mit zunehmender Artefaktdichte im 
Verlauf der Untersuchung verfestigt sich der bereits in einem Zitat gefasste Eindruck, dass der »Designklassiker [...] ein Möbelstück [ist], »das zunächst einmal einen hohen Bekanntheitsgrad aufweist, der sich meist auch aus einem hohen Wiedererkennungswert speist« (s. o.). Gerade die Außergewöhnlichkeit der Artefakte, gerade das nicht Mustergültige, eben nicht zur Norm oder zum Standard führende scheinen die Wahrscheinlichkeit immens zu erhöhen, überhaupt in den Klassikerstand erhoben zu werden. Die Festschreibung des Außergewöhnlichen (- in FRANCKscher Diktion des »Originellen« -) als etwas Bleibendes sozusagen.

Damit sind wir auch wieder ganz nah bei LENZE und der "(Re-)Integration des Außeralltäglichen in den Alltag“ (vgl. LENZE 2002: 166). Designklassiker scheinen eine Art Mutation der Guten Form zu verkörpern - doch sind ihrer Bedeutung Distinktionsbedürfnisse und -potentiale mit eingeschrieben, so dass sie auf eine sehr eigentümliche Weise mutiert wirken. Besteht eine der Grundideen der guten Form in zeitloser Gültigkeit (- ein sehr kontrovers diskutierbares Konzept, als Langlebigkeit weit weniger problematisch -) und dem Versuch, unmodisch, funktional sowie ebenso sachlich wie sachgerecht zu gestalten, so bringen sich mit dem Designklassiker und seinem Bruder (oder Zwilling) Moderner Klassiker ganz andere ausgezeichnete Formen in Position.

Ihre Qualität besteht für sw, den aktivsten Klassikerproduzenten, primär in deren Überdauern am Markt, wird aber in anderer Art verwendet, als es z. B. für BUSSEs Longlife-Design-Award gilt. Die von Sw präferierte Kombination Moderner Klassiker ist eigentlich ein Oxymoron. Außerdem sollen die damit bezeichneten Artefakte auch noch Geschichte gemacht haben .... Entsteht die besondere, ja mythische Qualität von Artefakten nach dieser Definition erst durch ihr Überdauern und besteht sie in deren Überdauern, dann kann dieses nicht ernsthaft mit einem Begriff des Gegenwärtigen kombiniert werden. Auch dann nicht, wenn der »Modus des Dauerns « zum Überdauern und damit zu jenem paradoxen, permanenten Jetzt führt, das FRANCK in seinem Essay Die Zeit: Eine soziale Konstruktion? ins Spiel bringt und das er als »Präsenz« in Mentaler Kapitalismus weiter ausführt. (FRANCK 2004: 1) [online] http://www. iemar.tuwien.ac.at/publications/GF_prog.pdf [05.03.2018]. 


\section{STARDESIGNER ODER GESTALTER DES ALLTÄGLICHEN?}

BREUER formuliert zur Gleichzeitigkeit von modernem Klassiker und klassischer Moderne:

»Bei den Wortschöpfungen Moderne Klassiker und Klassische Moderne geht es nun heute nicht mehr um den in der Moderne enthaltenen Gegensatz von modern und alt sowie um das Vorhandensein beziehungsweise die Ablehnung des Klassischen. Vielmehr wird eine Koexistenz von beiden behauptet, sowohl die rauctoritas historiaer des Klassikers, die die Nobilitierung zum Wahren, Vollkommenen und zum lange Gültigen beschwört, als auch der Aktualität der Objekte. Es entstehen zwei Formen von Vergangenheit: die eine, die sich durch modischen Wechsel verschleißt und dadurch ungültig wird, und die andere, die inaktuell ist, aber sich durch Beharrungsvermögen erhalten hat und auf eine paradoxe Weise inaktuell gültig bleibt." (BREUER 2001: 39f)

CACCIOLA merkt dazu in ihrer Untersuchung an, dass die Klassische Moderne sich "viel eher der Kunstwissenschaft als der Designgeschichte zuordnen" lässt (s. u.) und vertieft in einer Fußnote:

"Im Übrigen - und vermutlich bereits als eine Folge der Offenheit des Begriffes - umfasst die smoderne-Klassiker Definition einzelne Designstücke: Auch wenn man von smodernen Klassikern spricht, so kann man, im Gegensatz zu den bildenden Künsten, doch nicht von einer >Klassischen Moderner in der Designgeschichte sprechen." (CACCIOLA 2008: 364, Fußnote 1124) 


\section{Designklassiker: Ein Kampf gegen das Jetzt?}

Die Frage, warum Artefakte auf eine bestimmte Art und Weise »Bestand « haben sollten, der damit auch auf einer anderen Ebene Ausdruck findet, kann als heikel bezeichnet werden, aber notwendig ist sie zugleich. Mit Bezug auf Designartefakte und in Verbindung mit dem Klassiker-Begriff geht es ja nicht nur um einen Bestand, den ein Artefakt im Sinne seiner Langlebigkeit haben soll. Und doch: Gerade an jener echten oder artifiziellen, weil behaupteten Langlebigkeit der Gestaltung muss sich in diesem Falle gerieben werden. FRANCK lädt uns mit dem Modus des Dauerns oder der Präsenz schon eine Hypothek auf die Schultern, die dem Verklärungsobjekt Designklassiker eine - unerwartete - Berechtigung für seinen stolzen Gang durch die Jahrzehnte mitgibt.

Die klassische Moderne, auf die der Moderne Klassiker anspielt - in der Kunst gibt es sie, in der Designgeschichte nicht (s. o.). Aus Sicht der Kunstgeschichte beginnt sie auf der Schwelle des 19. zum 20. Jhd. Folgt man BAUMAN, besteht die feste Moderne schon seit 300 Jahren. (BAUMAN in einem Vortrag anlässlich der ANSE-Konferenz 2004) [online] http://www.anse.eu/wpcontent/uploads/doc/Conferences/bauman\%2odtsch.pdf [06.03.2018].

In der Architektur wird sie in den 6oern, spätestens den 7oern des 20. Jhd.s von der Postmoderne abgelöst, für die Designgeschichte ist MEMPHIS als Urknall letzterer anzunehmen. Modernus steht im Lateinischen für »neu«, modern liegt damit auf einer Linie mit Bedeutungen wie »der herrschenden Mode entsprechend «, »dem neuesten Stand entsprechend«, »neuzeitlich«, »heutig«, »zeitgemäß« oder auch »der neuen Zeit zuzurechnen«. (DUDEN) [online] http://www.duden.de/rechtschreibung/modern_neu_modisch [06.03. 2018]. Binden wir das wieder bei GEORG FRANCK an, bei dem es »[...] jetzt [ist], seitdem die Zeit vergeht (FRANCK 2004: 1), so wäre modern schlicht mit jetzt gleichzusetzen. Was den Designklassiker betrifft, so haben wir neben den anderen Definitionsversuchen bei GEORG FRANCK gefunden, dass er, obschon in die Jahre gekommen, »der Trivialisierung widersteh[e] «, womit er die idealtypische Verkörperung seines Modus des Dauerns darstellt. Stellen wir uns damit gegen den Verlauf der Zeit, wenn wir etwas zum Klassiker erklären und setzen damit den Anspruch in die Welt, dass etwas der Veränderung trotzen möge, weil wir das so wollen? Oder sind diese Versuche, zeitweilige Beständigkeit angesichts einer flüchtigen Moderne (vgl. BAUMAN) herzustellen, nur Entsprechungen zu der Art, wie wir mit unserer eigenen Präsenz und dem Zustreben auf unser eigenes Vergehen umgehen? 


\section{STARDESIGNER ODER GESTALTER DES ALLTÄGLICHEN?}

LATOUR und LOWE wie auch STERLING haben schon Ideen formuliert, wie Artefakte in Bezug auf ihre eigene Existenz im Verlauf der Zeit anders betrachtet werden können. Erstere steigen mit dem Begriff der Trajektorie in den Ring, letzterer mit dem Neologismus des SPIME. Die Trajektorie wird hier von NEUBERT besprochen:

"Vor diesem Hintergrund schlagen Latour und Lowe schließlich vor, Kunstwerke nicht als Objekte, sondern als Trajektorien zu betrachten. Unter diesem Begriff versteht man in der Physik die Ortskurve eines Elements, also den Bewegungspfad in Raum und Zeit. Im mathematischen Sinn zielt der Begriff der Trajektorie dagegen vereinfacht formuliert auf die Zustandsveränderung eines komplexen Systems. Nimmt man beide Aspekte zusammen, definiert die Trajektorie damit ein spezifisches Verhältnis von Transport und Transformation, genau jenes Verhältnis also, das für die Beschreibung von Medienvorgängen innerhalb der Akteur-NetzwerkTheorie von zentraler Relevanz ist und das nach Latour für die Mediationstypen sowohl der Wissenschaft wie der Kunst einschlägig ist. Die zentrale Veränderungsoperation, der sich die Naturwissenschaften zur Herstellung ihrer Referenz bedienen, ist die In-Formation, wörtlich also das In-Form-Bringen eines materialen Elements, das den Übergang zwischen physischer und symbolischer Welt leistet und sich in zahlreichen, kleinen, sukzessiven Schritten vollzieht. Resultat sind letztlich In-Skriptionen, also Register, Listen, Zeichnungen, Journale oder Karten. Auf seinem Übertragungsweg durchläuft das Element eine Kette von Übersetzungen, bei dem es einerseits durch Mediatoren verändert wird, andererseits eine gewisse Konstanz bewahrt. Die Referenzketten der Wissenschaft tendieren nun dazu, die Mediatoren und Transformationen zum Verschwinden zu bringen. Beim Ideal des immutable mobiles, der veränderungslosen Übertragung, sind schließlich alle Zwischenschritte getilgt, alle Mediatoren durch Intermediäre, alle White Boxes durch Black Boxes ersetzt, bis schließlich nur noch die Endpunkte der Kette sichtbar sind: hier materielle Physik, dort mentale Repräsentation, hier kalkulierbare Natur - res extensa -, dort kalkulierender Geist - res cogitans. An anderer Stelle kontrastiert Latour diese Rationalität der Wissenschaft mit dem Mediationstyp der Kunst, der im Gegensatz zu den szientifischen Referenzketten die Effekte der Mediatoren und die Transformationen reflektiere und sichtbar mache: Wahrheit darf nicht medial konstruiert sein, Schönheit muss dies aber. [!]《 (NEUBERT in: HENSEL und SCHRÖTER 2012: 54)

Ganz vertraut steht der Klassiker im Lichte dieser Ausführungen da und noch deutlicher als die soziale und mediale Konstruktion, die er ist und immer schon war. Das SPIME hingegen scheint mit seinem Grundzug, dass der Artefaktzustand eine seiner temporären Manifestationen im Verlauf der Zeit sei, bestens in die heutige Zeit der 3D-Drucker zu passen: 


\section{AM ENDE WAR ES NUR EIN WORT: ZWEI REZEPTIONSSTUDIEN}

"Die Rationalität dieses Objekt-Typs beschreibt Sterling unter dem Begriff des SPIMEs, eines Neologismus, gebildet aus space und time oder auch aus speculative und imaginary: "SPIMES, are manufactured objects whose informational support is so overwhelmingly rich that they are regarded as material instantiations of an immaterial system. They are designed on screen, fabricated by digital means, and precisely tracked through space and time throughout their earthly sojourn. SPIMES are sustainable, enhanceable, uniquely identifiable, and made of substances that [...] will be folded back into the production stream of future SPIMES. [...] The SPIME is a set of relationships first and always, and an object now and then. [Hervorhebung des fremdsprachlichen Zitats durch den Verfasser] Ganz wie das Kunstwerk bei Latour fasst Sterling die Gegenstände des Designs nicht als stabile Entitäten, sondern als Trajektorien auf, welche die Dimension des Transports, also der zeitlich-räumlichen Koordinatenveränderung, mit der Dimension der Transformation, also der internen Zustandsänderung, verbindet. Das SPIME wäre ein mehr oder weniger veränderliches mobiles Element, das zwischen Information und Material, Ding und Zeichen changiert.« (ebd.: 56)

Sind also auch Designklassiker »mehr oder weniger veränderliche [...] mobile [...] Element[e], die zwischen verschiedenen Zuständen changieren können, als Folge einer >Reihe von Beziehungen`? Zieht man für diesen Zusammenhang noch einmal die Hohepriester für Moderne Klassiker zu Rate, ist ihnen dieses zu entlocken:

»Rolf Fehlbaum, der Gründer des Vitra Design Museums, weiß es aus täglichem Umgang: >Das dauerhaft Stimulierende ist das, was einen Klassiker ausmacht.< Dies ist zugleich auch die Antwort an die Kritiker, die vor einem Klassikerkult warnen. Sie fürchten, die Wertschätzung der 'Stilmöbel des 20. Jahrhundertsı verstelle den Blick für das gegenwärtige Designschaffen. Und sie vermuten, so mancher halte sich nur deshalb an die Klassiker, weil er auf Nummer Sicher gehen will - aus Mangel an geschmacklichem Urteilsvermögen. Dieses Buch macht aus Klassikern keine musealen Kunstobjekte. Schon deshalb nicht, weil die Zahl der jahrzehntelang bewährten Möbel und Lampen immer wieder durch jüngere Modelle ergänzt wird, die ihre Klassikerqualität nach mindestens zehn Jahren Marktpräsenz bewiesen haben. Auch deshalb nicht, weil Produkte, die vom Markt verschwanden, hier nicht mehr aufgeführt sind - nicht alle Klassiker sind unsterblich." (JAHR 1998: 5)

Geht man von solch einer Position aus, kann ein Klassiker seinen Status sehr wohl verlieren und er muss es auch, denn sonst könnten ja keine neuen nachkommen, »die ihre Klassikerqualität nach mindestens zehn Jahren Marktpräsenz bewiesen haben«. Das Buch der Designer (2010) und erst recht Das Buch der Klassiker (2011) könnten Entwerfende wie Artefakte gar nicht mehr fassen .... Jene Produkte, die vom Markt verschwunden sind, werden wohl eben so 
STARDESIGNER ODER GESTALTER DES ALLTÄGLICHEN?

zwangsläufig wie die vielen Prominenten aus der rezipierenden Öffentlichkeit entschwinden, die über die Jahre nicht mehr vom Publikum in ihrem Prominentenstatus bestätigt wurden (vgl. WIPPERSBERG 2007: 276f). 


\section{Klassiker-Profile nach Publikationen}

Der Klassikerkorpus, den die untersuchten Publikationen pro Jahrzehnt des 20. Jhd.s und bis ins 21. Jhd. aufgebaut haben, wird nun in Gänze dargestellt. Eine Feinunterteilung wird nach den Hauptfundworten Designklassiker und Designikonen vorgenommen. Im Spezialfall sw werden auch Moderne Klassiker abgebildet. Außerdem wird der geringste zeitliche Abstand zum Zeitpunkt der Studie ausgewiesen. Gibt es in einer Dekade keine Artefaktfunde, entfällt sie.

\section{Architektur \& Wohnen}

In toto 168 Artefakte.

- Spanne in Jahren: Designklassiker von 1897-1978; Designikonen von 1900-2007.

- Schwerpunkte: Bei den Designklassikern ein erster Schwerpunkt in den 1910ern und 1920ern des 20. Jhd.s, Spitzenwert in den 1950ern; bei den Designikonen relativ gleichmäßige Nennungen bis in die 1940er, ab den 1950ern eine starke Zunahme der Zahlen (Spitzenwert in den 1960ern), die dennoch nur mit den Designklassikern in den 1910ern gleichziehen. Bemerkenswert: 34 Designikonen aus den 1980er-20ooer-Jahren.

- Geringster Abstand zum Zeitpunkt der Studie: Designklassiker 29 Jahre, Designikonen 6 Jahre.

\section{Designklassiker}

189oer: 1 CHARLES RENNIE MACKINTOSH: Stuhl ARGYLE 1897

1910er: 16 CHARLES RENNIE MACKINTOSH: 1) Stuhl D.S.3 1918 2) Tisch D.S.1 1918 3) Tisch BERLINO 19054 ) Tisch G.S.A. 19045) Stuhl WILLOW 119046$)$ Stuhl HILl HOUSE 1902 JOSEF HOFFMANN: 7) Fauteuil KUBUS 1910 8) Fauteuil ALLEEGASSE 1910 9) Sitzgruppe FLEDERMAUS 1907 10) Sessel KUNSTSCHAU 1908 11) Fauteuil PALAIS STOCLET 1905 12) Stuhl 670/669 SITZMASCHINE 1905 13) Sessel PURKERSDORF 1904 14) Fauteuil MUSIKZIMMER PURKERSDORF 1904 15) Fauteuil VILLA GALLIA 1903 16) Satztisch 1900

1920er: 16 LUDWIG MIES VAN DER ROHE: 1) Sessel BARCELONA 1929 2) Stuhl S533R 19273) Stuhl MR 19274) Sessel MR 1927 EILEEN GRAY: 5) Sessel BIBENDUM 1929 6) Tisch JEAN 1929 7) Teppich BLUE MARINE 1925 8) DAY BED 1925 9) Stuhl NON CONFORMIST 1926 10) Paravent BRICK SCREEN 1922 11) Beistelltisch DE STIJL 1922 FERDINAND KRAMER:12 Sofa FKo6 WESTHAUSEN 


\section{STARDESIGNER ODER GESTALTER DES ALLTÄGLICHEN?}

192613 Sessel FK1O WeISSENHOF 1926 14) Stuhl FKo2 KARNAK 1925 15) Hocker FKo3 ASWAN 192516 Liege FKo1 THEBAN 1925

1930er: 2 EILEEN GRAY: 1) Stuhl BONAPARTE 1935 LUDWIG MIES VAN DER ROHE: 2) Stuhl BRNO 1930

1940er: 6 EERO SAARINEN: 1) Sessel WOMB 1948 2) Sessel ORGANIC CHAIR (mit CHARLES EAMES) 1940 ILMARI TAPIOVAARA: 3) Stuhl \& Sessel DOMUS 1946 FERDINAND KRAMER: 4) Beistelltisch FK12 FORTYFORTY 1945 5) Tisch FKo6 ALDEN 1942 WILLY GUHL: 6) Stuhl BANKSTUHL 1941

1950er: 26 POUL KJÆRHOLM: 1) Hocker PK33 1959 2) Liege PK80 1957 3) Stuhl PK22 1956 4) Tisch PK61 1956 5) Stuhl PK2O 1956 FERDINAND KRAMER: 6) Tisch FKO7 FRANKFURT 1959 7) Liege FK12 SENCKENBERG 1952 8) Couchtisch FKO4 CALVERT 1951 9) Couchtisch FKO5 CHARLOTTE 1951 NORMAN CHERNER: 10) CHERNER CHAIR 1958 11) Sideboard MULTIFLEX 1958 12) KONWISER TABLE 1956 EERO SAARINEN: 13) Tische und Stuhl TuliP 1953 14) Stuhl SAARINEN EXECUTIVE 1950 ILMARI TAPIOVAARA: 15) Barhocker NANA 1956 16) Stuhl MADEMOISELLE 1956 17) Stuhl PIRKKA 1955 18) Tisch OVALETte 1954 19) Tisch trienna 1954 20) Stapelstuhl LuKKI 1952 WILLY GUHL: 21) Stuhl LOOP 1954 HARRY BERTOIA: 22) ASYMMETRIC CHAISE 1952 23) BARSTUHL 1952 24) BIRD CHAIR 1952 25) SIDE CHAIR 1952 26) DIAMOND CHAIR 1952

196oer: 5 POUL KJÆRHOLM: 1) Liege PK24 1956 2) Tisch PK54 19633) Stuhl PK9 1960 ARNE JACOBSEN 4) Tischleuchte AJ 1960 DIETER RAMS: 5) Regalsystem 6061960

1970er: 2 ANGELO MANGIAROtTi: 1) Stuhl SEDiA tRe 1978 2) Tisch eros 1971

Designikonen

190oer: 4 OTTO BLÜMEL: 1) Garderobe NYMPHENBURG 1908 JOSEF HOFFMANN: 2) Stuhl NR. 670/669 SITZMASCHINE 1905 CHARLES RENNIE MACKINTOSH: 3) Stuhl HILl HOUSE 1902 THONET: 4) Schreibtischfauteuil NR. 9 WIENER SESSEL

1910er: 2 BENNO MARSTALLER: 1) Stuhl BEMA/MORETTA 1917 JOSEF GOČÁR: 2) GLASSCHRANK 1913

1920er: 4 EILEEN GRAY: 1) ADJUSTABLE TABLE 1927 MART STAM: 2) S 33 KRAGSTUHL 1926 MARCEL BREUER: 3) B3 WASSILY-STUHL 1925 3) Kinderstuhl 1924 


\section{AM ENDE WAR ES NUR EIN WORT: ZWEI REZEPTIONSSTUDIEN}

1930er: 6 HOLGER NIELSEN: 1) VIPP-TRETEIMER 1939 FERRARI-HARDOY, KURCHAN, BONET: 2) Stuhl BUTTERFLY CHAIR 1939 HANS CORAY: 3) LANDI-Stuhl 1938 ALVAR AALTO: 4) Vase SAVOY 1936 CHRISTIAN DELL: 5) Lampe 6631 LUXUS 1934 ALVAR AALTO: 6) Hocker NO 601933

1940er: 5 CARLO MOLLINO: 1) Tisch ARABESCO 1949 EAMES: 2) Liegesessel LA CHAISE 1948 3) Schaukelstuhl RAR 1948 HANS WEGNER: 4) Stuhl PEACOCK 1947 FINN JUHL: 5) Sessel PELIKAN 1940

1950er: 14 NORMAN CHERNER: 1) CHERNER CHAIR 1958 ARNE JACOBSEN: 2) EGG CHAIR 1958 3) Stuhl AMEISE 1952 GIÒ PONTI: 4) Stuhl SUPERLEGGERA 6691957 ACHILLE und PIER GIACOMO CASTIGLIONI: 5) Hocker MEZZADRO 1957 POUL HENNINGSEN: 6) Hängeleuchte ARTICHOKE 1957 RAMS, GUGELOT: 7) Plattenspieler SK4 1956 GEORGE NELSON: 8) Sofa MARSHMALLOW 1956 EAMES: 9) Sessel LOUNGE CHAIR 1956 EERO SAARINEN: 10) Stuhl TULIP 1955 GEORGE NELSON: 11) Sessel COCONUT CHAIR 1955 WILLY GUHL: 12) Gartenstuhl LOOP 1954 EGON EIERMANN: 13) Tischgestell 11953 ROSEMARIE und RICO BALTENSWEILER: 14) Stehleuchte TYPE 6001951

1960er: 17 ANNA CASTELLI-FERRIERI: 1) Containerserie COMPONIBILI 1969 GAETANO PESCE: 2) Sessel und Hocker UP 5 und 61969 EERO AARNiO: 3) Hängesessel BUbBLE CHAIR 1968 GATTI, PAOLINI, TEODORO: 4) Sessel SACCO 1968 THORUP und BONDERUP: 5) Hängeleuchte SEMI 1968 GIANCARLO PIRETTI: 6) Klappstuhl PLIA 1968 ROLF HEIDE: 7) STAPELLIEGE 1967 DE PAS, D'URBino, LOMAZZI: 8) Sessel BLOW 1967 HELMUT BÄTZneR: 9) Stuhl BOFINGER BA 11711966 PIERRE PAULIN: 10) Sessel RIBBON 1966 JOE COLOMBO: 11) Tischleuchte SPIDER 1965 BRUNO MUNARI: 12) Hängeleuchte FALKLAND 1964 FRIEDRICH-WILHELM MÖLLER: 13) Sofa CONSETA 1964 PAUL SCHÄRER, FRITZ HALLER: 14) Möbelprogramm USM HALLER 1963 RICHARD SAPPER, MARCO ZANUSO: 15) Fernseher ALGOL 1963 ACHILLE und PIER GIACOMO CASTIGLIONI: 16) Stehleuchte ARCO 1962 VERNER PANTON: 17) PANTON CHAIR 1960

1970er: 8 VICO MAgISTRETTI: 1) Tischleuchte ATOLLO 1977 2) Sofa MARALUNGA 1973 ALESSANDRO MENDINI: 3) Sessel PROUST 1976 MICHEL DUCAROY: 4) Sofa TOGO 1973 RICHARD SAPPER: 5) Leuchtenserie TIZIO 1972 GUFRAM - GUIDO DROCCO Und FRANCO MELLO: 6) Garderobe CACTUS 1972 FRANK GEHRY: 7) WIGGLE CHAIR 1972 SUPERSTUDIO (DI FRANCIA, MAGRIS, FRASSINELLI, NATALINI): 8) Tisch QUADERNA 1970

1980er: 15 AXEL KUFUS: 1) Regalsystem FNP 1989 RON ARAD: 2) Sessel BIG EASY 1988 OTL AICHER: 3) KÜCHENWERKBANK 1988 GINBANDE: 4) Tisch TABULA RASA 1987 MICHELE DE LUCCHI: 5) Tischleuchte TOLOMEO 1987 6) Stuhl firSt 1982 MARC NEWSON: 7) Chaiselongue LOCKHEED LOUNGE 1986 GAETANO PESCE: 8) Sessel I FELTRI 1986 SHIRO KURAMATA: 9) Sessel HOW HIGH THE MOON 1986 JORGE PENSI: 10) Stuhl TOLEDO 1986 JASPER 


\section{STARDESIGNER ODER GESTALTER DES ALLTÄGLICHEN?}

MORRISON: 11) THINKING MAN'S CHAIR 1986 PHILIPPE STARCK: 12) COSTES CHAIR 1985 PETER MALY: 13) Sessel zYKLUS 1983 WOLFGANG LAUBERSHEIMER: 14) GESPANNTES REGAL 1982 TOSHIYUKI KITA: 15) Sessel WINK 1980

1990er: 9 KONSTANTIN GRCIC: 1) Leuchte MAYDAY 1999 INGO MAURER: 2) Leuchte ZETTEL'Z 1997 MARCEL WANDERS: 3) KNOTTED CHAIR 1996 ANTONIO CITTERIO: 4) Bürostuhl T-CHAIR 1994 RODY GRAUMANS: 5) Hängeleuchte 85 LAMPS 1993 PRODUKTENTW. ROERICHT: 6) STITZ 1993 SIEGER DESIGN: 7) Waschtischarmatur TARA 1992 TEJO REMY: 8) Kommode CHEST OF DRAWERS 1991 TOM DIXON: 9) Stuhl S-CHAIR 1991

200oer: 10 OSKAR ZIETA: 1) Hocker PLOPP 2007 BOUROULLEC: 2) Sofa ALCOVE 2006 JORIS LAARMAN: 3) Stuhl BONE CHAIR 2006 Front: 4) Stehleuchte HORSE LAMP 2006 BRUNO RAINALDI: 5) Bücherregal PTOLOMEO 2004 PATRICIA URQUIOLA: 6) Bett CLIP 2003 KONSTANTIN GRCIC: 7) Stuhl ONE 2003 TOKUJIN YOSHIOKA: 8) Sessel HONEYPOP 2000 MARTEN VAN SEVEREN: 9) Sessel LCP 2000 FRANCESCO BINFARÉ: 10) Sofa FLAP 2000

\section{art Das Kunstmagazin}

6 Artefakte.

- Spanne in Jahren: 1925-1988.

- Geringster Abstand zum Zeitpunkt der Studie: 25 Jahre

1920er: 2 MARCEL BREUER: Stuhl B3 1925 Stuhl WASSILY 1925

1930er: 1 FRANK LLOYD WRIGHT: Stuhl BARREL 1937

1980er: 3 MARC NEWSON: EMBRYO CHAIR 1988 MICHAEL GRAVES: Wasserkessel 90931985 ETTORE SOTTSASS: Raumteiler CARLTON 1981

\section{Der Spiegel}

3 Artefakte.

- Spanne in Jahren: 1934-2006.

- Geringster Abstand zum Zeitpunkt der Studie: 7 Jahre.

1930er: 1 SCHWEIZER ORDONNANZRAD 051934

1960er: 1 VERNER PANTON: SPIEGELKANTINE 1969

200oer: 1 KONSTANTIN GRCIC: Stuhl MYTO 2006 


\section{designreport}

2 Artefakte.

- Spanne in Jahren: 1969-1974.

- Geringster Abstand zum Zeitpunkt der Studie: 39 Jahre 1960er: 1 GÜNTER KUPETZ: PERLFLASCHE 1969 1970er: 1 GIJS BAKKER: STRIP CHAIR 1974

\section{Die Presse}

1 Artefakt.

- Geringster Abstand zum Zeitpunkt der Studie: 45 Jahre 1960er: 1 GATTI, PAOLINI, TEODORO: Sessel SACCO 1968

\section{Die Welt}

30 Artefakte.

- Spanne in Jahren: 1890-1995.

- Geringster Abstand zum Zeitpunkt der Studie: 19 Jahre 189oer: 1 WELTRAD 1890 1920er: 1 MERCEDES SSK 1928 1930er: 5 ALVAR AALTO: 1) Vase SAVOY 1936 2) 4001936 3) Paravent 100 1936 4) Hocker 6o 1933 GERRIT RIETVELD: 5) ZIG ZAG CHAIR 1934

1940er: 3 PORSCHE 3561948 ILMARI TAPIOVAARA: Stuhl DOMUS 1946 DURALEX GLAS 1945

1950er: 4 KAJ FRANCK: 1) Glasserie KARTIO 1958 2) Geschirr KILTA 1953 3) LOTUS SUPER SEVEN 1957 MARIMEKKO: 4) JOKAPOIKA-Shirt 1956

1960er: 7 ETTORE SOTTSASS: 1) Schreibmaschine VALENTINE 1969 PETER GHYCZY: 2) Sitzei EGG 1968 DARIO \& MARIO BELLINI: 3) Radio RK 5011968 4) DIE GOLDENE KAMERA 1966 MARIMEKKO: 5) UNIKKO-Print 1964 BRAUN 6) TOASTER 1963 MATHMOS: 7) ASTRO LAMP 1963 


\section{STARDESIGNER ODER GESTALTER DES ALLTÄGLICHEN?}

1970er: 2 RICHARD SAPPER: Espressokanne 90901978 ETTORE SOTTSASS: MICKY MAUS-Tisch 1972

1980er: 4 PHILIPPE STARCK: 1) HOT BERTAA KETTLE 1989 2) SAAB 900 CABRIOLET 1986 MICHAEL GRAVES: 3) 9093 BIRD KETTLE 1985 ETTORE SOTTSASS: 4) Raumteiler CARLTON 1981

1990er: 3 IKEA: PS-Kollektion 1995 JASPER MORRISON: THREE SOFA DE LUXE 1992 PHILIPPE STARCK: Zitronenpresse JUICY SALIF 1990

\section{Die Zeit}

5 Artefakte.

- Spanne in Jahren: 1933-1958.

- Geringster Abstand zum Zeitpunkt der Studie: 55 Jahre

1930er: 2 ALVAR AALTO: Vase SAVOY 1936 Hocker 601933

1950er: 3 ARABIA Serie FINEL 1958 MERCEDES SL 1954 MAX BILL: ULMER HOCKER 1954

\section{FAZ}

6 Artefakte.

- Spanne in Jahren: Designklassiker von 1949-2004.

- Geringster Abstand zum Zeitpunkt der Studie: 9 Jahre

1940er: 1 CARLO MOLLINO: Glastisch ARABESCO 1949

1950er: 2 EAMES: LOUNGE CHAIR 1956 MAX BILL: ULMER HOCKER 1954

1960er: 1 SERGIO RODRIGUES: Sessel MOLE 1961

1990er: 1 PHILIPPE STARCK: Thermoskanne HOT FREDO 1993

200oer: 1 JORIS LAARMAN: Heizkörper HEATWAVE 2004 


\section{form}

35 Artefakte (davon 28 in der Publikationsreihe Designklassiker)

- Spanne in Jahren: 1981-2006.

- Schwerpunkte: im Ganzen eine Häufung von den 1950ern bis in die 1990er mit einem besonderen Schwerpunkt in den 1950ern und 196oern.

- Geringster Abstand zum Zeitpunkt der Studie: 7 Jahre

\section{form-Buchreihe}

1950er: 4 PETER RAACKE: Besteck MONO 1959 WILHELM BRAUN-FELDWEG: Pendelleuchten HAVANNA 1959 JOHANNES POTENTE: Türklinke 1020 ADRIAN FRUTIGER: Schriftfamilie UNIVERS 1950-1956

1960er: 5 GÜNTER KUPETZ: 1) PERLFLASCHE 1969 FRIEDRICH WILHELM MÖLLER: 2) Polstersystem CONSETA 1964 FERDINAND PORSCHE: 3) PORSCHE 9111963 USM HALLER: 4) MÖBELBAUSYSTEM 1963 WALTER GROPIUS: 5) Teegeschirr TAC 11961

1970er: 3 RICHARD SAPPER: Espressokanne 90901978 Leuchte TIZIO 1972 VOLKSWAGEN: GOLF 1974

1980er: 4 MICHAEL GRAVES: 9093 BIRD KETTLE 1985 CARL F. DAU: RINGE 1985 APPLE: MACINTOSH 1982 KLAUS FRANCK Und WERNER SAUER: THE OFFICE SWIVEL CHAIR 1980

1990er: 5 VOLKSWAGEN: NEW BEETLE 1998 BURKHARDT LEITNER CONSTRUCTIV: CONSTRUCTIV CLIC 1997 RON ARAD: Regal BOOKWORM 1997 RUEDI KÜLLING: XEMEX-Uhren 1996 NOMOS GLASHÜTTE: TANGENTE 1992

200oer: 1 AXEL THALLEMER: PNEUMATISCHER MUSKEL 2001

\section{Zeitschrift form}

1950er: 2 EERO SAARINEN: Stuhl TULIP 1956 HARRY BERTOIA: DIAMOND CHAIR 1952

1960er: 1 GÜNTER FERDINAND RIS: Sofa SUNBALL 1969

1970er: 1 GRUPPO STRUM: Sitzobjekt PRATONE 1971 


\section{STARDESIGNER ODER GESTALTER DES ALLTÄGLICHEN?}

1990er: 1 FERNANDO und HUMBERTO CAMPANA: Sessel VERMELHA 1993

200oer: 2 JORIS LAARMAN: Stuhl BONE CHAIR 2006 MARTEN BAAS: Möbelserie SMOKE 2004 (Doppelcodierung: verbrannte Designklassiker; der Ver fasser)

\section{NZZ}

19 Artefakte.

- Spanne in Jahren: 1919-2009.

- Geringster Abstand zum Zeitpunkt der Studie: 4 Jahre.

1910er: 1 HEINRICH SACHS: BÜROKLAMMER 1919

1920er: 6 CARL SCHMID: 1) FIXPENCIL 1929 LUDWIG MIES VAN DER ROHE: 2) BARCELONA CHAIR 1929 LE CORBUSIER: 3) LC2 1928 EILEEN GRAY: 4) ADJUSTABLE TABLE 1927 5) DAYBED 1925 MARCEL BREUER: 6) Stuhl WASSILY 1925

1930er: 2 HANS CORAY: LANDI-Stuhl 1939 WERNER MOSER: FAUTEUIL 1437 1931

1940er: 4 HULDREICH ALTORFER: ALTORFER Stuhl 1949 ZENA: Sparschäler REX 1947 EAMES: Beinschienen 1942 HANS HILFIKER: SCHWEIZER BAHNHOFSUHR 1940

1950er: 2 EAMES: ALUMINIUM CHAIR und ALUMINIUM GROUP 1958

1970er: 2 EMBRU: Büromöbelprogramm ERGODATA 1978 RICHARD SAPPER: Tischleuchte TIZIO 1971

2000er: 2 DESIGNAGENTUR FREMDKÖRPER: Couchtisch A1 2009 KONSTANTIN GRCIC: Stuhl MYTO 2006 


\section{SCHÖNER WOHNEN}

Die Redaktion von Moderne Klassiker. Möbel die Geschichte machen wartet mit eigenen Maßstäbe für die Auswahl von modernen Klassikern auf:

1. Entwürfe müssen, vom Zeitpunkt der Buch-Publikation aus betrachtet, mindestens zehn Jahre alt sein, sie müssen zudem

2. entweder noch oder wieder produziert werden und

3. von einem bekannten Designer stammen, denn man kaufe ja nicht »[...] ein Möbel der Firma xy. Sondern einen Mies, einen Wegner, einen Eames oder Castiglioni.«(SCHÖNER WOHNEN 1989: 5)

Es findet sich kaum ein besserer Beleg für die Willkürlichkeit dieser Auswahlen, gerade in der Aufstellung jener nur scheinbar strengen Kriterien. Als stabiler Maßstab verbleibt nur die Jahrzehntschranke. Der durchproduzierte und deswegen seltenere Klassiker bekommt die Re-Editionen zur Seite gestellt, was die Auswahlbasis enorm verbreitert. Doch letztere sind nichts als Ergebnisse kuratorischer Entscheidungen, die jeweils einer Firmenpolitik zugrunde liegen, in deren Konsequenz Entwürfe wieder aufgelegt werden. Als letzter Qualitätsmaßstab wird der »bekannte[...] Designer« eingefordert: Doch wer ein bekannter Designer ist, entscheiden vor der Wiederauflage Unternehmer und sowohl davor als auch danach Redaktionen - was sich selbstredend auch gegenseitig beeinflusst. Auf dieser Basis war und ist der mutwilligen Konstruktion und Fortschreibung eines Klassikerkorpus Tür und Tor geöffnet, während seine normative Fassade äußerlich scheinbar gänzlich unberührt bleibt.

1998 wird in der 19. Auflage der gleichen Publikation im Kapitel Wie Klassiker zu ihrem zweiten Leben kommen vergleichsweise Sensationelles festgestellt, wenn man vergleicht, mit welchem hehren Anspruch das Verlagshaus im Jahr 1982 startete:

"Seit dem ersten Erscheinen dieses Buchs, seit 1982, sind Hunderte von Modellen nach 1900, neuerdings auch nach 1945, entdeckt und wieder produziert worden. Die drei Dutzend Möbel und Lampen, die für dieses Kapitel ausgewählt wurden, waren zum Zeitpunkt ihrer Entstehung ganz ungewöhnliche Produkte, unterschieden sich von der Masse des damals Üblichen. Sie waren ihrer Zeit voraus und auch aus diesem Grund nicht unbedingt Bestseller. Noch heute wirken sie modern. Dazu rechnen auch die Entwürfe von Avantgarde-Designern, die, oft zu Unrecht, nicht zu den großen Namen der klassischen Moderne zählen [...] Schließlich gehören zu den Re-Editionen auch Meisterwerke aus den Jahrzehnten nach 1945, die vergessen oder vom Markt verschwunden waren: [...] Kein Möbel der klassischen Moderne und auch keine Lampe ist von der Zeit des Entstehens 


\section{STARDESIGNER ODER GESTALTER DES ALLTÄGLICHEN?}

bis heute kontinuierlich produziert worden [Hervorhebung des Verfassers] - ausgenommen die sJung-Klassiker der letzten Jahrzehnte. Selbst die Herstellung des legendären Thonet-Stuhls Nr. 14 (heute 214) ist seit 1859 zweimal während der Kriegszeiten unterbrochen worden, abgesehen davon, dass er sein Äußeres in einigen Details verändert hat (davon soll später noch die Rede sein). Den Klassikern aus der Zeit vor 1945 bringt erst das zweite Leben nach 1945 allgemeine Anerkennung und - einem Teil wirtschaftlichen Erfolg. (ebd.: 237)

\section{Die Artefaktfunde aus sw im Detail}

Im Ganzen werden 135 Artefakte mit den Begriffen Designklassiker und Designikone bezeichnet - sie sind das Ergebnis der Kombination aus den Internetfunden und dem Poster "99 Designikonen«. Die Moderne(n) Klassiker/ Klassiker von morgen in den Buchpublikationen zählen 493 (386/107)!

- Spanne in Jahren:

Designklassiker 1932-2008

Designikonen 1900-2009

Moderne Klassiker 1859-1987 (in beiden untersuchten Auflagen)

- Geringster Abstand zum Zeitpunkt der Studie:

Designklassiker 5 Jahre

Designikonen 4 Jahre

Moderne Klassiker 27 Jahre

- Schwerpunkte: Für Designklassiker liegt der erste in den 1930ern, ein etwas deutlicherer in den 1960ern, der Spitzenwert in den 1950ern. Die Anzahl der Designikonen liegt in den 1950ern im Vergleich zu allen anderen Jahrzehnten doppelt so hoch. Die Moderne(n) Klassiker weisen ihren Spitzenwert in den 196oern auf (115), knapp vor den 1970ern (96) und mit einem deutlichen Abstand zu den 1950ern (56; das sind dennoch 46 mehr im Vergleich zu den Designklassikern und 38 mehr als die Designikonen). Die 1920er sind mit 41 Funden ebenfalls eine starke Dekade. Der Korpus der 19. Auflage von 1998 ist im Ganzen nahezu identisch, lediglich in den 186oern und 188oern fehlen in der neueren Ausgabe 3 Artefakte.

Der Übersichtlichkeit wegen sind die detaillierten Artefaktfunde aus den swPublikationen in einen Anhang zu diesem Kapitel ausgelagert. 
AM ENDE WAR ES NUR EIN WORT: ZWEI REZEPTIONSSTUDIEN

\section{Süddeutsche}

6 Artefakte.

- Spanne in Jahren: Designklassiker 1925-2008.

- Geringster Abstand zum Zeitpunkt der Studie: 5 Jahre

1920er: 1 MARCEL BREUER: Stuhl WASSILY 1925

1930er: 1 MART STAM: Stuhl S43 1931

1950er: 1 ARNE JACOBSEN: Stuhl 3117 (SERIE 7) 1955

2OOOer: 3 VERNER PANTON: PANTON JUNIOR 2008 PHILIPPE STARCK: LOU LOU GHOST (Kinderversion zum Modell LOUIS GHOST) 2008 LUDWIG MIES VAN DER ROHE: BARCELONA CHAIR Kinderversion 2007 


\section{Anhang}

404 zu den Klassiker-Profilen von SCHÖNER WOHNEN

\section{Designklassiker im Magazin Schöner Wohnen}

1930er: 6 HOLGER NIELSEN: 1) Tritteimer VIPP 1939 2) MORGAN 4/4 1936 BRUNO MATHSSON: 3) Falttisch 1935 WILHELM WAGENFELD: 4) EIERKOCH 1934 5) Porzellan für FÜrstenberg 1933 PIEtro chiesA: 6) Glas-Couchtisch FONTANA 1932

1940er: 2 NISSE STRINNING: Regalsystem STRING 1949 BøRGE MOGENSEN: SPROSSENSOFA 1945

1950er: 10 BØRGE MOGENSEN: 1) SPANISCHER STUHL 1958 2) JAGDSESSEL 1950 EAMES: 3) LOUNGE CHAIR 1956 ARNE JACOBSEN: 4) Hocker 31701955 WILHELM WAGENFELD: 5) Salz- \& Pfefferstreuer ZWILLINGE 1954 JEAN PROUVÉ: 6) Tisch COMPAS 1953 HERBERT KRENCHEL: 7) Schüsseln KRENIT 1953 EAMES: 8) RAR ROCKING CHAIR 1950 JACQUES ADNET: 9) Lederspiegel für HERMÈS 1950 EGON EIERMANN: 10) Stuhl SE68 1950

1960er: 9 VERNER PANTON: 1) BALL LAMP 1969 BONDERUP und THORUP: 2) Hängeleuchte SEMI 1968 ROBERT HAUSSMANN: 3) Freischwinger RH-304 1968 GATTI, PAOLINI, TEODORO: 4) Sessel SACCO 1968 GÜNTER BELTZIG: 5) Kinderstuhl JUNIOR 1966 FRIEDRICH-WILHELM MÖLLER: 6) Sofa CONSETA 1964 HANS BØLLING: 7) Figuren OPTIMIST \& PESSIMIST 1963 CHARLOTTE PERRIAND: 8) Wandleuchte APPLIQUE À VOLET PIVOTANT 1962 ARNE JACOBSEN: 9) Tischleuchte AJ 1960

1970er: 5 ERIK MAGNUSSEN: 1) Thermoskanne EM77 1977 RICHARD SAPPER: 2) Tischleuchte tizio 1974 FRANK GEHRY: 3) Stuhl Wiggle CHAIR 1972 PIERRE PAULIN: 4) Sessel PUMPKIN 1971 EERO AARNIO: 5) TOMATO CHAIR 1971

1980er: 3 HANNES WETTSTEIN: Hocker SPIDER 1988 OSCAR TUSQUETS: GAULINO CHAIR 1987 DE LUCCHI und FASSINA: Tischleuchte TOLOMEO 1987

200oer: 1 TERENCE WOODGATE: Tisch SURFACE 2008 


\section{Moderne Klassiker in der Publikation Moderne Klassiker. Möbel, die Geschichte machen 1989}

186oer: 3 THONET: Schaukelstuhl 8251860 Bugholzstuhl 214 (NR. 14) 1859 anonymer SHAKER: Schaukelstuhl 1860

188oer: 2 THONET: Kaffeehausstuhl NR. 141881 Tisch 10531880

190oer: 13 JOSEF hOFFMANN: 1) Tisch fledermaus 1909 2) Armlehnstuhl FLEDERMAUS 1909 3) Stuhl ARMLÖFFEL 1908 4) Schaukelstuhl 1905 5) Sessel CABInEtT 1903 6) PURKERSDORF-Stuhl 1903 7) Satztische um 1900 FRANK LLOYD WRIGHT: 8) Stuhl 601 ROBIE 1908 9) Armlehnstuhl 606 BARREL 1904/1937 CHARLES RENNIE MACKINTOSH: 10) Sessel WILLOW 11904 11) Stuhl HILLHOUSE 11903 OTTO WAGNER: 12) Deckenlampe TRAMWAY WTR 21900 THONET: 13) Armlehnstuhl 2091900

1910er: 8 CHARLES RENNIE MACKINTOSH: 1) Stuhl D.S.3 1918 2) Tisch 322 D.S.1 1918 3) Anrichte 327 D.S.5 1918 GERRIT THOMAS RIETVELD: 4) Sessel ROOD EN BLAUW 1918 FRANK LLOYD WRIGHT: 5) Tisch 605 ALLEN 1917 KAARE KLINT: 6) Armlehnstuhl FAABORG 1914 JOSEF HOfFMANn: 7) Sofa KUBUS 1910 WALTER GROPIUS: 8) Armlehnstuhl D 511910

1920er: 41 LUDWIG MIES VAN DER ROHE: 1) Armlehnstuhl BRNO (NR. 255) 1929 2) BARCELONA-Sessel 19293 ) Hocker BARCELONA 251 19293) Couchtisch 2591927 4) Stuhl B 421927 EILEEN GRAY: 5) Sofa MONTE CARLO 1929 6) Tisch JEAN 1929 7) Hocker TABOURET 1927 8) Hocker BAR STOOL NR. 1 1927 9) Tisch occasional table 1927 10) Tisch E 1027 1927 11) Stehlampe TUBE-LIGHT 1927 12) Sessel NONCONFORMIST 1926 13) Sessel TRANSAT 1926 14) DAYBED 1925 15) Sofa LOTA 1924 LE CORBUSIER-TEAM: 16) Hocker LC9 1929 17) Armlehn(dreh)stuhl LC7 1929 18) Hocker LC8 19) Drehhocker 1928 20) Liege LC4 1928 21) Sessel LC1 FAUTEUIL À DOSSIER BASCULANT 1928 22) Tisch LC6 1928 23) Regal CASIERS STANDARD 1925 MARCEL BREUeR: 24) Stuhl s 32 1928/1940 25) Armlehnstuhl D 40 1929/1929 26) Sessel D4 1926 27) WASSILIY-Sessel 50-125 1925/1927/1929 28) Satztische LACCIO 1925/1926 29) Kommode S41 E 1924 KAARE KLINT: 30) Hocker KLAPPSTUHL 1927 ALFRED ROTH: 31) Bett 4541927 ÉDOUARD-WILFRID BUQUET: 32) Tischlampe EB 271927 MART STAM: 33) Stuhl S 331926 PETER KELER: 34) Sessel D 1/ 31925 35) BAUHAUS-Wiege 1923 ERICH BRENDEL: 36) Tisch K 101924 WILHELM WAgENFELD: 37) WAGENFELD-Tischlampe 1924 38) Hängelampe L 401920 GERRIT THOMAS RIETVELD: 39) Tisch SCHROEDER 11923 WALTER GROPIUS: 40) Sessel F 511920 unbekannt: 41) Hängelampe OPAL 4119 um 1920

1930er: 36 JORGE FERRARI HARDOY, ANTONIO BONET, JUAN KURCHAN: 1) Sessel HARDOY 1938 HANS CORAY: 2) LANDI-Stuhl 1938 BRUNO MATHS- 


\section{STARDESIGNER ODER GESTALTER DES ALLTÄGLICHEN?}

SON: 3) Tisch MARIA FLAP MI 9011938 4) Sessel PERNILLA 1933-1935 CARL HANSEN: 5) Stuhl CH 18 C 1937/1938 ALVAR AALTO: 6) Liegesessel 391937 7) Servierwagen 981936 8) Sessel 406 1935-1939 9) Hocker K 65 1933/1935 10) Stühle 66 \& 68 1933-1935 11) Hocker 60 1930/1933 12) Tisch 904, 91 1930-1933 13) Sessel 41 (PAIMIO) 1929-1933 PIETRO CHIESA: 14) Tisch 2633 1937 JAC JACOBSEN: 15) Tischlampe LUXO L 11937 MARIO ASNAGO und CLAUdio VENDER: 16) Tisch 1936 GUISEPPE TERAgni: 17) Stuhl LARIANA 1936 KAARE KLINT: 18) Stuhl 41331936 Deckstuhl 1933 19) SAFARI-Stuhl 1933 GABRIELE MUCCHI: 20) Sessel GENNI 1935 GERRIT THOMAS RIETVELD: 21) Stuhl ZIG-ZAG 1934 MOGENS KOCH: 22) MK Anbauwand 1933 23) Kommode 1933 24) Klapptisch 1932 25) Armlehnstuhl MK klappsessel 1932 MARCEL BREUER: 26) Regal S44 1932 LUDWIG MIES VAN DER ROHE: 27) Liegesessel 242 1931/1932 28) Liege 2581928 GIO PONTI: 29) Hängelampe OO24, OO24S 1931 WILHELM KIENZLE: 30) Büchergestell 1930/1932 RENÉ HERBST: 31) Chaiselongue 1930 32) VERNICKELTER STUHL 1930 JEAN PROUVÉ: 33) Sessel D 801930 CHRISTIAN DELL: 34) Wandlampe 15-1192-21-20 1930 35) Tischlampe KAISER IDELL 15-1176-51 1930

1940er: 14 EAMES: 1) Armlehnstuhl DAX 1949/1953 2) Stuhl DSX 1949/ 1951 3) Sessel LCM 1946 4) Tisch CTM 403001011944 NISSE STRINNING: 5) Regal STRING 1949 OLE WANSCHER: 6) Sessel PJ 1491949 HANS J. WEGNER: 7) Sessel JH 5121949 8) Armlehnstuhl DER STUHL (JH 501) 1949 9) Sessel WINDSOR- Oder PFAUENSTUHL 1947 10) Schaukelstuhl J 16 1947 11) Armlehnstühle CHINA-STUHL 1944-1950 BøRGE MOGENSEN: 12) Sofa 2213 1945 13) Tisch 45001945 KAARE KLINT: 14) Hängeleuchte 101 ABC 1943

1950er: 56 POUL KJÆRHOLM: 1) Hocker 331959 2) Sofa 31-3 1958 3) Liege 801957 4) Dreisatztisch 711957 5) Armlehnstuhl 11 1957 6) Sofatisch 61 1956 7) Sessel NR. 221956 ARne JACOBSEn: 8) Tisch a 2221958 9) Sessel SCHWAN 33201958 10) Wandlampe AJ DISKUS 1956 11) Stuhl 31071955 12) Hocker 31701953 13) Stuhl 3100 »DIE AMEISE« 1952 EDELHARD HARLIS: 14) Sofa CALIFORNiA 1958 EAmes: 15) Sessel ALUMiniUm CHAIR EA 1241958 16) Armlehnstuhl EA 1071958 17) Hocker 40135601/ B 1956 18) LOUNGE CHAIR 1956 19) Stuhl DKR2 "WIRE CHAIR 1951 HANS J. WEGNER: 20) Stuhl CH 471958 21) Armlehnstuhl YPSILON (CH 24) 1951 POUL HENNINGSEN: 22) Hängeleuchte PH ZAPFEN 1958 23) Hängeleuchte PH5 1957 ACHILLE Und PIER GIACOMO CASTIGLIONI: 24) Hocker SELLA 1957 25) Hocker MEZZADRO 1957 DIETER RAMS: 26) Regal 571/72 1957 FRANCO ALBINI: 27) Bücherregal LIBRERIA 1957 GASTONE RINALDI: 28) Sofa SATURNO 1957 GIO PONTI: 29) Stuhl SUPERLEGGERA 1957 GIANFRANCO FRATTINI: 30) Sekretär 8041957 BøRGE MOGENSEN: 31) Sessel 22541956 EERO SAARINEN: 32) Tisch 1731956 33) Stuhl TULIP 1956 NANA und JÜRGEN DITZEL: 34) Kinderstuhl 1955 ROBERT HAUSSMAnN: 35) Sofa RH 302-3 1955 Tito AGNOLI: 36) Stehlampe AGNOLI 3871955 GEORGE NELSON: 37) Tisch 5559 1955 38) Tisch 5451-53 1953 HANS EICHENBERGER: 39) Armlehnstuhl 2220 P 1955 YNGVE EKSTRÖM: 40) Schrank FURUBO nr. 37-46 1955 HANS GUGELOT: 41) Regal M 125 1954/1956 OSVALDO BORSANI: 42) Liegesessel P 


\section{AM ENDE WAR ES NUR EIN WORT: ZWEI REZEPTIONSSTUDIEN}

40 1954/1955 43) Sofa D70 1953 ALVAR AALTO: 44) Hocker 6001954 45) Tisch MX 80o B 1954 FLORENCE KNOLL: 46) Sofa 12061954 EGON EIERMANN: 47) Sessel KORBSESSEL E 10 1954 48) Tisch ARBEITSTISCH 1953 49) Stuhl SE 181952 HARRY BERTOIA: 5O) Bank 4001952 51) Sessel 4211952 52) Stuhl 4201952 GINO SARFATTI: 53) Hängeleuchte 2097/30, 2097/50 1952 ISAMO NOGUCHI: 54) Hängeleuchte AKARI 1952 JEAN LOUIS DOMECQ: 55) Tischlampe ST 2/ 400 SR 1951 JEAN PROUVÉ: 56) Tisch 4568 um 1950

196oer: 115 ACHILle CASTiglioni: 1) Hocker PRIMATE 1968 2) Armlehnstuhl CASTIGLIA 1968 3) Stuhl TRIO 1965 4) Tischlampe TACCIA 1962 ANNIG C. SARIAN: 5) Bett ALISSO 1969 VICO MAGISTRETTI: 6) Tisch CAORI 1969 CLAUDIO SALOCCHI: 7) Sofa PAIONE (vorher TALETE) 1969 ERIK RASMUSSEN: 8) PFERDEDECKENSOFA 1969 ROLF HEIDE: 9) Sofabank 1969 10) Stapelliege 223/224 1967 11) Rolltische 7401 und 87011967 TITO AGNOLI: 12) Sofa 90001969 13) Bettcouch 1968 14) Bett L2 1966 15) OTTOMANA P 3 / S 1962 ALDO VAN DE NIEUWELAAR: 16) Tischlampe TC 61969 SERGIO ASTI: 17) Tischlampe DARUMA 1969 RUD THYGESEN und JOHNNY SÖRENSEN: 18) Sessel KÖNIGSMÖBEL 1969 KAZUHIDE TAKAHAMA: 19) Armlehnstuhl KAZUKI 1969 MARCO ALBINI, FRANCA HELG, ANTONIO PIVA: 20) Hängeleuchte AS 41 Z 1969 KLAUS VOGT: 21) Rolladenschrank 107-3 1969 BøRGE MOGENSEN: 22) Schaukelstuhl 2267-68 1968 BJÖRN LINAU und BO LINDEKRANTZ: 23) Hocker S 70-3 1968 R. PAMIO, R. TOSO, N. MASSARI-TOSO: 24) Regal CARIOCA 1968 ANTTI NURMESNIEMI: 25) Liegesessel F 10 (A) OO1 (B) 1968 HORST H. W. BRÜNING: 26) Tisch T 1281968 TOBIA SCARPA: 27) Tischlampe BIAGIO 1968 28) Sofa BASTIANO 53-146 1961 GATTI, PAOLINI, TEODORO: 29) Sessel SACCO 1968 POUL KJÆRHOLM: 30) Sessel NR. 201968 31) Liegestuhl 24196532 ) Stuhl NR. 91960 CARLO SCARPA: 33) Tisch DOGE 1968 PIET HeIN: 34) Tisch SUPERELLIPSE b 41968 JOE CESARE COlombo: 35) Tisch POKER 2511968 36) Stuhl 48671968 37) Stehlampe COUPE 33201967 38) Tischlampe SPIDER 2931966 39) Tischlampe COLOMBO 2811966 40) Sessel eldA 1964 Vico MAgistretti: 41) Tisch STADIO 1968 42) Stuhl SELENE 1967 43) Tische DEMETRIO 45 und 701966 44) Wandleuchte ECLISSE 1966 45) Wandleuchte MANIA 1964 VERNER PANTON: 46) Hängeleuchte FLOWERPOT 1968 47) PANTON-CHAIR 1955/ 1967 ANDERS PEHRSON: 48) Hängeleuchte BUMLING 1968 49) Hängeleuchte SUPERTUBE 1967 GIANCARLO PIRETTI: 50) Klappstuhl PLIA 1967/1968 ANNA CASTELLI-FIERI: 51) Stapelelemente 49701967 GAE AULENTI: 52) Tischlampe PIPISTRELLO 1967 53) Tisch JUMBO 56T 1965 54) Armlehn(klapp)stuhl APRIL 2121964 55) Armlehnstuhl soluS 220 1964 56) Schaukelstuhl SGARSUL 1962 GERD LANGE: 57) Stuhl SM $400 \mathrm{k} 1967$ FRANCO ALBINI: 58) CREDENZA 1967 CEDRIC HARTMAN: 59) Stehlampe BACKSLIDER 1966/1967 GIANFRANCO FRATTINI: 60) Satztische 7801966 MARIO BELLINI: 61) Tische I QUATTRO GATTI 1966 62) Sofa AMANTA 1966 GINO SARfatti: 63) Tischlampe 600 P 1966 Angelo MAngiarotti: 64) Tischlampe LESBO 1966 ALDO JACOBER: 65) Stuhl FIERA DI TRIESTE 1966 HELMUT BÄTZNER: 66) Stuhl BA 1171 (BOFINGER-Stuhl) 1966 WILLIE LANDEIS: 67) Sofa THROW AWAY 1965/1967 ELIO MARTINELLI: 68) Tischlampe 599 SER- 


\section{STARDESIGNER ODER GESTALTER DES ALLTÄGLICHEN?}

PENTE TAVOLO 1965 69) Deckenleuchte BOLLA (Blase) 1965 ETTORE SOTTSASS: 70) Tisch LOTOROSSO 1965 BøRGE MOGENSEN: 71) Tisch 6288, 6286 1965 72) Sessel 22041964 73) Armlehnstuhl 3239 1964 74) Satztisch 5377 A+B 1963 75) Armlehnstuhl ASSERBO 5041961 ACHILLE und PIER GIACOMO CASTIGLIONI: 76) Hängeleuchte BLACK \& WHITE 1965 77) Deckenleuchte LIGHTBALL 1965 78) Stehlampe TOLO 1962 79) Stehlampe ARCO 1962 80) Hängeleuchte SPLÜGENBRÄU 1961 AFRA und TOBIA SCARPA: 80) Vitrine TORCELLO NOCE 120491965 HANS J. WEGNER: 81) Sessel CH 441965 AUGUSTO SAVINI: 82) Armlehnstuhl PAMPLONA 1964/1965 LEILA und MASSIMO VIGNELLI: 83) Sofa SARATIGO D 85/2 PREBEN FABRICIUS und JÖRGEN KASTHOLM: 84) Sofa 6722 A 1964 85) Schalensessel 6725 TULPE 1964 MARCO ZANUSO und RICHARD SAPPER: 86) Sessel WOODLINE 1964 BRUNO MUNARI: 87) Hängeleuchte FALKLAND 2040 a 1964 EAMES: 88) Säulenfußtisch 1964 SILVIO COPPOLA: 89) Tisch 6121964 90) CREDENZA 603 SCANTONATA 1964 JENS MøLLER-JENSEN: 91) Deckenleuchte ALBERTSLUND 1964 TEAM FORM AG/PETER MALY: 92) Regal S 40/4O SN 1963 DIETER REINHOLD: 93) Regal WK 4701963 NANA DITZEL: 94) Wiege 1963 95) Hocker TIP-TOP NR. 311-314 1962 EDLEF BANDIXEN: 96) Tisch 5307 oder 20001963 ARNE JACOBSEN: 97) Armlehnstuhl 42351963 98) Hängeleuchte AJ PENDEL 1960 99) AJ Tischlampe 1960 DAVID ROWLAND: 100) Stuhl GF 40/ 41963 RUDOLF FRANK: 101) Sammlerschrank 1963 ULRICH P. WIESER: 102) UPW-Regal 1962 FRITZ HALLER: 103) USM HALLER Bürosystem 1962 FRIEDRICH-WILHELM MÖLLER: 104) Sofa CONSETA 1962 OLE WANSCHER: 105) Stuhl PJ 341962 106) Tisch PJ 24 1961/1962 107) Armlehnstuhl PJ 301 1961/1962 GIANDOMENICO BELOTTI: 108) SPAGHETTI-CHAIR 1962 DIETER RAMS: 109) Sesselprogramm 6201962 110) Regal 606 1960 111) Sessel 6021960 GRETE JALK: 112) Drehhocker 1961113 ) Stehpult 1961 FLORENCE KNOLL: 114) Sideboard 25481961 ANDREAS CHRISTEN: 115) Stapelbett 1960

1970er: 97 OTTO ZAPF: 1) Regal MANAGEMENT OFFICE 1977 CARLO SCARPA: 2) Regal LIBRERIA SERIE 193519773 ) Bett TOLEDO 1975 4) Schrank ZIBALDONE 1974 5) Tisch VALMARANA 1972 SIEGFRIED L. BENSINGER: 6) Sofa DIWAN 1977 VICO MAGISTRETTi: 7) Tischlampe ATOLLO 1977 8) Wandleuchte PORSENNA 1977 9) Regal NUVOLA ROSSA 1974 10) Hängeleuchte SNOW 1974 11) Sofa MARALUNGA 1973 GIOTTO STOPPINO und LODOVICO ACERBIS: 12) Sideboard SHERATON SH-2 1977 GIOVANNI OFFREDI: 13) Kommode BAULETTO 1977 14) Tisch CAVALETTO 1975 15) Tisch TeBE 1970 MARCELLO MORANDINI: 18) Schrank 18 D 1977 PETER MALY: 19) Vitrine QUADRAT 1977 ROBERT und TRIX HAUSMANN: 20) Rolladenschrank 1977 HANS EICHENBERger: 21) Sekretär 1977 22) Sessel HE 1106.001977 ENZO MARI: 23) Tisch CAPItello tONDO E 1977 24) Wandleuchte AggREgato BRACCIO 110 1974/1976 25) Stuhl DELFINA 1974 26) Tisch FRATE 1973/1974 27) Bett DAY-NIGHT 1971/1972 28) Stuhl BOX 1971 29) Stuhl SOF-SOF 1971 BRUNO NINABER: 30) Hängeleuchte TL RÖHRENLAMPE 1977 INGO MAURER: 31) Hängeleuchte HANA I 1977 NILS JøRGEN: 32) Stuhl SXS 1976/1977 CINI BOERI: 32) Tischlampe ABAT-JOUR 1976 33) Sofa STRIPS 1972 ELIO MARTINELli: 34) Tischlampe FLEX CALOTTA 1976 35) Hängeleuchte 1849 


\section{AM ENDE WAR ES NUR EIN WORT: ZWEI REZEPTIONSSTUDIEN}

LAMPARA 1974 TOMMASO CIMINI: 36) Stehleuchte DAPHINE 1976 ACHILLE CASTIGLIONI: 37) Stehlampe BIBIP 1976 38) Bodenlampe NOCE 11972 39) Tischlampe IPOTEnUSA 1972 40) Tisch SERVO MUTO 1970 PAUL TUTTLE: 41) Sessel ARCO 1976 42) Schaukelstuhl NONNA 1972 MARIO BELLINI: 43) Bett Coupé 1976 44) Stuhl 412 CAB 1977 45) Tisch 455 COlonnato ALTO 1977 46) Tisch 451 LA BASILICA 1976 47) Armlehnstuhl 401 BREAK 1976 48) Hängeleuchte AREA 50 1974 49) Bett BAMBOLETTONE 1972 DE PAS, D'URBINO, LOMAZZI: 50) Hocker GIOTTO 1975 51) Sessel FLAP 1973 KAZUHide TAKAHAMA: 52) Stehlampe SiRIO T 1977 53) Tisch Antella 1977 54) Tischlampe KAORI 1975 55) Kommode BRAMANTE 1975 56) Sessel SAGHI 1970 57) Schrank OLINTO 121970 GIGI SABADIN: 58) Tisch DAVIDE 1975 59) Stuhl ARCA 1973 PIERO DE MARTINI: 6o) Tisch LA BARCA 1975 HANS J. WEGNER: 61) Armlehnstuhl 621975 62) Armlehnstuhl JH 701 1970 RICHARD SAPPER: 63) Regal GENIA 1974 64) Tischlampe TIZIO 1970 BRUNO MUNARI: 65) Regal VADEMECUM 1974 66) Bett ABITACOLO 1971 TEAM FORM AG: 67) Regal MEDIUM PLUS 1974 ISAO HOSOE: 68) Tischlampe TAMA 1974 69) Tischlampe HEBI 1970 BRUNO GECCHELIN: 70) Stehlampe MEZZALUNA T 1974 71) Stehlampe DOMEA 1974 ÖRNI HALLOWEEN: 72) Hängeleuchte MACUMBA 1974 GERD LANGE: 73) Stuhl 2200 1973/1974 TOBIA SCARPA: 74) Wandleuchte ARIETTE 1, 2, 31973 PAOLO RIZZATtO: 75) Wandleuchte 2651973 PAOLO DEGANELLO/ARCHIZOOM: 76) Sessel AEO 1973 ROBERTO PAMIO: 77) Bett TAI 1972 BÖRGE LINDAU Und BOP LINDEKRANTZ: 78) Armlehnstuhl X75-2 1972 ULRICH BÖHME: 79) Schaukelstuhl S 8261971 JOE CESARE COLOMBO: 80) Hocker BIRILlO 1971 81) Container BOBY 3-2/C 1971 82) Stehlampe 6261971 ANGELO MANGIAROTTI: 83) Tisch EROS P 901971 GUISEPPE RAIMONDI: 84) Vitrine CRISTAL SYSTEM 1971 MARCO ZANUSO: 85) Tisch MARCUSO 2541971 GAE AULENTI: 86) Tisch FESTO 1971 RODNEY KINSMAN: 87) Stuhl OMK-STACK 1971 ADOLFO NATALINI, SUPERSTUDIO: 88) Tisch QUADERNA 283 (260) 1970/1971 ALESSANDRO BECCHI: 89) Sofa ANFIBIO 1970 BøGE MOGENSEN: 90) Tisch 6300, 63101970 RUD THYGESEN und JOHNNY SøRENSEN: 91) Hocker BO 4550 1974 92) Tisch MO 45551970 93) Armlehnstuhl KARMSTOL MO 54411970 ANDREW IVAR MORRISON Und BRUCE R. HANNAH: 94) Sessel 20311970 PIO MANZÙ und ACHILLE CASTIGLIONI: 95) Spannlampe PARENTESI 1970 RODOLFO BONETTO: 96) LINEARSYSTEM 1970 ANTTI NURMESNIEMI: 97) Liegesessel TUOLI 1968/1970

1970er: Klassiker von morgen: 16 ANNA CASTELLI-FIERI: 1) Hocker 4822/23/ 24/25 1979 ENZO MARI: 2) Bett POLLENA 1979 LEILA und MASSIMO VIGNELli: 3) Tisch METAFORA 1979 ACHILLE CASTiglioni: 4) Tisch Cumano 1979 5) Hängeleuchte FRISBI 1978 ALEXANDER BLOMBERG, JAN WICHERS: 6) Tisch DOMINO 1979 FRANCESCO SORO: 7) Sofa SIGLO 2O-102 1979 ANTONIO CITTERIO Und PAOLO NAVA: 8) Sofa DIESIS 1979 VICO MAGISTRETTI: 9) Tischlampe NEMEA 1979 GIANFRANCO FRATtini: 10) Stehlampe MEGARON 1979 MASAYUKI MATSUKAZE / CENTROKAPPA: 11) Armlehn(klapp) stuhl 5/4820 1979 STEFAN WEWERKA: 12) Tisch M 21979 AFRA und TOBIA SCARPA: 13) Tisch PIEdiferRo 1979 ETtORE SOtTSASS: 14) Tisch LE 


\section{STARDESIGNER ODER GESTALTER DES ALLTÄGLICHEN?}

STRUTTURE TREMANO 1978 ANGELO MANGIAROTTI: 15) TISCH INCAS E 2001978 ALDO VAN DE NIEUWELAAR: 16) AMSTERDAMER SCHRÄNKE 1978

1980er: Designklassiker: -

1980er: Klassiker von morgen: 92 ADOLFO NATALINI: 1) Tisch QUATTRO 1987 ARNO VOTTELER: 2) Armlehnstuhl s 12.101987 JOEY MANCINI und ADAM TIHANY: 3) Stuhl DUfKey 1987 AnNA CASTElli-Fieri: 4) Hocker 48101986 ACHILLE CASTIGLIONI Und CIANCARLO ROZZI: 5) Bett ITITITI 1986 PETER SHIRE: 6) Sofa BIG SUR 1986 MASSIMO MOROZZI: 7) Sofa DOMINO 1986 8) Tisch TANGRAM 1984 9) Bett WINSTON 1984 ACHILLE CASTIGLIONI: 10) Tisch DUETI 1986 11) Tischlampe GIBIGIANA 1981 MARIO BOTTA: 11) Armlehnstuhl QUINTA 1986 12) Armlehnstuhl SECONDA 1982 KISHO KUROKAWA: 13) Stuhl EDO 11986 TOBIAS GRAU: 14) Niedervoltsystem LUJA 1986 ROLF HEIDE: 15) Niedervoltsystem TANTRA 1986 PHILIPPE STARCK: 16) Hocker SARAPIS 1985 17) Sessel RICHARD III./PS 215 1985 18) Hocker MISS WIRT 1983 19) Regal MAC GEE/PS 2091983 20) Regal JON LID 1982 21) Tisch COSTES 1982 22) Armlehnstuhl COSTES 1982 23) Tisch TIPPY JACKSON 1981 LUCA MEDA: 24) Liege LES BEAUX JOURS 1985 CARLO FORCOLINI: 25) Tisch KARATE 1985 26) Wandleuchte ICARO 1985 27) Tisch APOCALYPSE NOW 1984 28) Stehlampe POLIFEMO 1983 29) Deckenleuchte ALESIA 1982 PAOlO DEGANELLO: 30) Tisch ARTIFICI 1985 31) Sessel torso 1982 32) Sofa SQUASH 1981 ANTONIO CitTERIO: 33) Sofa SITY 1985 ANTONIO CITTERIO und PAOLO NAVA: 34) Armlehnstuhl IALEA 1980 PAOLO RIZZATTO und ALBERTO MEDA: 35) Tischlampe BERENiCE D 121985 PAOLO RIZZATTO und SANDRO COLBERTALDO: 36) Deckenleuchte D 71981 PAOLO RIZZATTO und SANDRA SEVERI SARFATTI: 37) Wandleuchte D $5 a 1981$ MICHELE DE LUCCHI: 38) Tischlampe MECCANICA 1985 39) Tisch CONTINENTAL 1984 40) Tisch FLAMINGO 1984 MARIO BARBAGLIA und MARIO COLOMBO: 41) Tischlampe DOVe 1985 GerD lange: 42) Sessel DS 125/O1 1985 43) Regal WOGG 11983 JOACHIM FLACKE: 44) Kommode LIFE SERVICE 1985 DIETER RAMS: 45) Tisch 8601985 GIANCARLO PIRETTI: 46) Tisch DILUNGO 1985 INGO MAURER: 47) Niedervoltsystem YAYAHO 1985 BEN LÜBBERS/DIJKSTRA DESIGN TEAM: 48) Niedervoltsystem TROLLY 1985 PAOLO PALLUCCO: 49) Regal FRA' DOLCINO 1984 THOMAS SCHWEBEL: 50) DAS FUTON-BETT 1984 ANDREAS CHRISTEN: 51) Bett LEHNI 1984 JAN ARMGARD und INGO MAURER: 52) Klappliege TATTOMI 1984 PETER MALY: 53) Sofa ZYKLUS 1984 ANTONIA ASTORI: 54) Schrank AFORISMI 1984 55) Regal OIKOS DUE 1982 KAIROS (MASSIMO BONETTI, GUISEPPE MANENTE, ABRAMO MION): 56) Schrank SISAMO 1984 GIANFRANCO FRATTINI: 57) Sekretär SESAMO 1984 DANIELA PUPPA: 58) Deckenleuchte OLAMPIA 1984 MAURIZIO PEREGALLI: 59) Armlehnstuhl 107/112 1984 VLADIMIR HARDARSON: 60) Armlehnstuhl SOLEY 2750/3 1984 DE PAS, D'URBino, LOMAZZI: 61) Stuhl PALMIRA 1984 62) Sessel CAMPO 1984 63) Deckenleuchte SIDONE 1983 64) Liege GRAND' ITALIA 50/11 1980 HERBERT und JUTTA OHL: 65) Sessel CIRCO 1984 66) Stuhl SWING 1983 PASCAL MOURGUE: 67) Sessel ARC 1984 VICO MAGISTRETTI: 68) Sessel VERANDA 


\section{AM ENDE WAR ES NUR EIN WORT: ZWEI REZEPTIONSSTUDIEN}

1984 AFRA und TOBIA SCARPA: 69) Vitrine BISANTE 14.06 1981/1984 RODNEY KINSMAN: 70) Regal GRAFFITI 1983 ETTORE SOTTSASS: 71) Tischlampe PAUSANIA 1983 72) Sessel EASTSIDE 1983 73) Sessel WESTSIDE 1983 74) Stehlampe CALLIMACO 1982 75) Regal CARLTON 198176) Ecktisch CANTONE 1981 HANS EICHENBERGER: 77) Schrank WOGg 81983 PERRY A. KING: 78) Niedervoltsystem EXPANDED LINE KIT 1983 LIVIO und PIERO CASTIGLIONI: 79) Niedervoltsystem SCINTILLA 1983 JEAN MARC DE COSTA: 80) Deckenleuchte LIFT 1983 PELIKANDESIGN, N. GAMMELGAARD / L. MATHIESEN: 81) CAFÉ-STUHL 1983 HANNES WETTSTEIN / DESIGNSTUDIO ARCA: 82) Niedervoltsystem METRO 1982/1983 ERIK KROGH: 83) HVILESTOL (Liege) 1982 ANDREA BELLOSI: 84) Tischlampe ARC EN CIEL (Regenbogen) 1982 HERBERT OHL: 85) Stuhl O-LINIE 1982 CHARLES POLLOCK: 86) Armlehnstuhl PENELOPE 1982 JAVIER MARISCAL: 87) Servierwagen HILTON 1981 CINI BOERI: 88) Schrank DOUBLE FACE 1981 PAOLO PIVA: 89) Sofa ALANDA 1980 GAETANO PESCE: 90) Tisch SANSONE 1980 FRANCESCO SORO: 91) Tisch JONATHAN L. 1980 TOSHIYUKI KITA: 92) Sessel WINK 1980

\section{Designikonen auf dem Poster 99 Designikonen aus 11 Jahrzehnten}

1910er: 9 GERRIT THOMAS RIETVELD: 1) ROT-BLAUER STUHL 1918 JOSEF HOfFmann: 2) Sessel KUbUS 1910 FRAnK Lloyd Wright: 3) Stuhl 601 ROBIE 11908 OTTO BLÜMEL: 4) Garderobe NYMPHENBURG 1908 MARIO FORTUNY Y MADRAZO: 5) Stehleuchte FORTUNY MODA 1907 JOSEF HOFFMANN: 6) Stuhl SITZMASCHINE 1908 7) SILBERBESTECK NR. 1351905 CHARLES RENNIE MACKINTOSH: 8) Stuhl 312 WILLOW 11904 THONET: 9) Bugholzstuhl 2091900

1920er: 9 LUDWIG MIES VAN DER ROHE: 1) Stuhl BARCELONA 1929 ADOLF LOOS: 2) Trinkservice NO. 2481929 LE CORBUSIER, PIERRE JEANNERET, CHARLOTTE PERRIAND: 3) Liege CHAISELONGUE LC4 1929 LUDWIG MIES VAN DER ROHE: 4) FREISCHWINGER S 533 R 1927 EILEEN GRAY: 5) ADJUSTABLE TABLE E 10271927 MARCEL BREUER: 6) Faltsessel TECTA D4 1926 7) Sessel WASSILY 1925 8) Satztische B9 1925 WILHELM WAGENFELD: 9) BAUHAUSLEUCHTE WA 241924

1930er: 9 HANS CORAY: 1) LANDI-Stuhl 1938 ALVAR AALTO: 2) Vase SAVOY 1936 3) Hocker STOOL 601933 4) Sessel PAIMIO 1930 GERRIT THOMAS RIETVELD: 5) Stuhl Zig-ZAG 1934 GEORge CARWARDine: 6) Tischleuchte ANGLEPOISE 12271934 JEAN PROUVÉ: 7) STANDARD CHAIR 1934 MART STAM: 8) Freischwinger S 431931 CHRIsTIAN DELL: 9) Tischleuchte KAISER IDELL 66311931

1940er: 9 NISSE STRINNING: 1) Wandregal STRING 1949 HANS J. WEGNER: 2) THE CHAIR (PP 5O1) 1949 EERO SAARINEN: 3) WOMB CHAIR 1948 EAMES: 4) Liegesessel LA CHAISE 1948 5) LCW LOUNGE CHAIR WOOD 1945 


\section{STARDESIGNER ODER GESTALTER DES ALLTÄGLICHEN?}

GEORGE NELSON: 6) BALL CLOCK 1948 7) BUBBLE LAMP SAUCER 1947 ISAMO NOGUCHI: 8) COFFEE TABLE 1944 FINN JUHL: 9) PELICAN CHAIR 1940

1950er: 18 NORMAN CHERNER: 1) CHERNER ARM CHAIR 1958 ARNE JACOBSEN: 2) Sessel SCHWAN 1958 3) Sessel eI 1958 Poul HenningSen: 4) Hängeleuchte PH ZAPFEN 1958 GIO PONTI: 5) Stuhl SUPERLEGGERA 1957 EERO SAARINEN: 6) PEDESTAL COLLECTION Tisch TULIP 1956 7) PEDESTAL COLLECTION Stuhl TULIP 1956 GEORGE NELSON: 8) Sofa MARSHMALLOW 1956 9) COCONUT CHAIR 1955 10) PRETZEL CHAIR 1952 ILMARI TAPIOVAARA: 11) Stuhl MADEMOISELLE 1956 EAMES: 12) LOUNGE CHAIR 1956 ARNE JACOBSEN: 13) Stuhl 31071955 SORI YANAGI: 14) BUTTERFLY STOOL 1954 SERGE MOUILLE: 15) Stehleuchte 1953 HARRY BERTOIA: 16) DIAMOND CHAIR 1952 HANS J. WEGNER: 17) WISHBONE CHAIR ( $\mathrm{CH} \mathrm{24)} 1950$ anonym: 18) ACAPULCO CHAIR 1950er

1960er: 9 BONDERUP und THORUP: 1) Hängeleuchte SEMI 1968 GATTI, PAOLINI, TEODORO: 2) Sitzsack SACCO 1968 INGO MAURER: 3) Tischleuchte BULB 1966 POUL KJARHOLM: 4) Liegesessel PK 241965 JOE CESARE COLOMBO: 5) Sessel ELDA 1964 VERNER PANTON: 6) PANTON CHAIR 19621967 EERO ARNIO: 7) BALL CHAIR 1963 FRIEDRICH-WILHELM MÖLLER: 8) Sofa CONSETA 1963 ACHILle und Pier Giacomo CAStiglioni: 9) Stehleuchte ARCO 1962

1970er: 9 VICO MAGISTRETTI: 1) Tischleuchte ATOLLO 1977 ERIK MAGNUSSEN: 2) Thermoskanne EM77 1977 studio DDL: 3) Garderobe SCIANGAI 1973 MICHEL DUCAROY: 4) Sofa togo 1973 RICHARD SAPPER: 5) Tischleuchte TIZIO 1972 FRANK GEHRY: 6) WIGGLE CHAIR 1972 GUFRAM: 7) Garderobe CACTUS 1972 JOE CESARE COLOMBO: 8) Container BOBBY 1970 ACHILLE und PIER GIACOMO CASTIGLIONI: 9) Tischleuchte SNOOPY 1970

1980er: 9 JASPER MORRISON: 1) PLY CHAIR 1988 2) THINKING MAN'S CHAIR 1986 SHIRO KURAMATA: 3) Sessel HOW HIGH THE MOON 1986 RICHARD SAPPER: 4) Wasserkessel 90911983 MICHELE DE LUCCHI: 5) Stuhl FIRST 1983 PHILIPPE STARCK: 6) Stuhl COSTES 1982 ETTORE SOTTSASS: 7) Raumteiler CARLTON 1981 GAE AULENTI: 8) Beistelltisch TAVOLO CON RUOTE 1980 TOSHIYUKI KITA: 9) Sessel WINK 1980

1990er: 9 INGO MAURER: 1) Hängeleuchte ZETTEL'Z 1997 MARCEL WANDERS: 2) KNOTTED CHAIR 1996 PHILIPP MAINZER: 3) Hocker BACKENZAHN 1996 RON ARAD: 4) Bücherregal BOOKWORM 1994 RODY GRAUMANS: 5) Hängeleuchte 85 LAMPS 1993 MARC NEWSON: 6) WOODEN CHAIR 1992 FERNANDO Und HUMBERTO CAMPANA: 7) FAVELA CHAIR 1991 TOM DIXON: 8) S-CHAIR 1991 PHILIPPE STARCK: 9) Zitronenpresse JUICY SALIF 1990

200oer: 9 NAOTO FUKASAWA: 1) Sessel GRANDE PAPILIO 2009 STEFAN DIEZ: 2) Stuhl hOUdini 2009 RonAn und ERWAN BOUROUlLeC: 3) Stuhl 
AM ENDE WAR ES NUR EIN WORT: ZWEI REZEPTIONSSTUDIEN

VEGETAL 2008 HELLA JONGERIUS: 4) Sofa POLDER 2005 PATRICIA URQUIOLA: 5) Hängeleuchte CABOCHE 2005 KONSTANTIN GRCIC: 6) CHAIR ONE 2004 7) Leuchte MAYDAY 2000 PHILIPPE STARCK: 8) Sessel LOUIS GHOST 2002 ALFREDO HÄBERLI: 9) Weingläser ESSENCE 2001 


\section{Welche Beweiskraft haben diese Profile?}

Die Hypothese, dass der FRANCKsche Aufmerksamkeitsbegriff auf Artefakte ebenso angewendet werden kann wie auf Personen, darf auf Basis der dargestellten Profile als belegt gelten. Designklassiker können (wie die Design-Ikonen) als artefaktische Äquivalente zur Star-Designerin oder dem Star-Designer aufgefasst werden. Außerdem zeigen sie, dass es normierte oder auch nur in Ansätzen normierbare Ideen oder publizistisch gesehen allgemeingültige Vorstellungen von vorbildhaften Formen nicht gibt, die greifbar festhalten würde, was und wann diese seien. So, wie es keine wirkliche Übereinstimmung darüber gibt, wann und was Designklassiker, Designikonen oder Moderne Klassiker seien.

162 Artefakte bei A\&W und 628 bei sw weisen jedenfalls auf die Stellen hin, an denen die Deutungshoheit beansprucht zu werden scheint. Fehlende publikationsübergreifende Übereinstimmungen einerseits sowie eine gewisse Einigkeit trotz aller Differenz zwischen A\&W und sw (bei denen eine starke Konkurrenzsituation im gleichen Marktsegment anzunehmen ist), sind der beste Beleg für unterschiedliche Aufmerksamkeitsreliefs und daraus resultierende Favorisierungen. Daran wird deutlich, dass es faktisch keine Bewertungsmaßstäbe gibt, die als gesichert gelten können und über das hinausgehen, was im Rahmen materialgerechter Produktion und im Hinblick auf seinen Gebrauch von einem Artefakt selbstverständlich erwartet werden darf.

Entscheidungen solch eher zweckrationaler Prägung trifft man bestenfalls im Rahmen des BUNDESPREIS GUTE FORM/DESIGNPREIS DER BUNDESREPUBLIK DEUTSCHLAND, des IF-DESIGNAWARD oder auch beim RED DOT DESIGN AWARD an. Womöglich aber aufgrund einer Inflationierung der Preise und weiterer Vorkommnisse auch dort nicht mehr, nachdem die Berechtigung, den Bundesdesignpreis ausrichten zu dürfen, dem RAT FÜR FORMGEBUNG 2006 entzogen wurde: (DESIGNTAGEBUCH) [online] https://www.designtagebuch.de/ quo-vadis-designpreise-in-deutschland/ [06.03.2018].

Gleichwohl wird nach diesen wertmaßstäblich betrachtet ernüchternden Untersuchungsergebnissen im Weiteren weder nach strengeren Bewertungskriterien für Designklassiker gesucht noch ein Bewertungskanon angestrebt, der in die Zukunft weisen soll. Es kann ihn nicht mehr geben, da es sich um Geschmacksentscheidungen auf unterschiedlichsten Ebenen handelt, die, wie im Kapitel zur Aufmerksamkeit zuvor schon zu sehen war, von individuellen Aufmerksamkeitsreliefs und nicht mess- oder standardisierbaren Rahmenbe- 
dingungen unterschiedlichster Art abhängig sind. Was ebenfalls nicht außer Acht gelassen werden darf, ist, dass die Bewertung von Artefakten, wie sie hier für den deutschsprachigen Raum gezeigt wird, schon moralisch-ideologisch vorgeprägt sein könnte - durch bestehende Traditionen der GUTE(n) FORM, aber auch schon aus der davor aufgekommenen Idee der Geschmackserziehung und Volksbildung heraus. Diese manifestierte sich nach dem zweiten Weltkrieg in einem typisch deutschen Design und erreichte in der Gründung der HFG ULM einen zweiten und letzten Höhepunkt, bevor die GUTE FORM im Ulmer Neo-Funktionalismus implodierte. In anderen Ländern können völlig andere und ebenso unterschiedliche Vorstellungen über Designqualität bestehen, die in der vorliegenden Untersuchung gar keine Rolle gespielt haben.

Das NEUE DEUTSCHE DESIGN lässt in seinem Aufkommen wie in seinen Ausprägungen - im Verein mit der öffentlich wahrnehmbare Nobilitierung der Disziplin im Rahmen der Documenta 8 (vgl. CACCIOLA 2008: 21) - die Wurzel einer bis heute andauernden Entwicklung sichtbar werden, sich innerhalb der Disziplin den Fesseln einer gefühlten Festlegung auf normative Standards zu entziehen. Sie führt letztlich zum Autorendesign, das Strategien aus dem Bereich der Bildenden Kunst in den Handlungsrahmen des Designs zu transferieren sucht. 


\section{Käufer unterwerfen sich den Klassikern}

Wer einen Klassiker erwirbt und damit diesem Wertmaßstab folgt - sowie gleichzeitig unterstreichenden Ausdruck verleiht - der leistet individuelle Unsicherheitsabsorption - ein Begriff, der hier so verwendet wird wie bei HUBER in Bild Beobachter Milieu (2004) und ganz bewusst nicht im Sinne der Organisations- und Wirtschaftssoziologie verstanden:

"Soziale Systeme oder Milieus entwickeln bestimmte Routinen, Gewohnheiten oder ritualisierte Vorgehensweisen zur Absorption von Unsicherheit. [Hervorhebung des Verfassers] So kann ein besonderes Vokabular gewählt und benutzt werden, um sich gegen massive Unsicherheit zu schützen, ohne damit jedoch die Option aufzugeben, besondere Unsicherheiten auch als solche thematisieren und bezeichnen zu kön nen. So verwendet zum Beispiel die Kunstkritik einen besonderen Wortschatz, um Unsicherheiten abzuschaffen, der Kompetenz, Durchblick und Expertentum suggeriert, oder kunsthistorische Pleonasmen wie NeoGeo, Zweite Moderne, Kontextkunst, um durch eine scheinbar fachspezifische Etikettierung aufkeimende Unsicherheiten zu beheben.« (HUBER 2004: 192)

HUBER langt kurz danach beim Verstehen als Mittel zur Disziplinierung an und katapultiert uns damit unversehens zurück in den Diskurs um Aufmerksamkeitsregime und in die Disziplinargesellschaft (!):

"Verstehen dient der Disziplinierung und Kontrolle von richtigem (Hervorhebung im Original) Verhalten. Verstehen ist ein Disziplinierungsinstrument im Rahmen konventionalisierter Strategien zur Absorption von Unsicherheit. Die Sicherheit des Beobachters wird im Verstehen mit Unterwerfung bezahlt. Im Verstehen als einem standardisierten Ritual von Unsicherheitsabsorptionen entsteht das Subjekt als ein Unterworfenes." (ebd.: 193)

Ein weiterer Aspekt der Unsicherheitsabsorption in der Form der Auswirkungen des Expertentums wird in Rethinking Subpolitics: Beyond the sIron Cage of Modern Politics? von HOLZER und SøRENSEN (2003) beschrieben: Im Feld der Politik müssen Politiker in diesem speziellen Fall ihre Kritik an etwas auf den Konzepten derjenigen aufbauen, die sie ggf. kritisieren, womit jene Experten jeder Diskussion schon im Vorfeld ihren Stempel aufgedrückt haben:

"To some extent, politics cannot help but rely on the uncertainty absorption provided by scientists, engineers and their representatives, for example, their professional bodies. By the very nature of their subject matter, 
experts are able to impose their definition of reality on others - including actors in the political system. Current debates about the possibilities and risks of genetic engineering show how even the fiercest criticism has to rely on the concepts and agenda formulated by scientists."(HOLZER und SøRENSEN in: Theory Culture Society 2003; 20; 94) [online] https:// people.ucsc.edu/ rlipsch/migrated/Pol272/Holzer.pdf [27.12.2018]

Setzt man im Sinne von HOLZER und SøRENSEN zu einer Kritik der Wertmaßstäbe für Designklassiker etc. an, so muss diese Kritik sich an den vermeintlichen Wertmaßstäben jener abarbeiten, die wie in HUBERs Beispiel schon Scheinmaßstäbe angehäuft haben, mit denen sie der Diskussion bereits eine sichtbar wirkmächtige Richtung gaben. HUBERs Vorlage bedeutet in einer direkten Übertragung auf den Designmarkt, dass die Käufer sich den Urteilen von Experten und damit auch den von jenen gekürten Designklassikern unterwerfen, um individuelle Unsicherheitsabsorption zu betreiben. Designklassiker, Design-Ikone und Moderner Klassiker sind aus dem Munde der Experten nur noch Begriffe, die »Kompetenz, Durchblick und Expertentum suggerier[en]« sollen, letztlich aber auch nur die aufkeimenden Unsicherheiten der vermeintlichen Experten beseitigen helfen.

Anhand von HUBER und HOLZER lässt sich argumentieren, dass Ego als Subjekt in der disziplinarischen Gesellschaft mutwillig wieder zum Objekt werden kann und so ist Expertentum in der Folge als eine Herrschaftstechnik innerhalb derselben zu verstehen - mit der vermeintlichen Kanonisierung von Designklassikern als einer direkten Auswirkung davon. Selbst unter der Annahme einer starken »Interiorisierung [Hervorhebung im Original] disziplinärer Imperative« (CRARY 2002: 64) hören externe Bestrebungen zur Normierung damit jedoch nicht auf: Auch, wenn es keine Einigkeit in Bezug auf das Design gibt, muss ja die aufkeimende Unsicherheit der Käufer für ein sinnstiftendes Identitätssampling ebenso behoben werden wie die Unsicherheit der Experten .... 


\section{Die Supra-Designklassiker}

Die Artefaktprofile der 13 untersuchten Publikationen werfen die Frage auf, wie sich in der Qualität des Ausdrucks auch für diese eine vergleichbare Steigerungsebene mit den Star-Designern erreichen ließe. Beantwortet wird sie mit der Einführung der Komposita Supra- und Supra²-Designklassiker. Erstere sollen das artefaktische Äquivalent zum Star-Designer bezeichnen, letztere entstehen (zusammen mit Supra²-Designern), wenn die Ergebnisse nach der Anzahl der Artefakte pro Designer ausgewertet werden bzw. wenn man nur noch betrachtet, in wie vielen Publikationen Artefakte übergreifend genannt werden. Ein aktuelles Beispiel für einen Über-Designklassiker liegt mit dem Stuhl MASTERS vor, der im Jahr 2010 auf den Markt kommt und im Team von PHILIPPE STARCK und EUgeni QUITLlet für KARTELl entworfen wird. Der Produzent schreibt 2016 selbst dazu:

"Der Masters Stuhl, designed von Philippe Starck in 2010 [sic], ist bereits jetzt ein Klassiker. Der Masters kann mittlerweile schon als KartellIkone bezeichnet werden. Als Hommage an drei große Designklassiker vereint er drei Designelemente in einem Sitzmöbel. Arne Jacobsen, Eeero Saarinen [sic] und Charles Eames sind für immer verewigt in diesem einzigartigen Bestseller.« [Hervorhebungen durch den Verfasser] (KARTELL) [online] http://www.kartell.de/masters-o9-schwarz.html [12.09.2016, nicht mehr im Netz verfügbar]

Inzwischen ist die Beschreibung durch eine abgeschwächte Version ersetzt worden, die natürlich seine Auszeichnungen im Rahmen der bisherigen Aufmerksamkeitskarriere für werbliche Zwecke nutzt:

"Der Stuhl Masters ist eine Hommage an drei symbolhafte Stuhlklassiker, die von Philippe Starck neu interpretiert wurden. Der Stuhl serie 7 von Arne Jacobsen, der 'Tulip Armchair von Eero Saarinen und der 'Eiffel Chair von Charles Eames verflechten sich zu einer unverwechselbaren Silhouette. Masters ist leicht, praktisch und stapelbar. Für eine noch kostbarere, exklusivere und edlere Wirkung wird Masters auch mit einem überraschenden Metallic-Finish angeboten. Der Stuhl Masters wurde 2010 mit dem renommierten Preis des Chicago Athenaeum - Museum of Architecture and Design und 2013 mit dem Red Dot Design Award ausgezeichnet." (KARTELL) [online] https://kartell.de/ Masters--Deckende-Grau-754.html [06.03.2018] [Hervorhebungen durch den Verfasser] 
Eine kurze Analyse. Der Entwurf bündelt als Beitrag zum Designklassiker-Diskurs drei Entwürfe, die den Klassikerstatus alle bereits huckepack tragen, in einem, woraus ein Artefakt entsteht, das (vom Produzenten selbst) 2016 schon wieder zum Klassiker und zur Ikone innerhalb des eigenen Programms erklärt wird und das als »einzigartige[r] Bestseller« sowohl eine Alleinstellung anhand idiosynkratischer wie ökonomischer Kriterien behauptet.

Sucht man nach einer semantischen Analogie, so lässt sich von einem mit den Mitteln des Designs verkörperten Pleonasmus sprechen, da hier die Konturen sinngleicher Entwürfe - Stühle, mit einer besonderen Betonung auf den Sitzschalen - zu einem neuen Stuhl verschmolzen werden, dessen Neuigkeitswert prinzipiell darin besteht, dass das zunächst einmal möglich ist. Selbstredend ist der Designprozess dieser Synthese komplexer als solch eine Verkürzung:

Zunächst müssen drei Stuhlentwürfe, die in verschiedenen Materialien (Kunststoff, Metall, Schichtholz, Stoff und/oder Leder) ausgeführt sind, in einen anderen Kunststoff und aus Flächigkeit wie Volumen überwiegend in Konturen überführt werden - bis auf die Sitzflächen. Jeder Entwurf muss zudem gestalterisch Federn lassen. Von EAMES' EIFFEL CHAIR (auch DSR) verschwindet das Metallgestell und die Kontur der Rückenlehne fällt niedriger aus. SAARINENS TULIP ARMCHAIR büßt den Zentralfuß ein. Als gemeinsame Fuß-/ Beinlösung kommt eine Adaption des Metallgestells von JACOBSENs SERIE 7 zum Einsatz, dessen Sitzschalen-Rundungen nun wesentlich spitzer konturiert sind. Außerdem verschwindet der prägnante obere Teil der Rückenlehne des TULIP ARMCHAIR. Die Beine des SERIE 7 kommen nun ohne Rundungen direkt aus der gemeinsamen Sitzfläche, anstatt wie beim Original darunter montiert zu sein. Kontrovers diskutierbare Gestaltungslösungen finden sich am hinteren oberen Rand der Sitzschale, die - wohl aus Stabilitätsgründen und vermutlich auch dem Material geschuldet - stur gerade ausgeführt ist sowie an den Stellen, an denen die Konturen des SERIE 7 in seine außen liegenden Hinterbeine überführt werden müssen.

Im Sinne einer kuratorischen Re-Editions-Auswahl der beiden Gestalter passt er perfekt zu allen anderen Re-Editionen, denn er ist im Grunde nichts anderes und ein perfektes Distinktions-Convenienceprodukt noch dazu. Wann kann man schon einmal drei Stühle in einem erwerben, die dann zu viert trefflich dazu beitragen, besten klassischen Geschmack zu vergleichsweise günstigem Preis in die gute Stube zu bringen? Ein Fleißsternchen hat das Duo STARCK/QUITLLET mit Sicherheit für das beinahe ironische Grundkonzept verdient, das mit Blick auf STARCKs eigenen Status überwiegend als Arbeit am 


\title{
STARDESIGNER ODER GESTALTER DES ALLTÄGLICHEN?
}

eigenen Denkmal verstanden werden kann. Trotz aller Verbeugungen und einem Statement wie diesem aus dem Jahr 2008:

\begin{abstract}
»Ich war ein Produzent von Materialität. Ich schäme mich dafür. Ich will künftig ein Produzent von Konzepten sein. Das wird nützlicher sein." (PRÜFER in: DIE ZEIT NR. 14/2008) [online] http://www.zeit.de/2008/14/ Designer-Starck-14/komplettansicht [06.03.2018]
\end{abstract}

Die Auswertung der Fundstellen so benannter Designklassiker führt in Anlehnung an die Ranglistenbildung bei den Stardesignern zwangsläufig auch hier zur Frage nach Mehrfachnennungen, wozu ebenfalls nur nach der Konstituierung eines Korpus Ausschau zu halten ist, der sich durch eben diese bildet. Letztlich entsteht so ein Überblick jener wenigen postulierten Supra-Designklassiker, die dem Laienpublikum vom Fachpublikum in Analogie zu den StarDesignern angeboten werden. Er konstituiert sich aus übereinstimmenden Nennungen in den untersuchten Publikationen und zwei Erweiterungen des Korpus: erstens um die DVD-Reihe Design 1-4 von ARTE FRANCE (2012) sowie zweitens um die FORM-Buchreihe Design-Klassiker (1997-2004).

Zu diesem Zweck werden alle Funde von Designklassikern und Designikonen zusammen ausgewertet, da bei der Benennung von identischen Intentionen ausgegangen wird. Sobald ein Artefakt mindestens in zwei Publikationen vorkommt, wird es in die Liste aufgenommen. Der sich ergebende Korpus erstreckt sich über einen Zeitraum von 81 Jahren (genauer: von 1925-2006) und er umfasst 29 Artefakte, die sich von den 1920ern bis zu den 1980ern konzentrieren und einen Spitzenwert von 7 in den 196oern aufweisen. Der geringste zeitliche Abstand eines Fundes zur Studie beträgt zum Zeitpunkt der Erstellung acht Jahre.

\section{Publikationen}

1. 1968: Sessel SACCO; GATTO, PAOLINI, TEODORO

(A\&W, ART, DIE PRESSE, SW)

2. 1956: LOUNGE CHAIR; EAMES (A\&W, ART, F.A.Z., SW)

3. 1927: Beistelltisch E 1027; EILEEN GRAY (A\&W, ART, FORM, NZZ)

4. 1925: WASSILY-CHAIR; MARCEL BREUER (A\&W, ART, NZZ, SÜDDEUTSCHE) 


\section{Publikationen}

5. 1985: Wasserkessel 9093 BIRD KETTLE; MICHAEL GRAVES

(ART, DIE WELT, FORM)

6. 1971: Tischleuchte TIZIO; RICHARD SAPPER (A\&W, FORM, NZZ, SW)

7. 1964: Polstermöbelprogr. CONSETA; WILHELM MÖLLER (A\&W, FORM, SW)

8. 1963: Möbelprogr. USM HALLER; PAUL SCHÖNER, FRITZ HALLER (A\&W, FORM,SW)

9. 1936: Vase SAVOY; ALVAR AALTO (A\&W, DIE WELT, DIE ZEIT)

10. 1933: Hocker 6o; ALVAR AALTO (A\&W, DIE WELT, DIE ZEIT)

11. 1929: Sessel BARCELONA; LUDWIG MIES VAN DER ROHE (A\&W, ARTE, NZZ)

\section{Publikationen}

12. 2006: Stuhl MYTO, KONSTANTIN GRCIC (DER SPIEGEL, NZZ)

13. 2006: Stuhl BONE CHAIR; JORIS LAARMAN (A\&W, FORM)

14. 1997: Bücherregal BOOKWORM; RON ARAD (ARTE, FORM)

15. 1987: Tischleuchte TOLOMEO; MICHELE DE LUCCHI und FASSINA

(A\&W, SW)

16. 1981: Raumteiler CARLTON; ETTORE SOTTSASS (ART, DIE WELT)

17. 1978: Espressokanne 9090; RICHARD SAPPER (DIE WELT, FORM)

18. 1972: WIGGLE CHAIR; FRANK GEHRY (A\&W, SW)

19. 1969: PERLFLASCHE; GÜNTER KUPETZ (DESIGN REPORT, FORM)

20. 1969: Schreibmaschine VALENTINE; ETTORE SOTTSASS (ARTE, DIE WELT)

21. 1968: Hängeleuchte SEMI; BONDERUP und THORUP (A\&W, SW)

22. 1960: Tischleuchte AJ; ARNE JACOBSEN (A\&W, SW)

23. 1958: Tische und Stuhl TULIP; EERO SAARINNEN (A\&W, FORM)

24. 1952: DIAMOND CHAIR; HARRY BERTOIA (A\&W, SW)

25. 1950: RAR ROCKING CHAIR; EAMES (A\&W, SW)

26. 1949: Tisch ARABESCO; CARLO MOLLINO (A\&W, F.A.Z.)

27. 1946: Stuhl DOMUS; ILMARI TAPIOVAARA (A\&W, DIE WELT)

28. 1939: Treteimer VIPP; HOLGER NIELSEN (A\&W, SW)

29. 1939: LANDI-Stuhl; HANS CORAY (A\&W, NZZ)

Ein alptraumhaftes Szenario lässt eine Wohnung voll von Zeugnissen besten, klassisch-ikonischen Geschmacks aus dem Boden wachsen .... Bemerkenswert ist wieder einmal die relative Uneinigkeit in der Breite der "Nominierungen" - bei gleichzeitiger Befestigung bereits bestehender Monumente. 
Eine Einteilung nach Produktkategorien liefert die greifbarsten und nützlichsten Erkenntnisse: Sitzmöbel nehmen mit 14 Artefakten den größten Raum ein - insgesamt die Hälfte aller Funde, verteilt auf zehn Stühle, zwei Sessel, ein Sofa-Programm und einen Hocker. Deutlich abgeschlagen Leuchten und Haushaltsgegenstände mit je vier Funden, von denen letztere sich aufteilen in einen Wasserkessel, eine Espressokanne, eine Mineralwasserflasche und einen Mülleimer. Besonders ist hieran, dass ein Artefakt kein unmittelbares Privateigentum darstellt, da es sich um eine Pfandflasche handelt und eines den gesamten Bereich der Entsorgung vertritt: Womit einerseits die Ehre nicht statusfähiger Produkte gerettet wird und sich andererseits erweist, dass auch der Kauf eines Mülleimers noch Distinktionspotential in sich bergen kann. Außerdem haben sich drei Tische und drei Regale einen Platz in jenem konstruierten Design-Olymp erobert sowie eine Schreibmaschine (als einziges Gerät) und eine Vase (als einziger zugleich funktionaler Dekorationsgegenstand).

In nackten Zahlen tragen zu den 29 Platzierten bei: A\&W 22, sw zwölf, FORM zehn, DIE WELT sieben, ARTE und die NZZ je sechs, F.A.Z., DIE ZEIT und ART DAS KUNSTMAGAZIN je zwei Artefakte, SÜDDEUTSCHE, DESIGN REPORT und DER SPIEGEL je ein Artefakt. Eine weitere Auffälligkeit besteht darin, dass in keinem Fall mehr als vier unterschiedliche Fundstellen pro Artefakt auftreten: Das Mittelfeld wird von je dreien gebildet. Diesem an Zahl geringen, publikationsübergreifend zustimmungsfähigen Bestand Das Buch der Klassiker gegenüberstellend, das von SW 2011 zum eigenen fünfzigsten Geburtstag herausgegeben wird, beeindruckt dort eine Phalanx der "500 besten Möbel und Wohnaccessoires « den geneigten Leser. Der Verdacht liegt nahe, dass damit wieder einmal nicht weniger als die Existenzberechtigung der eigenen Deutungshoheit verteidigt werden soll.

\section{Von Supra²-Designern und Supra²-Designklassikern}

Supra²-Designer treten als Spitzengruppe hervor, wenn man das RankingSpielchen im Rahmen der Artefakt-Auswertung noch eine Runde weiterspielt und die Ergebnisse nach den Designern filtert, die mit mehr als einem Artefakt vertreten sind. Als Ausbeute verbleiben so nur noch drei Designer mit je zwei Artefakten: 
1. ALVAR AALTO mit einer Vase (SAVOY) und einem Hocker (6o),

2. CHARLES und RAY EAMES mit zwei Stühlen (RAR ROCKING CHAIR und LOUNGE CHAIR),

3. ETTORE SOTTSASS mit einer Schreibmaschine (VALENTINE) und einem Raumteiler/Regal (CARLTON).

Supra²-Designklassiker treten durch eine Auswahl nach der Zahl ihrer Nennungen hervor, was im untersuchten Korpus nur noch diejenigen betrifft, die ausschließlich in vier unterschiedlichen Publikationen als Designklassiker bezeichnet werden. Die Ausbeute hierfür beträgt vier:

1. WASSILY-Stuhl, MARCEL BREUER

2. Beistelltisch E 1027, EILEEN GRAY

3. LOUNGE CHAIR, CHARLES Und RAY EAMES

4. Sitzsack SACCO, GATTO/PAOLINI/TEODORO.

Damit ist aller Enden eines: Aus dem zugrundeliegenden Material lässt sich keine weitere Zuspitzung mehr erzeugen. Die Designer sind anhand der Anzahl gefundener Artefakte medienübergreifend auf die populärsten drei reduziert und damit wird auch die Stardesigner-Rangliste anhand anderer Vergleichskriterien vom Feld gefegt. Die Anzahl der Artefakte ist hiermit auf supraklassische vier eingedampft. Bewiesen ist damit, außer der Möglichkeit einer derartigen Interpretation: Wieder nichts.

Es sei denn, man nähme die übereinstimmenden Nennungen als ein zwar nicht wirklich ausgehandeltes, aber dennoch manifestes Verhandlungsergebnis an und ernst: Dann hätte die Auslese eine ewige Spitze an unverrückbaren Star-Designern und Designklassikern hervorgebracht. Dies jedoch auf der Basis von jenen entworfener und bereits auf die eine oder andere Weise als Klassiker markierter Artefakte und nicht mehr nach der Zahl über sie veröffentlichter Artikel. Ein ironisch gefärbter Tipp für angehende Klassikerproduzenten muss an dieser Stelle sein: Mit etwas, worauf man sitzen kann, liegt man sicherlich nicht schlecht, sofern man einen künftigen Klassiker zu entwerfen wünscht .... Beleuchtung bietet sich als Betätigungsfeld ebenso an wie Haushalt, Ablage und Aufbewahrung und damit kann eigentlich nur ein beruhigendes Fazit gezogen werden, da es immer noch die nützlichen Dinge sind, denen "Experten « ein dauerhaftes und beispielgebendes Anwesenheitsrecht in unserem Umfeld zubilligen möchten. 


\section{STARDESIGNER ODER GESTALTER DES ALLTÄGLICHEN?}

Zum Abschluss ist ebenso zwangsläufig ein Vergleich der bereits ermittelten Rangliste der Star-Designer mit den Supra-Designklassikern fällig. Er lässt nur 424 noch eine personale Deckungsgleichkeit auftauchen: KONSTANTIN GRCIC mit dem Stuhl MYTo. Die Auswertung der Designklassiker zeigte noch fünf und GRCIC kam auch dort schon vor. Sind also Bewertungen von Personen und Bewertungen von Artefakten tatsächlich zwei distinkte Vorgänge, die keine direkte Auswirkung aufeinander haben?

Die Hypothese, der Ruhm eines Gestalters könne sich auf die Bewertung der Artefakte (sowie vice versa) auswirken, scheitert an der Auswertung der untersuchten Publikationen, denn sonst hätten hier theoretisch mindestens Artefakte von PHILIPPE STARCK und auch JASPER MORRISON, MATTEO THUN und den BOUROUlLECs auftauchen können, die die Plätze vor GRCIC belegen. Natürlich greift diese Zuspitzung zu kurz, weil das Zustandekommen einer Besetzung mit Bedeutsamkeit oder auch Valorisierung (vgl. RECKWITZ 2017) ein komplexerer und komplizierter auszuwertender Vorgang ist als diese nur auf Zahlen basierende Simplifizierung. Dennoch bildet sie ab, was den Weg in die Verbreitungsmedien gefunden hat und sie bietet damit ein klareres Bild von der Unterschiedlichkeit des Vorbildgebenden bei unterschiedlichen Rezipienten. 


\section{Der Weg zum Ikonischen}

Nun richtet sich der Blick darauf, welches generelle Verhältnis Menschen zu jenen Artefakten, die im Feld des Designs entstehen, aus der Sicht der Wissenschaft entwickeln. Zum Einstieg RECKWITZ und dessen Blick auf das Design im Rahmen von Die Erfindung der Kreativität:

"[D]as Design [erweitert] seinen Anspruch in Richtung einer Totaltransformation der gesamten Artefaktwelt. Es versteht sich nicht als eine bloße Nische des Produktdesigns, sondern verfolgt das politische Projekt, der menschlichen Umwelt insgesamt eine die Sinne befriedigende und praktisch handhabbare Form zu geben. [...] In dieser Transformationsphase wird damit eine Struktur erprobt, die sich in den 1980er Jahren verallgemeinert und sich vom Bezug auf das kritische Radical Design [Hervorhebung im Original] löst. Das Design erhält nun den Status einer Generaldisziplin der Kreativökonomie. Zum einen avanciert der ästhetische Wert für eine immer größere Zahl von Produkten von einem Zusatzwert zu einer primären Eigenschaft, so dass die Produktsemantik den Kern der Ware ausmacht. Dies erlaubt es auch, nicht nur materiale Güter, sondern ganze Environments und Atmosphären zum Gegenstand einer Designgestaltung [Tautologie, der Verfasser] zu machen. Zum anderen forciert das Design als Generaldisziplin das dynamische und unendliche Spiel der Neuheit und Differenz für ein an Selbstästhetisierung interessiertes Publikum, indem es seit den 1980er Jahren ähnlich der Mode immer neue Stile (Neo-Primitivismus, Super-Normal-Bewegung etc.) entwickelt. Das modernistische Design, der >Design-Klassiker wird dann zu einem [Hervorhebung im Original] Stil unter mehreren. Die Faszination, die diese Entfesselung der Designstile für die Konsumenten bedeutet, manifestiert sich in der breiten massenmedialen Aufmerksamkeit für Design und in dessen Institutionalisierung als Kulturgut: in Designmuseen (erstmals in London 1989), in Designzeitschriften (so Wallpaper [Hervorhebung im Original], gegründet 1996) und den Publikationen von Designverlagen (etwa im international agierenden Taschen-Verlag, 1980 gegründet). Nach dem Vorbild des erfolgreichen Künstlers präsentiert das Feld des Designs seit den 1980er Jahren den Design(er)-star etwa Philippe Starck oder Terence Conran - als attraktives Kreativsubjekt. Im Designer scheinen ästhetische und ökonomische Komponenten eine Symbiose einzugehen. Das Design kann jedoch nur dadurch zur Generaldisziplin der Kreativökonomie werden, dass es über die Produktsemantik hinaus auf eine ästhetische Gestaltung von langfristig wirkenden Marken, schließlich von kollektiven Identitäten insgesamt abzielt und sich so in eine ästhetisch orientierte allgemeine Unternehmens und Organisationsberatung verwandelt." (RECKWITZ 2012: 180f) 


\section{STARDESIGNER ODER GESTALTER DES ALLTÄGLICHEN?}

Es verwundert nicht, dass die Aufmerksamkeit des aktuellen Star-Soziologen der Stunde beim Blick auf das Design den beiden Phänomenen »Design-Klassiker« und »Design(er)-star« nicht entkommt. Mit seiner Zuspitzung auf STARCK und CONRAN als »attraktive Kreativsubjekt[e]« liefert er eine erneute Bestätigung für die vorstehend dargestellten Ergebnisse. Bemerkenswert ist auch seine Feststellung, der Designklassiker (in einer fast erwartbaren Fixierung auf das »modernistische Design«) sei heute nur noch ein Stil unter vielen. In Form der Befestigungsliteratur liegen jedoch derartig viele eindeutige Belege für hegemoniale Bestrebungen im Sinne von Ordnungsmächten des Klassiker-Diskurses vor, dass diese stilistische Beschränkung bezweifelt werden darf. Schon die mit dem Beginn des 20. Jhd.s aufgekommenen Warenkunden stellen erste Manifestationen dieser Versuche von Meinungsbeeinflussungen dar.

Dennoch ist RECKWITz' Einschränkung der Bedeutung des Designklassikers als ein Stil unter vielen anderen paradoxerweise ebenso gerechtfertigt, denn die Designbranche steht nicht nur unter der Herrschaft des Ikonischen, sondern auch unter der Herrschaft des Neuen. Sie entkommt diesem Kreislauf nicht und sie setzt selbst aufs Neue Stil neben Stil. Ein stärker versachlichter Blick auf den Umgang mit und das Verständnis von Artefakten, die von Menschen gekauft werden, bietet sich unter Bezug auf MIKLAUTZ, KOHL, BREUER, LENZE, VEBLEN sowie LlOyd und SNELDERS: Mit dem Ziel, abseits der von Konsumforschung, Produktsemantikern und Markenstrategen bereits ausgetretenen Pfade einen anderen Eindruck davon zu gewinnen, wie Menschen mit Artefakten umgehen und welches Verhältnis sie zu ihnen aufbauen. Im Rahmen der Betrachtung von LLOYD und SNELDERS' Text über den JUICY SALIF werden auch die Positionen von ALESSI, COLLINS, ECO, NORMAN und SELLE in die Analyse dieses speziellen Artefaktes einbezogen. 


\section{Kristallisierter Sinn}

liefert einen bedeutsamen und grundlegenden Beitrag zur Diskussion um den Wert von Artefakten, der nicht nur im hiesigen Zusammenhang losgelöst von der reinen Existenz derselben betrachtet werden muss. MIKLAUTz' Argumentation liegen u. a. Gedanken von simmel aus dessen Philosophie des Geldes zu Grunde: Z. B. jener, dass

»[e]ine [seiner] wichtige[n] Grundannahme[n] [...] [darin bestehe], daß die menschliche Ordnung der Dinge nicht deren Eigenschaften folg[e], sondern völlig autonom davon strukturiert [sei] - sie [sei] nach Werten gebildet. Der Wert der Dinge aber [sei] aus ihrem snatürlichen Sein nicht ableitbar. Eigenschaften und Bewertung von Gegenständen verh[ie]lten sich seiner Ansicht nach absolut zufällig, ja der Wert ıbilde[...] gewissermaßen das Gegenstück zum Sein،. Der Wert g[e]lt[e] ihm als gleichgültig gegenüber dem Zustandekommen der Dinge, geradezu als Gegensatz zum gegebenen Objekt." (SIMMEL 1977, zitiert nach MIKLAUTZ 1996: 39f)

Die Frage nach der Entstehung des Werts beantwortet MIKLAUTZ mit der fundamentalen Feststellung, dass er »[...] keine den Dingen inhärente Eigenschaft [sei], sondern rein im Subjekt verbleibendes Urteil über sie.« (ebd.: 39f) Für MIKLAUTZ werden

"Artefakte [...] zum Zeichen ihrer Funktion und können auch als solche sgelesen werden. Darüber hinaus bilden Artefakte selbst ein strukturiertes Zeichensystem, das Unterschiede als bedeutsam setzt. Das heißt, Artefakte haben nicht nur eine Funktion, die sich in ihrer Verwendung realisiert, sondern auch eine Mitteilungs funktion in einem davon losgelösten System von Signifikationen.« (ebd.: 60)

Als "Zeichen ihrer Funktion" verwandeln Artefakte sich daraufhin in Symbole und diese sind dann

"[...] nicht bloß Zeichen. In ihrer symbolischen Dimension verweisen Artefakte als Objektiviationen menschlichen Handelns nicht nur auf, sondern sind vergegenständlichter, objektivierter Ausdruck kollektiver Erfahrung [Hervorhebungen im Original].« (ebd.: 70)

Wenige Seiten weiter fährt sie fort: »Artefakte bringen kollektive Wertvorstellungen zum Ausdruck, die in ihrer Aneignung durch den einzelnen bestätigt und - wenn auch fallweise modifiziert - reproduziert werden." (ebd.: 77) Hiermit sind schon fast alle wesentlichen Aussagen versammelt, die für eine indivi- 


\section{STARDESIGNER ODER GESTALTER DES ALLTÄGLICHEN?}

duelle Bewertung von Designklassikern und Designikonen als bestimmend zu gelten haben - wenn in den zuletzt zitierten Zeilen auch die Differenzierung zwischen dem Artefakt als solchem und seinem zusätzlich hervorgebrachten Wert fehlt. Man könnte auch noch einen Hinweis auf die Aushandlungsprozesse geben, die in ausdifferenzierten Gesellschaften zu einer stärkeren Zersplitterung des Kollektiven an sich führen und letztlich verschiedene Kollektive nebeneinander stehen lassen, die nur noch eine begrenzte Deutungshoheit für sich beanspruchen können. Zu Grunde liegt allem immer die Besetzung mit Bedeutsamkeit:

»Deutlich wurde [...], daß beliebige Produktbereiche bedeutsam besetzt werden können und je nach Gruppenzugehörigkeit auch unterschiedliche Bedeutung zugewiesen erhalten. Nie lässt sich diese besondere Bedeutung aber allein auf den Nutzen von Artefakten reduzieren - bei technischen Geräten ebensowenig wie bei Kleidung, bei der dies besonders offensichtlich scheint. Dieser >Eigenwert von Artefakten jenseits ihrer Nützlichkeit und Funktionalität und jenseits ihres ökonomischen Werts wird zwar von den Produzenten und Händlern geschickt gefördert und genutzt, ist in seiner Entstehung aber sicher nicht ausschließlich aus deren Agieren ableitbar. Die Objektivierung von Bedeutung scheint vielmehr kulturelle Wurzeln zu haben [Hervorhebung des Verfassers].« (ebd.: 156)

Dieser kulturellen Wurzeln werden wir gewahr mit jedem Designwettbewerbsergebnis, mit jedem postulierten Designklassiker, mit jedem in den Designikonenstand erhobenen Artefakt und ipso facto bei der Musealisierung. Die Auseinandersetzung mit solchen Formen der Vorbildhaftigkeit erfordert die persönliche Aneignung und ggf. Bestätigung - s. o.:

»Der Umgang mit Produkten setzt Prozesse der Aneignung voraus, in denen der Handelnde selbst zur Hervorbringung des von ihm konsumierten Produkts beiträgt. Aneignung meint, daß der Gegenstand der durch die Komplexität der Warenproduktion entstandenen Sphäre abstrakter, allgemeiner, fremder, beliebig gewordener Dinge entrissen werden, personalisiert und individualisiert werden muß. Es geht also bei Aneignung um mehr als ein bloßes Zum-Eigentum-Machen. Die Aneignung bringt das Produkt für den Besitzer eigentlich erst hervor und enthüllt es aus der Anonymität des Jedem-und-immer-Gleichen. [...] Folgt man Sahlins, ließe sich die kapitalistische Ökonomie selbst als kulturelles Produkt verstehen, in dem es darum geht, Bedeutung zu produzieren. Das Besondere daran wäre, daß der wichtigste Bereich der Herstellung von Sinn in der Produktion von Konsumgütern besteht, der alle anderen Bereiche dominiert. Eine totemistisch strukturierte Produktwelt wäre demnach die unsere Kultur kennzeichnende symbolische Form, d. h. das Medium, über das wir Realität konstituieren, Welt verstehbar machen und Orientierung in ihr ermöglichen.« (ebd.: 162f) 
Es erscheint keinesfalls als ein zu weit ausgreifender Schritt, den im Totemistischen steckenden Aspekt der Verehrung - wenn auch losgelöst vom religiösen Glauben - in den Bereich der persönlichen Bedeutungsproduktion einzuschließen. Notwendig ist aber auch, noch einmal hervorzuheben, dass es unterschiedliche und unterscheidbare Realitäten sind, die hier konstituiert werden und individuell zu persönlicher Kongruenz gebracht werden können oder müssen oder auch nicht.

Der Realität der produzierten Güter steht die Realität des von uns ebenso produzierten Wertes gegenüber (oder zur Seite). Die Besonderheit dieser Dualität besteht darin, die Realität der einen nicht abstreiten, die Realität des anderen aber für sich ablehnen zu können. Dadurch ist es möglich, sich der Bedeutung eines Artefakts als Manifestation eines Aushandlungsprozesses nicht zu unterwerfen oder anzuschließen. Lehnt man das Produkt als solches ab, entzieht man sich dem Anschluss an das Kollektive durch Konsumabstinenz. Fragen danach, auf welche Weise man ein konsumiertes Produkt durch Aneignung selbst mit hervorbringe, stellen sich mit jedem Konsum-Akt aufs Neue.

Der Gedanke, man enthülle es damit aus »der Anonymität des Jedemund-immer-Gleichen« (s. o.) ist ein überraschender Nebenaspekt, der sich in dieser Form bei keinem der anderen Autoren findet, die im Kapitel zur Anonymität betrachtet werden. MIKLAUTz geht damit von einer Form der Anonymität aus, die der Appropriation im Wege steht. Doch dreht sich hierbei nicht alles um ein sichtbares Herausragen aus der Masse des Gleichen für einen einzelnen Konsumenten (vermittels einer Auszeichnung), sondern es geht um das jeweils individuelle Anverwandeln aus einer Masse des für viele Gleichen. So handelt es sich um keine Auszeichnung mit Orientierungswert und -absicht, die Artefakte vor einem Kauf aus der Anonymität der Massenproduktion herausragen lassen soll, sondern um eine höchstpersönliche Aneignung durch den Konsumenten zur Überwindung der Anonymität von Artefakten nach einem Kauf. Mithin der Aufbau einer persönlichen Beziehung zum Objekt, wie er bei MILLER (2008) in The Comfort of Things behandelt wird. Der oben erwähnte Aspekt der Orientierung in der »Komplexität der Warenproduktion « ist wohl der wichtigste, denn Orientierung verspricht Sicherheit wie Unsicherheitsabsorption auf beiden Seiten - also für die Orientierung geben wollenden wie die suchenden. 


\section{Die Macht der Dinge}

Auch hier gilt die Beschäftigung unter anderem der Differenz zwischen dem Gebrauchswert einer Ware und dem, was darüber hinaus geht:

»Nun wissen wir allerdings aus unserer Alltagserfahrung, daß beim Kauf einer Ware deren Gebrauchswert zwar eine wichtige, aber keineswegs die einzige Rolle spielt. Eine beim Straßenhändler erworbene einfache Digitaluhr erfüllt ihren Gebrauchszweck als Zeitmesser nicht weniger gut als eine tausendmal teurere Rolex. Der Nährwert von Kaviar ist keineswegs höher als der von Haferflocken. Der Gebrauchswert eines bestimmten Gegenstandes allein kann es also nicht sein, der für den Käufer zum entscheidenden Stimulus wird, gerade diesen und keinen anderen zu erwerben. Es muß noch mehr hinzukommen: ein bestimmter Reiz, der von der angebotenen Ware ausgeht. Er kann von der Seltenheit des Gegenstands, seinem sozialen Prestigewert oder von dem ihm anhaftenden Glücksversprechen herrühren, er kann taktiler, olfaktorischer, visueller oder ganz allgemein ästhetischer Natur sein." (KOHL 2003: 112)

An diesem Punkt ist KOHL schon deutlich spezifischer als MIKLAUTZ, die die Besetzung mit Bedeutsamkeit noch auf einem allgemeineren Niveau diskutiert. Eine Tauglichkeit als Zeichenträger ist jedoch vergleichbar mit MIKLAUTZ' Gedanken, dass Artefakte sich zu Symbolen wandeln und damit »vergegenständlichter, objektivierter Ausdruck kollektiver Erfahrung « werden (vgl. MIKLAUTZ 1996: 70):

"Grundlegend ist zunächst einmal die Unterscheidung zwischen natürlichen Objekten und Artefakten. Beide Klassen von Dingen können als Zeichenträger fungieren. Doch scheinen sich die Artefakte hierzu besser zu eignen, da ihnen bereits im Zuge ihres Herstellungsverfahrens bestimmte Intentionen eingegeben worden sind. Sie verleihen ihnen eine Aussagekraft, die die physische Existenz ihrer Produzenten überdauert. [...] Durch ihre Gestaltung kommentieren sich die Artefakte also gewissermaßen selbst. Der primäre Bedeutungsgehalt des Artefakts entspricht dem Verwendungszweck, für den es angefertigt worden ist. Das heißt allerdings nicht, dass es nicht noch zusätzliche Bedeutungen gehabt haben kann oder später (Hervorhebung im Original) mit sekundären symbolischen Bedeutungen versehen worden ist." (ebd.: 121)

Die Beschreibung des Wertes einer Ware als eigenständige Kategorie, losgelöst von ihrem objektivierbaren Seinszustand und als »Resultat sozialer Konventionen", der auch ein "Begehren « auslöse, koinzidiert sowohl mit SIMMEL als auch mit VEBLENs Begriff des »honorific element«: 


\section{AM ENDE WAR ES NUR EIN WORT: ZWEI REZEPTIONSSTUDIEN}

"Der Schluß liegt also nahe, daß der Wert, der bestimmten Gegenständen zugemessen wird und der sich im Tauschakt realisiert, nicht notwendig und überall aus deren Nützlichkeit resultiert. Er läßt sich nicht objektivieren, weder anhand des in sie investierten Quantums an Arbeitszeit, noch anhand der Komplexität des Produktionsprozesses. Denn Wert ist keine den Gegenständen innewohnende Eigenschaft, sondern immer ein Resultat sozialer Konvention. Wie weiter oben bereits erwähnt, spielt bei der Wertbemessung eines Gegenstands das Begehren oft eine größere Rolle als dessen plane Nützlichkeit.« (ebd.: 127f)

\section{Zum direkten Vergleich ein Zitat von VEBLEN:}

"The habit of looking for the marks of superfluous expensiveness in goods, and of requiring that all goods should afford some utility of indirect or invidious sort, leads to a change in the standards by which the utility of goods is gauged. The honorific element and the element of brute efficiency [Hervorhebungen des Verfassers] are not held apart in the consumer's appreciation of commodities, and the two together got to make up the unanalysed aggregate serviceability of the goods. Under the resulting standard of serviceability, no article will pass muster on the strength of material sufficiency alone. In order to completeness and full acceptability to the consumer it must also show the honorific element [Hervorhebung des Verfassers]. It results that the producers of articles of consumption direct their efforts to the production of goods that shall meet this demand for the honorific element. They will do this with all the more alacrity and effect, since they are themselves under the dominance of the same standard of worth in goods, and would be sincerely grieved at the sight of goods which lack the proper honorific finish.« (VEBLEN 1994: 95)

Der Ehrbegriff, welcher in VEBLENs Formulierung "honorific element« mit eingeschlossen ist, lohnt eine kleine Ausbuchtung. Bei einer Übertragung in die deutsche Sprache muss man eigentlich davon ausgehen, dass das Ansehen und der Status als Grundlage passender wären: veBLENs conspicuous consumption wird üblicherweise mit Status- oder Geltungskonsum übersetzt. Dennoch bietet der Gedanke, dass wir selbst uns Ehre verschaffen durch den Erwerb eines Gegenstandes - weil ein UNS in den Augen anderer ehrender Bestandteil in ihm stecke -, einen Ansatzpunkt, um noch einmal mit leicht verschobenem Akzent über diese buchstäbliche Verkörperung sozialer Konventionen nachzudenken. Eine Henne und Ei-Diskussion muss dafür nicht geführt werden, weil die Genese offensichtlich ist. Nehmen wir MIKLAUTZ' auf SIMMEL gestützte Überlegungen für gegeben und der Wert einer Ware stellt dem folgend ein eigenständiges Produkt dar, das einem Artefakt erst nachträglich mitgegeben wird, so finden wir schon weit vor ihrer Zeit in veBLENs Zitat den Aspekt seiner möglichen Instrumentalisierung vor respektive einen Be- 


\title{
STARDESIGNER ODER GESTALTER DES ALLTÄGLICHEN?
}

leg für dessen Normierbarkeit. Oder auch eine direkte Übertragung und Integration sozialer Konventionen in die Genese von Artefakten. Als Mechanismen bei weitem am Einfachsten zu fassen sind in diesem Zusammenhang die finanzielle und stückzahlgebundene Begrenzung der Zugänglichkeit. Die Materialauswahl für die Produktion aus (der Konvention nach) edlen oder unedlen Materialien sorgt zum Einen für die pekuniäre Begrenzung oder Öffnung der Zugänglichkeit, die Verknappung zum Anderen. Diese entscheidet im Positionswettbewerb ebenfalls über Wohl und Wehe der Status-Aspiranten. Deren Streben nach Status- oder auch Identifikations-Artefakten fasst KOHL wie folgt zusammen:

\begin{abstract}
" $\mathrm{Da}$ die finanziellen Ressourcen der Bildungselite begrenzt sind, sucht sie sich mit Gegenständen zu umgeben, die von ihrem besonderen Geschmack zeugen: Antiquitäten, Designermöbel, avantgardistische Kunst und vieles andere mehr. Die Angehörigen der Bildungselite zeichnen sich durch ihre Kennerschaft aus, die sich selbst auf so banale Dinge wie Weinoder Käsesorten beziehen kann. Sie wollen exklusiv sein. Der ,Gute Geschmack erlaubt eine Abgrenzung sowohl gegenüber den oberen Gesellschaftsklassen als auch gegenüber den unteren sozialen Schichten. Daß diese Strategie mit relativ geringem pekuniärem Aufwand verbunden ist, erweist sich allerdings nicht nur als Vorteil. Hat sich ein bestimmter Trend erst einmal durchgesetzt, dann ist es für jeden, der seine Zugehörigkeit zur tonangebenden Gruppe signalisieren will, relativ einfach, in den Besitz der entsprechenden Prestigegüter zu gelangen. Auf diese Weise wird immer wieder von neuem dieselbe Spirale in Gang gesetzt. In der Gefahr, ihre Exklusivität zu verlieren, befinden sich die Angehörigen der Bildungselite in der schwierigen Lage, ständig neue Statusobjekte entdecken zu müssen, um ihren Rang in der sozialen Hierarchie nicht zu verlieren.« (KOHL 2003: 131)
\end{abstract}

»In der Gefahr, ihre Exklusivität zu verlieren«, befinden sich selbst jene, die gesellschaftlich oberhalb der eben beschriebenen Bildungselite angesiedelt werden, da diese mittels des eigenen guten Geschmacks nicht nur eine Abgrenzung nach unten, sondern auch nach oben versucht. Durch das Aufschließen von unten steigt oberhalb der Druck, sich mit Hilfe neuer Prestigegüter wieder von unterhalb abzusetzen, um weiterhin die Zugehörigkeit zu den eigenen tonangebenden Gruppen zu signalisieren und deren Geschlossenheit zu wahren. Dies erscheint allerdings aufgrund weniger stark begrenzter finanzieller Ressourcen weit weniger problematisch. Die aktuellste, obschon ebenso amerikanisch geprägte Fortschreibung der damaligen veBLENschen Zeitdiagnostik, die direkt an den von KOHL verwendeten Begriff der Bildungselite angebunden werden kann, findet sich in CURRID-HALKETTs The Sum of Small 
Things. A Theory of the Aspirational Class (2017), worin sich VEBLENs conspicuous consumption zur inconspicuous consumption wandelt. CURRID-HALKETT gründet ihre Arbeit in BOURDIEUs Distinktion und Habitus und dem sozialen Kapital, was in folgendem Zitat zutreffend zum Ausdruck gebracht wird:

»The key to most all inconspicuous consumption is that it is nonvisible except to those in the know, and is difficult to emulate without tacit information or a significant amount of money. Inconspicuous consumption is the source of the new class divide." (CURRID-HALKETT 2017: 50)

Ein weiterer Bezug zu KOHLs Bildungselite sowie zu BOURDIEU, der auf eine ähnliche Art expliziert, wie diese sich selbst nach oben (wie auch jede andere Gruppe gegen ihr Umfeld) abgrenzen kann, wird hier gesetzt:

"Unlike conventional status goods, the new means by which members of the aspirational class define themselves are through goods that may just cost the same as they do for their middle-class counterparts but are only accessed through rarified information. As showy and material means of establishing status are more accessible, the aspirational class finds subtle symbols, cultural capital and language to distinguish itself from other groups, and its members use knowledge as an important dividing line between them and the rest. Thus the aspirational class members shape and demonstrate their position through information they can attain only through their peers and position as purveyors of cultural capital.« (ibid.: 51)

Als wenig verblüffendes Fazit verbleibt, dass sich trotz einer marginalen Begriffsänderung - die bedeutsamer klingt, als sie es in Wirklichkeit ist - und der Entkoppelung von monetärer oder stückzahlgebundener Zugangsbegrenzung absolut nichts an den Mechanismen der Abgrenzung an sich geändert hat. Womit sich wieder erweist, dass Statusgüter nur durch die Existenz von in Gruppen verhandelten Wertsetzungen zu solchen werden. Die Unsichtbarkeit der neuen Verhandlungsebenen und die Unkenntnis der nicht im Besitz des nötigen Herrschaftswissens befindlichen stellen neue Zugangskontrollen dar, die so präzise wirken wie die bei VEBLEN wirksamen pekuniären Beschränkungen. 


\title{
Die Erfindung des modernen Klassikers
}

\begin{abstract}
Das Aufkommen der Massenproduktion erzwingt einerseits die Erfindung von Strategien zu ihrer Differenzierung und es erzwingt andererseits auch bei den Designer eine scheinbare Gegenposition:
\end{abstract}

\begin{abstract}
"Designer mussten sich [...] verstreuten Nutzungsbereichen und kleineren Marktsegmenten zuwenden, um sich vom Massenprodukt abzuwenden. Eine Standardisierung, wie sie die Moderne der zoer Jahre programmatisch für alle anstrebte, um ihren [sic] Demokratisierungsanspruch gerecht zu werden, war schon in den 6oer Jahren nicht mehr möglich. Die Einheitsform entsprach nicht mehr dem Käuferinteresse diversifizierter Kreise. Die Objekte mussten sich unterscheiden. Am einfachsten war dies, wenn man sie als Persönlichkeiten von Persönlichkeiten erscheinen ließ. Auf diese Weise konnte man Individualität in der Massenindustrie suggerieren." (BREUER 2001: 103f)
\end{abstract}

BREUER dekonstruiert im Verlauf den modernen Klassiker als eine Erfindung, die man in der Nachfolge der guten Form auf das Siegertreppchen zu stellen versuchte und noch versucht - mit sehr ähnlichen Hegemonialansprüchen:

"Es kam früh auf, was Klaus-Jürgen Sembach in seinem Buch Moderne Klassiker: Möbel, die Geschichte machen [Hervorhebung im Original] als Auswahlkriterium für seine Klassiker formulierte: >Der Designer muss bekannt sein - denn wer so einen Klassiker besitzt und kauft, besitzt und kauft nicht ein Möbel der Firma XY, sondern einen Mies, einen Wegner, einen Eames oder einen Castiglioni. Zu Stücken dieser Art haben ihre Besitzer eine besondere Beziehung. Nicht nur weil sie möglicherweise einen hohen materiellen Wert darstellen, sondern, weil sie eine Geschichte haben. Man kann was über sie erzählen`. Gillo Dorfles [Ispirazione Italiana; Ausstellungskatalog, der Verfasser] hat im Rückblick auf den Beginn der italienischen Erfolgsstory von einem smythischen Phänomen، gesprochen: dem so genannten italienischen Stil [...] In vielen Fällen folgt der Prozess der Nobilitierung eines Designobjektes zum Klassiker dem der Wahl und Pflege von Kunstwerken in Museen - es tritt eine Art Musealisierung ein. Mit dieser Beschreibung wird der Annahme widersprochen, dass sich ein Klassiker aufgrund von gewissen profilierten Eigenschaften quasi wie von selbst herausbildet und sich über lange Zeit bewährt. [...] Sondern der Begriff weist auf Bemühungen hin, um ein Produkt herum eine ganze Welt von museumsähnlichen Institutionen und Strategien aufzubauen. Und darum geht es eigentlich bei der Erfindung des Modernen Klassikers. Es ist die De- und Re-Kontextualisierung des Objekts, die das Ding zum Kultobjekt erhebt. Das massenhaft produzierte Gebrauchsobjekt wird durch den neuen Kontext zum preziösen Einzelwerk geadelt. [...] Das bedeutende Museum muss sich nicht mehr mit be- 


\section{AM ENDE WAR ES NUR EIN WORT: ZWEI REZEPTIONSSTUDIEN}

deutender Kunst oder renommierten Namen legitimieren, denn es produziert die Aura des Dings mit - [...].«(ebd.: 104)

Museen werden hier noch ganz nah an der Wunderkammer belassen und massenhaft produzierten Gebrauchsobjekten wird dadurch eigentlich kurzfristig ihre Museumswürdigkeit abgesprochen. Doch das Museum als Ort preziöser Einzelwerke kann die Massenware zum gleichwertigen Ausstellungsgut adeln:

"Was aber hat Kult-Marketing mit Musealisierung zu tun? Das Museum hat sich als Ort und Raum der Übereinkünfte bewährt - dessen, was hochwertig und von dauerhaftem Wert ist; der Zuschreibung von dem, was Kunst ist angesichts einer schon lange währenden Gewissheit, dass es keine verbindlichen Qualitätskriterien für Kunst mehr gibt. Es ist der Raum der Auratisierung eines Dings." (ebd.: 107)

Design-Ausstellungen wie-Sammlungen machen sich also bereits hinreichend erprobte Methoden zu Nutze und letztlich ist es nur eine Frage der Wartezeit, bis die heiligen Hallen sich dann auch endlich der Gebrauchskultur öffnen dies allerdings unter ganz anderen Vorzeichen als es z. B. in einem Museum für Völkerkunde geschähe. Denn dort geht es nicht um das Sein der Artefakte als Artefakte, sondern um einen Blick in deren Eingebettetsein in eine andere Kultur:

"Kuratoren sind sich darüber im Klaren, dass jede Ausstellung den Ruf eines Produktes festigt. So hat auch die Ausstellungstätigkeit zur italienischen Designgeschichte, vorzugsweise der 6oer Jahre, den Mythos der linea italianar mitkonstituiert und verstärkt. [...] Ein weiteres Mittel zur Konstruktion einer Designgeschichte sind Sammlungen. Sie dekontextualisieren naturgemäß Einzelobjekte aus ihrem historischen Zusammenhang und fügen sie in einen neuen Kosmos ein. [...] Die Wiederholung und der Wiedererkennungseffekt in außergewöhnlichen Zusammenhängen macht sie zu Berühmtheiten.« (ebd.: 113f)

BREUER resümiert, »[d]ie Erfindung des Klassikers dien[e] [...] dazu, eine Konvention aufzustellen, eine Verabredung über den Status von Bildern, Objekten und Texten, ein Prozess, der immer wieder neu aufgefrischt werden muss, indem man ihm neue Klassiker beifügt." (ebd: 118) Dieser Prozess einer neuerlichen Verkultung von Gegenständen ist nur denkbar durch ein Differenzmanagement in Bezug auf die Art der musealen Präsentationen. Einerseits erlaubt man sich dort den Kunstgriff der Vereinzelung von Massenprodukten. Andererseits werden bewusst Orte musealer Präsentation genutzt, deren Kontext eine Nähe zum Kunstwerk mitschwingen lässt. Zudem wird durch 
die Gründung spezialisierter Museen oder den Aufbau neuer Sammlungen in bestehenden Kontexten eine neue Spezifität begründet und damit eine neue 436 Nische für neue Übereinkünfte geschaffen.

\section{Postmodernes Charisma}

Die Charismatisierung als »(Re-)Integration des Außeralltäglichen« ist LENzEs Ansatzpunkt, der eine anders gelagerte Deutung der schon von KOHL und BREUER gefundenen Verkultung anbietet:

"Das >Charisma der Postmoderne` will [...], wie die Magie, Transzenden-
tes erfahrbar machen. Im charismatischen Objekt scheinen die Grenzen
der Lebenswelt aufgelöst, die Verheißungen erlebbar. [...] Das >fetischis-
tische Produkt kann zusammen mit dem Starphänomen als Ausgangs-
punkt einer solchen (Re-)Integration des Außeralltäglichen in den Alltag
angesehen werden." (LENZE 2002: 166)

BÖHME und SELLE tendieren zu ähnlichen Formulierungen, wenn sie im Zusammenhang neuerlicher Fetischisierung von der "Wiederverzauberung" (вӧнME 2012: 23) oder dem »[t]ranszendentale[n] Sinn des Gestalteten" (SELLE 2007: 390) schreiben. Weiter vorne war bereits zu lesen, dass ein Entreißen aus scheinbarer Anonymität, die Fixierung der Aufmerksamkeit auf etwas eine gut eingeübte und bestens ritualisierte menschliche Strategie im sozialen Raum ist. Brüchig wird LENZEs Idee dann, wenn man sich vor Augen führt, dass es eigentlich nichts Außeralltägliches mehr gibt, das reïntegriert werden könnte oder müsste - zumindest an dem Punkt, der von einer klassischen Fetisch-Vorstellung (vgl. KOHL) besetzt gehalten wird. Es gibt jenes Außeralltägliche im magischen Sinne nicht mehr, das neben unserer Alltagswelt existiert und dessen Existenz wir uns nicht erklären können. Wir selbst waren und sind es, die unseren Alltag von seiner Banalität befreien und ihn mit Besonderheit aufladen oder anreichern wollen (s. o.) und die damit das Außergewöhnliche oder Außeralltägliche jenseits des Magischen neu zu definieren such(t)en:

»Verehrte Gegensände waren im Lauf okzidentaler Rationalisierung immer mehr verehrten Ideen gewichen. Seitdem sich aber, wie die Religion in Freuds sZukunft einer Illusion', auch diese Ideen als Illusionen erwiesen und selbst die ,Vernunft-Disziplinen Wissenschaft und Technik ihre heilsversprechenden Visionen einbüßten, muß der westliche Mensch Sinn in anderen >Provinzen s suchen. Im Grunde scheint es wie eine Kehrtwendung der Geschichte, daß es nun wieder mystifizierte Gegenstände 


\title{
AM ENDE WAR ES NUR EIN WORT: ZWEI REZEPTIONSSTUDIEN
}

und Personen sind, denen sich in Verehrung zugewandt wird. [...] Gegenwärtig treten solche Objekt-Charismen jedoch offensichtlich wieder gehäuft auf, sie können daher in meinen Augen neben dem Charisma von Stars als die typischen Ausformungen eines skontemporären Charismass bezeichnet werden." (LENZE 2002: 165)

Zum Zweck der Bestimmung des Wertes einer Ware versucht sich auch LENZE an Differenzierungen zwischen Tauschwert, Gebrauchswert und dem, was er in letzter Konsequenz als den eigentlichen Wert einer fetischisierten Ware betrachten müsste:

\begin{abstract}
»Betrachtet man eine einzelne Ware isoliert, so ist einzig ihr ,Gebrauchswert erkennbar, also die Erfahrung, daß sie ein nützlicher Gegenstand ist. Um den Wert der Ware wahrnehmen zu können, muß sie in ein Austauschverhältnis mit anderen Waren treten. Dieses Verhältnis bestimmt ihren Tauschwert. Im Tauschwert wird der Wert der Ware in Beziehung zu anderen sichtbar. Der Tauschwert ist jedoch lediglich Wertverhältnis, er serschafft nicht den Wert der Ware.« (ebd.: 169)
\end{abstract}

Wenn wir noch einmal zu MIKLAUTZ mit ihrem Rückgriff auf SIMMEL zurückkehren und uns erinnern, dass SIMMEL den Wert einer Ware als ein getrennt von ihr bestehendes Konstrukt, ein »im Subjekt verbleibendes Urteil über sie« bezeichnet, dann können Artefakte in ihrer Rezeption gar nicht anders als polyvalent gedacht werden: Weil Menschen zu höchst unterschiedlicher Besetzung mit Bedeutsamkeit fähig sind. LENZE selbst legt sich für Artefakte auf den Begriff des Produktfetischismus fest:

"Zur Unterscheidung von der Marxschen Begrifflichkeit soll im folgenden der Begriff >Produktfetischismus< verwendet werden. Interessieren soll das ,Charismatisches, mit dem Produkte menschlicher Arbeit umgeben sein können. [...]. Es geht also nicht um eine Decouvrierung der Mystifiziertheit von Waren im Allgemeinen, sondern um eine Bezeichnung jener Produkte innerhalb der Warenwelt, die für den Menschen besondere Bedeutung besitzen. Damit rückt die Verwendung des Fetisch-Begriffs wieder in die Nähe ihrer ursprünglichen Bedeutung. (ebd.: 170)

Die Frage nach dem Bedeutungsraum des Wortes Fetisch für LENZE muss natürlich geklärt werden, nachdem er ihn wieder in die »Nähe [seiner] ursprünglichen Bedeutung « rücken sieht - was ja dem Glauben an einem Artefakt innewohnende magische Kräfte entspräche:

"Neben dem verbreiteten Technikskeptizismus hat schon viel früher und mit wahrscheinlich weit größeren Auswirkungen ein anderer Faktor die Produkte endgültig von ihrem Fetischcharakter befreit. Abgesehen von 


\section{STARDESIGNER ODER GESTALTER DES ALLTÄGLICHEN?}

den absoluten Premiumprodukten, die sozusagen als sIkonen des Kapitalismus fungieren, hat das Konkurrenzprinzip der kapitalistischen Marktwirtschaft zu einem Überangebot an austauschbaren Produkten geführt. Allgegenwärtigkeit und Austauschbarkeit sind Gegenspieler des Geheimnisvollen und Besonderen und damit auch Gegenspieler des fetischistischen Produkts. Jenseits des Besonderen verlieren die Artefakte viel von ihrer symbolischen Funktion für das kulturelle Leben des Menschen. Wenn man Objekte also allgemein als Objekte kristallisierten Sinns beschreibt (vgl. z. B. Miklautz 1996), so ist deren Verbindung zum Signifikanten im beginnenden Spätkapitalismus undeutlich und lose. Was hier mit Produktfetischismus bezeichnet wurde, also die dingliche >Kristallisation elementaren (transzendenten) Sinns, tritt daher in zunehmend gesättigten und übersättigten Märkten immer seltener auf. Sogar die erwähnten Premiumprodukte verlieren, betrachtet man sie hinsichtlich ihrer Produkteigenschaften, viel von ihrem Fetischwert. Wirkliche technische Besonderheiten, die Menschen begeistern können, gibt es nur noch sehr selten.« (ebd.: 182f)

Dieser Absatz lässt den Verfasser mit Enttäuschung zurück, denn auch LENZE scheint den von ihm bevorzugten Begriff im »Überangebot an austauschbaren Produkten « kaum noch irgendwo aus- oder festmachen zu können. Technikskeptizismus als Gegenspieler von Objektcharismen kann nur darauf verweisen, dass der Glaube an die technische Machbarkeit und ihre Verkörperung in Artefakten selbst in den Stand eines Fetischs erhoben wird, so dass jener aus einer Ablehnungshaltung heraus zum Stein des Anstoßes und zu einem Grund von Ablehnung werden kann, was dann Grund für seinen Bedeutungsverlust ist. Das Konkurrenzprinzip führt außerdem dazu, dass Artefakte aus der Massenproduktion gewöhnlich statt außergewöhnlich werden. Diese Vorstellung von Außergewöhnlichkeit ist leicht zu dechiffrieren, handelt es sich doch um nichts Anderes als Seltenheit, die etwas außergewöhnlich macht und gewöhnlich kann demzufolge in diesem Sinn nur noch als weit verbreitet gelesen werden.

Eine Unschärfe in seiner Argumentation tritt ebenfalls zu Tage: Die Quadrotomie allgegenwärtig/autauschbar - geheimnisvoll/besonders bezeichnet sein Verständnis des Dilemmas der Besetzung mit Bedeutsamkeit recht genau. Gleichzeitig expliziert sie, was für LENZE in seiner Zeit noch ein fetischistisches Produkt sein könnte: Dieses steht jedoch meilenweit neben einer magischen Beseeltheit in der Landschaft, obwohl er exakt die gleichen damit zusammenhängenden Begrifflichkeiten verwendet.

Großzügig interpretiert LENZE auch Produkteigenschaften im Sinne von »technische[n] Besonderheiten« als Möglichkeiten, aus einem (Premium-)Produkt ein Artefakt mit »Fetischwert« zu machen, was wieder zu BÖHME in die 
Zukunft weist. Für LENZE handelt es sich jedoch um keine geheimnisvolle, magische Beseeltheit mehr, sondern um ein aufs-Podest-stellen als Folge präzisen, möglicherweise spezialisierten Wissens um technische Besonderheiten, mit Hilfe dessen auch wieder die Geschlossenheit von Gruppen hergestellt und behauptet werden kann. So bleibt Insiderwissen im Verein mit Nichtwissen Voraussetzung für Abgrenzung. Wenige Seiten weiter nimmt er von dieser Idee selbst Abschied, wenn er feststellt, dass Charismatisierungen im Rahmen der Selbstdefinition auch wieder zurückgenommen werden (könn(t)en):

"Das >Charisma der Vernunft, das sich im Technik- und Wissenschaftsglauben und zuletzt in den Ideologien der 68er und der Umweltbewegung bemerkbar machte, wird vielfach ersetzt, zumindest aber überdeckt, von einem spezifisch magischen Charisma, das die Heilsversprechung nicht im technischen Fortschritt, sondern im Konsum von charismatisierten Angeboten offenbart. Konkret begeistert den Menschen heute weniger ein Produkt, das zukunftsweisende Technik verspricht, als vielmehr eine Marke, die eine zukunftsweisende Lebenseinstellung kommuniziert. [...] Die Autoren einer Studie zum >Markenmythos behaupten sogar: 'In einer Zeit, in der viele traditionelle, gesellschaftliche Orientierungsmuster konturenlos werden und verschwimmen, bietet die Selbstdefinition über Produkte und Marken nahezu die einzige Möglichkeit der Identitätsstiftung.« (ebd.: 184)

In einer Welt, in der Marken als Einzige noch "zukunftsweisende Lebenseinstellung[en] kommunizier[en] «, werden nach LENZEs Meinung verschiedene Wertesysteme verschränkt, wobei er sich letztlich wieder SIMMEL und MIKLAUTZ annähert, als er feststellt, dass »[...] die ssymbolische Welt ‘ der Marke für den Konsumenten zum Objekt [gehöre], auch wenn er kognitiv den Gebrauchswert des Produkts vom >Bedeutungswert ‘ der Marke trenn[e].« (ebd.: 186) Andersartig an seiner Art der Beschreibung ist im Vergleich zu jenen die Erweiterung der Objektsphäre um die symbolische Welt der Marken. SIMMEL musste sich in seiner Zeit noch nicht mit derart ausgefeilten und allumfassenden Markenarchitekturen auseinandersetzen, wie wir sie heute gewöhnt sind. Auf Ebene der Selbstentwürfe argumentiert LENZE eben schon und auch jetzt wieder ähnlich wie KELLER (2008), die sich mit der Identitätskonstruktion von Star-Nutzern in der Mediengesellschaft beschäftigt:

"Charismatisch institutionalisierte Marken sichern somit nicht nur den share-holder-valuer eines Unternehmens, sie haben als Objekte skristallisierten Sinns', als `Konstruktionshilfen individueller und gruppenspezifischer Identität, einen kulturell wirksamen ssozialen Bedeutungswertı." (ebd.: 193) 
An diesem Punkt lässt LENZE BREUER deutlich hinter sich und schließt eher bei MIKLAUTZ und deren kulturell verwurzelter Objektivierung von Bedeu440 tung an - weil auch er die ständig neu verhandelten Konventionen für kulturell wirksam hält und sie damit aus der Sphäre rein ökonomisch motivierter Überlegungen befreit, die im Rahmen der BREUERschen Gedankenwelt nur als ausschließliche Kapitalismus- und Designkritik gelesen werden können. So bietet er veränderte Deutungsmöglichkeiten für neue Diesseitsreligionen an. (vgl. ebd.: 197)

\section{The Theory of the Leisure Class}

VEBLEN macht das Aufkommen des ostentativen Konsums an einer gleichzeitig mit dem Konzept des Eigentums entstehenden Klasse der feinen Leute fest, die in der Lage sind, sich dem Müßiggang hinzugeben und deshalb Mittel und Wege suchen und auch finden, diese generelle Klassendifferenz intern wie extern weiter auszudifferenzieren: „From the ownership of women the concept of ownership extends itself to include the products of their industry, and so there arises the ownership of things as well as of persons." (VEBLEN 1994: 16) Mit dem Konzept des Eigentums gewinnt der Besitz von Reichtum an Bedeutung, der einen Wandel vom Nachweis persönlicher Leistungsfähigkeit zu einem Wert an sich durchmacht und fürderhin die übliche Grundlage für Ansehen und Wertschätzung darstellt:

„Gradually, as industrial activity further replaces predatory activity in
the community's everyday life and in men's habits of thought, accumu-
lated property more and more replaces trophies of predatory exploit as
the conventional exponent of prepotence and success. With the growth
of settled industry, therefore, the possession of wealth gains in relative
importance and effectiveness as a customary basis of repute and esteem.
[...] The possession of wealth, which was at the outset valued simply as an
evidence of efficiency, becomes, in popular apprehension, itself a meri-
torious act. Wealth is now intrinsically honourable and confers honour
on its possessor." (ibid.: 18)

Es kann schon an dieser Stelle nicht verwundern, dass sich Parallelen zur Akkumulation von Aufmerksamkeit aufdrängen und der Ruhm sich mit ins Bild schiebt, der seinem Empfänger auf die gleiche Weise Ehre verschafft. Auch Anzeichen des Verschwenderischen seien es, die ein Artefakt neben seiner rein nützlichen Seite haben müsse, um vollständig gebrauchsfähig zu sein (!) 
- hier ist noch einmal zu einem Teil der vorstehend bereits zitierten Passage zurückzukehren, ohne jedoch den Ausdruck honorific element in den Vordergrund zu stellen:

"The habit of looking for the marks of superfluous expensiveness in goods, and of requiring that all goods should afford some utility of indirect or invidious sort, leads to a change in the standards by which the utility of goods is gauged. The honorific element and the element of brute efficiency are not held apart in the consumer's appreciation of commodities, and the two together got to make up the unanalysed aggregate serviceability of the goods." (ibid: 95)

Geradezu aufreizend wirkt der folgende Gedanke, mancher Ware sei eine zeremonielle Unterlegenheit oder auch Unreinheit zu eigen, weil sie als Folge ihrer geringen Produktionskosten so gewöhnlich wäre, dass sie eben nichts ehrendes mehr an sich hätte - allein dadurch, dass sie in der Reichweite von zu vielen läge:

»The ceremonial inferiority or uncleanness in consumable goods due to rcommonness or in other words to their slight cost of production, has been taken very seriously by many persons. The objection to machine products is often formulated as an objection to the commonness of such goods. What is common is within the (pecuniary) reach of many people. Its consumption is therefore not honorific, since it does not serve the purpose of a favourable invidious comparison [Hervorhebung des Verfassers] with other consumers.« (ibid: 97)

Vorteilhafter Ausgang eines auf Neid basierenden Vergleichs - für jenen, mit dem andere sich vergleichen: eine Formulierung, die man sich auf der Zunge zergehen lassen darf. Hier wird bewusst eine freiere Auslegung von "favourable invidious comparison" gewählt, denn die Hauptbedeutungen von invidious (undankbar oder ärgerlich) erscheinen in diesem Zusammenhang sehr unpassend. Im Besonderen ist es jedoch die Benennung der Betrachtungsebenen, die diesen VeBLENschen Satz so interessant macht. Der Kauf unterlegener Artefakte lohne sich für jene, die etwas sie Ehrendes davon erwarten, nicht. Ein Teil ihres Urteils fiele also auf der Basis der Erreichbarkeit für viele.

Besonders daran ist die Verkettung zweier Blickrichtungen auf das Gleiche und dass die Betrachtungsrichtung der einen Seite im Zusammenhang mit der Erreichbarkeit die Entscheidung der anderen mit beeinflusst. Der Käufer eines überlegenen Artefaktes muss den Ausgang eines neidvollen sozialen Vergleichs von unten im Rahmen seiner von oberhalb geführten Betrachtung von vornherein mit einkalkulieren. Als Statusobjekt kann für diesen 
Fall nur eines in Frage kommen, das eben nicht in der Reichweite all zu vieler von unten zu ihm heraufschauender Mitkonsumenten liegt. Dieses wird von der anderen Seite als außerhalb der persönlichen Reichweite liegend betrachtet und die Mechanik des neidvollen Vergleichs bringt das den anderen Ehrende schon durch die schiere Nichterreichbarkeit hervor, ist also ohne diese zwei differenten Parteien gar nicht denkbar. Die Bedeutung von VEBLENs Ausdrucks honorific element ist somit bereits auf die reine pekuniäre Erreichbarkeit und quantitative Knappheit reduziert und mehr hat er aus heutiger Sicht nicht zu diesem Diskurs beizutragen, wie sich bis heute auch an dieser Mechanik nichts geändert hat.

\title{
What was Philippe Starck thinking of?
}

\begin{abstract}
"This is not a very good lemon squeezer: but that's not its only function. I had this idea that when a couple gets married it's the sort of thing they would get as a wedding present. So when the new husband's parents come round, he and his father sit in the living room with a beer, watching television and the new mother-in-law and daughter-in-law sit in the kitchen to get to know each other better. >Look what we got as a present, $<$ the daughter-in-law will say. ..." (STARCK in: MORGAN 1998: 9)
\end{abstract}

Der artefaktische Auslöser dieser Untersuchung ist hiermit erreicht und so wird die Suche nach einer Antwort auf die Frage, welche Intentionen PHILIPPE STARCK gehabt haben könnte, als er den JUICY SALIF entwarf, ein vorläufiges Ende finden. Ein Kernzitat steckt schon in LLOYD und SNELDERS' Zusammenfassung:

"We argue, using Philippe Starck's Juicy Salif lemon squeezer as a case study, that the personal creativity of a designer forms a necessary condition for a design's success. It does not, however, form a sufficient condition." (LLOYD und SNELDERS 2003: 237)

Wenn individuelle Kreativität auch ein notwendiger Bestandteil des Erfolgs einer Gestaltungslösung wäre - womit die Autoren viel Wasser auf die Mühlen aller seither angetretenen Autorendesigner leiten -, schränken sie gleichwohl ein, dass dies als alleinige Voraussetzung noch nicht ausreichend sei und suchen nach weiteren Gründen für den Verkaufserfolg des JUICY SALIF. Inwiefern könnte es in diesem Zusammenhang bedeutsam sein, darüber nachzusinnen, was PHILIPPE STARCK sich beim Entwurf gedacht hat? 
Wenn man den Vorgang unter der Prämisse eines (Be-)Gründungsmythos betrachten will, ist das wesentlich und dann hätte STARCK etwas zu dessen Ergründung beizutragen: Doch einen Entwurf im Nachhinein als »made to start the conversation" (ebd.: 243) zu bezeichnen, wirkt so, als müsse die nicht als Zitronenpresse verwendbare Zitronenpresse schnell mit einer weiteren Existenzberechtigung versehen werden, weil sie für jenes Nichtfunktionieren kritisiert wurde. Man könnte sich die Frage stellen, ob es - ausgehend von der Nichterfüllung einer intendierten Funktion - eine andere Funktion in dem Sinne gäbe, wie STARCK sie legitimierend nachgeschoben hat: "Sometimes you must choose why you design - in this case not to squeeze lemons, even though as a lemon squeezer it works." (ebd.: 243) Also sprach STARCK und wurde zu Recht in die Ecke des Genius-Narrativs gestellt, der sich aus dem wenige Seiten zuvor schon erwähnten Mythos von der eigenen Omnipotenz speist. Die Autoren beziehen sich hier auf FORTY (1986/1995). Der ansatzweise ehrenhaft zitierende, teils frei paraphrasierende und umstellende, den Originaltext nicht sauber kennzeichnende Umgang der Autoren mit FORTYs Worten ist mindestens fragwürdig zu nennen. In der Synopse der beiden Originalpassagen sind die inkriminierten Stellen hervorgehoben:

LLOYD und SNELDERS: »Design has come to be regarded as belonging entirely within the realm of the designer Forty writes, and this has had pernicious consequences, particularly in design schools where students learn to indulge what Forty refers to as sthe myth of their own omnipotencer. Designers describe their work as if they had overall power, at the expense of neglecting ideology as a determinant of design." (LLOYD und SNELDERS 2003: 237)

FORTY: »Because designers generally talk and write only about what they do themselves, design has come to be regarded as belonging entirely within their realm. This misunderstanding has reappeared in innumerable books and in the coverage of design in the press and on television. It has also, with more serious consequences, been taught in schools of design, where students are liable to acquire grandiose illusions about the nature of their skills, with the result that they become frustrated in their subsequent careers." (FORTY 1995: 241)

"For most designers, however, the solution to the problem lies not in theory, but in collusion with the myth of their own omnipotence and in wholly ignoring their rôle as agents of ideology. Although some designers do acknowledge that they are involved in the transmission of ideas over which they have no control and which they may not fully under stand, it is more common to hear them describing their work as if they had overall power:" (ibid.: 242) 
LLOYD und SNELDERS' voriger Aussage kann nicht zugestimmt werden. Aus der Perspektive dieser Arbeit wird Ideologie als Determinante von Design 444 von Designern ganz und gar nicht übersehen. Vielmehr stellt es sich so dar, dass mit dem Aufkommen des Autorendesigns und dem Verschwinden der Metaerzählungen (im Sinne von LYOTARD) die Metaideologien durch Individualideologien ersetzt wurden, die man auch als Personalstile bezeichnen könnte. Dies in zunehmendem Maße, je mehr sich Designer aus der Serienproduktion zurückziehen und sich Verknappungs- und Distributionsstrategien anverwandeln, die im Kunstmarkt üblich sind (vgl. auch BREUER 2001). Schädlich (pernicious) ist diese Einstellung womöglich dennoch. Das Autorendesign fordert für sich ein, dass der merkantile Erfolg einer Gestaltungslösung dem individuellen Stil und den Intentionen des einzelnen Designers geschuldet sein soll:

"The second is the attribution of the design's success; is it to the intentions of the designer (in which case there is a good argument for omnipotence) or to cultural or ideological factors in the consuming public (in which case there is a good argument for impotence).... We also discuss whether ideological factors - what Forty refers to as ideas embodied in the product and held in common by the people for whom the product was intended - could provide a sufficient condition for a product's success." (LLOYD und SNELDERS 2003: 238)

Aufgrund eigener Befunde wird hier die Meinung vertreten, dass Designer die Prominenten der zweiten Reihe sind und ganz andere Determinanten einen behaupteten oder tatsächlichen Erfolg eines Artefaktes herbeiführen, die hauptsächlich der Kontingenz eines nicht präzise zu fassenden Marktgeschehens geschuldet sind. Somit ist die Rückführung der Allmachtsphantasie durch LLOYD und SNELDERS in die eben schon beschriebene Impotenz zutreffend.

In stürmische Gewässer bewegen sich die Autoren, wenn sie behaupten, die Tatsache, dass ein Produkt existiere, sage mehr aus über die Menschen, die es kaufen und benutzen als über die ihm zugrundeliegenden Intentionen des Gestalters (vgl. ebd.: 244). Produkte kommen zunächst als Ergebnis eines Zusammenwirkens von Designern und deren Auftraggebern zustande und entstehen üblicherweise aus der Antizipation eines behaupteten oder festgestellten Zielgruppengeschmacks, der heute wohl zumeist durch die Marketingabteilung eines Auftraggebers in ein Profil, eine Persona oder ein Milieu eingepasst wird. Danach hat sich ein auftragnehmender oder im Unternehmen arbeitender Designer zu richten. So, wie LLOYD und SNELDERS es weiter vor- 
ne schon im Rückgriff auf FORTY beschreiben, dass der Omnipotenz-Mythos im Design, der schon in der Ausbildung an den Designschulen grundgelegt werde, andere ideologische Einflüsse wie auch kulturelle Faktoren ausblende, geht deren Argumentation im Vergleich mit der Realität einer immer noch berufsvorbereitenden Ausbildung klar an derselben vorbei.

Zudem muss sich das Produkt, nachdem es schon im Rahmen einer Kultur entsteht, deren Einflüssen es sich gar nicht entziehen kann, auch den Fährnissen des Marktes stellen. Die Tatsache, dass Menschen Produkte kaufen und benutzen, sagt zwar sehr wohl etwas über diese aus. Doch dass sie das können, sorgt für sich gesehen noch nicht dafür, dass ein bestimmtes Produkt existiert. Im Falle des JUICY SALIF müssen noch andere Faktoren als die der angebotenen Begründungslegende zu seinem Erfolg geführt haben - diese lagen jedoch nicht im Rahmen von STARCKs Gestaltungspotenz:

"The function of the product becomes that of smarker for a set of values and ideas with which informed consumers align themselves." (ebd.: 244)

Diese Aussage wird als Kernsatz ihres Artikels gewertet, da der JUICY SALIF damit eine neue Funktion erfüllt: Er wird zu einem Identifikationsartefakt - was auf eine eigentümliche Weise jenen der religiösen Sorte entspricht: Das Kopftuch, die Kippa oder das Kreuz sollten als Anhaltspunkt für Identifikationsartefakte dieser Art genügen. Der Halbsatz »with which informed customers align themselves« ist ebenso ein Ankerpunkt für CURRID-HALKETTs »in the know« (s. o.). Diese Identifikationsfunktion wird dem Produkt jedoch nicht durch das gestalterische Talent von PHILIPPE STARCK in die Wiege gelegt, sondern sie wird durch die Kaufentscheidungen vieler Konsumenten hervorgebracht, die mit ihren Einkäufen ein als solches wahrnehmbares und dann in diesem Sinne wieder vorzeigbares Identifikationsartefakt erzeugt haben.

Natürlich ist das nicht machbar ohne einen Produzenten, der das Wagnis eingeht, ein solches Produkt in den Markt zu bringen! ALESSI ist mit der in Verkaufszahlen ausgedrückten Beliebtheit erfolgreich umgegangen: Durch Varianten des Entwurfs, wie es sie im Falle des JUICY SALIF zunächst zu seinem zehnjährigen Jubiläum als vergoldete »Anniversary Edition 2000« (Auflage 9999 Ex. zum Preis von je 148,- €) gibt. Zu seinem 25jährigen Jubiläum wird die Serienproduktion um eine Variante mit einem mattweißen Keramiküberzug erweitert. Außerdem wird eine auf 299 Exemplare limitierte Version in Bronzeguß aufgelegt - zum Preis von je 1000,- $€$. 


\section{STARDESIGNER ODER GESTALTER DES ALLTÄGLICHEN?}

Der Marktpreis für JUICY SALIFs in normalsterblichem SILBER oder WEISS hingegen liegt im März 2018 bei 62,- €. (ALESSI) [online] https://www.alessi.com/ 446 de_de/juicy-salif.html [06.03.2018 ${ }^{1}$

Ist in der Bilanz des Kapitels Aufmerksamkeit noch anhand der Arbeit von KLAMER et al. diskutiert worden, dass man primär keinen STARCK kaufe, sondern eine Zitronenpresse von STARCK und dass demzufolge die Entscheidung für eine Artefakt-Kategorie vor der Entscheidung für ein Artefakt von ALESSI und/oder STARCK stünde, so ist im Falle des JUICY SALIF und seines Markterfolges diese Frage tatsächlich noch einmal zu stellen und sie erfährt jetzt eine andere Antwort.

Geht man davon aus, dass PHILIPPE STARCK ein Artefakt entwerfen will, das nicht seiner ihm eigentlich zugedachten Funktion gemäß funktionieren wird, dann ist er in der Lage, übliche Funktionserwägungen völlig außer Acht zu lassen, weil er für einen Auftraggeber tätig wird, der sich bereits einen $\mathrm{Na}$ men mit außergewöhnlichen Entwürfen von Designern gemacht hat, die mit dem Zusatznutzen eines bereits bestehenden Rufes potentiell mehr Verkäufe für ALESSI generieren können. STARCK kann also einfach entwerfen, wozu er Lust hat und dem Design eine Vorgehensweise aus der Kunst überstülpen. Unter dieser Prämisse können Artefakte die oben schon beschriebene Funktion bekommen und die Hypothese, der Funktionsraum von Artefakten, die der Hand von Designern entstammen, sei in der jüngeren Vergangenheit erweitert worden, muss mit Ja beantwortet werden - was zur Folge hat, dass sonst übliche Nutzenerwägungen in solchen Fällen nicht mehr gelten.

Bevor die Betrachtungen zum JUICY SALIF ihr Ende erreichen, folgen zum Vergleich mit und in Ergänzung zu LLOYD und SNELDERS ein paar Stimmen weiterer Autoren, die sich ebenfalls mit diesem Artefakt auseinandergesetzt haben. ECO formuliert in Quasi dasselbe mit anderen Worten:

"Als Michelangelo beauftragt wurde, die Kuppel des Petersdoms zu entwerfen, wird die unausgesprochene Erwartung gewesen sein, daß diese Kuppel nicht nur schön, harmonisch und großartig werde, sondern auch, daß sie nicht einstürzte - und dasselbe erwartet man heute, was weiß ich, von Renzo Piano, wenn man ihm den Auftrag erteilt, ein Museum zu entwerfen. Es mögen dies juristisch-kommerzielle Kriterien sein, aber sie sind nicht kunstfremd, denn zum Wert eines Kunstwerks gehört auch die Perfektion seines Funktionierens. Als Philippe Starck mit dem Entwurf einer Zitronenpresse beauftragt wurde, hat man da nicht in sei-

1 Als Nebenaspekt: Verschachtelt im Sinne verschachtelter Beachtlichkeit sind hier die Marke ALESSI und die Personenmarke PHILIPPE STARCK. 


\section{AM ENDE WAR ES NUR EIN WORT: ZWEI REZEPTIONSSTUDIEN}

nen Vertrag hineingeschrieben, daß zu den Funktionen des Geräts nicht nur gehören sollte, den Saft aus der Zitrone fließen zu lassen, sondern auch, die Kerne zurückzuhalten? Offenbar nicht, denn Starcks Zitronenpresse läßt die Kerne ins Glas fallen, vielleicht weil dem Designer eine irgendwie geartete Auffangrinne unästhetisch erschien. Wäre in seinem Vertrag präzisiert worden, daß die neue Zitronenpresse ungeachtet ihrer neuen Form alle Merkmale einer traditionellen Zitronenpresse haben sollte, dann hätte der Auftraggeber das Recht gehabt, dem Designer das Objekt zurückzugeben. Daß dies nicht geschehen ist, liegt vermutlich daran, daß der Auftraggeber gar keine echte Zitronenpresse haben wollte, sondern ein Kunstwerk und conversation piece, das die Käufer als eine abstrakte Skulptur begehren würden (die übrigens sehr schön anzusehen ist, dabei beunruhigend wie ein Tiefseeungeheuer) oder jedenfalls als ein Prestigeobjekt, nicht als ein Haushaltsgerät, das man praktisch benutzen kann." (ECO 2006: 25)

NORMAN ordnet den JUICY SALIF in seiner Publikation Emotional Design der Kategorie seductive zu (vgl. NORMAN 2005: 113f) weil er in PHILIPPE STARCKs Entwurf verführerische Qualitäten zum Ausdruck gebracht sieht, die uns erst in zweiter Linie - nach dem Wunsch, das Artefakt zu erwerben- darüber nachdenken ließen, wozu es gut sei und was es kostet. So stellt sich eine nur vordergründig unscheinbare Erweiterung der möglichen Gründe für einen Einkauf ein: Denn wenn dieses Artefakt unsere Handlungsrationalität derart signifikant außer Kraft setzt, dass das reine Habenwollen gegenüber den Nutzenerwägungen obsiegt, dann hat auch diese Verkörperung einer Funktionslosigkeit mit neuer Funktion gesiegt.

SELLE (2007: 153f) bietet uns eine weitere Deutungsmöglichkeit für den JUICY SALIF an mit einer (wie gleich zu sehen sein wird) annähernd parallel liegenden Analyse des Wasserkessels BOLLITORE, 1983 von RICHARD SAPPER für ALESSI entworfen, die mit den folgenden emblematischen Sätzen beginnt:

"Es gibt Produkte, deren Aufgabe darin besteht, jeden praktischen Zweck zu transzendieren. Ihr Sinn ist, als Phänotyp zu existieren und aus der unübersichtlichen Landschaft zeitgenössischer Designleistungen herauszuragen.«

Genau genommen existieren alle Designleistungen als Phänotypen, da es der Natur der Sache nach keinen Genotyp für Artefakte gibt - es sei denn, der planerische Daseinszweck eines Artefaktes würde als sein Genotyp betrachtet und die verkäufliche Gestalt als Phänotyp .... Doch mit dem Herausragen als Anknüpfungspunkt zum Kapitel Prominenz (genauer: bezogen auf ein Her- 


\title{
STARDESIGNER ODER GESTALTER DES ALLTÄGLICHEN?
}

\author{
ausragen im WIPPERSBERGschen Sinne) versöhnt man sich mit dieser unge- \\ nauen Formulierung. Wenige Seiten weiter heißt es:
}

»Ein Designer ist heute jemand, der unermüdlich öffentliche Kunststücke der Produktinnovation vorführen soll. Der bollitore [Hervorhebung im Original] ist ein solches Kunststück. Er soll nicht im Gebrauch unter der Hand verschwinden, sondern auffallen und als artistische Leistung anerkannt werden. Dazu sucht und findet er die Nähe der Medien. Für Fotografen ist dieses Objekt ein gefundenes Fressen. Aufgrund seiner skulpturalen Kompaktheit lässt es sich bildbeherrschend in Szene setzen, und wegen seiner spiegelnden Oberfläche sind überraschende Effekte unvermeidlich. Ist dieses Objekt vielleicht überhaupt nur für das Fotografieren entworfen worden? >Durch die Verbindung von traditionellem Küchengerät und aggressiv-moderner Form wurde er in den achtziger Jahren zu einem Kultobjekt, das mehr betrachtet und photographiert wurde, als tatsächlich verwendet.« (SELLE 2007b: 155; Bezug auf sSPARKE 1989: 225«)

Obwohl es sich im Falle des JUICY SALIF um ein nominell völlig anderes Artefakt handelt, sind die gänzlich veränderten Entwurfsprinzipien und ihre Auswirkungen für seine Nutzung klar erkennbar die gleichen. Bevor ALBERTO ALESSI selbst zu Wort kommt, bleibt Raum für MICHAEL COLLINS, der sich kurz vor dem zehnjährigen Marktjubiläum sehr launig über die Zitronenpresse äußerte, deren »Zweck [es] nicht ist, verwendet zu werden«:

"Untersuchen wir also die Zitronenpresse Juicy Salif [Hervorhebung im Original] von Philippe Starck aus dem Jahr 1990. Kaufen wir die Zitronenpresse, denn das ist die billigste Methode, Philippe Starck beim Abendessen zu haben, oder eher beim Abendessen in der Küche, wo wir heute essen. Wir lieben Küchen und Kitsch. Wir verwenden Juicy Salif [Hervorhebung im Original] nicht. Ihr Zweck ist nicht, verwendet zu werden, sondern wie ein Kunstwerk bewundert und nicht berührt werden. Sie soll analysiert werden, man soll darüber diskutieren. Vorsicht aber, wenn wir Juicy Salif [Hervorhebung im Original] doch verwenden. Macht es etwas aus, dass der Zitronensaft schlechter über den spinnenartigen Kopf der Presse tröpfelt als das Regenwasser durch einen 1000 Jahre alten Kanal vom Dach zum Boden rinnt? Macht es etwas aus, dass die Zitronensäure mit der Zeit den Aluminiumkörper unseres dreibeinigen Spinnenwesens aus dem Weltall zerstören wird? Macht es etwas aus, dass der Druck, der nötig ist, um den Kopf von Juicy Salif [Hervorhebung im Original] mit Zitronensaft zu salben, so stark ist, dass die dreibeinige Konstruktion umkippt und die scharfen Füße sich in den Küchentisch aus Holz graben? Nein, denn wir haben einen Philippe Starck, DEN [Hervorhebung im Original] Philippe Starck in unserem Heim und unserem Herzen. Macht es etwas aus, dass die alte, anonyme Zitronenpresse aus Glas den Zweck mindestens so gut erfüllt, wenn nicht sogar besser? Nein, denn wir haben einen Philippe Starck in der Küche! Fotografieren wir also diese Juicy 


\section{AM ENDE WAR ES NUR EIN WORT: ZWEI REZEPTIONSSTUDIEN}

Salif [Hervorhebung im Original], denn sie wurde entworfen, um fotografiert zu werden. Sie ist fotogener als ihr Schöpfer. (COLLINS 1999: 10f)

Wie bereits angekündigt: Auch Produzent ALESSI äußert sich ebenfalls immer wieder zum JUICY SALIF: Zwei Publikationen begleiten das Artefakt bisher auf seinem Weg. Thre Titel lauten 10 Years without squeezing a lemon und 25 Years without squeezing a lemon und sind zum jeweiligen Jubiläum erschienen. Als Autor zeichnet jeweils MICHEL COGO verantwortlich.

2017 schreibt ALBERTO ALESSI auch in der bei RIZZOLI erschienenen Publikation The Dream Factory. Alessi since $1921^{2}$ darüber. Wenngleich ich ALEsSI die nötige Distanz abspreche, um auf einer rein wissenschaftlichen Ebene über den JUICY SALIF schreiben zu können, sind seine Einlassungen dennoch als Selbstzeugnis interessant genug. Die generelle Einstellung zum Design im Hause ALESSI ist aus dessen Sicht diese:

"A true work of design must move people, convey feelings, bring back memories, surprise, transgress ... it has to make us feel with greater precision that we are living our only life ... in other words, it has to be poetic. Design is one of the most appropriate forms of expression of our day and age." (ALESSI 2017: 93)

Zum JUICY SALIF formuliert er dieses:

"Juicy Salif [Hervorhebung im Original] is an excellent example of our company practice as artistic mediators in the areas of greatest turbulence in the realm of Creative Possibility. The object is unsurpassed in its capacity to generate debate around its nature and meaning, thanks also to the ruthless use of what semiologists refer to as the decorative veil destined to inexorably cover, albeit in a less evident way, each creation made by humans. To offer it a reason for its existence, we should unquestionably refer to the theories of André Leroy-Gourham [sic; LEROI-GOURHAN], who believes the notion of functional approximation to be crucial, which he uses to indicate the fact that there has always been a certain freedom in the interpretation between Form and Function. It is precisely from this continuous game between Form and Function that the afore-mentioned decorative veil comes to be, which the semiologist Jean-Marie Floch says is the manifestation of the mythical and aesthetic dimension of the object. Besides being the most controversial citrus squeezer of the twentieth

2 Zum Neuigkeitswert der Publikation von RIzzoli: Eigentlich handelt es sich hierbei nur um eine umgestaltete, etwas überarbeitete und erweiterte englische Neuauflage um den Kern einer schon im Jahr 1998/2000 bei ELECTA (MAILAND) auf Italienisch/Deutsch erschienenen Publikation, die sogar den gleichen Titel trägt (La Fabbrica dei Sogni/Die Traumfabrik. Alessi seit 1921) - was aber nicht ausgewiesen wird. 


\section{STARDESIGNER ODER GESTALTER DES ALLTÄGLICHEN?}

century, Juicy Salif [Hervorhebung im Original] is also one of the icons of 1990 design, and it continues to be one of the most provocatively intelligent objects in Alessi's catalog." (ibid.: 96)

Fernab von solch bemüht weitschweifigen, semiologischen Begründungsversuchen erscheint es in diesem Zusammenhang völlig ausreichend, den schmückenden Schleier, den ALESSI über all seine Produkte ziehen lässt, dort zu belassen und sich auf eine Passage aus einem Interview mit DEZEEN aus dem Jahr 2014 zurückzubeziehen:

"Alessi says that the project was deliberately poking fun at the idea that form should follow function. II am very happy with this project because I consider it a big joke to everybody, ‘ he says. II is the most controversial squeezer of the century I must say, but one of the most amusing projects I have done in my career." (HOBSON in: DEZEEN am 09.06.2014) [online] https://www.dezeen.com/2014/o7/og/movie-alberto-alessi-juicy-salifcontroversial-lemon-squeezer-philippe-starck [06.03.2018]

Es folgt das trockene Fazit von LLOYD und SNELDERS, bei denen die Präzision ihrer Analyse bedauerlicherweise etwas nachlässt, denn ihr Fokus verschiebt sich in der conclusio auf das, was in der Forschungspraxis als Everyday Design in dem Sinne verstanden wird, wie WAKKARY und MAESTRI sowie KIM und LEE es untersuchen:

"The main conclusions of our analysis suggest that we should conduct our search for the reasons of a particular design's success by looking for descriptions of engaged use that contradict, ignore, but sometimes support the original intentions of the designer." (LLOYD und SNELDERS 2003: 252)

Die alltägliche Aneignung und auch Umnutzung von Artefakten, die aus der Hand von Designern stammen, aber zeitweilig nicht mehr in dem Sinne eingesetzt werden, wie es ursprünglich intendiert war (vgl. hierzu WAKKARY und MAESTRI 2007 \& 2008 sowie KIM und LEE 2014), wirft gänzlich veränderte Fragen auf. Sie stellen den Benutzer als Gestalter seines Alltags in einer ganz anderen Rolle als der des Betrachters eines Artefaktes in den Mittelpunkt der Forscheraufmerksamkeit. Unter Bezug auf LLOYD und SNELDERs' main conclusions wird bezweifelt, dass der erstaunliche Verkaufserfolg des JUICY SALIF dadurch ergründet werden könnte, dass man zu belegen versucht, inwieweit eine mögliche Umnutzung Konsumenten dazu bewegt haben könnte, dieses Artefakt zu erwerben (z. B. im Sinne der Bassena; vgl. WENZL-BACHMAYER 2009). Dass ein Artefakt nicht für seinen vorgeblichen Verwendungszweck eingesetzt werden kann und deswegen die Rolle eines reinen Dekorationsgegen- 
standes annimmt, ist noch kein Anzeichen für eine Umnutzung, die der ursprünglichen Intention von STARCK widerspräche, sie ignorierte oder diese unterstützte. Die tatsächliche Funktion des Produktes zu ignorieren, dürfte uns so ebenfalls nicht zu des Pudels Kern vordringen lassen, denn wenn wir nach Lage der Dinge davon ausgehen müssen, dass dieses Artefakt eine neue Funktion hat, die gerade nicht darin besteht, als Zitronenpresse zu funktionieren, dann wird es genau deswegen gekauft und die vermutete ursprüngliche Intention des Gestalters wird im Kauf erfüllt. Damit wäre indirekt der Beweis für die (in diesem Sinne nachgeschobene) Originalintention von STARCK erbracht, nämlich ein conversation starter zu sein und LLOYD und SNELDERS' Hypothese wäre belegt, ohne dass sie das in dieser Art angestrebt hätten.

Zusammenfassend hat PHILIPPE STARCK ein Produkt entworfen, das seine im weitesten Sinne skulpturalen Qualitäten unter der Maskerade einer Zitronenpresse versteckt, die auch im JETSON-esken Googie- und Space Age-Design der 5oer Jahre des 20. Jhd.s verwurzelt zu sein scheinen. Verblüffend daran und auch an der bewusst herbeigeführten Verkunstung ist deren serieller Verkaufserfolg. Zum Zeitpunkt des Artikels von LLOYD und SNELDERS sollen bereits 550.000 Exemplare davon abgesetzt worden sein (ebd.: 238) - was auf der Basis des aktuellen Marktpreises (62,- $€$ im Jahr 2018) vor 16 Jahren einem Umsatz von über 34 Mio. $€$ entsprochen hätte. Er wäre rein quantitativ gesehen ein Kandidat für den Busse-Longlife-Design-Award. (Online-Ausgabe des Handbuchs der Kulturpreise, ARCULT) [online] http://www.kulturpreise. de/web/preise_info.php?cPath=4_57\&preisd_id=2589 [18.05.2018]

Im Gegensatz zu den bei KLAMER et al. beschriebenen Aufmerksamkeitsmechanismen des Kunstmarktes, die in der Erregung der Aufmerksamkeit für ein singuläres Kunstwerk den Auslöser für weitere Verkäufe sehen - wodurch auch das Ansehen des Künstlers weiter gesteigert wird - bei denen es aber erneut nur um singuläre oder in kleinen bis kleinsten Auflagen hergestellte Werke geht (weil höhere Auflagenzahlen deren gefühlten und damit auch tatsächlichen Wert verringern würden), musste der JUICY SALIF unter solchen Einschränkungen als Design-Artefakt nie leiden.

Die Anniversary Edition 2000 macht sich erst zu diesem Zeitpunkt zum ersten Mal in der Produktionsgeschichte dieses Artefaktes die Mechanismen künstlicher Verknappung zu Nutze und nobilitiert das Artefakt durch die polierte Vergoldung - ab dann auch mit dem Hinweis, dass die Nutzung als Zitronenpresse nicht empfohlen werde, da die Vergoldung unter der Säure leide. Die limitierte Version in Bronzeguss führt über das Material final in den Bereich der Kunst zurück. In Verbindung mit einem gegenüber der Anniversary 


\title{
STARDESIGNER ODER GESTALTER DES ALLTÄGLICHEN?
}

Edition kräftig angehobenen Preis bei einer im Vergleich dazu auf drei Hundertstel reduzierten Auflagenzahl macht dies endgültig deutlich, wie diese Design-Skulptur (auch oder hauptsächlich?) platziert werden sollte: als Kunstwerk - im Zeitalter seiner technischen Reproduzierbarkeit.

\section{Zwischenbilanz}

Welches Verhältnis entwickelt sich aus wissenschaftlicher Sicht zwischen Menschen und den Dingen in ihren Leben? Festzuhalten ist, dass wir neben der Tatsache, selbige zu erdenken und zu produzieren, auch deren Wert erzeugen, weil wir zur Besetzung mit Bedeutsamkeit in der Lage sind und diese »Objektivierung von Bedeutung [...] kulturelle Wurzeln zu haben« scheint. (MIKLAUTZ 1996: 156). Das, was über den reinen Gebrauchswert einer Ware hinausgeht, verleiht Artefakten im übertragenen Sinne soziale Macht, die im Statuswettkampf als Waffe und zur Differenzierung eingesetzt werden kann. Die Kanonisierung dieser Waffen wird auch mit Hilfe bereits etablierter Institutionen vorangetrieben, namentlich den Museen, in deren Hallen man Artefakte zu erinnerungswürdiger Vorbildhaftigkeit erhebt. WALKER merkt 1992 an, »daß auch die Designgeschichte Objekte zum Fetisch macht«:

\begin{abstract}
»Roland Barthes Äußerungen über die Wirkung eines neuen Autos [der Citroën DS, Ergänzung des Verfassers] lenken die Aufmerksamkeit auf die Aura, von der Objekte umgeben sein können, wenn sie auf Automobilausstellungen im Scheinwerferlicht stehen. Viele Werbeanzeigen und viele Illustrationen in Büchern über Design vermitteln denselben Eindruck. Industrieprodukte werden dargestellt als wären sie kostbare Kunstwerke: weit ab von den Menschen und ihrer alltäglichen Umgebung, umstrahlt von einem Heiligenschein aus Licht, wird das Designobjekt zum Fetisch. An Büchern wie One Hundred Great Product Designs [Hervorhebung im Original] (1970) und Cult Objects [Hervorhebung im Original] (1985) läßt sich zeigen, daß auch die Designgeschichte Objekte zum Fetisch macht.« (WALKER 1992: 74)
\end{abstract}

In unseren Sprachschatz fließen diese Fetische u. a. durch Wortschöpfungen wie Designklassiker oder Moderner Klassiker ein, die »das Ding [in ein] Kultobjekt« (BREUER 2001: 104) verwandeln, womit auch »[...] eine Verabredung über den Status von [...] Objekten [...]« (ebd.: 118) stattfindet. Diese Verabredungen stecken auch in Begriffen zu deren Kategorisierung und Binnendifferenzierung: 
»[...] eine Unterscheidung zwischen Gebrauchsgegenständen, Prestigegütern, Repräsentationsgegenständen, Tauschgütern und weiteren Unterklassen von Gegenständen .... Allerdings kann ein bestimmter Gegenstand mehr als nur eine dieser Funktionen übernehmen, und zwar sowohl gleichzeitig als auch in zeitlicher Abfolge. Die Übergänge zwischen den Klassen sind daher fließend." (KOHL 2003: 122)

Nach LENZEs Betrachtungsweise entstehen durch diese Verabredungen postmoderne "Objekt-Charismen" (LENZE 2002: 165), was er als "(Re)-Integration des Außeralltäglichen in den Alltag" (ebd.: 166) bezeichnet: Eine Formulierung, der hier nochmals deutlich widersprochen werden muss, da wir selbst durch die Besetzung mit Bedeutsamkeit unseren Alltag von seiner Banalität zu befreien versuchen. LENZEs magische Außeralltäglichkeit existiert nicht mehr und im Kontext der Designerprominenz hat die eben erwähnte Besetzung mit Bedeutsamkeit routinierte, annähernd industrialisierte Züge angenommen, die auch als Prominenzierungsstrategien bezeichnet werden können.

Gerade am Beispiel des JUICY SALIF lässt sich das bestens demonstrieren: In (vermutlich sehr) seltenen Fällen kann es zu Objekt-Charismen kommen, die einem Artefakt sowohl Verkaufszahlen als auch einen Produktlebenszyklus verschaffen, die in diesem Fall beide Ausdruck einer reinen Besetzung mit Bedeutsamkeit sind, mit der in diesem speziellen Fall sogar das Nicht-Funktionieren überspielt werden kann und wird.

Das hiesige Kronzeugenartefakt wartet immer noch auf seine De-Charismatisierung: Als Beleg hierfür werden die Editionen zum 10- und 25jährigen Produktionsjubiläum sowie die Ausweitung des Standard-Angebots um die Variante mit Keramiküberzug gewertet. Damit ist endlich auch das Gussaluminium vor der Zitronensäure geschützt, was sich in Anbetracht des verschobenen Funktionsverständnisses als hinreißend überflüssige Maßnahme darstellt. Zumindest im Hinblick auf die Praktikabilität.

Zum Abschluss dieses Zwischenstopps kann eine weitere Hypothese als belegt gelten. Genauer: Jene, dass Artefakte aus dem Bereich des Alltagsdesigns in den Bereich des Stardesigns überwechseln können. Dies anhand einer prinzipiell möglichen Wertsetzung als Designklassiker, Design-Ikone oder Moderner Klassiker. Gleichfalls der Versuch, sie von hier nach dort überwechseln lassen: Was seine Anfänge entweder in Einreichungen zu Wettbewerben hat oder in der Kür im Rahmen der Befestigungsliteratur. 


\title{
Befestigungsliteratur; die zweite Rezeptionsstudie
}

\begin{abstract}
Charismatisierende Blicke auf das Design manifestieren sich auch in der Gattung der hier so benannten Befestigungsliteratur, deren einziges Ziel eine fortwährende Kanonisierung von Designartefakten zu sein scheint - nebst deren De- und Re-Varianten. Bücher halten »Verabredung[en] über den Status von [...] Objekten [...]« (s. o.) fest - oder auch ihren Bedeutungsgehalt (s. u.). KOHL, CACCIOLA und auch WALKER bemerken dazu:
\end{abstract}

"Dienen dagegen natürliche Objekte als Zeichenträger, dann lässt sich ihr Bedeutungsgehalt nur bewahren, wenn er kontinuierlich von Generation zu Generation weitergegeben wird. In diesen Fällen bleibt er an das Medium der Sprache gebunden, es sei denn, die mündlichen Überlieferungen wären irgendwann einmal niedergeschrieben worden. Ansonsten erlischt mit dem physischen Ende einer menschlichen Gruppe auch die Erinnerung an die Bedeutung, die sie mit bestimmten natürlichen Objekten verknüpft hat.« (KOHL 2003: 122)

"Was in Periodika erscheint, verbreitet sich schnell; was als Buch gedruckt wird, hat bleibenden Wert und wird unter Umständen kaum in Frage gestellt." (CACCIOLA 2008: 6)

»Wenn eine größere Anzahl vom Abhandlungen mehr oder weniger denselben sgroßen oder swegweisenden Designern gewidmet ist und ihre ,klassischen oder ,Kult-Objekter gewürdigt werden, kann man zu Recht davon sprechen, daß ein Kanon aufgestellt ist, der den Kanonbildungen von großen Künstlern und Meisterwerken in Literatur, Musik und bildender Kunst vergleichbar ist. Wer solche Darstellungen kritisiert, wird nicht gleich in Abrede stellen wollen, daß es qualitative Unterschiede zwischen einzelnen Designern und zwischen den Objekten gibt, aber er wird den Einwand vortragen, daß ein Gebirge nicht nur aus den Gipfeln besteht. Die Designgeschichte muß auch schlechte und mittelmäßige Beispiele zur Kenntnis nehmen, um die qualitativen Unterschiede durch den Vergleich mit den besten herauszustellen. Auch der Prozeß der Kanonbildung selbst kann in Frage gestellt werden: er ist eine Setzung der Fachleute, nicht ein Naturphänomen, und zum Beispiel erhebt sich immer wieder die Frage, warum so wenig Frauen Zutritt zum Pantheon der Designer haben. Kritik am Kanon beruht auch auf dem Verdacht, ihm liege ein simplifizierter Geschichtsbegriff zugrunde, nämlich die Vorstellung des Stafettenlaufs: der Stab genialer Begabung oder avantgardistischer Innovation wird aus der Hand eines Designers zum nächsten in einer endlosen Staffel von Glanzleistungen weitergereicht." (WALKER 1992: 79) 
Der Begriff Fortifikationsliteratur , aus dem der hiesige Begriff der Befestigungsliteratur abgeleitet wird, muss kurz expliziert werden. Fortifikationsliteratur meint jene Traktate, die die Befestigung von Burgen und Städten, also ihre militärische Absicherung gegen Angriffe von außen beschreiben. BÜCHI hat 2015 mit Die Fortifikationsliteratur des 16. und 17. Jahrhunderts eine entsprechende Arbeit veröffentlicht. Ausgehend von einer Übersetzung der Fortifikation als Festungs- oder Befestigungswerk wird der Fokus hier auf jene Bedeutungsaspekte von Befestigung gelegt, die im Widerstandsfähigmachen, Haltbarmachen, der Festigung, Stärkung und auch Verteidigung liegen, um damit den Kern der Befestigungsliteratur nach hiesiger Lesart zu definieren, der in der Schaffung von Bedeutungszuschreibungen und Tradierungsangeboten liegt, die für Artefakte fixiert werden (sollen).

Die Befestigungsliteratur wird als Verteidigungsanlage für Wertmaßstäbe unterschiedlichster Art - und Qualität - betrachtet, auch wenn es keine wirklichen Kämpfe um die Deutungshoheit sind, die hier ausgefochten werden. Gleichwohl unternehmen unterschiedliche Seiten Vorstöße zur Definition von Maßstäbe setzendem und vorbildhaftem Design, die den Anspruch erheben, unsere Vorstellungen von Designqualität zu formen und zu beeinflussen. Deswegen können sie in einem Kapitel über die Rezeption von Designartefakten nicht außer Acht gelassen werden.

Greifen wir noch einmal zwei naheliegende Pole ideologisch geprägter Formungen des Designs und der Verbraucher-Erziehung heraus, dann stellen die Warenkunden des 20. Jhd.s und die Gute Form zwei manifeste Ausdrücke von Expertenkulturen dar, die den Übertritt vom Fachpublikum zum allgemeinen Publikum zu erreichen suchen. Normierungsversuche wie diese beiden lassen im Verlauf des bereits beschriebenen Entschwindens der Metaerzählungen in der Postmoderne neben anderen Gründen selbige ihre Macht verlieren. Dem menschlichen Wunsch, Maßstäbe zu schaffen und zu setzen, tut dies indes keinen Abbruch. Er äußert sich nur kleinteiliger und mit einer geringeren Reichweite denn ehedem.

Da Büchern im Vergleich zu Zeitschriften eine größere Bedeutung für die Konstitution des kollektiven Gedächtnisses zugemessen wird (s. o.), liegt eine weitere Betrachtung in der Folge der ersten Rezeptionsstudie nahe. Ohne ein weiteres Mal die gleiche Detailtiefe anzustreben, sollen entlang einer repräsentativen Auswahl jüngerer Publikationen Charakteristika dieser Veröffentlichungen aufgezeigt und mit den Ergebnissen der ersten Studie verglichen werden. Diese hat in Bezug auf Artefakte bereits den Nachweis erbracht, dass der Korpus bis auf einige allgemeine Kategorien, unter denen vermeintliche 


\section{STARDESIGNER ODER GESTALTER DES ALLTÄGLICHEN?}

Qualitäten von Artefakten subsummiert werden, keine verallgemeinerbaren Ansätze aufweist, die explizierbar machen, was und unter welchen Bedingungen Designklassiker, Designikonen oder Moderne Klassiker seien. In deren Folge wird der Versuch gestartet, herauszufinden, ob die Publikationen

1. Klassiker des Produktdesign (EISELE 2014),

2. die Buchreihe Design-Klassiker des FORM-Verlags (1997-2004),

3. Geschichte des Designs (HAUfFE 2014),

4. Design-Atlas von 1850 bis heute (MORTEO 2010),

5. Top Design des 20. Jahrhunderts (JAHR 1999),

6. Das Buch der Klassiker (SCHÄFER 2011),

7. Design-Klassiker. Vom Barcelona-Sessel bis zum iPad (WILKINSON 2013) oder auch

8. Masters and their Pieces: Best of Furniture Design (ROTH 2012)

dem Diskurs eine Dimension hinzufügen, die doch noch etwas Greifbares neben die bereits konstatierte Inhaltsleere setzt. Erweitert wird dieser Korpus zudem noch um die DVD-Reihe Design 1-4 von ARTE (2012). Ein konstanter Nebenschauplatz der folgenden Betrachtungen bleibt im Rückgriff auf die Rangliste der Stardesigner die STARCK-Quote, die für jede Publikation mit ermittelt wird und der Ausweis von Übereinstimmungen mit den zehn Ranglistenplatzierten nebst einer Auflistung der jeweils abgebildeten Artefakte.

Die bis jetzt herausgearbeiteten Verhandlungsergebnisse zu Artefaktqualitäten besagen, dass ein Designklassiker für einen Minimalkonsens steht, der einem Konglomerat aus Zeitlosigkeit, Innovation, Funktionsgerechtigkeit, Gültigkeit und Vorbildhaftigkeit entspricht, was auch als Alltäglichkeit höchster Qualität zusammengefasst werden kann. Der generalistische Ansatz, der in diesen Kategorien zum Ausdruck kommt, kann seine gefühlt hohe Plausibilität - mit der letztlich nichts Konkretes zum Ausdruck gebracht wird - ebenso wenig verhehlen, wie es schon die Debatte um GEORG FRANCK und dessen Idee einer Aufmerksamkeitsökonomie verdeutlicht. Der Auswahl voran eine Rezension zu den Phaidon Design Classics, die FRENZL 2007 für den DESIGN REPORT (3/2007) schreibt. Sein damaliges Fazit nach präzise formulierter Kritik lautet:

»Nach Durchsicht der Bände hat man ein Platzproblem im Bücherregal und zusätzlich ein paar Erkenntnisse gewonnen: erstens: Sachliche Fehler werden auch durch mehrfachen Abdruck in immer gewichtigeren Werken nicht richtig. Zweitens: Je dicker ein Buch ist, umso größer ist die Chance, dass kein einziger Rezensent wirklich darin liest. Drittens: Was 


\section{AM ENDE WAR ES NUR EIN WORT: ZWEI REZEPTIONSSTUDIEN}

ein Designklassiker ist und was nicht, ist letztlich wohl eine subjektive und zeitbezogene Entscheidung und zumindest bei Alltagsprodukten und Lebensmitteln auch eine länderspezifische Angelegenheit. Und viertens: Das ultimative, umfassende Werk zum Thema >Designklassiker wird es deshalb wohl nie geben können - aber vielleicht ist das auch gar nicht nötig." (FRENZL in: DESIGN REPORT 3/2007) [online] https:// www.designreport.de/DRMainFachartikelarchivDruckDetail.asp?artikelid=30958613\&action=print\&object=DR\&db=FAArchiv [18.07.2013, inzwischen nicht mehr im Netz verfügbar]

Dies im Hinterkopf kann man sich die Analyse später erschienener Publikationen dennoch nicht ersparen und die Erwartungen an den mit sieben Jahren Zeitabstand zu FRENZL gedruckten Band Klassiker des Produktdesign, der als erstes unter die Lupe genommen wird, sind aus verschiedenen Gründen deutlich höher. 


\section{Klassiker des Produktdesign}

Der Klappentext des in der RECLAM UNIVERSAL-BIBLIOTHEK erschienenen Werkes verspricht, "150 beispielhafte Klassiker des Produktdesigns in Text und Bild« vorzustellen. In seinem Vorwort werden die Maßstäbe festgelegt, an denen sich die Artefaktauswahl der Autorin messen lassen muss:

„Ein >Klassiker zu sein, ist kein objektives Merkmal eines Designobjektes: Vielmehr entstehen Designklassiker in komplexen Prozessen gesellschaftlicher Auseinandersetzung und Aneignung. Prädestiniert dafür, sich als Designklassiker zu etablieren, sind Produkte, die in ihrer eigenen Zeit und darüber hinaus als besonders gültige Gestaltungslösungen verstanden werden. Es sind Produkte, die Maßstäbe gesetzt haben, indem sie über Generationen hinweg als besonders wichtig oder gar vorbildhaft anerkannt wurden [Hervorhebungen des Verfassers]; Objekte, die durch Zeigen und Abbilden, durch Reden und Schreiben immer wieder neu reflektiert und durch museale und mediale Inszenierungen zu einem System von Bedeutungen geworden sind; Objekte, die weit über ihren praktischen Nutzen hinausweisen: $\mathrm{Ob}$ im musealen Kontext wie ein Kunstobjekt präsentiert oder medial zum Mythos überhöht, wurden Produkte, die ursprünglich für einen zutiefst alltäglichen, praktischen Gebrauch entwickelt wurden, zu Objekten der Begierde und / oder der sozialen Distinktion." (EISELE 2014: 9)

Zur angestrebten Darstellungsweise wird ausgeführt:

"Mit dieser Publikation soll das eigentlich Außerordentliche der Designklassiker in Wort und [Hervorhebung im Original] Bild erfasst werden: Mit kurzen Texten und wenigen, aber besonders charakteristischen Bildern wird das designhistorisch Bedeutende vorgestellt - das, was die zutiefst banalen Alltagsdinge zu Klassikern des Produktdesigns macht. [...] Angesichts der Beschränkung auf 150 Objekte war aus der großen Bandbreite eine Auswahl zu treffen, die sich auf die Frage nach der Innovationskraft eines Produktes in seiner Zeit konzentriert und die genannten Wechselwirkungen mit medialen und rezeptionsästhetischen Phänomenen berücksichtigt, letztlich aber auch aus den subjektiven Erfahrungen und Bewertungen der Autorin schöpft." (ebd.: 1of)

Zu den Auswahlkriterien gibt es diese Erklärungen:

"Die ausgewählten Gegenstände spiegeln zum einen die Tradition der dekorativen Künste, zu der Dinge des täglichen Gebrauchs wie Möbel oder Geschirr gehören, die früher manuell beziehungsweise handwerklich hergestellt wurden. Zum zweiten werden Gegenstände behandelt, die keine kunsthandwerklichen Vorbilder haben - klassisches Industriedesign: Au- 


\section{AM ENDE WAR ES NUR EIN WORT: ZWEI REZEPTIONSSTUDIEN}

tomobile, elektrische oder elektronische Geräte bis hin zu mobilen Endgeräten. Vertreten sind jedoch auch konzeptionelle Entwürfe, die nie massenindustriell umgesetzt wurden, oder Kleinserien, die als gestalterische Statements ihrer Zeit gelten mögen. Dies trägt der Tatsache Rechnung, dass Produktdesign im Kern zwar auf Vervielfältigung zielt, aber auch experimentelle Momente beinhalten kann, die über ihre Zeit hinaus Wirksamkeit entfalten." (ebd.: 11)

Die Annahme, dass diese Veröffentlichung eine normative Position im Reigen des Zeigens und Abbildens, des Redens und Schreibens anstreben würde, kann weder durch die Auswahl der Artefakte noch durch die Art der Beschreibungen Bestätigung finden - speziell unter den formulierten Prämissen »besonders gültige Gestaltungslösungen« und »über Generationen hinweg als besonders wichtig oder gar vorbildhaft anerkannt«. Seitenwege, die durch konzeptionelle Entwürfe und Kleinserien beschritten werden, legen schon weitere Ausnahme-Ebenen für die Aufnahme ssubjektive[r] Erfahrungen und Bewertungen der Autorin« an, die bereits den »normativen « Ansprüchen der sw-Veröffentlichungen zu eigen ist und auch kongruent mit FRENZLs obiger Feststellung.

Zudem leistet sich die Artefaktauswahl weit ausgreifende Verletzungen der Regel, dass »die zutiefst banalen Alltagsdinge zu Klassikern des Produktdesign" geworden seien. Man muss sich im Zusammenhang vergegenwärtigen, dass die vorstehenden Zeilen von derselben Autorin stammen, die in ihrer Dissertation aus dem Jahre 2000 zur Arbeit von DES-IN noch formuliert hat:

"DES-IN bewies, daß auch gebrauchte, billige und sunfeiner Materialien eine eigenständige Ästhetik besitzen und führte vor, daß Design-Objekte nicht als ästhetische Manifestationen mit zeitloser Gültigkeit aufzufassen sind, die dem Betrachter als Beispiele für eine vollkommen sguter Gestaltung wie ein Kunstobjekt vorgeführt werden (Hervorhebung des Verfassers), sondern daß sie im Gegenteil als Gebrauchsgegenstände funktionieren müssen, die durch ihren tagtäglichen Einsatz in Mitleidenschaft gezogen und verschlissen werden." (EISELE 2000: 114)

Um eine ermüdende und prognostisch wenig ertragreich erscheinende Detailanalyse des betrachteten Werks auslassen zu können, sollen nur wenige Beispiele die Zweifel an Sinnhaftigkeit und Zielführung ihres Vorhabens verdeutlichen. Im Verlauf der mit Sachlichkeit überschriebenen Seiten stehen in trautem Verein neben dem FORD MODEL T und BEHRENS' Wasserkessel der HILL-HOUSE-Stuhl von MACKINTOSH (ebd.: 42) und die SiTZMASCHINE von HOFFMANN (ebd.: 44), die als Einzelentwürfe für ein Wohnhaus und als Sitzmöbel für ein Sanatorium beim besten Willen keine banalen Alltags- 
entwürfe mehr repräsentieren. Wenngleich sie durchaus unter dem Aspekt einer formal und auch funktional versachlichten Art der Gestaltung einsor460 tiert werden könn(t)en.

Die Klassische Moderne zeigt einen Kanon der üblichen Verdächtigen, der wie selbstverständlich das nie in Serie gefertigte TEE-EXTRAKTKÄNNCHEN von MARIANNE BRANDT beinhaltet (ebd.: 64), aber auch ihre vielfach verkauften KANDEMLAMPEN (ebd.: 82) und den BARCELONA-Stuhl VAN DER ROHEs (ebd.: 84). Angereichert wird er um die mehr als zehntausendfach produzierte FRANKFURTER KÜCHE von SCHÜTTE-LIHOTZKY (ebd.: 70), die als Wohnungsausstattung ebenso einen Spezialfall wie auch LE CORBUSIER (ebd.: 78-81) und EILEEN GRAY mit ihrem Beistelltischchen (ebd.: 72) darstellt. Letzteres war einmal ein Einzelentwurf für GRAYs Villa.

So geht es hin und her und diese Rhythmusstörungen werden auch in den folgenden Abschnitten durchgehalten: Man findet in der Gute Form betitelten Sektion den DIAMOND CHAIR von BERTOIA (ebd.: 148) sowie das KNOLL-Sofa 1206 (ebd.: 160). Der Funktionale[...] Minimalismus vereint den CITROËN DS und den extrem aufwendig zu fertigenden EI-Sessel von ARNE JACOBSEN Seite an Seite mit dem LEGo-Stein und der BARBIE. In den 7oern des 20. Jhd.s taucht PRATONE von GRUPPO STRUM (ebd.: 264) auf, in den 8oern die Chaiselongue LOCKHEED LOUNGE von MARC NEWSON (ebd.: 318) und wie selbstverständlich in den goern auch die Zitronenpresse JUICY SALIF von PHILIPPE STARCK (ebd.: 326).

Doch das soll nicht weiter verwundern, ist dieses Prinzip doch Grundstein der Publikation. Seine Fortsetzung muss weder weiter noch näher betrachtet werden. Einige Seiten zuvor erbrachte die Auswertung der ersten Rezeptionsstudie bereits das Ergebnis, dass gerade die Außergewöhnlichkeit, das eben nicht Alltägliche, Mustergültige oder Vorbildhafte, zur Norm oder zum Standard führende die Wahrscheinlichkeit immens zu erhöhen scheinen, überhaupt in den Klassikerstand erhoben zu werden und damit der eigentlichen Definition des Begriffes zu 100 Prozent zu widersprechen.

Zur Ehrenrettung von EISELE sei angemerkt, dass die PERLENFLASCHE von GÜNTER KUPETZ darin vorkommt (ebd.: 252), dass mit GROS' REIFENSOFA (DES-IN; ebd.: 274) frühes Re-und Upcycling präsent ist, dass mit STILETTOS CONSUMER'S REST (ebd.: 296) pointierte Konsumkritik Einzug hält und KUNSTFLUGS ELEKTRONISCHER HANDRECHNER (ebd.: 312) die komplette Virtualisierung des Designs vorwegnimmt - auch wenn es sich bei den letzten dreien nur um kleinserielle oder theoretische Aufweitungen damaliger Diskurse handelt. Weitere Bezeichnungen wurden in dieser Publikation nicht geson- 
AM ENDE WAR ES NUR EIN WORT: ZWEI REZEPTIONSSTUDIEN

dert gesucht, da der Titel bereits für alle gelisteten Artefakte die Generalvermutung des Klassikerstatus als gegeben setzt.

EISELES STARCK-Quote beläuft sich mit dem Stuhl costes sowie der Zitronenpresse JUICY SALIF auf zwei (ebd.: 304-305 \& 326-327). Die Anzahl an Übereinstimmungen mit der Rangliste beträgt: FÜNF.

1. STARCK (s. o.)

2. GIUGIARO: GOLF I (ebd.: 269-270)

3. GRCIC Leuchte MAYDAY (mit KLAUS HACKL) (ebd.: 344-345), Stuhl ONE (ebd.: 354-355)

4. MORRISON THINKING MAN'S CHAIR (ebd.: 320-321), PLY CHAIR (ebd.: 324-325)

5. RAMS PHONOSUPER SK4 (ebd.: 178-179), Regalsystem 606 (ebd.: 204-205) 


\section{Hat der Designklassiker im 21. Jhd. 462 einen neuen Bedeutungskern?}

Man könnte nach diesem Einstieg die generelle Feststellung treffen, dass Artefakte, mit denen Gestalter eine bestimmte subjektive Entwicklung auf die Spitze treiben, die auch als Endergebnisse jeweils individueller Ausdifferenzierungslinien betrachtet werden können, gerade deswegen keine Fortsetzung in Form der Nachahmung oder davon inspirierter Entwürfe erfahren und deshalb auch nicht mehr als vorbildhaft angesehen werden. Von Kopien oder me too-Produkten einmal abgesehen. Eine Konsequenz dieser Art von Argumentation ist die Festsetzung des Status des Originellen als Klassiker (vgl. im Gegensatz FRANCK 1998: 165). Zur Auffrischung nochmals BREUER mit den frühen Anfängen solcher Entwicklungen:

»Die Einheitsform entsprach nicht mehr dem Käuferinteresse diversifizierter Kreise. Die Objekte mussten sich unterscheiden. Am einfachsten war dies, wenn man sie als Persönlichkeiten von Persönlichkeiten erscheinen ließ. Auf diese Weise konnte man Individualität in der Massenindustrie suggerieren." (BREUER 2001: 103f)

Die (subjektive) Besetzung mit außergewöhnlicher Bedeutung wirft eine Frage auf: Ist es inzwischen die Tatsache, dass ein Produkt durch unverkennbare Idiosynkrasien geprägt ist, die mittlerweile den eigentlichen, stillschweigend (un-)verhandelten Bedeutungskern von Designklassikern, Designikonen oder des Modernen Klassikers ausmacht? Wenn man jene Bewertungsmaßstäbe anlegt, die für singuläre Erzeugnisse der Bildenden Kunst gelten (was durch die langanhaltende Tendenz zu kleinserieller Verknappung im Feld des Designs bereits Ausdruck findet), dann sind solche Artefakte dem vergleichbare Setzungen und sie beanspruchen, Singularitäten zu sein.

Eine dies massiv stützende Argumentation liegt seit Oktober 2017 mit Die Gesellschaft der Singularitäten: Zum Strukturwandel der Moderne von RECKWITZ vor. Dieser bietet überdies einen Anstoß zu weiterer Differenzierung, weil er für seine auf KARPIK und KOPYTOFF aufbauende Vorstellung von einer Ökonomie der Singularitäten (!) zwischen einem an KANT angelehnten Allgemein-Besonderen, den Idiosynkrasien und den Singularitäten differenziert. Idiosynkratisch sind für RECKWITZ nur individuelle "Eigentümlichkeiten«, die sich dadurch auszeichnen, »dasjenige an den Entitäten der Welt [...] [zu sein], was sich nicht in die Begriffe oder Schemata des Allgemeinen eingliedern lässt« (RECKWITZ 2017: 49). 
So grundsätzlich individuell und nur an ein jeweils einziges spezifisches Artefakt gebunden ist das in dieser Arbeit bisher grundgelegte Verständnis der Idiosynkrasie nicht. Im Feld des Designs ist ein idiosynkratisches Artefakt nach bisherigem Verständnis bereits eines, das sich in der Sphäre der Massenproduktion und unter Annahme einer stilistischen Standardisierung durch stilistische Individualität (und möglicherweise auch schon durch Verknappung) vom RECKWITZschen Allgemein-Besonderen unterscheidet.

RECKWITZ fasst die Idiosynkrasie im Sinne einer grundsätzlichen Inkommensurabilität aber als Grundprinzip der Eigentümlichkeit für jeden Menschen auf sowie darüber hinaus als »einfach da«-Sein im Sinne der Mannigfaltigkeit (vgl. ebd.: 50; Hervorhebung im Original). Für eine Anlehnung an jene Zeitdiagnostik müsste der hiesige Begriff der Idiosynkrasie vermutlich nur durch seinen der Singularität ersetzt werden und man säße wieder im gleichen Boot. Doch weiter im Text: Die nach EISELE noch verbleibende Befestigungsliteratur lässt bereits Prognosen über die Qualitäten der anderen, oben aufgeführten Publikationen zu. Begonnen wird mit dem FORM-Verlag. 


\section{form-Verlag: Sonderhefte Der Klassiker-Boom und Design mit Bestand}

Die Zeitschrift ForM thematisiert das Phänomen der Klassiker mit zwei Sonderveröffentlichungen in den Jahren 2007 und 2009: Der Klassiker-Boom (FORM 215/2007) und Design mit Bestand (FORM 227/2009). Das erste Heft unter dem Primat des Sammelns fällt wegen eben jenes Schwerpunktes durch das Raster. Doch wartet es mit einem rudimentären Definitionsversuch auf, den die Autorin des Artikels Mit Klassikern leben/Hunting Classics u. a. an die Meinung eines Online-Händlers für "Designklassiker des 20. Jahrhunderts" anlehnt, dass »[...] [d]ie Geschichte, die Formgebung und das Material [...] entscheidend « seien. Selbst führt sie aus:

"Die Geschichte der Klassiker beginnt mit der industriellen Produktion etwa 1850. Denn nur ein Objekt, das in relativ hoher Auflage produziert wird, hat überhaupt eine Chance, von vielen Menschen möglichst oft gesehen und benutzt zu werden und so ein Klassiker zu werden." (ALTEMEIER in: FORM 215/2007: 12)

Damit werden immerhin ein Zeitrahmen und als greifbares Merkmal die Massenproduktion ausgewiesen. Wodurch eine relativ direkte Linie zum zweiten Sonderheft führt, das eine bewusste Konzentration auf echte Longseller anstrebt, die einer Definition von RIDO BUSSE folgen, »der neben dem Plagiarius seit 31 Jahren auch den Longlife Design Award verleiht«:

»Produkte sind für mich dann Longseller, wenn sie mindestens acht Jahre auf dem Markt, aber nicht älter als 50 Jahre sind. Busses Definition zufolge gehören Designklassiker wie beispielsweise Mies van der Rohes Barcelona Stuhl von 1939 nicht in die Kategorie Longseller - und sind somit von seinem Wettbewerb ausgeschlossen. Im Gegensatz zum Designklassiker ist der Longseller laut Busse vor allem an wirtschaftliche Kriterien gekoppelt: Er muss einen Umsatz von mindestens 1 Million Euro gemacht haben oder in einer Stückzahl von mindestens 100 ooo hergestellt worden sein." (ALTEMEIER in: FORM 227/2009: 3)

Unter anderem diese Beschränkung ist es, die auch das zweite Sonderheft durch das Sieb fallen lässt. Seine grundsätzliche Disqualifikation ergibt sich jedoch daraus, dass die ab Seite 16 aufgeführten Longseller sämtlich als Advertorial gekennzeichnet sind: Diese Sonderveröffentlichung erfüllt in erster Linie werbliche Zwecke, auch, wenn sie auf der Longseller-Prämisse BUSSEs aufbaut. Ein erstaunlicher Satz fällt im Zusammenhang mit dem wirtschaftlichen 
Kontrast des Longsellers zum Designklassiker, so wie BUSSE ihn sieht, denn dadurch wird dem Designklassiker ja ein wirtschaftlicher Erfolg im Sinne eines Longsellers gerade nicht unterstellt. Der Longseller unterscheidet sich also nicht nicht nur in wirtschaftlicher Hinsicht, sondern in BUSSEs Spezialfall auch durch eine nur temporäre Kanonisierung. Er hätte jedoch die Chance, in jenes zweite Kanonisierungs-Segment zu gelangen, das all jene Begriffe um den Designklassiker besetzt halten, nachdem er in der Alltäglichkeit angekommen ist - falls er sich länger als 50 Jahre verkauft. Außerdem muss noch angemerkt werden, dass mit dem Text Die Lebensbegleiter/Universal Design Classics (TERstiege in: ebd.: 13-15), der sich an einer weiteren, ebenfalls erfolglosen Definition des Designklassikers versucht, die Einschränkung auf Longseller wieder verwässert wird. 


\section{form-Verlag: Design-Klassiker}

Diese Buchreihe, vom FORM-Verlag in Zusammenarbeit mit BIRKHÄUSER in den goern des 20. und den Nullerjahren des 21. Jhd.s aufgelegt, leistet mit insgesamt 28 monographischen Veröffentlichungen ebenfalls einen gut sichtbaren Beitrag zur Klassikerproduktion. Damit will sie wohl auch zur Einspeisung in den Erneuerungskreislauf beitragen. Dies geschieht rein quantitativ durch die Attribuierung: Normativität wird letztlich durch nichts Anderes als den Titel der Reihe postuliert. BIRKHÄUSER schreibt zur Ankündigung der einzelnen Bände:

»Viele Dinge sind schön. Viele Dinge sind nützlich. Aber nur wenige schreiben schon kurz nach ihrem Erscheinen Geschichte. Die Bücher der Reihe >Design-Klassiker w widmen sich ausgewählten Produkten, die in Form, Funktion und Markenkommunikation neue Maßstäbe setzten. Jeder Band informiert mit zahlreichen Fotos und kurzen, aufschlussreichen Texten über die Geschichte des jeweiligen Kult-Objekts sowie über die Personen, die sie entworfen haben." (books.google.de) [online] https:// books.google.de/books/about/Die_XEMEX_Uhren_von_Ruedi_Külling. html?id=vOu4GqQ9raEC\&redir_esc $=y$ [06.03.2018)

Ein zehnbändiges Paket wird auf diese Weise beworben:

Jedes der beschriebenen Produkte hat im 20. Jahrhundert Weltruhm erlangt, und so schreibt jede der Produktmonografien ein Stück Kulturgeschichte. (books.google.de) [online] https://books.google.de/books/ about/Design_Klassiker.html?id=atNWHQAACAAJ\&redir_esc=y

[06.03.2018]

Das komplette Titelverzeichnis wurde verlagsseitig zur Verfügung gestellt, doch die schiere Anzahl der Bände und die teils schwierige Beschaffungssituation ließen eine tiefere Beschäftigung aussichtslos erscheinen. Stichprobenartige Einblicke in 12 der 28 Publikationen förderten keine als maßgeblich zu wertenden Aussagen zu Tage, ebenso wenig Hinweise auf greifbare Gründe für den Weltruhm oder die Entwicklung zum Kult-Objekt. Zwei der hervorstechenden Merkmale sind die Langlebigkeit und die produzierte Stückzahl einiger Entwürfe. Hierfür stehen besonders ZIPPO, CONSETA, USM HALLER MÖBELBAUSYSTEM, THONET NR. 14 und die Mineralwasserflasche von KUPETZ. Das Spektrum der klassikerisierten Artefakte umfasst neben Automobilen auch Schmuck, Uhren, einen Personal Computer und sogar den pneu- 
matischen Muskel von FESTO. Neben »klassischen« Klassikern repräsentieren die übrigen Entwürfe - auch nach der Art der Vermarktung - wohl eher die Art, Maßstäbe zu setzen (s. o.), die auch im Sinne einer Festschreibung des Status des Originellen gedeutet werden können. Zum Überblick eine Liste aller veröffentlichten Bände:

1. 1997 Der Bookworm von Ron Arad; VOLKER ALBUS

2. 1997 Der Wasserkessel von Michael Graves; GEORG-CHRISTOF BERTSCH

3. 1997 Das USM Haller Möbelbausystem; KLAUS KLEMP

4. 1997 Der Porsche 911 von Ferdinand Porsche; ULRICH VON MENDE

5. 1997 Der Apple Macintosh; BERNHARD E. BÜRDEK

6. 1997 Die Espressokanne von Richard Sapper; SIEGFRIED GRONERT

7. 1997 The Tizio-Light by Richard Sapper; HANS HÖGER

8. 1997 Die Liege LC4 von Le Corbusier, Pierre Jeanneret und Charlotte Perriand; VOLKER FISCHER

9. 1997 Die Bauhaus-Leuchte von Carl Jacob Jucker und Wilhelm Wagenfeld; MAGDALENA DROSTE

10. 1998 Der Beistelltisch E 1027 von Eileen Gray; PETER ADAM

11. 1998 The Office Swivel Chair by Klaus Franck and Werner Sauer; ELKE TRAPPSCHUH

12. 1998 Der Kaffeehausstuhl NR. 14 von Michael Thonet; ANDREA GLEINIGER

13. 1998 Die Univers von Adrian Frutiger; FRIEDRICH FRIEDL

14. 1998 Das Teegeschirr TAC 1 von Walter Gropius; BERND FRITZ

15. 1998 Die Lucky Strike-Packung von Raymond Loewy; STEPHEN BAYLEY

16. 1998 Die Türklinke 1020 von Johannes Potente; ANDREA SCHOLTZ

17. 1998 Beetlemania Der neue Käfer ist da! ; CHRISTIAN MARQUART

18. 1999 The VW Golf; ULRICH VON MENDE

19. 1999 Das Mono-Besteck von Peter Raacke; GERDA MÜLLER KRAUSPE

20. 1999 Die Mineralwasserflasche von Günter Kupetz; MARCUS BOTSCH

21. 1999 Das Polstersystem Conseta von Friedrich Wilhelm Möller; G. SIEBKE und S. WITTORD

22. 1999 Das Zippo von George G. Blaisdell; TOBIAS KUHN

23. 1999 Die Ringe von Carl F. Dau; HANS-ULRICH LEHMANN

24. 2000 Die Xemex-Uhren von Ruedi Külling; CHRISTIAN JAQUET

25. 2001 constructiv CLIC von Burkhardt Leitner constructiv; ULRICH FLEISCHMANN

26. 2001 Der Pneumatische Muskel von Axel Thallemer; ABSOLON DALE-HAMPSTEAD 


\section{STARDESIGNER ODER GESTALTER DES ALLTÄGLICHEN?}

27. 2001 Die Havanna-Pendelleuchten von Wilhelm Braun-Feldweg;

THOMAS HEYDEN

28. 2004 Die Tangente von NOMOS Glashütte; HANS IRREK

Die STARCK-Quote dieser Publikations-Reihe liegt bei NULL - keiner seiner Entwürfe wird in diesem Rahmen mit einer Monographie gewürdigt, was durchaus kongruent dazu ist, dass er als Stardesigner in der FORM im zuvor untersuchten Publikationskorpus ebenfalls keine Erwähnung findet. Die Anzahl an Übereinstimmungen mit der Rangliste beträgt: NULL. 


\section{Geschichte des Designs}

Im Rahmen jenes Werkes werden zehn Alltagsgegenstände als Alltagsikonen bezeichnet. Denkt man über die Auswahl nach, erscheint sie im üblichen Bewertungskontext der Designikone zumindest gewöhnungsbedürftig, aber im Sinne von SACHSSE (in WENZL-BACHMAYER 2009: 10) auch stimmig. HAUFFE wählt:
1. die Büroklammer,
2. den THONET-Stuhl Nr. 14,
3. die LONDON UNDERGROUND TUBE MAP,
4. die Kaffeemaschine MOKA EXPRESS,
5. die Eierschachtel,
6. den Einkaufswagen,
7. die Kreditkarte,
8. den TRABANT,
9. das Fischstäbchen und
10. den TETRA PAK.

HAUFFEs Kriterien beziehen sich ganz konsequent auf die allgemeine Bekanntheit alltäglicher Gebrauchsgegenstände und eine - bis auf wenige Ausnahmen - großserielle Massenproduktion. Seine Auswahl erfüllt alle oben bereits herausgearbeiteten Kriterien und kann damit eine Gültigkeit für sich beanspruchen, die in den anderen Publikationen nicht auszumachen ist. Nach Art der Auswahl sind HAUfFEs Alltagsikonen vergleichbar mit jenen, die im Ausstellungskatalog zu Humble Masterpieces (ANTONELLI 2005) aufgeführt werden. Jedoch entkommt auch dieser Autor der Falle bestimmter Signalwörter nicht. So wird

1. der PHONOSUPER SK4 des Teams GUGELOT/RAMS als »Ikone moderner Gestaltung a ausgewiesen (ebd.: 208),

2. die Schreibtischleuchte TIZIO von RICHARD SAPPER als »Ikone modernen Lampendesigns" bezeichnet (ebd.: 231),

3. MENDINIs Stuhl RE-DESIGN THONET »stellt die Ikonen des klassischen Designs zur Disposition« (ebd.: 250),

4. das iPhone 4 wird »wie seine Vorgänger aus der Reihe iPhone 3 [...] schnell zum Kulthandy" (ebd.: 277) und so avanciert auch 


\section{STARDESIGNER ODER GESTALTER DES ALLTÄGLICHEN?}

5. GRCICS Stuhl CHAIR ONE »[a]ufgrund seiner neuartigen ästhetischen Erscheinung [...] schnell zum Klassiker« (ebd.: 294).

HAUFFES STARCK-Quote liegt mit dem Wasserkessel HOT BERTAA (ebd.: 261), dem JUICY SALIF (ebd.: 304) und den Lampen der GUN-Kollektion (ebd.: 305) bei DREI. Die Anzahl an Übereinstimmungen mit der Rangliste beträgt: ACHT. $\mathrm{Da}$ in diesem - wieder einmal speziellen Fall - nicht nur Abbildungen, sondern z. T. auch nur textliche Einordnungen der übereinstimmenden Personen vorliegen, werden sie hier abschließend aufgeführt:

1. STARCK (s. o.)

2. COLANI wird als »Außenseiter des Designs « (ebd.: 243) und als »[e]in umstrittener Vertreter des Designs (ebd.: 291) bezeichnet

3. CONRAN wird als Gründer von HABITAT erwähnt (ebd.: 230)

4. GRCIC wird im Rahmen eines Kurzprofils als »zu den international erfolgreichsten und bekanntesten Designern der Gegenwart« zählend benannt (ebd.: 294); nebst Abbildung des Stuhls CHAIR ONE (ebd.: 295)

5. LOVEGROVE: Abbildung der Wasserflasche für TY NANT (ebd.: 292) und Erwähnung von: DNA STAIRCASE, SUPERNATURAL CHAIR sowie der Straßenlampe SOLAR TREE

6. MORRISON wird als Erfinder des Begriffs »No Design« (ebd.: 258) und als »wichtigste[r] Vertreter der sneuen Einfachheit، im Design« (ebd.: 259) erwähnt; Kurzprofil und Abbildung des Stuhls THINKING MAN'S CHAIR (ebd.: 259)

7. RAMS: Abbildung PHONOSUPER SK4 (ebd.: 208)

8. THUN wird primär im Rahmen eines Kurzprofils vorgestellt (ebd.: 252) 


\section{Designatlas von 1850 bis heute}

ENRICO MORTEO führt in seinem 2010 schon in zweiter Auflage erschienenen Band Designklassiker im Detail und Designklassiker im Vergleich auf. Die Designklassiker im Detail sind - bis auf wenige Ausnahmen - wieder einmal alte Vertraute, zieht man den bereits untersuchten Zeitschriftenkorpus zum Vergleich heran:

1. SCHWEIZER MESSER, 1891 (KARL ELSENER, VICTORIA) (ebd.: 40-41)

2. COCA COLA-Flasche, 1915 (EARL R. DEAN nach einer Idee von CLYDE EDWARDS) (ebd.: 54-55)

3. Stuhl fledermaUs, 1907 (JOSEF HOFFMANN) (ebd.: 64-65)

4. Stuhl für das CAFÉ MUSEUM, 1899 (ADOLF LOOS) (ebd.: 66-67)

5. Stuhl WASSILY, 1925 (MARCEL BREUer) (ebd.: 88-89)

6. Freischwinger S33/B3, 1926/1928 (STAM/BREUER) (ebd.: 90-91)

7. Fotoapparat ROLLeIfLeX 6×6, 1928 (REINHOLD HeIDECKE) (ebd.: 98-99)

8. CHAISE LONGUE À REGLAGE CONTINU, 1927/28 (LE CORBUSIER, JEANNERET, PERRIAND) (ebd.: 110-111)

9. Sessel Paimio, 1931 (ALVAR AAlto) (ebd.: 120-121)

10. Vase SAVOY, 1936 (ALVAR AALTO) (ebd.: 126-127)

11. Sessel BKF (BUTtERFLY), 1939 (HARDOY, KURCHAN, BONET) (ebd.: 134-135)

12. Wohnwagen AIRSTREAM CLIPPER, 1936 (WALLACE, MERLE, BYAM) (ebd.: 142-143)

13. Sessel 904, 1930 (RENZO FRAU) (ebd.: 162-163)

14. Standleuchte LUMinator, 1933 (PIETRO CHIESA) (ebd.: 166-167)

15. Espressokanne MOKA EPRESS, 1933 (ALFONSO BIALETTI) (ebd.: 172-173)

16. Pkw COUPÉ CISITALIA 202, 1947 (BATTISTA »PININ« FARINA) (ebd.: 190-191)

17. Motorroller PIAGgiO VESPA, 1946 (CORRADINO D'ASCANIO) (ebd.: 196-197)

18. ANT CHAIR, 1952 (ARNE JACOBSEN) (ebd.: 206-207)

19. Stuhl SUPERLEgGerA, 1957 (GIO PONTI) (ebd.: 22O-221)

20. LEGO-Stein, 1958 (OLE KIRK CHRISTIANSEN) (ebd.: 254-255)

21. Stühle ALUMinUm GROUP, 1958 (CHARLES Und RAY EAMES) (ebd.: 258-259)

22. Pkw MORRIS MINI MINOR, 1959 (ALEC ISSIGONIS) (ebd.: 280-281) 


\section{STARDESIGNER ODER GESTALTER DES ALLTÄGLICHEN?}

23. PANTON CHAIR, 1959-1967 (VERNER PANTON) (ebd.: 292-293)

24. Polstermöbel Up, 1969 (GAETANO PESCE) (ebd.: 316-317)

472 25. Schreibmaschine VALENTINE, 1969 (ETTORE SOTTSASS, PERRY KING, OLIVETTI) (ebd.: 320-321)

26. Stuhl CAB, 1977 (MARIO BELLini) (ebd.: 334-335)

27. WALKMAN, 1979 (MORITA, IBUKA, OHSONE, SONY) (ebd.: 338-339)

28. Armbanduhr SWATcH, 1983 (ebd.: 352-353)

Einen völlig anderen Weg beschreitet MORTEO im Kontrast zu allen anderen betrachteten Autoren mit seinem Ansatz, Designklassiker im Vergleich aufzuführen. Hierfür werden Kombinationen zusammengestellt, die vom Prinzip her eine Nähe zu den Vergleichen in Global Village (vgl. SACHSSE in: WENZLBACHMAYER 2011: 15-44) erkennen lassen. Verbunden sind alle durch eine unmittelbare Zeitgenossenschaft. Ihre Vergleichsbasis wird zum besseren Verständnis in groben Zügen wiedergegeben:

1. Sessel Mr 90 (BARCELONA), 1929 und Stuhl Mr 50 (BRNO), 1929/30 (LUDWIG MIES VAN DER ROHE): Vergleich aufgrund von Bandstahl als Material für Traversen und Rahmen, das dem BARCELONA-CHAIR schon immer, dem BRNO-Stuhl erst in seiner zweiten Auflage zu eigen ist. (ebd.: 94-95)

2. Leuchte ANGLEPOISE, 1932/33 (GEORGE CARWARDINE) und Leuchte LUXO L-1, 1937/ 38 (JACOB JACOBSEN): Vergleich aufgrund einer weiterentwickelten, ausgereiften (Neu-)Konstruktion eines Patents - die LUXO L-1 basiert auf der eingekauften, weil patentierten, Konstruktion der ANGLEPOISE (ebd.: 132-133)

3. DIAMOND-Serie (HARRY BERTOIA), 1950-52 und WIRE CHAIR-Serie (CHARLES und RAY EAMES) 1951-53: Vergleich aufgrund der ähnlichen und gleich gefertigten Sitzschale (Drahtgeflecht in Punktschweißtechnik) (ebd.: 246-247)

4. Hängesessel EGG, 1957, (NANNA DITZEL) und Sessel ÆGGET, 1958 (ARNE JACOBSEN): Vergleich aufgrund einer annähernd ähnlichen formalen Idee für eine Sitzschale, die den Körper umgibt (ebd.: 250-251)

5. Sessel LOUNGE CHAIR, 1956 (CHARLES EAMES) und Stuhlprogramm TULIP CHAIR, 1956 (EERO SAARINNEN): Vergleich aufgrund der allgemeinen Einordnung in das organische Design - was von MORTEO aber widerlegt wird (Funktion des Sessels als Basis der Formgebung bei EAMES vs. angestrebte formale Einheitlichkeit im Entwurf bei SAARINEN) (ebd.: 252-253) 
6. Fischdämpfer, 1957 (ROBERTO SAMBONET) und Gusseisentopf, 1960 (TIMO SARPANEVA): Vergleich, weil es sich um zwei Küchengeräte handelt, die jedes für sich höchst funktional sind - eines der angreifbarsten Paare. (ebd.: 260-261)

7. Fernseher ALGOL, 1964, Radio TS 502, 1964 und Telefon GRILLO, 1962-66 (alle MARCO ZANUSO und RICHARD SAPPER): Vergleich dreier Entwürfe des selben Entwerfer-Gespanns. Die Vergleichsbasis ist die unaufdringliche, dienende Technik. (ebd.: 274-275)

8. Sessel MIES, 1962 (ARCHIZOOM) und Serie QUADERNA, 1971 (SUPERSTUDIO): Vergleich zweier inkommensurabel radikaler Beispiele italienischer Gestaltung, die am ehesten darüber zu verbinden sind, dass sie als Provokationen galten. (ebd.: 310-311)

9. Stuhl SOF SOF, 1971 (ENZO MARI) und Stuhl SIDE CHAIR, 1972 (FRANK GEHRY): Vergleich aufgrund postulierter Einfachheit in der Gestaltung. (ebd.: 324-325)

10. Leuchte BOALUM, 1969 (GIANFRANCO FRATTINI und LIVIO CASTIGLIONI) und Leuchte TIZIO, 1972 (RICHARD SAPPER): Vergleich von jeweils revolutionärer, zum Entwurf passender oder eigens dafür entwickelter Technik, die diese Umsetzung in einen Entwurf überhaupt erst ermöglicht. (ebd.: 328-329)

11. Regal CARLTON, 1981 (ETTORE SOTTSASS) und Schrank CABINA, 1983 (ALDO ROSSI): Vergleich wegen unterschiedlicher Ausdrücke einer Krise der Moderne und jeweils individueller entwerferischer Auswege. (ebd.: 344-345)

12. Leuchte TOLOMEO, 1986 (MICHELE DE LUCCHI und GIANCARLO FASSINA) und Leuchte CONSTANZA, 1986 (PAOLO RIZZATO): Vergleich zweier Gegensätze - die TOLOMEO wird hier als Weiterentwicklung der NASKA 1 gezeigt und mit der »auf technisch aktualisierte Weise "neu interpretierten klassischen Lampenschirmform bei der CONSTANZA gepaart. MORTEO weist hier leider nicht auf die nahezu hundertprozentige Deckungsgleichheit der - der TOLOMEO angeblich zugrundeliegenden - NASKA 1 zUr LUXO L-1 (und damit auch der Verbindung zur ANGLEPOISE) hin. (ebd.: 358-359)

Die Unterschiedlichkeit dieser 12 Vergleiche lässt deutlich werden, dass potentielle Vergleichbarkeiten zunächst überhaupt einmal identifiziert werden müssen und dass diese sowohl anhand höchst unterschiedlicher subjektiver wie auch »objektiver« Kriterien gefunden werden können. Dafür müssen sie aber auch immer auf einem sauber recherchierten Sachstand beruhen, was MORTEOs Ansatz aber keinesfalls schmälern soll. Seine Bemühungen weisen 


\section{STARDESIGNER ODER GESTALTER DES ALLTÄGLICHEN?}

in eine mögliche Richtung, mit der überhaupt einmal Ebenen der Vergleichbarkeit dargestellt werden - wie subjektiv sie auf den ersten Blick auch erschei-

474 nen mögen. Vom bisher wahrnehmbarem, rein aufzählenden Wiederkäuen von Designklassikern unterscheidet er sich jedoch ebenfalls nicht, denn auch er wartet mit keinerlei Begründungen dafür auf, weswegen seine Vergleichsauswahlen zu den Designklassikern zu zählen seien.

MORTEOS STARCK-Quote liegt mit den Stühlen COSTES (ebd.: 370) und LOUIS GHOST (ebd.: 371) sowie dem JUICY SALIF (ebd.: 373) bei DREI. Die Anzahl an Übereinstimmungen mit der Rangliste beträgt SECHS:

1. STARCK (s. o.)

2. BOUROUlLeC: Regal CLOUd (ebd.: 401), Schreibtisch JOYN (ebd.: 400)

3. GRCIC: Stuhl ONE (ebd.: 12), Leuchte MAY DAY (ebd.: 395), Tisch MONO (ebd.: 402)

4. LOVEgROVE: Thermoskanne BASIC (ebd.: 369), Wasserflasche TY NANT (ebd.: 396)

5. MORRISON: Stuhl AIR (ebd.: 12), Stuhl PLY CHAIR (ebd.: 374), Stuhl THINKING MAN'S CHAIR (ebd.: 375)

6. RAMS: PHONOSUPER SK4 (ebd.: 225), Regalsystem 606 (ebd.: 226), PHONO TRANSISTOR TP 1 (ebd.: 227), Tischfeuerzeug TFG 2 (ebd.: 227) 


\section{Topdesign des 20. Jahrhunderts \& Das Buch der Klassiker}

Diese beiden Publikationen aus dem Hause SCHÖNER WOHNEN schlagen in die gleiche Kerbe wie die Reihe Moderne Klassiker. Möbel, die Geschichte machen. In Topdesign des 20. Jahrhunderts ist es "Eine Auswahl vom Besten: 600 schöne Dinge zum Wohnen«, die "Orientierung in der Welt der Designklassiker« (Rückentext) verspricht. In Das Buch der Klassiker. Die 500 besten Möbel und Wohnaccessoire3 (zum 50jährigen Jubiläum der Zeitschrift SCHÖNER WOHNEN) sind es eben 100 Artefakte weniger. Und wieder einmal heißt es: Hereinspaziert in die Manege der Begründungsprosa!

\section{Topdesign des 20. Jahrhunderts}

"[...] eine Auswahl des besten Designs aus aller Welt und aus allen Jahrzehnten. Nach welchen Gesichtspunkten wurde die Auswahl getroffen? Ausgewählt wurden Objekte, die repräsentativ sind für ihre Zeit, nicht ein Querschnitt oder Durchschnitt, sondern die Spitzenleistungen: Topdesign. Die Bewertung orientiert sich an drei Kriterien: Innovation, Perfektion, Faszination. Innovativ ist ein Design, wenn es einem Gegenstand eine vollkommen neue Form gibt (wie bei Mart Stams Freischwinger-Stuhl) oder eine bisher nicht bekannte Funktion (wie bei Carwardines verstellbarer Anglepoise-Leuchte) - oder wenn eine neues Material in einem neuen Verfahren verarbeitet wird (wie bei Pantons Kunststoffstuhl). Perfektion erreicht ein Design durch Weiterentwicklung bekannter Erkenntnisse. Ergebnis ist eine verbesserte Funktion, eine verfeinerte Gestaltung oder beides (wie bei Sappers sTizio-Leuchte). Faszination ist die Anmutung, die ein Gegenstand vermittelt: die unmittelbare spoetischer Ausstrahlung (wie bei Lampen von Ingo Maurer). Möbel mit solchen Eigenschaften nennt man gemeinhin Klassiker. Manchen Produkten hat man schon bei ihrem Erscheinen Klassikerqualität zugesprochen. Design der Spitzenklasse wird schnell durch Auszeichngen geehrt, wird in den Medien beachtet oder wird in die Sammlungen bedeutender Museen aufgenommen. Die Qualität eines Klassikers erweist sich selbstverständlich auch durch seine Langlebigkeit. Die Reife der Gestaltung, die Harmonie von Form und Funktion lassen ein Produkt zeitlos und rewig jung، erscheinen." (JAHR 1999: 6) 


\section{STARDESIGNER ODER GESTALTER DES ALLTÄGLICHEN?}

Die STARCK-Quote für Topdesign liegt bei DREIZEHN:

Stühle:

1. COSTES (ebd.: 124),

2. LORD YO (ebd.: 164),

3. DR. GLOB (ebd.: 124),

4. LOUIS XX (ebd.: 151),

Hocker:

5. BUBU (ebd.: 156) und

6. WW STOOL (ebd.: 151),

7. Türklinke 1191 (ebd.: 140),

8. Tischleuchte ARA (ebd.: 130),

9. Tisch TIPPY JACKSON (ebd.: 132),

10. Zitronenpresse JUICY SALIF (ebd.: 138),

11. Radio POE (ebd.: 164),

12. Armatur und

13. Badewanne für AXOR/HOESCH / DURAVIT (ebd.: 16o).

Die Anzahl an Übereinstimmungen mit der Rangliste beträgt SIEBEN:

1. STARCK (s. o.)

2. COLANI: Sanitärkollektion COLANI (ebd.: 114)

3. GRCIC: Tisch TAM TAM (ebd.: 148)

4. LOVEgROVE: Thermoskanne BASIC (ebd.: 158)

5. MORRISON: Türklinke 1144 (ebd.: 140), Geschirr MOON (ebd.: 159), Kommoden UNIVERSAL SYSTEM (ebd.: 148), PLY CHAIR (ebd.: 132) THINKING MAN'S CHAIR (ebd.: 125)

6. RAMS: PHONOSUPER SK4 (ebd.: 80), Regalsystem 606 (ebd.: 90), Sitzmöbel-Programm 620 (ebd.: 88)

7. THUN: Waschbecken MATTEO THUN (ebd.: 160)

2011 tänzelt das sw-Pferdchen erneut in: Das Buch der Klassiker

"Klassiker stehen für höchste ästhetische Qualität. In Literatur oder Musik heißt das manchmal: Sie stehen so hoch über allem, dass wir in unserem Alltag keinen rechten Zugang mehr zu ihnen finden. Beim Design ist es eher umgekehrt. Gerade das letzte Jahrhundert hat eine Fülle legendärer Entwürfe hervorgebracht, die auch heutige Gestalter faszinieren - 


\section{AM ENDE WAR ES NUR EIN WORT: ZWEI REZEPTIONSSTUDIEN}

und sie bei der Suche nach den Formen von morgen inspirieren. Dieses Buch ist eine Bestandsaufnahme und präsentiert jung gebliebene Möbel und Wohnaccessoires aus dem 20. Jahrhundert. Und die stärksten Stücke von heute, denen wir prophezeien, dass sie auch morgen noch Gültigkeit haben werden. Lassen Sie sich überraschen - durch Entdeckungen und Wiederentdeckungen.« (SCHÄFER 2011: 3)

"Die Auswahl. 10 Jahre ist das 21. Jahrhundert alt. Welche Möbel werden typisch für diese Dekade sein? Später, durch den Filter der Zeit, wird man das leicht sehen - aber heute? 30.000 neue Möbel werden jedes Jahr auf der Kölner Messe gezeigt - plus Leuchten, Bad- und Küchenaccessoires: 800 Kandidaten schafften es über mehrere Runden bis ins Finale: Es sind die Favoriten der Redakteure, die Lieblinge unserer Stylisten und Architekten. 6 Juroren sollten schließlich entscheiden, paritätisch geteilt: drei aus der Redaktion, dazu drei renommierte Experten von außen, damit keine Betriebsblindheit aufkommt. [HADI TEHERANI, DIETER ZIMMER, PETER SCHMIDT, Hinzufügung des Verfassers] 200 Wohnobjekte dürfen sich jetzt mit dem SCHÖNER WOHNEN-Logo-»Neuer Klassiker« schmücken. Wir glauben: Sie stehen stilbildend für unsere Zeit.« (ebd.: 6)

Die STARCK-Quote für Das Buch der Klassiker liegt bei ELF:

Stühle:

1. PIP-E (ebd.: 149)

2. COSTES (ebd.: 189)

3. LORD YO (ebd.: 197) und

4. DR. NO (ebd.: 197)

Tischleuchten:

5. ARA (ebd.: 188) und

6. MISS SISSI (ebd.: 197)

7. Zitronenpresse JUICY SALIF (ebd.: 196)

8. LAZY WORKING SOFA (ebd.: 197)

9. STARCK CLASSIC-Armatur (ebd.: 197)

10. Waschbecken und

11. Badewanne der Serie STARCK 1 (ebd.: 197). 


\section{STARDESIGNER ODER GESTALTER DES ALLTÄGLICHEN?}

Die Anzahl an Übereinstimmungen mit der Rangliste beträgt ACHT:

1. STARCK (s. o.)

2. BOUROUllec: Sofa Alcove (ebd.: 14), Sessel facetT (ebd.: 25), Stuhl STEELWOOD (ebd.: 35), Wanddekoration CLOUdS (ebd.: 94-95), Stuhl VegETAL (ebd.: 142-143)

3. COLANI: Kunststoffstuhl 1967 (ebd.: 176)

4. GRCIC: Stuhl MONZA (ebd.: 16) Hocker MIURA (ebd.: 18)

Küchenmaschinen PREP EXPERT (ebd.: 129)

5. LOVEGROVE: Gartenleuchte SOlAR BUD (ebd.: 196)

6. MORRISON: Sofa PLACE (ebd.: 32) Tisch ATM Dining TABLE (ebd.: 48), Tisch BAC (ebd.: 53), Stühle AIR CHAIR (ebd.: 148), THINKING MAN's CHAIR (ebd.: 188)

7. RAMS: Sitzmöbel-Programm 620 (ebd.: 174)

8. THUN: Lichtleiste METER BY METER (ebd.: 80), Messerserie TWIN 1731 (ebd.: 127), Sofa MATERASSI (ebd.: 196)

Man kann man sich im Weiteren die Mühe sparen, zum Haruspex zu werden. Die Maßstabsprosa von Topdesign wird in Das Buch der Klassiker zwar durch externe Experten nobilitiert, doch letztlich kommt man auch hier trotz aller Objektivierungsversuche nicht über den Anspruch hinaus, den schon die erste Warenkunde des 20. Jhd.s in sich trägt. Womit sich der Kreis wieder schließt und diese Art von Publikation eigentlich in bewundernswerter Weise selbst zum Klassiker geworden ist - in echter Vorbildhaftigkeit und immer eingedenk der nicht vorhandenen "strengen Kriterien«:

"Der präsentierte Warenbestand spiegelt also keineswegs die Produktvielfalt der jeweiligen Epoche, sondern vielmehr das ethisch und ästhetisch motivierte Qualitätsverständnis von Experten, die der Verbraucherschaft ihren strengen Kriterien genügende Waren empfahlen.« (BRÄUER (DVD) 2004, im Vorwort) 


\section{Die Designklassiker. Vom Barcelona-Sessel bis zum iPad}

unterscheiden sich - darin den Auswahlen von EISELE wie auch den Publikationen des FORM-Verlages gleichend - insofern, als auch Ausflüge ins Automobil-, Industrie- und Grafikdesign unternommen werden und die Anzahl nur bei knapp unter 100 Artefakten liegt, die sich über einen Zeitraum von 153 Jahren erstrecken. Der englische Originaltitel lautet schlicht: Great Designs. Der Kernsatz:

„Dieses Buch präsentiert eine Auswahl der berühmtesten Designklassiker der letzten 150 Jahre, vom klassischen Bugholzstuhl von Thonet bis zu den neuesten Kreationen von Thomas Heatherwick, Jonathan Ive und Philippe Starck.« (WILKINSON 2013: 7)

Es gibt auch hier wieder keine Begründungen für die Verleihung des Status Designklassiker wie für die Auswahl der Artefakte. Bei den Beschreibungen allerdings leistet man sich eine wohltuende Detailversessenheit, die bei vielen Entwürfen eine zusätzliche Doppelseite umfasst und durch produktspezifische Informationen zu überzeugen weiß, also im besten Sinne einen Bildungsanspruch einlöst.

Die STARCK-Quote liegt bei zWEI: sein Stuhl MASTERS beschließt das Buch und als Referenz dazu - natürlich - der JUICY SALIF, sollte man vergessen haben, wo STARCK einzusortieren wäre ... (ebd.: 248-249). Die Anzahl an Übereinstimmungen mit der Rangliste beträgt VIER:
1. STARCK (s. o.)
2. BOUROULleC: Regalsystem BRICK (ebd.: 232-233)
3. GRCIC: Hocker MIURA (ebd.: 240-241)
4. RAMS: PHONOSUPER SK4 (ebd.: 144-145) 


\section{Masters and their Pieces. Best of furniture design}

"Einen hab' ich noch«, um es mit HEINZ ERHARDT zu sagen. Ein Buch, das von MANUELA ROTH für den VERBAND DER CREATIVEN INNENEINRICHTER verfasst und 2012 auf den Markt gebracht wurde. Es ist als Auftragsarbeit von zweifelhafter Aussagekraft, aber gerade deswegen auch von speziellem Interesse.

Anhand dieses Verkaufskatalogs in Buchverkleidung, der in der Ausstattung einer nobel gemachten Monographie nicht nachsteht und als Artefakt in diesem Fall fast eine eigene Analyse wert wäre, lässt sich abschließend noch einmal die in einem normativen Sinne eigentlich nicht vorhandene Bedeutung und die äußerst schwach ausgeprägte Aussagekraft fast aller hier referierten Veröffentlichungen zusammenfassen. Schon im Titel wird mit den Masters eine Meisterschaft im Berufskontext postuliert, aus der sich im übertragenen Sinne automatisch und unausgesprochen die Meisterstückhaftigkeit der vorgestellten Artefakte ergeben sollte. Der Klappentext versucht wie fast immer eine erste Einhegung (alle folgenden Hervorhebungen, soweit nicht anders gekennzeichnet, durch den Verfasser):

"Was macht ein Möbelstück zum Klassiker? Welches Wohndesign ist zeitlos beliebt und immer aktuell - und warum? Ästhetische Qualität durch Geradlinigkeit in der Gestaltung, konsequente Farb- und Formgebung sind ebenso maßgeblich wie Beständigkeit durch hochwertige Materialien und perfekte Verarbeitung. Und natürlich genau so entscheidend - wenn nicht noch entscheidender - ist die in jeglicher Hinsicht überzeugende Funktionalität dieser Wohnobjekte. Der Titel präsentiert die stilprägenden Ikonen des Einrichtungsdesigns und ihre Schöpfer: das kühne Design der 1920er Jahre, der Aufschwung der Wirtschaftswunderjahre, die poppig bunten Kreationen aus den 1970er Jahren oder die reduzierten Entwürfe der neuen Klassiker von heute und morgen. Anschaulich werden die wichtigsten europäischen Möbeldesigner des 20. und 21. Jahrhunderts und ihre bedeutendsten Arbeiten vorgestellt. Die Produkte, die alle auch heutzutage erwerbbar sind, werden sowohl in ihren Entstehungskontext gesetzt als auch in zeitgemäßen Einrichtungscollagen im >Realeinsatz präsentiert.« (BRAUN PUBLISHING) [online] https://www.braun-publishing.ch/de/design/masterstheir-pieceebd.:html [06.03.2018]

Zum Beginn folgt ein Geleit in bereits geläufiger Einleitungs- und Begründungsprosa vom Vorsitzenden des Aufsichtsrats der CREATIVE INNENEINRICHTER GMBH \& CO.KG: 
"Liebe Leserinnen und Leser, sicherlich wurden über Designer und Möbelklassiker schon viele Bücher geschrieben. Möbel wurden als Kulturgüter von Kunsthistorikern aufgearbeitet und in zeitlicher Ordnung dem Publikum präsentiert, Designer und Architekten nach Ausstellungen, Veröffentlichungen und Auktionsergebnissen gewürdigt. Wessen Entwürfe sind aber wirklich in den letzten 100 Jahren in einer breiteren Gruppe unserer Gesellschaft angekommen? Wessen Meisterstücke haben nicht nur den Weg in unsere Museen, sondern auch in unsere Wohnungen gefunden? Das vorliegende Buch beschäftigt sich mit den 42 wichtigsten Möbeldesignern und deren besten Entwürfen. Alle Möbelobjekte haben eines gemein, sie sind immer noch - oder wieder - in Produktion. Das ist die Vorgabe für die Auswahl der Produkte. Ist nicht auch der Markterfolg ein Gradmesser für gute Gestaltung? Kein Unternehmen kann es sich leisten, nicht kommerziell erfolgreiche Produkte weiter herzustellen. Das Buch schafft durch diese Auswahl zweierlei, eine Retrospektive des Möbeldesigns und eine aktuelle Übersicht der wesentlichen Einrichtungsgegenstände, die heute immer noch in ausgewählten Einrichtungshäusern erwerbbar sind [Hervorhebungen des Verfassers].« (LEMBERT in: ROTH 2012: 4)

Aus diesen an Zahl geringen Zeilen tritt uns sein Statusverständnis unmissverständlich entgegen: »[S]icherlich « würdigt LEMBERT die Versuche Dritter, Möbel kulturgeschichtlich aufzuarbeiten und zu präsentieren, doch am wichtigsten ist ihm der eigene Hegemonialanspruch, der sich in vordergründig harmlosen Wörtern wie »sicherlich « und »aber wirklich« manifestiert, mit denen die Berechtigung vorheriger Bemühungen mit einem Handstreich beiseit gewischt wird. Antworten auf die gestellten Fragen liefert selbstverständlich nur »[d]as vorliegende Buch", das sich »mit den 42 wichtigsten Möbeldesignern und deren besten Entwürfen « beschäftigt und »eine aktuelle Übersicht der wesentlichen Einrichtungsgegenstände« liefert. Dass in dieser Publikation Möbelentwürfe gezeigt werden, die für die Masse der Käufer eine entscheidende Bedeutung haben oder haben werden, ist mit allergrößter Leichtigkeit zu bezweifeln. Auch, wenn 42 an anderer Stelle im fiktionalen Raum bereits als Antwort auf die Frage nach dem Sinn des Lebens präsentiert wurde.

Aspekte einer mit sw geteilten Scheinmaßstäblichkeit finden sich ebenfalls, wenn »Möbelobjekte [als] [...] noch - oder wieder - in Produktion« eingeordnet werden. Interessant wird es mit der Frage, ob nicht Markterfolg ein Gradmesser für gute Gestaltung sei, deren textliche Nachgeburt dann einfach unterstellt, ein Produkt, das noch "erwerbbar sei, sei auch kommerziell erfolgreich. Eine Quantifizierung in der Art, wie es im Rahmen von BUSSES Longlife-Design-Award geschieht, wäre durchaus hilfreich, um den tatsächlichen ökonomischen Erfolg verlässlicher einzuschätzen. 


\section{STARDESIGNER ODER GESTALTER DES ALLTÄGLICHEN?}

Die Profile der Designerinnen und Designer umfassen vordergründig nur drei, doch eigentlich fünf Frauen: EILEEN GRAY, HELLA JONGERIUS und PATRICIA URQUIOLA. Außerdem 38 Männer und sie geben einen rudimentären Einblick in deren Biografien, wiewohl sie nicht viel Greifbares zu deren Bedeutung ausweisen. Ebenso wenig, weshalb die ausgewählten Möbel »Meister«-»Stücke« seien, doch hieran ist man ja inzwischen gewöhnt. Außer der Tatsache, dass sie alle "noch - oder wieder - in Produktion« sind, ist nichts in Erfahrung zu bringen (s. o.). Als Erklärung zu den möglicherweise verwirrenden Zahlen sei angemerkt, dass RAY EAMES nur im Zusammenhang mit CHARLES erwähnt wird, wie auch JEANETTE ALTHERR nur als ein Teil des Teams LIEVORE, ALTHERR, MOLINA. Ganz genau genommen wären es sechs Frauen, denn auf den Seiten zu LE CORBUSIER ist auch CHARLOTTE PERRIAND mit zwei Entwürfen versteckt (ebd.: 28-29) und im Text seines Profils wird sie kurz als Partnerin für den (ab ihrem Eintritt in seine Firma) Entwurf eigener Möbel erwähnt (ebd.: 21).

Nach 129 Seiten ist die Autorin mit DIETER RAMS fast mit den käuflichen Klassiker-Variationen des Verbandes durch, die auf die eine oder andere Art als solche benannt werden. Die verbleibenden fast 200 Seiten füllen weitere, unter den auch hier angelegten Maßstäben durchaus bekannt zu nennende Designer. Sie stellen damit nichts anderes mehr dar als einen Möbelkatalog mit integrierten Designerportraits, innerhalb dessen nur noch MAARTEN VAN SEVERENs Stuhl ».03" mit dem Halbsatz »ein schlichtes Design-Kultobjekt des 20. Jahrhunderts« herausragen gelassen wird. Um einen Eindruck von der Quantität wie auch der Qualität der Betextung zu geben, werden in gewohnter Weise Personen mit ihren entsprechend hervorhebenden Fundwörtern und Formulierungen nebst Seitenangaben aufgelistet:

- EILEen GRAy: Sofa MONTE CARLO

»Die ausladenden Kurven des Sofas Monte Carlo zusammen mit der geschickten Nutzung leeren Raumes machen es zu einem absoluten Kultobjekt des 20. Jahrhunderts.« (ebd.: 10)

- LUDWIG MIES VAN DER ROHE: Stühle BARCELONA und BRNO

"Der legendäre Stuhl Barcelona wurde für die Weltausstellung in Barcelona 1929 entworfen." (ebd.: 14)

"Viele seiner Arbeiten, wie der >Barcelona ${ }^{\circledR}<$ Sessel und der Stuhl >Brno<, dessen Lederpolsterung und Chromrahmen einen ansprechenden Kon- 


\section{AM ENDE WAR ES NUR EIN WORT: ZWEI REZEPTIONSSTUDIEN}

trast zwischen traditionellem Luxus und modernem Chic bilden, sind Kultobjekte modernistischen Designs geworden. (ebd.: 15)

- MART STAM: Freischwinger 333

"Dieser Stuhl mit Kultsymbolcharakter war schnell der Auslöser für eine ganze Gattung von Designerstühlen, denn ähnliche Modelle finden sich auch bei Ludwig Mies van der Rohe, Eileen Gray und Marcel Breuer.« (ebd.: 37)

- JEAN PROUVÉ: Tisch GUÉRIDON

"Die klare Formensprache des Tisches Guéridon macht ihn zu einem Klassiker des 20. Jahrhunderts und ist ein gutes Beispiel von Prouvés Ingenieuransatz in seinen Designs." (ebd.: 47)

- EgON EIERMAnN: Stuhl SE 68 und Tischgestell EIERMANN 1

"Mit seiner Kombination aus dünnem Stahlrahmen und gebogenen Schichtholzschalen für die Sitzfläche und die Rückenlehne ist der minimalistische Stuhl SE 68 eines von Eiermanns berühmtesten Designs." (ebd.: 60)

"1953 entwarf er seinen legendären Schreibtisch, das Tischgestell •Eiermann $1<. .(e b d .:$ 61)

"Der Eiermann Tischrahmen ist ein echtes Design-Kultobjekt der Mitte des letzten Jahrhunderts." (ebd.: 64)

- CHARLES Und RAY EAMES: PLYWOOD LOUNGE CHAIR und EXECUTIVE CHAIR

"Der Plywood Lounge Chair aus gebogenem Schichtholz ist eines der kultigsten Designobjekte des 20. Jahrhunderts.« (ebd.: 70)

"Auch als Time-Life Chair bekannt, ist der Executive Chair ein Kultobjekt, das ursprünglich für die Chefetagen des Time-Life Building in New York 1960 entworfen wurde.« (ebd.: 75)

- FRITZ HALLER Und PAUL SCHÄRER: USM MÖBELBAUSYSTEM HALLER

»Heute ist das USM Möbelbausystem Haller ein Design-Klassiker des 20. Jahrhunderts und wurde in die permanente Sammlung des Museum of Modern Art in New York aufgenommen." (ebd.: 101)

- VERNER PANTON: PANTON STUHL

"Der revolutionäre Panton-Stuhl war der erste aus einem einzigen Stück Polypropylen gezogene Kunststoffstuhl. 1967 wurde er das erste Mal in 


\section{STARDESIGNER ODER GESTALTER DES ALLTÄGLICHEN?}

Serie produziert und zählt seitdem als Kultobjekt des 20. Jahrhunderts." (ebd.: 104)

- PierRe PAUlin: tONGUe CHAir

"Der Tongue Chair ist sicherlich Paulins gewagtestes und verspieltestes Design. Der Benutzer lehnt sich zurück auf einer gebogenen, herausgestreckten Zunge. Seine fließende Form machte den Stuhl in den 196oer Jahren legendär.« (ebd.: 113)

- MAARTEN VAN SEVEREN: Stuhl .03

"Seine berühmteste Arbeit ist der Stuhl >.03‘, ein schlichtes DesignKultobjekt des 20. Jahrhunderts." (ebd.: 217)

Es tritt hervor: das absolute, legendäre, berühmte Kultobjekt mit Kultsymbolcharakter. Der Klassiker bleibt sogar in der Unterzahl! Damit hat es sich auch schon, denn mehr wird zum Grund der Auswahl wie als etwaige Begründungen zum postulierten Status nicht aufgeboten. So reduziert sich die Bedeutung von Meister und ihre Stücke. Das Beste des Möbeldesigns in einem übergeordneten Sinne auf NICHTS - denn in dieser Publikation findet man keine ernsthaft wertsetzenden Aussagen vor. Als Werbeprospekt im Überformat ist sie ein scheinheiliger Popanz: Schön durchfotografiert und bestens produziert, mit grobleinenem Einband, mattgoldener Druckfarbe und Effektlack auf dem Schutzumschlag.

Die STARCK-Quote liegt bei NULL. Die Anzahl an Übereinstimmungen mit der Rangliste beträgt VIER. Von diesen wird jedoch kein einziger Entwurf (nicht einmal die von DIETER RAMS!) von der Autorin als Designklassiker o. ä. markiert, was allein schon in Anbetracht von RAMs' andernorts mehr als nur scheinbar befestigtem Status kräftig verwundert:

1. BOUROUllec: Stuhl Steelwood, Raumelement ALgues, Stuhl VegeTAL, Stuhl SLOW, Stuhl SPRING, Stuhlprogramm STRIPEd, Sofa ALCOVE, Bürosystem JOYn, Bürostuhl wORKNEST, Bürosystem PLAYns (ebd.: 310-317)

2. GRCIC: Hocker OSOROM, STUHL MARS, Sekretär ORCUS, STUHL VENUS, Stuhl mOnZa, Stuhl B, Stuhl myto, Tische DIANA, Sessel CRASH, Stuhl 3600, Barhocker ONE, Stuhl WAVER (ebd.: 268-277)

3. MORRISON: Stuhl BASEL, Stuhl hal, Stuhl trattoria, Stuhlprogramme HI PAD und LOW PAD, Bürostühle LOTUS, Klappstuhl AIR, Hocker/Ti- 
AM ENDE WAR ES NUR EIN WORT: ZWEI REZEPTIONSSTUDIEN

sche Cork, Sofa Superoblong, Sofa elan, Stuhl sim, Sessel monopod, Tische ATLAS, Stuhl CRATE (ebd.: 232-241)

4. RAMS: Sitzmöbel-Programm 620, Regalsystem 606, Container-Programm 980/981 (ebd.: 124-129) 


\section{Finale Auswertung der Befestigungsliteratur}

Betrachtet man die STARCK-Quote mit allen weiteren Funden zusammen, entsteht eine Rangliste der in der Befestigungsliteratur vorgestellten Designer, die sich für einen Vergleich mit der bereits ermittelten Star-Designer-Rangliste eignet und sie sieht anders aus als die bereits vorliegende. Alle zehn Designer, die im bereits untersuchten Zeitschriftenkorpus gefunden wurden, sind in erwartbar wechselnder Häufigkeit auch prominent in der Befestigungsliteratur vertreten. Dadurch wird die Plausibilität der aus der Korpusauswertung herausragenden Sinnangebote gestützt, denn in umgekehrter Richtung betrachtet sollten Angebote aus der Befestigungsliteratur Auswirkungen in weiteren Verbreitungsmedien haben, wenn man davon ausgehen kann, dass Prominenz Spiralen zieht. Im Ergebnis treffen alle in Paaren zusammen und PHILIPPE STARCK büßt seine Spitzenposition ein:

1. GRCIC, RAMS: je 7 Fundstellen

2. MORRISON, STARCK: je 6 Fundstellen

3. BOUROULlEC, LOVEGROVE: je 4 Fundstellen

4. COLANI, THUN: je 3 Fundstellen

5. CONRAN, GIUGIARO: je 1 Fundstelle

Für einen direkten Vergleich noch einmal die Rangliste der ersten Studie:

1. PHILIPPE STARCK: 12 Fundstellen, 99 Artikel

2. Giorgetto giugiaro: 8 Fundstellen, 24 Artikel

3. JASPER MORRISON: 8 Fundstellen, 11 Artikel

4. LUIGI COLANI: 7 Fundstellen, 20 Artikel

5. MAtTeO Thun: 7 Fundstellen, 19 Artikel

6. Gebrüder BOUROULlEC: 6 Fundstellen, 18 Artikel

7. KONSTANTIN GRCIC: 6 Fundstellen, 18 Artikel

8. TERENCE CONRAN: 6 Fundstellen, 7 Artikel

9. DIETER RAMS: 6 Fundstellen, 7 Artikel

10. ROSS LOVEGROVE: 6 Fundstellen, 6 Artikel

Welche Artefakte werden nun in der Befestigungsliteratur übereinstimmend für befestigungswürdig erachtet? Im Gegensatz zum Zeitschriftenkorpus zählt hier nicht mehr die Markierung mit einem bestimmten Begriff, sondern aus- 
schließlich ihre Abbildung liefert den Grund für die Aufnahme. Im Ganzen sind es davon siebzehn, die sich wie folgt auf sechs der zehn Designer verteilen:

- PHILIPPE STARCK: 2

Stuhl costes (4 Fundstellen)

Zitronenpresse JUICY SALIF (6 Fundstellen)

- JASPER MORRISON: 2

Stuhl PLY CHAIR (2 Fundstellen)

Stuhl THINKING MAN'S CHAIR (4 Fundstellen)

- Gebrüder Bouroullec: 4

Bürosystem JOYN (2 Fundstellen)

Sofa Alcove (2 Fundstellen)

Stuhl STEELWOOD (2 Fundstellen)

Stuhl vegetal (2 Fundstellen)

- KOnStAntin GRCiC: 5

Leuchte MAYdAY (2 Fundstellen)

Stuhl MONZA (2 Fundstellen)

Hocker MIURA (2 Fundstellen)

Sitzobjekt OSOROM (2 Fundstellen)

Stuhl CHAIR ONE (3 Fundstellen)

- dieter Rams: 3

PHONOSUPER SK4 ( 5 Fundstellen)

Regalsystem 606 (5 Fundstellen)

Sesselprogramm 620 (3 Fundstellen)

- ROSS LOVEgROVE: 2

Wasserflasche für TY NANT (2 Fundstellen)

Thermoskanne BASIC (2 Fundstellen)

In Abhängigkeit von der Zahl ihrer Fundstellen interpretiert, können als Spitzengruppe nur noch jene ausgewählt werden, die in mindestens drei Publikationen zu finden sind. Nach jenem Ausleseschritt verbleiben sieben Artefakte von vier Designern, was die Liste in interessanter Weise verändert:

1. PHILIPPE STARCK: Zitronenpresse JUICY SALIF (6 Fundstellen)

2. DIETER RAMS: PHONOSUPER SK4 (5 Fundstellen)

Regalsystem 606 (5 Fundstellen) 
3. JASPER MORRISON, PHILIPPE STARCK: Stuhl THINKIng MAN's CHAIR (4 Fundstellen)

Stuhl costes (4 Fundstellen)

4. KONSTANTIN GRCIC, DIETER RAMS:

Stuhl CHAIR ONE (3 Fundstellen)

Sesselprogramm 620 (3 Fundstellen)

Designgeschichtlich betrachtet werden demnach die publizistische Hauptperson des Designbooms der 8oer und der goer des 20. Jhd.s sowie ein Vertreter des deutschen Funktionalismus, der Erfinder des No-Design (oder auch Verfechter des SUPERNORMAL-en) und einer von dessen Assistenten als jene Gestalter ausgewiesen, die als unverhandelt übereinstimmungsfähige Verhandlungsergebnisse in den Scheinwerferkegeln einer Manege stehen, die es ohne die hiesigen Auswahlmaßstäbe eigentlich gar nicht gäbe, da all dem keines der üblichen Legitimationsrituale (Wettbewerbe) voranging.

Überraschend ist auch die Tatsache, dass der Altvordere mit drei Artefakten sich nach Zahlen auf der Spitzenposition befindet, gefolgt vom ehemaligen Meister der Publicity mit zweien und dass dessen Identifikationsartefakt allen sachlich-neutralen Designstrategen den Rang ab läuft. Wie auch sein Durchbruchsentwurf im Mittelfeld noch gut mithält. Wenn wir noch kurz zu den Supra²-Designern und den Supra²-Designklassikern der Zeitschriftenstudie zurückblicken, so sind keine Übereinstimmungen zwischen hier und dort mehr zu finden. Als valider Befund verbleibt jedoch die hundertprozentige Übereinstimmung der quantitativ aus Zeitschriften- und Befestigungsliteraturkorpus herausragenden Personen.

Enden soll dieses Kapitel mit einem Bezug zu seinem Beginn, der auch eine weitere Begründung für die Untersuchung der publizistischen Kanonisierung im Rahmen dieser Arbeit liefert: Mit einem Zitat WALKERs, in dem er sich zu »vor-kanonischen Deutungen« äußert, die unmittelbar zum bei GEORG FRANCK aufgeführten Aufmerksamkeitsspeicher des Ruhms (FRANCK 1998: 118) wie auch zu WIPPERSBERGs Prominenzierungsspirale aufschließen:

"Die bisherige Designgeschichte hat der Natur des Kanons und der kritischen Tätigkeit der Kanonbildung noch nicht viel Aufmerksamkeit gewidmet. Eine Ausnahme bildet das Buch von Juan Bonta Architecture and Its Interpretation [Hervorhebung im Original] (1979), das in einer Fallstudie nachweist, wie der Barcelona-Pavillon von Mies van der Rohe seit 1929 von der Kritik gewürdigt und im Lauf mehrerer Jahrzehnte für kanonisch erklärt wurde. Auf der Grundlage dieses Beispiels läßt sich ein erstes, noch vor-kanonisches Stadium nachwei- 


\section{AM ENDE WAR ES NUR EIN WORT: ZWEI REZEPTIONSSTUDIEN}

sen: das Werk wird zunehmend erwähnt und gelobt, und in der Fachliteratur tauchen erste Hinweise auf seinen zukünftigen kanonischen Status auf. Wenn sich innerhalb der Forschung eine einzige positive Würdigung oder Deutung herauskristallisiert hat, gewinnt das Werk kanonischen Rang. Bonta sieht in den vor-kanonischen Deutungen die größere schöpferische Leistung. [Hervorhebung des Verfassers] Wenn das Werk erst einmal im Kanon verankert ist, gehen anfängliche Einsichten häufig verloren [hier liegt eine Parallele zur Erklärung des Ruhm bei FRANCK; Anmerkung des Verfassers] oder werden durch ständiges Wiederkäuen durch Schreiber, die in immer größerer Entfernung zum Original stehen, verzerrt. Wenn Werke den kanonischen Status verfehlen, werden sie aus der Tradition ausgerissen wie Unkraut und vergessen; sie werden schlicht unsichtbar. Auf die Kanonisierung der Werke folgt eine Phase der Verbreitung, in der die maßgebliche Interpretation der Fachwelt durch populäre Darstellungen vor einem breiteren Publikum vorgetragen wird. Für die weitere Entwicklung zeichnen sich drei Möglichkeiten ab: das Werk kann zu einem Kulturdenkmal außerhalb aller Kritik werden, sein Ruhm kann sinken, bis es vergessen wird, oder es kann eine Neuinterpretation und Neubewertung erfahren, wenn eine jüngere Generation von Kritikern es aus einem neuen Blickwinkel betrachtet.« (WALKER 1992: 79f) 


\section{Welche Erkenntnisse lassen sich aus den beiden Studien gewinnen? Zehn Schlussfolgerungen}

- Erstens: Außer der bis zum Überdruss ausgewiesenen, argumentativen Inhaltsleere ist mit der konstatierten Schein-Maßstäblichkeit eine nicht vorhandene Definition ex negativo aufgestellt. Durch ihre schiere, zunächst unvermutete Existenz wird auch das Niveau dargelegt, auf dem sich die hehre Vorbildhaftigkeit im fachlichen Gebrauch sprachlich wie inhaltlich bewegt.

- Zweitens: An den Beginn mit FRENZL anschließend, ist zu konstatieren, dass Inhaltsleere auch durch permanente Wiederholungen nicht gehaltvoller wird. In sämtlichen referierten Werken wurden lediglich subjektive Entscheidungen gefunden: Es gibt schlicht nichts, was normativ darüber hinaus weisen will oder auch nur in Ansätzen kann. Zum Aspekt der Normativität wird auch in Achtens noch einmal Stellung bezogen.

- Drittens: Wird die Summe dieser subjektiven Entscheidungen nicht kritisiert, sondern als das genommen, was sie ist - ein Teil des Allgemein-Besonderen (vgl. bei RECKWITZ 2017) -, dann steht den Konsumenten eine Überfülle desselben gegenüber, aus dem sie nach Lust und Laune das ihnen Genehme herausfischen können, um dadurch diese Sinnangebote erst in Funktion zu setzen und zugleich an ihrem eigenen Aufmerksamkeitsrelief zu arbeiten.

- Viertens: Einem Nebel gleich wabert eine durch fortwährenden Wandel an ihren Rändern charakterisierte Masse von Artefakten durch diese spezielle Gattung der Verbreitungsmedien. Von ihrem Zuschnitt her muss die Befestigungsliteratur noch als Fachliteratur gewertet werden und die in ihr gezeigten Artefakte stellen die Menge stillschweigend nicht verhandelter, aber dennoch existenter Verhandlungsergebnisse dar. Interpretiert man die Befestigungsliteratur der zweiten Studie in Anlehnung an die Sphären der Prominenz als einen Teil des Fachpublikums, dann stellt der untersuchte Zeitschriften-Korpus der ersten Studie im Kontrast dazu einen Teil des allgemeinen Publikums dar, das für die Aufrechterhaltung allgemeiner Prominenz zuständig sein soll. Das Fachpublikum macht nun mit 
seinen Sinnangeboten den Versuch, die Bereichsprominenz auszuweiten und eine allgemeine(re) Prominenz zu erreichen. Dies dürfte bekannt vorkommen. Im Übrigen hat die Analyse der Funde einen auf gar nicht so schwachen Beinen daherkommenden Beweis dafür erbracht, dass die in der Fachpresse in Gang gesetzten Prominenzierungsspiralen der zehn gefundenen Designer erfolgreich in der Breite angekommen sind.

- Fünftens: Die von allen Autoren vorgestellten Artefakte haben als die Sinnangebote, die sie darstellen, ein Einflusspotential, weil sie kulturell und sozial wirksam werden können. Sobald ein geneigter Leser aus dem zuletzt referierten Band für sich herausliest, dass JASPER MORRISON einer der 42 wichtigsten europäischen Möbeldesigner des 21. Jhd.s ist und diesen Maßstab für sich annimmt, wird und ist dieses Sinnangebot wirksam. [Es muss festgehalten werden, dass diese Auswahl völlig willkürlich ist, es hätte auch jede(n) der restlichen 41 in dieser Publikation erwähnten Personen treffen können.] Fügen wir dieser Argumentationskette noch ein paar Glieder hinzu, dann kann jener Leser annehmen, dass das abgebildete Sofa SUPEROBLONG einer von JASPER MORRISONS besten Entwürfen sei. Diese Besetzung mit Bedeutung von dritter Stelle kann also von einem Individuum angenommen oder abgelehnt oder auch mit einer eigenen Besetzung mit Bedeutung überschrieben werden. Aus gegebenem Anlass rufe ich einen Gedankengang vom Beginn dieses Kapitels in Erinnerung: Die gleichzeitige Existenz eines Artefaktes »Sofa SUPEROBLONG, entworfen vON JASPER MORRISON « und des von einer Fachpublikation produzierten Wertes (der da zusammengefasst und in ein Postulat verwandelt lautet: Einer der 42 wichtigsten europäischen Möbeldesigner hat dieses Sofa entworfen, das zu seinen besten Entwürfen zählt.), versetzt den Rezipienten in die Lage, einen Teil dieser Dualität, nämlich die Wertsetzung, für sich abzulehnen - wenngleich die reale Existenz des Artefakts als solche nicht abgestritten werden kann. Die Trennung des sozial produzierten Wertes vom Artefakt, dem er zugeschrieben wird, ermöglicht auch die Produktion weiterer Werte und anderer Zuschreibungen, die nicht deckungsgleich mit schon bekannten sein müssen. In anderen Fachpublikationen können andere Werte für das gleiche Artefakt postuliert werden, die es zum Beispiel zu einem seiner schlechtesten Entwürfe erklären. Oder es wird durch Auslassung im Rahmen eines weiteren Wertesystems der Bedeutungslosigkeit anheim gegeben, wogegen dort wieder andere Artefakte favorisiert mit Bedeutung besetzt werden können. Derlei lässt sich weiter 
vorne auch schon bei HAUFFE erlesen, bei dem COLANI als "Außenseiter des Designs« so wie als »einer seiner umstrittenen Vertreter« bezeichnet wird, während die Auswertung des Zeitschriftenkorpus ihn einhellig als mit Lob überschüttet ausweist.

- Sechstens: Der Leser trennt auf der Basis seines individuellen Beachtungsreliefs in der Rezeption dieser Rezeption jene intendierte Wertsetzung zum Zweck der Annahme eines Sinnangebots von seiner individuellen In-Wert-Setzung oder Nicht-in-Wert-Setzung. So langt man wieder bei MIKLAUTZ an, der das hiesige Wertsetzungsangebot als Artefakt ein Teil kollektiver Wertvorstellungen wäre, »die in ihrer Aneignung durch den einzelnen bestätigt und - wenn auch fallweise modifiziert - reproduziert werden." (MIKLAUTZ 1996: 77) Dieser Lesart folgend, ist die Befestigungsliteratur belegtermaßen nichts anderes als eine weitere Replikationsmaschinerie für ein Sammelsurium an Wertsetzungsangeboten, deren Annahme durch ein allgemeines Publikum ebenso unsicher bleibt wie die Annahme eines Stars durch dasselbe.

- Siebtens: Aus den analysierten Publikationen tritt in der Summe ein Artefakt-Korpus zu Tage, der als unverhandeltes Verhandlungsergebnis aufgefasst werden muss und die Ausbeute an Artefakten stellt Sinnangebote in zweierlei Hinsicht dar. Lässt man die geringe argumentative Durchdringungstiefe dieser Wertsetzungen beiseite, richten sie sich einerseits an die Konsumenten. Andererseits steht dieses Oberflächenphänomen für jede Publikation, die sich auf's Neue an einer Definition des »ultimative[n], umfassende[n] Werk[es] zum Thema ১Designklassiker« versucht (vgl. mit FRENZL, vorstehend), als Auswahloption zur Verfügung. Auf diese kann sich wiederum bezogen werden oder auch nicht. Nachdem EISELE noch davon schrieb, dass Artefakte »durch Zeigen und Abbilden, durch Reden und Schreiben immer wieder neu reflektiert und durch museale und mediale Inszenierungen zu einem System von Bedeutungen geworden « seien (EISELE 2014: 9), muss als wesentliches Ergebnis der vorliegenden Analyse das Gegenteil herausgehoben werden: Die Vermutung, die mit den WARBURGschen Schlagbildern seit dem Beginn dieser Arbeit im Raum steht, war qualitativ weder durch die erste Rezeptionsstudie noch durch die im zweiten Schritt analysierten Exemplare von Befestigungsliteratur zu entkräften. Es wird nichts neu reflektiert, sondern nur repetiert und die »System[e] von Bedeutungen« beschränken sich auf - ein weder erklärendes 
noch legitimierendes - Benennen und Abbilden. Bezieht man noch einmal die Zuspitzung in der Form der Supra- und Supra²-Designklassiker und auch die wenige Zeilen zuvor präsentierte Auswertung der Befestigungsliteratur mit ein, so stellt sich nur eine sehr geringe Anzahl von übereinstimmungsfähigen Artefakten ein, die tatsächlich publikationsübergreifend entweder als Klassiker (o. ä.) markiert werden oder durch Erwähnung als etwas gekennzeichnet, woran man nicht vorbeikäme. Geringe Einigkeit bei großer Differenz ist das greifbare Ergebnis dieser Besetzungen mit Bedeutsamkeit und gerade diese Uneinigkeit bietet potentiellen Käufern immer noch breiten Raum zu individueller Orientierung. So, wie sie zu jeweils individuellen "System[en] von Bedeutungen« (s. o.) führt, die der von RECKWITZ diagnostizierten Zersplitterung in Singularitäten (die weit mehr als eine Zeitströmung darstellen,) deutlich eher entspricht. Im Gegensatz dazu kann die Befestigungsliteratur dem Anspruch der Orientierung, mit dem sie sich umgibt, gerade nicht standhalten. Auch aus der Perspektive dieser Arbeit bilanziert CACCIOLA jenen Aspekt für den Spezialfall der Rezeption von Reeditionen abschließend. Wobei ihre Aussage durch Ersetzung problemlos auf die hier untersuchten Designklassiker, Modernen Klassiker oder Designikonen übertragbar ist:

»Die Medien wie Fachzeitschriften und die populärwissenschaftliche Li teratur haben ihr Bild nur zweidimensional aufgewertet und unkritisch multipliziert. Es lässt sich deshalb ohne Weiteres erkennen, dass die Häufigkeit an Präsenz der Reeditionen in der Literatur umgekehrt proportional zu dem daraus zu ziehenden Erkenntniswert ist, den diese Präsenz liefert." (CACCIOLA 2008: 392)

- Achtens: Wie kann man mit der Tatsache umgehen, dass die individuellen In-Wert-Setzungen von Wertsetzungsangeboten bei Konsumenten jeweils individuelle Beachtungsreliefs zur Grundlage haben, die sich Normierungsvorschlägen dieser Art problemlos entziehen können? Nehmen wir dazu für einen Moment bei selle Platz, der 2007 in einer Neuauflage der Geschichte des Design in Deutschland im Rahmen eines Essays über den DEUTSCHEn WERKBUND schreibt:

"Was als anerkanntes Design gelten soll, ist immer ein Interpretat gewesen. Und Interpreten gab und gibt es viele: Hersteller, Entwerfer, Gebraucher, Kritiker, Historiker, Medien, Institutionen usw. [...] Konnte es je ein ästhetisch korrektes Design für alle geben? Im Zeitalter sozialer Differenzierung durch Design und Konsum erscheint eine allgemeinverbindliche 


\section{STARDESIGNER ODER GESTALTER DES ALLTÄGLICHEN?}

Norm kaum denkbar und ist ästhetische Produzenten- und Konsumentenerziehung fragwürdig geworden. (SELLE 2007: 363)

Fragen nach der »Genese und Durchsetzungsfähigkeit normativer Konstrukte« (ebd.: 363) stellen sich auch über ein Jahrzehnt nach dieser im Endergebnis vernichtenden Bilanz der Aktivitäten des DWB noch und gerade in Anbetracht aller hier referierten Publikationen erneut. Denn jede einzelne beansprucht schon eine, wenn nicht DIE Antwort darauf zu geben. Hierzu noch eine weitere Sottise SELLES:

"Der ironische Kulturflaneur Gregor von Rezzori hätte es `Epochenverschleppung genannt - das lange Überleben eines von der gesellschaftlichen Entwicklung überholten Habitus [...]« (ebd.: 367)

Wird der »daraus zu ziehende[...] Erkenntniswert« (s. o.) nicht an seinen erkennbaren Defiziten festgemacht, sondern nimmt man ihn analog zu Drittens und Fünftens wieder zur Basis möglicher realer Auswirkungen, so wird von allen vorstehend vorgestellten Sinnangeboten bis heute der epochenverschleppende Anspruch zum Ausdruck gebracht, die Eindrücke und Meinungen (mit) zu beeinflussen, die Konsumenten von Artefakten gewinnen und haben. Ein Ausweg ist nicht in Sicht.

- Neuntens: WIPPERSBERg folgend ist die erneute Erwähnung in einem Verbreitungsmedium völlig ausreichend, um einen jener erneuten Erinnerungsanlässe im Sinne der angenommenen Prominenzierungsspirale gesetzt zu haben. Sie wird erkennbar in Funktion gesetzt.

- Zehntens: Jenseits der Akzeptanz von normativen Ansprüchen, die im Rahmen dieser Arbeit nur insoweit als Konstrukt ernstgenommen werden, als sie den verwendeten Begriffen und im Zusammenhang vorgestellten Artefakten unterlegt zu sein scheinen, wird die referierte Befestigungsliteratur in diesem ersten Schritt nur an ihrem eigenen Anspruch gemessen: Er ist das Papier nicht wert, auf dem er sich gedruckt findet. Faktisch überprüfbar wäre die (Nicht- oder) Annahme dieser Wertsetzungen nur dann, wenn man sich anschickte, um u. a. mit einer groß angelegten Konsumentenbefragung die Ausrichtung des Käuferverhaltens anhand solcher Wertsetzungsangebote zu überprüfen, sonst bliebe sie nichts als Spekulation. Denn bisher wurde nur untersucht, in welcher Form Sinn- 
angebote in den Verbreitungsmedien unterbreitet werden und ob diese sich auf belegbare Wertmaßstäbe stützen. Wie darauf reagiert wird oder ob die In-Wert-Setzung messbare ökonomische Auswirkungen hat, kann aktuell nicht festgestellt werden: Es handelt sich bisher um nicht mehr und nicht weniger als selbstreferentielle Bezugnahmen, anhand derer noch keine Aussagen über eine externe ökonomische Wirkung möglich sind.

\section{Eine spielerische Anbindung an die tatsächliche Fortifikationsliteratur:}

Auf einer leichten Anhöhe liegt eine Feste sonnenüberstrahlt in freiem Lande. In ihren Mauern ein Palas (der repräsentative Saalbau), in dem über die Maßstäbe für prominente Designer und auch Designklassiker entschieden wird. Ihre überaus prächtige Anlage demonstriert dem Umland, wie bedeutsam das ist, was es dort zu verteidigen gilt. Zu einem fiktiven Verteidigungs-Szenario ausgemalt wird dieses Bild mit Hilfe einiger Fachbegriffe des Festungsbaus, die sich von außen nach innen auf das Forschungsfeld übertragen lassen.

Ab dem Glacis (Erdanschüttungen vor dem Graben, die tote Winkel verhindern und Teil der Außenböschung sind) liegt das Feld des Designs in seiner Gänze vor uns. Auf der Contrescarpe (der Außenböschung) sind all jene versammelt, die zum hindernisbewehrten Kern des Ruhms vordringen wollen und gleichzeitig alle anderen abwehren, die noch von außen heranbranden. Hinter ihr liegt die erste Reihe der Verbreitungsmedien auf dem gedeckte[n] Weg (ein von außen nicht einsehbarer Verbindungsweg) in Stellung - vor der allgemeinen Prominenz, die den Graben hält.

Die Escarpe (die äußere Mauer der Festung) wird von der Bereichsprominenz verteidigt. Auf den Courtinen (den Wallabschnitten zwischen den Bastionen) paradiert ein Teil der Wächter des Stardesigns und schiebt mit den Star-Designern und den Designklassikern seine Bastionen (aus dem Wall herausragende Verteidigungswerke) in den Raum vor.

Wie Ravelins (Wallschilde zum Schutz desselben) steht die Befestigungsliteratur zur Verteidigung vor den Courtinen bereit und lässt nur wenige in den inneren Kreis der »normative[n] Konstrukte« vordringen. In der stolzen Zitadelle (dem Rückzugsort der Garnison) residieren die Designikonen und die Designlegenden. Der davorliegende Zwinger (ein räumlich enges, aber offenes Vertei- 


\section{STARDESIGNER ODER GESTALTER DES ALLTÄGLICHEN?}

digungsareal) wird von den Super-, Pop- und Weltstars des Designs geschützt. Was wir vorfinden, wenn wir zum Gipfel der Erinnerungsanlässe vordringen, 496 wurde bereits beschrieben: Leere Räume, die wirken, als wären die Verteidiger still und heimlich durch gut versteckte Gänge abgezogen und hätten alles mitgenommen. Gab es ein Geheimnis, hinter das man hätte kommen können? 


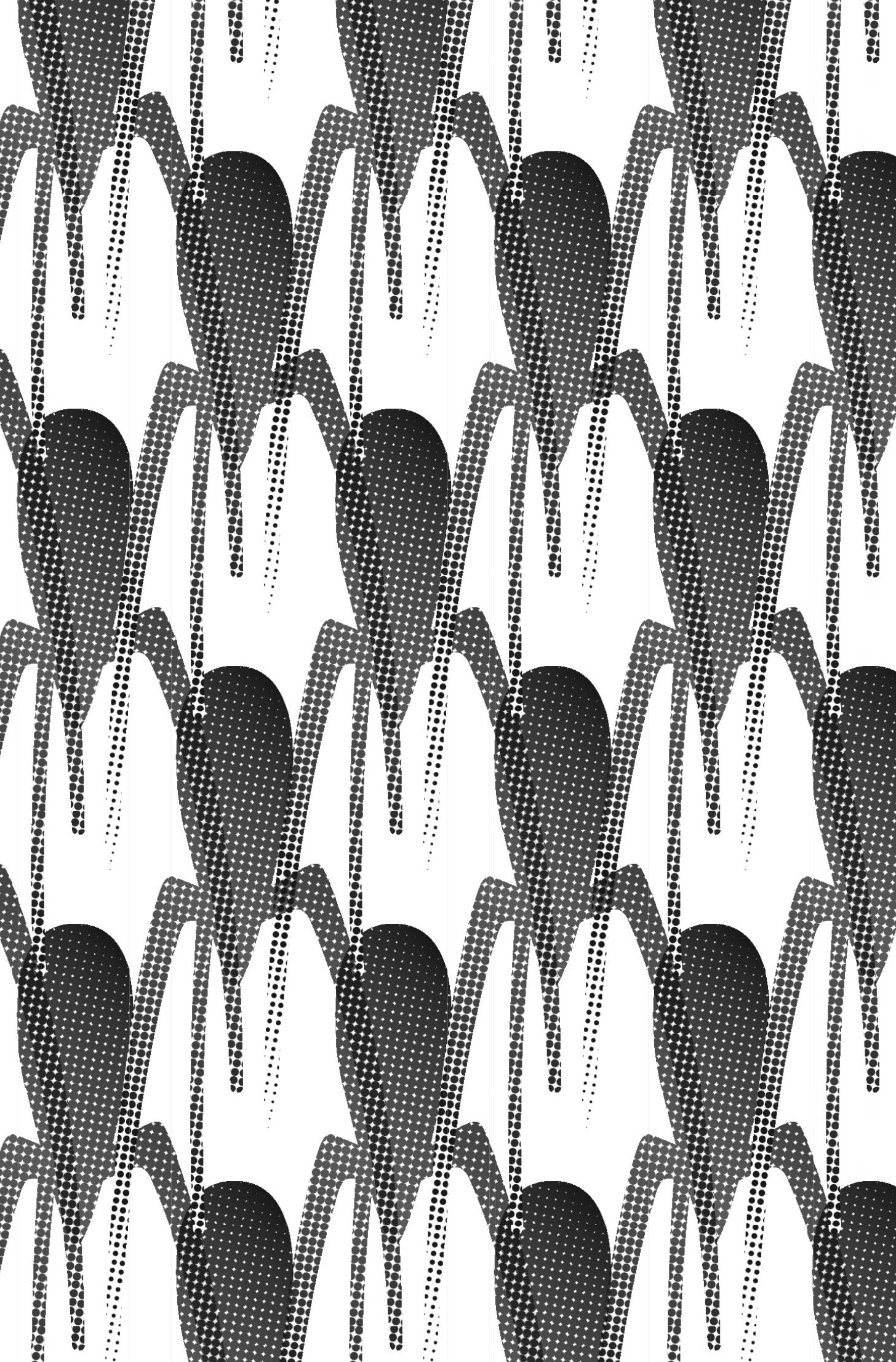




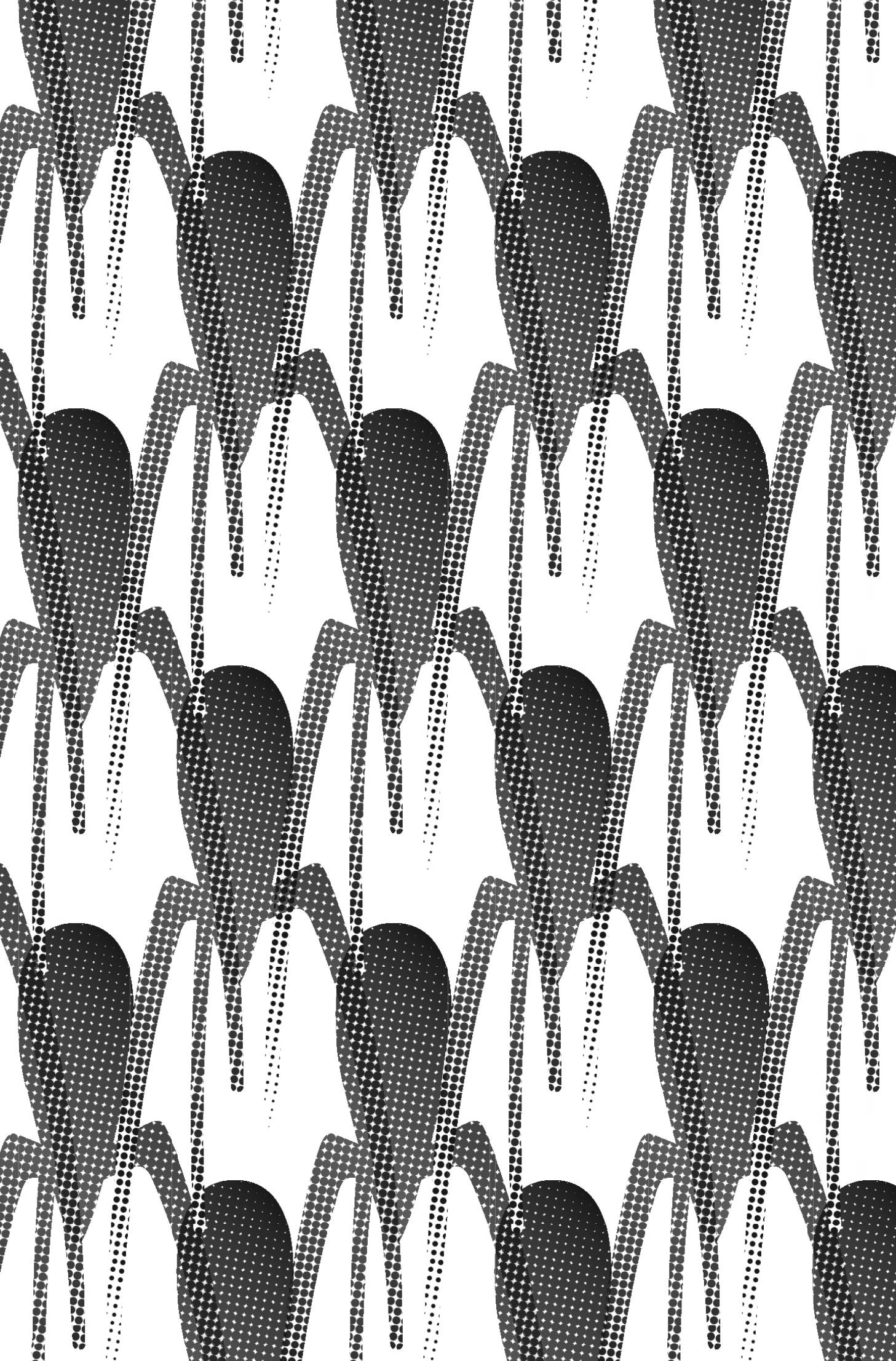




\section{Anhang zu \\ Philippe Starck}

\section{Architektur und Wohnen}

Stardesigner, Superstar

"An dem umtriebigen Franzosen, Phillipe [sic] Starck, mögen sich die Geister scheiden, aber ein Stück vom Superstar Philippe Starck findet sich in nahezu jedem Haushalt. Der Stardesigner engagierte die jungen Talente und nominierte sie bald darauf für den A\&W-Mentorpreis." (ARCHITEKTUR UND WOHNEN ONLINE) [online] http://www.awmagazin.de/ design-style/aw-designer-des-jahres/artikel/radi-designergruppe [10.12.2018]

\section{art Das Kunstmagazin}

Popstar des Designs, Superstar, Superstar des Designs, Stardesigner; 7 Artikel

"Der französische Stardesigner Philippe Starck ist so begeistert, dass [sic] die Lockheed Lounge für das von ihm eingerichtete Paramount-Hotel in New York ordert." (ART DAS KUNSTMAGAZIN ONLINE) [online] http:// www.art-magazin.de/div/heftarchiv/2001/9/OGOWTEGWPPOPTPOGWCAOWGCSCSTGWTROTRSH/Der-letzte-Futurist [12.07.2013; nicht mehr im Netz verfügbar] Print-Ausgabe og/2001: 52-59

"Seinen ersten öffentlichen Bau in Paris mußte Philippe Starck gemeinsam mit dem Architekten Luc Arsene-Henry entwerfen zur [sic] $\mathrm{Zu}-$ sammenarbeit war der Star-Designer gezwungen, weil er kein Diplom in Architektur besitzt." (ART DAS KUNSTMAGAZIN ONLINE) [online] http:// www.art-magazin.de/div/heftarchiv/1999/2/OGOWTEGOTTTPWPOGCHORGEOPAAGWTROCPOR/Den-Studenten-gef\%E4llt-ihr-neuesGeb\%E4ude-nicht [12.07.2013; nicht mehr im Netz verfügbar] Print-Ausgabe 02/1999: 117

"Auch später gelang es Daum immer wieder, aktuelle Trends aufzugreifen und zu prägen - zuletzt etwa in Zusammenarbeit mit dem Star-Designer Philippe Starck." (ART DAS KUNSTMAGAZIN ONLINE) [online] http://www. art-magazin.de/div/heftarchiv/1996/4/OGOWTEGOTTAPRPOGCETGWHPTSGWTROEHCE/Glaskunst-aus-B\%F6hmen-zwang-das-Unternehmen-in-die-Knie [12.07.2013; nicht mehr im Netz verfügbar] Print-Ausgabe 04/1996: 127 


\section{STARDESIGNER ODER GESTALTER DES ALLTÄGLICHEN?}

"Schragers Hotels, die meist von Stardesigner Philippe Starck eingerichtet wurden, sorgen in Amerika und Europa für Furore." (ART DAS KUNSTMAGAZIN ONLINE) [online] http://www.art-magazin.de/div/heftarchiv/2001/11/OGOWTEGWPPOOOPOGWCAOWGCSTWOGWTROTAOT/Hotelprojekt-abgesagt [12.07.2013; nicht mehr im Netz verfügbar] Print-Ausgabe 11/2001: 160

»Der französische Stardesigner Philippe Starck will in Mailand ein MiniWindrad für Jedermann vorstellen." (ART DAS KUNSTMAGAZIN ONLINE am 30.04.2008) [online] http://www.art-magazin.de/design/6134/philippe_starck_windenergie [12.07.2013; nicht mehr im Netz verfügbar]

"Wer überhaupt etwas von den gebrüllten Monologen mitbekommen will, muss dem Superstar des Designs schon angestrengt lauschen, mit in den Nacken gelegtem Kopf, stundenlang." (ART DAS KUNSTMAGAZIN ONLINE) [online] http://www.art-magazin.de/div/heftarchiv/2003/5/EGOWTEGWPPEPSPOGWTRWOPEH/Ein-starkes-St\%FCck [05.07.2013; nicht mehr im Netz verfügbar] Print-Ausgabe 05/2003: 95-96

„Es waren Verkaufs-Hits wie dieser, die Philippe Starck das Attribut >Popstar des Designs einbrachten. Er riss die Grenzen zwischen Gestaltung und Unterhaltung mit Wonne nieder. Starck-Objekte wurden in den Medien gefeiert wie neue Platten von Madonna oder Michael Jackson. Mit seinen Auftritten trug der kameraverliebte Franzose das alte Berufsbild des Formgebers, der im graugetünchten Studio verbissen um Funktionalität ringt, endgültig zu Grabe. Den Designer Philippe Starck gab es schon in den Siebzigern - damals arbeitete er als Art Director beim Modeunternehmen Pierre Cardin. Superstar Philippe Starck jedoch ist ein Produkt der postmodern verspielten achtziger Jahre." (ART DAS KUNSTMAGAZIN ONLINE) [online] http://www.art-magazin.de/div/heftarchiv/2003/3/ EGOWTEGWPPEPEPOGWTRWPHHE/Der-Superstar-des-Designs-entdeckt-die-Moral [05.07.2013; nicht mehr im Netz verfügbar] Print-Ausgabe 03/2003: 84-86

\section{Der Spiegel}

Stardesigner, Branchenstar, Rockstar des Designs, Rockstar des modernen Designs; 23 Artikel

"Die Karriere des 38jährigen Parisers, der innerhalb von fünf Jahren vom Nobody zum Branchenstar aufstieg, hat Experten und Konkurrenten gleichermaßen verblüfft. Auch Starck wundert sich gern öffentlich: >Eigentlich habe ich von Ästhetik gar keine Ahnung،, kokettiert er zuweilen. Er wisse weder, was sguter Geschmack noch 'was schön istı." (DER SPIEGEL 16/1987: 240) [online] http://www.spiegel.de/spiegel/print/ d-13522335.html [10.12.2018] 


\section{AM ENDE WAR ES NUR EIN WORT: ZWEI REZEPTIONSSTUDIEN}

mWirklich eindrucksvoll, urteilte Frankreichs Star-Designer Philippe Starck nach einem Rundgang über den spanischen Messestand." (DER SPIEGEL 39/1988: 235) [online] http://www.spiegel.de/spiegel/print/d13531324.html [10.12.2018]

"Philippe Starck, 45, Stardesigner aus Frankreich, fordert französische Architekten und die Bauindustrie heraus. Über das französische Versandhaus '3 Suisses، offeriert er den Bauplan für ein rund 140 Quadratmeter großes Einfamilienhaus, eine >Mischung aus chinesischer Pagode, russischem Landhaus und kanadischer Holzfällerhütter.» (DER SPIEGEL 28/ 1994: 186) [online] http://www.spiegel.de/spiegel/print/d-9285346.html [10.12.2018]

"SPIEGEL: Warum sucht ein Stardesigner die Volksnähe? STARCK: Ich interessiere mich nicht für Schlösser, sondern für die Häuser der Armen, die man im Französischen die scabanes nennt: das Haus eines kleinen Fischers, die Häuser der Elendsviertel mit ihren Wellblechdächern. Das sind Häuser, die den Minimalanforderungen genügen, dem Leben Schutz zu gewähren. Ich verachte alles, was dazu dient, Macht und Geld zu zeigen. Und die Macht des Geldes zeigt man im allgemeinen mit dem Schloß. Mein schematisches Haus ist das Gegenteil davon." (MÖNNINGER in: DER SPIEGEL 45/1994: 238) [online] http://www.spiegel.de/spiegel/print/ d-9292081.html [10.12.2018]

"Dabei müßte sich die Ministerin nur ein wenig im dunklen Wald von Rambouillet bei Paris umschauen. Dort hat sich der französische Stardesigner Philippe Starck, 45, ein Holzhaus hingebaut. Nach Möbeln, Haushaltsgeräten und teuren Inneneinrichtungen entwarf Starck erstmals ein Eigenheim: Statt einer Millionärsvilla ist dabei eine ruppige, aber großzügige Urhütte aus Glas und Baumstämmen herausgekommen.« (DER SPIEGEL 45/1994: 236) [online] http://www.spiegel.de/spiegel/print/ d-13684736.html [10.12.2018]

"Schwieriger zu beurteilen ist die Umweltverträglichkeit eines sogenannten Öko-Fernsehers mit einem Gehäuse aus mit giftigem Klebstoff verleimten Sägespänen, wie ihn Star-Designer Philippe Starck ersonnen hat. Wenn das Gerät, ein schnellebiges Spaßprodukt, schrottreif ist, wandert das Innere des angeblichen Öko-Apparates zum Elektronikmüll.« (LAKOTTA in: SPIEGEL SPECIAL 6/1995: 125) [online] http://www.spiegel.de/ spiegel/spiegelspecial/d-9184522.html [10.12.2018]

"Mineralwasserflaschen, Zahnbürsten, Klobürsten, Motorräder, Fernseher, Hotels, Fertighäuser, Nudeln - kaum ein Gebrauchsartikel, dem sich der Stardesigner Philippe Starck, 48, nicht formvollendend gewidmet hätte. Und seine eigene Wenigkeit stilisiert der Franzose seit Jahren zu einer Mischung aus Erfinder, Popstar und Philosoph." (HAGMANN in: SPIEGEL 


\section{STARDESIGNER ODER GESTALTER DES ALLTÄGLICHEN?}

SPECIAL 10/1997: 104) [online] http://www.spiegel.de/spiegel/spiegelspecial/d-8788148.html [10.12.2018]

"Philippe Starck, 49, französischer Stardesigner, debütiert als Modeschöpfer. Seine federleichte elastische Stretchröhre dient ebenso leichtgewichtigen Models als Mehrzweckfummel. Das dehnbare kkleine Schwarzer (Markenname: Starck-Naked) gibt ein schulterfreies Minikleid ab, bei Bedarf auch eine knöchellange Abendrobe mit Spaghettiträgern." (DER SPIEGEL 33/1998: 176) [online] http://www.spiegel.de/spiegel/print/d7960350.html [10.12.2018]

"Sicher wird Philippe Starck wieder was Neues präsentieren, einen taillierten Kleiderschrank vielleicht, irgendein Teil jedenfalls, das sich im Alltag dann als furchtbar unpraktisch erweist. Glücklicherweise geht der Trend auf der Mailänder Möbelmesse (11.4.-16.4.) aber weg vom Star-Designer. Stattdessen bestimmen neue Materialien und Verarbeitungstechnologien die Entwürfe, die auf rund 150 ooo Quadratmetern gezeigt werden." (KUlturSPIEGEL 4/2000: 4) [online] http://www.spiegel.de/spiegel/kulturspiegel/d-16352595.html [10.12.2018]

"Von der Zahnbürste bis zur Bushaltestelle - es gibt kaum einen Alltagsgegenstand, den der Franzose Philippe Starck noch nicht designt hätte. Luxusphantasien wie das voll verspiegelte Badezimmer machten ihn zum >Rockstar des Designs«. Keiner hat das Lebensgefühl der achtziger und neunziger Jahre in eine so aufregende Formensprache gebracht wie der französische Star-Designer und Innenarchitekt Philippe Starck. [...] Übertroffen wird der Designer Starck in seiner eigenwilligen Kreativität und pulsierenden Energie nur noch von dem Innenarchitekten Starck: Als sKulträumer werden seine Ausstattungen schon seit Jahren gefeiert. Und als 1989 die Innenräume des New Yorker Hotels `Royalton` fertig waren, sorgten die komplett verspiegelten Badezimmer dafür, dass er zum >Rockstar des modernen Designsı ausgerufen wurde." (SIEDENBERG in: SPIEGEL ONLINE vom 28. JULI 2000) [online] http://www.spiegel.de/ kultur/gesellschaft/philippe-starck-verzierung-des-alltags-a-87015.html [10.12.2018]

"Erneut hat Stardesigner Philippe Starck ein New Yorker Hotel ausgestattet: Das >Hudson ‘ hat viele winzige Zimmer - und ist doch ein wirrer Geniestreich.« (PAUL in: DER SPIEGEL 47/2000: 278) [online] http://www. spiegel.de/spiegel/print/d-17871161.html [10.12.2018]

»Für die Ausgestaltung des Kristallpalastes, 3000 Quadratmeter groß, hatte Star-Designer Philippe Starck freie Hand erhalten." (DER SPIEGEL 46/2003: 79) [online] http://www.spiegel.de/spiegel/print/d-29136642. html [10.12.2018] 


\section{AM ENDE WAR ES NUR EIN WORT: ZWEI REZEPTIONSSTUDIEN}

Stardesigner Philippe Starck wendet sich von seiner Zunft ab. [...] Stardesigner Philippe Starck hat seine Zunft für überflüssig erklärt: IIch glaube nicht, dass Design sinnvoll ist. Das ist längst völlig unwichtig geworden', sagte der Franzose in einem Gespräch, das in der neuen Ausgabe des manager magazins am Freitag (21.Oktober) erscheint. Auch Konsumenten, die sich bei ihrer Kaufentscheidung ausschließlich an bekannten Labels oder aktuellen Designtrends orientieren, kritisiert Starck heftig: > Die sind schlichtweg dumm.r (PITTNER in: MANAGER MAGAZIN ONLINE vom 20.10.2005) [online] http://www.manager-magazin.de/lifestyle/technik/ a-380395.html [10.12.2018]

"Die Ausstattung der bis zu 540 Quadratmeter großen Lofts: Etagengärten, Sanitäranlagen von Stardesigner Philipp Starck, Sonnenschutzanlage auf der Westseite und ein Doorman-Service rund um die Uhr." (MANAGER MAGAZIN ONLINE vom 09.11.2007) [online] http://www.manager-magazin.de/lifestyle/wohnen/a-516104.html [10.12.2018]

»Der Künstler Salvador Dalí machte das Hotel Le Meurice in Paris berühmt. Stardesigner Philippe Starck gestaltete das Haus nun im Stil des schillernden Gastes." (SISTENICH in: SPIEGEL ONLINE vom 28.03.2008) [online] http://www.spiegel.de/reise/staedte/starcks-designkur-im-meurice-dali-lebt-a-543771.html [10.12.2018]

"Der Lan-Club im 4. Stock der Zwillingstürme an der Straße des Aufbaus des Landes ist der letzte Schrei in Peking. Eingerichtet hat ihn der Pariser Stardesigner Philippe Starck. Hier schaut vorbei, wer zur Hautevolee der Hauptstadt zählen will." (LORENZ in: SPIEGEL SPECIAL 3/2008: 24f) [online] http://www.spiegel.de/spiegel/spiegelspecial/d-57119181.html [10.12.2018]

"Zudem möbeln die Firmen wegen des Flächenmangels immer öfter historische Gebäude auf. So wie im Glockenbachviertel. Dort entstehen bis Ende 2008 in einem unter Denkmalschutz stehenden Gebäude 65 vom Stardesigner Philippe Starck entworfene Luxuswohnungen. Der Großteil davon ist laut dem Baukonzern Vivacon bereits verkauft." (LILL in: MANAGER MAGAZIN ONLINE vom 13.08.2008) [online] http://www.manager-magazin.de/lifestyle/wohnen/a-571505-2.html [10.12.2018]

"Bis Herbst kommenden Jahres soll das Luxushotel in der Nähe des Triumphbogens jetzt renoviert werden. Dafür hat der neue Besitzer Alexandre Allard den französischen Stardesigner Philippe Starck engagiert." (SPIEGEL ONLINE vom 27.06.2008) [online] http://www.spiegel.de/ reise/staedte/abschied-vom-royal-monceau-champagner-zum-glasbrucha-562510.html [10.12.2018] 


\section{STARDESIGNER ODER GESTALTER DES ALLTÄGLICHEN?}

"Ein weiterer Museumsteil wurde vom Stardesigner Philippe Starck entworfen. Für den Großteil des Gebäudes zeichnet aber - Italien lässt grüßen - Alessandro Mendini verantwortlich, ein Architekt, der es bunt und fröhlich liebt." (HEIMANN in: MANAGER MAGAZIN ONLINE vom 17.09.2008) [online] http://www.manager-magazin.de/lifestyle/wohnen/a-578429-3. html [10.12.2018]

"Bei der Ausstattung der Badezimmer wirkt die Firma Duravit aus Hornberg im Schwarzwald mit, die Tausende WCs und Bidets aus Keramik lieferte. Auch ihr Waschtisch sTonner, gestaltet von Stardesigner Philippe Starck, ist tausendfach im Burj Chalifa vertreten. Die gleiche Handschrift tragen die 5000 Armaturen aus der Luxuskollektion >Axor Starck', die von HansGrohe aus dem Schwarzwald geliefert wurden." (MANAGER MAGAZIN ONLINE vom 06.01.2010) [online] http://www.manager-magazin.de/ lifestyle/reise/a-670265-3.html [10.12.2018]

"Pompöser Luxus für Superreiche: In Paris eröffnet am Montag das Royal Monceau nach einer Renovierung durch den Stardesigner Starck. [...] Um sich abzuheben, setzt das neue Royal Monceau ganz auf den weniger klassischen Luxus. Die neuen Eigentümer des 2008 geschlossenen Hauses engagierten den französische [sic] Star-Designer und Innenarchitekten Philippe Starck für die Renovierung des Palasts. (HAASE in: SPIEGEL ONLINE vom 18.10.2010) [online] http://www.spiegel.de/reise/europa/luxushotel-boom-in-paris-20-ooo-euro-pro-nacht-inklusive-gitarre-a-723644. html [10.12.2018]

»Ein prägnantes Beispiel für die Entgrenzung bietet die von Stardesigner Philippe Starck für die Marke Warendorf entworfene >Library: Offene Regalfächer umgeben die Küchenschränke, die sich als solche kaum zu erkennen geben." (ZIMMERMANN in: MANAGER MAGAZIN ONLINE vom 02.03.2011) [online] http://www.manager-magazin.de/lifestyle/artikel/ a-748053.html [10.12.2018]

"Philippe Starck, 63, französischer Star-Designer, nähert sich seinem alljährlichen Burnout. Jeden September, so berichtet es der Gestalter von Uhren, Stühlen oder ganzen Hoteleinrichtungen, sei er so erschöpft, dass er sich in eine Kurklinik am Bodensee begeben müsse. Grund dafür sei das enorme Arbeitspensum, das er im Sommer absolviere, der Jahreszeit seiner Kreativität. Um die 150 Produkte entwirft Starck nach eigenen Worten innerhalb weniger Monate." (DER SPIEGEL 32/2012: 145) [online] http://www.spiegel.de/spiegel/print/d-87649576.html [10.12.2018] 
AM ENDE WAR ES NUR EIN WORT: ZWEI REZEPTIONSSTUDIEN

\section{Der Standard}

Designstar, (der französische) Stardesigner, Star, die Madonna unter den Designern; 14 Artikel

"In den goer-Jahren begann das Driade-Projekt der nicht formalen Wohnung zu reifen, nachdem Stardesigner Philippe Starck Driade zu Weltruhm verhalf." (KNESS-BASTARLI in: DER STANDARD ONLINE vom 27.03.2002) [online] https://derstandard.at/893809/Wald-und-Brand [10.12.2018]

"Ausgesucht wird das Logo von einem Expertenkomitee, den [sic] unter anderen der französische Star-Designer Philippe Starck und die italienische Modeschöpferin Laura Biagiotti angehören." (DER STANDARD ONLINE vom 13.09.2002) [online] https://derstandard.at/1069979/Auf-Logo-Suche [10.12.2018]

"Im Mai 2003 hat die Vivacon AG mit der Immobilien-Entwicklungsgesellschaft des französischen Stardesigners Philippe Starck, der Yoo Ltd. mit Sitz in London, die Yoo Deutschland GmbH gegründet. [...] Philippe Starck gilt als der meist gefeierte und kommerziell erfolgreichste Designer weltweit." (EURO ADHOC in: DER STANDARD ONLINE vom 18.11.2003) [online] https://derstandard.at/1486483 [04.07.2013; nicht mehr im Netz verfügbar] Eine gleichlautende Pressemitteilung findet sich hier: (PRESSRELATIONS PRESSEPORTAL) [online] http://presseservice.pressrelations.de/ standard/result_main.cfm?aktion=jour_pm\&r=140014\&quelle=0\&pfach=1\&n_firmanr_=110380\&sektor=pm\&detail=1 [10.12.2018]

"Sollte es an Geschmacksicherheit [sic], nicht aber an Geld mangeln, kann man aber auch auf diesem Gebiet auf den Stardesigner zählen, der dann aus rund 500 Klassikermöbeln von Größen wie Arne Jacobsen, Le Corbusier oder, genau, Starck das Passende raussucht. [...] Wer in Sachen Wohnen weder ein noch aus weiß, kann sich von Stardesigner Philippe Starck mehr als inspirieren lassen. Gegen Entgelt steht er mit Rat und Tat zur Seite." (HAUSENBLAS und MÜLLER in: DER STANDARD ONLINE vom 02.02.2004) [online] https://derstandard.at/1488757/Was-Phil-will [10.12.2018]

"Das Design kommt vom französischen Star-Designer Philippe Starck." (DER STANDARD ONLINE vom 05.02.2006) [online] https://derstandard. at/2591167/Strabag-baut-fuer-Emir-von-Katar [10.12.2018]

»Der französische Stardesigner Philippe Starck stellte ein Mini-Windrad für jedermann im Rahmen der italienischen Designwoche Green Energy Design in Mailand vor." (DER STANDARD ONLINE vom 07.05.2008) [online] https://derstandard.at/3321994/Mini-Windrad-fuer-die-Terrasse [10.12.2018] 


\section{STARDESIGNER ODER GESTALTER DES ALLTÄGLICHEN?}

„Der Besitzer des >Royal Monceau will nach den Entwürfen des französischen Stardesigners Philippe Starck ein jüngeres Haus aus dem >Royal Monceau machen." (DER STANDARD ONLINE vom 17.06.2008) [online] https://derstandard.at/3379617/Ausverkauf-im-Luxushotel [10.12.2018]

"Der französische Stardesigner Philippe Starck will in Mailand ein Mini-Windrad für jede/r [sic] vorstellen. sSelbst Energie herzustellen wird nun noch einfacher, man benötigt nur ein Stückchen Garten oder eine Terrasse , sagte Starck der französischen Zeitung `Le Figaro über seine sindividuelle, erschwingliche und demokratischer Erfindung."(DER STANDARD ONLINE vom 04.07.2008) [online] https://derstandard.at/3321526/ Ein-Windrad-im-Garten [10.12.2018]

"Sie haben grade zwei großartige Designer genannt - wie wichtig ist es, in Ihrem Metier mit den Stars zusammenzuarbeiten? [Hervorhebung des Verfassers] ALESSI: Ich suche nach dem Talent, dem kreativen Geist, nicht nach dem Ruhm. Und um ehrlich zu sein - der Ruhm eines Designers ist in meinem Geschäft nicht so wichtig, wie man glauben möchte. [...] Zaha Hadid, die Vasen für Sie entworfen hat, schafft doch unglaublich viel Aufmerksamkeit? Design wird doch immer mehr personalisiert - sogar Sofas haben $\mathrm{Na-}$ men. [Hervorhebung des Verfassers] ALESSI: Zum Teil ja. Aber der Beitrag eines Stardesigners oder Architekten ist mittel- bis langfristig kein Indikator für einen guten Verkauf. Das ist meine Erfahrung. Philippe Stark [sic], vor Zaha Hadid der medialste aller Designer, hat viel für mich gemacht. An der Stelle muss ich einwerfen: Kein Mensch wusste, wer Ettore Sottsas [sic] war - verrückt, nicht? Aber zurück zu Starck. Wenn wir ein Produkt eingeführt haben mit dem Claim >Design by Philippe Starck, haben wir trotzdem nicht wesentlich mehr verkauft. [...] Philippe Starck ist die Madonna unter den Designern - er hat sich immer wieder neu erfunden - auch in den Produkten, die er mit Alessi gemacht hat - ist das nicht eine Formel? [Hervorhebung des Verfassers] « (TÖLKE in: DER STANDARD ONLINE vom 13.06.2010) [online] https://derstandard.at/1577836998732/Interview-Der-erste-Eindruck-zaehlt [10.12.2018]

"Der französische Stardesigner Philippe Starck wirbt mit einer Plastiktrinkflasche bei Kindern dafür, Wasser aus der Leitung zu trinken.« (DER STANDARD ONLINE vom 06.10.2010) [online] https://derstandard.at/ 1285200148018/Philippe-Starck-entwarf-Flasche-fuer-Leitungswasser [10.12.2018]

"Das Rätsel der Zusammenarbeit von Steve Jobs und des Stardesigners Philippe Starck ist aufgeklärt: Es geht um einen der wenigen Luxus-Träume, die sich der eher bescheiden lebende Apple-Gründer vor seinem frühen Tod noch erfüllen wollte. Apple-Gründer Steve Jobs hat als todkranker Mann noch an einer Luxus-Yacht gearbeitet, seine Witwe Laurene Powell Jobs bringt das Projekt jetzt zu Ende. Der französische Stardesigner Philippe Starck sei weiterhin daran beteiligt, sagte seine Spreche- 


\section{AM ENDE WAR ES NUR EIN WORT: ZWEI REZEPTIONSSTUDIEN}

rin einem Blog des ,Wall Street Journak.« (DER STANDARD ONLINE vom 17.04.2012) [online] https://derstandard.at/1334530995791/Witwe-vonSteve-Jobs-baut-seine-Yacht-zu-Ende [10.12.2018]

"Das Schiff war auf Antrag des französischen Stardesigners Philippe Starck von einem Gerichtsvollzieher vorübergehend beschlagnahmt worden." (DER STANDARD ONLINE vom 24.12.2012) [online] https://derstandard.at/1355460509852/Millionenstreit-um-Jacht-von-Apple-GruenderJobs-beigelegt [10.12.2018]

»Bei diesem Entwurf bedient sich der Designstar aus Frankreich wie so oft der Übertreibung: Ein überdimensionaler Lautsprecher erinnert an den Trichter eines Grammophons und damit an eine Epoche, die Lichtjahre vom digitalen Zeitalter entfernt scheint." (HILPOLD und DUMBS in: DER STANDARD ONLINE vom 09.06.2004) [online] https://derstandard. at/1649213/Das-geht-auf-den-Sender [10.12.2018]

"Spricht man internationale Designstars auf österreichisches Design an, gibt's oft nur Achselzucken. Philippe Starck nannte gar Friedensreich Hundertwasser." (HAUSENBLAS in: DER STANDARD ONLINE vom 18.02.2011) [online] https://derstandard.at/1577837055432/Interview-mit-MAK-Design-Kurator-Es-geht-ums-Entdecken [10.12.2018]

\section{design report}

Stardesigner, Star, Superstar; 6 Artikel

"Nach dem Studium sind Sie gleich zu Konstantin Grcic gegangen? Zunächst für die Dauer eines Praktikums. Damals war Konstantin noch nicht so bekannt wie heute. Überhaupt war die Designwelt noch nicht so vom Starrummel geprägt. Es gab einen Superstar namens Philippe Starck und die anderen waren halt Designer. Als ich bei Konstantin anfing, hatte er nur einen Mitarbeiter, das war sein damaliger Assistent Stefan Diez." (MEYER in: DESIGN REPORT 05/2009) [online] https://www.designreport. de/Fachartikelarchiv/32038554/Nitzan-Cohen.html [12.07.2013; nicht mehr im Netz verfügbar]

"Das Artfizielle, das einer ,Welt seine Perfektion verleiht, lässt sich im Bad durchgängig inszenieren. Der letzte Star unter den Designern, die dieses Potenzial umzusetzen wussten, war Philippe Starck." (REINHARDT in: DESIGN REPORT 06/2001) [online] https://www.designreport.de/ DRmainfachartikelarchivDetail.asp?artikelid $=1000001215 \&$ objec$\mathrm{t}=\mathrm{DR} \& \mathrm{db}=$ FAArchiv\&AnzahlAnsicht=10\&Ansicht=kurz\&Sortierrichtung=absteigend\&startpage $=689 \&$ searchausgabe $=\&$ searchjahrgang $=\&-$ searchvolltext $=\&$ btnreset $=\&$ thesaurus $=[12.07 .2013$; nicht mehr im Netz verfügbar] 


\section{STARDESIGNER ODER GESTALTER DES ALLTÄGLICHEN?}

"Auch wenn das einzelne Produkt vielleicht gar nicht in Serie geht, öffnet es doch so manche Tür. Wiegand selbst hat sogar Anlaß zu konkreten Hoffnungen. Schließlich besuchte Philippe Starck den Stand von Pool Products. Der Star-Designer war begeistert von dem Regal und will sich um Firmenkontakte bemühen." (WOHLLAIB in: DESIGN REPORT 07+08/1999) [online] https://www.designreport.de/DRMainFachartikelarchivDruckDetail.asp?artikelid $=1000001205 \&$ action $=$ print\&object $=\mathrm{DR} \& \mathrm{db}=\mathrm{FAAr}-$ chiv [12.07.2013; nicht mehr im Netz verfügbar]

»Später verpflichtete Kartell Stardesigner wie Philippe Starck und experimentierte mit transluzenten Materialien und matten Oberflächen." (DESIGN REPORT 02/2013) [online] https://www.designreport.de/DRmain fachartikelarchivDetail.asp?artikelid=33345720\&object $=$ DR\&db=FA-

Archiv\&AnzahlAnsicht=10\&Ansicht=kurz\&Sortierrichtung=absteigend\&startpage $=7 \&$ searchausgabe $=\&$ searchjahrgang $=\&$ searchvolltext $=\& b$ tnreset $=\&$ thesaurus $=[12.07 .2013$; nicht mehr im Netz verfügbar $]$

"Ein Sofa ist ein Sofa und Philippe der Große Starck ist ein Mythos. [...] Zugegeben: Niemand kann und niemand muß täglich das Rad neu erfinden, auch kein Star-Designer. Doch spätestens mit dem Hautgout des Selbstplagiats hört der Spaß auf. Und: Was bleibt vom Bubble Club ohne jede künstlerische Innovation? Ein unpraktisches Sitzmöbel, das gut erfüllt, was Hans und Franz sich unter Design vorstellen und somit eine clevere Marketingidee ist." (GEBERZAHN und QUADEJACOB in: DESIGN REPORT 04/2001) [online] https://www.designreport.de/ drmainfachartikelarchivDetail.asp?artikelid $=1000001077 \&$ object $=\mathrm{dr} \& \mathrm{~d}-$ $\mathrm{b}=$ FAArchiv\&AnzahlAnsicht $=10 \&$ Ansicht $=$ kurz\&Sortierrichtung $=$ abstei gend\&startpage $=659 \&$ searchausgabe $=\&$ searchjahrgang $=\&$ searchvoll text $=\&$ btnreset $=\&$ thesaurus $=[05.07 .2013$; nicht mehr ins Netz verfügbar $]$

»Seit den 8oer Jahren des vergangenen Jahrhunderts, der Blütezeit der Postmoderne, hat das Thema Design sukzessive breitere Bevölkerungsschichten erreicht. Die Karrieren von Stardesignern wie Philippe Starck sind dafür ebenso Beweis wie Regale voller Designhotel-Publikationen oder Design-Guides, die man inzwischen auch in Buchhandlungen von Provinzbahnhöfen findet; Design ist wesentlicher Bestandteil des Lifestyles geworden.(ADAM in: DESIGN REPORT 02/2008) [online] https:// www.designreport.de/DRmainfachartikelarchivDetail.asp?artikelid= 31437633\&object=DR\&db=FAArchiv\&AnzahlAnsicht=10\&Ansicht $=$ suxvhtdg\&Sortierrichtung=absteigend \&startpage $=256 \&$ searchausgabe $=\&-$ searchjahrgang $=\&$ searchvolltext $=\&$ btnreset $=\&$ thesaurus $=[05.07 .2013$; nicht mehr im Netz verfügbar] 


\section{Die Presse}

Stardesigner; 4 Artikel

»Mit seiner Timehouse Project Developement GmbH ist er in Österreich exklusiver Partner von ,Yoo - einer Baumarke, die Stardesigner Philippe Starck 1999 mit einem britischen Developer entwickelt hat.« (MÜLLNER in: DIE PRESSE ONLINE vom 16.11.2007) [online] https://diepresse.com/ home/leben/wohnen/343794/Durchgestylt-von-der-Decke-bis-zum-Boden?from=suche.intern.portal [10.12.2018]

"Bis Anfang nächsten Jahres sollen hier unter dem Namen "Yoo Berlin« 87 Wohnungen mit Größen bis zu 230 Quadratmetern bezugsfertig sein. Der Entwurf stammt vom Berliner Architekten Eike Becker, für die Innenarchitektur zeichnet der Stardesigner Philippe Starck verantwortlich. Das spiegelt sich in den Preisen wider: Für ein Penthouse im neuen Berliner Luxuswohntempel werden 12.500 Euro pro Quadratmeter veranschlagt." (LENOBLE in: DIE PRESSE ONLINE vom 24.08.2012) [online] https://diepresse.com/home/leben/wohnen/1282824/Berlin_Luxus-istkein-Tabu-mehr?from=suche.intern.portal [10.12.2018]

"Das Schiff war auf Antrag des französischen Stardesigners Philippe Starck von einem Gerichtsvollzieher vorübergehend beschlagnahmt wor den. Starck hatte bei den Erben des im vergangenen Jahr gestorbenen Apple-Gurus eine noch offene Zahlung von fast drei Millionen Euro für seinen Anteil an der Planung der fast 80 Meter langen Jacht angemahnt." (DIE PRESSE ONLINE vom 25.12.2012) [online] https://diepresse.com/ home/leben/mensch/1327101/Millionenstreit-um-Jacht-von-Steve-Jobsbeigelegt-?from=suche.intern.portal [10.12.2018]

"Urheber des Ganzen und erprobter Konstrukteur von Hotelatmosphären ist ,Yoo Design`. Ein Studio, das John Hitchcox, ein englischer Immobilienentwickler, gemeinsam mit dem Stardesigner Phlippe Starck 1999 gegründet hat." (DIE PRESSE, Print-Ausgabe vom 03.12.2012) [online] https:// diepresse.com/home/leben/kreativ/1340318/Zu-Gast_Starck-Klimt-undLoos?from=suche.intern.portal [10.12.2018]

\section{Die Welt}

Design-Popstar, Stardesigner; 8 Artikel

"Der Design-Popstar der Postmoderne [...] Philippe Starck, 1949 in Paris geboren, ist einer der wichtigsten zeitgenössischen Designer.« (WELT AM SONNTAG ONLINE vom 04.09.2005) [online] https://www.welt.de/ print-wams/article131652/Der-Design-Popstar-der-Postmoderne.html [10.12.2018] 


\section{STARDESIGNER ODER GESTALTER DES ALLTÄGLICHEN?}

»Immer wieder bleibt man schon beim flüchtigen Durchblättern fasziniert hängen, zum Beispiel bei der skurrilen >Hudson Hotel Bar in New York, die Stardesigner Philippe Starck gestylt hat." (WELT AM SONNTAG ONLINE vom 03.02.2002) [online] https://www.welt.de/print-wams/article600241/Treffpunkte-fuer-Design-Liebhaber.html [10.12.2018]

„Das spektakuläre Design des schneeweißen Schiffs, das einem modernen Kriegsschiff ähnelt, soll der französische Stardesigner Philippe Starck entworfen haben." (DIE WELT ONLINE vom 20.02.2008) [online] https:// www.welt.de/welt_print/article1703003/Megajacht-Sigma-auf-Testfahrtin-der-Foerde.html [10.12.2018]

"Entworfen vom Pariser Stardesigner Philippe Starck, bietet die Superyacht Anlass zu vielen Spekulationen." (HALBE in: DIE WELT ONLINE vom 01.03.2008) [online] https://www.welt.de/welt_print/article1743261/Jelaenger-je-lieber.html [10.12.2018]

"Stardesigner Starck soll Frankreichs Image aufpolieren [...] Frankreich will zur EU-Ratspräsidentschaft nach Angaben des Stardesigners Philippe Starck weg vom Baskenmützen- und Baguette-Image. Für die Zeit an der Spitze der Europäischen Union ab Juli habe die französische Regierung ihn als >Art Director engagiert, sagte Starck. [...] Starck ist seit den 8oer-Jahren einer der bekanntesten Designer weltweit." (DIE WELT ONLINE vom 03.04.2008) [online] http://www.welt.de/welt_print/article 1865600/Stardesigner-Starck-soll-Frankreichs-Image-aufpolieren.html [28.06.2013; nicht mehr im Netz verfügbar]

"Yoo ist eine Immobilienmarke, vor elf Jahren von Immobilienguru John Hitchcox und Stardesigner Philippe Starck ins Leben gerufen." (SMITH in: DIE WELT ONLINE vom 12.09.2010) [online] https://www.welt.de/finanzen/immobilien/article9584816/Millionaere-zieht-es-in-Berliner-Luxus-Wohnungen.html [10.12.2018]

"Die Nutzer von Bus und Metro in Paris fahren ab nächstem Jahr mit einer besonderen Monatskarte: Der Star-Designer Philippe Starck entwarf den neuen Pass in den Farben grau und flieder. Sein Ziel sei eine Karte, auf die die Franzosen stolz sein könnten, sagte der Designer." (WELT KOMPAKT ONLINE vom 26.01.2012) [online] https://www.welt.de/print/ welt_kompakt/vermischtes/article13834294/Aus-aller-Welt-Kompakt. html [10.12.2018]

»Gleich neben dem größten Antiquitätenflohmarkt von Paris hat Stardesigner Philippe Starck gemeinsam mit einem Unternehmer-Ehepaar ein Restaurant eröffnet - mit guter Hausmannskost." (DW EUROMAXX in: DIE WELT ONLINE vom 13.03.2013) [online] http://www.welt.de/reise/ 


\section{AM ENDE WAR ES NUR EIN WORT: ZWEI REZEPTIONSSTUDIEN}

staedtereisen/article114385635/Ein-Restaurant-im-Philippe-Starck-Design.html [28.06.2013; nicht mehr im Netz verfügbar]

\section{Die Zeit}

Stardesigner; 3 Artikel

»Philippe Starck ist der Stardesigner der vergangenen zwei Jahrzehnte. Dennoch sagt er heute: 'Alles, was ich gestaltet habe, ist absolut unnötig." (PRÜFER in: DIE ZEIT ONLINE am 26.03.2008, ZEITMAGAZIN LEBEN NR. 14 vom 27.03.2008) [online] http://www.zeit.de/2008/14/Designer-Starck-14 [10.12.2018]

" Die Schönheitı, sagte der Surrealist André Breton, swird wie ein Beben sein.< Die berühmte Zitronenpresse Juicy Salif des französischen Stardesigners Philippe Starck kann er dabei nicht gemeint haben. Denn erstens schuf Starck dieses Aluminiumobjekt erst 1990, 24 Jahre nach Bretons Tod. Und zweitens ist die Presse alles andere als schön: Sie sieht eher aus wie eine bösartige Spinne. Außerdem ist sie völlig unpraktisch: Ihre spitzen Füße bohren sich in die Arbeitsplatte, es gibt nicht einmal eine Schale, um die Zitronenkerne aufzufangen. Aber sie gilt als eines der wichtigsten Werke von Philippe Starck - und als >Designklassiker،. Weshalb ich mir die Frage stelle, ob Design überhaupt irgendetwas mit Schönheit zu tun hat. Und ich meine: Die Schönheit einer jungen Kellnerin ist ein Höhepunkt allen Designs und ohnehin durch nichts zu übertreffen." (SIEBECK in: DIE ZEIT ONLINE am 31.10.2007, ZEITMAGAZIN LEBEN NR. 45 vom 01.11.2007) [online] http://www.zeit.de/2007/45/Siebeck-45 [10.12.2018]

»Für das Hudson in New York oder das Sanderson in London ließ er von dem französischen Star-Designer Philippe Starck tollkühne Interieurs entwerfen, Stil-Mixturen aus Moderne, High Tech, Barock und Blockhütten-Rustikalität. Sie sollten der perfekte Laufsteg sein für die Jungen, Schönen und Wichtigen, die immerfort nach neuen Styling-Inspirationen gieren." (HANSELMANN in: DIE ZEIT ONLINE am 18.09.2003; Print-Ausgabe NR. 39/2003) [online] http://www.zeit.de/2003/39/Hotel_Hillside_ neu $[10.12 .2018]$

\section{FAZ}

Designstar, Stardesigner; 7 Artikel

»Beim Namen Kartell denken viele Jüngere auch an Philippe Starck, den französischen Stardesigner, der für den Umbruch im Hause Castelli-Luti steht. Den Mann aus Paris holte Luti nach Italien, um dem Unternehmen seine neue Seeler einzuhauchen. Mit Erfolg: Ihm verdankt Kartell sei- 


\section{STARDESIGNER ODER GESTALTER DES ALLTÄGLICHEN?}

nen Bestseller - den Stuhl >Louis Ghost‘, der selbst gut zehn Jahre nach seiner ersten Erscheinung die Designwelt noch heute spaltet. Denn die vorgeblich schlichte Kopie eines barocken Klassikers besteht aus ebenjenem Material, das für viele immer noch etwas von billig hat: Plastik. [...] Luti will Qualität, wenn auch nicht um jeden Preis. Die Idee, dass er einen Designklassiker in jeden Haushalt bringt und sich jeder einen rechten< Starck leisten kann, selbst wenn dieser schon wie >Louis Ghost geadelt ist und in einem Designmuseum steht, findet er mehr als nur charmant." (SCHMITT P. in: FRANKFURTER ALLGEMEINE SONNTAGSZEITUNG NR. 4/2013: 48) [online] https://fazarchiv.faz.net/document?id=FAZN_20130126_2040832\#start [10.12.2018]

"Philipp Starck avancierte mit Pariser Bars und der Einrichtung der Amtswohnung von François Mitterrand zum Stardesigner.« (BARTETZKO in: FRANKFURTER ALLGEMEINE ZEITUNG NR. 118/2009: z6) [online] https:// fazarchiv.faz.net/document?id=FAZ_FD1200905232273203\#start [10.12.2018]

"Das Besondere an dem Projekt: Die Innenarchitektur stammt von dem französischen Stardesigner Philippe Starck, der zudem die Gemeinschaftsflächen, wie zum Beispiel die Lobby, die Flure und Wellness-Areale, entworfen hat. Auch die Grundrisse der Bäder und die Boden- und Wandbeläge hat Starck gestaltet." (HARRIEHAUSEN in: FRANKFURTER ALLGEMEINE SONNTAGSZEITUNG NR. 45/2006: v21) [online] https://fazarchiv.faz.net/ document?id=FAS_So420061112843045\#start [10.12.2018]

"Herr Leffin, verdoppeln Sie bis Ende 2005 den Umsatz? Das ist sicherlich möglich, weil wir nun mit dem Stardesigner Philippe Starck eine neue Nische besetzen - die Designerwohnungen. Das erste Philippe-StarckObjekt am Yachthafen in Hamburg hat ein Volumen von 29 Millionen Euro. Mit Luxusimmobilien ergänzen wir ideal unser Kerngeschäft." (SCHMITT T. in: FRANKFURTER ALLGEMEINE SONNTAGSZEITUNG NR. 25/2004: 44) [online] https://fazarchiv.faz.net/document?id=FAS_SD 1200406202366341\#start [10.12.2018]

"Das momentan ıbeste Projekt،, das der Franzose nach eigenen Angaben bieten kann, dürfen Nori und K gemeinsam zur Schau stellen: Es handelt sich um eine Baby-Flasche, die Starck für die amerikanische Kaufhaus-Kette Target entworfen hat. > Das war eine Sensation<, sagt der Stardesigner, sund für 3,99 Dollar gab's noch eine Rassel im Deckel dazu.« (SCHMITT in: FRANKFURTER ALLGEMEINE SONNTAGSZEITUNG NR. 3 / 2003: 43) [online] https://fazarchiv.faz.net/document?id=FAS_SD1200 301191722675\#start [10.12.2018]

»Der französische Stardesigner Philippe Starck, der den Kunststoffen viel zu verdanken hat, spricht gerne davon, um wieviel ökologischer doch 


\section{AM ENDE WAR ES NUR EIN WORT: ZWEI REZEPTIONSSTUDIEN}

ein Stuhl aus Polypropylen im Vergleich zu einem aus natürlich gewachsenem Holz ist." (SCHMITT P. in: FRANKFURTER ALLGEMEINE ZEITUNG NR. 88/2003: 11) [online] https://fazarchiv.faz.net/document?id=FAZ FD1200304141832909\#start [10.12.2018]

"Reiche und Berühmte wie Modezar Gianni Versace flogen auf das Winterquartier mit Sonnengarantie in Floridas Süden, wo Designstar Philippe Starck mit dem Styling nobler Beachhotels die Meßlatte hoch legte." (SACHS in: FRANKFURTER ALLGEMEINE SONNTAGSZEITUNG NR. 34/2005: 55) [online] https://fazarchiv.faz.net/document?id=FAS SD120050828335912\#start [10.12.2018]

\section{NZZ}

Designstar, Stardesigner; 2 Artikel

"Die wegen ihrer kristallenen Transparenz berühmten Stühle >La Marier von Philippe Starck haben plötzlich Farbe angenommen; immer noch durchsichtig, erstrahlen sie nun am Messestand von Kartell in Pastelltönen von Lila bis Rosa. Und mit dem neuen Sessel `Ero/s/^ mit eiförmiger Sitzfläche im Stil der Seventies doppelt der französische Stardesigner gleich noch nach. Die Sessel sind in durchsichtig glänzendem Polykarbonat in kräftigen Farben, aber auch - hier lassen ein weiteres Mal die siebziger Jahre grüssen - in den lange verpönten Rauchglastönen zu haben." (MEIER in: NEUE ZÜRCHER ZEITUNG ONLINE am 14.04.2001) [online] https://www.nzz.ch/article7BOYU-1.487232 [10.12.2018]

"Dies seien nicht einfach die Spielereien eines Designers, kommuniziert man beim Auftraggeber Yachtplus. Vielmehr würden darüber hinaus auch höchste Ansprüche an den Schiffsbau erfüllt. Auch der französische Designstar Philippe Starck legt Wert darauf, zu betonen, dass die Superjacht A, die er für den russischen Industriellen Andrei Melnitschenko entworfen hat, nicht einfach aus einer Laune heraus der Form einer Welle entspreche, sondern weil sie damit weniger Treibstoff verbrauche und zudem der Jacht jene Vulgarität nehme, die solche Protz-Boote sonst so an sich hätten." (STREIFF CORTI in: NEUE ZÜRCHER ZEITUNG ONLINE am 10.07.2011) [online] https://www.nzz.ch/design_ahoi-1.11285162 [10.12.2018] 


\section{STARDESIGNER ODER GESTALTER DES ALLTÄGLICHEN?}

\section{SCHÖNER WOHNEN}

Designikone, Designstar, Stardesigner; 10 Artikel

"Für viele von uns ist das Sofa wie ein Nest und zum Mittelpunkt der Wohnung geworden<, sagt Star-Designer Philippe Starck. Und deswegen hat er eines entworfen: >My World.." (SCHÖNER WOHNEN ONLINE) [online] https://www.schoener-wohnen.de/tipps-trends/32902-rtkl-sofa-my-world-von-philippe-starck-individuell-zu-konfigurieren [10.12.2018]

"Zu den Ausstellungsobjekten gehören beispielsweise die ,Vier Jahreszeiten-Entwürfe von Hella Jongerius für die Porzellanmanufaktur Nymphenburg. Auch Arbeiten der Star-Designer Ronan und Erwan Bouroullec, Patricia Urquiola, Philippe Starck und Produkte aus der Feder von Julia Lohmann, Robert Stadler oder Jaime Hayón sind zu sehen.« (SCHÖNER WOHNEN ONLINE) [online] https://www.schoener-wohnen.de/tipps-trends/32447-rtkl-romantisches-design-koelner-museum [10.12.2018]

"Parrothat die Lautsprecher 'Zimku< [sic: Zikmu] im Jahr 2008 von Philippe Starck entwerfen lassen. Jetzt durfte der Stardesigner 'Zimku< [sic] anmalen. Die Lautsprecher kommen in frischen Farben daher." (SCHÖNER WOHNEN ONLINE) [online] http://www.schoener-wohnen.de/news/schoener-wohnen-news/94458-lautsprecher-zimku-von-philippe-starck.html [04.07.2013; nicht mehr im Netz verfügbar] [sic]-Beleg: (www.starck.com) [online] https://www.starck.com/ooDATA/cms/design/attachments/ 2fd56ba46be3co7dac1998dac2fa1248.pdf [10.12.2018]

"Dedon hat für die neue Kollektion Philippe Starck gebeten. Der Stardesigner durfte sich austoben - das Ergebnis ist >Play<. Mit dabei ist ein Sessel zum Abhängen: der Hängesessel >Play`." (SCHÖNER WOHNEN ONLINE) [online] https://www.schoener-wohnen.de/tipps-trends/28110-rtkl-haengesessel-play-von-philippe-starck-fuer-dedon [10.12.2018]

"Die Innenausstattung übernimmt der Stardesigner Philippe Starck. Unterstützt wird er von Architekt Eike Becker und der Peach Property Group.« (scHÖNER WOHNEN ONLINE) [online] https://www.schoenerwohnen.de/tipps-trends/29094-rtkl-yoo-berlin-inspired-starck [10.12.2018]

»Die >Primary< bringt mit leuchtend gelb verspiegelten Glasfronten, mit ihrem dekorativen Schliff und den verspielten Wandapplikationen den Neobarock in die Küche. Zusätzlich hat der Stardesigner bei allen vier Varianten der Reihe sStarck by Warendorf durch freistehende Funktionstische mit hochglänzend verchromten Trompetenfüßen ein markantes Signal seiner Kreativität gesetzt.« (SCHÖNER WOHNEN ONLINE) [online] 


\section{AM ENDE WAR ES NUR EIN WORT: ZWEI REZEPTIONSSTUDIEN}

https://www.schoener-wohnen.de/einrichten/raeume/28743-rtkl-visionaer-kueche-primary-von-philippe-starck-fuer-warendorf [10.12.2018]

"Internationale Stardesigner wie Philippe Starck und Antonio Citterio haben bereits Armaturen für den Hersteller aus dem Schwarzwald entworfen. Doch schon lange vorher hatte Hansgrohe innovatives Design auf den Markt gebracht: Ende der 2oer Jahre wurde die Blechbrause mit Porzellangriff zum Bestseller, in den 6oer Jahren kam selecta، heraus, die erste Handbrause mit verstellbarem Strahl." (SCHÖNER WOHNEN ONLINE) [online] https://www.schoener-wohnen.de/moebel/34267-bstr-die-wichtigstendeutschen-moebelhersteller/115247-img-hansgrohe-die-innovativen\# show [10.12.2018]

"Ein überdimensioniertes, weiches Kopfteil bringt Cassinas Bett ,Volager mit. Entworfen hat das Schlafzimmermöbel Designstar Philippe Starck." (SCHÖNER WOHNEN ONLINE) [online] https://www.schoener-wohnen.de/ tipps-trends/tipp-des-tages/32009-rtkl-bett-volage-von-philippe-starckfuer-cassina [10.12.2018]

"Diese Badezimmerarmatur kommt von Philippe Starck, zeigt die Handschrift des französischen Design-Stars auf den ersten Blick und spart ordentlich Wasser." (sCHÖNER WOHNEN ONLINE) [online] https://www. schoener-wohnen.de/tipps-trends/31980-rtkl-badkollektion-axorstarck-organic-senkt-den-wasserverbrauch [10.12.2018]

»Mr. Impossibler nennt Designikone Philippe Starck seinen Entwurf von einem Stuhl, der jahrelang nicht gebaut werden konnte. Das Material hat nicht gestimmt. Inzwischen hat der Meister zusammen mit Kartell eine Lösung gefunden - und erklärt im Interview, wie es geht." (SCHÖNER WOHNEN ONLINE) [online] https://www.schoener-wohnen.de/tipps-trends/ 29396-rtkl-philippe-starck-im-interview-bei-kartell [10.12.2018]

\section{Süddeutsche}

Stardesigner, Star, der französische Alles-Designer, der selbsternannte König des Designs; 13 Artikel

"Der Star-Designer Philippe Starck baut gerade sein erstes Haus in Deutschland. [...] Wer schon immer wohnen wollte wie Star-Designer Philippe Starck, kann sich diesen Traum in Hamburg erfüllen. [...] Der Star-Designer, der schon dem Paramount Hotel in New York, dem Pariser Café Costes und dem Delano Hotel in Miami zu Weltruhm verhalf, will in Deutschland nur in exponierter Lage bauen. Thomas Becker, Geschäftsführer von Yoo, schwärmt für das Projekt: >Das sind nicht nur Wohnungen mit einer exklusiven Ausstattung. Jede Wohnung ist ein 


\section{STARDESIGNER ODER GESTALTER DES ALLTÄGLICHEN?}

Gesamtkunstwerk, ein Design-Unikat von Philippe Starck.« (HOFFMANN in: SÜDDEUTSCHE ZEITUNG ONLINE am 10.05.2010) [online] http://www. sueddeutsche.de/geld/hamburger-hafencity-starcke-stuecke-zum-wohnen1.564926 [10.12.2018]

»Nun steht das Haus vor der Umwandlung in eine Luxusanlage: Die Wohnungen hat der französische Stardesigner Philippe Starck entworfen, die Quadratmeterpreise erreichen mit bis zu 7000 Euro Spitzenniveau, die ersten Promis aus der Unterhaltungsbranche haben sich eingekauft ein Traum für Investoren. (MAYER in: SÜDDEUTSCHE ZEITUNG ONLINE am 19.05.2010) [online] http://www.sueddeutsche.de/muenchen/serie-ueberdie-not-in-der-grossstadt-die-stadt-des-schoenen-scheins-1.92886o [10.12.2018]

"Der Club nimmt die ganze vierte Etage des Einkaufszentrums ein, fast 6000 Quadratmeter. Der französische Stardesigner Philippe Starck hat die Inneneinrichtung entworfen." (VOUGIOUKAS in: SÜDDEUTSCHE ZEITUNG ONLINE am 17.05.2010) [online] http://www.sueddeutsche.de/ wirtschaft/generationswechsel-in-familienfirmen-chinas-naechste-mitte-1.480625 [10.12.2018]

«Der Besitzer des >Royal Monceau< ist seit vergangenem Jahr der Jungmilliardär Alexandre Allard, der sein Vermögen mit dem Internet gemacht hat. Er will ein jüngeres Haus aus dem >Royal Monceau machen, nach dem Entwurf des französischen Stardesigners Philippe Starck." (SÜDDEUTSCHE ZEITUNG ONLINE am 10.05.2010) [online] http://www.sueddeutsche.de/reise/luxus-hotel-in-paris-alles-muss-raus-1.599196 [10.12.2018]

"Sarkozy ließ im Palais Bourbon palettenweise kleine Aktentaschen verteilen, um die Abgeordneten auf den kommende Woche beginnenden französischen Ratsvorsitz der Europäischen Union einzustimmen, wie die Tageszeitung Le Parisien berichtete. In jeder Aktentasche befand sich neben einem Notizblock und einem Stift - eine graue Krawatte. Auch dass Stardesigner Philippe Starck die Halsbinden entworfen hat, machte die Sache nciht [sic] besser:« (SÜDDEUTSCHE ZEITUNG ONLINE am 17.05.2010) [online] https://www.sueddeutsche.de/leben/vip-klick-federline-vs-spears-erbittertes-tauziehen-1.581378-5 [10.12.2018]

"Bei der Innenausstattung haben oft die Frauen das Sagen. Hala Fares, Ehefrau des libanesischen Geschäftsmannes Issam Fares, ließ ihre 65-Meter-Yacht vom Stardesigner Philippe Starck gestalten. Der zierte sich anfangs zwar (,Yachten sind das dämlichste kapitalistische Spielzeug, das man sich vorstellen kann`), erlag aber schließlich doch dem lukrativen Angebot." (ECKARDT in: SÜDDEUTSCHE ZEITUNG ONLINE am 17.05.2010) [online] http://www.sueddeutsche.de/leben/luxus-yachten-wer-hat-dielaengste-1.574214 [10.12.2018] 


\section{AM ENDE WAR ES NUR EIN WORT: ZWEI REZEPTIONSSTUDIEN}

"Wie eine perfekte Symbiose aus edler Erscheinung und hochwertigem Inhalt aussehen kann, hat Stardesigner Philippe Starck vorgeführt. Für die britische Health-Food-Marke OAO entwarf er 1999 eine puristische Bio-Linie für Müsli und Hülsenfrüchte, Schachteln aus recyceltem Karton, in die er das Markenlogo prägte." (HERWIG in: SÜDDEUTSCHE ZEITUNG ONLINE am 27.02.2011) [online] http://www.sueddeutsche.de/leben/oeko-produkte-und-design-zu-schoen-um-bio-zu-sein-1.1064933 [10.12.2018]

»Um sich abzuheben, setzt das neue >Royal Monceau ganz auf den weniger klassischen Luxus. Die neuen Eigentümer des 2008 geschlossenen Hauses engagierten den französische [sic] Star-Designer und Innenarchitekten Philippe Starck für die Renovierung des Palasts." (HAASE in: SÜDDEUTSCHE ZEITUNG ONLINE am 20.10.2010) [online] http://www. sueddeutsche.de/reise/luxushotels-in-paris-euro-pro-nacht-1.1013070 [10.12.2018]

»In der Thalkirchner Straße am Alten Südfriedhof ist das ehemalige Arbeitsamt in eine weitere Nobelunterkunft umgewandelt worden, eingerichtet vom französischen Star-Designer Philippe Starck." (RIEHL in: SÜDDEUTSCHE ZEITUNG ONLINE am 14.03.2011) [online] http://www. sueddeutsche.de/muenchen/muenchen/luxuswohnungen-in-muenchen-trutzburgen-des-wohlstands-1.1002614 [04.07.2013; nicht mehr im Netz verfügbar]

»Am 1. Juli übernimmt Frankreich die EU-Ratspräsidentschaft. Weil sich die Franzosen aber ein Pop-Phänomen zum Staatspräsidenten erkoren haben, wird an diesem Tag ein weiteres Pop-Phänomen mit den Vollmachten eines >Art Directors der französischen EU-Ratspräsidentschaft ausgestattet. Der seit den achtziger Jahren des vorigen Jahrhunderts (gefühlt aber: Jahrtausends) als sStardesigner bekannte Gestalter Philippe Starck sei, so Starck über Starck, dazu bestimmt, seine sehr, sehr markante, sehr interessante, sehr kreative Präsidentschaft der Franzosen auf sozusagen sehr markante, sehr interessante und sehr kreative Weise zu illuminieren." (MATZIG in: SÜDDEUTSCHE ZEITUNG ONLINE am 03.04.2008) [online] http://www.sueddeutsche.de/leben/philippe-starckschafft-die-albernen-bommel-ab-1.264263-4 [10.12.2018]

"Da kommen zu einem Maskenball 500 Menschen, aber nur fünf mit einer Maske auf. Da entsteigt der Star - der französische Alles-Designer Philippe Starck - vor seinem Schloss zu Fanfarenklängen einer Kutsche, und trägt eine schwarze Motorrad-Lederkluft und natürlich keine Maske. sJa! Großartig! Super! Und noch mal! bestöhnt ihn die Fotografenschar. [...] Der selbsternannte >König des Designs läd [sic] in die Thalkirchner Straße 54 ein. Zur Saal-Party und Probe-Wohnungsbesichtigung im ersten und zweiten Stock. Die Gäste begutachteten dort die Einrichtungsvorschläge von Philippe Starck - eine Hand am Rotweinglas und die ande- 


\section{STARDESIGNER ODER GESTALTER DES ALLTÄGLICHEN?}

re in der Hosentasche." (CRONE in: SÜDDEUTSCHE ZEITUNG ONLINE am o8.12.2008) [online] http://www.sueddeutsche.de/muenchen/szenariozum-maskenball-das-ikea-schloss-1.870611 [10.12.2018]

"Ein Stardesigner erobert das bisher streng wissenschaftliche Feld der Astronautik. Jahrzehntelang herrschte hier Funktionalismus, nun könnte ein Pilotensitz zum Designklassiker werden. (sÜDDEUTSCHE ZEITUNG ONLINE am 01.10.2007, Text aus SÜDDEUTSCHE ZEITUNG MAGAZIN NR. 40/2007) [online] http://sz-magazin.sueddeutsche.de/texte/anzeigen/ 3613 [10.12.2018]

»Man könnte meinen, der Stardesigner Philippe Starck würde aus Prinzip nur in Hotels absteigen, die er selbst gestaltet hat, in London also im 'Sanderson oder im 'St. Martins Laner. Zu meinem Erstaunen habe ich neulich erfahren, dass er dort das gleiche Lieblingshotel hat wie ich - das `No. 11 Cadogan Gardens` oder kurz: das >No. 11،. Ehrlich gesagt, so viel Geschmack hätte ich dem Mann gar nicht zugetraut. (TASCHEN in: SÜDDEUTSCHE ZEITUNG ONLINE am 05.07.2006, Text aus SÜDDEUTSCHE ZEITUNG MAGAZIN NR. 27/2006) [online] http://sz-magazin.sueddeutsche.de /texte/anzeigen/1391 [10.12.2018] 


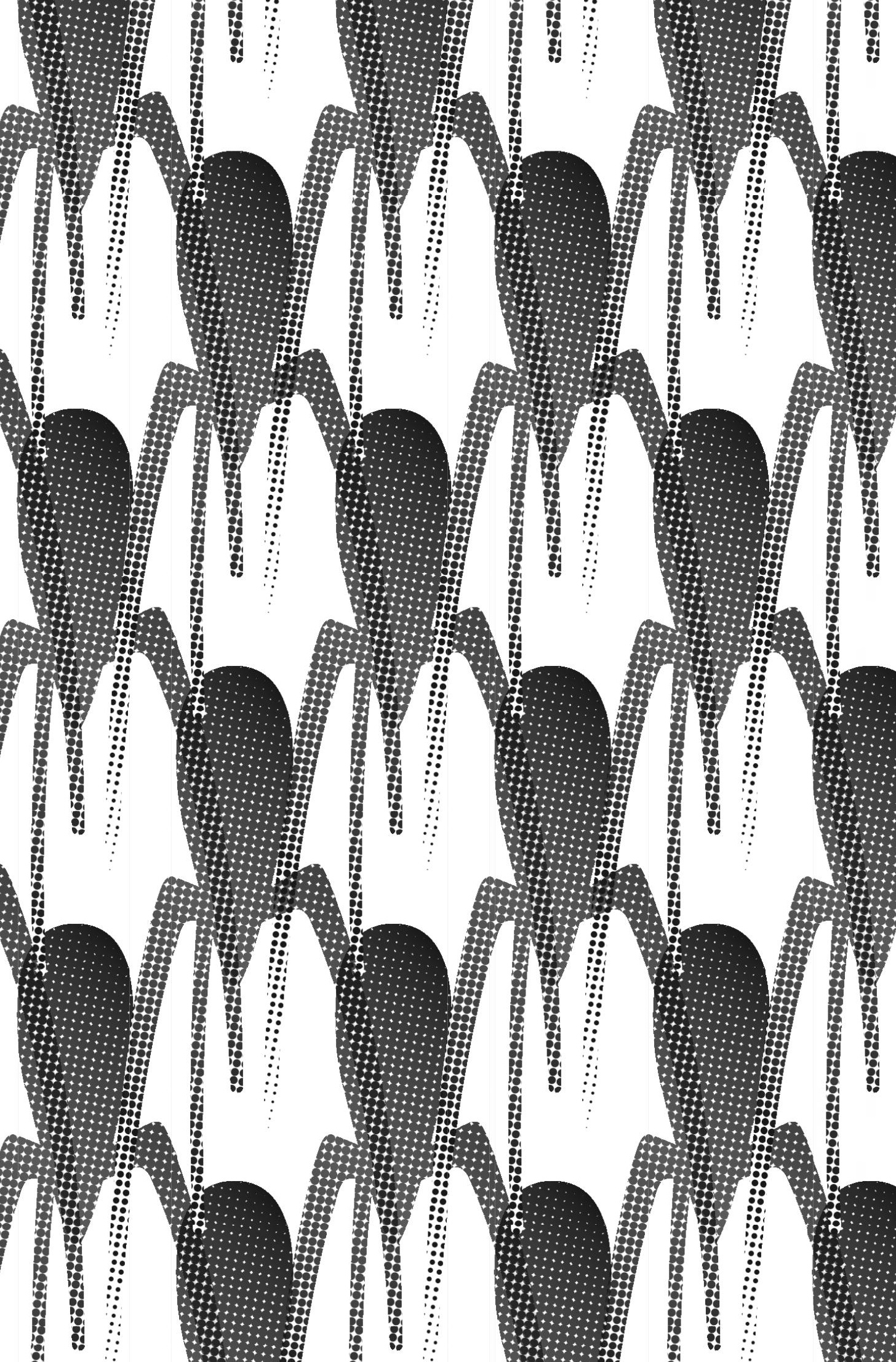




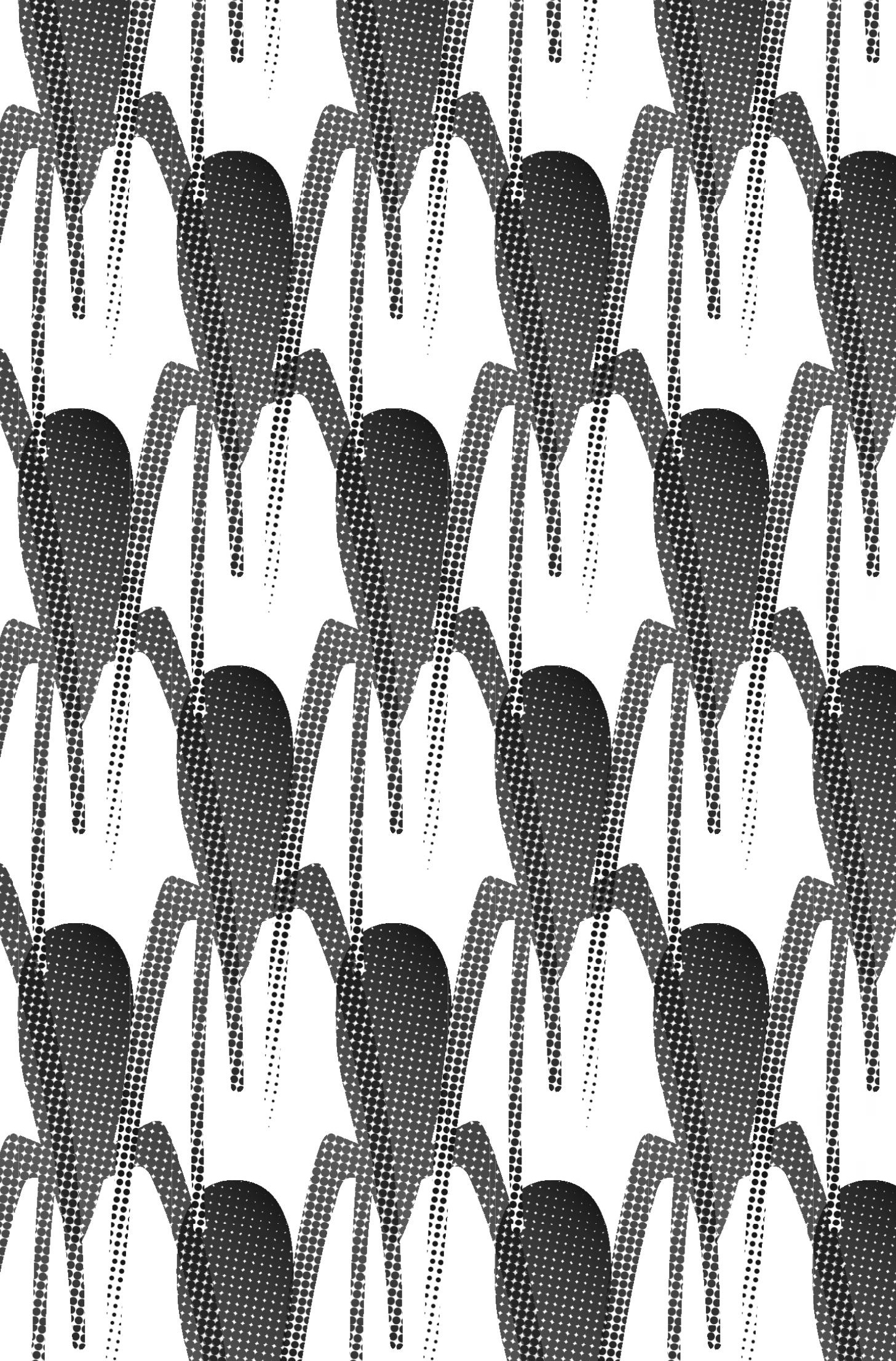




\section{Anhang zu \\ Giorgetto Giugiaro}

\section{Der Spiegel}

Stardesigner, Weltklasse-Designer; 6 Artikel

»Nachdem jedoch Jobs das Ruder wieder übernommen und seinen Motivationsvortrag gehalten hatte, entschied sich Ive zu bleiben. Doch Jobs wollte zunächst einen Weltklasse-Designer von außen holen. Er verhandelte mit Richard Sapper, dem Designer des IBM ThinkPad, und mit Giorgetto Giugiaro, dem Designer des Ferrari 250 und des Maserati Ghibli I.« (ISAACSON in: DER SPIEGEL 41/2011: 79) [online] http://www.spiegel.de/ spiegel/print/d-80818247.html [10.12.2018]

»Hätte zum Beispiel Stardesigner Giorgetto Giugiaro von der Firma Italdesign vor zwei, drei Jahren die Studie eines künftigen Maserati präsentiert - es wäre zweifellos ein flacher Renner geworden." (HAUPT und PAETSCH in: SPIEGEL ONLINE am 02.03.2000) [online] http://www.spiegel. de/auto/fahrberichte/trends-aus-genf-am-anfang-war-der-van-a-67382. html [10.12.2018]

"Die schmalen Lichtbänder am Heck des Coupés tauschte der italienische Star-Designer beim Spyder gegen konventionell-klobige Dreiecksleuchten.« (SPIEGEL ONLINE am 31.07.2001) [online] http://www.spiegel.de/ auto/fahrberichte/maserati-spyder-bulliges-luxus-schnaeppchen-a147802.html [10.12.2018]

"Sogar die italienische Exotenmarke Maserati, bisher nur für elegante Sportwagen und Limousinen bekannt, ließ von Stardesigner Giorgetto Giugiaro einen Zwitter aus Kombi und Geländewagen kreieren." (WÜsT in: DER SPIEGEL 3/2003: 138) [online] http://www.spiegel.de/spiegel/print/ d-26109894.html [10.12.2018]

"Das konturlose Blechkleid - der Croma wird ausschließlich als Kombi angeboten - greift keinerlei Traditionen auf, lässt aber auch keine neue Formensprache erkennen. Star-Designer Giorgetto Giugiaro soll ihn nach einer roriginellen Stilformel (Fiat-Text) geformt haben." (WÜsT in: DER SPIEGEL 16/2005: 196) [online] http://www.spiegel.de/spiegel/print/ d-40077705.html [10.12.2018] 


\section{STARDESIGNER ODER GESTALTER DES ALLTÄGLICHEN?}

»Nach Sommer-, Sport- und Winterreifen haben die Holländer jetzt auch einen markant gestalteten Geländewagen-Pneu vom italienischen StarDesigner Giugiaro entwerfen lassen." (WESSELHÖFT in: SPIEGEL ONLINE am 13.10.2005) [online] http://www.spiegel.de/auto/aktuell/designerreifen-w-wie-wolfgangsee-a-379339.html [10.12.2018]

\section{Der Standard}

Stardesigner

"Der Evanda folgt auf die 1997 eingeführte Mittelklasse-Limo Leganza. Star-Designer Giorgetto Giugiaro durfte Hand anlegen." (DER STANDARD ONLINE am 31.08.2004) [online] https://derstandard.at/1205240/Korea-evandiert?_slide $=2$ [10.12.2018]

\section{Die Welt}

Stardesigner; 4 Artikel

"Ein Luxussportwagen von Stardesigner Giugiaro mit zwölf Zylindern und 500 PS , Die Seele sucht einen Körper, umschreibt Stardesigner Giorgetto Giugiaro die Materialisierung seiner Idee.« (zÖLLTER in: DIE WELT ONLINE am 12.05.2001) [online] https://www.welt.de/print-welt/article 450548/Wenn-Maenner-von-Fahrspass-traeumen.html [10.12.2018]

"Trotz der Namensgleichheit wirkt der 159, er wird in Genf der Öffentlichkeit vorgestellt, auf den ersten Blick eher wie eine Überarbeitung des abgelösten 156. Die Front mit den schlitzartigen Scheinwerfergehäusen entspricht dem neuen, von Stardesigner Giorgetto Giugiaro auch am Sportcoupé Brera verwirklichten Familiengesicht." (IMHOF in: WELT AM SONNTAG ONLINE am 27.02.2005) [online] http://www.welt.de/printwams/article124268/Am-Tuergriff-sollt-ihr-ihn-erkennen.html [10.12.2018]

„Gezeichnet mit zeitlos-eleganten Linien von Stardesigner Giorgetto Giuagario [sic] - dem Couturier des VW Golf I - entwickelte sich der edel ausgestattete Delta zum ersten noblen Kompaktklassemodell für Schöngeister, Kreative und Erfolgsmenschen.« (NICKEL in: PS WELT ONLINE am 02.06.2010) [online] http://www.welt.de/motor/article7884273/DerDelta-brachte-Lancia-Ruhm-und-Rallyesiege.html [10.12.2018]

"Der Panda, Anfang der 8oer Jahre als rollende Kister von Stardesigner Giorgetto Giugiaro bewusst kastenförmig gezeichnet, ist bis heute Synonym für funktionales Design und perfekte Raumausnutzung." (IMHOF in: 


\section{AM ENDE WAR ES NUR EIN WORT: ZWEI REZEPTIONSSTUDIEN}

WELT AM SONNTAG ONLINE am 18.09.2011) [online] https://www.welt.de/ print/wams/motor/article1360568o/Weich-statt-kantig.html [10.12.2018]

\section{Die Zeit}

Stardesigner

"Auch der Turiner Stardesigner Giorgetto Guigiaro [sic], der auch manchen Japan-Modellen zu gefälligen Blechkleidern verholfen hat, warnte jüngst in einem Interview der Wirtschaftszeitung Nihon Keizai Shimbun vor einer Sackgasse beim Versuch, Europas Nobelmarken zu überholen: >Der überhastete Modellwechsel überzeugt den Verbraucher nicht und schadet der Identifizierung des Käufers mit seiner Marke.< Da bleibt Imagebildung leicht auf der Strecke. Wirklicher Fortschritt nicht weniger." (BECKER in: DIE ZEIT 31/1986) [online] http://www.zeit.de/1986/31/den-stern-im-visier/komplettansicht [10.12.2018]

\section{FAZ}

Stardesigner, Designstar; 4 Artikel

"Im Gegensatz zum üblichen Klischee vom italienischen Stardesigner hat Giugiaro nicht nur Luxusware geschaffen, wie die Formen von schnittigen Sportwagen, sondern vor allem die Massenware auf den Straßen geprägt." (PILLER in: FRANKFURTER ALLGEMEINE ZEITUNG NR. 119/2010: 14) [online] https://fazarchiv.faz.net/document?id=FAZ_FD120100526 2714574\#start [10.12.2018]

"Wegen der schlechten Arbeitsmoral an den Fließbändern beauftragte Fiat den Stardesigner Giorgetto Giugiaro mit der Konstruktion eines Kleinwagens, der unempfindlich sein sollte gegen schwankende Fertigungsqua lität. Damit entstand der Fiat Panda, ein Erfolg auf dem Markt." (PILLER in: FRANKFURTER ALLGEMEINE ZEITUNG NR. 155/2009: ug) [online] https:// fazarchiv.faz.net/document?id=FAZ_FD1200907082327381\#start [10.12.2018]

»Die Turiner - von denen Pininfarina und Bertone mit Ständen auf der IAA vertreten sind, während sich andere wie der Stardesigner Giorgetto Giugiaro nur mit einem Rundgang begnügten - erleben höchst unterschiedliche Entwicklungen der verschiedenen Unternehmen, aber auch ihrer drei wichtigsten Sparten Autodesign, technische Entwicklung und Kleinserienproduktion." (PILLER in: FRANKFURTER ALLGEMEINE ZEITUNG NR. 212/2003: 15) [online] https://fazarchiv.faz.net/document?id=FAZ_ FD2200309122016553\#start [10.12.2018] 


\section{STARDESIGNER ODER GESTALTER DES ALLTÄGLICHEN?}

„Das für die Zukunft interessanteste Arbeitsfeld sieht der Stardesigner in China, wo Giugiaro bereits nicht nur einfache Fortbewegungsmittel, sondern auch eine repräsentative Luxuslimousine für einen lokalen Autohersteller entworfen hat. [...] Nach dem in der Vergangenheit oft wiederholten Vorwurf des allzu hausbackenen und wenig italienischen Designs prangt nun sogar an einigen neuen Alfa Romeos der Schriftzug ,Giugiaro Design،, nachdem dort die Form von Front und Hinterteil aufgefrischt wurde. Den Autoren der erfolgreichen Grundform des besagten Alfa Romeo 156, vor einigen Jahren gefeiert als Reinkarnation italienischen Stils, hat die Fiat-Gruppe längst an den Volkswagen-Konzern verloren. Auf diese Weise sucht der Fiat-Konzern nun wenigstens Flagge zu zeigen mit dem Namen des italienischen Designstars und dessen Linien." (PILLER in: FRANKFURTER ALLGEMEINE ZEITUNG NR. 208/2003: 15) [online] https://fazarchiv.faz.net/document?id=FAZ_FD2200309082006919 \#start [10.12.2018]

\section{form}

Stardesigner

"Nachdenken über das, was alles und wie eine Armbanduhr sein kann - Electronic-Designer-Uhren: sT180o von Elektronikrechnerhersteller Texas Instruments und `Tachymeter Sports mit versetztem Digital-Display von dem japanischen Uhrengiganten Seiko, gestaltet von dem italienischen Stardesigner G. Giugiaro." (LEUSCHEL in: FORM 111: 26) [online] http://www.form.de/w3fa.php?nodeId=116\&lang=1\&id=1085\&ausgabe=111\&bildid=9830 [05.07.2013; nicht mehr im Netz verfügbar]

\section{$\mathrm{NZZ}$}

Stardesigner, Turiner Altmeister; 3 Artikel

"Pony hiess der erste Hyundai, der vom italienischen Stardesigner Giorgio [sic] Giugiaro gezeichnet wurde und an der Turiner Motor Show 1975 seine Weltpremiere hatte. Aus dem Pony ist in der Zwischenzeit ein wilder Hengst geworden: Hyundai stürmt mit seinen Modellen über alle Kontinente. Aus dem Unternehmen, das in den ersten Jahrzehnten insbesondere mit preisgünstigen, billig wirkenden Autos Furore machte, ist ein höchst profitabler Konzern mit Qualitätsfahrzeugen geworden, der seit 1998 auch 39 Prozent von Kia besitzt." (EHREnSPERger in: NeUE ZÜRCHER ZEITUNG ONLINE am 11.03.2010) [online] https://www.nzz.ch/magazin/mobil/hyundai_kaempft_sich_aggressiv_nach_vorne-1.5188406 [10.12.2018]

"Der Turiner Altmeister hat ebenso zum spektakulären Turnaround beim Fiat-Konzern beigetragen. Nicht nur die rassigen Alfa-Romeo-Modelle 


\section{AM ENDE WAR ES NUR EIN WORT: ZWEI REZEPTIONSSTUDIEN}

Brera und 159 tragen seine Handschrift. Von Giugiaro entworfen wurde auch der Fiat Grande Punto, ohne dessen Erfolg es der Fiat-Konzern kaum mehr hätte schaffen können. Der Stardesigner gibt sich indessen bescheiden. Eine gewisse Diskretion gehört ja zu seinem Geschäft. Er will nicht einmal beantworten, auf welche seiner bisherigen Kreationen er am meisten stolz ist." (TZERMIAS in: NEUE ZÜRCHER ZEITUNG ONLINE am 29.10.2007) [online] https://www.nzz.ch/kein_erfolg_ohne_gutes_ design-1.576310 [10.12.2018]

"'Die Seele sucht einen Körper, umschreibt Stardesigner Giorgetto Giugiaro die Materialisierung seiner Idee. Blumige Worte für die Identitätssuche der britischen Traditionsmarke Aston Martin. Sie möchte Giugiaro mit dem innovativen Sportwagenkonzept Aston Martin DB 2020 unterstützen." (NEUE ZÜRCHER ZEITUNG ONLINE am 07.08.2001) [online] https:// www.nzz.ch/article7HQMK-1.462183 [10.12.2018]

\section{Süddeutsche}

Stardesigner; 5 Artikel

"Doch auch das Produkt zeugt vom neuen Fiat-Geist, der schon allzu lange auf sich warten ließ. Stardesigner Giorgio [sic] Giugiaro hat sich mächtig ins Zeug gelegt, dem Punto jene Eigenständigkeit anzupassen, die einen Fiat früher als eigenständiges Fahrzeug auswies." (ZÖLLTER in: SZ vom 25.09.1993, SÜDDEUTSCHE ZEITUNG ONLINE am 07.08.2012) [online] http://www.sueddeutsche.de/auto/fiat-punto-aufbruch-in-eine-neueaera-1.611313 [11.02.2019]

"Giorgetto Giugiaro, italienischer Stardesigner und Eigentümer der Firma Italdesign, zeichnete auch diesen Seat mit dem bulligen Heck. Zwar versuchen ein hochgezogenes Heckleuchtenband, mächtige Stoßfänger, die angesetzte Heckschürze und ein aufgeschraubter Flügel das Heck zu gliedern und dessen Wucht ein wenig zu entschärfen. Doch der erste Eindruck bleibt: Der ansonsten eher filigrane Córdoba trägt hinten tüchtig auf. (ZÖLLTER in: SZ vom 18.12.1993, SÜDDEUTSCHE ZEITUNG ONLINE am 17.05.2010) [online] http://www.sueddeutsche.de/auto/seat-crdoba-fuerden-kuehlen-rechner-1.609665 [10.12.2018]

»Mehr als vier Milliarden Mark ließ sich Seat die Forschung und Entwicklung des neuen Modells kosten. Nach acht Millionen Testkilometern stand der Golf-Rivale aus dem eigenen Konzern auf den Rädern. Erneut vom italienischen Star-Designer Giorgio [sic] Giugiaro in Form gebracht, hebt er sich doch ganz entscheidend vonder [sic] Masse seiner rabgerundeten Konkurrenz ab. Wohl folgt Giugiaro dem Kleinwagen-Tend [sic] der rrunden Linien<, doch ein gewisser kantiger Touch ist erfreulicherweise 


\section{STARDESIGNER ODER GESTALTER DES ALLTÄGLICHEN?}

unverkennbar. Das eigenständige Profil firmiert unter dem Begriff svitales, mediterranes Design`." [Modell IBIZA, der Verfasser] (RECKZIEGEL in: SZ vom 08.05.1993, SÜDDEUTSCHE ZEITUNG ONLINE am 17.05.2010) [online] http://www.sueddeutsche.de/auto/seat-ibiza-ein-stolzer-spanier1.616035 [10.12.2018]

"Als wir vor einigen Monaten den BS6 [BRILLIANCE, Ergänzung des Verfassers] getestet haben, beschlichen uns doch Zweifel im Hinblick auf die chinesische Ingenieurskunst. Die 4,8 Meter lange Limousine sieht zwar schick aus (die Karosserie wurde vom italienischen Star-Designer Giugiaro entworfen), das Fahrwerk ist ordentlich gemacht (Porsche half bei der Entwicklung). Und auch wenn der Motor (kommt von Mitsubishi) mit seinen 130 PS für ein Luxusauto etwas schwachbrüstig und mit dem hakeligen Fünfganggetriebe nicht gerade ein Motivationsbündel ist wir sind da schon Schlimmeres gefahren." (VIEHMANN in: SÜDDEUTSCHE ZEITUNG ONLINE am 17.05.2010) [online] http://www.sueddeutsche.de/ auto/neuvorstellung-brilliance-bs-und-bc-brilliance-legt-nach-1.628570 [10.12.2018]

"Als der in kräftigem Leuchtorange lackierte Passat LS im Jahr 1973 vom Band rollte, waren die Lebensretter noch nicht verpflichtend. Kinder tobten sorglos auf der Rückbank herum und Papa kurbelte an einem spindeldürren Volant ohne Pralltopf. Dabei war der VW Typ 32, von StarDesigner Giugiaro quasi als Zubrot zum Golf entworfen, ein Wolfsburger Quantensprung in Sachen Sicherheit, Komfort und Raumgefühl.« (SÜDDEUTSCHE ZEITUNG ONLINE am 10.11.2008) [online] http://www. sueddeutsche.de/auto/autoklassiker-jahre-passat-evolution-eines-zwitters-1.542336 [10.12.2018] 


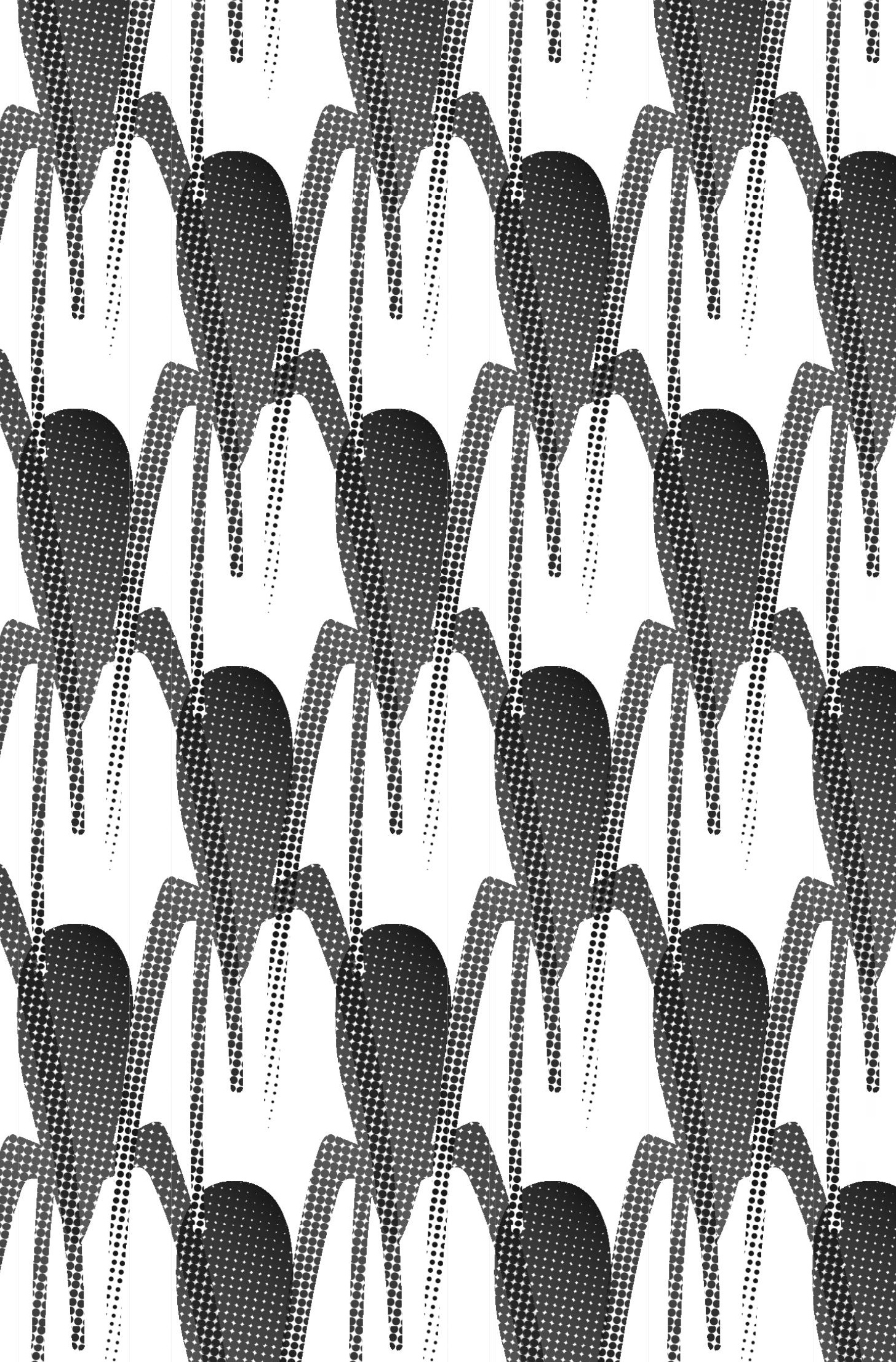




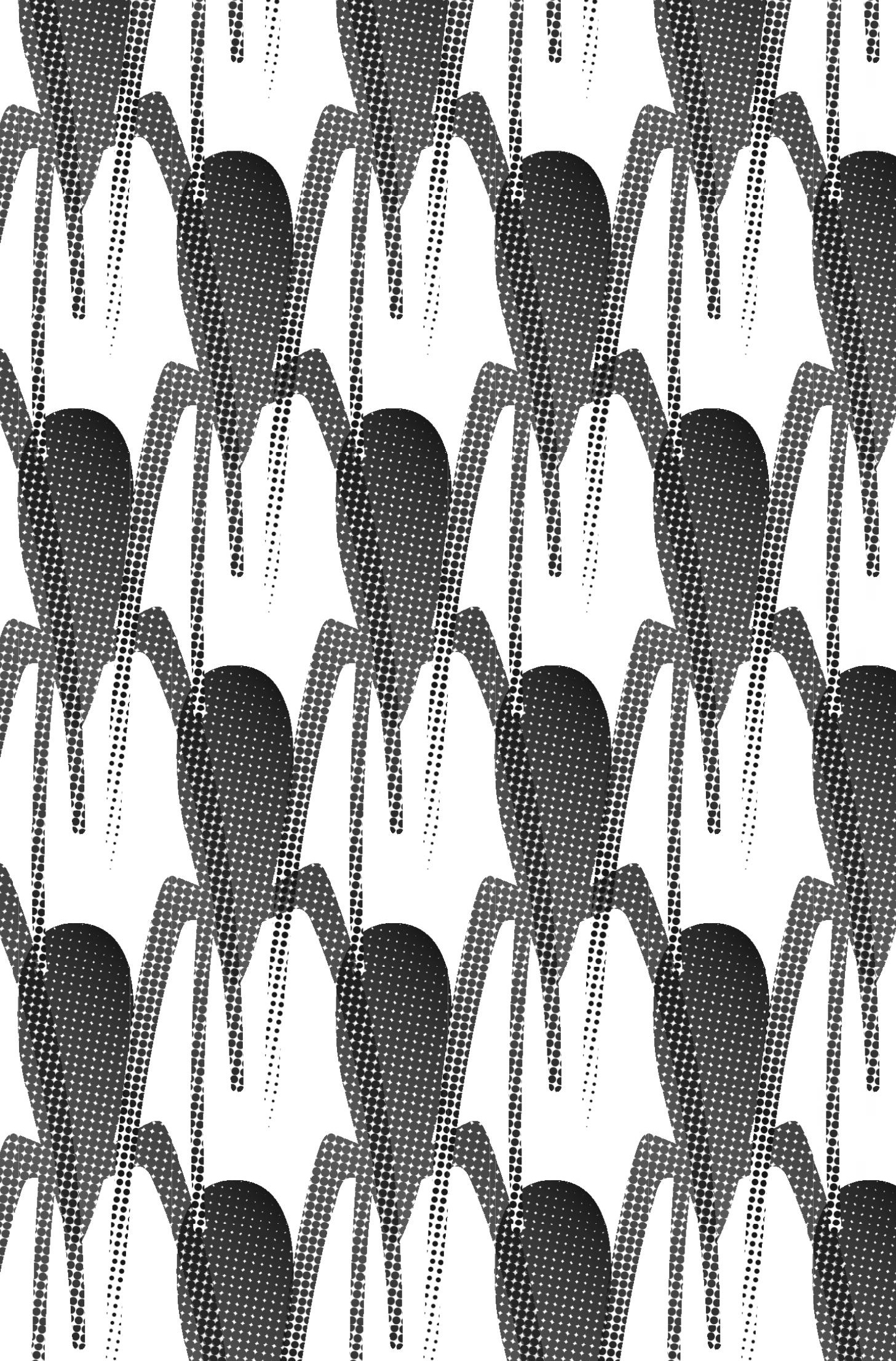




\title{
Anhang zu Jasper Morrison
}

\section{art Das Kunstmagazin}

Stardesigner

\begin{abstract}
"Von neuem Minimalismus war oft die Rede in den neunziger Jahren gemeint waren [sic] die luxuriöse Eleganz von Stardesignern wie Jasper Morrison oder Ron Arad. Erst jetzt wird der Begriff wirklich mit Leben gefüllt. Das Billy-Regal nicht zu verdrängen, sondern zu ergänzen - so viel Realismus hätten die Design-Genies vergangener Zeiten nicht aufgebracht." (SCHLÜTER in: ART DAS KUNSTMAGAZIN 02/2004: 48-52) [online] https://www.art-magazin.de/div/heftarchiv/2004/2/OGOWTEGW PPRPWPOGOASTSGCWOWRGWTRWOATR/Ein-Trio-trotzt-der-Krise [12.07.2013; nicht mehr im Netz verfügbar]
\end{abstract}

\section{Der Spiegel}

Stardesigner

"Der britische Designer Jasper Morrison glaubt, dass >der Niedergang der Moderne an ihrer Humorlosigkeit lag،. Das lässt dieses Mal auf ein lustiges sInternationales Design Jahrbuch hoffen, denn Morrison darf 100 Objekte dafür auswählen und ausstellen. Die Humorprüfung hat beispielsweise die Fliegenklatsche von Philippe Starck bestanden, aber auch ein Teetisch von Achille Castiglioni, ein WMF-Messbecher, Sitzkissen und das Apple eMate. Für die Objekte entwirft der Stardesigner eine Podestlandschaft, hängt Großfotos dazu und beschallt die Installation mit einem Sound-Design." (KULTURSPIEGEL 1/200o) [online] http://www.spiegel.de/spiegel/kulturspiegel/d-15956162.html [10.12.2018]

\section{Der Standard}

Designstar, Star-Gestalter, Antistar des Designs, der zu den absoluten Designstars zählende;

2 Artikel

"Star-Gestalter Jasper Morrison über gerade Linien und Schieflagen So gefragt seine asketischen Kreationen sind, er selbst würde am liebsten hinter ihnen verschwinden: Jasper Morrison ist der Antistar des Designs. Jasper Morrison fällt auf. Nicht auf die Art, wie sonst so viele in sei- 


\section{STARDESIGNER ODER GESTALTER DES ALLTÄGLICHEN?}

nem Business auffallen. Jasper Morrison umgibt kein Glitzer und kein Glamour, er schwingt keine beeindruckenden Reden und er gehört auch nicht zu jenen, deren Äußeres auf den ersten Blick ins Auge sticht. Jasper Morrison fällt auf, weil er so unauffällig ist. Dunkle schwere Hornbrillen und ein Blick, der sich dahinter versteckt, betont einfache Kleidung und ein Körper, der instinktiv eine defensive Haltung einnimmt. Auf die Frage ,Was ist Ihnen peinlich?,, antwortete der zu den absoluten Designstars zählende 44-jährige Brite einmal: ,Öffentlich aufzutreten‘. Fototermine und Interviews: Bitte, nur wenn es unbedingt sein muss. Homestorys und Societyevents: No way.« (HILPOLD in: DER STANDARD ONLINE am 24.06.2004) [online] https://derstandard.at/1698272/Weniger-waehrt-am-laengsten [10.12.2018]

"Ein anderer Weg, das Stigma des langweilig durchschnittlichen Einheitswarenproduzenten abzulegen, führte für Firmen wie Rowenta und Krups über das Engagement von Designstars wie Jasper Morrison oder Konstantin Grcic. Beiden Produktdesignern gelang es, der gemeinen Mittelklassekaffeemaschine die Exklusivität, Intelligenz und Präzision zu geben, die sonst nur ein Oberligamodell hat.« (HAUSENBLAS und BURGER in: DER STANDARD ONLINE am 30.06.2005) [online] https://derstandard.at/ 2095955/Identitaetsfrage-Design [10.12.2018]

\section{Die Welt}

der britische Design-Guru

"Weniger akademisch, aber nicht minder euphorisch äußert sich Grcics Lehrer, der britische Design-Guru Jasper Morrison, über seinen ehemaligen Schüler: 'Das eigentlich Bemerkenswerte an Konstantins Arbeit ist die bewundernswerte Normalität seiner Entwürfe.« (WEIFL in: WELT AM SONNTAG ONLINE am 12.03.2006) [online] https://www.welt.de/ print-wams/article139609/Wer-ist-eigentlich-Konstantin-Grcic.html [10.12.2018]

\section{Die Zeit}

\section{Stardesigner, Superstar des Industriedesigns; 2 Artikel}

"Sie sind nur wenige Fußgängerminuten vom Hauptbahnhof entfernt, gleich daneben steht der expressionistische Backsteinbau von Fritz Höger, vor der Haustür wird vielleicht eine vom englischen Stardesigner Jasper Morrison entworfene Straßenbahn halten, gleich nebenan hausen Journalisten von Zeitung und Fernsehen." (VON RADZIEWSKY in: DIE ZEIT 22/1997) [online] http://www.zeit.de/1997/22/Alchimie_im_Damenbad/ komplettansicht [10.12.2018] 


\section{AM ENDE WAR ES NUR EIN WORT: ZWEI REZEPTIONSSTUDIEN}

"Zeitmagazin: Herr Morrison, Sie sind vor 25 Jahren angetreten mit dem Anspruch, als Designer hinter Ihren Produkten zu verschwinden. Heute sind Sie ein Superstar des Industriedesigns. Was ist eigentlich schiefgelaufen? Jasper Morrison [Hervorhebungen des Verfassers]: Möglicherweise musste ich lernen, dass man heute als Person nicht mehr völlig im Hintergrund bleiben darf, wenn man als Designer erfolgreich sein will. Vielleicht habe ich mit meiner Art zu arbeiten einen Weg gefunden, Aufmerksamkeit für meine Auffassung von Design zu schaffen." (PRÜFER in: ZEITMAGAZIN 22/2010) [online] http://www.zeit.de/2010/22/Einfach-JasperMorrison/komplettansicht [10.12.2018]

\section{FAZ}

Stardesigner

"Als in den wilden Achtzigern der Stuhl schließlich zum Kunstwerk mutierte, gab es kein Halten mehr. Jede Inspirationsquelle - von der Totenba hre bis zum Gebärstuhl - wurde gnadenlos ausgeschöpft. Stardesigner wie Shiro Kuramata, Jasper Morrison oder Ron Arad kreierten nun Stühle wie kafkaeske Drahtkäfige, minimalistische Folterwerkzeuge oder wie amorphe Amöben mit dem Charme eines breitgelutschten Kirschkaugummis." (LEYDECKER in: FRANKFURTER ALLGEMEINE ZEITUNG NR. 14/ 2001: 53) [online] https://fazarchiv.faz.net/document?id=FAZ_FD1200 10117744627\#start [10.12.2018]

\section{NZZ}

Stardesigner

"Für denjenigen, der auch gerne in freier Luft seinen Gedanken nachhängt, hat der englische Stardesigner Jasper Morrison mit dem >Thinking ManOs Chair [sic] die passende Sitzgelegenheit erfunden (Capellini).» (MEIER in: NEUE ZÜRCHER ZEITUNG ONLINE am 24.04.2001) [online] https://www.nzz.ch/article>BR8U-1.490242 [10.12.2018] 
STARDESIGNER ODER GESTALTER DES ALLTÄGLICHEN?

\section{Süddeutsche}

Stardesigner

"Tony Blair sonnte sich im Glanz von Stardesignern wie Tom Dixon, James Dyson, Nick Crosbie oder Jasper Morrison >Cool Britanniar war geniales Marketing. Blair startete eine Charmeoffensive für die Designnation England und stärkte das Design Council mit sechs Millionen Pfund im Jahr." (HERWIG in: SÜDDEUTSCHE ZEITUNG ONLINE am 19.05.2010) [online] http://www.sueddeutsche.de/kultur/cool-germania-provinziell-ineffektiv-teuer-schafft-die-designzentren-ab-1.895759 [10.12.2018] 


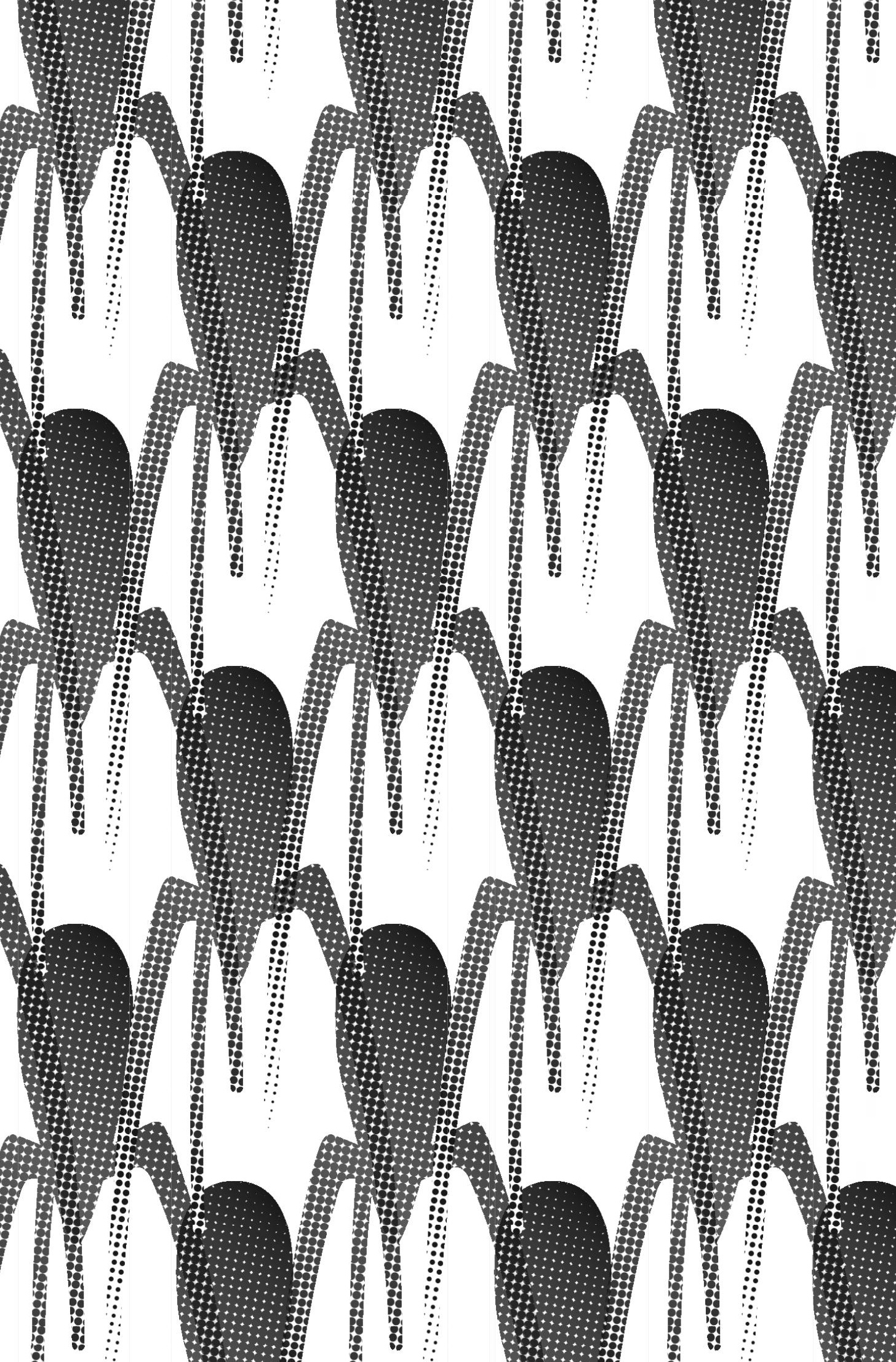




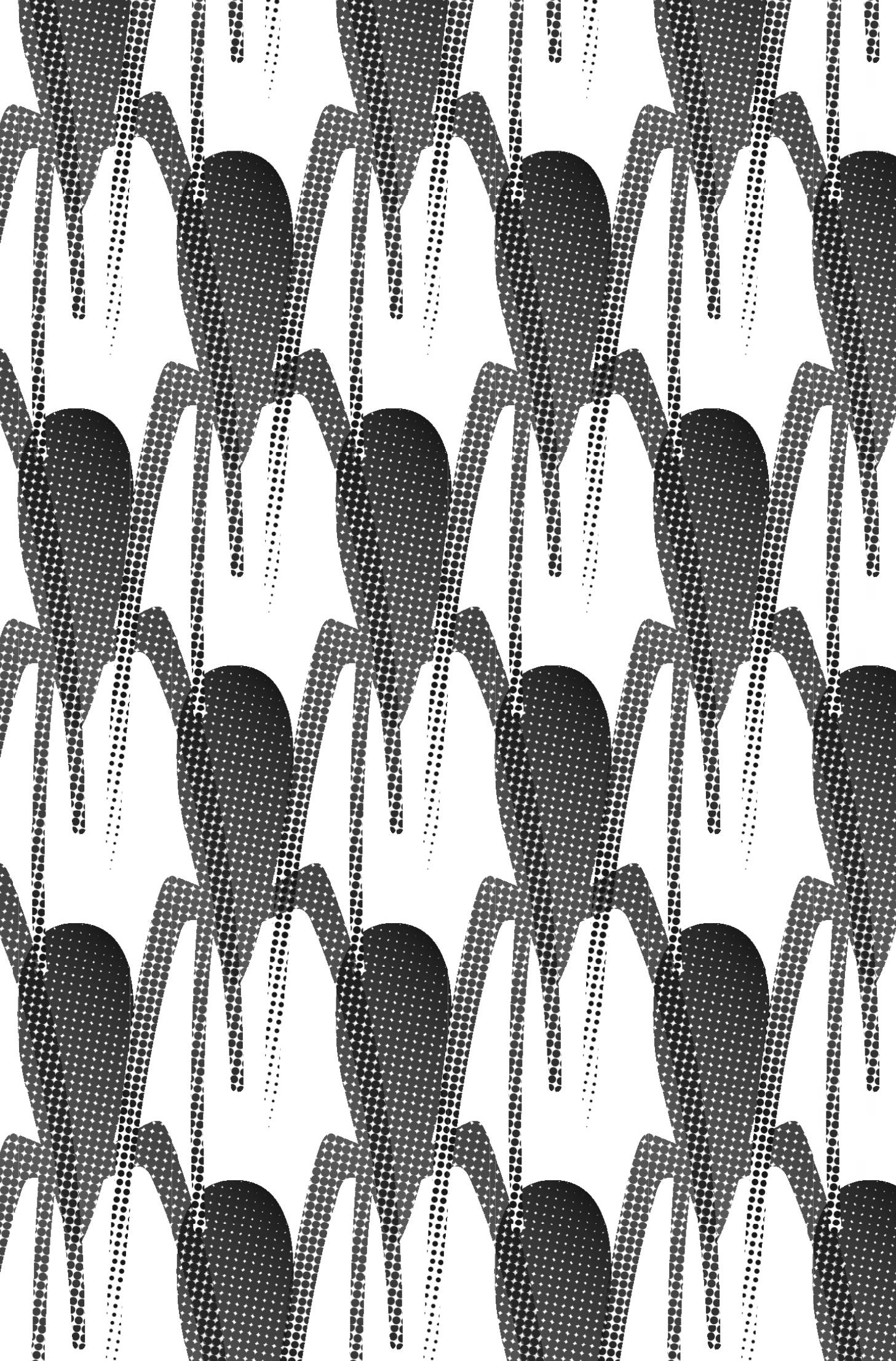




\section{Anhang zu \\ Luigi Colani}

\section{art Das Kunstmagazin}

Stardesigner

"Der DDR-Volkswagen sTrabantı, liebevoll 'Trabi oder auch >Rennpapper genannt, kriegt eins auf die Schnauze. Und zwar von Star-Designer Luigi Colani." (ART DAS KUNSTMAGAZIN 7/2002: 12) [online] http:// www.art-magazin.de/div/heftarchiv/2002/7/OGOWTEGWPPWPCPOGOTPCSGAAAWHGWTRWPEPA/Colani-motzt-die-Rennpappe-auf [12.07.2013; nicht mehr im Netz verfügbar]

\section{Der Spiegel}

Stardesigner; 4 Artikel

"Noch auf der Internationalen Funkausstellung präsentierte RFT mit Stardesigner Luigi Colani einen eiförmigen Fernseher, 1997 waren Gewinne und 200 Millionen Mark Umsatz geplant." (DER SPIEGEL 25/ 1996: 102) [online] http://www.spiegel.de/spiegel/print/d-8939349.html [10.12.2018]

"Alle führenden europäischen Autohersteller gehen mit ihren aktuellen Baureihen an den Start. Blickfang ist dort ein vom Star-Designer Luigi Colani entworfener Lastkraftwagen." (MANAGER MAGAZIN ONLINE am 22.04.2001) [online] http://www.manager-magazin.de/unternehmen/ artikel/a-129762.html [10.12.2018]

»Fertighäuser haben normalerweise das Image spießiger Architektur. Doch einige renommierte Architekten und Stardesigner wie Gustav Peichl, Jette Joop und Luigi Colani zeigen, dass es auch anders geht, und präsentieren ihre extravaganten Varianten." (HOENIG in: MANAGER MAGAZIN am 23.03.2006) [online] http://www.manager-magazin.de/lifestyle/ wohnen/a-406856.html [10.12.2018] 


\section{STARDESIGNER ODER GESTALTER DES ALLTÄGLICHEN?}

"Auch der 'Stardesigner Luigi Colani, an der Phonstärke gemessen Frau Engelen-Kefer absolut ebenbürtig, war schwer zu bremsen in seiner Philippika gegen alles und jedes: die Banken und die Automobilindustrie, Politiker und andere Ahnungslose." (MOHR in: DER SPIEGEL ONLINE am 24.04.2009) [online] http://www.spiegel.de/kultur/gesellschaft/krisentalk-bei-illner-opel-corsa-fuer-alle-a-62086o.html [10.12.2018]

\section{Der Standard}

Stardesigner, Superstar, Visionär der Designwelt

"Luigi Colani galt über Jahrzehnte als Visionär der Designwelt - Für manche ist er mit seinen 20.00o Entwürfen ein Superstar, für andere ein Spinner [...] Der Standard: Sie gelten als einer der ersten Stardesigner. Wie denken Sie heute über diesen Begriff? Colani [Hervorhebungen des Verfassers]: Ich wurde vom Pasadena Art Center College mit dem Visionary Design Award für mein Lebenswerk ausgezeichnet, vom französischen Salon d'Automobile bekam ich den Grand Prix de Design, und das London Design Museum hat mir eine ganze Ausstellung gewidmet. In China nennt man mich den da Vinci des Kunststoffzeitalters ... Ehre, wem Ehre gebührt." (HAUSENBLAS in: DER STANDARD ONLINE am 26.06.2009) [online] https://derstandard.at/1577836915410/Interview-mit-Luigi-ColaniNimm-deine-Maeuse-und-verschwinde [10.12.2018]

\section{Die Presse}

Stardesigner

"Old Europe hatte sich schon in den Siebzigerjahren von dem Erfolgsauto verabschiedet [Der VW KÄFER. Anmerkung des Verfassers], was der Stardesigner Luigi Colani bis heute nicht begreifen will: ,Was bauen die Armleuchter heute für Autos! Die begreifen nicht, dass das einmal ein geniales Auto war! « (SCHEIDL in: DIE PRESSE am 31.03.2010) [online] https:// diepresse.com/home/diverse/zeichen/238620/Wie-gutes-Parfum?from=suche.intern.portal [05.07.2013; nicht mehr im Netz verfügbar]

\section{Die Welt}

(der renommierte) Stardesigner; 6 Artikel

"In Friedrichshafen und in Karlsruhe will sich der Stardesigner mit zwei Millionenprojekten verewigen " (TRUST in: DIE WELT ONLINE am 23.05.2001) [online] http://www.welt.de/print-welt/article452692/Colanimacht-das-Laendle-rund.html [10.12.2018] 


\section{AM ENDE WAR ES NUR EIN WORT: ZWEI REZEPTIONSSTUDIEN}

»Er ist ein Visionär, hat es aber schwer im eigenen Land. Deshalb ist er seit Jahrzehnten auch in Asien aktiv. Die Rede ist von dem 1928 in Berlin geborenen Lutz Colani. Jetzt will der Stardesigner, der sich schon lange Luigi nennt, in Mecklenburg-Vorpommern Autos bauen lassen." (DIE WELT ONLINE am 28.11.2001) [online] http://www.welt.de/print-welt/article489768/Luigi-Colani-will-im-Nordosten-Autos-bauen.html [10.12.2018]

»Total blau: Star-Designer Colani hat für das Outfit der Polizei Großes vor [...] Endlich mal eine Uniform für Hamburgs Polizei, bei deren Anblick die Bürger erzittern! Star-Designer Luigi Colani, dessen Vorfahren schon die kaiserliche Armee in Tuch kleideten, legt sein Goldhändchen an das Lieblingsprojekt von Innensenator Ronald Schill. Weg mit den >Fäkalienfarben<, so der Meister, her mit einer blauen Uniform, sdie brachialisch [sic] und Furcht einflößend sein soll. [...] 500 Euro Kosten pro Uniform dürfen es maximal sein. Star-Designer Colani hat schon mal vorsorglich angekündigt, sich nicht einengen lassen zu wollen. Der Mann braucht Spielraum, weil er schon in drei Monaten die ersten fantastischen Skizzen der blauen Uniformen in einer stollen Ausstellung، präsentieren will." (DIE WELT ONLINE am 23.10.2002) [online] http://www.welt.de/print-welt/ article417776/Die-schaerfste-Uniform-im-Lande.html [10.12.2018]

"Luigi Colani ist von seiner neuesten Kreation begeistert. >Das neue Stadion in Karlsruhe wird eine Weltsensation, ein absolutes Novum. So etwas hat es noch nie gegeben', schwärmt der Stardesigner von seinem Neuentwurf des Wildparkstadions. [...] Die neuen sSuper-Arenen in Hamburg oder Gelsenkirchen sollen bald schon der Vergangenheit angehören, selbst Stadien wie in Amsterdam und Paris sollen veraltet sein im Vergleich zum Projekt des Stardesigners? Colani ist davon überzeugt. [...] Warum sich der renommierte Stardesigner ausgerechnet die Stadt eines Regionalligisten für das weltbewegende Projekt ausgesucht hat? 'Karlsruhe ist eine runde Stadt, das gefällt mir, erklärt der Schweizer [sic], >ich ziehe demnächst auch ganz nach Karlsruhe.< Kritiker sind dagegen der Meinung, Colani hätte mit Ausnahme des noch unerfahrenen Dietrich niemanden von seinen ehrgeizigen Plänen überzeugen können. (WAGNER in: DIE WELT ONLINE am 28.08.2000) [online] http://www.welt.de/ print-welt/article530453/Colani-und-KSC-planen-Stadion-der-Zukunft. html [10.12.2018]

"Stardesigner Colani präsentiert in Hannover Lastwagen der Zukunft« (DIE WELT ONLINE am 12.09.2002) [online] http://www.welt.de/printwelt/article411148/Stardesigner-Colani-praesentiert-in-Hannover-Lastwagen-der-Zukunft.html [28.06.2013; nicht mehr im Netz verfügbar] 


\section{STARDESIGNER ODER GESTALTER DES ALLTÄGLICHEN?}

„Für ihre Plastik aus bunten Spülflaschen zeichnete der Stardesigner Luigi Colani die 23-jährige Julia Berghoff aus Gütersloh mit dem > Großen Hellweg Kreativ-Preis` aus (700o Euro)." (HOFFMANS in: WELT AM SONNTAG ONLINE am 06.10.2002) [online] http://www.welt.de/print-wams/article607712/Kultur-Highlights.html [10.12.2018]

\section{Die Zeit}

Stardesigner, Topdesigner; 2 Artikel

"Doch obwohl die Qualität der Geräte stimmte und Stardesigner Luigi Colani für ansprechende Formen der RFT-Produkte sorgte, scheiterte der schöne Plan. RFT blieb ein No-name im Westen, der Marktanteil kümmerte um ein bis zwei Prozent, und der Umsatz erreichte beispielsweise statt der anvisierten 200 Millionen Mark für das vergangene Jahr gerade 72 Millionen Mark." (BLUETHMANN in: DIE ZEIT 34/1996) [online] http:// www.zeit.de/1996/34/Murks_im_Markt/komplettansicht [10.12.2018]

»Der Bremerhavener Autohändler Jörn Baecker ist auf Luigi Colani nicht mehr gut zu sprechen. Der Topdesigner hatte versprochen, Geländewagen aus Baeckers Importbeständen kostenlos mit einem exklusiven Styling zu versehen. Teure Vorbereitungen wurden getroffen, aber Colani ließ dann nichts mehr von sich hören. Jetzt ist Baecker sauer.« (WETZEL in: DIE ZEIT 09/1990) [online] http://www.zeit.de/1990/og/wartenauf-kolibris [10.12.2018]

\section{FAZ}

Popstar des Designs, Stardesigner; 4 Artikel

»Umgebaut von Stardesigner Luigi Colani, eine Idee von Dietrich, sollte das Wildparkstadion zu einer Arena für Sport, Kultur und Bildung werden. Kostenpunkt: bis zu 90 Millionen Mark." (TRUST in: FRANKFURTER ALLGEMEINE SONNTAGSZEITUNG NR. 24/2001: 20) [online] https://fazarchiv. faz.net/document?id=FAS_SFAS20010617950244\#start [10.12.2018]

„Einen besonderen Umsatzschub verspricht sich Lieven von der Zusammenarbeit mit dem Stardesigner Luigi Colani. Lieven ist zwar nicht der erste, der die Entwurfstalente des Deutschen mit dem italienischen Namen für die Computerindustrie nutzt; bereits auf der Cebit 1992 war eine >Colani-Maus zu besichtigen. Er macht es aber besonders gründlich. Zunächst für fünf Jahre hat er sich Exklusivrechte für PC-bezogene Entwürfe des Designers gesichert." (HIELLE in: FRANKFURTER ALLGEMEINE ZEITUNG 


\section{AM ENDE WAR ES NUR EIN WORT: ZWEI REZEPTIONSSTUDIEN}

NR. 14/1993: 15) [online] https://fazarchiv.faz.net/document?id=FAZ_ F19930118VOBI---100\#start [10.12.2018]

"Zur Steigerung der Aufmerksamkeit hatte Peter Hengstmann, gegenwärtig Vorstandsvorsitzender von RFT, beim Stardesigner Luigi Colani einen höchst individuell gestylten Fernsehempfänger in Auftrag gegeben; er wurde vom Meister persönlich auf der Funkausstellung in Berlin präsentiert. Genützt hat es wenig." (FRANKFURTER ALLGEMEINE ZEITUNG NR. 239/1993: 24) [online] https://fazarchiv.faz.net/document?id=FAZ F19931014RFTAG--100\#start [10.12.2018]

"Hoch aktuell gerade Salvador Dalí als erster Popstar des Jahrhunderts (so oder so ähnlich im Moment fast überall zu lesen), Luigi Colani als der rerste Popstar des Designs (so der SWR), gefolgt vom >Popstar des Kabarettsı (NZZ Online), nämlich Helmut Qualtinger." (REENTS in: FRANKFURTER ALLGEMEINE ZEITUNG NR. 111/2004: 33) [online] https://fazarchiv. faz.net/document?id=FAZ_FD1200405132325574\#start [10.12.2018] 


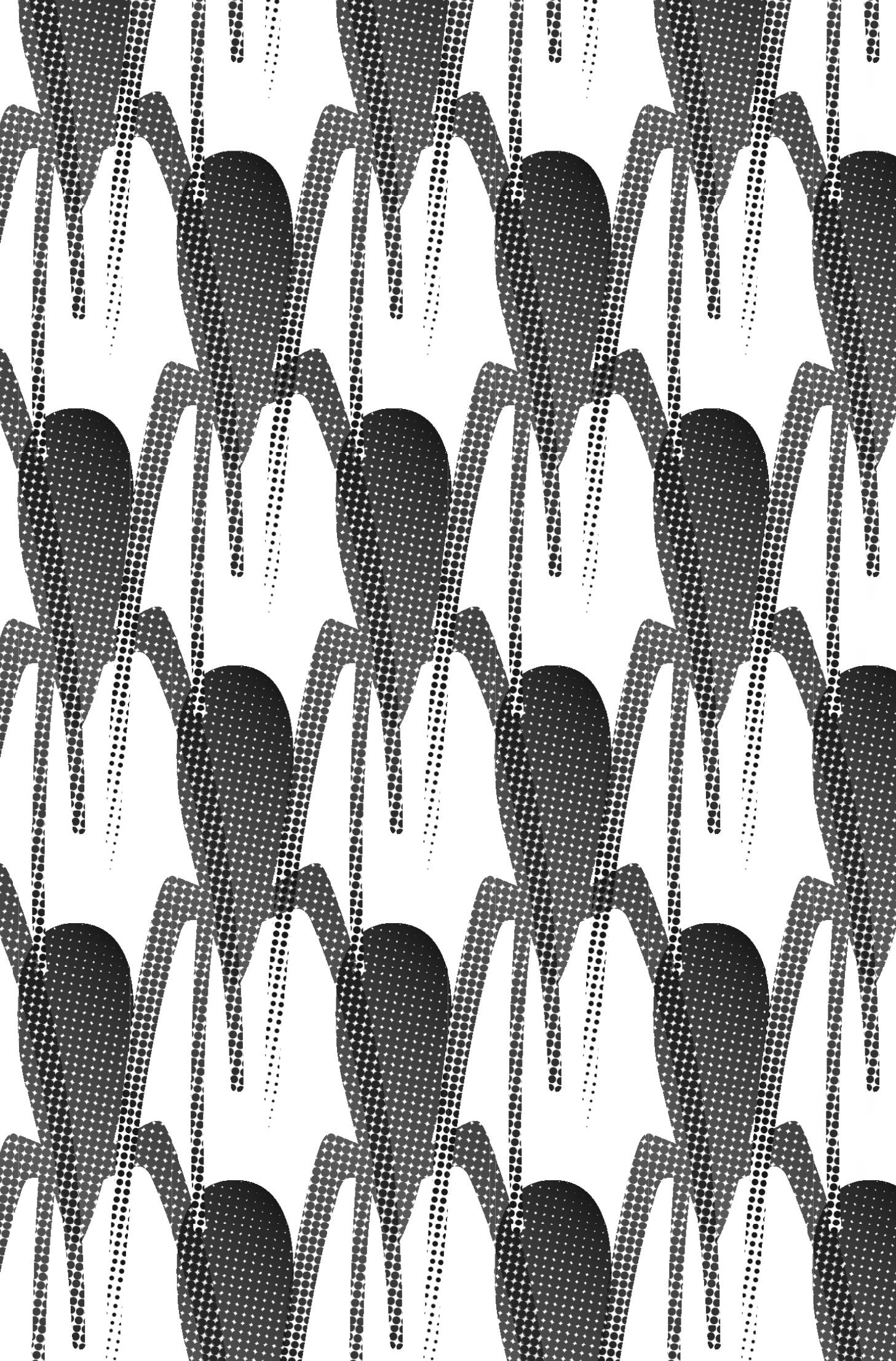




\section{Anhang zu \\ Matteo Thun}

\section{art Das Kunstmagazin}

Stardesigner

»Die gesamte Inneneinrichtung des von Alsop \& Störmer entworfenen Baus stammt vom italienischen Star-Designer Matteo Thun." (ART DAS KUNSTMAGAZIN 03/2001: 9) [online] http://www.art-magazin.de/ div/heftarchiv/2001/3/OGOWTEWPPOPEPOGWCAOWGCSWTHGWT ROHTTS/Design-inklusive [12.07.2013; nicht mehr im Netz verfügbar]

\section{Die Presse}

\section{Stardesigner; 3 Artikel}

"Nun bastelt der Stardesigner an einem neuen Erscheinungsbild der weststeirischen Stainzermilch-Produkte. Warum das Grundnahrungsmittel Milch überhaupt Design benötigen soll, sieht Thun pragmatisch: Österreichische Milch braucht Alleinstellungsmerkmale: Die Qualität der lokalen Molkerei muss im Laden, am Küchentisch, am Arbeitsplatz einen Wiedererkennungswert finden. Schließlich sei Design auch für Klein- und Mittelbetriebe nicht Luxus, sondern eine Möglichkeit, Mehrwert und Profit zu generieren." (BAUMHACKL in: DIE PRESSE ONLINE am 19.12.2003) [online] https://diepresse.com/home/leben/mode/237254/Thun_MeinEcho-nicht-mein-Ego-steht-im-Vordergrund?from=suche.intern.portal [05.07.2013; nicht mehr im Netz verfügbar]

"Julius V. ließ das Meinl-Logo 2004 vom italienischen Stardesigner Matteo Thun auffrischen." (DIE PRESSE ONLINE am 18.03.2006) [online] https://diepresse.com/home/wirtschaft/economist/75335/Portraet_Dereinsame-Kampf-des-Julius-V?from=suche.intern.portal [05.07.2013; nicht mehr im Netz verfügbar]

"Zusätzlich will man mit einer von Stardesigner Matteo Thun entwikkelten neuen Designlinie für die Gastronomie die Kaffeehauskultur dem Zeitgeist anpassen." (SCHUH in: DIE PRESSE ONLINE am 14.06.2012) [online] https://diepresse.com/home/panorama/oesterreich/765966/Meinl_ Ein-PopupKaffeehaus-zum-15oer?from=suche.intern.portal [11.12.2018] 


\section{STARDESIGNER ODER GESTALTER DES ALLTÄGLICHEN?}

\section{Der Standard}

Stardesigner, Star-Gestalter, Star; 4 Artikel

"Auf dem Vigiljoch in Südtirol lockt nun ein höchst unkonventionelles Wellness Hotel, gestaltet von Stardesigner Matteo Thun [...] Irgendwann nahm er im Bestreben, seinen Bettenturm zu vermeiden<, Kontakt auf mit dem ebenfalls in Meran gebürtigen Stardesigner und Architekten Matteo Thun, und es kam - nein, nicht wie es kommen musste, sondern wie es eben kaum jemals kommt: Ein völlig neues Gebäude mit einer Hausphilosophie, so eigenwillig, klar und funktionell wie die Entwürfe Thuns." (PHILIPP in: DER STANDARD ONLINE am 27.10.2003) [online] https:// derstandard.at/1438040/Bergstation-Erholung [11.12.2018]

"Auch die Designerhotels Nhow Hotel und Straf sind Aushängeschilder für Mailand. Der Stardesigner Matteo Thun hat im neuen Designviertel um die Via Tortona einen alten Industriekomplex in ein neues Kreativhotel umgebaut." (KNESS-BASTAROLI in: DER STANDARD ONLINE am 14.03.2001) [online] https://derstandard.at/1297820312291/Viel-Designund-Platz-fuer-neue-Gemuesegaerten [11.12.2018]

"Der Bozener Architekt Matteo Thun hat bei seinen Projekten den >Homo Universalis im Auge und trifft damit den Gusto der Zeit. Jüngstes Glanzstück des Stardesigners ist eine Filiale der Italorestaurantkette Vapiano am Westbahnhof." (PRIESCHING in: DER STANDARD ONLINE am 06.11.2011) [online] https://derstandard.at/1319181958501/Entschleunigung-imFluesterhotel [11.12.2018]

"der standard: Systemgastronomie klingt ganz schön unsexy für einen StarGestalter. matteo thun [Hervorhebungen des Verfassers]: Jeder Gestalter spricht immer von seinem Traum - aber das ist schon lange nicht mehr das Thema. Es geht nicht mehr um Stars, um große Namen. Ich arbeite täglich an der Preisästhetik, an der sbeauty of economy«. Diese Arbeit an Kostenstrukturen generiert eine neue Ästhetik. Das ist natürlich kein Thema, über das gern gesprochen wird. (MÜLLER in: DER STANDARD ONLINE am 02.01.2008) [online] https://derstandard.at/3162716/Der-Preisist-schoen [11.12.2018]

\section{Die Welt}

der international bekannte Designer, Stardesigner, einer der renommiertesten Designer Italiens; 4 Artikel

»Die Einrichtung in Eichenholz und Leder, ergänzt durch einen echten Olivenbaum, ist hochwertig und schick. Gestaltet hat sie der international bekannte Designer Matteo Thun, der in Hamburg auch das 'Si- 


\section{AM ENDE WAR ES NUR EIN WORT: ZWEI REZEPTIONSSTUDIEN}

des-Hotel und das Porsche-Design-Geschäft am Neuen Wall entworfen hat." (DIE WELT ONLINE am 01.11.2007) [online] http://www.welt. de/welt_print/article1319204/Das-dritte-Hamburger-Vapiano-bittet-zuTisch.html [11.12.2018]

"Der Mailänder Stardesigner Matteo Thun, der mit seiner Frau Erica zur Eröffnung kam, zeichnet für das Innenraumkonzept verantwortlich. Die Gäste waren begeistert." (DIE WELT ONLINE am 28.04.2001) [online] http://www.welt.de/print-welt/article448023/Leute-von-Welt.html [11.12.2018]

"St. Barth ist das Lieblingsreiseziel von Italiens Star-Designer Matteo Thun. Hier verrät er, warum [...] Matteo Thun, 49, gebürtiger Südtiroler, ist einer der renommiertesten Designer Italiens. Er lebt in Mailand und hat verschiedenste Alltagsgegenstände entworfen, u. a. für Swatch, AEG und Villeroy \& Boch, außerdem schuf er das Interieur des "Side«-Designhotels in Hamburg." (WELT AM SONNTAG ONLINE am 14.04.2002) [online] http://www.welt.de/print-wams/article6o2386/Sehnsucht-nachKaribik.html [11.12.2018]

"Das ıSider - ein Designhotel der Fünf-Sterne-Kategorie. Der Mailänder Stardesigner Matteo Thun hat hier Hand angelegt. Geschaffen wurde eine 24 Meter hohe Atrium-Hotelhalle mit ausgefeilten Lichtinstallationen, eine gläserne Fassade und ein minimalistisch-sinnliches Innenraumkonzept.« (ELLERMANN in: DIE WELT ONLINE am 13.01.2001) [online] http:// www.welt.de/print-welt/article427944/Mit-Luxushotels-auf-Expansionskurs.html [11.12.2018]

\section{Die Zeit}

Stardesigner

"Sie sagen heute, es gäbe keine klare Handschrift, die die einzelnen Thun-Objekte verbindet. Wie passt das zusammen mit der Chiffre von Matteo Thun, dem Stardesigner? [Hervorhebung des Verfassers] Für mich gibt es zwei fantastische Figuren im Designbereich: den schillernden Luigi Colani und Philippe Starck. Starck besitzt formale Visionen und geniale Kommunikationsfähigkeiten. Seine Handschrift hat einen Wert. Meine Handschrift ist diametral entgegengesetzt. Sie passt sich jeder Marke und Situation an. Heute sind 80 Prozent der Produkte meines Studios nicht mehr »signiert«, sondern verkaufen sich, weil sie Innovationen enthalten.(RENGER in: DIE ZEIT NR. 44/2005) [online] https://www.zeit.de/2005/44/Thun_ LT [14.01.2019] Nicht mehr darstellbar - Fehlermeldung: This page contains the following errors: error on line 5 at column 5: Encoding error Below is a rendering of the page up to the first error. 


\section{STARDESIGNER ODER GESTALTER DES ALLTÄGLICHEN?}

\section{FAZ}

Stardesigner; 4 Artikel

"Mit den spartanischen Studentenbuden vergangener Zeiten haben sie auch nicht mehr viel gemein. Die meisten Apartments werden möbliert vermietet, Stardesigner wie Matteo Thun haben sie eingerichtet." (OBERHUBER in: FRANKFURTER ALLGEMEINE SONNTAGSZEITUNG NR. 42/2011: 48) [online] https://fazarchiv.faz.net/document?id=FAS_SD1201110233 275834\#start [11.12.2018]

"Was daran liegen mag, dass das für den Entwurf verantwortliche Architekturbüro Baumann/Zillich tatsächlich in Berlin sitzt. Den Innenbereich allerdings hat der Südtiroler Stardesigner Matteo Thun gestaltet und zwar mit einer Lust am Minimalismus, wie sie in dieser Landschaft wahrscheinlich nur jemand aufbringen kann, der wie Thun aus einer Familie stammt, die ihr Vermögen aus der Produktion schauderhaft kitschiger Porzellanengelchen bezieht. (MARGUIER in: FRANKFURTER ALLGEMEINE ZEITUNG NR. 248/2008: r1) [online] https://fazarchiv.faz.net/ document?id=FAZ_FRB200810231979617\#start [11.12.2018]

"Das Hotel, für dessen Gestaltung die drei Stardesigner John Seifert (London), Matteo Thun (Mailand) und Adam Tihany (New York) verantwortlich zeichnen, wird im November dieses Jahres eröffnet und bringt dann in den gut erschlossenen Frankfurter Markt noch einmal 428 modernste Zimmer und Suiten." (NOACK in: FRANKFURTER ALLGEMEINE ZEITUNG NR. 245/2005: 22) [online] https://fazarchiv.faz.net/document?id=FAZ _ FD220051021416852\#start [11.12.2018]

„Er ist ein hinreißender Landschaftsfotograf, der die Öffentlichkeitsarbeit der Familie gestaltet und dabei die Idee der Sammeltassen wieder neu belebt hat, ein genial einfacher Einfall. Er hat von dem Stardesigner Matteo Thun ein Tässchen mit einem Tellerchen entwerfen lassen, das er jährlich von einem anderen Künstler bemalen läßt. Diese Sammeltäßchen sind so begehrt, daß sich ihre Produktion mittlerweile zu einem eigenen erfolgreichen Betriebszweig ausgeweitet hat, eine Augenweide, die sich an die Lippen führen läßt." (BADDE in: FRANKFURTER ALLGEMEINE MAGAZIN NR. 924/1997: 10) [online] https://fazarchiv.faz.net/ document?id=FAZM_M9711140013\#start [09.04.2018] 
AM ENDE WAR ES NUR EIN WORT: ZWEI REZEPTIONSSTUDIEN

\section{SCHÖNER WOHNEN}

Designstar, Stardesigner; 2 Artikel

"Er übertrug sehr erfolgreich die Idee, Hotels durch Stardesigner aufzuwerten, mit austauschbaren Raummodulen in die für Investoren attraktive Großserie." (SCHÖNER WOHNEN ONLINE) [online] https://www. schoener-wohnen.de/designer-lexikon/17611-dlxk-matteo-thun\#37998

[11.12.2018]

"So wird die von Design-Star Mattheo [sic] Thun entworfene Leuchte zu einem zeitlos schönen Blickfang, der die Natur ins Wohnzimmer bringt." (SCHÖNER WOHNEN ONLINE) [online] http://www.schoener-wohnen.de/ einrichten/moebel/leuchten/215721-die-schoensten-stehleuchten-6.html\#show [04.07.2013; nicht mehr im Netz verfügbar] Inzwischen ohne begleitenden Text: [online] http://www.schoener-wohnen.de/moebel/ 37419-prkt-stehleuchte-arba [11.12.2018]

\section{Süddeutsche Zeitung}

Stardesigner

"Der Konkurrent GriffnerHaus ist schon vor sechs Jahr auf die Idee gekommen und hat einen berühmten Mann für sich arbeiten lassen. StarDesigner Matteo Thun schuf ein Haus aus Holz und Glas. Auf der Griffner-Homepage heißt es dazu: 'O sole mio<ist mittlerweile das am häufigsten publizierte Fertighaus im deutschsprachigen Raum." (SCHRIMM in: SÜDDEUTSCHE ZEITUNG ONLINE am 17.05.2010) [online] http://www.sueddeutsche.de/geld/jette-joop-als-architektin-eine-villa-von-der-stange$1.564794[11.12 .2018]$ 


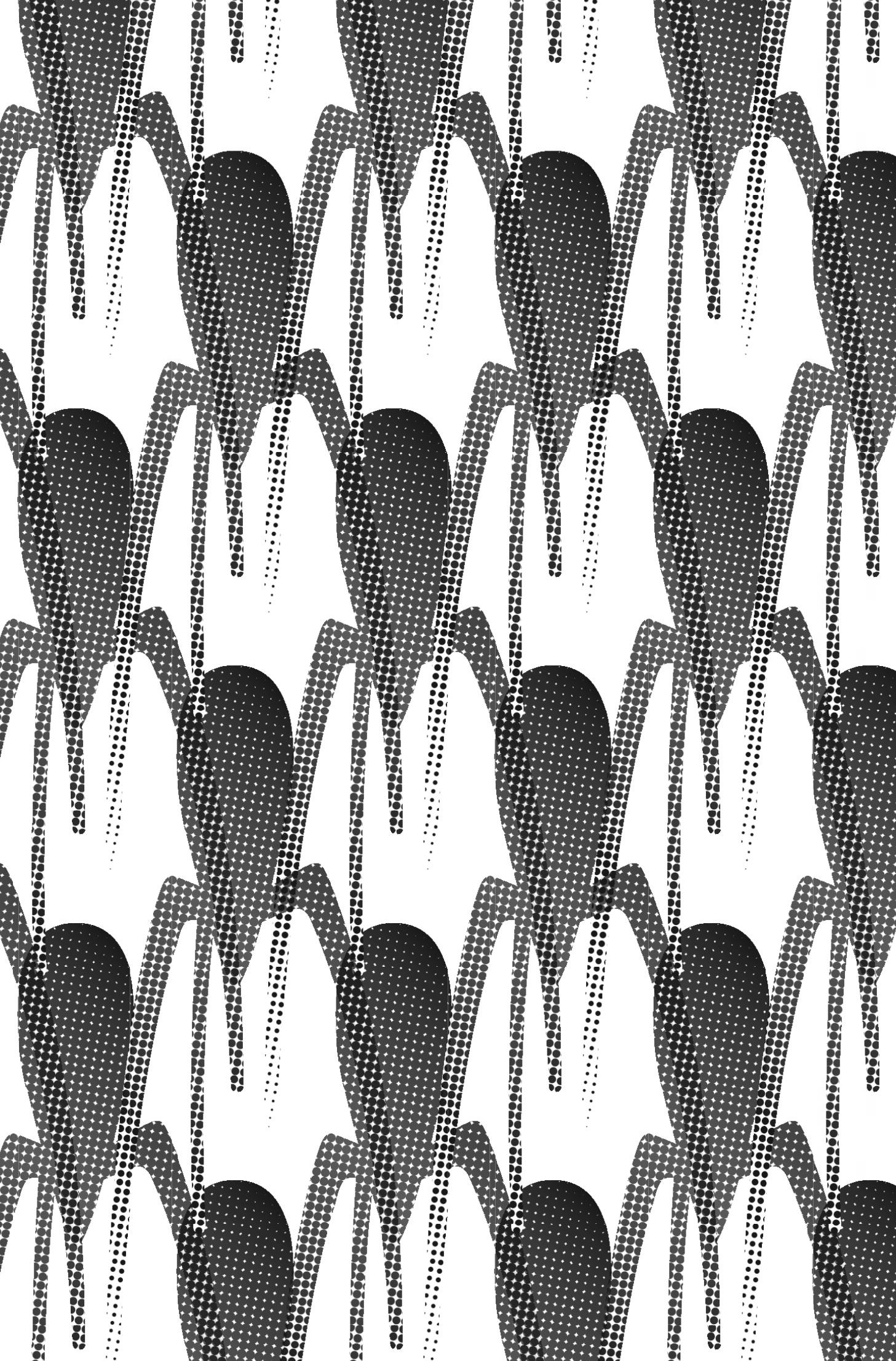




\section{Anhang zu den Gebrüdern Bouroullec}

\section{Architektur und Wohnen}

Stardesigner

»Ausstellung mit Frankreichs Stardesignern Ronan \& Erwan Bouroullec. Im Rahmen der Munich Creative Business Week eröffneten die Neuen Werkstätten am Promenadeplatz 8 in München am 10. Februar 2012 eine exklusive Ausstellung der französischen Stardesigner Ronan und Erwan Bouroullec unter der Schirmherrschaft von Vitra und mit A\&W als Medienpartner." (ARCHITEKTUR UND WOHNEN ONLINE 2012) [online] http:// www.awmagazin.de/design-style/design-news/artikel/ausstellung-mitfrankreichs-stardesignern-ronan-erwan-bouroullec [12.12.2018]

\section{art Das Kunstmagazin}

Shooting Stars der internationalen Designszene

"Die beiden Shooting Stars der internationalen Design-Szene errichten sich selbst ein Denkmal, bevor jemand auf den Gedanken kommen könnte, sie hätten es nicht verdient." (SCHLÜTER in: ART DAS KUNSTMAGAZIN 08/2004: 136) [online] http://www.art-magazin.de/div/heftarchiv/2004/8/OGOWTEGWPPRPHPOGOASTGCWAPCGWTRWWOCC/ Container-mit-Witz [12.07.2013; nicht mehr im Netz verfügbar]

\section{Der Standard}

Designstars, Stardesigner, Topdesigner; 4 Artikel

"Auf den ersten Blick ein ungewöhnlicher Ort, den französischen Designer Ronan Bouroullec zu treffen, der gemeinsam mit seinem Bruder Erwan zu einer Handvoll internationaler Topdesigner gehört. [...] Erwan und Ronan Bouroullec gehören zu den Top Ten des internationalen Designs - RONDO sprach mit Ronan über Ludwig XIV., Hässlichkeit und Bruderzwist" (HAUSENBLAS in: DER STANDARD ONLINE am 26.09.2013) [online] https://derstandard.at/1379291943363/Die-Brueder-Bouroullec-Wir-streiten-fast-immer [12.12.2018] 


\section{STARDESIGNER ODER GESTALTER DES ALLTÄGLICHEN?}

»Ronan ist der ältere der Gebrüder Bouroullec. Über Stardesigner und Arbeitsweisen im Interview mit Michael Hausenblas" (HAUSENBLAS in: DER STANDARD ONLINE am 23.09.2002) [online] https://derstandard.at/ 1075522/Haiku-und-Disney [12.12.2018]

"Vor zehn Jahren gehörte der Outdoor Sessel von Ronan \& Erwan Bouroullec zu einem der ersten Serienprodukte der experimentell arbeitenden französischen Stardesigner. Auftraggeber war die ebenfalls dem Experiment aufgeschlossene Möbelmarke Ligne Roset." (EDELMANN in DER STANDARD ONLINE am 04.02.2011) [online] https://derstandard. at/1577837052030/Moebelmesse-Koeln-Stubenrocker?_artikelIndex=4 [12.12.2018]

»Nun also ein Vorhangsystem. ,Wir mögen es, uns einer Sache zu stellen, die wir noch nicht kennen<, erklärt Ronan Bouroullec. In ihrem Atelier in Paris präsentierten die beiden Designstars vorab das neue Aufhängungssystem, das vor kurzem auf der Kölner Möbelmesse lanciert wurde.« (ESCHBACH in: DER STANDARD ONLINE am 28.01.2013) [online] https:// derstandard.at/1358304373497/Guter-Stoff [12.12.2018]

\section{Die Presse}

Stardesigner

"Für Stardesigner wie sie sind Messen wie die IMM Cologne die Showbühne. Vor allem, wenn sie sich wie in diesem Jahr in die prominente Ehrengalerie der "Designer des Jahres« einreihen." (DIE PRESSE ONLINE 2013) [online] https://diepresse.com/home/leben/kreativ/1332069/DasSchaulaufen-der-Designermoebel?from=suche.intern.portal [12.12.2018]

\section{Die Welt}

Stars der internationalen Designszene

"Die beiden französischen Bouroullec-Brüder gehören zu den Stars der internationalen Design-Szene." (BALLSCHMITER in: DIE WELT ONLINE am 31.03.2013) [online] http://www.welt.de/print/wams/lifestyle/article 114899004/Von-der-Schwierigkeit-der-Einfachheit.html [12.12.2018] 


\section{SCHÖNER WOHNEN}

Designstars, Stardesigner, die französischen Kult-Designer, der berühmte Franzose; 9 Artikel

"Maximale Reduktion wählten die Designstars Ronan und Erwan Bouroullec als Credo bei der Gestaltung von >Pilar. Ihre schlanke Stuhlkollektion ist ab sofort bei Magis zu haben. [...] So wenig wie möglich, so viel wie nötig: >Pilar, das neue Sitzmöbel der Stardesigner Ronan und Erwan Bouroullec, wirkt trotz kleinstem Materialaufwand enorm elegant." (SCHÖNER WOHNEN ONLINE) [online] https://www.schoener-wohnen. de/tipps-trends/32542-rtkl-stuhl-pila-von-den-bruedern-bouroullec [12.12.2018]

"Experten predigen seit Jahren: Computerarbeiter unserer Tage verbringen deutlich zu viel Zeit im Sitzen. Besser: Zwischendurch aufstehen und im Stehen weitermachen. Wie das einfach und bequem gelingen kann, führt uns einer der neuesten Entwürfe der französischen Star-Designer Ronan und Erwan Bouroullec nun mit sTyde vor, ihrem neuen Schreibtisch für Vitra." (SCHÖNER WOHNEN ONLINE) [online] https://www.schoenerwohnen.de/tipps-trends/tipp-des-tages/33024-rtkl-schreibtisch-tydevon-ronan-und-erwan-bouroullec-fuer-vitra [12.12.2018]

"Das Sofa der französischen Stardesigner Ronan \& Erwan Bouroullec zeigt Mut zur Farbe und ist in unserem Beispiel mit einem Stoff in einem Koralleton bezogen." (scHÖNER WOHNEN ONLINE) [online] https://www. schoener-wohnen.de/einrichten/wohnen-mit-farben/34724-bstr-einrichten-mit-rottoenen-von-rosa-bis-koralle/120792-img-modern-rosa-undlachs-zu-holz\#show [04.07.2013; nicht mehr im Netz verfügbar]

"'Osso erinnert an ein zartes Blütenblatt und ist konsequent nachhaltig hergestellt: Der neue Stuhl der Star-Designer Ronan und Erwan Bouroullec soll in Sachen Form und Produktionsprozess Maßstäbe setzen." (SCHÖNER WOHNEN ONLINE) [online] https://www.schoener-wohnen.de/ tipps-trends/32028-rtkl-stuhl-osso-von-ronan-und-erwan-bouroullec [12.12.2018]

»Neues von Hay und den Brüdern Bouroullec: Die Star-Designer haben Stühle, Bänke und Tische für die Universität Kopenhagen entworfen. [...] Gemeinsam mit der dänischen Marke Hay haben die französischen Kult-Designer Ronan und Erwan Bouroullec eine neue Möbelkollektion entworfen.» (SCHÖNER WOHNEN ONLINE) [online] http://www.schoenerwohnen.de/news/tipp-des-tages/215544-moebel-von-den-bouroullecsbald-bei-hay.html [04.07.2013; nicht mehr im Netz verfügbar] 


\section{STARDESIGNER ODER GESTALTER DES ALLTÄGLICHEN?}

»Zu den Ausstellungsobjekten gehören beispielsweise die ,Vier Jahreszeiten«-Entwürfe von Hella Jongerius für die Porzellanmanufaktur Nymphenburg. Auch Arbeiten der Star-Designer Ronan und Erwan Bouroullec, Patricia Urquiola, Philippe Starck und Produkte aus der Feder von Julia Lohmann, Robert Stadler oder Jaime Hayón sind zu sehen." (SCHÖNER WOHNEN ONLINE) [online] https://www.schoener-wohnen.de/ tipps-trends/32447-rtkl-romantisches-design-koelner-museum

[12.12.2018]

"Folio ist Regal und kleiner Schrank zugleich. Entworfen haben es die Star-Designer Ronan and [sic] Erwan Bouroullec für Established \& Sons." (SCHÖNER WOHNEN ONLINE) [online] https://www.schoener-wohnen.de/ tipps-trends/tipp-des-tages/31308-rtkl-regal-zum-zuziehen-bei-established-sons [12.12.2018]

"So wie wir unsere Sachen einfach an einen Felsvorsprung hängen, ehe wir ins Wasser springen, brauchen wir auch im Alltag kleine Möglichkeiten, etwas zu verstauen<, erläutert Star-Designer Ronan Bouroullec. Gemeinsam mit Bruder Erwan hat der berühmte Franzose ,Corniches für Vitra gestaltet." (SCHÖNER WOHNEN ONLINE) [online] https://www. schoener-wohnen.de/tipps-trends/31509-rtkl-mini-regal-cornichesals-flexible-ablage-bei-vitra [12.12.2018]

"Bitte hinlegen: Das Sofa >Ploum Bouroullec, mit organischer Form, niedriger Sitztiefe und Stretch-Stoff war der heimliche Liebling auf dem Ligne-Roset-Stand. Jeder wollte mal probesitzen-und nicht mehr aufstehen." (SCHÖNER WOHNEN ONLINE) [online] https://www.schoener-wohnen.de/einrichten/wohntrends/34481bstr-die-schoensten-sofas-der-imm-2011\#96364-img-sofa-ploum-vonligne-roset [12.12.2018] 


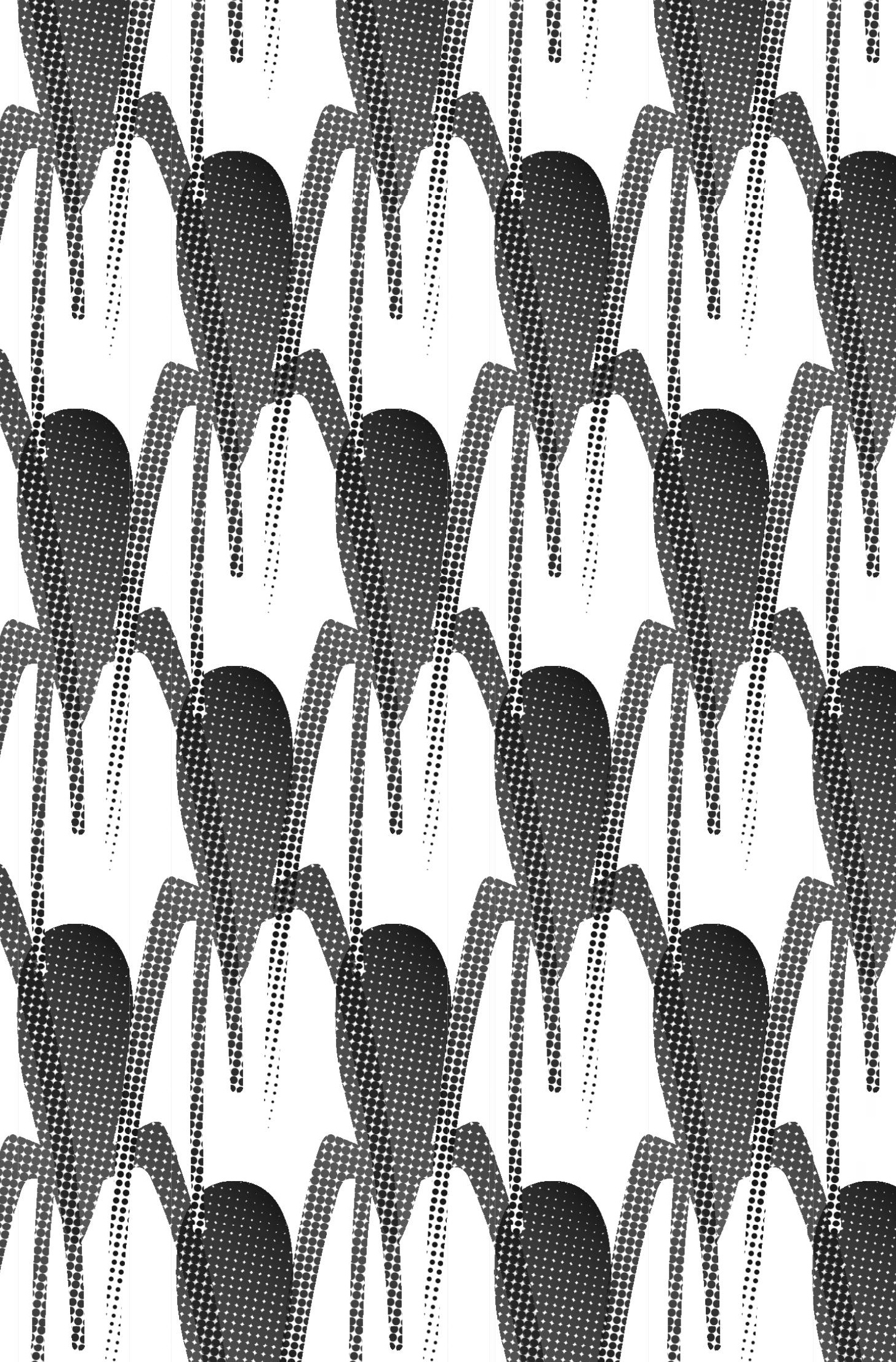




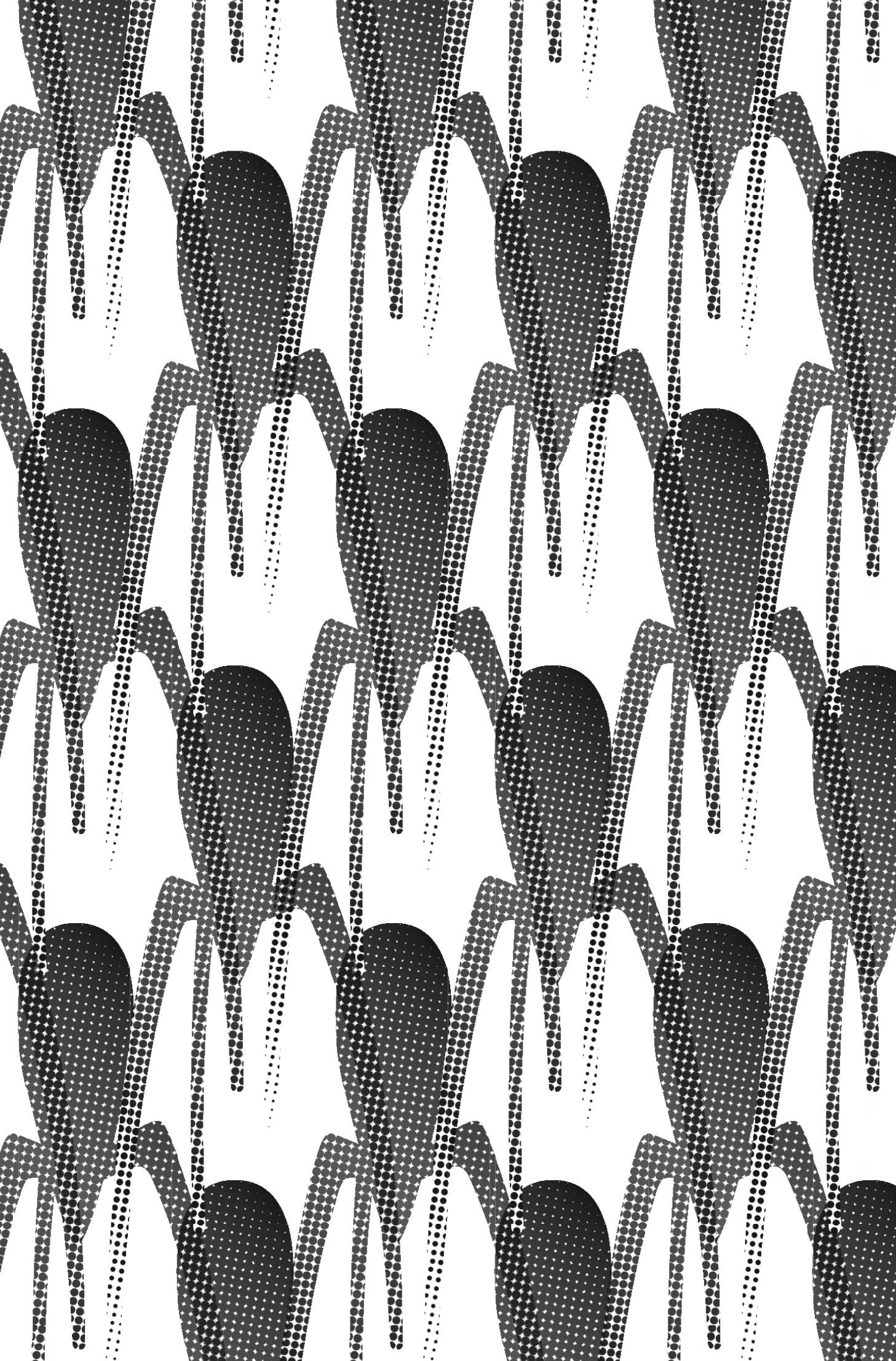




\section{Anhang zu Konstantin Grcic}

\section{art Das Kunstmagazin}

Stardesigner, Design-Star(s); 4 Artikel

"Der zum Designer des Jahres gewählte Vito Acconci musste sich für seine Soundinstallation, an der er noch wenige Stunden vor der Eröffnung arbeitete, mit Räumlichkeiten gleich neben einem für die Messe gestarteten Hundedesign-Shop begnügen. Dort führten [sic] Design-Stars Konstantin Grcic einen Spiegel für eitle Pudel vor, Toyo ITO einen Kinderwagen für lauffaule Kläffer. Reiser + Umemoto zeigten Haute-Couture für Chihuahuas und Kazuyo Sejima ein luxuriöses Kuschelkissen für zarte Vierbeiner." (BODIN in: ART DAS KUNSTMAGAZIN ONLINE am 10.12.2012) [online] http://www.art-magazin.de/design/57410/ [14.07.2013; nicht mehr im Netz verfügbar]

»Die italienische Firma >Magisı etwa hatte Fukasawas Hockerserie >Déjà-Vu< in ihre Kollektion aufgenommen - zwischen Entwürfen von etablierten Designstars wie Enzo Mari, Ron Arad oder Konstantin Grcic." (RADERSCHAD in ART DAS KUNSTMAGAZIN 10/2007: 56-61) [online] http:// www.art-magazin.de/div/heftarchiv/2007/10/OGOWTEGWPPCOPPOGSCRTTGAAOACGROEPASSH/Die-letzten-Dinge-des-Alltags [12.07.2013; nicht mehr im Netz verfügbar]

"Seine Kollektion wuchs langsam. Bei der Auswahl der Entwürfe orientierte er sich von Anfang an weniger an Marktsignalen als an einem »typischen Kribbeln im Bauch«. Heute sagt er: "Es ist wie beim Verlieben." Entsprechend wählerisch ist Nils Holger Moormann, wenn es um sein Programm geht: Junge wie ältere Designer machen ihm ständig Avancen und schicken Modelle und Ideen ein. Oft vergeblich. Moormann erwirbt, um zu besitzen: In Teamwork mit den Auserwählten und seinem Hausdesigner überarbeitet er die Entwürfe solange, bis sie perfekt in die Kollektion passen. Zur Zeit hat er 30 Modelle im Angebot - Möbel in einem funktionalistischen, auf klare Formen reduzierten Design. Aber mit Raffinesse: »In jedem meiner Produkte steckt eine wirkliche Erfindung", erklärt Moormann stolz. Besonders augenfällig ist das innovative Extra beim dem zweifach prämierten Regal >Es` (1999) des Münchner Star-Designers Konstantin Grcic: Das Gestell aus Holzstäben und Brettern steht stets schief; die flexible Konstruktion nimmt bei jeder neuen Belastung eine andere stabile Position ein." (NICOLAUS und KAPITZA in: ART DAS KUNSTMAGAZIN 2/2003: 58-65) [online] http://www.art- 


\section{STARDESIGNER ODER GESTALTER DES ALLTÄGLICHEN?}

magazin.de/div/heftarchiv/2003/2/OGOWTEGWPPEPWPOGOCPHOGACWOAGWTRWPHPC/Bauhaus-und-Lederhose [12.07.2013; nichtmehr im Netz verfügbar]

"Bei den vorangegangen Designparcours durfte man idealerweise noch die berühmten Münchner Vertreter ihrer Zunft beschnuppern, etwa den Stardesigner Konstantin Grcic und die Modekonzeptualistin Ayzit Bostan." (SONNA in: ART DAS KUNSTMAGAZIN ONLINE am 28.02.2008) [online] http://www.art-magazin.de/design/4419/designparcours_muenchen [12.07.2013; nicht mehr im Netz verfügbar]

\section{Der Spiegel}

einer der renommiertesten deutschen Designer, einer der gefragtesten deutschen Designer

"Konstantin Grcic, einer der renommiertesten deutschen Designer, gestaltet seit Neuestem auch Sofas. Selbst sitzt er allerdings lieber auf Stühlen. [...] Frage: Sie sind einer der gefragtesten deutschen Designer. Aber wir haben gehört, dass Sie privat gar kein Sofa besitzen. Stimmt das? Grcic [Hervorhebungen des Verfassers]: Ja, ich habe noch nie eins besessen. Ich habe auch noch nie wirklich ein Sofa entworfen. Jetzt machen wir gerade das erste." (SIEBKE in: MANAGER MAGAZIN ONLINE am 10.06.2011; Seite 1 von 3) [online] http://www.manager-magazin.de/lifestyle/stil/ a-767191.html [13.12.2018]

\section{Der Standard}

Designstar, Stardesigner; 3 Artikel

"Ein anderer Weg, das Stigma des langweilig durchschnittlichen Einheitswarenproduzenten abzulegen, führte für Firmen wie Rowenta und Krups über das Engagement von Designstars wie Jasper Morrison oder Konstantin Grcic. Beiden Produktdesignern gelang es, der gemeinen Mittelklassekaffeemaschine die Exklusivität, Intelligenz und Präzision zu geben, die sonst nur ein Oberligamodell hat." (HAUSENBLAS und BURGER in: DER STANDARD ONLINE am 30.06.2005) [online] https://derstandard.at/ 2095955/Identitaetsfrage-Design [13.12.2018]

»Der Münchner Konstantin Grcic, gerüstet mit dem Zeug zum Stardesigner, der Österreicher Robert Stadler und der Niederländer Jurgen Bey, allesamt um die 39, beschäftigen sich in der Schau 'Vanishing point 2 nicht unbedingt mit der Erfüllung wundersamer Möbellösungen, dennoch zeigen sie Design anders." (HAUSENBLAS in: DER STANDARD ONLINE am 13.06.2004) [online] https://derstandard.at/1683847/Frage-Zeichen $[13.12 .2018]$ 


\section{AM ENDE WAR ES NUR EIN WORT: ZWEI REZEPTIONSSTUDIEN}

"Der Münchner Designstar Konstantin Grcic steuerte zur zweiten Vitra Edition ein wuchtiges Stahlmöbel für den Außenbereich bei, rund 20.000 Euro muss ein Sammler für das exquisite Gartenbankerl lockermachen. (ESCHBACH in: DER STANDARD ONLINE am 24.11.2007) [online] https:// derstandard.at/3121202/Million-Dollar-Sofa [13.12.2018]

\section{Die Welt}

Design-Star, der unumstrittene Star der deutschen Design-Szene

"Erst half Münchens Design-Star beim ’kritischen Rückbau< im Haus der Kunst. Jetzt stellt er dort in einer Retrospektive sein gesamtes bisheriges Schaffen zur Diskussion [...] Grcic ist der Darling der Münchner und unumstrittene Star der deutschen Design-Szene. Einer, der mit 41 museumsreif ist. Von dem die Kollegen voller Hochachtung sprechen. Und mit dem das Goethe-Institut Sympathiewerbung für Deutschland im Ausland betreibt." (WEISS in: WELT AM SONNTAG ONLINE am 12.03.2006) [online] https://www.welt.de/print-wams/article139609/Wer-ist-eigentlichKonstantin-Grcic.html [13.12.2018]

\section{$N Z Z$}

Designstar, Star, einer der renommiertesten deutschen Industriedesigner; 2 Artikel

"Die beiden Unternehmer waren sich schnell einig, dass als Designer eines neuen Stuhls nur einer infrage kommen konnte: Konstantin Grcic, einer der renommiertesten deutschen Industriedesigner. Schliesslich gibt der Münchner Designstar mit seinen Entwürfen der Unruhe eine Form." (ESCHBACH in: NEUE ZÜRCHER ZEITUNG ONLINE am 27.01.2012) [online] https://www.nzz.ch/fuers_leben_lernen-1.14568027 [13.12.2018]

"Der eigentliche Star der Messe ist Konstantin Grcic. [...] Im sicheren Bewusstsein, dass es sich um einen Designklassiker der Zukunft handelt, wird der Stuhl nicht nur auf der Messe, sondern auch in der Sala d'Onore der Triennale präsentiert. Dort wird in einem fiktiven Labor mittels Modellen, Skizzen und Fotografien ein Eindruck vom Entstehungsprozess vermittelt." [Stuhl MYTO, Ergänzung des Verfassers] (ESCHBACH in: NEUE ZÜRCHER ZEITUNG ONLINE am 19.04.2008) [online] https://www.nzz.ch/ stars_und_selbstdarsteller-1.713889 [13.12.2018] 


\section{STARDESIGNER ODER GESTALTER DES ALLTÄGLICHEN?}

\section{SCHÖNER WOHNEN}

Stardesigner, der bekannte Münchner Designer, Designer mit großen Namen; 6 Artikel

"Gestatten, >Tom \& Jerry von Star-Designer Konstantin Grcic und werden bei Magis gefertigt. [...] Gestaltet hat die beiden der bekannte Münchner Designer Konstatin [sic] Grcic und der orientierte sich bei sTom \& Jerry an klassischen Werkstatthockern." (SCHÖNER WOHNEN ONLINE) [online] https://www. schoener-wohnen.de/tipps-trends/31619-rtkl-hocker-tom-jerry-aus-massivem-buchenholz [13.12.2018]

"Einen sehr guten Stand hat der Tisch >8-Pack von Stardesigner Konstantin Grcic. Der Berliner [sic] Gestalter hat dem Tisch nämlich eine ganze Reihe Beine geschenkt." (SCHÖNER WOHNEN ONLINE) [online] http:// www.schoener-wohnen.de/news/tipp-des-tages/209158-tisch-mit-achtbeinen-von-konstantin-grc.html [04.07.2013; nicht mehr im Netz verfügbar]

"Schulstühle sind funktional aber meistens ziemlich hässlich. Dass es schöner geht, möchte Flötotto mit >Pro< beweisen. Star-Designer Konstantin Grcic hat das Schulmöbel entwickelt, dafür gab es den Interieur Innovation Award 2012." (SCHÖNER WOHNEN ONLINE) [online] https:// www.schoener-wohnen.de/tipps-trends/30859-rtkl-schulstuhl-pro-vonkonstantin-grcic [13.12.2018]

"Der Stuhl ist eigentlich aus Holz gemacht. Doch nur ein Werkstoff wäre für den Stardesigner Konstantin Grcic zu einfach - daher hat der Stuhl eine Achse aus Aluminium."(sCHÖNER WOHNEN ONLINE) [online] http:// www.schoener-wohnen.de/news/schoener-wohnen-news/95150-stuhlb-von-konstantin-grcic-bei-bd-de.html [04.07.2013; nicht mehr im Netz verfügbar]

(Inzwischen wurde der Text in einer anderen Version online eingestellt dieses Mal ohne Star-Attribute: (schÖNER WOHNEN ONLINE) [online] https://www.schoener-wohnen.de/moebel/34799-bstr-praktische-klappstuehle/141518-img-klappstuhl-b-chair-von-bd-barcelona [13.12.2018])

"Star-Designer Konstantin Grcic hat den Stuhl für die >Marsotto Edizioni< entworfen. In der Edition findet sich Marmor, nichts als Marmor. Sechs Designer mit großen Namen wie Naoto Fukasawa, James Irvine oder eben Konstantin Grcic haben ihre Entwürfe bei Marsotto in Stein verewigt." (SCHÖNER WOHNEN ONLINE) [online] https://www.schoenerwohnen.de/tipps-trends/28354-rtkl-stuhl-sultan-von-konstantin-grcic [13.12.2018] 


\section{AM ENDE WAR ES NUR EIN WORT: ZWEI REZEPTIONSSTUDIEN}

"Eine iPod-Docking-Station, selbst gebaut aus Holz, Metall und kleinen, günstigen Lautsprechern mit USB-Anschluss, das findet sich im Netz bei ssueddeutsche.der. Star-Designer Konstantin Grcic und Praktikantin Charlotte Talbot hatten laut Artikel sviel Spaß< beim Austüfteln der Selbstbau-Anleitung." (SCHÖNER WOHNEN ONLINE) [online] https://www. schoener-wohnen.de/tipps-trends/31233-rtkl-moebel-marke-eigenbau [13.12.2018] 


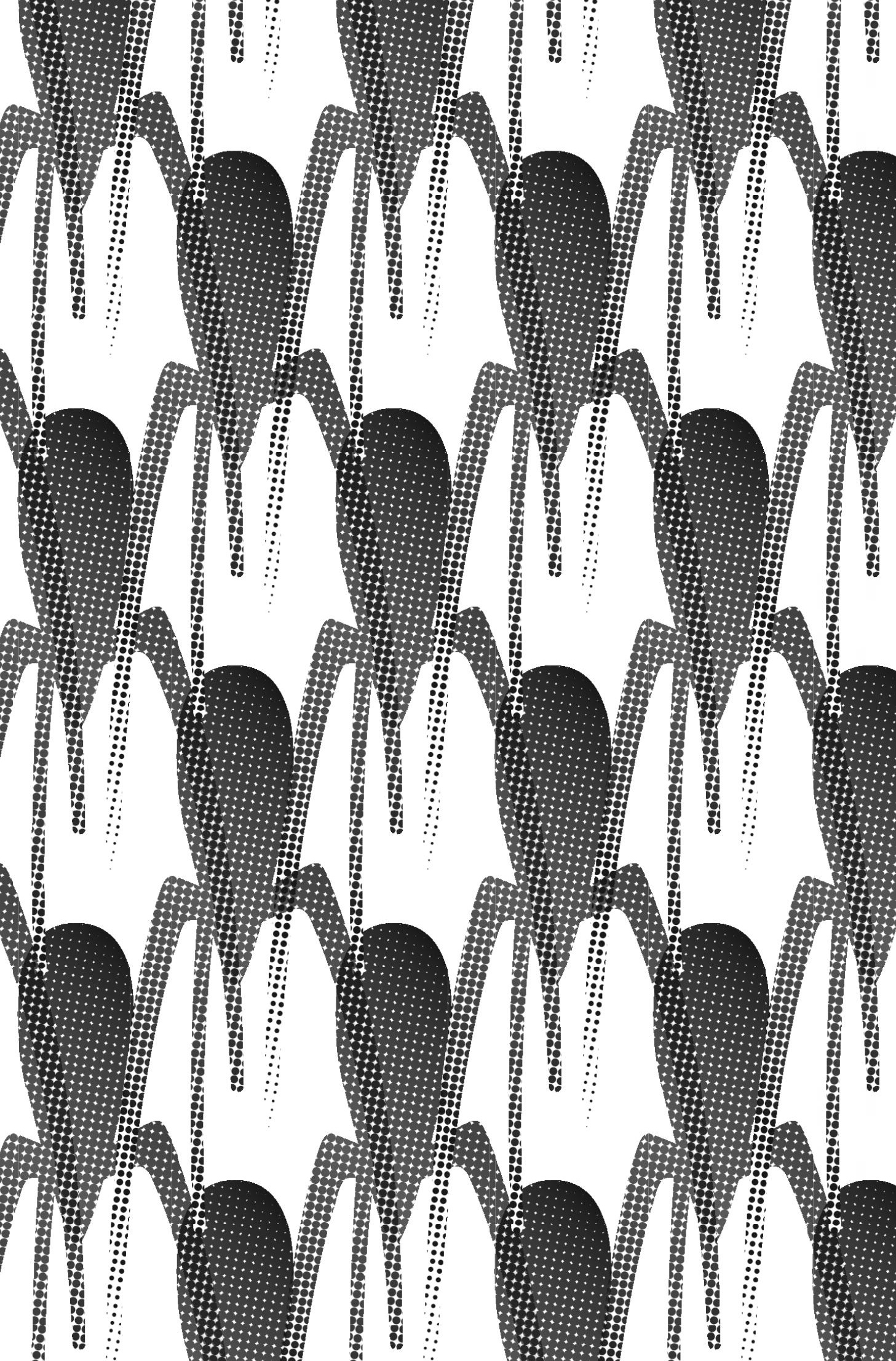




\section{Anhang zu \\ Dieter Rams}

\section{Architektur und Wohnen}

Altmeister des deutschen Designs

"Als kürzlich im Frankfurter Museum für Angewandte Kunst die Ausstellung über Rams' Werk eröffnet wurde, sah sich der Altmeister des deutschen Designs fast den ganzen Abend von einer Horde junger Fans umringt: [...] " (FRENZL in: ARCHITEKTUR UND WOHNEN 04/2010) [online] http://www.awmagazin.de/wohnen/moebel-produkte/artikel/klares-und-einfaches-design [13.12.2018]

\section{Der Spiegel}

Designstar

»Er war erst Innenarchitekt, dann Produktdesigner, später Leiter der Produktabteilung und schließlich Direktor für Produktdesign. Längst sind seine Entwürfe zu Sammlerstücken geworden, im MoMA ausgestellt, es gibt Bücher, die sich seinem Schaffen widmen, und erst vor Kurzem war im Museum für Angewandte Kunst in Frankfurt eine große Werkschau zu sehen, die zuvor in Osaka, Tokio und London gezeigt worden war. [...] Dabei wollte Dieter Rams nie ein Designstar werden. >Der Ausgangspunkt meiner Arbeit war immer, Ordnung zu schaffen<, sagt Rams, ,das Chaos zu eliminieren, sich auf das Wesentliche zu konzentrieren.« (zUBER in: MANAGER MAGAZIN ONLINE am 29.10.2010) [online] http://www. manager-magazin.de/lifestyle/hardware/a-725602.html [13.12.2018]

\section{Der Standard}

Altmeister des deutschen Designs

»Als ein Highlight dürften auch bei der fünften Auflage die sogenannten Talks gelten, im Rahmen derer auch heuer internationale Designgrößen wie Ravi Naidoo, Doshi Levien, Jerszey Seymour oder der Altmeister des deutschen Designs, Dieter Rams, im Künstlerhauskino vortragen. (HAUSENBLAS in: DER STANDARD ONLINE am 30.09.2011) [online] https://derstandard.at/1577837109495/Vienna-Design-Week-Design-

nimmt-Platz [13.12.2018] 


\section{STARDESIGNER ODER GESTALTER DES ALLTÄGLICHEN?}

\section{Die Zeit}

berühmtester deutscher Industriedesigner, der bedeutendste deutsche Produktdesigner, Designstar, die Ikone des Industriedesigns; 2 Artikel

"Dieter Rams ist die Ikone des Industriedesigns. Seine Entwürfe stehen im Museum of Modern Art und im Kanzleramt. Dabei wollte er immer nur eines: das Chaos beseitigen. [...] Der sbedeutendste deutsche Produktdesigner, Träger des Großen Verdienstkreuzes des Verdienstordens der Bundesrepublik Deutschland, Ehrendoktor des Royal College of Art, sitzt an seinem Schreibtisch in Kronberg im Taunus, die weißen Haare gescheitelt, die runde Eulen-Brille auf der Nase, und gibt sich bescheiden. [...] Längst sind seine Entwürfe zu Sammlerstücken geworden, im MoMA ausgestellt, es gibt Bücher, die sich seinem Schaffen widmen, und erst vor Kurzem war im Museum für Angewandte Kunst in Frankfurt eine große Werkschau zu sehen, die zuvor in Osaka, Tokio und London gezeigt worden war. Dabei wollte Dieter Rams nie ein Designstar werden. >Der Ausgangspunkt meiner Arbeit war immer, Ordnung zu schaffen<, sagt Rams, >das Chaos zu eliminieren, sich auf das Wesentliche zu konzentrieren.« (ZUBER in: DIE ZEIT ONLINE am 19.10.2010) [online] http://www.zeit.de/lebensart/2010-10/braun-dieter-rams/komplett ansicht [13.12.2018]

„Dieter Rams, berühmtester deutscher Industriedesigner, wünscht sich manchmal Maschinen, die uns zum besseren Nachdenken verhelfen. Und die Welt mal gründlich aufräumen [...] Dieter Rams, 75, ist der bedeutendste deutsche Industriedesigner. Von 1955 bis 1997 war er für das Produktdesign von Braun verantwortlich und machte den Elektronikhersteller weltbekannt. Seine Ideen beeinflussen noch heute Kreative weltweit. Rams ist Vorbild von Apple-Designer Jonathan Ive." (PRÜFER in: ZEITMAGAZIN LEBEN 14/2008) [online] http://www.zeit.de/2008/14/TraumDieter-Rams [13.12.2018]

\section{FAZ}

Stardesigner, des bekannten Gestalters

"Das Institut für Neue Technische Form (Intef) hat dem Stardesigner Dieter Rams ein besonderes Geburtstagsgeschenk gemacht. Institutsleiter Michael Schneider eröffnete am Sonntag eine Präsentation von einigen Objekten des bekannten Gestalters, der vor einiger Zeit für sein Lebenswerk mit dem höchsten Designpreis der Bundesrepublik gewürdigt wurde." (HEIN in: FRANKFURTER ALLGEMEINE ZEITUNG, NR. 119/ 2012: 44) [online] https://fazarchiv.faz.net/document?id=RMO_FAB 201205233506289\#start [09.04.2018] 


\section{SCHÖNER WOHNEN}

Designstar, die Ikone des deutschen Industriedesigns, der bedeutendste deutsche

Produktdesigner

"Dieter Rams ist die Ikone des deutschen Industriedesigns. Seine Entwürfe für den Elektronikhersteller Braun stehen im Museum of Modern Art, seine Sessel im Kanzleramt. Ihm werden Ausstellungen und Bücher gewidmet. [...] Der >bedeutendste deutsche Produktdesigner ('Die Zeit), Träger des Großen Verdienstkreuzes des Verdienstordens der Bundesrepublik Deutschland, Ehrendoktor des Royal College of Art, sitzt an seinem Schreibtisch in Kronberg im Taunus, die weißen Haare gescheitelt, die runde Eulen-Brille auf der Nase, und gibt sich bescheiden. [...] Längst sind seine Entwürfe zu Sammlerstücken geworden, im MoMA ausgestellt, es gibt Bücher, die sich seinem Schaffen widmen, und erst vor Kurzem war im Museum für Angewandte Kunst in Frankfurt eine große Werkschau zu sehen, die zuvor in Osaka, Tokio und London gezeigt worden war. Dabei wollte Dieter Rams nie ein Designstar werden." (ZUBER in: SCHÖNER WOHNEN ONLINE) [online] https://www.schoenerwohnen.de/moebel/29726-rtkl-dieter-rams [13.12.2018] großteils wortgleich mit dem zuvor zitierten ZEIT-Artikel - dies ist die Erstveröffentlichung (laut ZEIT-Artikel) 


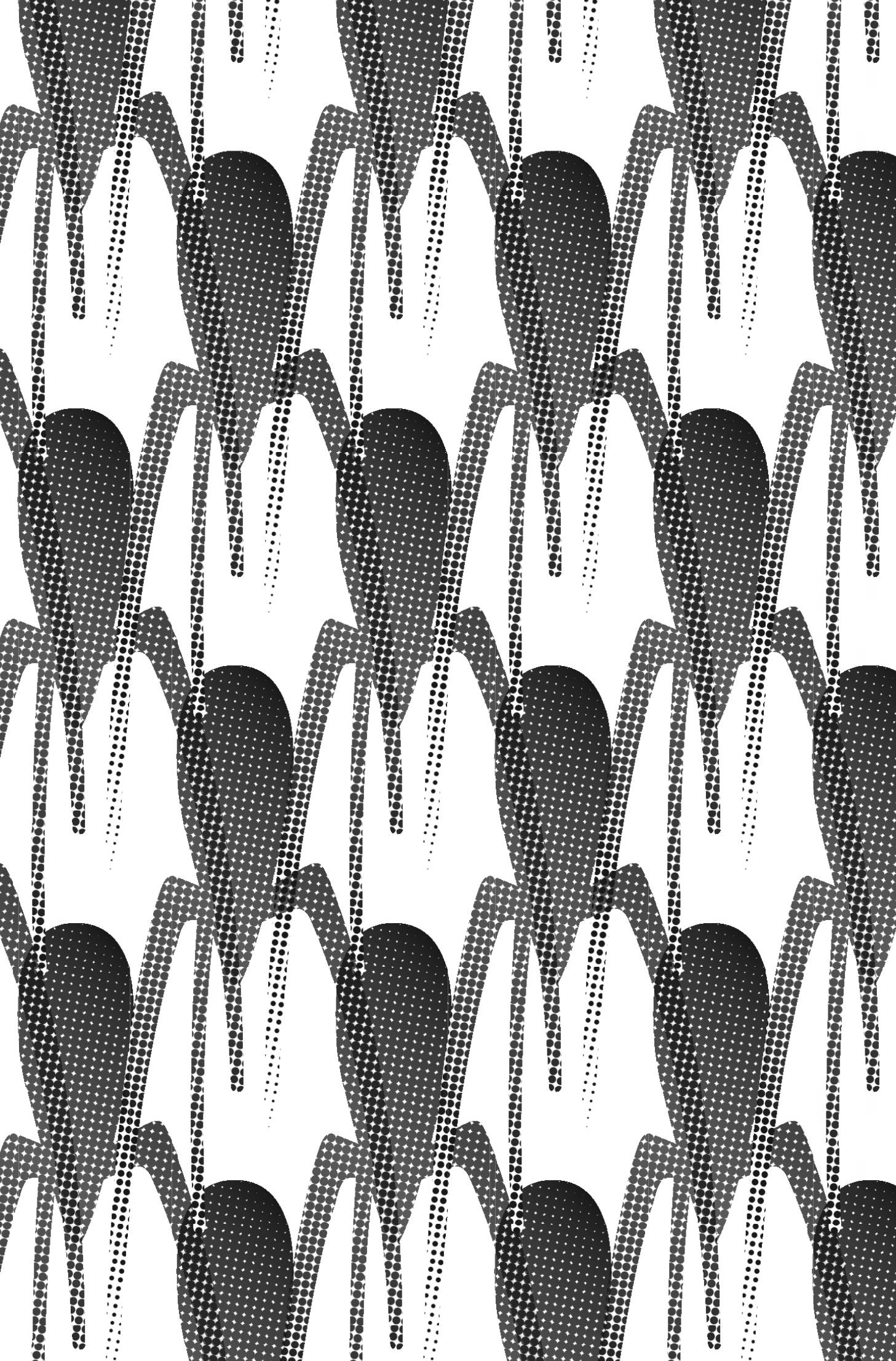




\section{Anhang zu \\ Terence Conran}

\section{Der Spiegel}

Designstar

"Draußen vor der Tür des Lokals Lenbach, das der britische Designstar Sir Terence Conran nach den sieben biblischen Todsünden Neid, Gier, Lust, Zorn, Eitelkeit, Völlerei und Trägheit gestaltet hat, stand ein schwarzer Mann mit der Statur eines Geldschranks." (HÜETLIN in: DER SPIEGEL 25/2003: 186) [online] http://www.spiegel.de/spiegel/print/d-27390366. html [13.1.2018]

\section{Design report}

Designstar

mDesigners into Schools Week nennt sich die Initiative, die vor einem Jahr in Englands Gymnasien debütierte. Renommierte Designer aller Sparten wurden dazu eingeladen, eine Woche lang ein Designprojekt mit 11bis 16-jährigen Schülern durchzuführen. Die Themen konnten die Gestalter selbst bestimmen; umso facettenreicher fiel das Angebot der durchgeführten Projekte auch aus. Designstar Sir Terence Conran beispielsweise nahm sich mit seinen Schülern des Redesigns einer Schulcafeteria an." (SPOHR in: DESIGN REPORT 7+8/2003) [online] http://www.designreport.de/DRmainfachartikelarchivDetail.asp?artikelid=1000001316\&object $=$ DR\&db=FAArchiv\&AnzahlAnsicht $=10 \&$ Ansicht $=$ kurz\&Sortier richtung=absteigend\&startpage $=2 \&$ searchausgabe $=$ Alle\%2oAusgaben \&searchjahrgang=Alle\%2OJahrg\% $C_{3} \%$ A4nge\&searchvolltext=Designstar \&btnreset=\&thesaurus= [05.07.2013; nicht mehr im Netz verfügbar]

\section{Der Standard}

\section{Stardesigner}

"Das seit vergangenen September geschlossene Cafe Drechsler am Wiener Naschmarkt erhält einen neuen Betreiber - und ein neues Aussehen. Wie die Tageszeitung >Die Presser (Dienstag-Ausgabe) berichtet, soll der britische Stardesigner Terence Conran an das Traditionskaffeehaus Hand anlegen und es sachte renovieren." (DER STANDARD ONLINE am 05.04.2006) 


\section{STARDESIGNER ODER GESTALTER DES ALLTÄGLICHEN?}

[online] https://derstandard.at/2392481/Hotel-Triest-uebernimmt-Cafe-Drechsler [09.04.2018]

\section{Die Welt}

Stardesigner

"Tipps von Stardesigner Terence Conran" (WELT AM SONNTAG ONLINE am 13.04.2008) [online] http://www.welt.de/wams_print/article1896393/ Tipps-von-Stardesigner-Terence-Conran.html [28.06.2013; nicht mehr im Netz verfügbar]

\section{Die Zeit}

Stardesigner; 2 Artikel

"Weitere Kosten in Höhe von 30 Millionen Mark werden für die nötigen Verbesserungen erwartet, noch einmal 42 Millionen Mark wollte BA ohnehin in die Erneuerung der Kabinen durch Stardesigner Terence Conran stecken." (SPAETH in: DIE ZEIT 03/2001) [online] http://www.zeit. de/2001/03/Bald_wieder_Ueberschall_/komplettansicht [13.12.2018]

"Glasgow hat eine Vision, den Glauben an sich selbst und den Willen zum Erfolg؛, erkannte Englands Stardesigner Sir Terence Conran. >Kein Zweifel, Glasgow ist heute die aufregendste Stadt Britanniens.< Conran, erklärter Mackintosh-Fan, will nächstes Jahr einen Shop in Glasgow eröffnen." (SAGER in: DIE ZEIT 38/1996) [online] http://www.zeit.de/1996/38/ Die_Mackintosh-Falle_-UZ_Wie_Glasgow_sein_Image_poliert/komplettansicht [13.12.2018]

\section{Süddeutsche Zeitung}

Stardesigner

»Dort ist 1997 ein für diese Zeit außergewöhnliches Lokal im ehemaligen Bernheimer Haus entstanden: das sLenbach،. Der britische Stardesigner Terence Conran hat das Interieur den sieben Todsünden gewidmet - vor allem der Eitelkeit wird hier gefrönt. So ziert eine Art Laufsteg das Lokal, in dem früher der junge Wilde Stefan Marquardt gekocht hat und somit der Völlerei als Helfershelfer diente." (BECKER in: SÜDDEUTSCHE ZEITUNG ONLINE am 09.06.2010) [online] http://www.sueddeutsche.de/ muenchen/lenbach-gaerten-speisen-im-geiste-der-koenige-1.363229

[13.12.2018] 


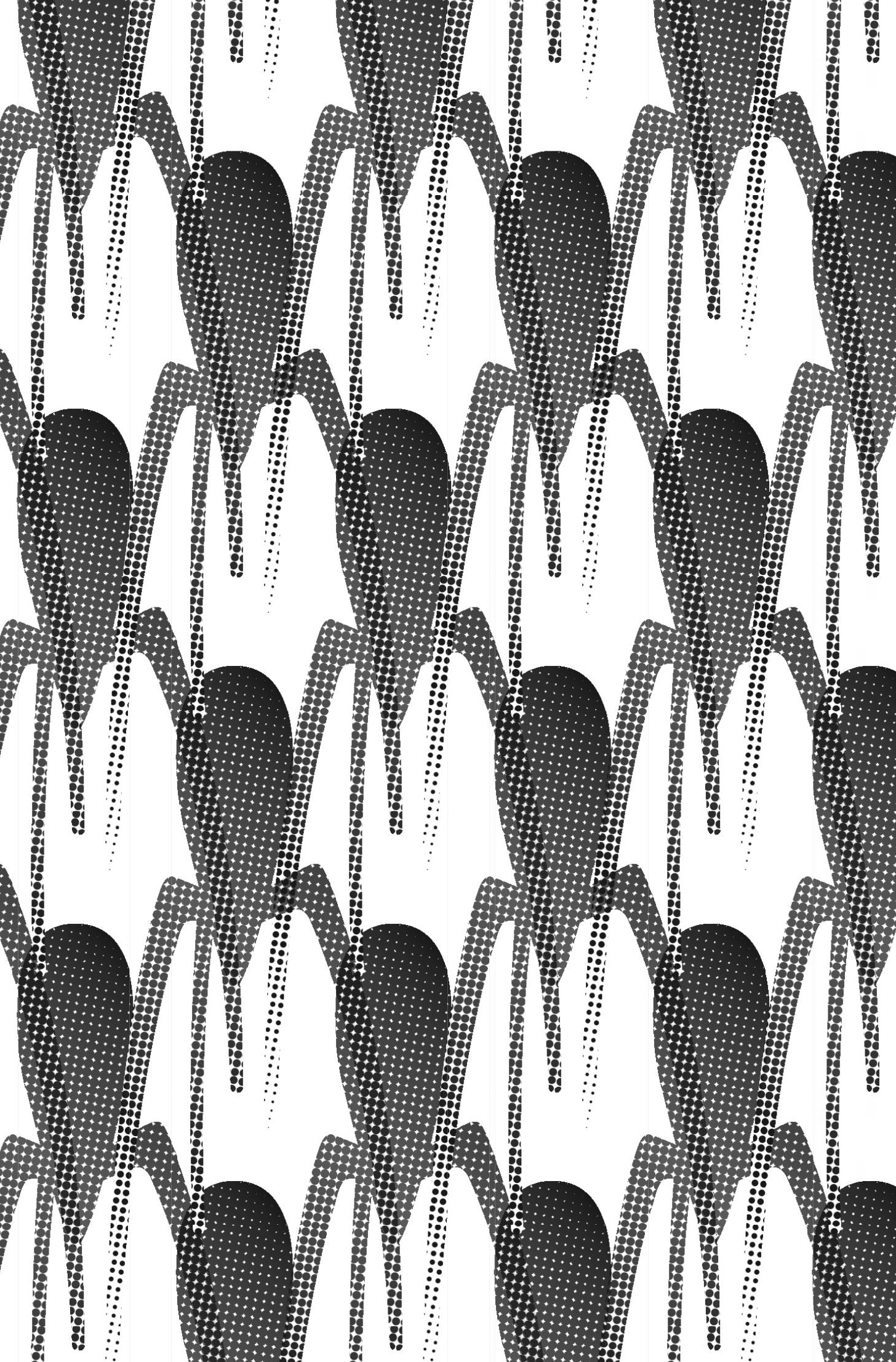




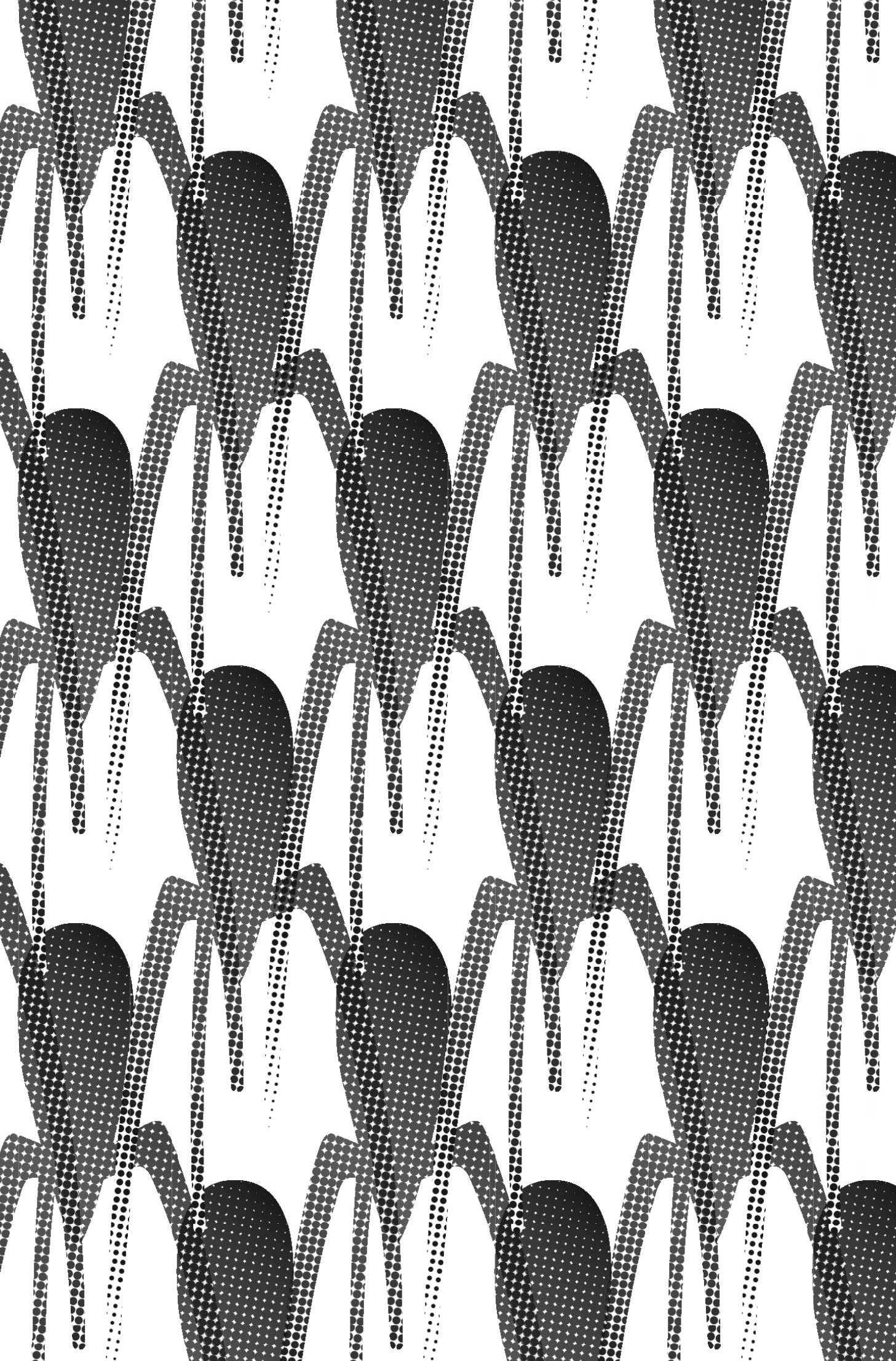




\section{Anhang zu \\ Ross Lovegrove}

\section{Architektur und Wohnen}

schillernde Persönlichkeit der internationalen Designerszene

"Der Name rollt auf der Zunge und hört sich an wie ein PR-cleveres Pseudonym - Ross Lovegrove. Klingt sexy. Wer so heißt, hat das Zeug zum Star in der Tasche. Lovegrove (auf Deutsch: Liebeswäldchen) hat es im Blut. Für ihn gilt wirklich `nomen est omen<, denn Lovegrove ist einer, der den Wald liebt - und neben ihm die Natur per se, die er mit seiner Arbeit thematisiert. Der britische Designer, 47, ist Absolvent des Royal College of Art und seit ein paar Jahren schillernde Persönlichkeit der internationalen Designerszene." (FRIEDRICH und MECKE in: ARCHITEKTUR UND WOHNEN 01/2006 SPECIAL) [online] http://www.awmagazin.de/design-style/ aw-designer-des-jahres/artikel/ross-lovegrove [13.12.2018]

\section{Der Spiegel}

Stardesigner

"Autodesigner tummeln sich gern auf der Möbelmesse in Mailand, einer der weltweit wichtigsten ihrer Art. Diesmal feiert dort - zwischen Sesseln, Lampen und Tischen - eine [sic] E-Auto von Renault Weltpremiere, das vom britischen Stardesigner Ross Lovegrove entworfen wurde." (PANDER in: SPIEGEL ONLINE am 10.04.2013) [online] http://www. spiegel.de/auto/aktuell/renault-elektro-studie-twin-z-interieur-von-designer-ross-lovegrove-a-893380.html [13.12.2018]

\section{Der Standard}

\section{Stardesigner}

"Wien - >Wien in neuem Licht‘, aus diesem Titel könnte >Neues Licht für Wien werden. Ersterer bezieht sich auf die Präsentation des Solar Tree, einer Straßenlampe in Form eines Baumes. Entworfen wurde die futuristische Beleuchtung vom Londoner Stardesigner Ross Lovegrove für das Museum für angewandte Kunst (MAK) am Stubenring in Wien." (MILJKOVIC in: DER STANDARD ONLINE am 30.11.2007) [online] https://derstandard. at/3060038/Neue-Baeume-fuer-das-Stadtbild [09.04.2018] 
STARDESIGNER ODER GESTALTER DES ALLTÄGLICHEN?

\section{design report}

"Konsequent arbeitet sich der türkische Bad-Riese Vitra zur anspruchsvollen Designmarke im Badezimmer vor und steht spätestens mit dieser ISH auf gleicher Augenhöhe mit den etablierten Marken. Diesmal zeigten gleich drei Designer ihre neuen Arbeiten: Noa Design, Matteo Thun (der sich anscheinend auf keine Marke festlegen will) und Ross Lovegrove, Art Director bei Vitra. Lovegrove zeigt mit der Kollektion >Mod, dass er seine organische Grundhaltung variieren kann, und greift bewusst den aufkommenden Einfluss der linearen, grafischen Innenarchitektur auf. Die Herausforderung für den Stardesigner bestand darin, eine Designlogik zu erarbeiten, die ein modulares System ergibt, das subtile Verweise auf einen sparsamen Gebrauch von Wasser enthält." (REINHARDT in: DESIGN REPORT 05/2007) [online] http://www.designreport.de/Fachartikel archiv/1000000712/Infrastruktur-im-Badezimmer.html [05.07.2013; nicht mehr im Netz verfügbar

\section{Die Presse}

Stardesigner

»Der britische Stardesigner Ross Lovegrove hat die Solarleuchte innerhalb von nur 16 Wochen entwickelt und gebaut - und zwar auf einen Anruf hin, den er im Frühjahr von Peter Noever, Direktor des Museums angewandter Kunst (MAK), bekommen hatte. Anlass für Noevers Hilferuf war die Entscheidung der Stadt, den gesamten Ring einheitlich mit reproduzierten, historischen Bogenlampen zu beleuchten. Als sbarbarisch und kitschig، hatte Noever die Kandelaber damals bezeichnet und in einem offenen Brief an Planungsstadtrat Rudolf Schicker gegen die >Geschmacksdiktatur der Bürokraten gewettert." (ZNIDARIC in: DIE PRESSE ONLINE am 08.10.2007) [online] https://diepresse.com/home/panorama/ oesterreich/335442/Wiens-Designerleuchte_Licht-aus-nach-drei-Wochen ?from=suche.intern.portal [13.12.2018]

\section{FAZ}

Stardesigner, einer der wichtigsten und innovativsten zeitgenössischen Industriedesigner

"Zumindest haben in den vergangenen Jahren auch Stardesigner den Bambus für sich entdeckt. [...] Der britische Designer Ross Lovegrove schließlich hat 99 Fahrräder aus dem fasrigem Gras kreiert und sie für jeweils 6500 Euro angeboten. Dabei war die Idee eigentlich nicht neu: Das erste Fahrrad aus Bambus gab es in England schon 1894."Im Marginaltext: »Design am Ring Ross Lovegrove gilt als einer der wichtigsten 


\section{AM ENDE WAR ES NUR EIN WORT: ZWEI REZEPTIONSSTUDIEN}

und innovativsten zeitgenössischen Industriedesigner. Seine Entwürfe sind oft von der Natur inspiriert, statt als Designer bezeichnet er sich lieber als evolutionary biologist [...].«(GUNKEL in: FRANKFURTER ALLGEMEINE SONNTAGSZEITUNG NR. 39/2007: 62) [online] https://fazarchiv. faz.net/document?id=FAS__SD1200709301303852\&offset=30\#start [09.04.2018] 


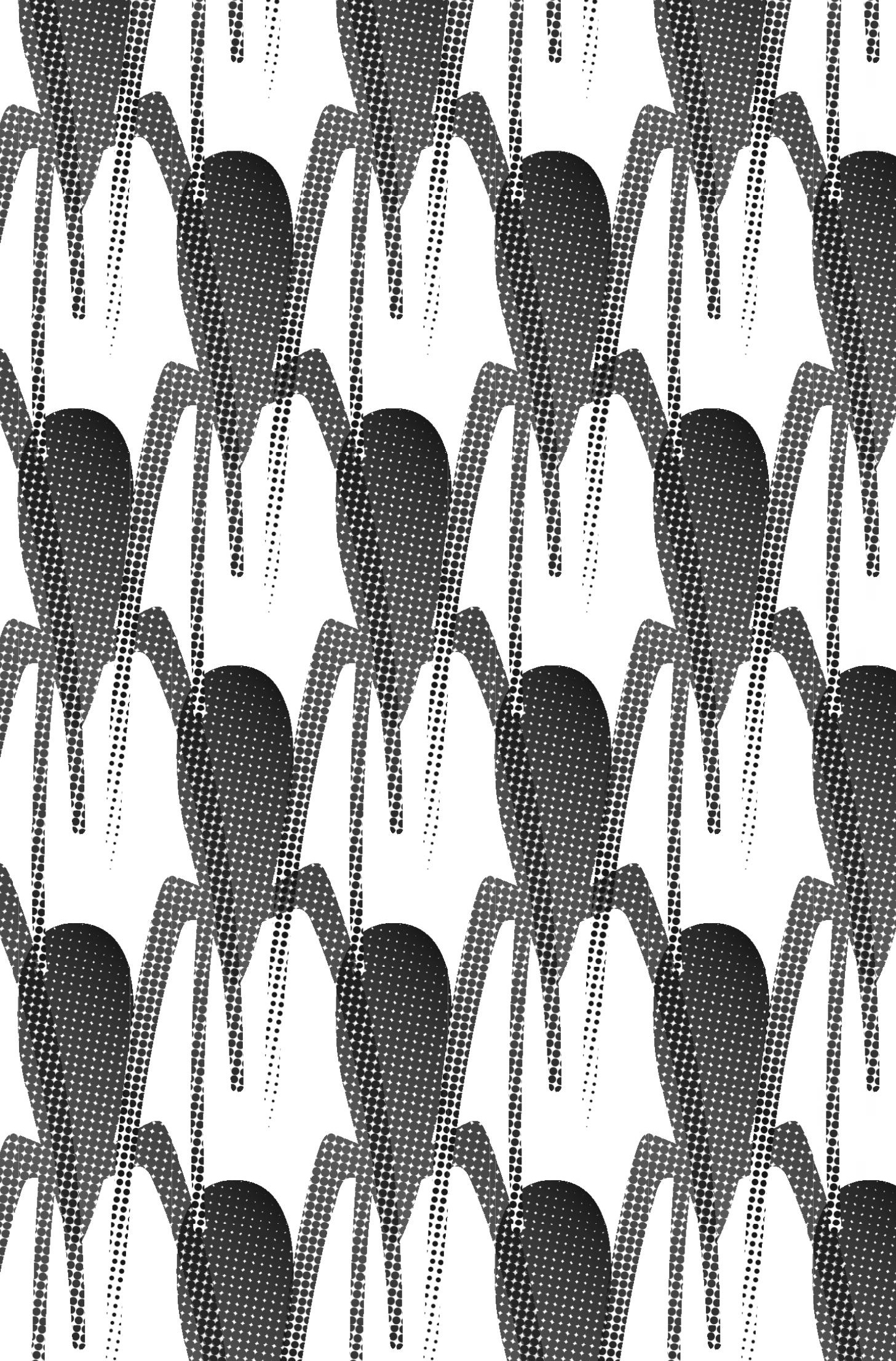


VI. betrachtungen $_{\text {Schluss- }}$ 
»Das Subjekt begehrt, gesehen zu werden.«

Andreas Reckwitz 


\section{Aufmerksamkeit}

Für das Feld des Designs konnte ich zeigen, dass Aufmerksamkeit dort kein nur an aufmerksamen Individuen zu beobachtendes Rezeptionsphänomen ist und dass sie nur als soziale Aufmerksamkeit einen Sinn ergibt, ohne die begriffliche Symbole wie Anerkennung, Prestige, Reputation und Ruhm weder Sinn noch Wirkung hätten. Aufmerksamkeit wurde von so gut wie allen $\mathrm{Au}-$ toren als positive Aufmerksamkeit verwendet und auch die eben angeführten Begriffe sind ohne sie so gut wie undenkbar.

Nur EDER (vgl. EDER 2002: 38f) weist deutlich darauf hin, dass auch Spott und Verachtung Formen von Aufmerksamkeit darstellen, dass sie jedoch nur in Form von Liebe und Bewunderung als Einkommen gelten, das berechnet und mit dem gerechnet wird. An GEORG FRANCKs Anstoß für Untertitel wie Betrachtung der Aufmerksamkeit lieferndem Essay zur Ökonomie der Aufmerksamkeit ist zu Recht wie zu Unrecht einiges kritisiert worden. So stand es außer Frage, dass die bisher geäußerte Kritik aufgearbeitet werden musste, denn der Tatsache, dass dieser Essay bis heute nachwirkt, wurde zuletzt erst durch BERNARDY (2014) weiteres Gewicht verliehen.

Prädominante Kritik wird am unfundierten Einsatz ökonomischer Begriffe geäußert, die FRANCK als Metaphern (oder Anlässe zum »Äquivalenzdenken«, vgl. FRANCK 1998: 97) verwendet. Seine Zukunftsvision fragt danach, ob der Handel mit Geld (als symbolisch generalisiertem Kommunikationsmedium) durch den Handel mit Aufmerksamkeit ersetzt wird - in anderen, seinen Worten: »ob auch Beachtung zu Reichtümern akkumuliert und zu Reichtum heckendem Reichtum kapitalisiert« wird (ebd.: 113f). Reagiert hat man darauf mit disziplinär geäußerter Kritik an einem meiner Meinung nach nicht disziplinär gemeinten Gedankenbild. 
Am Schlusspunkt dieser Arbeit ist mir das Gegengewicht, das von GEORG FRANCK selbst 1998 schon in seinen Essay hineinformuliert wurde, einer nochmaligen Hervorhebung wert, weil die prädominante Lesart seines Essays auch zur prädominanten Art der Kritik führt. Diese scheint bei der Lektüre fortwährend zu überlesen, dass FRANCK selbst schon konstatiert, für die »Ausbildung einer Währung « mangele es an einem gültigen Zahlungsmittel und dass es »[e]ben dieser Maßstab [sei] [...], der im zwischenmenschlichen Tausch der Beachtung fehl[e]«: »Am Fehlen einer geeigneten Währung [bräche] sich die Neigung zum Äquivalenzdenken.« (für beide Zitate ebd.: 97).

Das Aufmerksamkeitssparkonto (STRUBE in: BLEICHER und HICKETHIER 2002: 79), über das sich Anschluss zum symbolischen kulturellen Kapital BOURDIEUs anbietet, stellt im Nachhinein betrachtet die Direttissima zu meinem eigenen Ansatz dar, ein Theoriemodell für den ökonomieähnlichen Tausch von Ansehen zu entwickeln. Vermittels dessen soll die Frage beantwortet werden, wann eine im Sinne einer Aufmerksamkeitsökonomie relevante Währung, nämlich reine Aufmerksamkeit (im Sinne begrifflich verkörperten und dadurch auch sozial wirksamen Ansehens) überhaupt angeboten oder ausgegeben wird, wenn man die Ökonomiemetapher als »Vergesellschaftung durch Tausch auf dem Markt“ (WEBER 2010: 489) im Sinne eines Tauschangebots und einer Zahlungsmethode ausreizt. Aus Sicht dieser Arbeit ist die bei GEORG FRANCK beschriebene Potenz im Sinne eines real existierenden Zahlungsmittels bis zur Widerlegung bewiesen, weil reale Zahlungsvorgänge mit akkumulierter Aufmerksamkeit (die einer Ökonomie der Aufmerksamkeit zugrundeliegen müssen) aufgezeigt werden können.

Ich postuliere, dass Aufmerksamkeit als Währung tatsächlich existiert und dass somit auch eine Ökonomie der Aufmerksamkeit existiert, doch nicht in voller Ausprägung kapitalgebundenener und -gesteuerter Märkte, sondern eher als ein Sub-Markt, in dem ebenso um Aufmerksamkeit wie um das begrifflich definierte Zahlungsmittel in Form akkumulierter Aufmerksamkeit gefeilscht und konkurriert wird. Jenes hat einen - für das Individuum - in hohem Maße schwankenden, weil sowohl steigerungsfähigen als auch fallen könnenden Kurswert für die Person, der er zugeschrieben wird. Selbst unter dem Gesichtspunkt der Erwartung, dass ein Zahlungsmittel »seine spezifische Begehrtheit und Verwendbarkeit als Zahlungsmittel bewahren werde« (ebd.: 489), verliert sich seine Parallelisierbarkeit nicht, da auch das Geld im Börsenhandel Kursschwankungen unterliegt.

Als wesentlichster Unterschied manifestiert sich der Vergleich mit anderen Währungen, deren Wert im Verhältnis zueinander ausgehandelt wird, 
während es beim Kurswert der Aufmerksamkeit darum geht, welche Akkumulationsstufe einer Person zugeschrieben wird. Diese Akkumulationsstufen werden in der Folge miteinander verglichen. Die jeweiligen sozialen Werte der begrifflichen Symbole sind aber ebenfalls von hoher Stabilität. Eine Kursschwankung im Sub-Markt der Aufmerksamkeitsökonomie entsteht so durch den potentiell wechselnden Kurswert eines Individuums statt durch einen wechselnden Kurswert des Zahlungsmittels. Die dominante Kritik an der "zukünftigen« Ökonomisierung der Aufmerksamkeit greift deswegen zu kurz, weil sie erstens als Tausch von Ansehen schon längst ökonomisiert ist und weil zweitens begriffliche Symbole wie Prestige, Reputation und Ruhm tatsächlich im übertragenen Sinne wie Währungsäquivalente genutzt werden. Drittens sind die Überlegungen von SIEGERT hinsichtlich der Kopplung der Währungen von Geldökonomie und Aufmerksamkeitsökonomie (in: BECK und SCHWEIGER 2001: 119) einerseits Wasser auf die Mühlen des hiesigen Theoriemodells wie andererseits auch ein deutlicher Hinweis auf deren friedliche Koexistenz. Aufmerksamkeit sollte im theoretischen Diskurs als Währung in einem Sub-Markt in sozialökonomischer Betrachtungsweise - ganz im Sinne der WEBERschen Marktgemeinschaft (vgl. WEBER 2010: 48gff) - akzeptiert werden und in diesem Sinne Verwendung finden, da es sich um eine (soziale) Währung handelt, die einerseits von allen Marktteilnehmern seit langer Zeit akzeptiert und andererseits auch real gehandelt wird.

Verwunderlich ist bis heute, dass GEORG FRANCK die förmlich greifbare Quantifizierbarkeit sozialer Aufmerksamkeit als Zahlungsmittel, die in den von ihm selbstverständlich verwendeten Begriffen mitschwingt, nicht selbst konkreter unter dem Gesichtspunkt ihres nicht im fachlichen Sinne ökonomischen und dennoch tatsächlichen Tausches betrachtet hat. Seinem Ergebnis nach fehlt diesem Tausch der Maßstab (s. o.). An eben jenem Punkt treffen die ungerechtfertigte Kritik wie die Behebung des scheinbaren Mangels zusammen. Ich wage die Vermutung, dass er in seinem Bestreben, ein in die Zukunft weisendes Modell für den Handel mit Aufmerksamkeit darzustellen, das die Geldökonomie ablösen werde, erstens aufmerksamkeitsheischend und zweitens genauso betriebsblind war wie die Kritiker aus den Reihen der Ökonomietheorie, die angesichts einer Verletzung der Grenzen ihrer Felder nicht mehr in der Lage schienen, jenen fremdartig bis absurd erscheinenden Ansatz weiter zu denken, als eine rein fachliche Kritik reichen kann. Vom tauschbaren sozialen Wert des Einzelnen, der sich dadurch generiere, »in wie vielen Gedächtnissen er wie stark gespeichert« sei (STRUBE in: BLEICHER und HICKETHIER 2002: 80), führt eine direkte Linie zu WALDENFELS, der die Reakti- 
on des Individuums auf seine "umworbene und angestachelte Aufmerksamkeit« (WALDENFELS 2004: 136f) mit der »Ausbildung eines >Beachtungsreliefs«", als Produkt »einer ständig sich erneuernden Zentrierung und Marginalisierung« beschreibt. (ebd.: 101f). Seine Fragen nach dem notwendigen »Kontrast eines Unauffälligen, das unbemerkt bleibt« sowie einer »Form der Zurückhaltung, die auf ihre lautlose und heimliche Art aufmerken läßt« (ebd.: 283), weisen voraus zur Anonymität wie zu den Problemen, die mit diesem befragten Postulat verbunden sind.

Aspekte der Machtausübung in einer Aufmerksamkeitsgesellschaft tragen eine wichtige Wendung in dieses Kapitel hinein und zeigen deutliche Verbindungen vieler der vorgestellten Gedankengebäude auf. Wo bei CRARY in Aufmerksamkeitsregimen von der "Interiorisierung [Hervorhebung im Original] disziplinärer Imperative« durch das aufmerksame Individuum zu lesen ist (CRARY 2002: 44), nimmt RECKWITZ 2015 in gleichem Bezug ebenfalls FOUCAULT (Überwachen und Strafen) zur Grundlage, wenn er in seinem Essay Die Transformation der Sichtbarkeitsordnungen behauptet, dass »[d]as Subjekt begehr[e], gesehen zu werden [Hervorhebung im Original] «: Dies ganz im Sinne »aktive[r], gewollte[r] Konkurrenz um Aufmerksamkeit« und Sichtbarkeit (s. o.) verstanden. WALDENFELS sieht die Aufmerksamkeit des Individuums von der »Verführungskraft der Dinge« (!) umgarnt (WALDENFELS 2004: 136f). BERNARDY widmet sich ihm als einem den »Urteilen und Bewertungen anderer aus jeweils unterschiedlichen Gründen ausgeliefert[en] « (BERNARDY 2014: 79f), dessen »Selbstdarstellung eine Form der Aufmerksamkeitsbeschaffung» darstelle (ebd.: 142f).

Diese beiden Gedankengänge können bruchlos an CRARYs Idee der Interiorisierung und RECKWITZ’ »Konkurrenz um Aufmerksamkeit « angeschlossen werden. Gerade die zuletzt angesprochenen Aspekte weisen nochmals deutlich darauf hin, dass die soziale Aufmerksamkeit in viel stärkerem Maße ein weit über psychologische Gründungen hinausreichendes oder an Einzelwesen festzumachendes Meta-Phänomen ist, das erst aus einer (design-)soziologischen Perspektive die nötige Reichweite entwickelt, um für dieses soziale Feld anwendbar zu werden. So wird auch deutlich, warum eine rein ökonomiegeleitete Kritik an GEORG FRANCK zu kurz greift: Sie kann durch die Beschränkung auf fachliche Fehler im Sinne der Ökonomie-Theorie nicht mehr leisten. Das ist in diesem Fall jedoch deutlich zu wenig. Wendet man den Blick von der Gruppe auf das aufmerksame Individuum, so steht dieses vor der Herausforderung, die eigene Aufmerksamkeit im Umgang mit derselben wie einen Zeit- und Nutzenhaushalt zu führen. Mit jenen Mechanismen auf individuel- 
ler Ebene wie auch in den Auswirkungen innerhalb sozialer Felder muss jeder Mensch umgehen - mit Sicherheit in unterschiedlichen Abstufungen. Doch weder in der Rolle des Konsumenten kann man der Anforderung entkommen, mit der eigenen Aufmerksamkeit hauszuhalten, noch in der des Designers, sich zu präsentieren, um die der anderen zu wecken. Inhärenten Zwängen zur Selbstkontrolle und zur Selbstpräsentation kann man nur noch mit Verunaufmerksamung und Ausmerksamkeit entgegentreten. Diese Okkasionalismen sind ebenso ironisch zu sehen wie ernst zu nehmen.

Für das Design als hier unter dem Aspekt der Rezeption untersuchtes soziales Feld sind Strategien der Selbstdarstellung und Maßnahmen zur Aufmerksamkeitsbeschaffung ein Teil der notwendigen professionellen Kompetenz von Designern. Die Aufmerksamkeit, die von Designartefakten an sich wie im sozialen Vergleich mit der Nutzung durch andere erregt wird, kann wie ein Kippschalter gedacht werden, der dann gerade nicht als ein Ersatz für Geld dient, sondern als ein wesentlich komplizierter zu bestätigender Einflussfaktor aufgefasst und untersucht werden muss: Als individuell wie sozial wirksamer Denkanstoß vor einer Kaufentscheidung ebenso wie auch in actu dafür oder dagegen und in jeder unausgesprochenen Überlegung zur eigenen sozialen Positionierung. 
»Designer dienen als charismatische Figuren zur Verkaufsförderung.« John A. Walker 


\section{Prominenz}

Erkenntnisse über die Prominenz von Star-Designern waren, ausgehend von dem Problem, dass die Forschungsansätze konventioneller Starforschung für diese Form der Bereichsprominenz nicht tauglich sind, nur auf andere Art zu gewinnen. Eine der Schwierigkeiten lag darin, dass für die Verbreitungsmedien das Sozialleben von Star-Designern außerhalb ihrer Berufstätigkeit im Sinne einer publizistischen Verwertbarkeit keine Rendite verspricht. Das dürfte einer der Hauptgründe dafür sein, dass sie es nicht bis in die Klatschspalten geschafft haben (- mit Ausnahme von Modedesignern). sовICH beleuchtet dies 2011 schlaglichtartig in einem Artikel für das ARTNET-Magazin, der eigentlich die Rolle von RAY EAMES an der Seite ihres Mannes im Rahmen einer Dokumentarfilm-Rezension betrachten soll:

»Der Mythos Biografie hat im Designgeschäft - anders als bei Schriftstellern oder Schauspielern - auch keine Tradition; kaum einer würde sich dem Werk eines Wilhelm Wagenfeld oder Hans J. Wegner über deren private Affären nähern." (SOBICH in: ARTNET ONLINE am 28.12.2011) [online] https://static1.squarespace.com/static/531257b2e4boooec7f8181oc/ t/5321f4fbe4bodoc37a43e434/1394734331408/Eames+do+artikel.pdf [14.12.2018]

RECKWITZ sieht zwar eine Verschiebung zu den »alltäglich-außeralltäglichen Eigenschaften der Kreativen selbst« als gegeben (RECKWITZ in: MOEBIUS und SCHROER 201O: 55), doch solches ist nach Lage der hiesigen Studienergebnisse für Designer nicht zutreffend. Erstens treten sie im Gegensatz zu Schauspielern nicht in fiktionalen Rollen auf, die im Vergleich zur eigentlichen Person ein Interesse an jenem Kontrast und den besonderen, berufsspezifischen Reibungsflächen hervorrufen würden. Zweitens gibt es - außer meiner Idee einer Fangemeinde, die sich als Rezeptionsphalanx in den Verbreitungsme- 
dien austobt - kein Fan-Umfeld, das über manifeste Kaufentscheidungen der Konsumenten hinausreichen würde. Drittens sind die von ihnen entworfenen Artefakte zwingend mit in den Blick zu nehmen, weil sie A) zu einer eigenen Form der Prominenz gelangen wie sie B) die Art der Kommunikation über sie wie über die Designer beeinflussen - mit Bezug auf die Blickrichtungen wie auch auf die Trennung zwischen Produkt und Gestalter.

Star-Designer erfüllen wie alle anderen Prominenten prinzipiell die Kriterien im Sinne des Entrümpelungsvorschlags von WIPPERSBERG, indem sie aus ihrem Umfeld als Bereichsprominente herausragen gelassen und damit zunächst schlicht bekannter als die anderen gemacht werden. Designer können jedoch nicht in gleicher Weise zu Prominenten gemacht werden, wie es mit Künstlern oder den Objekten des Interesses der bisherigen, konventionellen Starforschung geschieht. Sofern Designer nicht ihre Marke SIND (wie im Feld der Mode oder bei dem Versuch, sich als Autorendesigner zu positionieren), haben sie hinter dem Stil der Marken, für die sie arbeiten, zurückzutreten. Dies vollzieht sich immer im Rahmen der durch die Marke gesetzten Grenzen, die in Abhängigkeit vom Produktbereich mal enger gesteckt sein können und mal weiter gefasst sind. Als Werk-Stars sind prominente Designer die Prominenten der zweiten Reihe, denn ihre Art der Prominenz ist eine des Abglanzes, wie sie bei GEORG FRANCK zu finden ist (FRANCK 1998: 131f). Der Grund hierfür liegt im Zugang zu ihr als Folge der Einreichung von Artefakten bei Designwettbewerben, an deren Ende diese für ihre wie auch immer geartete Designqualität ausgezeichnet werden und deren Auszeichnung erst in der Folge auf Designer und Hersteller abstrahlt.

Das Feld des Designs hat - wie das Feld der Kunst - eine eigene illusio. Durch die Klassifizierung als Werk-Stars sind Designer und Künstler miteinander verbunden, die illusio des jeweiligen Feldes aber trennt sie wieder und schreibt die Rollen und das Potential der Prominenz empfangenden auf unterschiedliche Arten fest. Alle Bestrebungen, das Design in die Nähe der Kunst zu rücken, sind vergeblich, weil Designer nicht in der Form als werkschöpfende Individuen betrachtet werden können, wie es im Feld der Kunst geschieht. Zudem kommt es in der Massenproduktion weitestgehend nicht auf Personaloder Individualstile nach Art von Künstlern oder Modedesignern an.

Wo die illusio im Feld der Kunst das Anwachsen des persönlichen Ansehens an der Hervorbringung von Werken festmacht und eine unmittelbare Zuschreibung als Autor des Werks für die Person des Künstlers gegeben ist, gilt dies im Feld des Designs nicht. Wo die illusio im Feld der Kunst dafür sorgt, dass höhere Stückzahlen devalorisierend wirken, weil dadurch die ge- 
heiligte Unikatskultur entweiht wird, wo die Vervielfältigungen dem Singulären einen Teil seines Wertes nehmen, gilt dies im Feld des Designs ursprünglich nicht. Die Anpassungen desselben gehen aber so weit, in der Kleinserie als dem feldspezifischen Antagonisten zur Massenproduktion den Ausweg aus derselben und damit auch eine Nobilitierungsstrategie durch die diametral entgegengesetzte Form der Besonderung zu wählen. Dies führt seit der Zeit des Neuen Deutschen Designs auch wieder zum Einzug der handwerklichen Produktion als Gegenreaktion auf die Massenproduktion und die Begrenzungen durch den Funktionalismus.

Nur in Sonderformen der Abglanz-Prominenz (der Kopie des Unikats in Form der Fälschung und des Serienprodukts in Form des Plagiats - von RIDO BUSSE alljährlich mit dem PLAGIARIUS ausgezeichnet) verbinden sich das Feld der Kunst und das Feld des Designs wieder in dem Bestreben, etwas vom jeweiligen Ruhm eines Originals auf andere Mühlen umzuleiten. Genauer betrachtet allerdings nur in ökonomischer Hinsicht, durch Übertölpelung des Konsumenten. Ein Abglanz von Prominenz für den Fälscher wird im Feld der Kunst nicht angestrebt ${ }^{1}$.

Prominenz-Zuwächse gehen in beiden Feldern annähernd gleichartig vonstatten. Zunächst muss jeweils eine Form der Bereichsprominenz erreicht werden, die sich zu allgemeiner Prominenz ausweiten kann. Unterschiede zwischen beiden Feldern bestehen laut KLAMER et al. (2011) konstitutionell in der Kompetitivität und der Heterogenität resp. Homogenität der Märkte. Wenn diese die Chancen von Künstlern, ihre Werke zu verkaufen, ohne Aufmerksamkeit oder Prominenz deutlich sinken sehen, dann ist gedanklich die Volte angebracht, sich zu fragen, ob nicht in diesem Markt der Prominenz die Reputation den eigentlichen Gradmesser der Produktqualität einer Person als prominente Person darstellt, die wiederum in ihren unterschiedlichen Stufen auf unterschiedliche Qualitätsstufen von Prominenz verweist und damit

1 Hier ist seine Anonymität sogar eine Grundbedingung, da er sich im Ergebnis nicht mit fremden Federn schmücken möchte wie im Feld des Designs, wo das Nachahmen im Sinne eines me too-Produktes oder einer Kopie ökonomische Profite ohne echte entwickelnde Eigenleistung verspricht. Im Feld der Kunst wird eine Eigenleistung erforderlich, die in der nahezu vollständigen Mimikry eines künstlerischen Stiles besteht, um entweder möglichst ununterscheidbare Replikate des (eigentlich) unikatären zu erzeugen oder um dem Markt nicht originale Originale unterzujubeln. Sie ist mit erheblichem Aufwand verbunden. Ein guter Ruf als Fälscher entwickelt wohl seine ganz eigene Dynamik, wogegen man sich mit der Kopie auf dem Felde des Designs die Entwurfs- und Entwicklungskosten spart, um vom gleichen Kuchen wie der Originalhersteller zu naschen. 
doch querschnittartige Annahmen über die Produktqualität der Prominenz zulässt: Womit auch zwischen minder- und höherwertiger Prominenz unterschieden werden kann wie zwischen minder- und hochwertigen Produkten im Markt der Massengüterproduktion. Die Trajektorie der Prominenz legt dies sehr nahe. Auf dem Weg von ihrem Nullpunkt bis zum Ruhm ist der Übertritt von der Bereichsprominenz zur allgemeinen Prominenz ein als solches qualifizierbares Beispiel, ebenso wie jene unterschiedlichen begrifflichen Qualitätsstufen auf dem Weg zum Ruhm.

Der Transfer von ökonomischen Profiten in symbolisches Kapital findet im Feld des Designs durch Auszeichnungen wie z. B. den LONGLIFE-DESIGNAWARD (s. o.) statt. Symbolisches Kapital wird in Form von Zusatzbenennungen für den Verkauf von Artefakten (designed by ...) genutzt, es wird durch die Aufnahme in die Designsammlungen von Museen, durch Einzelausstellungen von Designern sowie Erwähnungen in Publikationen zur Designgeschichte oder in Designlexika erzeugt. Die Erinnerungsanlässe für die Aufrechterhaltung des Prominenten-Status, die nach wippersbergs Modell einer Prominenzierungsspirale immer wieder gesetzt werden müssen, werden in der Befestigungsliteratur und im untersuchten Zeitschriftenkorpus geschaffen, die von ihrem Zuschnitt her auch die Bereichsprominenz und die allgemeine Prominenz voneinander trennen.

Designer versuchen (als Autorendesigner) Erinnerungsanlässe zu schaffen, wie die Presse (mit Berichten über Star-Designer und Designklassiker und der damit einhergehenden Verkultung), wie die Museen (mit Einzelausstellungen von Designern in der Art von Kunstausstellungen) und alle zusammen ziehen dem Design damit einen Mantel über, den es so ebenso wenig benötigt, wie er ihm passt. Warum es im Feld des Designs mit Blick auf die Prominenz seiner Hauptakteure immer wieder auf diesen Flirt mit der Bildenden Kunst hinausläuft, kann nur noch mit der die Designer wie die wertsetzenden Personen und Institutionen affizierenden Strahlkraft der Sozialfigur des Künstlers und dem besondernden Sozialprestige des Feldes der Kunst gedeutet werden. Sie scheinen den Beweggrund zu liefern, dass entwerfende Personen ebenfalls als Hauptfiguren im Sinne eines Stars im Scheinwerferlicht stehen wollen und auch von anderen dorthin befördert werden. WALKER schreibt dazu treffend:

"Die Faszination von der Gestalt des 'großen Designers erweist sich trotz endloser Kritik im Designdiskurs unter anderem deshalb als so zählebig, weil von der Ideologie des Individualismus und der romantischen Vorstellung des großen Künstlers noch immer große Macht auf Wirtschaft und Massenmedien, auf Designer und Konsumenten ausstrahlt. Designer die- 
nen als charismatische Figuren zur Verkaufsförderung. Ganze Stöße von Produkten tragen Etiketten mit dem Namen eines individuellen ,Urhebers` (das Gegenstück zur Künstlersignatur auf Gemälden), auch wenn die Produkte von einem Team, einem Modehaus oder einer Handelsgesellschaft hergestellt werden." (WALKER 1992: 68f)

Doch wo im Feld der Kunst (, Musik, Literatur ...) der Künstler quasi seine Kunst IST und von außen auch in dieser Personalunion wahrgenommen wird (als Konstituens der illusio des Feldes), verbleibt der Designer im Feld des Designs in der Rolle des Entwerfenden neben den Artefakten und steckt im Rahmen der sie hervorbringenden Strukturen und Prozesse wie in der Zusammenarbeit mit allen anderen Akteuren fest. Dort, in den Begrenzungen durch die Rahmenbedingungen von Marken und Aufträgen, in der Nutzbarkeit der Artefakte im Rahmen des produzierbaren wie in den Einschränkungen durch gesetzliche Regulierungen und (u. a.) ergonomische Anforderungen liegen die Grenzen der entwerferischen Freiheit. Sie reichen nie so weit wie die imaginierten im Feld der Kunst. Der Wunsch, diese zu überwinden, erscheint gleichermaßen verständlich wie sinnlos. Versuche, sich selbst in das Feld der Kunst einzuschreiben, wirken unreif, ebenso wie der unbedacht daherkommende Jubel über diese Übergriffe aus den Reihen derjenigen, die den Wert der Artefakte einerseits publizistisch (mit)produzieren und andererseits jenes Verhalten anstacheln. 
»Anonymität existiert in einem objektivierbaren, quasi »naturwüchsigen« Sinne nicht. Artefakte werden für anonym erklärt und dadurch wird Anonymität erst hergestellt.«

Markus Köck 


\section{Anonymität}

Nehmen wir eine Aufmerksamkeitsgesellschaft an, die die Basis einer Aufmerksamkeitsökonomie bildet, so stellt in ihr die Anonymität den unvermeidlichen Gegenpol zum Star-Sein dar. Als Begriff führen viele sie im Munde und sie lohnte gerade für das Feld des Designs eine ausführliche Auseinandersetzung, weil sie (vom Zeitpunkt des Abschlusses dieser Arbeit aus betrachtet) begrifflich wie theoretisch und auch konzeptionell jede Menge Spuren in den letzten sechs Jahrzehnten hinterlassen hat. Als Grund für Ausstellungen und Hauptargument in theoretischen Auseinandersetzungen wie als Thema wissenschaftlicher Untersuchungen im Zusammenhang mit Design. Als USP von ideologisch geprägten Abspaltungen aus dem Pool der Designer mit manifestartigen Haltungen wie NO DESIGN oder SUPERNORMAL und auch als Teil von Markenkonzepten (IKEA, MANUFACTUM, MUJI). Lässt man all dies in der Phrase anonymes Design kulminieren, so ist

1. festzustellen, dass selbiges in einem objektivierbaren, quasi »naturwüchsigen « Sinne nicht existiert, sondern dass Artefakte

2. für anonym erklärt werden (können) und dadurch

3. die Anonymität erst hergestellt wird -

was in den untersuchten Arbeiten und Publikationen auf sieben feststellbar unterschiedliche Arten geschieht. Die Behauptung des anonymen Designs entreißt die so bezeichneten Artefakte sogleich wieder ihrer tatsächlichen Anonymität und beendet den Zustand des noch-nicht-Kennens, in dem diese unsere Aufmerksamkeit noch nicht erregt haben.

In der genaueren Betrachtung, dadurch, dass wir sie ins Scheinwerferlicht stellen, arbeiten wir daran, ihren "Überschuss an Fremdheit" (WALDENFELS 2004: 253) zu reduzieren. Dessen Fingerzeig zum »Kontrast eines Unauffälli- 
gen, das unbemerkt bleibt« (ebd.: 283) wäre nicht notwendig gewesen, doch ist er willkommen, weil es aus Sicht dieser Arbeit eine interessante Tatsache darstellt, dass auch der Phänomenologe am Ende seiner Betrachtungen zur Aufmerksamkeit die Notwendigkeit dieser Kontrastierung sieht und so formuliert. Jener »Kontrast eines Unauffälligen, das unbemerkt bleibt«, löst sich in der Sekunde des Erkennens als (noch) Unauffälligem in Nichts auf - weil schon das Bemerken und erst Recht das Benennen jenen Zustand beenden. Als Kernbedeutung der Anonymität bleibt für das Feld des Designs nur noch ein Zustand des noch-nicht-Kennens auf dem Spielfeld zurück.

Die Untersuchung von Händlerkonzepten, die auf behaupteter oder erzwungener Anonymität beruhen, ergab, dass diese auf Dauer nicht durchzuhalten sind und von jenen, die sie zu einem Teil ihres Markenkonzeptes gemacht haben, sowohl selbst unterlaufen wird als auch unterlaufen werden muss. Aus den sieben unterschiedlichen Arten, Anonymität zu fassen oder sich zu ihr zu verhalten, stelle ich vier Besonderheiten noch einmal exemplarisch heraus:

Die erste Besonderheit tritt uns - gleichsam einer Zeitkapsel entsteigend - in Form des Glaubens an ein Zeitalter der Anonymität für Designer entgegen. Das kommt in ALLISONs Masterarbeit mit der Vorstellung zum Ausdruck, dass Anonymität im Entwurf und durch Entwerfen herstellbar werde und dass das Verschwinden eines erkennbaren Personalstils sich aus den Anforderungen des Berufsfeldes im Rahmen der Massenproduktion und als selbstverständliche Folge der Arbeitsteilung immer größer werdender Teams zwangsläufig ergeben werde. Die seither sichtbar gewordene Entwicklung (als deren Eisbergspitze das Autorendesign) weist das Gegenteil als Realität aus und hält jenen Gedanken im Reich der Utopie gefangen.

Die zweite Besonderheit ist eine unter spezifisch nationalen Gesichtspunkten entstandene Haltung zur Anonymität in unmittelbarem Bezug zu einer als nationalitätsspezifisch wahrgenommenen Designkultur. Hierfür lässt sich KAJ FRANCK als Repräsentant einer spezifisch finnischen Design-Identität im WKII-Nachkriegs-Europa zutreffend heranziehen. Genauso verhält es sich über dreißig Jahre später mit der Publikation der JAPANESE SOCIETY FOR THE SCIENCE OF DESIGN. Wo ersterer für seine Disziplin mit Blick auf großseriell hergestellte Produkte den Rückzug aus der ersten Reihe und ein aktives Verschwinden der Designer hinter der Herstellerbezeichnung einfordert (ebenfalls eine Prominenz der zweiten Reihe), sucht letztere nach den Wurzeln einer 
anonymen Entwurfshaltung und findet sie u. a. als Ergebnis einer nationalkulturellen Entwicklung. Wobei in der verkörperten Abwesenheit von Eigenreklame die japanische Position als moralische Frage (bei gleichzeitiger Verantwortungsübernahme via Herstellerkennzeichnung) sinngemäß gleichauf mit KAJ FRANCKs früheren Forderungen liegt.

Einzigartig am Fall KAJ FRANCK ist bis heute die unmittelbare und heftige Auswirkung in FINNLAND: Eine eigentlich unspektakuläre Pressestunde von ARABIA am 11.09.1965, in der »die neue Linie für die Vermarktung von Konsumgegenständen [vorgestellt wird], die nunmehr darin best[eht], den Designernamen bei Serienprodukten wegzulassen « - sowie ein Vortrag über Anonymität von KAJ FRANCK im gleichen Jahr für ORNAMO (den Initiativausschuss der Dachorganisation für industrielle Künste in Finnland) - hat nationsweite Gefühlsaufwallungen in Form einer breiten Debatte in der Presse sowie eine deutliche Verunsicherung bei den Konsumenten zur Folge (MERENMIES 1998: 84ff, 90 $)^{1}$. Im gesamten Erstreckungsbereich dieser Untersuchung findet sich keine weitere Verlautbarung anderer Designer, die ähnlich weitreichende und erfassbare Konsequenzen hatte.

Die dritte Besonderheit weist bei mehreren Autoren mit jeweils leicht verschobenen Akzenten eine (teilweise auch konsum-) kritische Haltung zum Design als Disziplin per se aus, die alle dazu veranlasst, sich das wirkliche Design als besser gar nicht von den Designern erdacht zu wünschen. Diese Paradoxie ist genußfähig. Alternativ will man Designer generell aus der Verantwortung für das Entwerfen entfernen resp. ihnen nahelegen, dies selbst zu tun. Solche Haltungen können heute aus der Disziplin heraus und auch aus meiner Perspektive wie selbstverständlich nicht mehr vertreten werden. Bei FRIEDL und OHLHAUSER werden die Designer in den späten 7oern des 20. Jhd.s als Bedürfnismanipulatoren gebrandmarkt (FRIEDL und OHLHAUSER 1979: 14), die sich für Das gewöhnliche Design gar nicht interessieren würden, weil es sich, wie VON KORNATZKI ihnen sekundierte, nicht in den Dienst der Umsatzsteigerung stellen lasse und weil andere Menschen »viel vernünftiger gestalte[te]n als wir vernunftbesessenen Designer« (FRIEDL und OHLHAUSER sowie VON KORNATZKI in: FRIEDL und OHLHAUSER 1979: 16f, 39f).

1 Ornamo heute: (BELLO für ORNAMO ONLINE am 07.06.2017) [online] https://www.ornamo.fi/en/blogi/making-future-tangible/?highlight=Kaj+Franck [14.12.2018] 


\section{STARDESIGNER ODER GESTALTER DES ALLTÄGLICHEN?}

LICHTENSTEIN verbrüdert sich damit im Geiste und führt eine ganz ähnliche Argumentation in den späten 8oern des 20. Jhd.s mit der Ausstellung Unbekannt - Vertraut noch einmal fort, in der »anonymes Design « als ein »nicht im Atelier eines ausgebildeten Designers entstandenes vorgestellt wird (LICHTENSTEIN 1987: 13). LICHTENSTEINS »unabsichtliches Inkognito erscheint vor dem Hintergrund einer Herstellung von Anonymität aus heutiger Sicht noch einmal in einem anderen Licht, weil im Übersehenwerden, der Tatsache, dass "sich bisher kaum jemand für ihre Arbeit interessierte (ebd.: 13) der WALDENFELSsche »Überschuss an Fremdheit« noch bestehen bleibt. Doch legt LICHTENSTEIN die Anonymität in Verbindung dazu bewusst im Sinne einer »Geltung" aus, die "nicht personenbezogen" sei (ebd.: 13) und spricht sich damit deutlich für die Unauffälligkeit aus, wie er damit auf den Topos des Alltagsdesigns verweist, der auch in Veröffentlichungen wie ANTONELLI (2005) und CLIVIO et al. (2009) zu finden ist.

Die vierte Besonderheit hat auf andere Art unmittelbar mit dem tatsächlichen Gebrauch von Artefakten zu tun und ist nicht an Fragen der Moral oder Aspekte der Konsumkritik gebunden, womit sie sich auch der Idee eines Zeitalters der Anonymität annähert. Eine Anonymität durch Gebrauch, die auch als eine Anonymität im Gebrauch reformuliert werden kann (vgl. WENZL-BACHMAYER 2009: 9), steht als Retter der Funktionsrationalität in einem völlig unideologischen Sinne allein in diesem Umfeld. Unauffälligkeit im Gebrauch verkörpert eine Einstellung zum Design A) aus der Sicht seines Gebrauchers und B) als Arbeitsethik, die als Forderung nach echter Funktionsgerechtigkeit von fachlich gesehen perfekt ausgeführten Artefakten den Werkzeug- und Prothesencharakter in den Vordergrund stellt und damit eine Stimme der Vernunft ohne jedwedes gesellschaftskritisches Gekrächze in den Obertönen erklingen lässt. 

»Dienen dagegen natürliche Objekte als Zeichenträger, dann lässt sich ihr Bedeutungsgehalt nur bewahren, wenn er kontinuierlich von Generation zu Generation weitergegeben wird." 


\section{Rezeption}

Ein vordergründig einfaches Rubrum, unter dem sehr viele unterschiedliche Facetten zu versammeln waren. Zwei quantitative Studien als Basis zur Untersuchung der Designrezeption legten den strukturellen Kern des Kerns frei. In mehreren getrennten Suchläufen untersuchte ich die publizistische Rezeption von Designern und Artefakten und konnte die medialen Konstruktionen von Star-Images sowie die Re-Popularisierung von Designklassikern im Feld des Designs dokumentieren. Als Topos sind Ranglistenbildungen im Feld des Designs keine Neuheit - erinnert sei hier z. B. an JAY DOBLIN und The 100 , best designed products (DOBLIN in: FORTUNE April 1959: 135-141).

Die Besonderheit meiner beiden Studien - verglichen mit auf persönlichem Geschmack und anderen Formen von Werturteilen basierender Bewertungen - liegt in der rein quantitativen Abbildung publizistisch wahrnehmbarer Rezeption. Zunächst ergaben sich aus dem Korpus der Zeitschriften und dem Korpus der Befestigungsliteratur zwei Listen von je zehn deckungsgleichen Personen, die auf der Anzahl der Fundstellen (im Sinne der Anzahl unterschiedlicher Publikationen) und - als zweitem Kriterium - auf der Anzahl der gefundenen Artikel pro Person basierten. Die Rangfolge im Korpus der Zeitschriften:

1. PHilipPe STARCK; 12 Fundstellen, 99 Artikel

2. GIORgetTO GIUGIARO; 8 Fundstellen, 24 Artikel

3. JASPER MORRISON; 8 Fundstellen, 11 Artikel

4. LUIGI COLANI; 7 Fundstellen, 20 Artikel

5. Matteo thun; 7 Fundstellen, 19 Artikel

6. die Gebrüder BOUROUlLec; 6 Fundstellen, 18 Artikel

7. KOnSTANTIN GRCIC; 6 Fundstellen, 18 Artikel 


\section{STARDESIGNER ODER GESTALTER DES ALLTÄGLICHEN?}

8. TERENCE CONRAN; 6 Fundstellen, 7 Artikel

9. DIETER RAMS; 6 Fundstellen, 7 Artikel

10. ROSS LOVEGROVE; 6 Fundstellen, 6 Artikel

Im Korpus der Befestigungsliteratur wurde wegen der geringen Zahl von acht Buchpublikationen nur die Anzahl der Fundstellen (im oben bereits definierten Sinne) zugrunde gelegt. Unter dieser Prämisse wurden folgende Designer gefunden:

1. GRCIC, RAMS: je 7 Fundstellen

2. MORRISON, STARCK: je 6 Fundstellen

3. BOUROULlEC, LOVEGROVE: je 4 Fundstellen

4. COLANI, THUN: je 3 Fundstellen

5. CONRAN, GIUGIARO: je 1 Fundstelle

Als valider Befund beider Studien tritt also die hundertprozentige Übereinstimmung der gefundenen Personen zutage. In der Trennung zwischen Bereichsprominenz (repräsentiert durch die Befestigungsliteratur) und allgemeiner Prominenz (repräsentiert durch die Zeitschriftenstudie) sind mit der Art der publizistischen Rezeption auch Belege für die Prominenzierungsspirale von WIPPERSBERG gefunden worden: Erstens dafür, dass und wie Erinnerungsanlässe geschaffen werden (was speziell für bereits klassikerisierte Artefakte von hoher Bedeutung ist) und zweitens für den Übertritt von einer Form der Prominenz zu einer anderen.

Das merkwürdigste Ergebnis blieb die geringe Zahl wertender Verlangsamungen (vgl. KELLER 2008), die in der FORM und im DESIGN REPORT auftraten, welche als Fachpublikationen wie eine Kontrollgruppe den 11 anderen Zeitschriften gegenüberstanden und eigentlich die Störeinflüsse allgemeiner Prominenz etwas korrigieren sollten.

Unter sprachlichen Aspekten betrachtet wurde in den untersuchten Artikeln im Zusammenhang mit Star-Designern nahezu alles aufgeboten, was an Breitseiten des Lobes und der Ehre von der schreibenden Zunft auf die Personen ihres Interesses abgefeuert werden kann. Neben kreativ eingesetzten Komparativen, Superlativen ähnlichen Bezeichnungen und echten Superlativen wurde der Begriff der Designikone für Personen wie für Artefakte verwendet und als höchstes der sprachlichen Verehrungsmerkmale schrieb sw den Status der Designlegende im Ganzen 16 Personen zu. 
Eine weitere Besonderheit trat in der Nationalisierung der Besonderung und in nationalisierender Vereinnahmung an den Tag. Letztere jedoch im eigenen Sprachraum deutlich weniger als für dem Ausland entstammende Designer, denen nationenweit gültiger Ruhm damit kurioserweise doppelt von außen zugeschrieben wurde. Eine interne Steigerungslogik konnte ebenfalls ausgewiesen werden, die beim bekannten Designer begann und die über den Star-Designer, seine Nationalisierungs-Varianten und den Weltklasse-Designer bis zur Designlegende in den durch Zuschreibungen geschaffenen Design-Olymp hinaufmäanderte. Vor diesen Ruhmeshallen antichambriert der Designernachwuchs. Er wird u. a. als neuer Star, Jungstar, kommender Designstar oder Designhoffnung tituliert und verharrt in einer identischen Startblock-Position wie ehedem der finnische Designernachwuchs. Darauf wartend, Hoffnungen zu erfüllen (welche?) oder Legenden aus dem Olymp entfernt zu sehen, um selbst ins Prominenzkarussel der Großen aufrücken zu können, in dem man dann zum (nie so bezeichneten Altstar) reifen kann: Die noch zukünftigen Optionen sind, als früherer Star deklassiert oder als älterer Star klassikerisiert zu werden (vgl. BOURDIEU 1999: 403).

Um die danach erfassten Artefakte mit den Star-Designern vergleichen zu können, wurden diese mit dem Fokus auf die Anzahl ihrer Nennungen in den untersuchten Zeitschriften erfasst und durch das Kompositum SupraDesignklassiker auch auf eine qualitativ den Star-Designern gleichgesetzte verbale Steigerungsstufe gehoben. Die Rangfolge derselben stellt sich so dar:

4 Fundstellen

- 1968 Sessel SACCO; GATTO, PAOLINI, TEOdORO (A\&W, ART DAS KUNSTMAGAZIN, DIE PRESSE, SW)

- 1956 LOUNGE CHAIR; EAMES (A\&W, ART, F.A.Z., SW)

- 1927 Beistelltisch E 1027; EILEEN GRAY (A\&W, ART, FORM, NZZ)

- 1925 WASSILY-CHAIR; MARCEL BREUER (A\&W, ART, NZZ, SÜDDEUTSCHE)

3 Fundstellen

- 19859093 BIRD KETTLE; MichaEL GRAVES (ART DAS KUNSTMAGAZIN, DIE WELT, FORM)

- 1971 Tischleuchte TIZIO; RICHARD SAPPER (A\&W, FORM, NZZ, SW)

- 1964 Polstermöbelprogramm CONSETA; WILHELM MÖLLER (A\&W, FORM, SW) 


\section{STARDESIGNER ODER GESTALTER DES ALLTÄGLICHEN?}

- 1963 Möbelprogramm USM HALLER; PAUl SCHÖNER, FRITZ HALLER (A\&W, FORM, SW)

594 - 1936 Vase SAVOY; ALVAR AALTO (A\&W, DIE WELt, DIE ZEIT)

- 1933 Hocker 6o; ALVAR Aalto (A\&W, Die Welt, DiE Zeit)

- 1929 Sessel barcelona; LUdWIg Mies VAN DER ROHE (A\&W, ARTE, NZZ)

2 Fundstellen

- 2006 Stuhl myto, KONSTANTIN GRCiC (DER SPIEgel, NZZ); BONE CHAIR, JORIS LAARMAN (A\&W, FORM)

- 1997 Bücherregal BOOKWORM, RON ARAD (ARTE, FORM)

- 1987 Tischleuchte TOLOMEO, DE LUCCHI, FASSINA (A\&W, SW)

- 1981 Raumteiler CARLTON, ETTORE SOTTSASS (ART, DIE WELT)

- 1978 Espressokanne 909o, RICHARD SAPPER (DIE WELt, FORM)

- 1972 WIGGLE CHAIR, FRANK GEHRY (A\&W, SW)

- 1969 Perlflasche, GÜNTER KUPETZ (DESIGN REPORT, FORM); Schreibmaschine VALENTINE, ETTORE SOTTSASS (ARTE, DIE WELT)

- 1968 Hängeleuchte SEMI, BONDERUP, THORUP (A\&W, SW)

- 1960 Tischleuchte AJ, ARNE JACOBSEN (A\&W, SW)

- 1958 Tische und Stuhl tulip, EERO SAARINNEn (A\&W, FORM)

- 1952 diamond chair, haRRY bertoia (A\&W, SW)

- 1950 Rar rocking chair, eames (a\&W, SW)

- 1949 Tisch ARABESCO, CARLO MOlLino (A\&W, F.A.Z.)

- 1946 Stuhl domUs, ilmari taPiovaARA (A\&W, DIE WELt)

- 1939 Treteimer VIPP, HOLGER NIELSEN (A\&W, SW);

LANDI-Stuhl; HANS CORAY (A\&W, NZZ)

Bereits bei einem oberflächlichen Blick fällt auf, dass kein anderer Designer der zuvor präsentierten Star-Designer-Rangliste außer KONSTANTIN GRCIC mit einem als Designklassiker, Moderner Klassiker oder als Designikone bezeichneten Artefakt vertreten ist.

Der nächste Schritt bestand in der Suche nach Artefakten im Korpus der Befestigungsliteratur. Eine Abbildung stellte deren grundlegendes Aufnahmekriterium dar. Auf die Tatsache, dass PHILIPPE STARCK sich in der Zeitschriftenstudie in quantitativer Betrachtungsweise als die medial gesehen prominenteste der zehn ermittelten Personen herausgestellt hatte, wurde mit Konsequenzen für die Suchschwerpunkte der noch folgenden Suchläufe reagiert. So ist für jede Publikation auch ihre STARCK-Quote mitermittelt worden sowie die Übereinstimmungen mit den bereits ranglistenplatzierten. 
Die Deckungsgleichheit der Personen wurde oben bereits herausgestellt, darüber hinaus verteilten sich siebzehn Artefakte auf nur noch sechs der zehn Listenplatzierten. Diese werden hier zunächst wieder in der Reihenfolge der obigen Listenplätze aufgeführt, mit der Zahl der pro Designer gefundenen Artefakte in Klammern:
1. PHILIPPE STARCK (2)
2. GIORGETTO GIUGIARO
3. JASPER MORRISON (2)
4. LUIGI COLANI
5. MATTEO THUN
6. die Gebrüder BOUROULLEC (4)
7. KONSTANTIN GRCIC (5)
8. TERENCE CONRAN
9. DIETER RAMS (3)
10. ROSS LOVEGROVE (2)

Unter der Prämisse, dass Artefakte in mindestens drei verschiedenen Publikationen abgebildet sein mussten, dampfte eine Feininterpretation die Liste auf sieben Artefakte von sechs Designern ein, die mit keinem der Artefakte aus der Zeitschriftenstudie übereinstimmten und als einzigen Designer wieder nur KONSTANTIN GRCIC als Doppelung führten:

1. PHILIPPE STARCK: Zitronenpresse JUICY SALIF (6 Fundstellen)

2. DIETER RAMS: PHONOSUPER SK4 (5 Fundstellen); Regalsystem 606 (5 Fundstellen)

3. JASPER MORRISON: THINKING MAN'S CHAIR (4 Fundstellen); PHILIPPE STARCK: Stuhl cOSTES (4 Fundstellen)

4. KONSTANTIN GRCIC: CHAIR OnE (3 Fundstellen); Dieter RAMS: Sesselprogramm 620 (3 Fundstellen)

Von DIETER RAMS absehend liegt das Geburtsdatum aller Designer deutlich nach dem zweiten Weltkrieg. Die Artefakte umfassen unter dem Aspekt ihrer Inverkehrbringung einen Zeitraum, der von den 5oern des 20. bis in die Nullerjahre des 21. Jhd.s reicht. Als Hauptauslöser dieser Arbeit spielt die an Platz eins befindliche Zitronenpresse JUICY SALIF speziell für dieses Kapitel eine besondere Rolle, weil sie

1. ein Entwurf des Spitzenplatzierten der Zeitschriftenstudie ist und damit der publizistisch betrachtet prominentesten Person im Sinne einer allgemeinen Prominenz, 
2. im Markt neben den Standardmodellen durch Kleinserien als Kunstwerk im Zeitalter seiner technischen Reproduzierbarkeit platziert wird,

3. wegen ihres nach Stückzahl sowie Produktionszeitraum großen Verkaufserfolges, denn sie würde quantitativ den Longlife-Design-AwardKriterien von BUSSE entsprechen,

4. weil sie auch schon zum Forschungsgegenstand anderer Arbeiten wurde (u. a. LLOYD und SNELDERS 2003 sowie Erwähnungen bei NORMAN 2005 und ECO 2006) und

5. weil sie für diese Arbeit das Kronzeugenartefakt darstellt, anhand dessen etwas über unser verändertes Verhältnis zu Artefakten, ein verändertes Verhältnis der Designer zum Entwurf im Rahmen ihrer Disziplin und den - wenn auch nicht generell - erweiterten Funktionsumfang von Artefakten ausgesagt werden kann.

Den Kernbegriff hierzu finden wir im Identifikationsartefakt verkörpert. Verglichen mit einer funktionalistischen Designauffassung gründet seine Entstehung in gänzlich veränderten Entwurfsprinzipien und auch seine Nutzung ist eine andere. Dadurch werden unsere Verhältnisse zu jenen Dingen in unseren Leben, die aus Designerhand stammen und bisher primär als Werkzeuge oder Prothesen gedacht waren, ebenfalls beeinflusst und verändern sich. Sein postmodernes Objekt-Charisma (vgl. LENZE 2002: 165) verwandelt »das Ding [in ein] Kultobjekt « und erzeugt damit einen Teil der »Verabredung[en] über den Status von Objekten« (vgl. BREUER 2001: 104, 118). Diese sind ausschließliches Ergebnis subjektiver Besetzungen mit außergewöhnlicher Bedeutung. Ein Identifikationsartefakt entsteht in den Reihen seiner Rezipienten als Ergebnis von Prozessen, die außerhalb der Einflussmöglichkeiten von Gestaltern liegen. Seitdem Artefakte dieser Art in Verkehr gebracht und im Markt akzeptiert wurden, ist es auch möglich, diesen Entwurfs-Topos gezielt einzusetzen, indem funktionalistische Entwurfskriterien bewusst außer Acht gelassen werden - wie immer ohne Erfolgsgarantie. Ganz aktuell gestützt wird meine Argumentation, dass der unverhandelte Bedeutungskern von Designklassikern, Designikonen oder Modernen Klassikern - auf deren Rezeption bezogen - inzwischen aus ihren unverkennbaren Idiosynkrasien bestünde (anstatt in nachahmenswerter, dauerhafter Vorbildhaftigkeit) durch RECKWITz' Die Gesellschaft der Singularitäten (erschienen im Oktober 2017).

Auf die Erkenntnisse der Prominenzforschung bezogen, musste die Vorbildhaftigkeit des Klassikerbegriffs auch für das Feld des Designs entrümpelt werden, wonach nur noch das schlichte Herausragen aus der Masse als einziges Differenzierungsmerkmal verblieb, dem ein Aufmerksamwerden und 
eine Integration in ein je individuelles Aufmerksamkeitsprofil folgen können. Der Designklassiker wurde im Rahmen der untersuchten Publikationen in ein Korsett aus Zeitlosigkeit, Innovation, Funktionsgerechtigkeit, Gültigkeit und Vorbildhaftigkeit gezwängt. Auf der wissenschaftlichen Seite leuchtete er als Maßstab einer Alltäglichkeit höchster Qualität am Firmament, der die aufgefundenen Artefakte in ihrer Außergewöhnlichkeit größtenteils himmelschreiend widersprachen - was ebenso der Fall war, wenn streng nach Duden Mustergültigkeit und Dauerhaftigkeit den Ausschlag hätten geben sollen.

Die Rezeption zusammenfassend entsteht für das Feld des Designs folgendes publizistisch gespiegelte Bild seiner Hauptakteure und der von ihnen entworfenen Artefakte: Die publizistische Produktion des Ikonischen geht mit sprachlichen Überbietungsstrategien (Hand in Hand mit argumentativer Inhaltsleere) vonstatten und ist über Publikationsgrenzen hinweg geeint in reiner Schein-Maßstäblichkeit. Sie wird weder auf Seiten der Theoretiker in den Reihen der Befestigungsliteratur noch in der Populärpublizistik mit auch nur in Ansätzen normativ weiter darüber hinausweisen sollendem unterfüttert. Reflektion findet nicht statt, sondern nur weder explizierende noch legitimierende Repetition in Varianzen.

Der Schlagbild-Charakter hätte nicht deutlicher zutage treten können und zugleich ist zu sehen, dass bis heute der epochenverschleppende Anspruch aufrechterhalten wird, damit auch Konsumentenbildung zu betreiben. Als Teil des Allgemein-Besonderen (vgl. RECKWITz 2017) treten die ermittelten Personen und Artefakte den Konsumenten und auch allen später Schreibenden als Sinnangebote gegenüber, die als stillschweigend unverhandelte, aber nichtsdestotrotz existente Verhandlungsergebnisse aufgefasst werden müssen. Aus deren Reihen fischen sich Konsumenten wie Autoren immer noch und immer wieder nach Lust und Laune das ihnen genehme heraus - wodurch diese Sinnangebote in Funktion gesetzt werden.

Die Konsumenten, die auch als Mitglieder der Aspirational Class aufgefasst werden können (vgl. CURRID-HALKETT 2017), arbeiten auf dieser Basis an ihren eigenen Aufmerksamkeitsprofilen wie an denen der anderen mit und die Autoren tragen ebenfalls ihr Scherflein zu den »Verabredung[en] über den Status von Objekten« (s. o.) bei. Womöglich empfinden letztere sich dabei ebenso wie erstere als Teil einer großen Geschmacksgemeinschaft. Sinnangebote werden dergestalt kulturell und sozial wirksam. Ihre großen Differenzen bei Personen wie bei Artefakten bieten jede Menge Raum zu individueller Orientierung, nachdem die Zeiten einer in der Breite anerkannten Deutungshoheit vorbei sind. Die unvermeidliche Bruchlinie liegt dort, wo die intendierte Wert- 
STARDESIGNER ODER GESTALTER DES ALLTÄGLICHEN?

setzung des Sinnangebots auf die subjektive In-Wert-Setzung oder Nicht-inWert-Setzung durch die Konsumenten trifft und sie sich in ihrer Kontingenz auch weiterhin als Inhibitor von Erfolgsrezepten behauptet. 




\section{Hypothesen}

Nach dem Rückblick auf die vier Großkapitel steht noch eine Überprüfung der aufgestellten Hypothesen aus.

1. Der FRANCKsche Aufmerksamkeitsbegriff lässt sich auf Artefakte ebenso anwenden wie auf Personen:

Sie kann als belegt gelten, da Designklassiker wie Design-Ikonen und auch Moderne Klassiker als artefaktische Äquivalente zu Star-Designern gelten können.

2. Stardesign hat eigene Aufmerksamkeitsstufen. Wird eine bestimmte Aufmerksamkeitsschwelle nicht überschritten, sinkt das Artefakt in die Aufmerksamkeitslosigkeit zurück:

Dies wäre aus heutiger Sicht nicht mehr so zu formulieren sowie um Personen zu erweitern. Doch schon in der Urform besteht eine Verbindung zur Prominenzierungsspirale und den Erinnerungsanlässen. Für Artefakte hat zu gelten, dass, wenn sie gar keine Aufmerksamkeit erregen, schon diese minimale Schwelle nicht überwunden und ein Prominenzierungsprozess im Sinne seiner Erkennbarkeit gar nicht erst in Gang gesetzt wird. Die Aufmerksamkeitslosigkeit käme für diesen Fall einem Verbleib in der Unauffälligkeit/Anonymität gleich, für Personen gälten nämliche Konsequenzen. Unterschiedliche Aufmerksamkeitsstufen für letztere sind z. B. unter Bezug auf WIPPERSBERG durch die Trennung zwischen Bereichsprominenz und allgemeiner Prominenz gegeben, was durch eine deutliche Zunahme derselben beim Übertritt von ersterer zu letzterer gekennzeichnet ist. Auf der Ebene der sprachlichen Zuschreibungen lassen sich zudem graduelle Steigerungsstufen ausmachen, die von der Bekanntheit als geringstem Wert auf dem Weg 
zur Weltgeltung und der nachfolgenden Absetzung ins Legendäre durch gut erkennbare Zwischenstufen markiert werden. Für Personen muss noch hinzugefügt werden, dass sie wieder in die Aufmerksamkeitslosigkeit zurücksinken können, wenn die Zahl der Erinnerungsanlässe signifikant abnimmt und damit auch der Prominentenstatus keine Gültigkeit mehr hat (vgl. WIPPERSBERG 2007: 276f). Insoweit kann diese Hypothese für Artefakte wie für Personen als belegt gelten.

3. Artefakte können vom Alltagsdesign zum Star-Design überwechseln, da es sich um Zuschreibungen handelt, nicht um Eigenschaften des Designs: Dies kann anhand einer möglichen und immer erst nachfolgenden Wertsetzung als Designklassiker, Design-Ikone oder Moderner Klassiker für Artefakte, die bis zu jenem Moment einfach nur als solche existierten, als belegt gelten. Gleichfalls der Versuch, diese von hier nach dort überwechseln zu lassen. Die Anfänge hierfür können in der aktiven Einreichung zu Wettbewerben wie in der passiven Kür im Rahmen der Befestigungsliteratur liegen.

4. Star-Qualität als Produktmerkmal: Wird schon im Entwurf versucht, den Starfaktor zu antizipieren und zu integrieren, die Zuschreibung zu entwerfen?

In Ansätzen betrachte ich die Hypothese als belegt. Die Starqualität als Produktmerkmal wurde anhand ZIMMERMAN und AYOOBs Artikel entlang ihrer Überlegungen zu Celebrity Endorsed Products einer genaueren Betrachtung unterzogen. Das überzeugende, nutzbare Produktmerkmal wurde an dieser Stelle als Konsumentenerzählung beschrieben, die auf einer parasozialen Be with-Interaktion beruhe, also einer sinnstiftenden Verbindung zwischen Produkt und Prominentem, die Konsumenten das Artefakt als Extension des Prominenten erleben lässt, die ihn dadurch ins eigene Leben integriert. Eine erfolgreiche Aufladung von Artefakten mit »celebrity content" und die Möglichkeit zur »celebrity consumption« stellen für diesen Spezialfall eine wie auch immer fassbare Starqualität als Produktmerkmal dar und dies in Form eines Teils der Produkt-Erzählung. Das Herumeiern von ZIMMERMAN und AYOOB hinsichtlich der Konzeption zeigte die Schwierigkeit auf, eben jenes je ne sais quoi als ein greifbares zu explizieren (JUNGEN hat ähnliches im Rahmen seiner 2011 erschienenen Dissertation unternommen). Jene Versuche, Explikationen zu liefern und Hinweise darauf zu geben, wie solches besser erreicht werden könnte, werden von mir als Belege dafür gewertet, dass versucht wird, jene Starqualität mitzuentwerfen. Man 
versucht, Produkterfolge im Vorhinein abzusichern, dem Geheimnis auf die Spur zu kommen, auf das im Gegensatz zum Startum nur geschlossen werden kann (KELLER 2008: 149). Ein Stochern im Nebel, das mit BOLZ nur so zu kontern ist:

"Die Komplexität unserer Gesellschaft schließt aber Rezepte des Erfolgs, Spielregeln für Sieger aus. So wächst das Bedürfnis nach Rezepten mit der Unmöglichkeit ihrer Bewährung." (WERTEINDEX) [online] http://werte index.de/werte/ [25.06.2018]

5. Der Ruhm eines Gestalters kann sich auf die Bewertung der Artefakte auswirken wie vice versa:

Dies kann nach Auswertung der untersuchten Publikationen unter quantitativen Gesichtspunkten nur für unzutreffend erklärt werden: Belege, die diese Vermutung gestützt hätten, wurden nicht gefunden. Während beide Studien zunächst noch die gleichen Designer als präferierte auswiesen und damit einen gelungenen Übertritt der zehn von der Bereichsprominenz zur allgemeinen Prominenz nahelegten, differierten sie in der Spanne der Artefakte extrem und es fand sich keine artefaktische Übereinstimmung unter ihnen. Der Zahl von 29 Artefakten als Kondensat des Zeitschriftenkorpus standen zunächst 17, nach der Feinauswertung noch 7 aus den Reihen der Befestigungsliteratur gegenüber. Die einzige Übereinstimmung von Designern besteht zwischen den beiden Studien in KONSTANTIN GRCIC. Schon in der Zeitschriftenstudie fand sich PHILIPPE STARCK, der in der größten Zahl an Artikeln erwähnt wurde, mit keinem einzigen Artefakt wieder, das mit den vorstehenden Suchwörtern bezeichnet worden wäre - was ein relevantes Kriterium dargestellt hätte. Genauso verhält es sich (bis auf die bereits erwähnte Ausnahme) mit den anderen Listenplatzierten.

6. Der Funktionsraum von Artefakten hat sich verändert - für Designer wie für Nutzer:

Ein letzter Haken hinter den letzten Punkt, denn der Funktionsraum von Artefakten im Feld des Designs hat sich de facto erweitert, da es inzwischen Funktionen von Designartefakten gibt, die über ein entwurfswie individuenbezogenes gut funktionieren ins Soziale hinausreichen. Was in der Konsequenz bedeutet, dass die bisher üblichen Nutzenerwägungen in solchen Fällen nicht mehr gelten: Hinzu tritt ein neuer, sozialer, nicht entwerfbarer Nutzen, der für die Identifikationsartefakte darin besteht, dass sie eben genau dieses sind. Gleich der Einflusslosigkeit 


\section{STARDESIGNER ODER GESTALTER DES ALLTÄGLICHEN?}

der Designer auf die grundsätzliche Entstehung derselben (s. o.) haben Gestalter in anderer Hinsicht ebenso wenig Einfluss auf die Entstehung dieses speziellen, sozialen Nutzens, der erst nach der Inverkehrbringung des Artefakts durch Kaufentscheidungen erzeugt und im Weiteren sozial ausgehandelt wird. Der Begriff der Aushandlung ist hierbei mit Vorsicht zu genießen, wie es vorstehend schon beschrieben wurde. Trotzdem hat sich der Funktionsraum auch für Designer verändert. Artefakte wie die Zitronenpresse JUICY SALIF, die eine eigentlich von ihnen erwartete Funktion nicht zufriedenstellend erfüllen, danach aber durch die Erzeugung dieses sozialen Werts eine weitere Funktion bekommen, können von anderen Designern als Anlass genommen werden, gleich STARCK die bisher im Feld des Designs noch hochgehaltene Funktionsrationalität außer Acht zu lassen. So können sie zu Geburtshelfern von Produkten werden, die eine andere Form sozialer Wertsetzung prinzipiell möglich machen, die sich in ihren unmittelbaren Auswirkungen aber nicht von der Wertsetzung als Designklassiker (oder der Design-Ikone/ oder als Moderner Klassiker) unterscheidet. 




\section{Ausblick}

\section{Am Ende einerseits: die Desiderate}

Nach dem erkenntnisreichen Start meiner Prominenzforschung im Feld des Designs blieben (wie es nicht anders zu erwarten war) über diese Untersuchung hinausgehende Fragen offen. Eine jener unbeantworteten Fragen ist diese: Wie reagieren die Akteure im Feld des Designs auf seine Rezeption? Deren publizistische Rezeption und die damit gleichzeitig stattfindende, externe Produktion der Prominenz wirft nämlich auch die Frage auf, ob sich auf der Seite der Rezipierten ein dadurch verändertes oder daran angepasstes Verhalten manifestiere, das Rezipierende in einer bestimmten Weise adressieren würde, um damit (u. a. im RECKWITZschen Sinne) absichtsvoll und strategiegeleitet zur Sichtbarkeit zu streben. Dazu müssten selbstständige Designer, die Unternehmen, die sie beauftragen und auch Lehrkräfte an (staatlichen) Hochschulen (in deren Berufungskommissionen) im Rahmen von Experteninterviews standardisiert, aber offen befragen. Mögliche Interview-Leitfäden sind bereits angedacht, werden zum gegenwärtigen Zeitpunkt und an dieser Stelle jedoch noch nicht preisgegeben, um zukünftige eigene Untersuchungen nicht zu gefährden.

Eine weitere Frage lautet: Wie wirken diese Sinnangebote auf Konsumenten und wie werden diese von jenen in Wert gesetzt? Dazu wären Untersuchungen nötig, die mit einem anderen Fokus geführt werden müssten als z. B. jene von MILLER für The Comfort of Things, der als Anthropologe eine Ergründung der persönlichen Bedeutung von Artefakten für Menschen im Sinne ihrer höchstpersönlichen Lebensgeschichte betrieb. Mikrosoziologisch wäre nach dem Zustandekommen von Formen vorgestellter Gemeinschaften (vgl. AN- 
DERSON) wie Interpretationsgemeinschaften (vgl. CRARY) oder auch eines consumer tribe (vgl. HARARI) zu suchen - in direktem Zusammenhang und mit einer Fokussierung auf als Designklassiker, Design-Ikonen oder Moderne Klassiker ausgerufene Artefakte. Jedoch nicht auf der Suche nach deren feldspezifischer Relevanz als Generatoren von Bereichsprominenz. Sondern in der Bedeutung für die Konsumenten, um zu ergründen, ob und wie diese sich einerseits individuell zu jenen Ausrufungen positionieren und wie sich andererseits die consumer tribes $z$. B. des JUICY SALIF (STARCK), des BARCELONA CHAIR (VAN DER ROHE) oder des LOUNGE CHAIR (EAMES) formieren konnten. Das Prinzip lässt sich selbstredend auch noch auf andere Artefakte ausdehnen - der Fundus ist groß.

\section{Am Ende andererseits: die Frage nach der Übertragbarkeit und An- schlussfähigkeit meiner Forschungsergebnisse}

Sie sind nicht als feldspezifisch zu betrachten, denn Anschlussfähigkeit besteht sowohl zur Konsumsoziologie wie auch zur Prominenz- und Emotionsforschung. Darüber hinaus wäre eine Ausdehnung in den Bereich der Linguistik denkbar. Die untersuchten Texte bieten sich ebenso für eine kritische Diskursanalyse an.

\section{Wohin kann uns das führen?}

Das Einflusspotential (m)einer Dissertation wird auch von mir nicht überschätzt. Ich rechne nicht damit, dass sich an dem schlagbildhaften Umgang der Journalisten im Bereich der untersuchten Zeitschriften wie der anderen Publikationen auf absehbare Zeit etwas ändern wird. Dass Designer dort in brevi zwar publikumswirksam, aber auch anhand realistischer, tatsächlich nachvollziehbarer (weil tatsächlich aufgeführter) Meinungen und Kriterien in ihrer Bedeutung, der Spezifität ihrer Leistungen und der Qualität ihrer Entwürfe im Vergleich zu anderen beschrieben würden, lässt sich bis auf Weiteres im Reich der Utopie verorten. Der Star-Designer ist als Wertsetzungs-Abziehbild einfach (zu) bequem. Obschon der Anspruch bereits seit langer Zeit im Raum steht: Schon KAJ FRANCK verlangte 1965, »[a]nstatt vom Namen eines Designers zu leben« eine »vernünftige Information, die eine Grundlage für eine sachliche Bewertung schaffen kann, indem sie Angaben über den Gebrauch, die Herstellung, das Material, die Eigenschaften - sowie 
über die Formgebung - des Produktes macht.« (für beide Zitate: MERENMIES 1998: im Anhang)

\section{In Reflektion der eigenen Rolle zwei letzte Gedankengänge}

Wünschenswert ist einerseits ein aufrichtigerer Umgang mit der Verantwortung, die im (auch populär-)wissenschaftlichen Schreiben liegt. Ich war immer wieder verwundert über die Nachlässigkeit, mit der auch in Publikationen mit einem vermeintlichen Anspruch die Stardesigner-Leier gedreht wurde, ohne die eigene Fachlichkeit für eine dann natürlich auch angreifbare eigene Maßstäblichkeit zu nutzen. Diese würde tatsächliche Verhandlungen über "System[e] von Bedeutungen« ermöglichen und diese Systeme auch tatsächlich erzeugen. Womit anders greifbare Beiträge zu den »komplexen Prozessen gesellschaftlicher Auseinandersetzung und Aneignung" produziert werden könnten, die es erst noch zu erforschen gilt (für beide Zitate: EISELE 2014: 9).

Andererseits wäre - aus heutiger Sicht völlig utopisch - eine Rückbesinnung auf das Wesen des Designs im Sinne seiner (funktionalen) Funktionserfüllung wünschenswert und dies in mehrerlei Hinsicht, doch ohne hiermit eine Neo-Neo-Funktionalismus-Debatte anstoßen zu wollen. Hochschulen für Gestaltung hätten durchaus die Aufgabe, darüber nachzudenken, welche Kriterien bei der Berufung von Professoren zugrunde gelegt werden sollten, die über einen »bestehenden Ruf als Designer oder »internationale Beachtung» hinausgingen und was Anziehungskraft für Studierende oder die Position in Hochschulrankings für ihr Selbstverständnis bedeuten. Im Rahmen der Designausbildung wäre zu thematisieren, in welcher Form Vorbildhaftigkeit im Feld des Designs eine Rolle spielt, welche Kriterien dafür relevant sein könnten und sowohl ob als auch was individueller Ruhm als Ziel im Rahmen der persönlichen Berufsausübung für die Studierenden bedeutet.

Bei Designern könnte ein Denkprozess darüber in Gang kommen, welche Kriterien für persönlichen und geschäftlichen Erfolg sie anlegen und wie sie sich dazu positionieren. Zur Sichtbarkeit streben wir alle und so werden wir der »[...] Anerkennung des Ruhms als eine[m] der Grundphänomene des Gemeinschaftslebens [...]« (WIPPERSBERG 2007: 249) mit seinen Auswirkungen nach allen Seiten auch weiterhin nicht entkommen. 


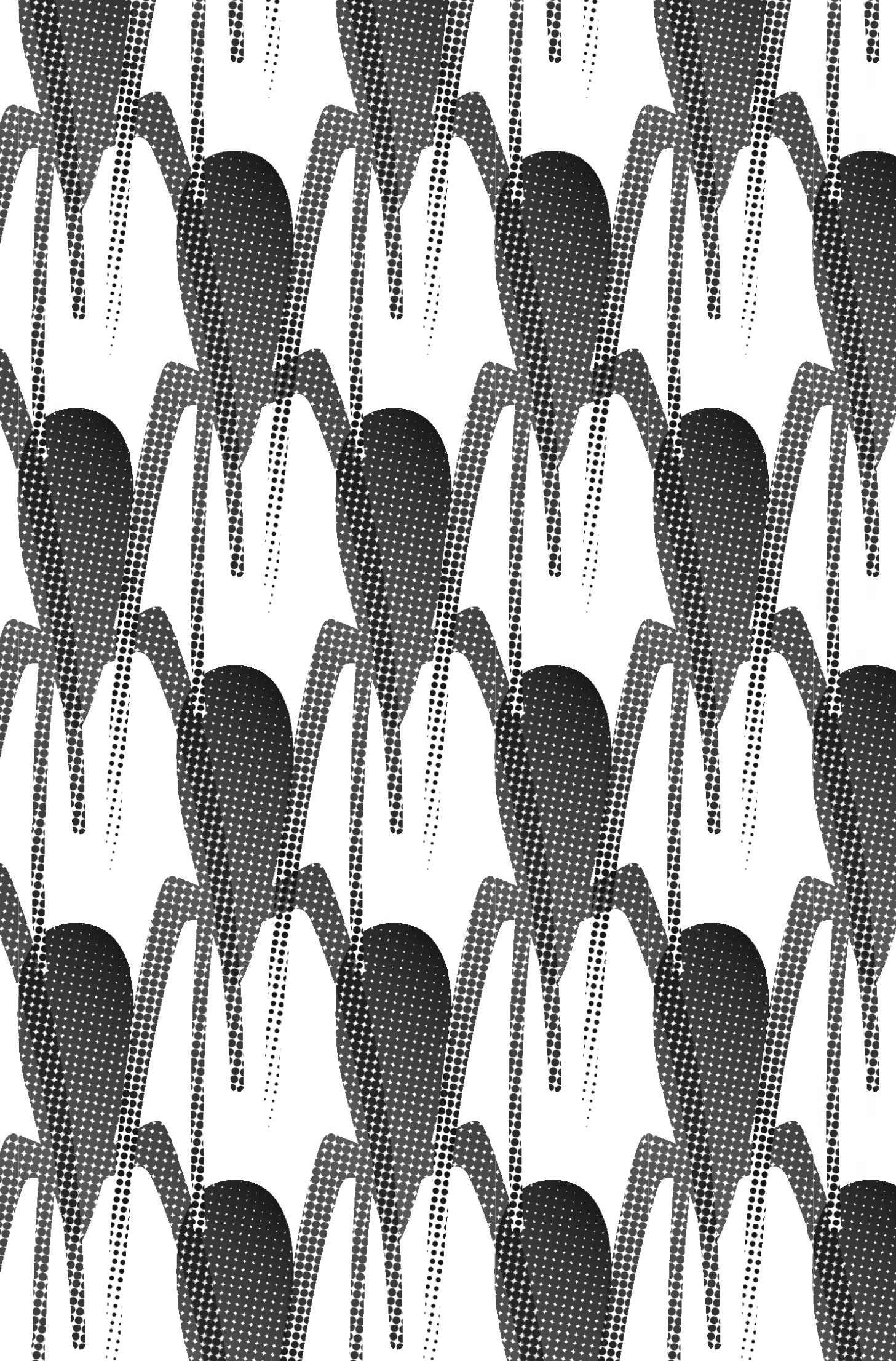




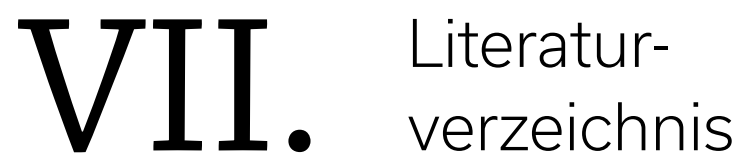




\section{STARDESIGNER ODER GESTALTER DES ALLTÄGLICHEN?}

ADAM, PETER (2001, 2., unveränd. Aufl.): Der Beistelltisch E 1027 von Eileen Gray, Reihe Designklassiker (Hrsg.: Volker Fischer), Frankfurt/Main: Verlag form $612 \mathrm{GmbH}$

ALBUS, VOLKeR (1997): Der Bookworm von Ron Arad, Reihe Designklassiker (Hrsg.: Volker Fischer), Frankfurt/Main: Verlag form GmbH

DERS. und CHRISTIAN BORNGRÄBER (1992): Design Bilanz. Neues Deutsches Design der 8oer Jahre in Objekten, Bildern, Daten und Texten, Reihe DuMont Dokumente, Köln: DuMont Buchverlag

ALESSI, ALBERTO (2000): Die Traumfabrik. Alessi seit 1921, Mailand: Electa

DERS. (2017): The Dream Factory. Alessi since 1921, New York: Rizzoli

ALLISON, DAVID HENSEL (1966): Anonymity in Design, Masterarbeit am Department of Art am Graduate College der University of Iowa

ALTEMEIER, KATHARINA (2007): Mit Klassikern leben. Hunting Classics, in: o. V.: form Sonderveröffentlichung 215, Der Klassiker-Boom. Collecting Design Classics, Basel: Birkhäuser Verlag AG, S. 12-18

[online] http://old.form.de/data/f/fo215_design_classics.pdf [16.01.2019]

DIES. (2009): Editorial, in: o. V.: form Sonderveröffentlichung 227, Design mit Bestand. Products in the Long Run, Basel: Birkhäuser Verlag AG, S. 3 [online] http://old.form.de/data/2/227_longseller.pdf [16.01.2019]

ANDERSON, MARK LYNN (2016): The Silent Screen. 1895-1927, in: Lewis, Jon (Hrsg.): Producing, New Brunswick: Rutgers University Press, S. 15-35; S. 2 of

ANTONELLI, PAOLA (2006): Humble Masterpieces. 100 Everyday Marvels of Design, London: Thames \& Hudson Ltd.

ARTE (2012): Design 1-4. Postmoderne Archäologie: 24 Designklassiker auf vier DVD, Reihe arte Edition, Fridolfing: absolut MEDIEN GmbH 
BADE, ANDREAS (2002): Kritische Anmerkungen zur neuen Ökonomie der Aufmerksamkeit, in: Bleicher, Joan K. und Knut Hickethier (Hrsg.): Aufmerksamkeit, Medien und Ökonomie, Münster: LIT-Verlag, S. 179-193

BARTSCHERER, THOMAS und RODERICK COOVER (2011): Switching Codes. Thinking through Digital Technology in the Humanities and the Arts, Chicago: The University of Chicago Press

BAYLEY, STEPHEN (1998): Die Lucky Strike-Packung von Raymond Loewy, Reihe Designklassiker (Hrsg.: Volker Fischer), Frankfurt/Main: Verlag form GmbH

BECK, KLAUS und WOLFGANG SCHWEIGER (2001): Attention Please!: OnlineKommunikation und Aufmerksamkeit, München: Verlag Reinhard Fischer

BERNARDY, JÖRG (2014): Aufmerksamkeit als Kapital. Formen des mentalen Kapitalismus, Marburg: Tectum-Verlag

BERTSCH, GEORG-CHRISTOF (1999, 2. Aufl.): Der Wasserkessel von Michael Graves, Reihe Designklassiker (Hrsg.: Volker Fischer), Frankfurt/Main: Verlag form $\mathrm{GmbH}$

BLAKLEY, JOHANNA (2008) in: Lanham, Richard A. und David Merkoski (Hrsg.): The Economics of Attention, Los Angeles: University of Southern California, Annenberg School for Communication, The Norman Lear Center, S. 22 [online] https://learcenter.org/wp-content/uploads/2014/10/EconofAttention2.pdf [31.01.2019]

BLEICHER, JOAN K. und KNUT HICKETHIER (2002): Aufmerksamkeit, Medien und Ökonomie, Münster: LIT-Verlag

BÖHNISCH-BREDNICH, BRIGITTE (2002): Der Manufactum-Katalog: Museale Objekte und Modernes Einkaufen, in: Gyr, Ueli (Hrsg.): Schweizerisches Archiv für Volkskunde, 98. Jg, Heft 1, Basel: Schweizerische Gesellschaft für Volkskunde, S. 151-165

BOTSCH, MARCUS (1999): Die Mineralwasserflasche von Günter Kupetz, Reihe Designklassiker (Hrsg.: Volker Fischer), Frankfurt/Main: Verlag form GmbH 


\section{STARDESIGNER ODER GESTALTER DES ALLTÄGLICHEN?}

BOURDIEU, PIERRE (1999): Die Regeln der Kunst. Genese und Struktur des literarischen Feldes, Frankfurt/Main: Suhrkamp Verlag

BRÄUER, HASSO (2004): Archiv des Deutschen Alltagsdesigns [DVD], Digitale Bibliothek 56, Berlin: Directmedia Publishing

BREUER, GERDA (2001): Die Erfindung des Modernen Klassikers. Avantgarde und ewige Aktualität, Ostfildern-Ruit: Hatje Cantz Verlag

BÜCHI, TOBIAS (2015): Die Fortifikationsliteratur des 16. und 17. Jahrhunderts. Traktate deutscher Sprache im internationalen Kontext, Dissertation an der ETH Zürich (2009), Edition Bibliothek Werner Oechslin, Basel: Schwabe Verlag

BÜRDEK, BERNHARD E. (2001, 3. Aufl.): Der Apple Macintosh, Reihe Designklassiker (Hrsg.: Volker Fischer), Frankfurt/Main: Verlag form $\mathrm{GmbH}$

BYSTRÖM JANARV, GÖREL (1997): The Eye wants to travel, in: o. V.: Low Budget. Objectos do Quotidiano, Ausstellungskatalog, Belém: Centro Cultural de Belém, S. 24-25

CACCIOLA, DONATELLA (2008): Moderne Klassiker: die wiedergefundene Zeit. Die Reeditionen von Sitzmöbeln in Deutschland und in Italien und ihre Rezeption, Dissertation an der Technischen Universität Delft

CLIVIO, FRANCO, HANS HANSEN und PIERRE MENDELL (2009): Hidden Forms. Seeing and Understanding Things, Series Writings on Design der Zurich University of the Arts, Basel: Birkhäuser Verlag AG

COLLINS, MICHAEL (1999): Alessi, Reihe Design Classics, München: Bassermann Verlag

CRARY, JONATHAN (2001): Suspensions of Perception: Attention, Spectacle and Modern Culture, Cambridge/Massachusetts: The MIT Press

DERS. (2002): Aufmerksamkeit. Wahrnehmung und moderne Kultur, Frankfurt/ Main: Suhrkamp Verlag 
CURRID-HALKETT, ELIZABETH (2017): The Sum of small Things. A Theory of the Aspirational Class, Princeton: Princeton University Press

DAHINDEN, URS (2001): Informationsflut und Aufmerksamkeitsmangel - Überlegungen zu einer Sozialökonomie der Aufmerksamkeit, in: Beck, Klaus und Wolfgang Schweiger (Hrsg.), Attention Please!: Online-Kommunikation und Aufmerksamkeit, München: Verlag Reinhard Fischer, S. 39-55

DIETZ, SIMONE (2007): Die Menschenwürde der Rampensau. Selbstdarstellungskultur in der massenmedialen Gesellschaft, in: Kannetzky, Frank und Henning Tegtmeyer (Hrsg.): Personalität. Studien zu einem Schlüsselbegriff der Philosophie, Leipziger Schriften zur Philosophie Nr. 19, Leipzig: Leipziger Universitätsverlag, S. 119-142

[online] http://www.philosophie.hhu.de/fileadmin/redaktion/Fakultaeten/ Philosophische_Fakultaet/Philosophie/Professur_Prof._Dr._Dietz/Dateien/ Publikationen/2007_Dietz_Die_Menschenwuerde_der_Rampensau.pdf [14.02.2019]

DOBLIN, JAY (1959). The 100 best designed products, in: Fortune April 1959, S. 135-141

[online] http://www.fulltable.com/vts/f/fortune/design/a.htm [14.02.2019] [online] https://archive.org/stream/newsreleasejanjun1959illi/newsreleasejanjun1959illi_djvu.txt [14.02.2019]

ECO, UMBERTO (2014, 3. Aufl.): Quasi dasselbe mit anderen Worten, München: Deutscher Taschenbuchverlag GmbH \& Co. KG

EDER, JENS (2002): Aufmerksamkeit ist keine Selbstverständlichkeit. Eine Diskurskritik und ein Klärungsvorschlag, in: Bleicher, Joan K. und Knut Hickethier (Hrsg.): Aufmerksamkeit, Medien und Ökonomie, Münster: LIT-Verlag, S. 15-47

EISELE, PETRA (2000): Deutsches Design als Experiment - Theoretische Neuansätze und ästhetische Manifestationen seit den sechziger Jahren, Dissertation an der Fakultät für Bildende Kunst der Hochschule der Künste Berlin

DIES. (2014): Klassiker des Produktdesign, Stuttgart: Philipp Reclam jun. GmbH \& Co. KG 


\section{STARDESIGNER ODER GESTALTER DES ALLTÄGLICHEN?}

FAULSTICH, WERNER (2000): Sternchen, Star, Superstar, Megastar, Gigastar. Vorüberlegungen zu einer Theorie des Stars als Herzstück populärer Weltkultur, in: Caroline Y. Robertson und Carsten Winter (Hrsg.): Kulturwandel und Globalisierung, Baden-Baden: Nomos Verlagsgesellschaft, S. 293-306

DERS. und HELMUT KORTE (1997): Der Star. Geschichte, Rezeption, Bedeutung, München: Wilhelm Fink Verlag

FORM (2007): Sonderveröffentlichung 215, Der Klassiker-Boom. Collecting Design Classics, Basel: Birkhäuser Verlag AG [online] http://old.form.de/data/f/fo215_design_classics.pdf [16.01.2019]

DIES. (2009): Sonderveröffentlichung 227, Design mit Bestand. Products in the Long Run, Basel: Birkhäuser Verlag AG

[online] http://old.form.de/data/2/227_longseller.pdf[16.01.2019]

FRANCK, GEORG (1998): Ökonomie der Aufmerksamkeit. Ein Entwurf, München: Carl Hanser Verlag

DERS. (2005): Mentaler Kapitalismus. Eine politische Ökonomie des Geistes, München: Carl Hanser Verlag

FRIEDL, FRIEDRICH und GERD OHLHAUSER (1979): Das gewöhnliche Design, Köln: Rheinland-Verlag GmbH (in Kommission bei Rudolf Habelt-Verlag GmbH Bonn)

FUCHS-HEINRITZ, WERNER, D. KLIMKE, R. LAUTMANN, O. RAMMSTEDT, U. STÄHELI, C. WEISCHER und H. WIENOLD (2013): Lexikon zur Soziologie, Wiesbaden: VS Verlag für Sozialwissenschaften

GLASER, BARNEY G. und ANSELM L. STRAUSS (2008: 1. Nachdr. der 2., korr. Aufl. 2005): Grounded Theory. Strategien qualitativer Forschung, Bern: Verlag Hans Huber

GLEININGER, ANDREA (1998): Der Kaffeehausstuhl Nr. 14 von Michael Thonet, Reihe Designklassiker (Hrsg.: Volker Fischer), Frankfurt/Main: Verlag form $\mathrm{GmbH}$ 
GYR, UELI (Hrsg.) (2002): Schweizerisches Archiv für Volkskunde, 98. Jg, Heft 1, Basel: Schweizerische Gesellschaft für Volkskunde

HARARI, YUVAL NOAH (2014): Sapiens. A Brief History of Humankind, London: Vintage Penguin Random House

HAUFFE, THOMAS (2014): Geschichte des Designs, Köln: DuMont Buchverlag

HENSEL, THOMAS und JENS SCHRÖTER (2012): Zeitschrift für Ästhetik und Allgemeine Kunstwissenschaft, Schwerpunktthema: Akteur-Netzwerk-Theorie, Jg. 2012, Heft 57/1, Hamburg: Felix Meiner Verlag

HILDEBRAND, WALTER (1977): Wächter der Ordnung - Hüter der Freiheit. Der Auftrag der Eliten in unserer Zeit, in: Kaltenbrunner, Gerd-Klaus (Hrsg.): Rechtfertigung der Elite. Wider die Anmaßungen der Prominenz, Herderbücherei Initiative 29, Freiburg: Verlag Herder, S. 15-27

HOLZER, BORIS und MADS P. SøRENSEN (2003): Rethinking Subpolitics. Beyond the IIron Cager of Modern Politics?, in: Theory Culture Society, Vol. 20(2), London: SAGE, S. 79-102

HUBER, HANS DIETER (2004): Bild Beobachter Milieu. Entwurf einer allgemeinen Bildwissenschaft, Ostfildern-Ruit: Hatje Cantz

HUMMEL, JOHANNES und JOHANNES SCHMIDT (2001): Ökonomie der Aufmerksamkeit - eine neue ökonomische Theorie?, in: Beck, Klaus und Wolfgang Schweiger (Hrsg.), Attention Please!: Online-Kommunikation und Aufmerksamkeit, München: Verlag Reinhard Fischer S. 93-107

JAHR, ANGELIKA (Hrsg.) (1989, 10. Aufl.): Moderne Klassiker. Möbel, die Geschichte machen, Hamburg: Gruner + Jahr

DIES. (Hrsg.) (1998, 19. Aufl.): Moderne Klassiker. Möbel, die Geschichte machen, Hamburg: Gruner + Jahr

DIES. (Hrsg.) (2000): Top Design des 20. Jahrhunderts, Köln: Naumann \& Göbel Verlagsgesellschaft mbH 


\section{STARDESIGNER ODER GESTALTER DES ALLTÄGLICHEN?}

JANTUNEN, PÄIVI (2011): Esineitä ja lähikuvia. Designs and Impressions, Helsinki: WSOY - Werner Söderström Ltd.

JSSD (JAPANESE SOCIETY FOR THE SCIENCE OF DESIGN) (1993): Special Issue Anonymous Design, Tokyo

[online] https://ci.nii.ac.jp/vol_issue/nels/AN10434820/ISSooo0466471_en .html [18.03.2012; inzwischen nicht mehr in dieser Form im Netz verfügbar] [online] https://ci.nii.ac.jp/search?q=\%22Special+Issue+Anonymous+Design\%22+\&range $=0 \&$ count $=20 \&$ sortorder $=1 \&$ type $=0$ [15.02.2019]

JUNGEN, PATRIK (2011): Wirkung einer symbolischen Aussage einer Produktgestaltung auf die Markenbeurteilung, Dissertation an der Universität Gießen (2010), Schriftenreihe Studien zum Konsumentenverhalten, Band 35

KALTENBRUNNER, GERD-KLAUS (1977): Rechtfertigung der Elite. Wider die Anmaßungen der Prominenz, Herderbücherei Initiative 29, Freiburg: Verlag Herder

KANNETZKY, FRANK und HeNNING TEgTMEYER (2007): Personalität. Studien zu einem Schlüsselbegriff der Philosophie, Leipziger Schriften zur Philosophie Nr. 19, Leipzig: Leipziger Universitätsverlag

KEIL, CHARLY und BEN SINGER (2009): American Cinema 1910's. Themes and Variations, New Brunswick: Rutgers University Press

KELLER, KATRIN (2008): Der Star und seine Nutzer. Starkult und Identität in der Mediengesellschaft, Bielefeld: transcript Verlag

KERN, MARGIT, THOMAS KIRCHNER und HUBERTUS KOHLE (2004): Geschichte und Ästhetik. Festschrift für Werner Busch zum 6o. Geburtstag, München: Deutscher Kunstverlag

KLEMP, KLAUS (1999, 2., unveränd. Aufl.): Das USM Haller Möbelbausystem, Reihe Designklassiker (Hrsg.: Volker Fischer), Frankfurt/Main: Verlag form $\mathrm{GmbH}$ 
KIM, HYANGAH und WOOHUN LEE (2014): Everyday Design as a Design Resource, in: International Journal of Design Vol.8, No.1

[online] http://www.ijdesign.org/index.php/IJDesign/article/view/1258/607 [15.02.2019]

KOHL, KARL-HEINZ (2003): Die Macht der Dinge. Geschichte und Theorie sakraler Objekte, München: Verlag C. H. Beck

KÜSTER, ROLF L. A. (2001): Phänomenologie der Form. Designwissenschaftliche Untersuchungen zu Komplexität und Ordnung von Natur- und Artefaktform, Dissertation an der Hochschule für Bildende Künste Braunschweig

KUHN, TOBIAS (1999): Das Zippo von George G. Blaisdell, Reihe Designklassiker (Hrsg:: Volker Fischer), Frankfurt/Main: Verlag form GmbH

KURZ, MELANIE (2014): Inspirationsmythen. Zur Ideengeschichte des menschlichen Schöpfungsvermögens, Paderborn: Wilhelm Fink

LANG, WIEBKE (2010): Helden des Alltags - vom Umgang mit Dingen im Digitalen Zeitalter/ Heroes of the Everyday - dealing with things in the digital age, in: Schwartz-Clauss, Matthias und Alexander von Vegesack (Hrsg.): Die Essenz der Dinge/The Essence of Things, Ausstellungskatalog, Weil am Rhein: Vitra Design Museum, S. 6o-65

LANHAM, RICHARD A. und DAVID MERKOSKI (2008): The Economics of Attention, Los Angeles: University of Southern California, Annenberg School for Communication, The Norman Lear Center

[online] https://learcenter.org/wp-content/uploads/2014/10/EconofAttention2.pdf [31.01.2019]

LATOUR, BRUNO und ADAM LOWE (2010): The migration of the aura or how to explore the original through its fac similes*, in: Bartscherer, Thomas und Roderick Coover (Hrsg.) Switching Codes. Thinking through Digital Technology in the Humanities and the Arts, Chicago: The University of Chicago Press, S. 275-298

LEHMANN, HANS-ULRICH (1999): Die Ringe von C.-F. Dau, Reihe Designklassiker (Hrsg.: Volker Fischer), Frankfurt/Main: Verlag form GmbH 


\section{STARDESIGNER ODER GESTALTER DES ALLTÄGLICHEN?}

LEHNING, THOMAS (2002): Die Goldtruhen der Seeräuber, in: Bleicher, Joan K. und Knut Hickethier (Hrsg.): Aufmerksamkeit, Medien und Ökonomie, Münster: LIT-Verlag, S. 195-208

LENZE, MALTE (2002): Postmodernes Charisma. Marken und Stars statt Religion und Vernunft, Wiesbaden: Deutscher Universitäts-Verlag GmbH

LEWIS, JON (2016): Producing, New Brunswick: Rutgers University Press

LICHTENSTEIN, CLAUDE (1987): Unbekannt - Vertraut. "Anonymes" Design im Schweizer Gebrauchsgerät seit 1920, Reihe Schweizer Design-Pioniere 4, Museum für Gestaltung Zürich, Kunstgewerbemuseum, Wegleitung 36o, Zürich: Karl Schwegler AG

LLOYD, PETER und DIRK SNELDERS (2003): What was Philippe Starck thinking of?, in: Design Studies Volume 24, Issue 3, May 2003, S. 237-253 [online] https:// www.sciencedirect.com/journal/design-studies/vol/24/issue/3 [14.01.2019]

LOON, HENDRIK WILLEM VAN (1939): The Arts, New York: Simon and Schuster Inc.

LUDES, PETER (1997): Aufstieg und Niedergang von Stars als Teilprozeß der Menschheitsentwicklung, in: Faulstich, Werner und Helmut Korte (Hrsg.): Der Star. Geschichte, Rezeption, Bedeutung, München: Wilhelm Fink Verlag, S. 78-98

LÜTHY, MICHAEL (2004): Poetik der Nachträglichkeit oder Das Warten des Marcel Duchamp, in: Kern, Margit, Thomas Kirchner und Hubertus Kohle (Hrsg.): Geschichte und Ästhetik. Festschrift für Werner Busch zum 6o. Geburtstag, München: Deutscher Kunstverlag, S. 461-469

LUNA, IAN und LAUREN A. GOULD (2010): MUJI, New York: Rizzoli

MARQUART, CHRISTIAN (1998): Beetlemania. Der neue Käfer ist da!, Reihe Designklassiker (Hrsg.: Volker Fischer), Frankfurt/Main: Verlag form GmbH

MENDE, ULRICH VON (1999): Der VW Golf, Reihe Designklassiker (Hrsg.: Volker Fischer), Frankfurt/Main: Verlag form GmbH 
MERENMIES, CARITA (1998): Kaj Franck (1911-1989). Die designtheoretischen Strömungen unter dem Gesichtspunkt der Anonymität und deren Einfluss auf das Werk von Kaj Franck, Dissertation am Institut für Kunstgeschichte der Technischen Universität Graz

METELMANN, JÖRG (2002): Kultur und Quote. Willemsen moderiert: Georg Franck und Pierre Bourdieu zum sozialen Tausch, in: Bleicher, Joan K. und Knut Hickethier (Hrsg.): Aufmerksamkeit, Medien und Ökonomie, Münster: LITVerlag, S. 87-104

MIKLAUTZ, ELFIE (1996): Kristallisierter Sinn. Ein Beitrag zur soziologischen Theorie des Artefakts, München: Profil Verlag GmbH

MEULI, KASPAR (2001): Blonde Möbel, in: NZZ Folio Nr. 10, Oktober 2001, Zürich: Verlag NZZ-Folio

MIKOS, LOTHAR (2010): Der Fan, in: Moebius, Stephan und Markus Schroer (Hrsg.): Diven, Hacker, Spekulanten. Sozialfiguren der Gegenwart, Berlin: Suhrkamp Verlag, S. 108-118

MILLER, DANIEL (2008): The Comfort of Things, Cambridge (UK): Polity Press

MILLER, LILY ELIZABETH (2004): The changing nature of celebrity from entertainer to entrepreneur: Oprah Winfrey as tastemaker, Masterarbeit an der Faculty of the Graduate School of Arts and Sciences of Georgetown University, Washington D. C. [online] https://docplayer.net/37658477-The-changingnature-of-celebrity-from-entertainer-to-entrepreneur-oprah-winfrey-as-tastemaker.html [15.02.2019]

MOEBIUS, STEPHAN und MARKUS SCHROER (2010): Diven, Hacker, Spekulanten. Sozialfiguren der Gegenwart, Berlin: Suhrkamp Verlag

MORGAN, CONWAY LLOYD (1999): STARCK, New York: Universe Publishing

MORTEO, ENRICO (2010, 2. Aufl.): Design-Atlas von 1850 bis heute, Köln: DuMont Buchverlag 


\section{STARDESIGNER ODER GESTALTER DES ALLTÄGLICHEN?}

NEUBERGER, CHRISTOPH (2008): Die Allgegenwart des Widerspruchs. Paradoxien der Kommunikation, Rezeption und Vermittlung im Medienwandel, in: Pörksen, Bernhard, Wiebke Loosen und Armin Scholl (Hrsg.): Paradoxien des Journalismus. Wiesbaden: VS, S. 37-61 [online] https://www.academia. edu/2581632/Neuberger_Christoph_2008_Die_Allgegenwart_des_Widerspruchs._Paradoxien_der_Kommunikation_Rezeption_und_Vermittlung_ im_Medienwandel._In_P\%C3\%B6rksen_Bernhard_Loosen_Wiebke_Scholl_ Armin_Hrsg._Paradoxien_des_Journalismus._Wiesbaden_VS_S._37-61._ Erw._u._akt._Version [01.02.2019]

NEUBERT, CHRISTOPH (2012): Vom Disegno zur Digital Materiality - Operationsketten der Reproduktion zwischen künstlerischer, biologischer und technischer Vermittlung, in: Hensel, Thomas und Jens Schröter (Hrsg.): Zeitschrift für Ästhetik und Allgemeine Kunstwissenschaft, Schwerpunktthema: Akteur-Netzwerk-Theorie, Jg. 2012, Heft 57/1, Hamburg: Felix Meiner Verlag, S. 45-67

NZZ FOLIO Nr. 10 Oktober 2001, Zürich: Verlag NZZ-Folio

O. v. (1997): Low Budget. Objectos do Quotidiano, Ausstellungskatalog, Belém: Centro Cultural de Belém

PÖRKSEN, BERNHARD, WIEBKE LOOSEN und ARMIN SCHOLL (2008): Paradoxien des Journalismus, Wiesbaden: VS

PUNDT, CHRISTIAN (2002): Vom Geben und Nehmen im Kleinen und Großen. $\mathrm{Zu}$ Georg Francks Ökonomie der Aufmerksamkeit, in: Bleicher, Joan K. und Knut Hickethier (Hrsg.): Aufmerksamkeit, Medien und Ökonomie, Münster: LITVerlag, S. 49-73

QUINN, MOLLY JANE und JENNA TALBOT (2011): It's lonely in the modern world. The Essential Guide to Form, Function, and Ennui from the Creators of UnhappyHipsters.com, San Francisco: Chronicle Books

RAPPE, MICHAEL (2001): Zum Phänomen des Stars [online] https://www.michael-rappe.de/wp/wp-content/uploads/2009/o7/zumphaenomendesstars.pdf [12.01.2019] 
RECKWITZ, ANDREAS (2010): Der Kreative, in: Moebius, Stephan und Markus Schroer (Hrsg.): Diven, Hacker, Spekulanten. Sozialfiguren der Gegenwart, Berlin: Suhrkamp Verlag, S. 248-26o

DERS. (2012): Die Erfindung der Kreativität. Zum Prozess gesellschaftlicher Ästhetisierung, Berlin: Suhrkamp Verlag

DERS. (2017): Die Gesellschaft der Singularitäten. Zum Strukturwandel der Moderne, Berlin: Suhrkamp Verlag

RIBOT, THÉODULE (1890): The Psychology of attention, Chicago: The Open Court Publishing Company

RINALLO, DIEGO und EDOARDO SAVI (2011): Consuming Stardust: the Consumption of Celebrities Beyond Product Endorsements, in: Darren W. Dahl, Gita V. Johar und Stijn M. J. van Osselaer (Hrsg.), NA - Advances in Consumer Research, Volume 38, Duluth, MN: Association for Consumer Research, S. 802-803 [online] http://www.acrwebsite.org/volumes/v38/acr_v38_16156.pdf [14.02.2019]

ROBERTSON, CAROLINEY. und CARSTEN WINTER (2000): Kulturwandel und Globalisierung, Baden-Baden: Nomos Verlagsgesellschaft

ROTH, MANUELA (2013, 2. Aufl.): Masters and their pieces. Best of furniture design, Salenstein (Schweiz): Braun Publishing AG

SCHINDLER, INES, VERONIKA ZINK, JOHANNES WINDRICH und WINFRIED MENNINGHAUS (2012): Admiration and adoration: Their different ways of showing and shaping who we are, in: Koole, Sander L. und Klaus Rothemund (Hrsg.), Cognition \& Emotion, 27:1, London: Routledge, S. 85-118 [online] http://dx.doi. org/10.1080/02699931.2012.698253 [13.02.2019]

SCHNEIDER, BEAT (2005): Design - Eine Einführung. Entwurf im sozialen, kulturellen und wirtschaftlichen Kontext, Basel: Birkhäuser - Verlag für Architektur

SCHÖNER WOHNEN (2011 a): Das Buch der Designer. Die 150 wichtigsten Designer \& ihre wichtigsten Möbel, Hamburg: Gruner+Jahr 


\section{STARDESIGNER ODER GESTALTER DES ALLTÄGLICHEN?}

DIES. (2011 b): Das Buch der Klassiker. Die 500 besten Möbel und Wohnaccessoires, Hamburg: Gruner+Jahr

DIES. (2014): Heft September mit Poster "99 Designikonen aus 11 Jahrzehnten«, Hamburg: Gruner+Jahr AG \& CO KG, S. 74-80 und Poster

POYNOR, RICK (2003): Anarchie der Zeichen. Grafik-Design von den Achtzigern bis heute, Basel: Birkhäuser - Verlag für Architektur

SCHROER, MARKUS (2010): Der Star, in: Moebius, Stephan und Markus Schroer (Hrsg.): Diven, Hacker, Spekulanten. Sozialfiguren der Gegenwart, Berlin: Suhrkamp Verlag, S. 381-395

SCHULZE, GERHARD (1996, 6. Aufl.): Die Erlebnisgesellschaft. Kultursoziologie der Gegenwart, Frankfurt/Main: Campus Verlag

SCHWARTZ-CLAUSS, MATTHIAS (2010): Die Essenz der Dinge - Design und die Kunst der Reduktion/The Essence of Things - design and the art of reduction, in: Schwartz-Clauss, Matthias und Alexander von Vegesack (Hrsg.): Die Essenz der Dinge/The Essence of Things, Ausstellungskatalog, Weil am Rhein: Vitra Design Museum, S. 22-41

DERS. und ALEXANDER VON VEGESACK (Hrsg.): Die Essenz der Dinge/The Essence of Things, Ausstellungskatalog, Weil am Rhein: Vitra Design Museum

SEELENMEYER, PEGGY (2016): Superstar Designer. Über die Sichtbarkeit von Designerinnen in der heutigen Grafikelite, Bachelorarbeit im Fach Kommunikationsdesign an der Fachhochschule Potsdam [online] https://www.fh-potsdam. de/fileadmin/user_upload/gleichstellung/Genderpreis/1.Peggy_Seelenmeyer_Theorie_SuperstarDesigner.pdf [14.02.2019]

SELLE, GERT (2007 a): Geschichte des Design in Deutschland, Frankfurt/Main: Campus Verlag GmbH

DERS. (2007 b): Design im Alltag. Vom Thonetstuhl zum Mikrochip, Frankfurt/ Main: Campus Verlag GmbH 
SIEBKE, GUNDA und WITTORF, SUSANNE (1999): Das Polstersystem Conseta von Friedrich Wilhelm Möller, Reihe Designklassiker (Hrsg.: Volker Fischer), Frankfurt/Main: Verlag form GmbH

SIEGERT, GABRIELE (2001): Der Januskopf der Aufmerksamkeit. Überlegungen zur medienökonomischen Verortung von Aufmerksamkeit zwischen knappem Gut und Währung, in: Beck, Klaus und Wolfgang Schweiger (Hrsg.): Attention Please!: Online-Kommunikation und Aufmerksamkeit, München: Verlag Reinhard Fischer, S. 109-120

STERLING, BRUCE (2005): Shaping Things, Cambridge/Massachusetts: The MIT Press

STRUBE, KATJA (2002): Das Kapital in den Köpfen, in: Bleicher, Joan K. und Knut Hickethier (Hrsg.): Aufmerksamkeit, Medien und Ökonomie, Münster: LITVerlag, S. 75-86

UBER, HEINER (2009): Democratic Design - Möbel für die Menschheit, Ausstellungskatalog, Hofheim-Wallau: IKEA Deutschland GmbH \& Co. KG

VEBLEN, THORSTEIN (1994): The Theory of the Leisure Class, New York: Dover Publications (Reprint der Originalausgabe von 1899, New York: Macmillan

VIEIRA BAPTISTA, MIGUEL (1997): Compras em Lisboa, in: o. V. (1997): Low Budget. Objectos do Quotidiano, Ausstellungskatalog, Belém: Centro Cultural de Belém, S. 16

WAKKARY, RON und LEAH MAESTRI (2007): The Resourcefulness of Everyday Design, in: Creativity \& cognition 2007: seeding creativity: tools media, and environments; CC 2007; June 13-15, 2007, Washington, DC, USA; an ACM SIGCHI conference, New York: Association for Computing Machinery, Inc.

doi: 10.1145/1254960.1254984 S. 163-172

[online] http://www.sfu.ca/ rwakkary/papers/p163-wakkary.pdf [15.02.2019] [online] https://research.tue.nl/en/publications/the-resourcefulness-of-everyday-design [15.02.2019] 


\section{STARDESIGNER ODER GESTALTER DES ALLTÄGLICHEN?}

DIES. (2008): Aspects of Everyday Design: Resourcefulness, Adaptation, and Emergence, in: International Journal of Human-Computer Interaction, 24(5) 2008: Investigating and Cultivating Creativity, doi: 10.1080/10447310802142276, S. 1-14 [online] http://www.sfu.ca/ rwakkary/papers/HIHC_A_314393.pdf [15.o2. 2019

[online] https://www.tandfonline.com/doi/abs/10.1080/10447310802142276 [15.02.1019]

WALDENFELS, BERNHARD (2004): Phänomenologie der Aufmerksamkeit, Frankfurt/Main: Suhrkamp Verlag

WALKER, JOHN A. (1992): Designgeschichte. Perspektiven einer wissenschaftlichen Disziplin, München: scaneg Verlag

WARBURG, ABY (1920): Heidnisch-Antike Weissagung in Wort und Bild zu Luthers Zeiten, in: Sitzungsberichte der Heidelberger Akademie der Wissenschaften. Stiftung Heinrich Lanz. Philosophisch-historische Klasse, Jg. 1919, 26. Abhandlung, Heidelberg: Carl Winters Universitätsbuchhandlung, S. 35, S. $46 f$ [online] https://core.ac.uk/download/pdf/14505525.pdf [14.02.2019]

WEBER, MAX (2010): Wirtschaft und Gesellschaft, Reihe Zweitausendeins Klassiker Bibliothek, Frankfurt/Main: Der Wunderkammer Verlag GmbH für Zweitausendeins

WENZL-BACHMAYER, MONIKA (2009): Main Street. Design ohne Designer, Ausstellungskatalog, Wien: WAGNER:WERK Museum Postsparkasse

DIES. (2011): Global Village. Design - Ursprung und Moderne, Ausstellungskatalog, Wien: WAGNER:WERK Museum Postsparkasse

WILKINSON, PHILIP (2014): Designklassiker. Vom Barcelona-Sessel bis zum iPad, München: Dorling Kindersley

WIPPERSBERG, JULIA (2007): Prominenz. Entstehung, Erklärung, Erwartungen, Konstanz: UVK Verlagsgesellschaft mbH 


\section{LITERATURVERZEICHNIS}

ZAPP, EDUARD RICHARD (2000): Design und Designzentren, Dissertation an der Fakultät Sozialwissenschaft der Ruhr-Universität Bochum

ZIMMERMAN, JOHN und ELLEN AYOOB (2004): The Role of Products in ConsumerCelebrity Relationships, Pittsburgh: Carnegie Mellon University, Human Computer Interaction Institute, Paper 235 [online] https://kilthub.figshare.com/ articles/The_Role_of_Products_in_Consumer-Celebrity_Relationships/6470 540 [12.01.2019]

ZINK, VERONIKA (2014): Von der Verehrung. Eine kultursoziologische Untersuchung, Frankfurt/Main: Campus Verlag GmbH 


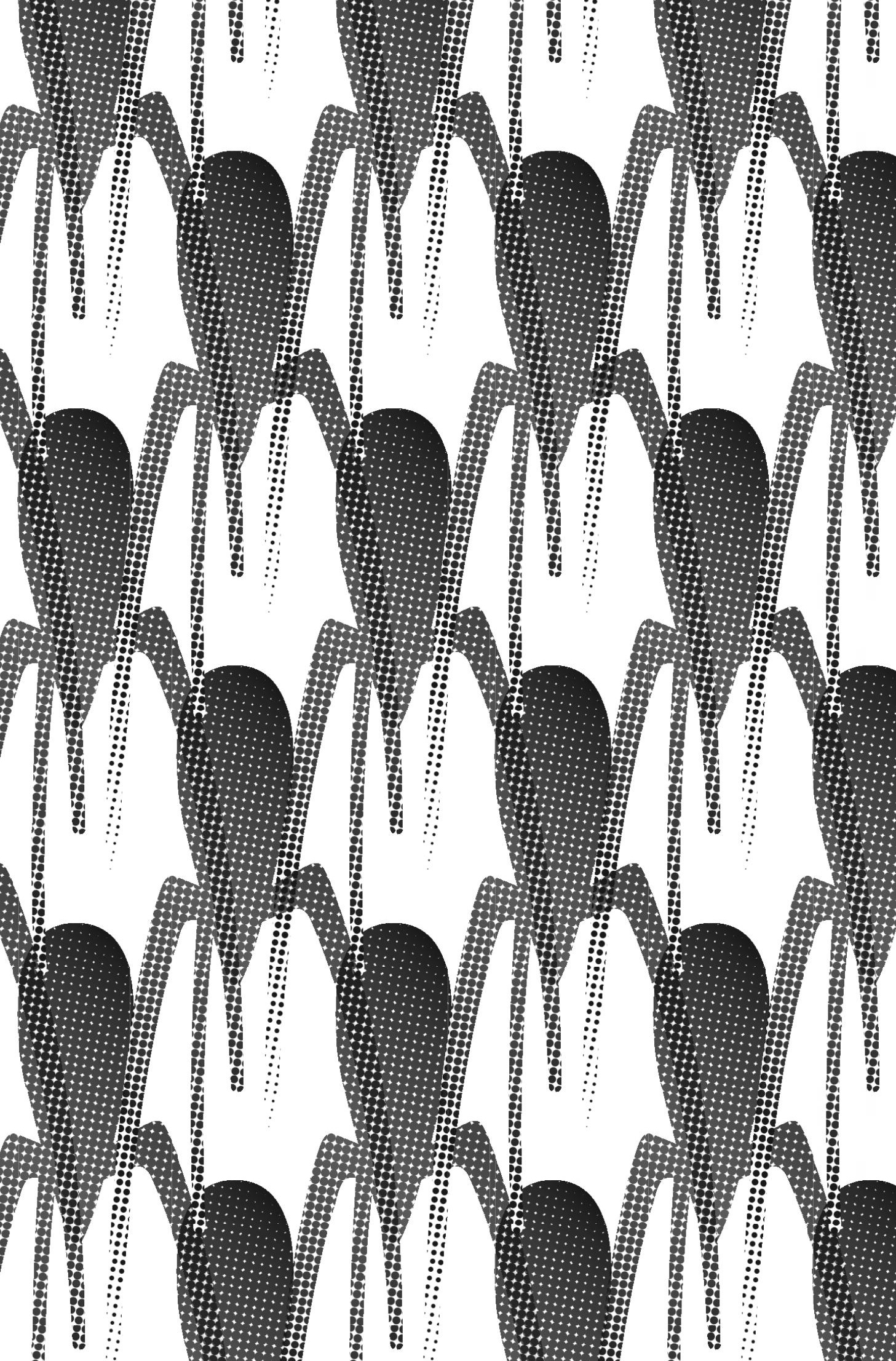




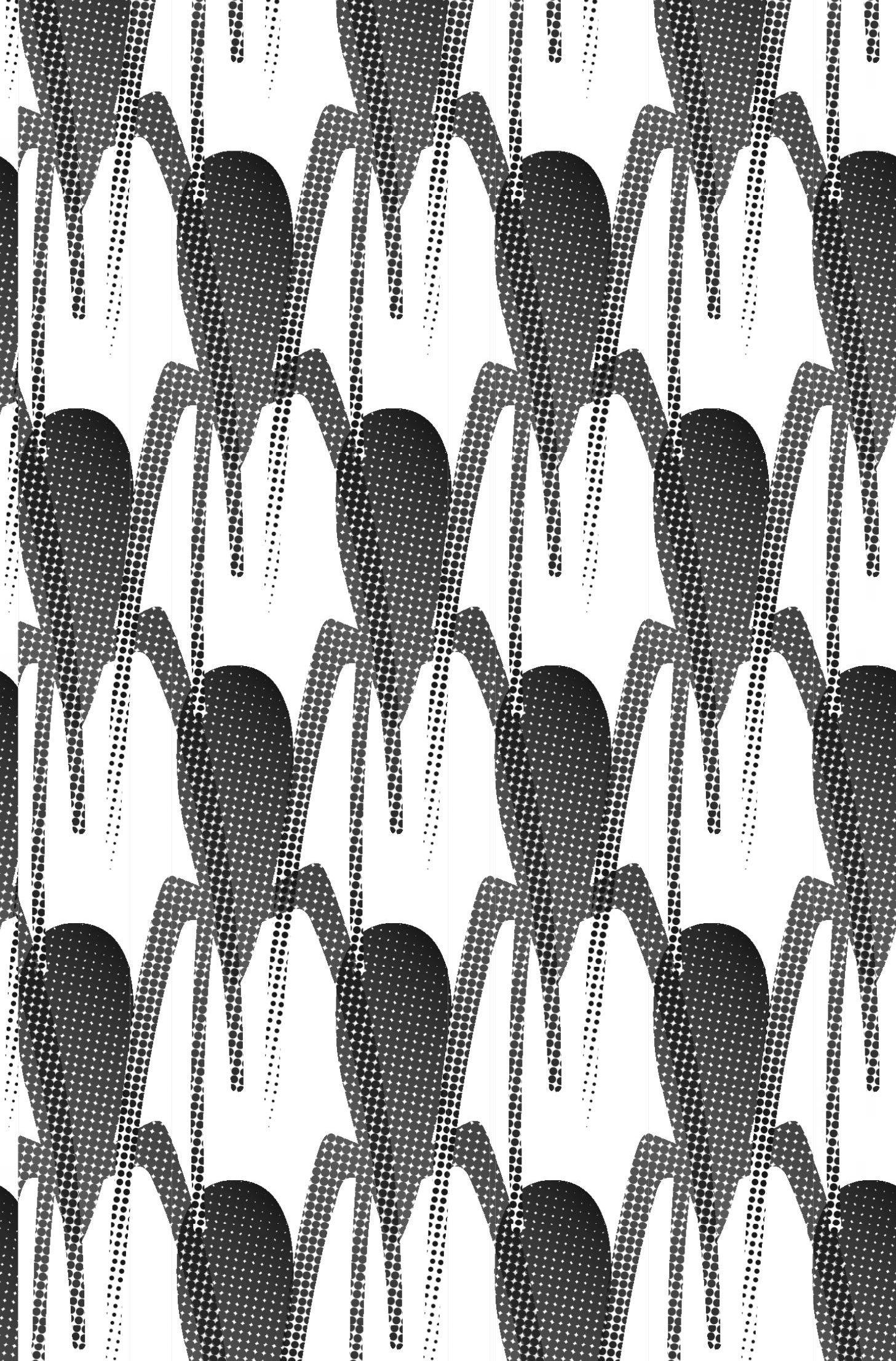




\section{Architektur und Design}

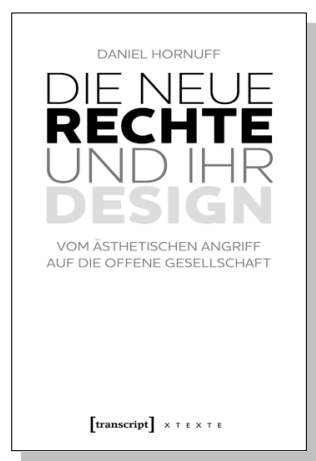

Daniel Hornuff

Die Neue Rechte und ihr Design

Vom ästhetischen Angriff auf die offene Gesellschaft

2019, 142 S., kart., Dispersionsbindung, 17 SW-Abbildungen

19,99 € (DE), 978-3-8376-4978-9

E-Book:

PDF: $17,99 €$ (DE), ISBN 978-3-8394-4978-3

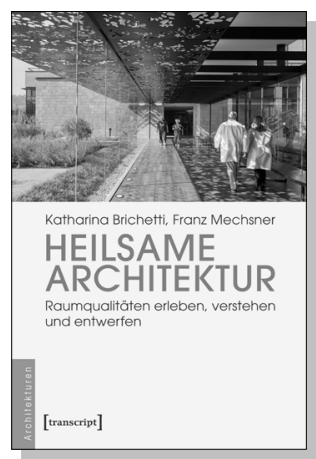

Katharina Brichetti, Franz Mechsner

\section{Heilsame Architektur}

Raumqualitäten erleben, verstehen und entwerfen

2019, 288 S., kart., Dispersionsbindung, SW-Abbildungen, 57 Farbabbildungen

29,99€ (DE), 978-3-8376-4503-3

E-Book:

PDF: $26,99 €$ (DE), ISBN 978-3-8394-4503-7

Christoph Rodatz, Pierre Smolarski (Hg.)

WIE KÖNNEN

WIR DEN

SCHADEN

MAXIMIEREN?

Gestaltung trotz Komplexität

Wie können wir den Schaden maximieren?

Gestaltung trotz Komplexität.

Beiträge zu einem Public Interest Design

April 2021, 234 S., kart.

29,00€ (DE), 978-3-8376-5784-5

E-Book: kostenlos erhältlich als Open-Access-Publikation

PDF: ISBN 978-3-8394-5784-9 


\section{Architektur und Design}

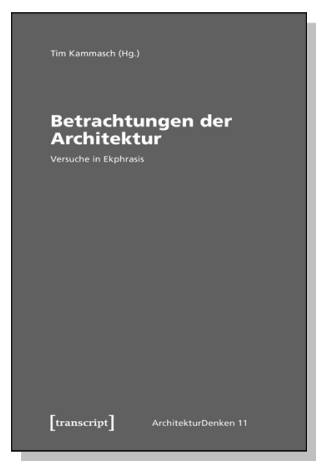

Tim Kammasch (Hg.)

Betrachtungen der Architektur

Versuche in Ekphrasis

2020, 326 S., kart., Dispersionsbindung, 63 SW-Abbildungen 30,00 € (DE), 978-3-8376-4994-9

E-Book:

PDF: $29,99 €$ (DE), ISBN 978-3-8394-4994-3

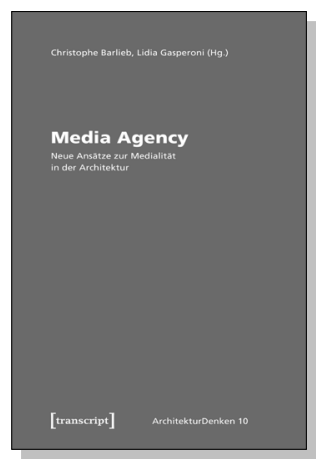

Christophe Barlieb, Lidia Gasperoni (Hg.)

Media Agency -

Neue Ansätze zur Medialität in der Architektur

2020, 224 S., Klappbroschur, Dispersionsbindung, 67 SW-Abbildungen

29,99€ (DE), 978-3-8376-4874-4

E-Book: kostenlos erhältlich als Open-Access-Publikation

PDF: ISBN 978-3-8394-4874-8

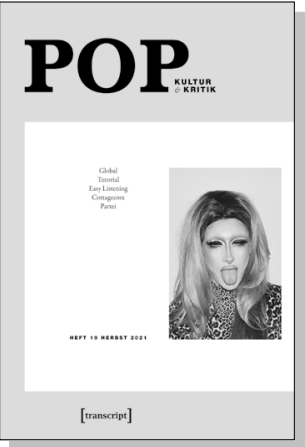

Thomas Hecken, Moritz Baßler, Elena Beregow,

Robin Curtis, Heinz Drügh, Mascha Jacobs,

Annekathrin Kohout, Nicolas Pethes, Miriam Zeh (Hg.)

POP

Kultur und Kritik (Jg. 10, 2/2021)

September 2021, 176 S., kart.

$16,80 €(D E), 978-3-8376-5394-6$

E-Book:

PDF: $16,80 €(D E)$, ISBN 978-3-8394-5394-0 
